\title{
DIE NATURWISSENSCHATIEN
}

IN IHRER ENTWICKLUNG UND

IN IHREM ZUSAMMENHANGE

DARGESTELLT YON

FRIEDRICH DANNEMANN

ZWEITE AUFLAGE

ERSTER BAND :

VON DEN ANFÄNGEN BIS ZUM WIEDERAUFLEBEN DER WISSENSCHAFTEN

YERLAG VON WILHELM ENGELMANN IN I.EIPZIO 

1. Sawlings 


bannemann. Entwicklung der Naturw, Bul. I.

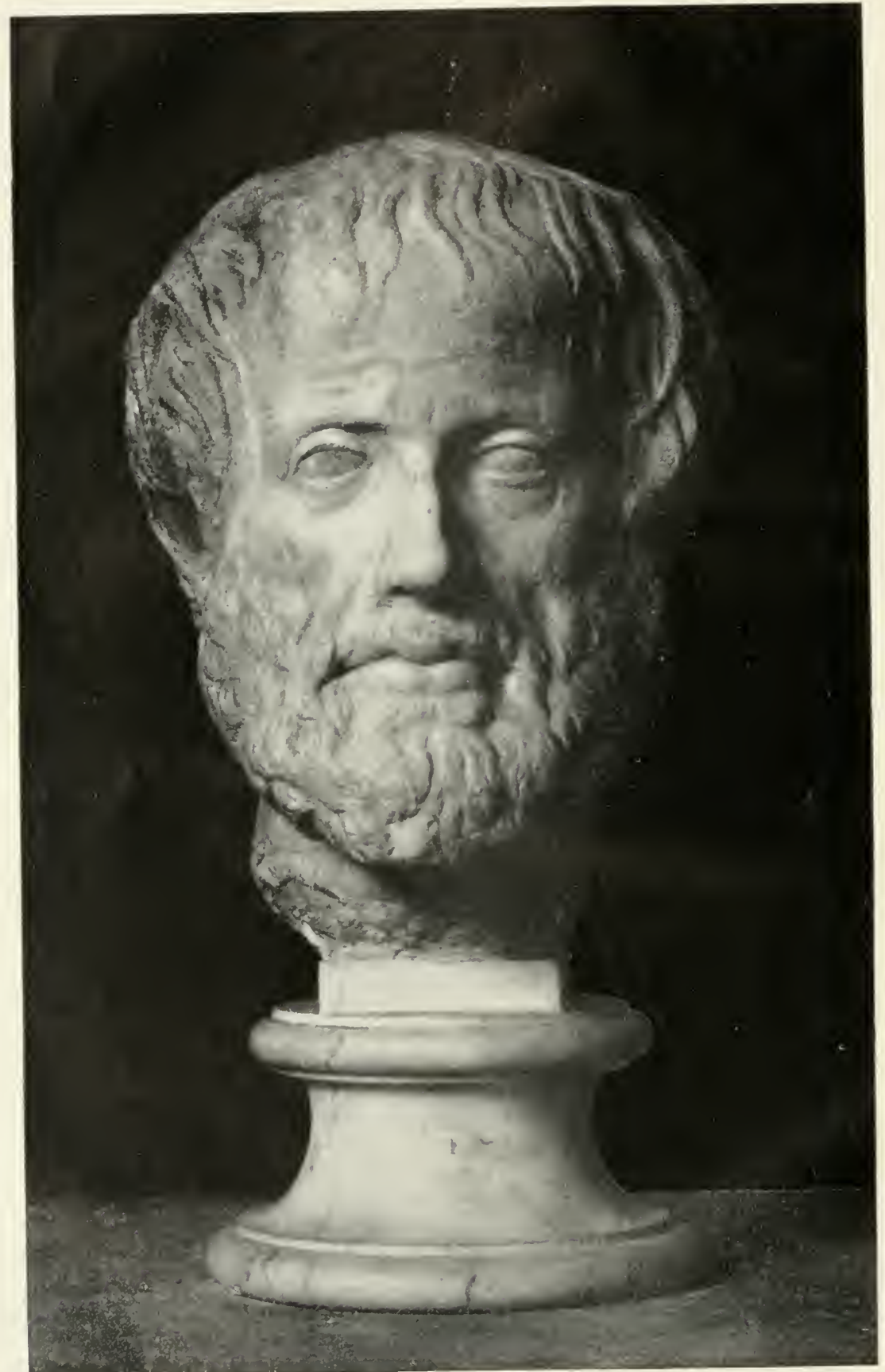

\section{ARISTOTELES}

Varmorkopf im k. k. Hofmuseum zu Wien). 


\title{
DIE NATURWISSENSCHAFTEN IN IHRER ENTWICKLUNG UND IN IHREM ZUSAMMENHANGE
}

\author{
DARGESTELLT VON
}

FRIEDRICH DANNEMANN

ZWEITE AUFLAGE

I. BAND:

VON DEN ANFÄNGEN BIS ZUM WIEDERAUFLEBEN

DER IISSENSCHAFTEN

MIT 64 ABBILDUNGEN IM TEXT UND

MIT EINEM BILDNIS VON ARISTOTLLES

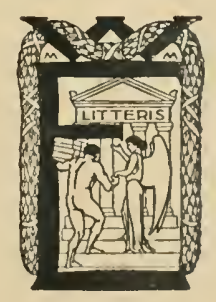

LEIPZIG

VERLAG VON WILHELM ENGELMANN 
Copyright 1920 by Wilhelm Engelmann, Leipzig. 
HERRN GEH. HOFRAT PROF. DR.

\section{EILHARD WIEDEMANN}

AUS DANKBARKEIT FÜR SEINE MITWIRKUNG BEI DER HERAUSGABE DER NEUEN AUFLAGE

GEWIDMET 



\section{Vorwort.}

Das vorliegende Werk wurde kurz vor dem Lriege vollendet. Die Aufnahme war so günstig, daß der erste Band schon wälrend des Krieges vergriffen war. Leider konnte die zweite Auflage, weil das deutsche Verlagsgeschäft mit außerordentlichen Schwierigkeiten zu kämpfen hat, niclit sofort erscheinen, so daß das vollständige Werk längere Zeit im Buchhandel fehlte.

Die zweite Auflage stellt sich nicht nur als eine vermehrte, sondern, zumal in einem Punkte, als eine ganz wesentlich verbesserte dar. $\mathrm{Da}$ es nämlich dem einzelnen nicht wohl möglich ist, auf allen Gebieten gleich grïndliche Vorarbeiten zu machen, haben sich mir dieses Mal einige herrorragende Forscher zugesellt. Insbesondere bin ich den Herren Geh. Hofrat Prof. Dr. E. Wiedemann (Erlangen), Prof. Dr. E. v. Lippmann (Halle a. S.) und Prof. Dr. J. Würschmidt (Erlangen) zu großem Dank verpflichtet. Ich empfing von den Genannten nicht nur zahlreiche Anregungen; sie haben auch die Korrektur des Satzes bis in alle Einzelheiten überwacht. Die Mehrzahl der von ihnen ausgehenden Verbesserungsvorschlïge konnte noch Terwendung finden. Manches ließ sich erst am Schlusse in einem besonderen Abschnitt (s. S. 478 bringen. Einzelne weitergehende Vorschläge mußten vorläufig zurückgestellt werden.

Wenn ich die drei ersten Bände den Herren Wiedemann, v. Lippmann und Würschmidt widme, so ist dies nur ein schwacher Ausdruck meines Dankes. Auch verkenne ich nicht, daß diese Mitwirkung in erster Linie erfolgt ist, um das Werk für den Gcbrauch geeigneter zu machen. Manche Anregung ging mir ferner in den zahlreichen Besprechnngen, sowie ron befreundeter Seite zu. Eine Aufzühlung würde zu weit führen. Doch drängt es mich, besonders für die naclifolgenden Bände den verstorbenen Geh. Rat. Dr. G. Berthold, cinen verdienten Forscher auf dem Gebiete der neueren Geschichte der Wissenschaften, zu nennen. Seine bedeutende Bibliothek, die durch Ankauf in den 
Besitz des Münchener Deutschen Museums für Meisterwerke anf dem Gebiete der Naturwissenschaften und der Technik übergegangen ist, stand mir jeder Zeit zur Verfügung. Auch der häufige persönliche Verkelı mit Berthold, den die Bayrische Akademie der Wissenschaften mit der Abfassung einer von ihr herauszugebenden großen Geschichte der Physik betrant hatte1), war für die Neuherausgabe des ganzen Werkes ron Belang.

Über die Ziele wiederhole ich hier die Worte, die ich der ersten Auflage rorausgeschickt habe: Die Anteilnahme an der Geschichte der Wissenschaften ist seit mehreren Jahrzehnten sehr lebhaft. Je mehr man erkennt, daß sich einer Enträtselung der Natur mit jedem Schritte weitere Schwierigkeiten entgegenstellen, um so lieber richtet man den Blick auch wieder ruickwärts, um den durchmessenen Weg zu überschanen und aus dem reichen Gesamtergebnis der bisherigen Forschung neue Hoffnung auf ein immer tieferes Eindringen in den Zusammenhang der Naturerscheinungen zu schöpfen. In dem Maße, wie sich ferner die Tätigkeit des einzelnen auf ein kleines Arbeitsfeld beschränkt, um so dringender wird das Bedürfnis, das Augenmerk häufiger auf die Gesamtwissenschaft zu richten. Sie in ihrem gegenwärtigen Umfange zu iiberschauen, ist nicht möglich. Wohl aber können wir sie uns in einem historischen Rückblick vergegenwärtigen, der die Haupttatsachen hervorhebt, sie rerknuipft und zu einer vertieften Auffassung anregt.

Eine wertvolle Frucht des geschichtlichen Studiums ist ferner darin zu erblicken, daß es vor dogmatischer Einseitigkeit bewahrt, wenn man sich die Wissenschaft als etwas Werdendes und infolgedessen Unfertiges vergegenwärtigt. Auch gelangt man zu der Einsicht, daß uns dieselben oder ähnliche Methoden und Schlußweisen, die man heute anwendet, in der Entwicklung der Wissenschaft begegnen. Manche Gebiete lassen sich daher kaum darstellen, ohne an die früheren Untersuchungen, Vorstellungen und Gedankengänge anzuknüpfen. Aus diesem Grunde ist die genetische Betrachtungsweise nicht nur in manche Lehrbücher eingedrungen. Es sind auch zahlreiche Geschichten der Einzelwissenschaften entstanden, und das Quellenstudium ist durch Neudrucke der oft schwer zugänglichen älteren Arbeiten belebt worden. Erinnert sei hier nur an Ostwalds großes Unternelimen. Seine

1) Berthold bat diese Arbeit nicht vollendet. Sie wurde später Gerland (-1800) und Würschmidt (1800-1900) übertragen. 
.Klassiker der exakten Wissenschaften“ enthalten in 195 Bänden die grundlegenden Abhandlungen aus den Gebieten der Mathematik, Astronomie, Physik, Kristallographie und Physiologie.

Das vorliegende Werk soll gewissermaßen den Rahmen für "Ostwalds Klassiker der exakten Wissenschaften" abgeben und dartun, wie sich die einzelnen Gebiete gegenseitig auf ihrem Werdegange beeinfluBt haben. Die Wissenschaftsgeschichte ist vor allem ein wichtiger Teil der Kulturgeschichte. Sie kann daher nur verstanden werden, wenn wir sie in ihrem Zusammenhange mit dieser und der allgemeinen Geschichte betrachten. Eine von solchen Gesichtspunkten ausgehende Darstellung des Entwicklungsganges der Naturwissenschaften ist von anderer Seite wohl kaum versucht worden. Wenn ein einzelner sie unternimmt, so muß er in mancher Beziehung um Nachsicht bitten. Eine Teilung der Arbeit unter viele erschien nicht angängig, wenn etwas Ganzes entstehen sollte.

Nicht nur dem Historiker, sondern auch dem Fachmanne, der ein Einzelgebiet bearbeitet, dem Lehrenden, dem Techniker, dem Arzte und jedem, der sich für die Naturwissenschaften lebhafter interessiert, diurfte damit gedient sein, ein Werk zu besitzen, das einen Gedanken zu rerwirklichen sucht, dem der Altmeister der historischen Forschung, Leopold v. Ranke, im fünften Bande seiner deutschen Geschichte Ausdruck verleiht. Ranke schreibt dort, es müsse ein herrliches Werk sein, einmal die Teilnahme, welche die Deutschen an der Fortbildung der Wissenschaften genommen, im Rahmen der europäischen Entwicklung mit gerechter Würdigung darzustellen. "Zu einer allgemeinen Geschichte der Nation“, fügt Ranke hinzu, „wäre ein solches eigentlich unentbehrlich."

Über dieses von Ranke gesteckte Ziel geht das vorliegende Werk allerdings noch hinaus, da es die Geschichte der exaliten Wissenschaften in ihrem ganzen Umfange schildert. Im übrigen dürfte die von Ranke gestellte Aufgabe erfüllt sein, da sich die ..Geschichte der Wissenschaften in Deutschland" nicht anders als im Rahmen der Gesamtentwicklung darstellen läßt. Wenn wir die letztere im Auge behalten, so sind die Naturwissenschaften nicht nur als ein Ergebnis der gesamten Kultur zu betrachten, sondern auch in ilıren Bezielıungen zu den ïbrigen Wissenschaften, insbesondere zur Philosophie, zur Mathematik, zur Medizin und 'Technik; und es ist zu zeigen, wie sich diese Zweige des Denkens und der Forschung gegenseitig gefördert und bedingt haben. 
Von einem Werke, das diese Aufgabe zu erfüllen sucht, darf man keine Vollständigkeit in Bezug auf die biographischen und bibliographischen Daten erwarten. Doch sind zumal die letzteren in solchem Umfange aufgenommen worden, daß es zwar nicht als Nachschlagebuch, wohl aber zur Einführung in das Studium der älteren und neueren naturwissenschaftlichen Literatur

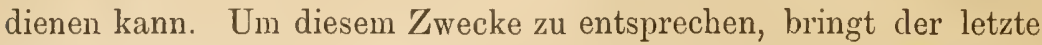
Band ausführliche, sich über alle Teile erstreckende Literatur-, Sach- und Namenregister. Die iubrigen Bände enthalten ein kïrzeres Sach- und Namenverzeichnis.

Die Geschichte der Naturwissenschaften ist einer der jüngsten Zweige der historischen Forschung. Daher ist besonders für die entlegeneren Zeiten vieles noch unaufgeklärt. Manches ist erst. neuerdings mit dem Fortschreiten der archäologischen und der philologischen Untersuchungen bekannt geworden. Es sei nur an die wertrollen Ergebnisse erinnert, die uns die Erschließung der altorientalischen Kultur und die Erforschung der arabischen Literaturschätze gebracht haben. Allerdings sind gerade hier die Urteile noch nicht genügend geklärt, ja häufig genug in wichtigen Punkten einander widersprechend. Für denjenigen, der in zusammenhängender Darstellung die Entwicklung der naturwissenschaftlichen Kenntnisse im Altertum und Mittelalfer schildern will, ergeben sich daraus nicht geringe Schwierigkeiten. Manche Angabe wird bei dem einen auf Zustimmung, bei dem anderen auf Widerspruch stoßen. Das Gleiche gilt von den Ansichten, die wir uns über die Zusammenhänge und die Ursachen bilden können.

Diese Umstände haben mich aber nicht abgehalten, ein Gesantbild zu entwerfen und damit eine schon lange angestrebte Aufgabe, deren Bewältigung immer dringender wird, in Angriff zu nehmen. Denn nur in dem Gesamtbilde erhalten die zahllosen Einzelergebnisse der Forschung erst ihren vollen Wert, während sie in ihrer Vereinzelung oft genug geringwertig oder gar bedeutungslos erscheinen.

Zur Belebung der Wissenschaftsgeschichte ist bisher recht wenig geschehen. Umfassende Vorlesungen darüber fellen selbst an den größeren Hochschulen wohl noch iiberall. Ja, es gibt sogar eine ganze Reihe von Universitäten, an denen auch nicht einmal das bescheidenste historische Kolleg uiber einen besonderen Zweig der so gewaltig emporgeblühtên Naturwissenschaften gehalten wird, wälırend Vorlesungen iiber die Geschichte der Philosophie, der Kunst, der Literaturen usw. nirgends fehlen. Was uns not- 
tut, ist ein besonderer Lehrstuhl für die Geschichte der Naturwissenschaften an jeder Hochschule. Solange solche fehlen, dürfte ein Werk wie das vorliegende dem wissenschaftlichen Nachwuchs einen gewissen Ersatz bieten. Ich habe es daher mit Freuden begrüßt, daß einzelne Hoclischullehrer ihre Hörer auf die Wichtigkeit des eindringenderen geschichtlichen Studiums hinweisen. So schreibt Herr Dr. A. Stock, Prof. an der Universität Berlin und am Kaiser-Wilhelmsinstitut in Dahlem, seit Jahren empfehle er seinen Hörern in der einführenden Vorlesung über experimentelle Chemie „Die Naturwissenschaften in ihrer Entwicklung und in ihrem Zusammenhange." Es ist also zu hoffen, daß das unter der Mitwirkung mehrerer Hochschullehrer erneut erscheinende Werk auch in dieser Hinsicht seine Aufgabe erfüllen wird.

Friedrich Dannemann. 


\section{Inhalt.}

\section{In Asien und in Ägypten entstehen die Anfänge der Wissen- schaften.}

(S. 1-62.)

1. Eiuleitendes. - 2. Die Kultur der alten Ägypter. - 3. Die Literatur der Ägypter. - 6. Mathematik und Technik der Ägypter. - 14. Die Anfänge der Metallurgie. - 15. Die babylonisch-assyrische Kultur. - 17. Keilschriftfunde. - 18. Die Mathematik der Babylonier. - 20. Der Ursprung der Astronomie. - 22. Einteilung des' Jahres. - 24. Anfänge der Astrologie. 26. Astronomische Urkunden. - 28. Finsternisse, Kometen, Schaltjahr. 31. Genauigkeit der Messungen. - 33. Die Chaldäer. - 35. Mondbewegung. 36. Der Gnomon. - 38. Maße und Gewichte. - 41. Die Gewinnung des Eisens. - 42. Kupfer, Zink und Zinn. - 44. Glasbereitung. - 45. Die Anfänge der Heilkunde. - 48. Erstes naturgeschichtliches Wissen. - 51. Die alte Kultur Süd- und Ostasiens. - 53. Die Mathẹmatik der Inder. - 56. Indische Rechenkunst. - 59. Heilkunde und Chemie bei den Indern. - 61. Die Astronomie der' Chinesen.

\section{Die Entwicklung der Wissenschaften bei den Griechen bis zum Zeitalter des Aristoteles.}

$$
\text { (S. 63-103.) }
$$

6อ̃. Anfänge der griechischen Astronomie. - 67. Anfänge der Erdbeschreibung. - 69. Jonische Naturphilosophie - 71. Nechanische Naturerklärung. - 73. Zweckbegriff. - 79. Pythagoras und seine Schule. 84. Quadratur des Kreises und Würfelverdopplung. - 86. Kegelschnitte. 89. Kalenderrechnung. - 91. Die sieben Planeten. - 93. Die heliozentrische Weltanschauung. - 96. Gestalt und Größe der Erde. - 97. Pflanzenkenntnis der Griechen. - 99. Die Anfänge der Zoologie. - 100. Keime der Descendenzlehre. - 101. Ursprung der griechischen Heilkunde.

\section{Das aristotelische Zeitalter.}

(S. 104-151.)

104. Aristoteles und seine Zeit. - 107. Die Werke des Aristoteles. 109. Die Philosophie des Aristoteles. - 112. Fall und Hebelgesetz. 114. Parallelogrammgesetz. - 115. Die Anfänge der Akustik und der Optik. 117. Das Himmelsgebäude nach Aristoteles. - 121. Die Natur der Weltkörper. - 123. Anfänge der physischen Erdkunde. - 125. Einsicht in die geologischen Vorgänge. - 127. Die vier aristotelischen Elemente. - 129. Die Begründung der Zoologie. - 133. Die Einteilung des Tierreichs. - 137. Bau und Lebensweise. - 138. Ernährung und Sexualität der Pflanzen. - 141. Botanik und Heilkunde. - 143. Geographie der Pflanzen. - 146. Bau und Entwicklung der Pflanzen. - 148. Nineralogie und Bergbau. - 149. Einfluß und Dauer des aristotelischen Lehrgebäudes. 


\section{Das alexandrinische Zeitalter.}

(S. 152-207.)

154. Die Begründung eines Systems der Mathematik. - 157. Das Leben und die Bedeutung des Archimedes. - 159. Die Erfindungen des Archimedes. 163. Die Anfänge der höheren Mathematik. - 165. Rotationskörper. 167. Kegelschnitte. - 170. Das archimedische Prinzip. - 172. Fortschritte der Optik und Akustik. - 174. Die Grundlagen der wissenschaftlichen Erdkunde. - 177. - Die Ausmessung der Erde. - 180. Die Bestimmung von Sternörtern. - 182. Entfernung und Größe von Mond und Sonne. - 184. Astronomie und Geometrie. - 186. Die Entdeckung der Präzession. - 188. Die Anfänge der wissenschaftlichen Kartographie. - 190. Physik der Gase und der Flüssigkeiten. - 193. Herons Apparate und Automaten. - 196. Wasserorgel. - 197. Thermoskop. - 198. Flaschenzug. - 199. Wegmesser. 200. Grundlagen der Vermessungskunde. - 201. Herons Werke. - 205̃. Naturbeschreibung und Medizin im alexandrinischen Zeitalter.

\section{Die Naturwissenschaften bei den Römern.}

S. 208-245.)

208. Allgemeingeschichtliches. - 209. Einfluß des Hellenismus. - 211. Meßkunst und dstronomie bei den Römern. - 213. Regelung des Kalenders. 215. Pflege der Ingenieurmechanik. - 219. Die Literatur während der Kaiserzeit. - 220. Plinius. - 222. Quellen des Plinius. - 226. Die „Naturgeschichte“ des Plinius. - 233. Fortschritte der Anatomie und der Heilkunde. - 239. Die Botanik als Hilfswissenschaft der Heilkunde. - 240. Die römische Naturauffassung bei Lukrez und Seneka. - 244. Chemische Kenntnisse und ihre Anwendungen.

\section{Der Ausgang der antiken Wissenschaft.}

$$
\text { S. } 246-284 \text {. }
$$

246. Das ptolemäische Weltsystem. - 249. Die Epizyklentheorie. 252. Hilfswissenschaften der Astronomie. - 25̃. Astronomische Meßwerkzeuge. - 257. Fortschritte der Geographie. - 258. Astronomie und Geographie. - 260. Physische Geographie. - 262. Forschungsreisen. - 265. Förderung der Optik. - 267. Theorie des Sehens. - 268 Elektrizität und Magnetismus. - 270. Die Anfänge der Chemie. - 272. Metallurgie und Alchemie. 277. Alchemie und Astrologie. - 278. Alchemistische Urkunden. - 281. Alterturn und Mittelalter.

\section{Der Verfall der Wissenschaften zu Beginn des Mittelalters.}

S. 285 - 295̃.)

285. Allgemeingeschichtliches. - 286. Wissenschaft und Kirche.

289. Christentum und Grermanentuu. - 291. Wissenschaft und Klosterwesen. 293. Die Erhaltung der alten Sclıriftwerke. - 294. Enzyklopädien der Wissenschaften.

\section{Das arabische Zeitalter.}

(S. $296-331$.)

296. Die IVissenschaften und der Islam. - 299. Vermittlerrolle der Araber. - 301. Die Bedeutung der arabischen Literatul, - 303. Mathematische Geographie und Astronomie. - 305. Astronomie und 'Trigonometrie. 306. Astronomische Instrumente. - 308. Der Kompab. - 310. Die Rechenkunst der Araber. - 312. Die Ausbreitung der arabischen Wissenschaft. 314. Die Optik hei den Arabern. - 319. Die Chemie im arabischen Zeit- 
alter. - 322. Alchemistische Schriften. - 324. Säuren und Metalle. - 325. Alchemistische Theorien. - 326. Stein der Weisen. - 327. Mineralogische Kenntnisse der Araber. - 328. Arabische Bearbeitungen der Zoologie. - 329. Botanische Schriften. - 330. Heilkunde. - 331. Verfall der arabischen Kultur.

\section{Die Wissenschaften unter dem Einfluß der christlich- germanischen Kultur.}

$$
\text { (S. 332-369.) }
$$

332. Allgemeingeschichtliches. - 335. Die Kultur im Reiche der Franken. - 336. Anfänge einer mitteleuropäischen Literatur. - 338. Christliche Völker und Islam. - 341. Erweiterung des geographischen Gesichtskreises. 342. Handel und Städtewesen. - 343. Die Wiederbelebung der alten Literatur. 346. Die Zoologie im Mittelalter. - 350. Die Botanik im Mittelalter. 352. Die ,Tiergeschichte" des Albertus Magnus. - 353. Roger Bacon. 355. Bacons Naturlehre. - 357. Bacons optische Kenntnisse. - 361. Mittelalterliches Denken. - 365. Die Naturwissenschaften im 14. Jahrhundert. 366. Das Weltbild des Mittelalters.

\section{Das Wiederaufleben der Wissenschaften.}

$$
\text { (S. } 370-402 .)
$$

370. Mittelalter und Renaissance. - 372. Dante nnd Petrarka. - 373. Die Ausbreitung des Humanismus, - 377. Humanismus und Kirche. - 379. Humanismus und Naturwissenschaft. - 382. Lionardo da Vinci. - 384. Lionardos Manuskripte. - 386. Lionardos Erfindungen. - 388. Wechselwirkung von Kunst und Wissenschaft. - 392. Das Wiedererwachen der Astronomie. 395. Astronomische Tafeln. - 396. Astronomische Instrumente. - 398. Astronomie und Nautik. - 400. Die Wiederbelebung der Naturbeschreibung.

\section{Die Begründung des heliozentrischen Weltsystems durch Koppernikus.}

$$
\text { (S. } 403-419 .)
$$

403. Koppernikus. - 407. Die Vorläufer des Koppernikus. - 408. Das Koppernikanische Weltsystem. - 412. Aufnahme und Ausbreitung der heliozentrischen Lehre. - 415. Das unendliche Universum. - 417. Astronomie und Kartographie.

\section{Die ersten Ansätze zur Neubegründung der anorganischen Naturwissenschaften.}

(S. 420-445.)

421. Die Physik im 16. Jahrhundert. - 428. Entdeckungen auf dem Gebiete der Optik. - 429. Die Lehre vom Magnetismus. - 430. Anfänge der Dynamik. - 431. Alchemie und Jatrochemie. - 435. Paracelsus, - 437. Die Neubegründung der Mineralogie. - 439. Agricolas mineralogische Schriften. 441. Anfänge der neueren Geologie. - 443. Anfänge der Paläontologie.

\section{Die ersten Ansätze zur Neubegründung der organischen Naturwissenschaften.}

$$
\text { (S. 446-467.) }
$$

446. Naturwissenschaften nnd Entdeckungsreisen. - 450. Die Erneuerung der Botanik. - 451. Kräuterbücher. - 455. Die Anordnung der Pflanzen. 458. Die Erneuerung der Zoologie. - 462. Das Wiederaufleben der Anatomie. - 464. Vesals anatomisches Hauptwerk. - 466. Anatomie und Chirurgie. 


\section{In Asien und in Ägypten entstehen die Anfänge der Wissenschaften.}

Den ersten naturwissenschaftlichen und mathematischen Lehrgebäuden, die in der Blütezeit des griechischen Geisteslebens entstanden, gingen ungemessene Zeiträume voraus, in denen die einfachsten Überlegungen und Beobachtungen, die Grundlagen aller Wissenschaft, teils zufällig, teils auch schon mit bestimmter $\mathrm{Ab}$ sicht angestellt, selten aber nach ihrem Werte gesichtet und aufgezeichnet wurden. Aus dieser Periode stammende Urkunden sind deshalb höchst spärlich, so daß sich die Wurzeln der Naturwissenschaften wie so mancher anderen Betätigungen des menschlichen Geistes, im Dunkel vorgeschichtlicher Zeiten verlieren. Soviel ist jedoch gewiß, daß wir diese Wurzeln nicht in Griechenland zu suchen haben, wo uns die ersten wissenschaftlichen Systeme entgegentreten.

In den Niederungen des Nils und des Euphrats, den ältesten Stätten der Kultur, haben sich auch die ersten Kenntnisse entwickelt, die sich über die Ergebnisse der oberflächlichen Betrachtung und der naiven Anschauung erhoben. Durch die Berührung mit den in Ägypten und in Vorderasien entstandenen Elementen entzündete sich alsdann der prometheische Funke, der in den Griechen schlummerte. Ihnen gelang es, diese Elemente nicht nur in sich aufzunehmen, sondern sie durch eigenes Forschen zu vervielfältigen und den Baum der Erkenntnis zu pflanzen, der nach einer langen Zeit der Dürre zu dem gewaltigen Stamme erwuchs, von dem die Segnungen der heutigen Kultur in erster Linie ausgegangen sind.

Die Entwicklung der Naturwissenschaften ist seit der frülesten Zeit mit derjenigen des mathematischen Denkens Hand in Hand gegangen. Auch in dieser Hinsicht sind die ersten Regungen auf die Ägypter und die Babylonier zurückzuführen. War man früher bezüglich dieser beiden Völker fast nur auf die uns durch die Literatur übermittelten, zum Teil recht zweifelhaften Berichte an- 
gewiesen, so hat unser Zeitalter, indem es den Schutt von den Ruinen Ägyptens und Mesopotamiens wegräumte und die alten Schriftzeichen entziffern lernte, die Geschichte, die Kenntnisse, ja das gesamte Leben jener ältesten Völker aus dem Dunkel und der Vergessenheit nach Jahrtausenden ans Licht gebracht.

Zwar ist die Kultur im Osten und im Süden Asiens vielleicht ebenso früh entstanden wie diejenige, die in den Tälern des Nils und des Euphrats emporblühte. Dennoch wird eine Geschichte der gesamten exakten Wissenschaften auf Indien und China nur wenig Rücksicht zu nehmen brauchen, weil die dort wohnende Bevölkerung sehr abgeschlossen lebte und infolgedessen auf die Entwicklung der naturwissenschaftlichen Kenntnisse in Vorderasien und Europa nur geringen Einfluß gehabt hat.

\section{Die Kultur der Ägypter.}

Wenden wir uns daher zunächst den Ägyptern zu, dem Volke, das wohl die älteste Literatur und die ersten mathematischen, naturwissenschaftlichen und medizinischen Kenntnisse hervorbrachte. Die griechische Überlieferung, nach welcher die Ägypter von Süden her aus Äthiopien in das Niltal eingewandert sind, hat der neveren anthropologischen und Altertumsforschung gegenüber nicht Stand gehalten 1). Wir müssen vielmehr annehmen, daß die alten Ägypter protosemitischen Ursprungs, also mit den Babyloniern durch $\mathrm{Ab}$ stammung verwandt waren 2). Darauf weisen nicht nur sprachliche Eigentümlichkeiten, sondern auch der Umstand hin, daß die Kultur sich in $\ddot{A}_{\text {gypten }}{ }^{3}$ ) von der Mündung aus stromaufwärts ausbreitete.

Der fruchtbare, zu beiden Ufern des Nils sich durch die Wüste hinziehende Streifen Landes, der das eigentliche Ägypten bildet, erwies sich in der Hand der geistig höher begabten Ankömmlinge als ein für die Entwicklung einer hohen Kultur vortrefflich geeigneter Boden. Zuerst erblühte sie in Memphis, in dessen Mauern

1) Die Verwandtschaft des Ägyptischen mit dem Semitischen wurde besonders durch Erman dargetan, der die ältesten Verbalformen verglich und zahlreiche Übereinstimmungen auffand. Daß der altägyptische Typus von dem der Neger stark abweicht, hat Virchow durch die Untersuchung der Königsmumien nachgewiesen (Ber. d. Berl. Akad. von 1888).

2) Siehe auch Wiedemann, Ägyptische Geschichte 1884. S. 22, sowie E. Meyer, Geschichte des Altertums 1. Bd. 1909. S. 44.

3) Näheres über den Namen und über die Geographie des alten Ägyptens. tindet man in Paulys Realencykl. d. klass. Altertumswiss. Bd. I. S. 978. 
die Wissenschaften gepflegt wurden und die K̈̈nstler Meisterwerke hervorbrachten. Die höchste Blüte entfaltete sie indessen, nachdem um das Jahr 1600 v. Chr. das neue Reich mit der Hauptstart Theben gegründet war. In der Nähe der beiden Hauptplätze entstanden in der Wüste monumentale Begräbnisstätten, welche den Wechsel der Zeiten in solchem Maße iiberstanden haben, daß durch die neuere archäologische Forschung, wie einer ibrer Hauptvertreter sagt ${ }^{1}$ ), nach und nach das ganze alte Ägypten wieder emporsteigt und im vollen Lichte der Geschichte erscheint, so daß die Menschen jener entlegenen Zeiten für uns die gleiche Wirklichkeit erhalten wie die alten Griechen und Römer.

Bis zum 19. Jahrhundert war man im wesentlichen auf die Berichte griechischer und römischer Schriftsteller angewiesen. Zahlreiche, mit der ägyptischen Hieroglyphenschrift bedeckte Schriftdenkmäler waren zwar nach Europa gelangt. Die Kenntnis dieser Schrift, sowie der daraus durch Abkürzung entstandenen hieratischen und demotischen Form ${ }^{2}$ ), war aber mit dem Ende des 3. Jahrhunderts infolge des siegreichen Vordringens des Christentums verloren gegangen. Um ihre Entzifferung bemühte $\operatorname{man}^{3}$ ) sich schon in 17. Jahrhundert. Sie gelang erst, als nach dem ägyptischen Feldzuge Napoleons die archäologische Erforschung des Nillandes in Angriff genommen wurde. Epochemachend war die Entdeckung einiger in Stein gemeißelter Erlasse, wie desjenigen von Rosette (1799). Es ist das eine Basalttafel (jetzt im Britischen Museum), welche die nämliche Bekanntmachung (von 197 v. Chr.) in drei verschiedenen Sprachen enthält. Der eine Text bedient sich der altägyptischen Sprache und der Hieroglyphenschrift. Die Übersetzungen dagegen sind in der Volkssprache und der ihr entsprechenden demotischen Schrift, sowie in griechischer Sprache und Schrift erfolgt. Das größte Verdienst um die Entzifferung hat sich Champollion, der Begründer der Ägyptologie, erworben. Unter den Fortsetzern seines Werkes ist vor allem Lepsius, der eine

1) G. Maspero, Gesch. d. morgenländischen Völker im Altertum. Leipzig 1877. S. 63.

2) So entstand z. B. aus der Eule Aie in der Hieroglyphenschrift $m$ bedeutet, das Zeichen 3 (hieratisch) und schließlich ) demotisch). Der demotischen Schrift bediente man sich in der griechisch-römischen Zeit besonders im Verkehr.

3) Z B. A thanasius Kircher $(1601-1680$, der sich auch um die Naturwissenschaften verdient gernacht hat s. a. anderen Stellen dieses Werkes). 
preußische Expédition zur Erforschung der Denkmäler Ägyptens (1842-45) leitete, zu nennen. Er entdeckte das in zwei Sprachen abgefaßte Dekret von Kanopos (238 v. Chr.), das einen Einblick in die Zeitrechnung der alten Ägypter gewährt. Zu den Steininschriften sind in großer Zahl Texte auf Papyrus, Leder und Tonscherben getreten. Auch Keilschriften haben sich auf ägyptischem Boden (in Tell el-Amarna; siehe S. 15) gefunden.

Der Gründung der ersten ägyptischen Dynastie, die um 3300 v. Chr. durch Mena (Menes) erfolgte, müssen schon ausgedehnte Zeiträume einer ruhigen Entwicklung vorausgegangen sein, da uns schon während der ersten Dynastien, deren die ägyptische Geschichte bis zum Beginn der griechischen Herrschaft insgesamt dreißig zählt, eine hochentwickelte Kultur entgegentritt. Dies spricht sich sowohl in den erhaltenen Baudenkmälern, wie in den schriftlichen Überlieferungen jenes Zeitraumes aus. So sind die während der vierten Dynastie von Chufu, Chafra und Menkera errichteten großen Pyramiden nicht nur wahre Wunder der Baukunst, sondern die ganze Anlage dieser, im 4. Jahrtausend v. Chr. Geburt entstandenen Werke weist auf astronomische und mathematische Kenntnisse hin, die man in solch altersgrauer Zeit kaum vermuten sollte. So sind die vier Seiten der Pyramiden genau nach den Haupthimmelsgegenden gerichtet, während der Winkel, den die Seitenwände mit der Grundfläche bilden, wenig oder gar nicht von $52^{\circ}$ abweicht, eine Tatsache, die, wie wir später sehen werden, auf elementare Kenntnisse in der Trigonometrie und Ahnlichkeitslehre hinweist.

Auch daß man schon ein Jahrtausend vor Menes, nämlich im Jahre 4241 v. Chr., in Unterägypten nach einem verbesserten Kalender zu rechnen begann, spricht dafür, daß die Ägypter bereits ein Kulturvolk waren, als sonst überall auf der Erde, Babylonien nicht ausgeschlossen, das Dunkel vorgeschichtlicher Zustände herrschte ${ }^{1}$.

Daß für die Anlage der altägyptischen Bauwerke häufig astronomische Gesichtspunkte maßgebend waren, beweist uns auch die Lage mancher Tempel. So ist durch den englischen Astronomen Lockyer ein Tempel bekannt geworden, dessen Hauptachse gegen den Aufgangspunkt des von den $\ddot{A} g y p t e r n$ als Gottheit

1) E. Meyer, Geschichte des Altertums. 1909. I. Band. S. 54. Siehe auch an späterer Stelle dieses Bandes. 
verehrten Sirius gerichtet ist ${ }^{1}$. Nach Lockyer weist die Achse eines anderen Tempels auf den Punkt, an dem die Sonne zur Zeit der Sommersonnenwende untergeht. Bei der gewaltigen Länge des Tempels vermochten die Sonnenstrahlen nur an diesem einen Zeitpunkt des Jahres durch den ganzen Tempel hindurch zu scheinen. Auf solche Weise wurden die Tempel zu astronomischen Observatorien, die eine genauere Bestimmung der Jahreslänge ermöglicht haben ${ }^{2}$ ).

Aus den ägyptischen Baudenkmälern läßt sich auch ermitteln, wann die Bewohner des Nillandes mit der babylonischen Sechsteilung des Kreises bekannt wurden. Bis zur Zeit der 18. Dynastie begegnen uns nämlich nur Verzierungen, die auf der Vierteilung des Kreises beruhen. Mit der 19. Dynastie tritt an Ornamenten und an Wagenrädern die Teilung nach der Sechs auf. Nun ist bekannt geworden, daß um jenen Zeitpunkt, als Vorderasien den Ägyptern tributpHlichtig wurde, Gesclienke an den Hof der Pharaonen gelangten, welche die Sechs- und Zwölfteilung des Kreises aufweisen ${ }^{3}$. W Wr können also an diesem Beispiel verfolgen, auf welchen Wegen die Kenntnisse von Volk zu Volk übermittelt wurden.

Der außerordentlich frühen Verwendung von Schriftzeichen entspricht es, daß die ältesten Dynastien bereits Aufzeichnungen sammelten. Im 3. Jahrtausend v. Chr. gab es schon besondere Beamte, welche die Bibliotheken verwalteten. Ja, ein Sohn des Mena, des Begründers der ersten Dynastie, wird als Verfasser medizinischer Schriften erwähnt 4 ).

Die ägyptische Bilder- oder Hieroglyphenschrift tritt uns auf den älteren ägyptischen Denkmälern als etwas Fertiges entgegen. Offenbar ist sie aber das Erzeugnis einer langen vorgeschichtlichen Entwicklung. Nicht nur Gegenstände, sondern auch abstrakte Begriffe und Zeitwörter vermochte diese Schrift zum Ausdruck zu bringen. Ohne Verkürzung und Vereinfachung finden wir die Hiero-

1) Zeitschrift der deutschen morgenländischen Gesellschaft. 1904. S. 386.

2) Nach Nissen und Lockyer. Siehe die Abhandlung Charliers i. d. Zeitschr: der morgenl. Gesellschaft. 1904. S. 386 u. f. Danach wiederholte sich ähnliches bei den älteren elıristlichen Kirchen. Thre Aclsse wurde mitunter gegen den Punkt des Horizontes gerichtet, an welchem die Sonne am Gedenktage des Heiligen der betreffenden Kirche unterging. Charlier will auf diese Weise das Alter von Kirchen auf astronomischem Wege bestimmt haben.

3) M. Cantor, Vorlesungen über Gesebichte der Mathematik. Bd. I 1880). S. 59.

4) G. Maspero, Geschichte der morgenländischen Völker im Altertum. Übersetyt von R. Pietschmann. Leipzig 1877. S. 54. 
glyphen $\left.{ }^{1}\right)$ nur auf Steindenkmälern, deren sorgfältig bearbeitete Fl ‘chen jeden Beschauer in Erstaunen setzen. Für den täglichen Gebrauch wurden die Zeichen später in solchem Grade vereinfacht, daß ihre ursprüngliche Form kaum wieder zu erkennen ist (s. S. 3).

Indes nicht nur von den Geschehnissen, der Tracht und den Gebräuchen, sondern auch von dem Wissen jener Zeiten können wir uns auf Grund der aus den Gräbern und Tempeln von Memplis und Theben herrührenden Schriftdenkmäler heute ein ziemlich zutreffendes Bild machen.

Daß schon zur Zeit des alten Reiches in Ägypten eine umfangreiche Literatur bestand, kann mit Sicherheit angenommen werden. Besaß doch, wie aus einer Grabinschrift bei Gizeh hervorgeht, ein Großwürdenträger, der um 2200 v. Chr. lebte, den Titel ..Verwalter des Bücherhauses“ ${ }^{2}$ ). Von jener ältesten Literatur sind jedoch nur spärliche Bruchteile erhalten geblieben. Neben religiösen, moralphilosophischen und geschichtlichen Schriften umfaßte diese Literatur auch Abhandlungen über Astronomie, Mathematik und Heilkunde, welche die Grundlagen für spätere vollständigere, auf uns gekommene ägyptische Schriftdenkmäler gebildet haben.

Ihren Höhepunkt erreichte die altägyptische Kultur um das Jahr 2000 vor Christi Geburt. Um diese Zeit wurde Ägypten zur Großmacht, die erobernd in Vorderasien eindrang und mit dem babylonischen Reich in enge Fühlung trat. Es entwickelte sich sogar ein reger schriftlicher Verkehr zwischen den Pharaonen und den Königen Babylons, sowie den asiatischen Vasallen. Dies beweisen die in großer Zahl im Jahre 1888 in Ägypten ${ }^{3}$ ) aufgefundenen Tontafeln mit Keilinschriften, welche heute den wertvollsten Schatz der Museen von Kairo, London und Paris bilden.

\section{Mathematik und Technik der Ägypter.}

In Ägypten, sagt Aristoteles (Metaphys. I, 1), entstand die mathematische Wissenschaft, denn hier war den Priestern die dazu nötige Muße vergönnt. Nach einer Erzählung Herodots ${ }^{4}$ ) dagegen entsprang für die Ägypter die Notwendigkeit, die Geometrie

1) Um ihre Entzifferung hat sich zuerst Thomas Young und später Champollion die größten Verdienste erworben.

2) Lepsius, Denkmäler II. 50 .

3. In Tell el-Amarna in Mittelägypten.

4) Herodot II. 109. 
zu erfinden, dem Umstande, daß die Grenzen ihrer Ländereien durch die jährlichen Überschwemmungen des Nils verwischt wurden und deshalb durch Vermessung wiederhergestellt werden mußten. Welche Bewandtnis es auch mit diesem Bericht des griechischen Geschichtsschreibers haben mag, jedenfalls ist die Geometrie der frühesten Kulturvölker aus den Bedürfnissen des Lebens hervorgegangen. Die Ansicht, daß sie einem idealistischen Drange entsprungen sei, dürfte nur für die späteren Entwicklungsstufen zutreffen ${ }^{1}$. Für das ehrwürdige Alter der Mathematik in Ägypten spricht auch die von dort stammende älteste Urkunde dieser Wissenschaft 2). Es ist dies eine Art Handbuch für den praktischen Gebrauch, das um das Jahr 1800 v. Chr. rerfaßt wurde und neben zahlreichen arithmetischen Aufgaben, bei denen schon die Bruchrechnung Anwendung findet, auch die erste Behandlung arithmetischer und geometrischer Reihen, Flächenberechnungen der einfacheren Figuren, wie sie für die Absteckung der Felder in Betracht kommen, sowie die Bestimmung des Rauminhalts ron Fruchtspeichern enthält. Sogar der Flächeninhalt des Kreises wird in diesem Papyrus ermittelt. Dies wird in der Weise bewerkstelligt, daß man ïber dem um $1 / 9$ verminderten Durchmesser ein Quadrat errichtet. Hieraus läßt sich für $\pi$ der überraschend genaue TVert 3,16 (statt 3,14 ) berechnen.

Bezeichnend sind die Worte, mit denen Ahmes sein Handbuch einleitet. Sie lauten: "Vorschrift, zu gelangen zur Kenntnis aller dunklen Dinge und Geheimnisse, welche in den Gegenständen enthalten sind." Sie erinnern an die 11/2 Jahrtausend später auftretenden Pythagoreer, die auch $Z$ ahl und Maß als wirkliche, in den Dingen geheimnisvoll schlummernde Wesen betrachteten. Auf das außerordentlich hohe Alter der Mathematik in Ägypten läßt sich übrigens auch daraus schließen, daß Ahmes in seiner Einleitung ausdrücklich sagt, er habe sein Buch nach alten Schriften verfaßt, die zur Zeit eines früheren Königs entstanden seien. Diese Schriften waren, wie aus jener Zeitangabe hervorgeht, etwa 500 Jahre

1) H. Hankel, Die Entwicklung der Mathematik in den letzten Jahrhunderten. Tübingen 1869.

2) Der Papyrus Rhind des Britischen Museums in London, den der Schreiber Ahmes des Hyksoskönigs Ra-a-us verfaßte. Die Entstehung dieser Schrift fällt zwischen 1700 und 2000 v. Chr. Das Dokument wurde übersetzt und erläutert herauggegcben von Eisenlohr, Leipzig 1877. Eine eingehende Besprechung seines Inhalts findet sich in M. Cantors Vorlesungen ïber Greschichte der Mathematik. Leipzig 1880. Bd. I. S. 19-52. 
älter als das Buch des Ahmes und setzen ihrerseits wieder eine lange Periode voraus, in welcher die niedergelegten Kenntnisse langsam heranwuchsen, ohne schriftlich festgelegt $\mathrm{zu}$ werden.

Ohne Zweifel hat man, da das Rechnen aus den Bedürfnissen des Lebens entsprungen ist, zuerst mit benannten Zahlen gerechnet und ist erst später zu abstrakten Zahlen übergegangen. Das Rechnen mit diesen stand, wie der Papyrus Rhind beweist, im 20. Jahrhundert v. Chr. bereits auf einer Höhe, wie man sie vor dem Bekanntwerden jener wichtigen Urkunde nicht vermuten konnte 1).

Ahmes setzt das Rechnen mit ganzen Zahlen voraus und befaßt sich in seinen Aufgaben unter Anwendung der Brüche besonders mit dem, was wir heute Gesellschaftsrechnung nennen. Die von ihm benutzten Brüche sind Stammbrüche, d. h. solche, die eins als Zähler haben. Einen Stammbruch schreibt er, indem er über die Zahl des Nenners einen Punkt setzt. Jeder andere Bruch wird als Summe von Stammbrichen ausgedrückt, z. B. $2 / 5$ durch $1 / 3$ und $1 / 15$, die ohne Additionszeichen nebeneinander gesetzt werden. Die Darstellung eines beliebigen Bruches durch Stammbrïche stellt Ahmes an die Spitze.

Um Brüche, die keine Stammbrüche sind, in Summen von Stammbriichen zu verwandeln, gibt A hmes eine Tafel der Brüche ${ }^{2}$ ) von der Form $\frac{2}{2 n+1}(n=1,2,3 \ldots 49)$. Brüche mit höherem Zähler werden in eine Summe gleichnamiger Briiche zerlegt. An solchen Stammbruchsummen werden die Grundrechnungsarten vollzogen.

Manche Aufgabe, die Ahmes bringt, stellt sich als eine Gleichung ersten Grades mit einer Unbekannten dar. Letztere wird als Haufen bezeichnet. So lautet ein Beispiel: „Haufen, sein $2 / 3$, sein $1 / 2$, sein $1 / 7$, sein Ganzes, es beträgt 33. " Das heißt nach heutiger Schreibweise: $2 / 3 x+1 / 2 x+1 / 7 x+x=33$. Um $x$ zu finden, wird dann $(2 / 3+1 / 2+1 / 7+1)$ so lange vervielfältigt, bis 33 herauskommt. Als weiteres Beispiel sei eine von den Aufgaben aus der Gesellschaftsrechnung mitgeteilt. Sie lautet: „Zu verteilen 700 Brote unter vier Personen, $2 / 3$ für den Einen, 1/2 für den Zweiten, 1/3 für den Dritten, $1 / 4$ für den Vierten." Als Gleichung geschrieben würde die Aufgabe in der Ausdrucksweise der heutigen

1) J. Tropfke, Geschichte der Elementarmathematik. Bd. I. S. 52.

2) Eisenlohr, Ein mathematisches Handbuch der alten Ägypter (2. Ausgabe). S. $46-48$. 
Arithmetik lauten: $2 / 3 x+1 / 2 x+1 / 3 x+1 / 4 x=700$. Der Wert für $\mathrm{x}$ wird dann nach folgender Vorschrift gefunden: Addiere $2 / 3$, $1 / 2,1 / 3$ und $1 / 4$; das gibt $1+1 / 2+1 / 4$. Teile dann 1 durch $1+1 / 2+1 / 4 ;$ das gibt $1 / 2+1 / 14$. Nimm dann $1 / 2$ und $1 / 14$ von 700 ; das ergibt 400 für $x$.

Außer der Hieroglyphe für die Unbekannte (unser $\mathrm{x}$ ) besaßen die alten Ägypter noch einige andere Operationszeichen. Z. B. galt ein Zeichen, das schreitende Beine darstellt, je nach der Richtung als Zeichen für die Addition oder als solches für die Subtraktion. Auch für die Gleichsetzung war ein Zeichen vorhanden. Bekannt war auch schon der Begriff der Wurzel. Bis vor kurzem nahm man an, daß die alten $\ddot{A} g y p t e r$ diesen Begriff nicht kannten. Neuerdings sind aber Papyrusfragmente (aus der 12. Dynastie) bekannt geworden, in denen sich vermerkt findet, daß $\sqrt{16}=4, \sqrt{6^{1 / 4}}=2 \frac{1}{2}$ und $\sqrt{19 / 16}=1 \frac{1}{4}$ ist $^{1}$ ).

Das Verfahren des Wurzelziehens dagegen ist wahrscheinlich erst in der pythagoreischen Schule entwickelt worden, als man größere Quadratzahlen bildete, deren Grundzahl nicht ohne weiteres ersichtlich war, vor allem aber, als es galt, nach dem pythagoreischen Lehrsatz die Hypotenuse aus den Katheten zu berechnen.

Ferner begegnen uns Gleichungen wie die folgenden:

$$
\begin{gathered}
2^{2}+\left(1^{1 / 2}\right)^{2}=\left(2^{1 / 2}\right)^{2} \\
6^{2}+8^{2}=10^{2} .
\end{gathered}
$$

Endlich sind Rollen aus der Zeit um 2000 v. Chr. bekannt geworden, in denen sich Anweisungen über die Festlegung der Wandrichtungen bei Tempelbauten finden. Das Verfahren bestand im "Seilspannen", das heißt, man teilte ein Seil im Verhältnis 3:4:5 und bildete aus diesen Stücken ein Dreieck, um so den gesuchten rechten Winkel zu erhalten. Darauf stuitzt sich die Ansicht, daß der pythagoreische Lehrsatz wohl auf ägyptische Anregungen zurïckzuführen sei $^{2}$ ).

Ganz geschickt waren die Ägypter, wie aus dem Handbuch des Ahmes hervorgeht, auch schon in der Lösung von Aufgaben, die auf die Anwendung von arithmetischen und geometrischen Reihen hinauslaufen. Auch hier mögen einige Beispiele mus nit den ersten Schritten auf diesem Gebiete bekannt machen. Alimes stellt die Aufgabe, 100 Brote an 5 Personen in arithmetischer

1) Schak im 38. und 40. Band der Zeitschrift für ägyptische Sprache.

2) Cantor im Archiv für Mathematik und Physik. 8. Bd. 1904. 
Progression so $\mathrm{zu}$ verteilen, daß die zwei ersten Personen, welche die geringeren Anteile erhalten, zusammen 1/7 von dem bekommen, was auf die 3 übrigen Personen entfällt. Ahmes setzt zunächst das kleinste Glied gleich 1 und sagt dann ohne Begründung: „Mache, wie geschieht, den Unterschied gleich 51/2“. So erhält er die arithmetische Reihe: $1,6 \frac{1}{2}, 12,17 \frac{1}{2}, 23$. Sie genügt zwar der Bedingung, daß die Summe der beiden ersten Glieder gleich $1 / 7$ von der Summe der drei letzten ist. Indessen enthält diese Reihe statt der gegebenen 100 nur 60 Einheiten. Da aber 100 das $1 \frac{2}{3}$ fache von 60 ist, verbessert $A h m e s$ den unrichtigen, aber auch nur vorläufigen Ansatz, indem er jedes Glied der Reihe mit $12 / 3$ multipliziert. Er findet so ganz richtig die allen Bedingungen entsprechende Reihe $12 / 3,10^{5} / 6,20,291 / 6,381 / 3$.

Bei einer anderen Aufgabe schimmert schon die Kenntnis der Summierungsformel ${ }^{1}$ ) für die geometrische Reihe durch. Als Summe der fünf ersten Potenzen ron sieben: $7+49+343+2401$ + 16807 wird 19607 gefunden. Dies geschieht nicht nur durch Addition, sondern indem Ahmes das Produkt von 2801 und 7 bildet. Letzteres Verfahren steht nun in auffallender Übereinstimmung mit der Summenformel $s=\frac{a^{n}-1}{a-1} \cdot a$. Denn für den vorliegenden Fall ist $\frac{a^{\mathrm{n}}-1}{\mathrm{a}-1} \cdot \mathrm{a}=\frac{7^{5}-1}{6} \cdot 7=2801 \cdot 7$.

Weit verbreitet war bei den Ägyptern wie bei den Griechen und den übrigen Völkern des Altertums das Rechenbrett (Abacus). Die Zahlen wurden eingeschrieben oder durch Steinchen, Stifte oder sonstige Marken bezeichnet ${ }^{2}$ ).

Vergegenwärtigt man sich die Wunder der Ingenieur- und der Baukunst, welche die alten Ägypter schufen, sowie ihre von Herodot erwähnten Kenntnisse in der Vermessungskunde, so muß man annehmen, daß die Geometrie bei diesem Volke nicht minder wie das Rechnen gepflegt wurde.

Höchst wahrscheinlich gab es auch für die Geometrie schon Lehrbücher von der Art, wie uns der Zufall ein solches in dem Handbuch des Ahmes für die Arithmetik in die Hände gespielt hat. Leider ist ein ausschließlich der Geometrie gewidmeter Papyrus bisher noch nicht entdeckt worden. Indessen hat sich das Handbuch des Ahmes auch für die Kenntnis des geometrischen Wissens

1) Cantor, Vorlesungen über Gesch. d. Mathem. Bd. I (1880). S. 37.

2) Näheres über das Verfahren und die erhaltenen Exemplare siehe bei Cantor, Vorlesungen über Gesch. d. Mathem. Bd. I. S. 43-45; 109-112 usw. 
der Ägypter als eine Fundgrube erwiesen $\%$. In welcher Weise die Fläche des Kreises ermittelt wurde, haben wir schon erwähnt. Hier sei noch ein Beispiel für die Dreiecksberechnung mitgeteilt. Es handelt sich um ein gleichschenkliges Dreieck, dessen Schenkel 10 und dessen Grundlinie 4 Maßeinheiten lang sind. „Die Hälfte von 4 wird mit 10 vervielfältigt; sein Flächeninhalt ist es." So lautet die Lösung bei Ahmes²). Eine Begründung dieses Verfahrens, das ja zwar kein richtiges, indessen, wenn die Basis verhältnismäßig klein ist, ein von der WVahrheit nur wenig abweichendes Ergebnis liefert, finclet sich bei Ahmes nicht. Seiner Lösung liegt die Formel $\frac{b}{2} \cdot a$ zugrunde (siehe Abb. 1), während die richtige Formel $\frac{\mathrm{b}}{2} \cdot \sqrt{\mathrm{a}^{2}-\frac{\mathrm{b}^{2}}{4}}$ lautet. Letztere läuft also auf die Ausziehung einer Quadratwurzel hinaus, ein Verfahren, das bei A hmes nirgends rorkommt, und das er vermutlich auch nicht kannte, so

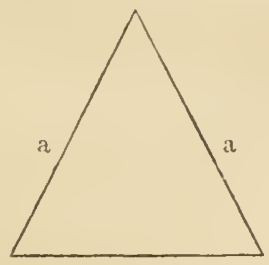

b daß wir eine genaue Berechnung des Flächeninhalts ron ihm auch nicht erwarten dürfen.

Handelte es sich um das Ausmessen von weniger einfachen Figuren, so bedienten sich die Ägypter der Zerlegung durch Hilfslinien. So hat man alte Zeichnungen gefunden, in denen das Paralleltrapez auf mehrfache Weise zerlegt ist (s. Abb. 2).

In den Geräten und Zieraten, die auf der Kreisteilung beruhen, kommt die Teilung in 4 und 8 , sowie in 6 und
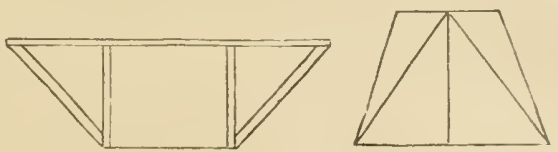

Abb. 2. Geometrische Elemente in altägyptischen Verzierungen ${ }^{3}$;.

12 Sektoren vor, während man einer Teilung in 5 und 10 Sektoren nicht begegnet 4 .

Nicht nur mit Flächen- und Inhaltsbestimmungen, sondern auch mit Streckenverlältnissen und den Eigenschaften der Winkel waren die $\ddot{A} g y p t e r$ zur Zeit des mittleren Reiches schon bis zu einem gewissen Grade vertraut. Auch dic Konstruktion des rechtwinkligen Dreiecks aus den Strecken 3,4 und 5 scheint ihnen schon sehr früh bekannt gewesen zu sein, wenn sie auch nicht

1) Cantor, Bd. I. S. 46.

2) Eisenlohr, Papyrus. S. 125.

3) Cantor, Bd. I. S. 58. Abb. 6 u. 7.

4) M. Cantor, Vorlesungen über Gesch. d. Mathem. Bd. I. S. 59. 
durch mathematische Ableitung, sondern als Erzeugnis der Erfahrung in ihren Besitz gelangt sein werden ${ }^{1}$ ).

Um die große Genauigkeit zu erklären, die uns bei den Pyramiden nicht nur in den Abmessungen des ganzen Bauwerkes, sondern auch in der Bearbeitung der einzelnen Steine begegnet, muß man bei den alten $\ddot{A}$ gyptern schon einige Bekanntschaft mit den Grundlehren der Ähnlichkeitslehre und der Trigonometrie voraussetzen. Dafür sprechen auch die Abschnitte, die Ahmes in seinem Handbuch dem Pyramidenbau widmet. In diesen Abschnitten begegnet uns nämlich ein Ausdruck ${ }^{2}$ ), der wahrscheinlich das Verhältnis der halben Diagonale zur Seitenkante der Pyramide bedeutet, also dem Cosinus des Winkels, den diese beiden Linien bilden, entsprechen würde. Dieses oder ein entsprechendes Verhältnis muß den Bauleitern und Steinmetzen stets gegenwärtig gewesen sein, da sich die genaue Übereinstimmung der Winkel, welche die Kanten mit dem Erdboden bilden, sonst nicht erklären läßt.

In Anbetracht dieser frühen Entwicklung der Geometrie muß es auffallen, daß die Ägypter die Kunst des perspektivischen Zeichnens noch nicht entwickelt haben, wie aus ihren Reliefs und Wandgemälden, die in so großer Fülle und in solch vortrefflichem Zustande auf unsere Zeit gelangt sind, hervorgeht.

Das Handbuch des Ahmes beweist, daß die Mathematik fast zwei Jahrtausende vor Beginn unserer Zeitrechnung in Ägypten schon eine hohe Entwicklungsstufe erreicht hatte. Dabei ist noch zu berücksichtigen, daß sich in dieser Urkunde manche Fehler finden, welche die Vermutung nahe legen, daß es sich hier nur um eine Schülerarbeit handelt. An die Mathematik der Ägypter haben zunächst die Griechen angeknüpft. Die ägyptische Stammbruchlehre läßt sich sogar über die Zeit der Araber hinaus, bis in das deutsche Mittelalter verfolgen. Ferner ist die Beweisform des Euklid, der wir noch heute folgen, ägyptischen Mustern nachgebildet ${ }^{3}$ ).

Wie auf dem Gebiete der Wissenschaften, so haben die Ägypter auch auf dem Gebiete der Technik Grundlegendes geschaffen. Vergegenwärtigt man sich ihre Leistungen auf diesem. Gebiete, so erscheint es durchaus berechtigt, von einer Ingenieurtechnik und einer Ingenieurmechanik schon bei den alten Ägyptern

1) Cantor, a. a. O. Bd. I. S. 59. Siehe auch S. 9.

2) Er lautet Seqt. Siehe Cantor, Gesch. d. Mathem. Bd. I. S. 52, sowio Eisenlohr, a. a. O. S. 135 (Anm. 3).

3) Tropfke, Gesch. d. Elementarmathematik. Bd. I. S. 74. 
zu reden $\left.{ }^{1}\right)$. Durch ähnliche Bedingungen hervorgerufen, entstanden diese Zweige menschlichen Schaffens bei den Bewohnern des Zweistromlandes, um dann ihre weitere Entwicklung zu erstaunlichen Leistungen bei den Griechen und den Römern zu erfahren.

Die Ingenieurtechnik entstand im steten Kampfe des Menschen mit den Kräften der Natur und durch sein Bestreben, sich nicht nur gegen diese Kräfte $\mathrm{zu}$ behaupten, sondern sie sich dienstbar zu machen. Die frühesten Aufgaben der Ingenieurtechnik betrafen das Wasser in allen seinen Formen und Wirkungen. Durch alle Mittel der künstlichen Bewässerung gelang es den $\ddot{\text { ggyptern und }}$ den Babyloniern, ihre Wohnsitze zu Kornkammern für die Alte Welt zu machen. Mit der Pflege und mit der Vernachlässigung der hierfür geschaffenen Einrichtungen stieg und sank die Bedeutung jener Länder und ihrer Bewohner. Da dem Unterlauf des Nils, sowie Mesopotamien der Regen fast ganz fehlt, so liel sich der Ackerbau in diesen Landstrichen nur dadurch heben, daß ein verwickeltes System von Stauwerken und Kanälen unter Anpassung an die wechselnde Wassermenge der Flüsse geschaffen wurde.

Aufgaben ganz anderer Art erwuchsen der Ingenieurmechanik schon im Altertum aus dem Bemühen, das Wasser als Verkehrsmittel zu benutzen, Wasserwege zu schaffen. Das Großartigste, was uns auf diesem Gebiete im alten $\ddot{A} g y p t e n$ begegnet, ist die Herstellung einer Verbindung zwischen dem Mittelländischen und dem Roten Meer. Man ist geneigt, die Idee und die Ausfiihrung dieses Projektes als etwas ganz Neuzeitliches zu betrachten, und dennoch sind der Plan und seine Verwirklichung uralt. Schon zur Zeit Ramses des Zweiten, um 1300 vor Christi Geburt, bestand ein Kanal, welcher den mittelsten der kleinen, auf der Landenge von Suez befindlichen Seen mit einem etwa $70 \mathrm{~km}$ westlich fließenden Arm des Nils verband. Was lag näher als der Gedanke, eine Fortsetzung nach dem Roten Meere zu schaffen und so zwei Weltmeere, wenn anch durch die Vermittelung eines Flusses, in Verbindung zu setzen? Unter den Ptolemüern und den Arabern wurde diese Wasserstraße ihrer Bedeutung entsprechend gut im Stande gehalten. Erst vom 8. Jahrhundert n. Chr. an verfiel der Kanal, welcher dem später infolge der Ent-

1) C. Merkel, Die Ingenieurtechnik im Aitcrtum. Berlin. J. Springer. 1900. An dies größere Werk lehnen sich die „Bilder aus der Ingenieurtechnik“ an, die Merkel als 60. Bändchen der Sammlung ..Aus Natur und Geisteswelt ${ }^{\text {t }}$ veröffentlichte (B. G. Teubner. Leipzig 1904). 
deckungsreisen aufkommenden Weltverkehr auch nicht genügt haben würde.

Geradezu rätselhaft sind die technischen Leistungen, die uns im alten Ägypten dort begegnen, wo es sich um die Fortbewegung gewaltiger Lasten handelt. Auf weite Strecken wurden Steinmassen fortgeschafft, deren Gewicht sich auf 3--400 Tonnen beziffert. Das Aufrichten der aus einem einzigen Granitblock gemeißelten, bis $\mathrm{zu} 30 \mathrm{~m}$ hohen, ein Gewicht von $3-400000 \mathrm{~kg}$ besitzenden Obelisken würde selbst der heutigen Technik große Schwierigkeiten bereiten ${ }^{1}$ ). Über die Ausführung bestehen nur Vermutungen. Daß es dabei an maschinellen Hilfsmitteln nicht fehlte, unterliegt indessen keinem Zweifel. Ungeheure Sklavenheere ersetzten zwar im Altertum bis zu einem gewissen Grade die Maschinen. Dies allein genügt indes nicht zur Erklärung solcher Leistungen. Es mußten intelligente Führer, die mit der Konstruktion und der Handhabung mechanischer, wenn auch nur empirisch beherrschter Mittel vertraut waren, hinzukommen.

Auch mit der Metallbereitung waren die Ägypter früh bekannt. Um die Zeit des Menes (3300 v. Chr.) war das Kupfer schon ziemlich verbreitet. Es wurde besonders auf der Halbinsel Sinai gewonnen. Silber und Eisen waren fast ebenso früh bekannt. Bis zum Jahre 3000 etwa haben die Ägypter reines Kupfer verwandt. Von diesem Zeitpunkt an haben sie das Kupfer mit Zinn legieren gelernt.

Das erste Metall, das die Völker der Alten Welt kennen und bearbeiten lernten, war ohne Zweifel das Gold. Für die Ägypter kam als Fundort besonders das Bergland zwischen dem Nile und dem Roten Meer in Betracht. Auch Arabien war reich an Gold. An den Küsten des Roten Meeres wird wohl auch Salomos Goldland Ophir zu suchen sein.

Eigentümlich ist dem ägyptischen Wesen, daß es vorwiegend auf das Praktische gerichtet war. Die alten Ägypter besaßen eine hochentwickelte Heilkunde; sie waren geschickt im Feldmessen und im Rechnen. Sie haben sich schon gut am Himmel zu orientieren verstanden. Die Sterne zu deuten, wie es die Babylonier taten, lag ihnen jedoch fern.

1) Ist doch bekannt, welche Mühe es kostete, den Obelisken von Heliopolis auf dem Platze vor der Peterskirche in Rom mit Hilfe zahlreicher Göpel und Flaschenzüge aufzurichten. Dieser Obelisk ist eine einzige Steinmasse von über $300000 \mathrm{~kg}$ Gewicht. Näheres siehe bei Beck in seinen Beiträgen zur Geschichte des Maschinenbaus. Berlin 1899. S. 192. 


\section{Die babylonisch-assyrische Kultur.}

Viel später als die Kultur der alten Ägypter ist diejenige der Babylonier auf Grund der archäologischen Durchforschung ihres Landes bekannt geworden. Auch hier lieferten die zwischen den Ruinen untergegangener Städte aufgehäuften oder verschütteten Trümmer eine bei weitem zuverlässigere und wertvollere Ausbeute als die auf uns gekommene, die Babylonier betreffende Literatur.

Das älteste Volk Mesopotamiens, von dem wir Kenntnis besitzen, sind die Sumerer. Man nimmt an, daß sie zur mongolischen Rasse im weiteren Sinne gehörten. Es wïrde danach ein gewisser Zusammenhang zwischen der ältesten ostasiatischen und der ersten Kultur Vorderasiens bestanden haben. Der Beginn. der letzteren wird bis in das 5. Jahrtausend v. Chr. zuriickverlegt.

Um das Jahr 3000 drang ein Volk semitischer Abstammung in Mesopotamien ein. Bis in jene Zeit hinauf besitzen wir geschriebene Urkunden, die allerdings über die Eroberung selbst. nichts besagen 1 . Wie in Ägypten entstanden zuerst einzelne. kleine Reiche, die später vereinigt wurden. Als der älteste König des gesamten Babyloniens wird der um 2200 v. Chr. lebende. Hammurabi genannt.

Wie später in Europa das Lateinische, so blieb in Vorderasien das Sumerische als die Sprache des älteren Kulturvolkes lange Zeit erhalten und für wissenschaftliche Zwecke im Gebrauch. Die frühzeitige, hohe Entwicklung des geistigen Lebens der Babylonier erkennen wir daraus, daß dieses Volk sich schon gegen das Ende des dritten Jahrtausends v. Chr. mit grammatischen Studien, wichtigen Rechtsfragen und vor allem mit der aufmerksamen Erforschung der Himmelserscheinungen beschäftigte.

Daß die Beziehungen des babylonischen Reiches bis nach Ägypten reichten, beweisen die erwähnten, aus dem 16. Jahrhundert v. Chr. stammenden Tell el-Amarna ${ }^{2}$-Funde, unter denen sich

- 1) Siehe „Der alte Orient.“ I., herausgegeben von del" vorderasiatischen Gesellschaft.

2) Ort zwischen Kairo und Theben, wo eine Anzahl Keilschrifttafeln entdeckt wurden. Sie befinden sich zum Teil im Museum der vorderasiatischen Altertümer in Berlin. In einem der Briefe (um $1400 \mathrm{v}$. Chr.) findet sich die erste Erwähnung Jerusalems. Die Berliner Sammlung enthält auch zahlreiche Tafeln der ältesten babylonischen Zeit (3000 v. Chr.). Bei ihrer Auffałdung waren die Schriftzüge durch Auflagerungen unkenntlich; nach An- 
Briefe des Königs von Babylonien an den ägyptischen Herrscher Amenophis IV. befinden. Neben dem babylonischen und dem ägyptischen bestand in Kleinasien das Reich der Hettiter (Chatti) ${ }^{1}$ ). $\mathrm{Da} ß$ auch Griechenland mit dem alten Orient in engen Beziehungen stand, hat die neuere archäologische Forschung gleichfalls dargetan. Die Vermittlung erfolgte insbesondere durch die Phönizier, die bis zum Jahre 1300 v. Chr. im Besitz von Kreta waren und damals das Ägäische Meer beherrschten.

Um 1300 v. Chr. eroberten die Assyrer das Zweistromland. Sie haben es durch ausgedehnte Bewässerungsanlagen gehoben, über die uns Herodot berichtet hat ${ }^{2}$. Nicht minder wurde die Wissenschaft gepflegt. Besonders seit der Zeit des Assyrerkönigs Assurbanipal oder Sardanapal (7. Jahrhundert v. Chr.) entwickelte sich die Astrologie zur astronomischen, auf steten und genauen Beobachtungen fußenden Wissenschaft. Mit der Entdeckung der Bibliothek dieses Königs gelangte auch ein großes babylonisches Werk iiber die Astrologie ans Tageslicht ${ }^{3}$ ), das seitdem die wichtigste Quelle für die astronomischen Kenntnisse der älteren babylonischen Zeit bildet.

Die in Ninive, Babylon und an anderen Stätten in neuerer Zeit durch die Ausgrabungen der Engländer, Amerikaner und neuerdings auch der Deutschen in großer Menge an das Tageslicht geförderten Schriftdenkmäler sind gebrannte Tontafeln, auf denen die Schriftziige als keilförmige Eindrücke eingeritzt sind (s. Abb. 3).

wendung verschiedener Reinigungsverfahren traten sie mit voller Deutlichkeit hervor. Erwähnenswert ist auch ein sumerisch-babylonisches Wörterbuch.

Von den Tell el-Amarna-Tafeln gelangten etwa 200 nach Berlin; die wertvollsten sind in London. Siehe auch C. Niebuhr, Die Amarna-Zeit. „Der Orient" I. 2. Heft. Berlin 1899.

1) Hettitische Schriftdenkmäler wurden in Nordsyrien und in Boghaz-Kiri (Kappadozien) gefunden. Sie bilden einen Teil der Berliner Sammlung vorderasiatischer Altertümer. Die Hettiter haben Bedeutendes auf dem Gebiete der Metallurgie geleistet. Es ist nicht unwahrscheinlich, daß durch sie metallurgische Kenntnisse, z. B. die Art der Gewinnung des Eisens, nach Ägypten und nach Babylonien gelangt sind (E. Reyer, Altorientalische Metallurgie. Zeitschrift der orientalischen Gesellschaft. 1884. S. 149).

2) Merkel, „Die Ingenieurtechnik des Altertums“, enthält darüber und über den Wasserbau der übrigen alten Völker (Chinesen, Griechen, Römer) das Nähere.

3) F. X. Kugler, Sternkunde und Sterndienst in Babel. Münster 1907. Der Inhalt der astrologischen Keilschriftfunde wurde im III. Bande des Londoner Inschriftenwerkes veröffentlicht. Die Übersetzung der astronomischen Keilschrifttafeln begann 1874. 
Ihre Entzifferung gelang erst, seitdem man (1835) mehrsprachige Texte entdeckte. Für diese Entzifferung und damit für die Erforschung der babylonischen und assyrischen Geschichte sind die Inschriften grundlegend gewesen, die sich in den Ruinen der persischen Königspaläste in Persepolis und Susa befinden. Heute sind Hunderttausende von Keilschrifttafeln zutage gefördert ${ }^{1}$ ). Eine ganze Bibliothek entdeckte 1848 der englische Altertumsforscher Layard ${ }^{2}$.

Fiir die Kenntnis der ältesten Entwicklung der Mathematik sind die sogenannten "Nippurtexte" von großer Wichtigkeit. Sie umfassen etwa 50000 Keilschrifttafeln, die in dem Tempel zu Nippur aufbewahrt und durch amerikanische Ausgrabungen ans Tageslicht gefördert wurden. Die "Nippurtafeln" sind in der Zeit von 2200-1350 v. Chr. entstanden. In Nippur wurden, wie die Texte bezeugen, nicht nur Mathematik, sondern auch Astronomie und Heilkunde betrieben $\left.{ }^{3}\right)$. Aus den gefundenen Multiplikationstafeln geht hervor, daß die Babylonier das Prinzip des Stellenwertes kannten, allerdings ohne sich der Null zu bedienen 4 .

Es ist anzunehmen, daß die Keilschrift in ähnlicher Weise aus einer hieroglyphischen oder Bilderschrift entstanden ist, wie es mit der hieratischen Schrift der Ägypter der Fall war. Durch Keilstriche wurden auch die Zahlen bezeichnet. Der Vertikalkeil Y bedeutete die Einheit. Zelın wurde durch zwei einen Winkel bildende Keile ausgedrückt \ und weitere Zahlen durch Nebeneinanderstellung dieser beiden Elemente gebildet. Für hundert war ein besonderes Zeichen, nämlich ein Vertikalkeil in Verbindung mit einem rechts davon stehenden Horizontalkeil im Gebrauch Y (irößere Zahlen wurden meist durch Nebeneinanderstellen, aber auch durch Vervielfältigung gebildet, indem die Zahl links von dem Zeichen als Falitor auftrat. Tausend z. B. wurde $\langle Y\rangle$, also 10 mal hundert geschrieben. Tausend selbst wird wieder mit Ḱoeffizienten versehen, um größere Zahlen auszudrücken, so daß z. B. $\langle\langle Y\rangle$ nicht etwa $20 \mathrm{mal}$ hundert, sondern $10 \mathrm{mal}$ tausend, also 10000 bedeutet. Es ist also eine Vervielfältigung von Einheiten ver-

1) Bezold, Ninive und Babylon, Nonographien zur Weltgeschichte. 1903. Mit 102 Abbildungen.)

2) A. H. Layard, Niniveh and its remains (1848).

3) Die Nippurtexte wurden unter der Oberleitung Hilprechts veroffentlicht: The Babylonian expedition of the university of Pennsylvania, Philadelphia.

4) Siehe S. 19 .

Dannemann, Die Naturwissenschaften. T. 131. 2. Aut1. 
schiedener dekadischer Ordnung, die uns bei den Babyloniern begegnet. Auch in der Bibel wird dieses Verfahren, in offenbarer Anlehnung an das babylonische, zur Abschätzung großer Mengen gebraucht 1 ).

Die Keilschrifttafeln besaßen vor den Papyrusrollen den Vorzug, daß sie so gut wie unzerstörbar waren, zumal wenn sie gebrannt wurden.

Ein sehr reiches Material förderte die Entdeckung der Bibliothek Assurbanipals (Sardanapals) durch Layard (s. vor. Seite) zutage. Dieser König (668-626) unterhielt eine Bibliothek, für die er zahlreiche Werke anderer Archive, die bis auf das Jahr 1900 v. Chr. zurückgehen, abschreiben ließ. Von dieser Sammlung sind etwa 25000 Tafeln auf uns gekommen. Sie sind die wichtigste Fundstelle der babylonisch-assyrischen Literatur. Für die Geschichte der Wissenschaften sind sie dadurch besonders wertvoll, daß sie manches Bruchstück mathematischer, medizinischer und astrologischer Werke enthalten. Bei der Eigenart und Unvollständigkeit dieser Urkunden kann es nicht wundernehmen, wenn sich im Beginn ihres Bekanntwerdens auch manche unhaltbare Kombination auf ihnen aufgebaut hat.

Die Bibliothek Sardanapals befindet sich heute im Britischen Museum. Sie wurde besonders in den letzten Jahrzehnten des 19. Jahrhunderts in Ninive ausgegraben und enthält allein etwa 4000 T'afeln mit astrologischen Aufzeichnungen. Seitdem erkannte man mit Bestimmtheit, daß die Astrologie auf die Babylonier und die Assyrer zurückgeht, während man früher darüber nur die Nachrichten der griechisch-römischen Literatur (z. B. Diodor, Bibliotheca historica 2,29 u. f.) besaß. Die astrologischen Keilschriftfunde der Bibliothek Sardanapals sind die weitaus wichtigsten, die man kennen gelernt hat.

\section{Die Mathematik der Babylonier.}

Außser der dezimalen Schreibweise findet sich bei den Babyloniern eine andere, die auf dem Sexagesimalsystem beruht und mit der Teilung des Kreisumfanges durch Abtragen des Radius, sowie der Einteilung des Jahres in 360 Tage zusammenhängt. Die Auffindung und die Entzifferung von Keilschrifttafeln hat bewiesen,

1) Beispiele führt Cantor Bd. I. S. 71 in größerer Zahl an. So heißt es Samuel I. 18: Saul hat tausend geschlagen, David aber zehntausend. Und an anderer Stelle: Tausend mal tausend dienten ihm (Daniel 7. 10). 
daß das Sexagesimalsystem von den Babyloniern schon unter Berücksichtigung des Prinzips des Stellenwertes angewandt wurde. So enthält eine Tafel, die 1854 bei Senkereh gefunden wurde, die ersten 60 Quadratzahlen in folgender Anordnung:

\begin{tabular}{|c|c|c|c|}
\hline 1 & ist $\mathrm{da}$ & Quadrat & von \\
\hline 4 & » & » & , \\
\hline 9 & . & » & $\gg$ \\
\hline & » & » & $"$ \\
\hline $1+4$ & " & $»$ & $»_{1}$ \\
\hline $1+21$ & » & , & $»$ \\
\hline $1+40$ & $\Rightarrow \quad$ & $\gg$ & » \\
\hline
\end{tabular}

Dies ist nur verständlich, wenn die 1 vor 4,21 und 40 als sexagesimale Einheit höherer Ordnung, nämlich als 60 aufgefaßt wird.

Ein anderes Täfelchen von Senkereh enthält die Kubikzahlen von 1 bis 32 unter Anwendung des Sexagesimalsystems und des Prinzips des Stellenwertes. Ob für fehlende Einheiten ein besonderes Symbol, also etwas, das der Null entspricht, gebraucht wurde, ist nicht ersichtlich, weil unter den Kubikzahlen von 1 bis 32 keine vorkommt, die nur aus Einheiten der ersten und dritten Stufe zusammengesetzt ist ${ }^{2}$. Neben ganzen, nach dem Sexagesimalsystem gebildeten Zahlen kommen auch Sexagesimalbriiche vor.

Während die Ägypter dem Zähler ihrer Brüche den konstanten Wert 1 beilegten, begegnet uns in den Briichen der Babylonier der konstante Nenner 60 oder $3600(60 \times 60)$. Die Brüche 1/2 oder $1 / 3$ wurden durch $30 / 60$ oder $20 / 60$ ausgedrückt und eine der Dezimalbruchform älnnliche Schreibweise benutzt ${ }^{3}$ ).

Das Sexagesimalsystem nahmen später die griechischen Astronomen an. Ihrem Beispiele folgten die Araber und das Mittelalter, bis endlich in der Neuzeit die dezimale Schreibweise aufkam.

Die für die Geschichte der Mathematik so wichtigen Tafeln von Senkereh dürften etwa um dieselbe Zeit entstanden sein, in

1) Auf den Tafeln sind die Zahlen selbstverständlich obne Zeichen nebeneinander gestellt.

Unter den neubabylonischen Tafeln der Berliner Sammlung findet sich der Grundriß eines größeren Gebäudıs. Anf diesem Grundriß sind die Abmessungen durch Zahlen nach dem Sexagesimalsystem verzeichnet, z. B. $11 \cdot 60+40(=700)$.

2) Nach E. v. Lippmann ist es sogar sehr unwahrscheinlich.

3) Siehe auch Tropfke, Geschichte der Elementarmathematik. Bd.I. S. 76. 
der das mathematische Handbuch des Ahmes in Ägypten verfaßt wurde.

Die Rechenkunst der Chaldäer war, nicht nur nach den gefundenen Schriftdenkmälern, sondern auch nach griechischen Quellenschriften zu urteilen, eine uralte. So heißt es bei Theon von Smyrna 1), die Ägypter hätten bei der Untersuchung der Planetenbewegungen gezeichnet, die Chaldäer dagegen gerechnet, und von diesen beiden Völkern hätten die griechischen Astronomen die Anfänge ihrer Kenntnisse erhalten. Daß indessen auch die geometrischen Kenntnisse der Babylonier nicht gering waren, ist aus ihren Wandzeichnungen und ihrer hochentwickelten Baukunst - wandten sie doch bereits lange vor den Etruskern Bogengewölbe an - zu schließen. So findet sich die Sechsteilung des Kreises als bewußte geometrische Konstruktion; eine Tontafel geometrischen Inhalts enthält sogar die Dreiteilung des rechten Winkels. An die Sechsteilung des Kreises schloß sich ferner die Teilung des ganzen Kreisumfanges in 360 Grade.

\section{Der Ursprung der Astronomie.}

Nachdem wir die Anfänge der Mathematik kennen gelernt haben, wenden wir uns den frühesten naturwissenschaftlichen Problemen zu, an denen șich das mathematische Denken erproben sollte. Die am Himmel sich abspielenden Vorgänge waren es, die zuerst den Begriff einer gesetzmäßig verlaufenden Erscheinung aufkommen ließen. Es ist daher kein Zufall, daß man sich diesen Vorgängen vor allen anderen mit forschendem Blick zuwandte und daß die Astronomie neben der Mathematik zu den ersten Betätigungen des menschlichen Geistes gehört, die Anspruch auf den Namen einer. Wissenschaft erheben können. Auch auf diesem Gebiete sind nicht etwa die Griechen die Urheber gewesen, sondern Hand in Hand mit der Entstehung der Mathematik entwickelte sich bei den Ägyptern und den Chaldäern, begünstigt durch die wolkenlose Atmosphäre des Niltals und Mesopotamiens, eine Summe von astronomischen Kenntnissen, die für die Griechen und die späteren Völker die Grundlage für jeden weiteren Fortschritt geworden sind.

Die frühesten astronomischen Eindrücke, denen sich der Mensch selbst auf der tiefsten Stufe seiner Entwicklung nicht entzogen

1) Theo Smyrnaeus (ed. Ed. Hiller). Leipzig 1878. S. 177. 
haben kann, sind die scheinbare tägliche Bewegung der Gestirne, die im steten Wechsel sich wiederholenden Lichtgestalten des Mondes, sowie die scheinbare jährliche Bewegung der Sonne mit dem dadurch bedingten Kreislauf der Jahreszeiten gewesen. Einer etwas aufmerksameren Beobachtung konnte es nicht entgehen, daß die Mehrzahl der Sterne ihre Stellung zueinander nicht verändert, während die Sonne, der Mond und die bald in die Augen fallenden Wandelsterne an den Fixsternen vorüberziehen.

So unterschieden schon die älteren ägyptischen Sternkundigen die "nimmer ruhenden" von den "sich nie rührenden" Sternen. $\mathrm{Zu}$ den ersteren zählten sie Jupiter, Saturn, Mars, den sie seiner Farbe wegen auch den Roten nannten, Merkur und Venus. Die Gruppierung der Sterne zu Sternbildern als erstes Mittel zur Orientierung am Fixsternhimmel rührt nicht, wie man früher annahm, von den Griechen her. Die Sternbilder entstanden vielmelır, wie die Astronomie überhaupt, im alten Orient.

Ein aus dem ersten nachchristlichen Jahrhundert stammendes ägyptisches Verzeichnis der Planeten und Tierkreisbilder ist vor einigen Jahren bekannt geworden ${ }^{1}$ ). Es lautet: Das Verzeichnis der fünf lebenden Sterne:

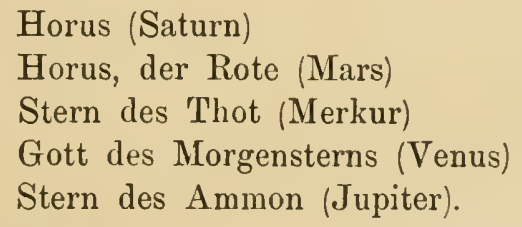

Horus (Saturn)

Horus, der Rote (Mars)

Stern des Thot (Merkur)

Gott des Morgensterns (Venus)

Stern des Ammon (Jupiter).

Die Tierkreisbilder werden genannt „Die zwölf Sterne fiir jeden der zwölf Monate“. Es gelang, die ägyptischen Benennungen für folgende Tierkreisbilder zu identifizieren: Wage, Stier, Zwillinge, Krebs (?), Löwe, Jungfrau, Schütze (?), Skorpion und Fische.

Schon den ältesten Beobachtern mußte es auffallen, daß hervorragende Fixsterne bald in der Nähe der untergehenden Sonne gesehen werden, dann in ihren Strahlen verschwinden, um nach einiger Zeit vor der aufgehenden Sonne zu erscheinen, und schließlich wieder in der Nacht zu glänzen.

So gelangte man zu der Erkenntnis, daß die Sonne im Laufe einer Periode, die sich mit demjenigen Zeitraum deckt, innerhalb

1) Wilhelm Spiegelberg, Orientalistische Literaturzeitung, 1902. S. 6. Es fand sich unter einer großen Menge Ostraka (durch Einritzen beschriebene Tonscherben), welche die Straßburger Bibliothek erwarb, und wurde von Spiegelberg entziffert. Der Text ist demotisch. 
dessen sich die Jahreszeiten abspielen, einen Umlauf am Himmel vollendet. Diejenigen Sternbilder, durch welche sich das Tagesgestirn dabei hindurchbewegt, nannte man den Tierkreis.

Unter allen Fixsternen schenkten die alten ägyptischen Astronomen dem Sirius die meiste Beachtung. Sie nannten ihn Sopd, woraus die Griechen Sothis gemacht haben. Mit dem heliakischen Aufgang ${ }^{1}$ ) des Sirius, der mit dem Beginn der Nilschwelle zusammenfiel, ließ man das Jahr anfangen. Man teilte es in zwölf Monate, von denen jeder dreißig Tage zählte2). Sternwarten befanden sich in Dendera, Memphis und Heliopolis. Dort wurden alle deutlich sichtbaren Sterne aufgezeichnet und in ihrer Bewegung verfolgt. Von den auf diese Weise entstandenen Tafeln sind nur wenige Trümmer auf uns gelangt. Den Himmel stellte man sich, wie es später der Verfasser der biblischen Schöpfungsgeschichte getan, als eine die Erde umgebende Flüssigkeit vor. Auf dieser ließ man die Gestirne schwimmen. Dementsprechend sehen wir auf ägyptischen Denkmälern jedes Gestirn, durch seinen Genius in Menschen- oder Tiergestalt repräsentiert, in einer Barke hinter dem Sonnengott Osiris herfahren.

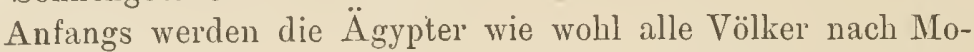
naten gerechnet haben. Daß sie so früh zu einem Sonnenjahr ïbergingen, hängt damit ..zusammen, daß die Nilschwellen, nach denen sich das Leben in Ägypten regelt, von dem Gang der Sonne abhängen. Das erste Anschwellen des Niles fiel Jahrtausende mit dem heliakischen Aufgang des Sirius, d. h. mit seinem Erscheinen in der Morgendänmerung zusammen ${ }^{3}$. Mit dem Zeitpunkt, an dem der Sirius frühmorgens wieder sichtbar wurde, ließen die $\ddot{A}$ gypter ihr Kalenderjahr beginnen. Es zerfiel in drei Jahres-

1) Geht ein Gestirn gleichzeitig mit der Sonne auf, so spricht man von seinem heliakischen oder Frühaufgang. Dabei ist der wahre Frühaufgang, der wohl ermittelt, aber nicht beobachtet werden kann, von dem sichtbaren Frühaufgang zu unterscheiden. Letzterer Zeitpunkt tritt ein, wenn das Gestirn schon etwas vor dem Aufgang der Sonne erscheint, so daß es in der Dämmerung wabrzunehmen ist. Der Zeitunterschied beläuft sich auf etwa 20 Tage. Ähnlich liegen die Verhältnisse beim heliakischen Untergang.

2) Der Beginn der ersten ägyptischen Kalenderorduung wird in das Jahr 4241 v. Chr. verlegt. (E. Meyer, Ägypten zur Zeit der Pyramidenerbauer. Leipzig 1908. Sendschrift der deutschen Orientgesellschaft.)

3) Der Sirius (Sothis) galt daher als der Stern der Isis, welche die Überschwemmung dadurch bewirkte, daß sie, die große Naturgöttin, eine T'räne in den Strom fallen ließ. Siehe auch die Abhandlung "Die Nilschwelle" von W. Capelle in den neuen Jahrbüchern f. d. klass. Altertum. 1914. S. 317. 
zeiten (Überschwemmung, Aussaat, Ernte) von je 4 Monaten zu 30 Tagen. Nach Ablauf dieser 360 Tage wurden 5 Tage eingeschoben, bevor man das neue Jahr beginnen ließ. Da aber das Jahr nicht 365, sondern etwa $3651 / 4$ Tage umfaßt, so mußte sich der Friihaufgang des Sirius alle vier Jahre um einen Tag verschieben, und erst nach Ablauf von 4.365 Jahren fiel der Frühaufgang des Sirius wieder mit dem Beginn des bürgerlichen Jahres von 365 Tagen zusammen. Daß es sich so verhielt, erkennt man noch aus manchen Grabinschriften, die das bürgerliche und das Siriusnenjahr nebeneinander aufweisen ${ }^{1}$ ).

Wie die astronomischen Elemente entstanden sind, hat gleichfalls die neuere archäologische Forschung dargetan. Die Astronomie wurde erst dadurch ermöglicht, daß zur Bestimmung von Winkeln und zur Ausbildung des Ziffernsystems und der Rechenkunst die Zeitmessung hinzutrat. Als die Erfinder eines Verfahrens, die Zeit genauer zu messen und einzuteilen, miissen die Babylonier gelten. Sie bedienten sich dazu der Wasseruhren (Klepsliydren) ${ }^{2}$.

In dem Augenblicke, in dem sich der obere Rand der Sonnenscheibe am Horizonte zeigte, öffnete man ein mit Vasser gefülltes Gefäß, das durch Zufluß stets gefüllt blieb. Der Abfluß geschah tropfenweise in einen Behälter und dauerte solange, bis sich der untere Rand der Sonnenscheibe vom Horizonte löste. Von diesem Augenblicke an sammelte man das abtropfende Wasser in einem zweiten, größeren Behälter, bis die Sonne am folgenden Morgen wieder aufging. Die Wassermengen in dem kleineren und diejenige in dem größeren Behälter wurden genau gewogen. Sie ergaben nicht nur ein bestimmtes Zeitverhältnis, sondern mit einiger Genauigkeit auch das Verhältnis des scheinbaren Sonnendurchmessers zum ganzen Kreise. Waren die Wassermengen $q$ und $Q$, so $\operatorname{ergab}(Q+q): q=360^{\circ}: D$ für den Durchmesser D der Sonne den Wert von etwa einem halben Grad. Die Babylonier setzten deshalb das Verhältnis des Sonnendurchmessers zur Ekliptik = 1:720 ${ }^{3}$.

1) Näheres über die Sothisperiode und andere im Altertum gebräuchliche Ären, d. h. der Einrichtung, die Jahre von einem allgemein anerkannten, festen Zeitpunkt ab zu rechnen, entliält Paulys Real-Encycl. d. klass. Altertumswissensch. unter „Aera“6 (1898. S. 606).

2) Ideler, Über die Sternkunde der Chaldäer. Abhandlungen der Berliner Akad. d. Wissensch. 1814/15. S. 214.

Wie die alten Astronomen hierbei verfuhren, hat $\mathrm{Pappus}$ in seinem Kommentar zum V. Buche des Almagest geschildert.

3) K. F. Ginzel, Die astronomischen Kenntnisse der Babylonier. In den Beiträgen zur alten Geschichte. Bd. I (1902). S. 350. 
Genau würde dieses Verfahren ja nur unter dem Äquator gewesen sein. Da indessen die Schiefe der Sphäre im Lande der Chaldäer nicht allzu groß ist, so ergab sich ein für rohe Messungen genügendes Resultat 1). Aus den babylonischen Überlieferungen ist ferner ersichtlich, daß man das Sonnenjahr zu 365 Tagen rechnete und selbst die ungleich schnelle Bewegung der Sonne während eines Jahres bemerkte ${ }^{2}$.

Den Tag teilten die Chaldäer in 12 Doppelstunden. Die Doppelstunde wurde erhalten, indem man die Zeit, welche die Sonnenscheibe gebraucht, um am Himmel um ihren eigenen Durchmesser vorzurücken, und die man als Doppelminute bezeichnen kann, dem Sexagesimalsystem gemäß mit 60 multiplizierte.

Dieses durch die Verbindung von Mathematik und Astronomie gewonnene System der Zeitmessung blieb für die Folge bestehen, so daß Babyloniens Kulturmission schon allein hieraus ersichtlich ist. Daß später der Zeitabschnitt, nach welchem man den Tag einteilte, und dementsprechend die Unterabteilungen jener Einheit, halbiert wurden, wodurch die heutige Stunde, Minute und Sekunde entstanden, ist von nebensächlicher Bedeutung.

Die Astronomie wurde von den ältesten Völkern nicht nur ihres Nutzens halber gepflegt, sie war gleichzeitig Vorbedeutungslehre, so daß sie infolge der fatalistischen, von der Phantasie beherrschten Anlage der Orientalen sehr bald in Astrologie ausartete. Dazu kam, daß jene Wissenschaft besonders von der Priesterkaste gepflegt wurde, die sich bemühte, ihr Ansehen zu erhöhen, indem sie ihr Tun und Treiben mit dem Schleier des Übernatürlichen und Geheimnisvollen umgab.

Die Anfänge der Astrologie, der man einen semitischen Ursprung zuzuschreiben hat, begegnen uns bei den Sumerern. Besonders der Venus schrieben sie Bedeutung zu. Auch die Symbole der Sonne und des Mondes kehren in ihren Urkunden wieder. Daneben findet sich oft eine Schlange, die vielleicht die Milchstraße vorstellen sollte. Die Anfänge einer wissenschaftlichen Astronomie entwickelten sich erst, nachdem der Stamm der Chaldäer um 1000 v. Chr. in Babylonien eingedrungen war. Von diesem Volksstamm ging der Name "Chaldäer" auf die babylonische Priesterschaft über. Wie diese Namensübertragung zu-

1) Vielleicht haben die Babylonier die Wasserwägung auf den Durchgang der Sonne durch den Meridian bezogen und so den durch die Schiefe der Sphäre bedingten Febler vermieden.

2) Siehe K. F. Ginzel a. a. O. S. 351 . 
stande kam, ist nicht bekannt 1). Man teilte jetzt, zwar immer mit dem Hauptzweck, die astrologischen Untersuchungen methodischer zu gestalten, Äquator und Ekliptik in 360 Grade, bediente sich der Tierkreiszeichen, verfolgte die Wandelsterne und sammelte zahlreiche Sternbeobachtungen, besonders seit der Regierung Nabonassars (747-734), die später die Astronomen Alexandriens benutzt haben, so daß sie uns noch heute im Almagest $\left.{ }^{2}\right)$ begegnen. Was vor dem chaldäischen Zeitalter an astronomischen Kenntnissen bestand, verdient nicht den Namen einer wissenschaftlichen Sternkunde. Daraus, daß man auf alten steinernen Urkunden mitunter ein Sternbild mit dem Bildnis einer Gottheit vereinigt findet, darf man keine allzuweit gehenden Schlüsse ziehen ${ }^{3}$ ).

Es kann nicht wundernehmen, daß uns unter den astrologischen Planetenbeobachtungen am häufigsten solche über die Venus begegnen. Ist sie doch, von Mond und Sonne abgesehen, das einzige Gestirn, das mitunter am Tage, selbst um Mittag, wahrgenommen wird. Die Annäherung der Venus an den Jupiter, den Mars

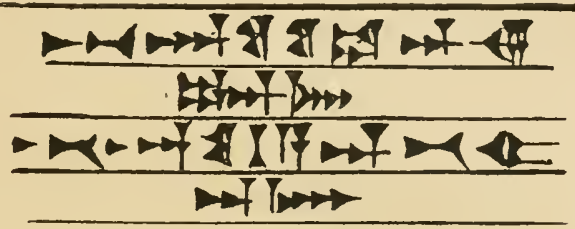

Abb. 3. Keilschriftprobe.

Dilbat ina sensi adi Istar kakkabi

Dilbat ina âribi Bilit ili

Die Übersetzung lautet:

Die Delephat bei aufgehender Soune ist die Istar unter den Sternen,

Die Delephat bei untergehender Sonne ist die Beltis unter den Göttern.

Dies bedeutet, daß die Delephat, d.i. die Venus, als Morgenstern der Stern der Istar-Astarte und als Abendstern der Stern der Beltis-Baaltis ist.

(III. Rawlinson 53, 36. 37.) und den Saturn, ihr Eintritt in den Hof des Mondes, ihr Verschwinden und ihre Wiederkehr galten als bedeutungsvolle Ereignisse. Daß die Venus als Abend- und als Morgenstern dasselbe Gestirn ist, wußten die Babylonier schon in der älteren Periode ihrer Astronomie, d. h. um 2000 v. Chr. (S. Abb. 3.)

An Fixsternen und Sternbildern zählen die Texte nach den bisherigen Feststellungen etwa 200 auf. Darunter begegnen uns schon früh als wichtigste gewisse Tierkreisbilder (Stier, Löwe, Zwillinge). Die Zuweisung von zwölf Tierkreisbildern an eben-

1) E. Meyer, Geschichte des Altertums. Bd. III. 1901. S. 132.

2) Arabischer Name des astronomischen Hauptwerkes von Ptolemäos.

3) E. Meyer, Geschichte des Altertums. Bd. I. S. 527. 
soviel Regionen der Ekliptik findet sich indessen erst in späteren rein astronomischen Texten ${ }^{1}$ ).

Neben den Keilschrifttafeln (s. Abb. 4) sind auch die Darstellungen, die sich auf Grenzsteinen, Reliefs und Grabdenkmälern $\left.{ }^{2}\right)$ finden, zu erwähnen. Sie gehen bis ins 14. Jahrhundert zurück.

Der hier wiedergegebene Grenzstein umfaßt 16 Symbole. Auf der dargestellten Seite befinden sich zu oberst die Venus, dann die Mondsicliel und daneben die Somne. Die linke Seite nimmt

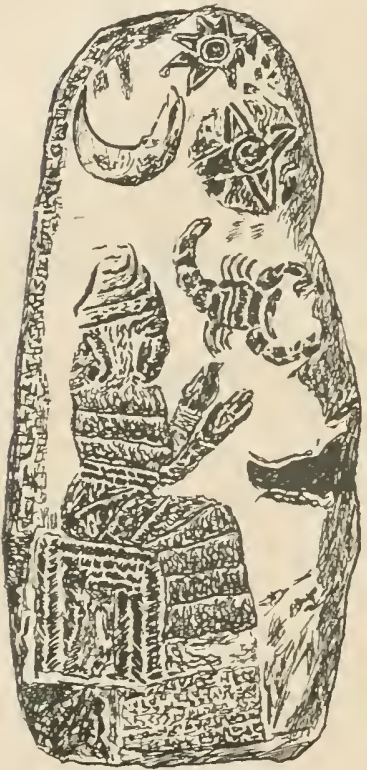

Abb. 4. eine thronende Gottheit ein, zu deren Füßen ein Hund sitzt. In der Kopfhöhe sehen wir einen Skorpion und darunter in der Höhe der Arme eine Lampe.

Regelmäßige Beobachtungen der Bahnen, welche die Planeten am Fixsternhimmel beschreiben, setzen erst um 750 ein. Später werden die fünf Planeten bestimmten Gottheiten zugeteilt und gelten als „Lenker der Schicksale". Seitdem ist die Sternbeobachtung von Astrologie und Fatalismus beherrscht und allein diese Periode ist es, von der die alten Schriftsteller Herodot (um 450 r. Chr.), Diodor (um 45 v. Chr.), Plinius (70 n. Chr.) berichten ${ }^{3}$ ).

Seit der Erschließung der Keilschriftfunde (die erste Übersetzung von Keilschrifttafeln astronomischen Inhalts erschien im Jahre 1874) wurde nachgewiesen, daß manche Namen von Sternbildern, in der ihnen von den Griechen und uns beigelegten Bedeutung, schon bei den BabyBabylonischer Grenzstein.

loniern vorkamen. In Mesopotamien aufgefundene Grenzsteine besitzen sogar graphische Darstellungen der Tierkreiszeichen, deren wir uns noch jetzt in Sternatlanten bedienen ${ }^{4}$ ). Wie es noch heute geschieht, teilten die Chaldäer den Tierkreis in 12 Sternbilder ein. Unter diesen begegnen uns die Wage, der Widder,

1) C. Bezold, Die Astrologie der Babylonier in Bolls Sternglaube und Sterndeutung. B. G. Teubner, Leipzig. 1918. S. 9.

2) So erscheinen die Plejaden in der Siebenzahl auf der Stele (Grabsäule) eines Königs des 7. vorchristlichen Jahrhunderts.

3) E. Meyer, Geschichte des Altertums. I (2). S. 369.

4 Ginzel, Die astronomischen Kenntnisse der Babylonier. 
der Stier, die Zwillinge, der Skorpion und der Schütze, die wir noch besitzen. Die übrigen Bilder haben sich geändert. Von Babylon hat sich die Zwölfteilung der Sonnenbahn dann nach Ägypten und nach Griechenland ausgebreitet. So wurde im Anfange des 19. Jahrhunderts in Dendera (Oberägypten) an der

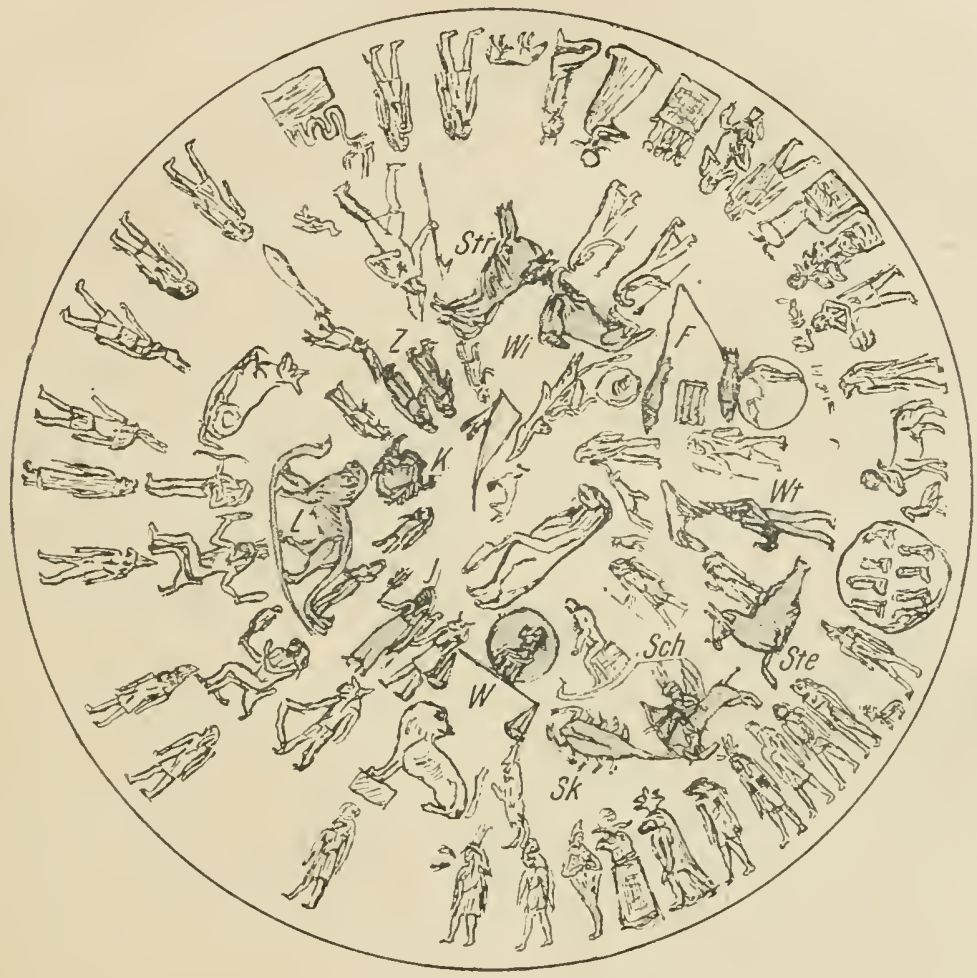

Abb. 5. Der Tierkreis von Dendera.

$\mathrm{Wi}=$ Widder $; \mathrm{Str}=$ Stier $; \mathrm{Z}=$ Zwillinge $; \mathrm{K}=\mathrm{Krebs} ; \mathrm{L}=$ Löwe; $J=$ Jungfrau; $W=W$ Wage; $S k=$ Skorpion; $S c h=$ Schütze; $\mathrm{St}=$ Steinbock; Wt $=$ Wasserträger; $\mathrm{F}=$ Fische.

Decke eines Tempels eine Darstellung des Tierkreises aufgefunden, die in Paris aufbewalurt wird. Die Tierkreiszeichen sind hier den ägyptischen Bildern eingefïgt (Abb. 5). Man schrieb diesem Dokumente anfangs ein sehr hohes Alter zu. Doch gilt es heute als ausgemacht, daß der Tierkreis von Dendera aus der Zeit der Römerherrschaft stammt. Man nimmt ferner an, daß die Griechen ihre Zeichen von den Chaldikern iibernahmen und daß die Ägypter 
die chaldäischen Zeichen mit ihren eigenen Bildern in Verbindung setzten.

Für die astrologische Richtung ${ }^{1}$ ) der ältesten Astronomie spricht ein chaldäisches Literaturdenkmal, das etwa zu der-

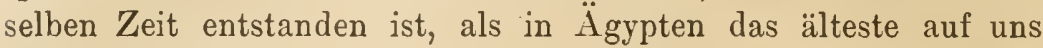
gelangte mathematische Lehrbuch geschrieben wurde (um 1700 v. Chr.). Es handelt sich um einen mit astrologischen Prophezeiungen versehenen Vorbedeutungskalender, den die moderne Orientforschung entziffert hat 2). Dieser Kalender euthält Voraussagen von Finsternissen nebst Andeutungen, welche Ereignisse die Folge jener Finsternisse sein würden.

In besonders hohem Grade werden ungewöhnliche, die Menschheit in abergläubische Furcht versetzende Himmelserscheinungen, wie Finsternisse und Kometen, die Aufmerksamkeit auf die Sternenwelt gerichtet haben. Bezüglich der Finsternisse und der Kometen wurden auch zuerst Aufzeichnungen gemacht. Sie reichen bei den Chinesen, den Ägyptern und den Chaldäern Jahrtausende vor den Beginn unserer Zeitrechnung zurück. Welcher Zeitraum mag verflossen sein, bis die Chaldäer endlich die Regel erkannten, daß die Wiederkehr der Finsternisse innerhalb 6585 Tagen erfolgt. Für das hohe Alter der orientalischen Astronomie spricht auch die Erzählung, daß Aristoteles ${ }^{3}$ ) die Begleiter Alexanders des Großen bat, in Babylon nach den alten astronomischen Beobachtungen der Chaldäer zu forschen. Daraufhin sollen denn auch Ziegel nach Griechenland gelangt sein, auf welchen Nachrichten über 2000 Jahre vor Alexander zurückreichende Beobachtungen eingegraben waren ${ }^{4}$ ). Die chinesischen Nachrichten über Kometen reichen wahrscheinlich ebensoweit zurück. Und die astronomischen Jahrbücher der Ägypter endlich berichten von nicht weniger als 373 Sonnen- und 832 Mondfinsternissen, die vor Beginn der alexandrinischen Periode beobachtet wurden ${ }^{5}$ ).

Die Dauer eines Umlaufs der Sonne wurde in Ägypten wie in Babylon anfangs zu 12 Monaten, jeder zu 30 Tagen, also zu

1) Eine ausführliche Abhandlung von Rie B über die Astrologie im Altertum enthält Paulys Reallexik, d. klass. Altert. Bd. II (1896). .S. 1802.

2) A. H. Sayce, The astronomy and astrology of the Babylonians with translations. London 1874. Siehe auch Cantor I. S. 38 (3. Aufl. 1907).

3) Nach Simplicius, Kommentar zu Aristoteles "De coelo".

4) Wolf, Geschichte der Astronomie. S. 10.

5) H. Suter, Die Geschichte der mathematischen Wissenschaften. Zürich 1873. S. 18. 
360 Tagen gerechnet. Jeder Monat zerfiel in 3 Dekaden, das Jahr somit in 36 Dekaden, denen 36 hervorragende Einzelsterne und Sternbilder zugeteilt waren. Die Abweichung eines Zeitraums von nur 360 Tagen von dem tropischen, auf $3651 / 4$ Tagen sich belaufenden Jahre war jedoch so groß, daß sie schon in der ältesten Zeit auffallen mußte. Man schaltete daher nach jedem Jahre 5 Tage ein, die man "die übrigen Tage" nannte. Diese Änderung der Zeitrechnung erfolgte jedenfalls schon während des alten Reiches, ja sie wird von den Ägyptern selbst in die Zeit vor Mena zurückrerlegt. Aber auch nach dieser Einrichtung bemerkten die Ägypter nach längerer Zeit, daß das Jahr zu kurz bemessen sei und infolgedessen eine Verschiebung der Feste eintrat. Diese Beobachtung führte dann zu einer 238 v. Chr. in Kraft tretenden Anordnung ${ }^{1}$ ), nach welcher jedes vierte Jahr zu 366 Tagen gerechnet werden sollte, „damit es nicht vorkommt, daß einige der öffentlichen Feste, die man im Winter begeht, dereinst im Sommer gefeiert werden".

Die Ägypter sind also dasjenige Volk, denen wir die Einrichtung des Schaltjahres verdanken. Die astronomischen Ratgeber, welche Cäsar bei seiner Kalenderverbesserung vom Jahre 46 v. Chr. zu Rate zog, kannten nämlich die in Ägypten getroffene Einrichtung. Dieser Umstand schmälert jedoch keineswegs das Verdienst Cäsars; ihm verdankt das Abendland die bis ins 16. Jahrhundert dauernde Feststellung seiner Zeitrechnung, die so sehr in Unordnung geraten war, daß im .Jahre $46 \mathrm{r}$. Chr. nicht weniger als 85 fehlende Tage eingeschaltet werden mulsten.

Bis in das 19. Jahrhundert beschränkte sich unser Wissen von der Astronomie des Altertums im wesentlichen auf dasjenige, was uns die Griechen davon iibermittelten. Einen weit tieferen Einblick in die Entstehung der Astronomie hat uns die Entzifferung der Keilschriftfunde gebracht, in denen die Chaldäer ihre astronomischen Kenntnisse niedergelegt haben ${ }^{2}$. Heute gilt als

1) R. Lepsius, Das bilingue Dekret von Kanopus. Berlin 1866. Die betreftende Inschrift wurde von Lepsius im Jalıre 1866 in Unterägypten gefunden.

2) Die aus dem Altertum auf uns überkommenen Nachrichten über die Astronomie der Babylonier hat Ideler zusammengestellt: Üher die Sternkunde der Chaldäer (Abhandlungen der Berliner Akademie d. Wissensch. v. $1814 / 15$ ).

Die in Idelers Schrift zusammengestellten und erläuterten Fragmente waren bis zur Entzifferung der Keilschriftunde, also bis 1870 etwa, die wichtigste Quelle für die Geschichte der babylonischen Astronomie. 
sicher, daß die Babylonier den Äquator und die Ekliptik, die meisten Sternbilder des Tierkreises und der übrigen Regionen des Himmels, sowie die Wandelsterne festgestellt batten und daß sie die Sterne systematisch beobachteten, lange bevor die Griechen dazu übergegangen waren ${ }^{1}$ ).

Zuerst wurde von der Keilschriftforschung Capella (ein Fixstern erster Größe im Fuhrmann) aus Abbildungen identifiziert. Dann geschah dasselbe für zahlreiche Sterne der Ekliptik. Sehr alt sind nicht nur die Tierkreiszeichen, die man auf Grenzsteinen aus dem 12. Jahrl. v. Chr. auffand, sondern auch die Einführung der etwa 30 Planeten- und Mondstationen, deren Gebrauch von Babylon wahrscheinlich nach Indien und nach China gewandert ist ${ }^{2}$.

Ferner begegnen uns schon in sehr alten Keilschrifttexten Namen für die Planeten. Sie sind mit bestimmten Gottheiten in Verbindung gesetzt, so Venus mit Istar (Astarte?), Mars mit dem Kriegsgott. Letztere Zuweisung begegnet uns bekanntlich fast immer wieder und ist aus der rötlichen Farbe des Gestirns erklärlich.

Die Planetenbeobachtungen der Babylonier beschränken sich im wesentlichen auf die Angabe der Stellung zu den Sternbildern, der Oppositionen und der Kehrpunkte, sowie der heliakischen Auf- und Untergänge. Ein Beispiel ${ }^{3}$ ) ist folgendes: „Im 7. Jahre des Kambyses, am 22. Abu des Jahres 523 v. Chr. befand sich Jupiter im ersten Teile von Siru (der Jungfrau) im heliakischen Untergange."

Die Finsternisse und die Kometen wurden frühzeitig als Vorbedeutungszeichen von ganz besonderer Wichtigkeit betrachtet und aus diesem Grunde mit großer Aufmerksamkeit verfolgt. Es finden sich auch Berichte über die Stellung, die bestimmte Planeten während einer Finsternis einnahmen. Solche, aus astrologischem Interesse unternommenen Aufzeichnungen gehen außerordentlich weit zurück. Aus ihnen entwickelte sich ein regelmäßiger Beobachtungsdienst ${ }^{4}$ ), der bis ins 8 . Jahrhundert v. Chr. zurückreicht und sich

1) F. Boll, Astronomische Beobachtungen im Altertum. Neue Jahrbücher f. d. klass. Altert. 1917. S. 17.

2) Siehe Ginzel, „Die astronomischen Kenntnisse der Babylonier und ihre kulturhistorische Bedeutung"6; in den Beiträgen zur alten Geschichte (Klio). 1 Bd. (1901).

3) Nach Ginzel a. a. O. S. 191.

4) Siehe Ginzel a. a. O. (Klio). 
nach der Regierungszeit Sardanapals, während des neubabylonischchaldäischen Reiches, wie die jüngsten Aufschlüsse ${ }^{1}$ ) ergeben haben, $\mathrm{zu}$ hoher Blïte entfaltete.

Das erwähnte, der Bibliothek Sardanapals entstammende astrologische Werk enthält ${ }^{2}$ ) Listen von Fixsternen, Angaben über Planeten, Kometen, Meteore, Verfinsterungen usw. Doch scheint weniger Wert auf die Tatsachen als auf die ihnen zugeschriebene Bedeutung gelegt zu $\operatorname{sein}^{3}$ ). Seit 700 v. Chr. zeigt sich aber deutlich das Bestreben, die Bewegungen der Himmelskörper mit möglichster Genauigkeit räumlich und zeitlich zu verfolgen. Die Winkel werden bis auf 6 Minuten, der Zeitablauf bis auf $3 / 4$ Minuten richtig bestimmt 4 . Die Zeitunterschiede zwischen Sonnenuntergang und Mondaufgang wurden so genau ermittelt, daß die erhaltenen Angaben noch für die heutige Astronomie von Wert sind. Nach Kugler, der sich um die Entzifferung der astronomischen Keilschrifttexte das größte Verdienst erworben hat, war es mit Hilfe dieser Texte möglich, einen Fehler aufzudecken, den die lieutigen Berechnungen der Mondbewegung aufwiesen. Wie weit sich die Genauigkeit einer Bestimmung durch die, über lange Zeiträume fortgesetzte Beobachtung einer periodischen Bewegung steigern läßt, zeigt folgendes Beispiel. Die Babylonier ermittelten, daß der Mond in 669 Monaten 723 32/360 Umläufe am Fixsternhimmel zurücklegt $\left.{ }^{5}\right)$. Daraus ergibt sich für die mittlere Dauer des synodischen Monats ein Wert von $29^{d} 12^{\mathrm{l}} 44^{\prime} 7,5^{\prime \prime}$. Die heutige Astronomie berechnet den mittleren synodischen Monat zu $29^{\mathrm{d}} 12^{\mathrm{h}} 44^{\prime} 2,9^{\prime \prime}$. Die Abweichung beträgt also nur wenige Sekunden.

Die mittlere tägliche Bewegung des Mondes, d. h. den Bogen, den dieses Gestirn durchschnittlich in 24 Stunden durcbläuft, bestimmten die Babylonier $\left.{ }^{6}\right)$ zu $13^{\circ} 10^{\prime} 35^{\prime \prime}$.

1) „Was auf diesem Gebiete die Assyriologie geleistet, gehört zu den erstaunlichsten Ergebnissen der Altertumsforschung und bildet einen der größten Triumphe der Keilsehriftenentzifferung" Bezold, Ninive und Babylon 1903. S. 89\%. Unter den Männern, wclche die Astronomie und die Keilschriftenkunde in einer Person vereinigen, ist besonders $\mathrm{F} . \mathrm{X} . \mathrm{Kugler} \mathrm{zu}$ nennen.

2) Nach Kugler.

3) F. X. Kugler, Sternkunde und Sterndienst in Babel. Münster 1907.

4) Nach Ginzel, Die astronomisehen Kenntnisse der Babylonier.

5) Ginzel, Die astronomischen Kenntnisse der Babylonier.

6) Wie Geminos mitteilt. Wann Geminos lebte, ist nicht genau bekannt (100 v.-100 n. Chr.). Er stammte aus Rhodos und schrieb eine Ein-

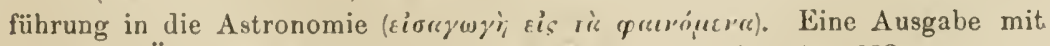
deutscher Übersetzung veröffentlichte K. Manitius. Leipzig 1898. 
Mit gleicher Sorgfalt wurden die Bewegungen der Planeten verfolgt. Sie galten den Babyloniern gleich Mond und Sonne als göttliche Wesen und ihre Wanderung durch die Sternbilder des Tierkreises, den die Babylonier als das „himmlische Erdreich“ bezeichneten, war ihrer Ansicht nach für die Geschichte der Erdbewohner von ausschlaggebender Bedeutung $\left.{ }^{\prime}\right)$. Diesen mythologischen Grundzug der babylonischen Sternkunde hat schon Diodor dargestellt. Er schreibt darüber:

„Die Chaldäer $\left.{ }^{2}\right)$ behaupten, die Welt sei ihrem Wesen nach ewig, sie habe nie einen Anfang genommen und könne auch niemals untergehen; aber durch eine göttliche Vorsehung sei das All geordnet und ausgebildet worden, und noch seien alle Veränderungen am Himmel nicht Wirkungen des Zufalls, auch nicht innerer Gesetze, sondern einer bestimmten und unwandelbar gültigen Entscheidung der Götter. Über die Gestirne haben die Chaldäer seit langer Zeit Beobachtungen angestellt, und niemand hat genauer als sie die Bewegungen und die Kräfte der einzelnen Sterne erforscht. Daher wissen sie auch so vieles von der Zukunft den Leuten vorherzusagen. Am wichtigsten ist ihnen die Untersuchung über die Bewegungen der fünf Sterne, die man Planeten heißt. Sie nemnen sie: ,Verkündiger'. Dem, der bei uns Saturn heißt, geben sie als dem ausgezeichnetsten, dem sie die meisten und die bedeutendsten Weissagungen verdanken, den Namen ,Sonnenstern'. Die vier andern aber haben bei ihnen dieselben Benennungen, wie bei unseren Sternkundigen: Mars, Venus, Merkur und Jupiter. Verkündiger nennen sie die Planeten deswegen, weil sie, während die anderen Sterne von ihrer ordentlichen Bahn nie abirren, allein ihre eigenen Bahnen gehen und eben damit die Zukunft andenten und den Menschen die Gnade der Götter kund machen. Vorbedeutungen, sagen sie, könne man teils an dem Aufgang, teils an dem Untergang der Planeten erkennen, manchmal auch an ihrer Farbe, wenn man aufmerksam darauf achte. Bald seien es heftige Stürme, die sie anzeigen, bald ungewöhnlich nasse oder trockene

1) Wie die Bewegung der Gestirne, so galt auch das Verhalten gewisser Tiere als Omen. In Babylon hat, nach dem Inhalt mancher Keilschriftexte zu urteilen, der Skorpion in dieser Hinsicht eine Rolle gespielt, wie sie heute beim Volke noch der Spinne zugeschrieben wird. Aus dem Verhalten der Skorpione suchte man z. B. das Schicksal der Heere oder den Verlauf öffentlicher Angelegenheiten vorherzusagen. (Mitteilungen zur Gesch. d. Medizin und der Naturwissensch. 1906. S. 326.)

2) Siehe Diodors von Sizilien historische Bibliothek, übersetzt von J. F. Wurm. Stuttgart 1827. Buch II. Kap. 30. 
Witterung, zuweilen Erscheinungen von Kometen, Sonnen- und Mondfinsternissen, überhaupt Veränderungen jeder Art im Luftraum, welche Nutzen oder Schaden bringen für ganze Völker und Länder nicht nur, sondern auch für Könige und gemeine Leute. Dem Laufe der Planeten seien Sterne untergeordnet, welche ,beratende Götter' heißen. Die eine Hälfte dieser Sterne führe die Aufsicht in dem Raum iuber der Erde, die andere unter der Erde. So überschauten sie, was unter den Menschen und was am Himmel vorgehe. Je nach 10 Tagen werde von den oberen zu den unteren einer der Sterne als Bote gesandt und ebenso wiederum einer von den unteren zu den oberen. Die Bewegung der untergeordneten Sterne sei fest bestimmt und gehe regelmäßig fort im ewigen Kreislauf. ,Fürsten der Götter' gebe es zwölf, und jedem von ihnen gehöre ein Monat und eines der zwölf Zeichen des Tierkreises zu, durch welche die Bahn der Sonne, des Mondes und der fünf Planeten gehe. Dort vollende auch die Sonne ihren Kreis in einem Jahre, und der Mond durchlaufe dort seinen Weg in einem Monat.*

Die chaldäischen Priester haben ihre astrologische Tätigkeit auch nach dem Beginn der Perserherrschaft eifrig fortgesetzt. Ähnlich wie die Mönche der späteren Zeit erblickten sie ihre Hauptaufgabe darin, daß sie das vorhandene Wissen durch Abschriften erhielten. Ihr Ansehen beruhte vor allem darauf, daß sie aus den Sternen Menschen- und Völkerschicksal verkündeten. $\mathrm{Zu}$ diesem Zwecke unterhielten sie in Verbindung mit den Tempeln Observatorien und an diesen wieder Schulen. Ihre Beobachtungen leiteten zu gewissen Zahlen, wach denen sie Finsternisse und Sternkonjunktionen berechneten. Solche Berechnungen sind noch auf Tontafeln erhalten, z. B. diejenige über die Mondfinsternis rom 16. Juli 523, die in den Almagest iibergegangen ist. Nach der herrschenden Anschauung sollten sich die Götter in den Gestirnen, besonders in den Planeten verkörpern und letztere die irdischen Vorgänge bestimmen. Es galt daher, für jede wichtige Handlung den richtigen $/ /$ eitpunkt $\mathrm{zu}$ bestimmen und ungünstige Konstellationen zu vermeiden. Eine Priesterschaft, die es wie die chaldäische verstand, diesen Glauben zu nähren, besaß dadurch Macht und Ansehen, sowie die Möglichkeit, sich reiche Mittel zu erwerben ${ }^{1}$.

1) Eingehender lıandelt von der kulturgeschichtlichen Bedeutung der babylonischen und der ägyptischen Priesterschaft E. Meyer im 1. Bande $(1,2)$ seiner Geschichte des Altertums. 
Bei den Planeten achteten die Chaldäer vor allem auf die gegenseitige Stellung, ihre Entfernung von Mond und Sonne, den Wechsel der Bewegungsrichtung und ihren Kehrpunkt. Man kann sich leicht vorstellen, mit welcher Spannung die alten Astronomen z. B. das Verschwinden der Venus in den Strahlen der Abendsonne (den heliakischen Untergang des Planeten) und ihr Wiederauftauchen kurz vor Sonnenaufgang (den heliakischen Aufgang der Venus) verfolgten.

Die Beobachtungen der heliakischen Auf- und Untergänge bildeten das Fundament der Planetenkunde 1). Die Umlaufszeit eines Planeten ist bekanntlich diejenige Zeit, nach welcher der Planet, von der Sonne gesehen, wieder bei demselben Fixstern angelangt ist. Nun läßt sich wohl der geozentrische Ort des Planeten direkt beobachten, nicht aber der heliozentrische. 'Dagegen war man in der Lage, durch die Beobachtung der heliakischen Auf- und Untergänge wenigstens annähernd die Zeit zu bestimmen, die zwischen zwei Konjunktionen des Planeten mit der Sonne verläuft, d. h. die synodische Umlaufszeit zu ermitteln. Ließen sich die Konjunktionen selbst auch nicht beobachten, so nahmen die Planeten doch während der heliakischen Auf- oder Untergänge dieselbe relative Stellung zur Sonne ein.

Um die Wanderung eines Planeten durch die Tierkreisbilder zu verfolgen, ist kein Gestirn geeigneter als Jupiter. Sein Durchgang zwischen den Hyaden und den Plejaden z. B. ist ein astronomisches Schauspiel, das sich den ältesten Beobachtern des Himmels einprägen mußte. Daß sich der Vorgang nach etwa 12 und beim Saturn nach etwa 30 Jahren wiederholt, mußte frühzeitig auffallen. Während für diese beiden, von Sonne und Erde weit entfernten und außerhalb der Erdbahn befindlichen äußeren Planeten die Umlaufsbewegung, vom geozentrischen und vom heliozentrischen Standpunkte gesehen, sich annähernd decken, waren die Erscheinungen für Mars, Venus und Merkur ihrer Nähe wegen bedeutend verwickelter. Doch ergaben die beiden scheinbaren Stillstände, die Opposition des Mars und das Verschwinden in den Sonnenstrahlen auch für diese Planeten eine Periode von steter Wiederkehr und bestimmter Dauer.

1) Nach Kugler, Sternkunde und Sterndienst in Babel. Assyriologische, astronomische und astralmythologische Untersuchungen. I. Buch: Entwicklung der babylonischen Planetenkunde von ihren Anfängen bis auf Christus. Münster 1907. S. 41. 
Zur Seleucidenzeit gelangte man sogar zu Planeten-Ephemeriden. Für Saturn z. B. wurde eine Periode von 59 Jahren, für Venus eine solche von 8 Jahren ermittelt. Der Fehler in der ersteren belief sich auf etwa einen halben Grad. Die aus den Ephemeriden berechnete Bewegung der Venus wich von der beobachteten sogar nur um 5 Minuten $\left.a b^{1}\right)$.

Venus galt mit Mond und Sonne als die Beherrscherin des Tierkreises. Die Symbole dieser Dreieinigkeit erscheinen seit dem 14. Jahrhundert auf den Spitzen der Grenzsteine (s. Abb. 4 auf S. 26) ${ }^{2}$ ). Diese Bedeutung der Venus erklärt sich daraus, daß sie alle übrigen Planeten an Glanz weit ïbertrifft. Beeinflußt durch chaldäische Weisheit nennt daher Plinius die Venus Nebenbuhlerin von Sonne und Mond, denn sie verbreite ein so helles Licht, daß es Schatten werfe.

Mit gleicher Sorgfalt wie die Bewegung der Sonne haben die Babylonier auch die Mondbewegung verfolgt. Welch langer Zeitraum mag dazu gehört liaben, bis ihre Aufzeichnungen jene Periode von 223 synodischen Monaten erkennen ließen, innerhalb deren der Mond beziiglich seiner Knoten und seiner Entfernung von der Erde fast zur selben Stellung zurückkehrt. Jene Periode von 18 Jahren und 11 Tagen bezeichneten die babylonischen Astronomen als Saros. Die Kenntnis dieser Periode ermöglichte ihnen die Voraussage von Finsternissen. Auch Ptolemäos handelt in seinem Almagest, dem bedeutendsten astronomischen Lehrbuch des Altertums, von dem wir später noch ausführlich liandeln werden, von mehreren Mondfinsternissen, welche die Chaldïer aufzeichneten. Die älteste chaldäische Beobachtung einer Mondfinsternis, die Ptolemäos verwertete, datiert vom Jahre 721 v. Chr. Daß Ptolemäos nicht auf noch ältere, zweifellos vorhandene chaldäische Daten zurïckgriff, ist wolil daraus erklärlich, daß er den älteren Angaben keine hinreichende Genauigkeit zusclırieb ${ }^{3}$ ). Die letzten chaldäischen Beobachtungen, die Ptolemäos erwähnt, gehören der '/eit um 240 v. Chr. an. Sie bezichen sich auf Vergleichungen von Merkur und Saturn in ihrer Stellung zu den Fixsterneı. Uin die erwïlnte Zeit latte indessen schon eine gegenseitige Durchdringung chaldäischer und griechischer Gelehrsamkeit stattgefunden. Schrieb doch schon um 280 v. Chr. der Babylonier

1) Siehe Kugler, Sternkunde und Sterndienst in Babel. Münster 1907.

2) Kugler, Im Bannkreis Babels. S. 57 .

3) Wolff, Geschichte der Astronomie. S. 10. 
Berososi) über die Geschichte seines Volkes ein Werk in griechischer Sprache, von dem leider nur Bruchstücke bei anderen Schriftstellern erhalten sind. Es ist das um so bedauerlicher, als das Werk manche Mitteilung über die Sternkunde der Chaldäer enthielt. Auch die jetzt durch die Keilschriftforschung erwiesene, offenbare Übereinstimmung der biblischen mit der babylonischen Schöpfungsgeschichte geht schon aus dem Bericht des Berosos hervor ${ }^{2}$.

Von den Chaldäern wanderte auch das älteste astronomische Werkzeug, der Gnomon, nach dem Zeugnisse Herodots nach Griechenland. Wann dies geschah, läßt sich mit Sicherheit nicht feststellen, zumal ron alten Schriftstellern rerschiedenen Personen (darunter Anaximander um 550 v. Chr.) das Verdienst zugeschrieben wird, dieses wichtige Werkzeug in Griechenland eingeführt zil haben.

Der Standpunkt, den die Astronomie bei den Chaldäern schließlich erreicht hatte, läßt sich in der Kürze wie folgt kennzeichnen $\left.{ }^{3}\right)$ : Beobachtungen, bei denen die Winkel bis auf $6^{\prime}$ und die Zeit bis auf $40^{\prime \prime}$ genau bestimmt waren, reichten bis ins 7. Jahrhundert v. Chr. zurück. Der Lauf der Sonne und die ungleiche Länge der Jahreszeiten waren bekannt. Vielleicht besaß man sogar eine rohe Kenntnis der Präzession der Nachtgleichen ${ }^{4}$. Die Länge der

1) Berosos war Priester in Babylon. Er gibt selbst an, daß er unter Alexander, dem Sohne Philipps, gelebt habe. Näheres siehe in Christ, Geschichte der griechischen Literatur. 1889. S. 412.

2 K. A. v. Zittel, Geschichte der Geologie u. Paläontologie. 1899. S. 2.

Die Aufzeichnungen des Berosos (Christ, a. a. O.) erregten bei den Juden und den Christen besonderes Interesse durch die mit der Bibel übereinstimmenden, jetzt auch durch Keilschrifttexte bestätigten Mythen von der Sündflut, dem Turmbau zu Babel usw.

3) Nach Ginzel, Das astronomische Wissen der Babylonier. (Klio. 1901.)

4) Nach einer von $H$. Winckler aufgestellten, jedoch sehr fragwürdigen Ansicht. Nach Winckler begann das babylonische Jahr mit dem Frühlingsäquinoktium. Nun wandern die Äquinoktialpunkte in $26000 \mathrm{Jahren}$ durch den ganzen Tierkreis. Der Frühlingspunkt verweilt somit in jedem Tierkreisbild etwa 2000 Jahre. In Anbetracht des großen Zeitraums, über den sich die babylonischen Beobachtungen erstreckten, konnte die Wanderung der Äquinoktien den Babyloniern nach Winckler nicht entgehen. Als ihre Beobachtungen, soweit Urkunden darüber vorliegen, begannen, befand sich der Frühlingspunkt im Stier. Im 8. Jahrhundert v. Chr. war die Frühjahrssonne in den Widder getreten, während sie jetzt schon in den Fischen steht. Damit hängt vielleicht zusammen, daß die Aufzählung der Sternbilder in dem bekannten Verse: Sunt aries taurus ... mit dem Widder beginnt. Daß die Namen der Tierkreisbilder zum Teil mit babylonischen Benennungen zu- 
Monate hatte man mit einer Genauigkeit ermittelt, welche der von Hipparch erreichten gleichkam. Der Begründung der Trigonometrie war durch eine Art Sehnenrechnung vorgearbeitet, so daß auch hierin die Chaldäer als die Vorläufer der Alexandriner, insbesondere des Hipparch, gelten können. Endlich vermochte man mit Hilfe von Ephemeriden den Lauf des Mondes und der Sonne, sowie das Eintreten der Finsternisse mit ziemlicher Sicherheit anzugeben.

Die besonders von Winckler vertretene Annahme von dem hohen Alter der babylonischen Astronomie hat neuerdings Kugler auf das richtige Maß zuriickgeführt 1 . Nach ihm gab es vor dem 8. Jahrhundert noch keine Himmelsbeobachtungen von wissenschaftlicher Genauigkeit. Man kann den Babyloniern daher nach Kugler auch nicht die Entdeckung der Präzession zuschreiben, wie es Winckler (siehe Anm. 4 S. 36) getan hat.

Erblicken wir das Ziel der Wissenschaft darin, daß man das Eintreten zukünftiger Erscheinungen mit einem gewissen Grade von Genauigkeit vorherzusagen vermag, so müssen wir zugeben, daß die Babylonier diese Stufe auf dem Gebiete der Astronomie schon erreicht hatten. Allem Anschein nach ruhte das astronomische Wissen eines Hipparch und eines Ptolemäos, an welche im 15. Jahrhundert Regiomontan und Koppernikus anknüpften, in letzter Linie auf den in Babylonien geschaffenen Grundlagen der Sternkunde 2 .

Ptolemäos beruft sich 13 mal auf babylonische Beobachtungen. Sie fallen alle in die Jahre 721-229 v. Chr. Die Astronomie hat danach wenigstens zum Teil ibren WVeg nach Griechenland über $\ddot{A} g y p t e n$ genommen ${ }^{3}$. Auch ihre astronomischen Hilfsmittel verdankten die Griechen zum 'Teil den Babyloniern, wie sie auch die Ekliptiksternbilder, die Einteilung der Ekliptik in 360 Grade und anderes mehr übernahmen. Durch die Babylonier sind sie ferner mit der Sarosperiode (s. S. 35), sowie mit der mittleren täglichen Geschwindigkeit des Mondes $\left(\begin{array}{llll}13^{\circ} & 10^{\prime} & 36^{\prime \prime}\end{array}\right)$ bekannt geworden.

sammenfallen, weist darauf hin, daß sie, wenn auch auf Umwegen, von den Babyloniern auf uns gelangt sind. (S. auch Bezold, Ninive u. Babylon. 1903.)

1) F. H. Kugler, Im Bannkreis Babels. Münster 1910.

2) Ginzel, Das astronomische Wissen der Babylonier (Klio. 1901. S. 209).

3) Dies entspricht auch einer Angabe des Josephus (Antiquit. I, 8). Siehe auch Kugler a. a. O. S. 117. 


\section{Die ersten Maße und Gewichte.}

Über die von den alten Völkern gebrauchten Maße und Gewichte hat schon vor 80 Jahren Boeckh, den man als den Begründer der vergleichenden Metrologie zu betrachten hat, eingehende Untersuchungen angestellt ${ }^{1}$. Boeckh kam zu dem Ergebnis, daß die meisten antiken Systeme ron den Babyloniern herstammen, daß sich bei dieser Entwicklung indessen auch in einem nicht geringen Grade ägyptischer Einfluß geltend macht. Diese Auffassung hat denn auch die neuere archäologische Forschung bestätigt und wesentlich vertieft ${ }^{2}$.

Die Babylonier fanden nicht nur die Mittel zur Zeitmessung und ein Zeitmaß, das sich bis auf den heutigen Tag erhalten hat, sondern sie schufen, wie neuere archäologische Forschungen dargetan, auch ein Maß- und Gewichtssystem, das für das Altertum grundlegend wurde.

Die Einheit für die Längenmessung, die Doppelelle, war $992 \frac{1}{3} \mathrm{~mm}$ lang. Dies Maß ist neuerdings auf Statuen bei Ausgrabungen entdeckt worden. Daß die babylonische Doppelelle und das Sekundenpendel fast übereinstimmen ${ }^{3}$ ), ist wohl als Zufall aufzufassen. Dagegen hat man angenommen, daß die Gewichtseinheit, die Mine, wie das heutige Kilogramm nach einem bestimmten Grundsatz aus der Längeneinheit abgeleitet worden sei ${ }^{4}$ ).

Wird die Doppelelle nämlich in 10 Teile zerlegt und dieses Zehntel als Kantenlänge für einen Würfel gewählt, den man mit Wasser füllt, so kommt das Gewicht dieser IVassermasse einem Kilogramm sehr nahe, da ja die Doppelelle nur wenig von dem Meter abwich. Das Gewicht dieser Wassermasse stimmt mit der Mine $(984 \mathrm{~g})$ nahezu überein. Die Hälfte dieses Gewichtes, die leichte Mine von $492 \mathrm{~g}$, war während des ganzen Altertums gebräuchlich ${ }^{5}$ ).

1) A. Boeckh, Metrologische Untersuchungen über Gewichte, Münzfüße und Maße des Altertums in ihrem Zusammenhange. Berlin 1838.

2) Siehe den Artikel „Gewichte" von Lehmann-Haupt in Paulys Reallexikon der klass. Altertumskunde. Supplement-Bd. III. (1918.) S. 588-65̃4.

3) Lehmann ist geneigt, hier eine absichtliche Verknüpfung anzunehmen. Beiträge zur alten Geschichte. Bd. I. (1902.) S. 355 .

4, C. F. Lehmann, Über die Beziehungen zwischen Zeit- und Raummessung im babylonischen Sexagesimalsystem (Klio. Bd. I. S. 381 u. f.).

5) Von-anderer Zeit wird bestritten, daß die alten Babylonier schon das Gewicht aus dem Längenmaß abgeleitet hätten und auf das Bedenkliche derartiger Spekulationen, wie sie Lehmann und besonders Winckler (s. S. 36) 
Mit der Anwendung des Hebels zum Abwägen von Waren, Heilmitteln usw. waren schon die ältesten Kulturvölker vertraut. Die Ausgrabungen in Mesopotamien haben zahlreiche, mitunter sehr handlich gestaltete (s. Abb. 6) Gewichtsstïcke zutage gefördert. In Ägypten hat man nicht nur solche bis herab zu Stücken, die wenige Gramm anzeigen, sondern auch zahlreiche $\mathrm{Ab}-$ bildungen von Wagen (siehe Abb. 7) gefunden. Die ägypti-

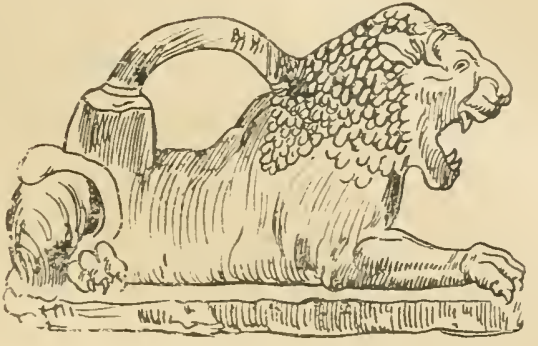

Abb. 6. Altbabylonisches Gewichtsstück. Nach Layard. schen Wagen waren sämtlich zweiarmig. An dem oberen Teile des Gestelles befand sich ein Lot, um die richtige Einstellung der
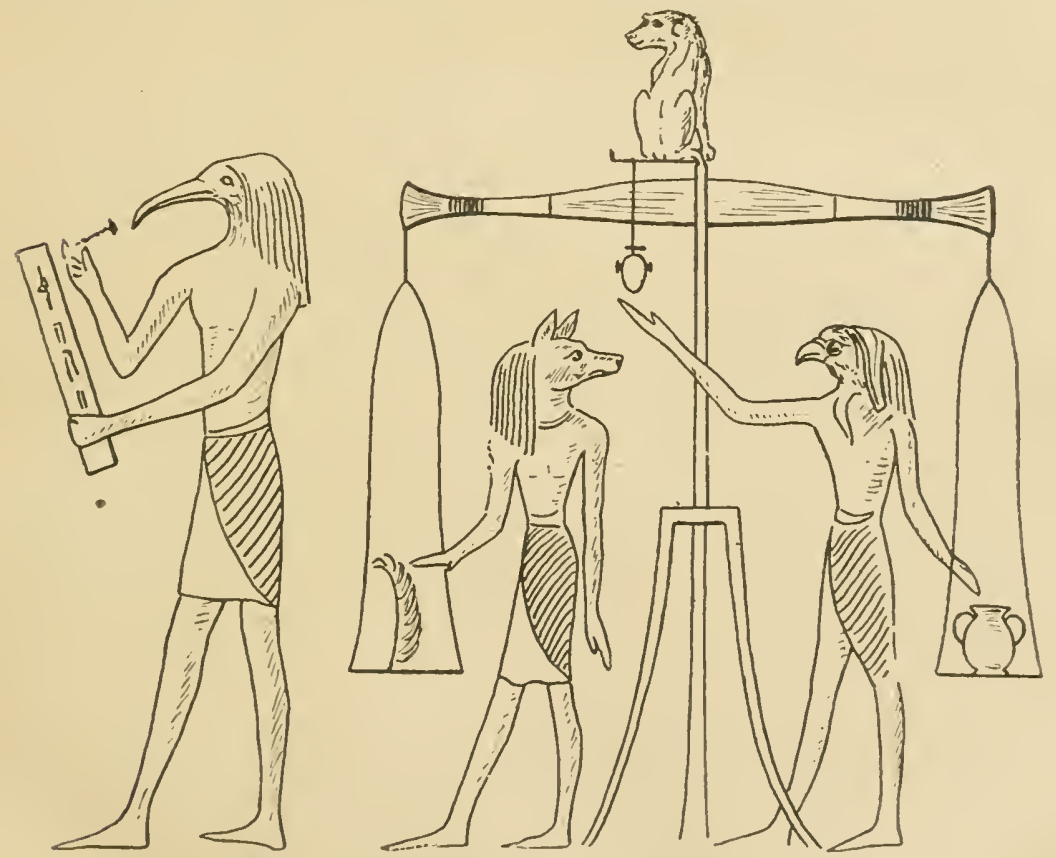

Abb. 7. Wage, einem altägyptischen Totenbuche entnommen

Wage zu kontrollieren. Die Ägypter müssen es verstanden haben, schon ziemlich empfindliche Wagen herzustellen. Aus den Rezepten anstellten, hingewiesen. Siehe u. a. E. Meyer, Geschichte d. Altertums. 1909. S. 518. 
des Papyrus Ebers geht nämlich hervor, daß man als kleinstes Gewichtsstück ein solches benutzte, das nur $0,71 \mathrm{~g}$ wog ${ }^{1}$.

Nach den bisher gewonnenen archäologischen Aufschlüssen haben sich die Ägypter der ungleicharmigen Wage noch nicht bedient. Daß die Agypter aber mit der Wirkung des ungleicharmigen Hebels schon in grauer Vorzeit bekannt waren, beweisen die Wandgemälde Thebens.

Die auf dem Prinzip des ungleicharmigen Hebels beruhende Schnellwage begegnet uns zuerst in Italien. Gut erhaltene Exemplare wurden in Etrurien und in Pompeji ausgegraben 2).

\section{Die Anfänge der Metallurgie und anderer chemisch- technischer Gewerbe.}

Nicht nur auf den Gebieten der Mathematik und der Astronomie, die wir bisher vorzugsweise gewürdigt haben, erlangten die Babylonier und die Ägypter im großen und ganzen die gleiche Stufe der Entwicklung, sondern auch im iibrigen ist die Höhe des Wissens und der Kultur im allgemeinen bei den beiden uralten, unter fast gleichen Bedingungen lebenden und wohl auch stammverwandten Völkern fast dieselbe gewesen. So haben die neueren Forschungen erwiesen, daß die Babylonier wie die Ägypter Eisen herstellten und verarbeiteten. Schon Lepsius lat darauf aufmerksam gemacht ${ }^{3}$, daß auf den, auch in den Farben so wohlerhaltenen, ägyptischen Wandbildern der Kriegshelm blau gemalt ist. Im Grabe Rhamses des Dritten sind auch die Schwerter blau gemalt. In beiden Fällen kann es sich wohl nur um die Wiedergabe eiserner Waffen handeln. Gemalte Holzlanzen der ägyptischen Gräber tragen rote und blaue Spitzen. Wir erkennen daraus, daß neben Eisen auch Kupfer zur Herstellung von Waffen gebraucht wurde. Um den Granit in solch vollkommener Weise

1) Das Medizinalgewicht, das der Verfasser des Papyrus Ebers seinen Rezepten als Einheit zugrunde legt, betrug nach F. Hultsch (Griech. u. röm. Metr. 1882, S. 374 u. 376) ungefähr $6 \mathrm{~g}$ und das kleinste Gewicht namens pek $0,71 \mathrm{~g}$. Vgl. R. Lepsius, Abhandl. d. Berliner Akademie, 1871. S. 41-43 und F. Chabas, Recherches sur les poids, mésures et monnaies des anc. Egypt. Paris 1876. S. 21, 38.

2 Näheres über die Geschichte der Wage, der Gewichte und des Wägens enthält die Schrift: Th. Ibel, Die Wage im Altertum und Mittelalter. Erlangen 1908.

3) Lepsius, Die Metalle in den ägyptischen Inschriften. Abhandl. d. Akademie d. Wissensch. zu Berlin. 1871. S. 111. 
zu bearbeiten, wie es ihre Sarkophage und Obelisken zeigen, mußten die Ägypter wohl auch schon mit dem Härten des Eisens vertraut $\operatorname{sein}^{1}$ ).

Neuerdings haben sowohl die ägyptischen als auch die babylonischen Ausgrabungen zahlreiche Beweisstücke für eine fruihe Bekanntschaft mit dem Eisen zutage gefördert. Immerhin ist nach

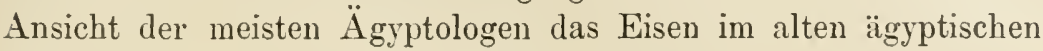
Reich noch sehr wenig in Gebrauch gewesen.

Als älteste Spur dieses Metalls gilt ein in dem Mauerwerk der um 2500 errichteten Cheops-Pyramide gefundenes Eisenstück. Ähnliche Funde liegen aus anderen fast ebenso alten Pyramiden vor (E. v. Lippmann, Alchemie, 1919, S. 610).

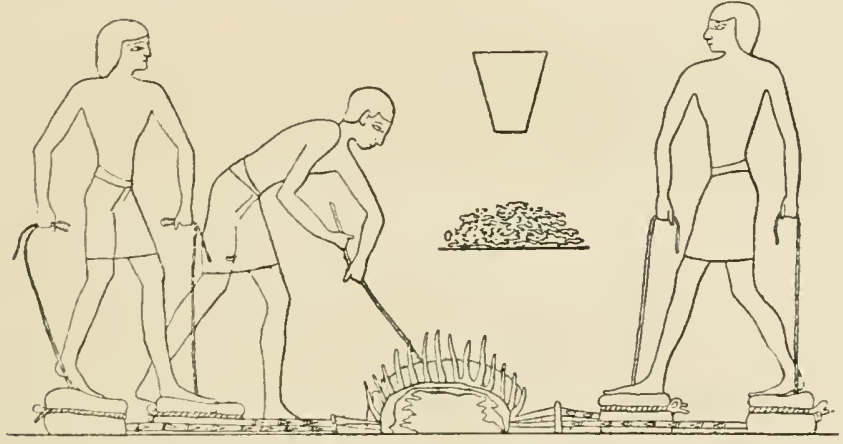

Abb. 8. Gewinnung von Eisen nach altägyptischen Wandgemälden.

Sicher ist die Erfindung des Eisens nicht einem bestimmten Volke zuzuschreiben, sondern sie ist zu verschiedenen Zeiten überall dort erfolgt, wo leicht reduzierbare Eisenerze zur Verfügung standen. Das war nicht nur in Ägypten, sondern auch in Indien, Persien, Palästina und anderen Ländern der alten Kulturwelt der Fall. Eisenerz fehlte auch im mittleren und südlichen Afrika nicht, und es ist anzunehmen, dals man auch dort auf eine primitive Art der Eisengewinnung, die man selbst bei den Hottentotten antrifft, gekommen ist. Die Frage, ob etwa die $\ddot{A}$ gypter durch die Nubier oder durch die Bewohner Vorderasiens mit der Eisengewinnung bekannt geworden sind oder ob sie sie selbstïndig entdeckt lıaben, wird sich wohl kaum je mit Sicherheit entscheiden lassen trotz aller Kontroversen, dic schon über diese Frage geführt wurden.

1) A. Rössing, Geschichte der Metalle. 1901. 
Die Art, wie die Ägypter Eisen darstellten, ist aus vorstehender Abbildung ersichtlich ${ }^{1}$. Sie benutzten Blasebälge aus Leder, die mit den Füßen getreten wurden. Ein Arbeiter bediente zwei solcher Säcke, von denen abwechselnd der eine durch den Zug einer Schnur mit Luft gefüllt wurde, während sich der andere unter dem Druck des Fußes entleerte. Die gepreßte Luft gelangte in eine Feuerung, in welcher das Eisenerz unter der reduzierenden Wirkung eines Kohlenfeuers zu Eisen niedergeschmolzen wurde. Den altägyptischen ähnliche Blasebälge sind noch heutzutage im Innern Afrikas in Gebrauch. Daß auch die Babylonier Eisen herstellten und verarbeiteten, ist nicht nur durch keilschriftliche Aufzeichnungen, sondern auch durch Funde von Helmen, Panzern und Geräten erwiesen.

Noch leichter als das Eisen aus seinen Erzen ließ sich das Kupfer aus Malachit erschmelzen. Zudem besaßen, die alten

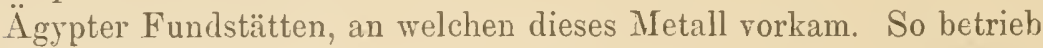
dieses Volk bereits im 5. Jahrtausend v. Chr. auf der Insel Meroë einen umfangreichen Bergbau auf Kupfer ${ }^{2}$.

Metallisches Zink ${ }^{3}$ ) und reines Zinn waren zwar den beiden ältesten Kulturrölkern nicht bekannt ${ }^{4}$ ), doch verstanden sie es, durch einen Zusatz von Erzen dieser Metalle, insbesondere von Galmei, beim Niederschmelzen der Kupfererze Bronze herzustellen, deren Verwendung zu Waffen, Schmucksachen und Geräten bis in die älteste Zeit hinaufreicht. Oft tragen auch die Bronzegegenstände Spuren einer Bearbeitung mit Stahl5). Am frühesten sind Silber

1) A. de Rochas, Les origines de la science et ses premières applications.

2) Rössing, Geschichte der Metalle. S. 11.

3) Die erste schriftliche Erwähnung findet das Zink bei Paracelsus. Er nannte es ,.ein gar fremdes Metall, sonderlich seltsamer als die anderen

4) Neuerdings hat man Gegenstände aus ziemlich reinem Zinn in spätägyptischen Gräbern gefunden. Die Römer unterschieden es als Plumbum candidum von dem Blei, das sie als Plumbum nigrum bezeichneten.

5) Rössing, a. a. O. S. 3. In manchen untersuchten Bronzen ist das Zinn ganz oder zum Teil durch Antimon ersetzt. Entweder wurde dieses Metall in Form von Antimonerz bei der Verhiittung der Kupfererze zugesetzt oder man war im Altertum schon mit der Gewinnung des metallischen Antimons vertraut. Die letztere Ansicht vertritt $\mathrm{Helm}$. Siehe den Jahresbericht über die Fortschritte der klassischen Altertumswissenschaft 1902. III. S. 26-82. (Stadler's Literaturbericht.)

Einen bei den Ausgrabungen in Sakkara zutage geförderten Bronzebarren von der Form, wie ihn die alten Abbildungen zeigen, untersuchte Berthelot (Comptes Rendus 1905. S. 183), Quelques métaux trouvés dans les fouilles archéologiques en Egypte. Dieser Barren enthielt 87,5\% Kupfer und 11,47\% Zinn. Der Rest bestand aus Blei und Patina. 
und besonders Gold gewonnen und verarbeitet worden, da beide Metalle an vielen Orten gediegen vorkommen und ihres Glanzes und ihrer Beständigkeit wegen geschätzt wurden. Die Ägypter betrieben Goldbergwerke in Nubien. Sie kannten die Kunst des Vergoldens und schmolzen Gold in einem bestimmten Verhältnisse mit Silber zu einer Legierung zusammen. Die Ausbeute Nubiens an Gold soll sich zur Zeit Rhamses des Zweiten auf viele Millionen jährlich beziffert haben.

Ein interessantes Schriftdenkmal aus jener Zeit ist ein Grubenriß, der sich auf einem in Turin bewahrten Papyros aus dem 15. Jahrhundert $r$. Chr. befindet. Er stellt den Plan eines Tagebaues auf Gold in allen seinen Einzelheiten dar und ist das älteste Dokument dieser Art, das auf uns gekommen ist ${ }^{1}$.

Eine aus Kupfer hergestellte Wasserleitung weist ein um 2500 v. Chr. entstandener Tempel auf, der in der Nähe des alten Memphis freigelegt wurde. Die Leitung hatte eine Länge von 400 Metern. Die Röhren bestanden aus getriebenem Kupfer und besaßen etwa $4 \mathrm{~cm}$ Durchmesser und $1 \mathrm{~mm}$ Wandstärke2). Die althergebrachte Meinung, daß der Name Kupfer von Cypern stamme, wird neuerdings angefochten. Das Kupfer wurde schon im Altertum auch in den Alpen und in Skandinavien gewonnen. Sein lateinischer Name "Cuprum" wurde wahrscheinlich von den Römern den nordischen Völkern entlehnt ${ }^{3}$.

Ein Beispiel von den Leistungen der alten Völker im Schmieden ist die beriihmte Eisensäule in Delhi. Sie wiegt $11000 \mathrm{~kg}$ und hat ein Alter von etwa 2000 Jahren 4). Die Säule besteht aus sehr reinem Eisen und ist trotz des feuchten Klimas des Landes kaum verrostet. Die Reisenden des Mittelalters erwähnen sie unter Ausdrücken der größten Bewunderung. Sie ist etwa $71 / 2 \mathrm{~m}$ hoch und besitzt einen Durchmesser von $1 / 2 \mathrm{~m}$.

Hand in Hand mit der Gewinnung und der Verarbeitung der Metalle ging die Herstellung von Glas, Email, gefärbten Glaswaren

1) E. Gerland im Archiv f. d. Gesch. d. Naturw. u. d. Technik. 1910. S. 304.

2) Mitteilungen zur Geschichte der Medizin und der Naturwissenschaften. 1909. S. 300.

3) L. Wilser in den Mitteilungen zur Geschichte der Medizin und der Naturwissenschaften. 1907. S. 487. Nach A. Ludwig stammt das Wort aus • dem Hebräischen (Zeitschr. f. d. Kunde des Morgenlandes. 1905. Bd. XIX. S. $239-240$.

4) Rössing, Geschichte der Metalle. S. 14, sowie die Abhandlung Eisen und Stahl in Indien von Dr. E. Schultze im Archiv f. d. Gesch. d. Naturw. a. d. Technik. 1910. S. 350. 
und von Erzeugnissen der Töpferei. Sowohl in Babylonien als in Ägypten war man mit diesen Gewerben vertraut. Die Glasflüsse und Emaillen wurden mit Kupferoxyd und mit Kobaltverbindungen rot und blau gefärbt. Daß man es auch in der Kunst des Schleifens weit gebracht hatte, beweist die Auffindung einer Linse durch Layard ${ }^{1}$ ) in den Ruinen Ninives. Diese Linse befindet sich im Britischen Museum; sie ist 0,2 Zoll dick und besitzt eine Brennweite von 4,2 Zoll. Welchem Zweck sie diente, läßt sich nicht angeben.

Die Glasbereitung, deren Erfindung man mit Unrecht den Phöniziern zugeschrieben hat, wurde in Ägypten schon in der ältesten Zeit geübt. Als Materialien wurden Sand, Soda, Muschelschalen usw. verwendet. Das bekannte Relief von Beni Hassan stellt nicht, wie man früher annahm, Glasbläser, sondern wahrscheinlich Metallarbeiter vor. Das Blasen des Glases kam nämlich erst um den Beginn unserer Zeitrechnung auf. Anfangs wurden die Gläser uiber einem Tonkern geformt, oder man goß die flüssige Glasmasse in Tonmodelle, die man hin- und herschwenkte, um dem erkaltenden Glase die gewünschte Form zu geben ${ }^{2}$ ). Eine ausführliche Darstellung über das Glas im Altertum verdankt man A. Kisa (A. Kisa, Das Glas im Altertume. 978 Seiten mit 395 Abbildungen im Text und zahlreichen Tafeln. Leipzig, K. W. Hiersemann 1908). K isa erwähnt ägyptische Glasfabriken, die zur Zeit Amenophis des Vierten in Tell el Amarna bestanden. Die Ägypter vertrieben ihre Erzeugnisse (z. B. Glasperlen) schon im Massenexport. Von Ägypten aus wurden die Phönizier und die übrigen Mittelmeervölker mit der Bereitung und der künstlerischen Verarbeitung des Glases bekannt.

Von sonstigen chemisch-technischen Gewerben wurden nicht nur die Töpferei unter Anwendung von Email, sondern auch die Färberei mit Benutzung des Alauns als Beize ausgeübt. Als Mineralfarben gebrauchte man Zinnober und Eisenoxyd, wie sie die Natur darbietet. Mennige, Bleiweiß und Kienruß wurden kïnstlich hergestellt. Indem man die in Ägypten natürlich vorkommende Soda der Natronseen mit Öl behandelte, gelangte man zur Erfindung der Seife.

1) A. H. Layard, Niniveh and its remains. London 1849.

2) A. C. Kisa, Die Erfindung des Glasblasens. Jahrbuch für Altertumskunde I. S. 1. 


\section{Die Anfänge der Heilkunde.}

Ein erstaunlich hohes Alter besitzt auch die Heilkunde. Manches ist darüber aus den in Ägypten gemachten Papyrusfunden und aus babylonischen Keilschrifttexten bekannt geworden, doch ist es oft nicht möglich, aus den Beschreibungen die Krankheiten wiederzuerkennen. Welche Entwicklung die Heilkunde in $\ddot{\text { gypten }}$ genommen, das nebenbei als ein gesundes Land galt, erkennen wir aus den Angaben Herodots. Er erzählt: „Die Heilkunde ist bei ihnen geteilt, jeder Arzt beschäftigt sich mit einer Art von Krankheit. Die einen sind Augenärzte, die anderen Ärzte für den Kopf, andere für die Zähne und wieder andere für nicht sichtbare Krankheiten" 1).

Nicht nur das Bedürfnis, Krankheiten zu heilen, sondern auch der Brauch, Leichen zu mumifizieren, wird die $\ddot{A}$ gypter frühzeitig zur Beschäftigung mit dem Bau des menschlichen Körpers geführt haben, wenn auch religiöse Gründe einer, zu wissenschaftlichen Zwecken erfolgenden Zergliederung der Leichen im Altertum wie im Mittelalter recht hindernd im Wege standen.

Das hohe Alter der babylonischen Heilkunde geht schon daraus hervor, daß die Gesetzessammlung Hammurabis auch von medizinischen Gebühren und von der Haftpflicht der Chirurgen handelt. Ein Paragraph ${ }^{2}$ ) bestimmt unter anderem, daß man einem Chirurgen, der das Auge eines Menschen öffne, um den Star zu operieren, beide Hände abhauen solle, wenn das Auge durch den chirurgischen Eingriff zerstört werde ${ }^{3}$ ). Nicht minder barbarisch

1) Herodot II. 84

2) Kodex Hammurabis. Siehe Mitteilungen z. Geschichte d. Mediziu u. d. Naturwissenschaften. 1903. Heft 1. S. 90. Hammurabi (Chammurabi) regierte von 1958-1916. Er hat die herrschenden Rechtsgrundsätze zusammengestellt. Das Gesetzbuch Hammurabis wurde 1901 gefunden.

3) Die Staroperation, der man bisher ein Alter von etwa 2000 Jahren zuschrieb, ist infolge dieser Erwähnung in der Gesetzessammlung $\mathbf{H a m m u r a b}$ is un weitere 2000 Jahre zurückzudatieren. Siehe H. Magnus, Zur Kenntnis der im Gesetzluche des Hainmurabi erwähnten Augenoperationen. Deutsche med. Wochenschrift. 1903. Nr. 23.

Es läßt sich mit Bestimmtheit annehmen, daß diese Gesetze schon vor ihrer Kodifizierung durch lange Zeiträume hindurch Geltung besaßen. Der 118. Paragraph der Sammlung Hammurabis lautet:

,Wenn ein Chirurg jemandem eine schwerc Wunde mit dem kupfernen Skorpionpfriemen macht und den Menschen tötet oder den Star eines Menschen mit dem kupfernen Skorpionpfriemen öffnet und das Auge des Menschen wird zerstört, seine Hände soll man ihm abhauen." 
waren die ägyptischen Vorschriften. Berichtet uns doch Diodor1), daß Ärzte, wenn der Patient starb, Gefalı liefen, als Mörder bestraft zu werden. Da jene ältesten Ärzte ihre Heilmittel aus allen Naturreichen wählten, so waren Medizin und Naturkunde von vornherein aufs engste miteinander verschwistert. Die medizinischen Papyrusfunde zählen ïber 50 Pflanzen auf, die zu Heilzwecken gebraucht wurden. Daneben fanden auch Organe und Sekrete von Tieren, wie Her'z, Leber, Blut, Galle usw., ferner Mineralien wie Kupfersalze und Natron Verwendung.

Ein interessanter Abschnitt aus der Geschichte der Heilkunde ist auch die Behandlung der Zahnkaries. Die Babylonier nahmen an, daß das Hohlwerden der Zähne von Würmern herrühre, welche die Zähne ausnagen sollten. Eine Heilung erwartete man von Beschwörungsformeln. Diese Formeln verbreiteten sich nach Europa und erhielten sich dort bis ins Mittelalter. An die Stelle der Beschwörung oder neben diese trat aber schon sehr frühzeitig eine sachgemäße Behandlung der Krankheit. Man stillte den Schmerz mit giftigen Kräutern und fiillte den hohlen Zahn mit Harz ${ }^{2}$.

Ein Keilschrifttext, der erkennen läßt, in welcher Art oft kosmogonische Vorstellungen mit Gebetformeln und Heilvorschriften vereinigt wurden, lautet folgendermaßen:

"Als Gott Anu schuf den Himmel,

der Himmel schuf die Erde,

die Erde schuf die Flüsse,

die Flüsse schufen die Kanäle,

die Kanäle schufen den Schlamm,

der Schlamm schuf den Wurm.

Da ging der Wurm; beim Anblick der Sonne weinte er.

Vor das Angesicht des Gottes Ea kamen seine Tränen:

Was gibst du mir zu meiner Speise?

Was gibst du mir zu meinem Tranke?

Ich gebe dir das Holz, das faul ist und die Frucht des Baumes.

Was ist für mich faules Holz und die Frucht des Baumes? Laß mich nisten im Innern des Zahnes.

1) Diodor, I. $82,3$.

2) In einem altbabylonischen Texte wird Bilsenkraut als ,die Pflanze, welche die Glieder lähmt" und „Fett vom Baume" (Harz) empfohlen. Mitteil. z. Gesch. d. Med. u. d. Naturwissensch. 1904. S. 221. 
Seine Höhlungen gib mir als Wohnung.

Aus dem Zahne will ich saugen sein Blut.

Weil du dies gesagt hast, IVurm, möge dich schlagen der Gott Ea

mit der Stärke seiner Hände.

Dies diene zur Beschwörung für den Schmerz der Zähne.

Dabei sollst du Bilsenkraut pulvern und mit Baumharz zusammenkneten.

Dies sollst du in den Zahn bringen, während du die Beschwörung dreimal hersagst 1)."

Daß sich durch das Zusammenleben in den oft stark bevölkerten Städten der alten Kulturwelt auch schon eine gewisse Wohnungs- und Volkshygiene herausbildete, darf als sichergestellt gelten. Die Erbauung der Stälte erfolgte oft schon nach bestimmten Plänen. Einen Stadtplan von Ninive hat man auf einer Statue gefunden, deren Alter auf 5000 Jahre beziffert wird. Selbst Wasserleitungen und Kloaken begegnen uns schon bei den Babyloniern und bei den Ägyptern. Wahrscheinlich sind die Griechen, wie in so vielen anderen Dingen, auch hierin die Schüler dieser Völker gewesen. Bei den Assyrern gab es um 700 v. Chr. Städte mit geraden, gepflasterten Straßen, die sogar Bürgersteige aufwiesen ${ }^{2}$ ).

Welchen Umfang die Kenntnisse der Ägypter in medizinischen, botanischen und zoologischen Dingen besaßen, kann man kaum noch feststellen. Viele Einzelheiten lassen sich zwar aus Abbildungen und den auf uns gekommenen Papyrusfunden entnehmen. Wir wissen ferner, daß die angewandte Botanik in $\ddot{g} g y p t e n$ und in Vorderasien ilıren Ursprung genommen hat. So wurden in Agypten drei Weizen- und zwei Gerstenarten, sowie die Hirse (Sorghum) gebaut ${ }^{3}$. Auch betrieb man den Anbau des Rizinus, der Dattel und der Feige, des Weinstocks, der Linsen, Erlosen usw.

1) F. v. Oefele, Zwei medizinische Keilschrifttexte in Urschrift, Umsehrift und Übersetzung. (Mitteil. zur Gesch. der Med, u. d. Naturwissensch. 1901. S. 217 u. f.)

2) H. A. Nielsen, Die Straßenhygiene im Altertum. Arch. f. Hygiene. Bd. 43 (1902). S. 85-115.

3) Eine Liste der in Ägypten und in Palästina angebauten Pflanzen enthält die Abhandlung von Warburg, ,Geschichte und Entwicklung der angewandten Botanik" (Berichte der Deutschen botanisehen Gesellschaft. 1901. S. 153). Für Ägypten kommen unter anderen in Betracht: drei Weizenarten, zwei Gerstenarten, Knoblauch, Porree, Schalotten, Lein, Papyrus, Ölbaum, 
Das umfangreichste medizinische Schriftdenkmal ist der $\mathrm{Pa}$ pyrus Ebers. Er stammt aus Theben und wurde vermutlich um 1500 v. Chr. niedergeschrieben. Der Papyrus Ebers ist in der Hauptsache eine Sammlung ron Rezepten (z. B. Rizinus gegen Verstopfung), Gebeten und Beschwörungsformeln für die verschiedensten Krankheiten. Er gestattet daher keinen Schluß auf den Stand der Medizin im allgemeinen. Obgleich wir keinen, die Chirurgie in gleicher Ausführlichkeit behandelnden Text besitzen, läßt sich aus den Beobachtungen gut geheilter Knochenbrüche und ähnlicher Dinge an Mumien wohl schließen, daß der Stand dieses, durch anatomische Kenntnisse bedingten medizinischen Wissenszweiges ein verhältnismäßig hoher gewesen ist ${ }^{1}$ ).

Die Bereitung der Arzneien erfolgte anfangs durch die Ärzte selbst. Indessen begegnen uns schon im alten Alexandrien und im alten Rom besondere Arzneibereiter. Die Einrichtung von Handapotheken geht bis in die älteste ägyptische Zeit zurück. Die ägyptische Sammlung des Berliner Museums besitzt eine aus dem Jahre 2000 v. Chr. stammende Handapotheke einer ägyptischen Königin. Diese Apotheke war laut geschriebener Widmung ein Geschenk. In den mit Pfropfen verschlossenen Alabastergefäßen befinden sich noch Wurzeln, die Heilzwecken dienten ${ }^{2}$.

\section{Erstes naturgeschichtliches Wissen.}

Manchen Aufschluß über das Verhältnis der alten Ägypter zu der sie umgebenden Tier- und Pflanzenwelt erhalten wir aus den Wandgemälden der Gräber und den Verzierungen der den Toten mit ins Grab gegebenen Schminktafeln. Der Papyrus Ebers enthält auch einige Andeutungen über die Entwicklung des Skarabäus aus dem Ei, der Schmeißfliege aus der Larve, des Frosches

Weinstock, Dattel, Feige, Melonen, Kürbis, Artischocke, Spargel, Rettich, Ackererbse, Pferdebohne, Linse, Kohl, Fenchel, Anis, Absynth, Schlafmohn, Rizinus, Granatapfel. Die meisten dieser Pflanzen wurden auch in Palästina angebaut, wo man auch schon das Pfropfen verstand. Als Werkzeuge sind der Pflug, die Egge, Sicheln, Hecheln und Dreschbretter nachgewiesen.

1) Im Papyrus Ebers finden sich einige Andeutungen, die erkennen lassen, daß die alten Ägypter die Heilung von Wunden durch Nähte förderten. Die erste Beschreibung dieses Verfahrens findet sich bei Celsus. Siehe Gurlts Geschichte der Chirurgie, sowie Erhardt, Die in der Chirurgie gebräuchlichen Nähte und Knoten in historischer Darstellung. (Volkmanns klin. Vorträge $\mathrm{Nr}$. 580/81.)

2) Tierärztliches Zentralblatt. 1903. Nr. 18. 
aus der Kaulquappe $\left.{ }^{1}\right)$. Eine Fülle wohlerhaltener Abbildungen von Tieren und Pflanzen enthalten die aus dem alten Reiche (der V. Dynastie) stammenden Gräber des Ptahhotep und des Ti. Sie gehören der Nekropole des alten Memphis an und liegen in der Nähe der Stufenpyramide von Sakkara. Das Grab des Ptahhotep zeigt uns den Verstorbenen umgeben von seinen Windhunden und Schoßaffen. Diener sind mit dem Schlachten von Opfertieren beschäftigt, oder sie führen Jagdbeute herbei, wie Gazellen und Löwen. Die Jagdszenen enthalten manche Beobachtung aus dem Tierleben, z. B. einen Löwen, der einen vor Schreck gelähmten Ochsen ïberfällt. Ausführlich wird die Weingewinnung dargestellt. Die Bilder zeigen die Pflege des Weinstocks, die Traubenlese und das Keltern. Sehr früh verschwinden aus den Abbildungen die Darstellungen phantastischer Mischgestalten. Besonders die Schmink-

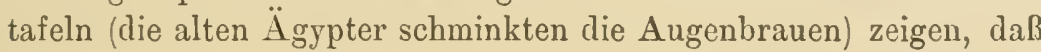
man schon von der ersten Dynastie an mit wenigen Ausnahmen nur wirklich beobachtete Tierformen zur Darstellung brachte ${ }^{2}$.

Mit dem Pferde sind die Ägypter und die Babylonier erst verhältnismäßig spät bekannt geworden. So enthält die Gesetzessammlung Hammurabis zahlreiche Bestimmungen, in denen von Rindern, Eseln, Schafen und anderen Haustieren die Rede ist, aber keine, die das Pferd betreffen. Dieses ist allem Anschein nach erst zu Beginn des 2. Jahrtausends durch arische Stämme, die vom Aralsee her vordrangen, nach Vorderasien und Ägypten gelangt. Durch die Einführung dęs Pfẹdes kam der Streitwagen in Aufnahme, welcher der Kriegsführung ein ganz neues Aussehen verlieh.

Den Übergang von Kulturpflanzen und Haustieren aus Asien nach Europa behandelt Victor Hehn auf Grund der Angaben der griechischen und der römischen Schriftsteller. In seinem Buche konnten, als es 1870 zuerst erschien, die wesentlichsten Ergebnisse der ägyptologischen und assyriologischen Forschungen noch nicht berücksichtigt werden. Die neueren Auflagen des seinerzeit epochemachenden Buches ron Hehn haben sich darin nur wenig geändert. Es ist das Verdienst Hehns, zuerst nachdrücklich darauf hingewiesen zu haben, daß die Fauna und die Flora der Kulturländer durch die Einwirkung des Menschen ganz wesentlich um-

1) R. Burckhardt, Geschichte d. Zoologie. S. 12. Leipzig, Göschensche Buchhandlung. 1907.

2) Eduard Meyer, Ägypten zur Zeit der Pyramidenerbauer. Leipzig 1908. (Sendschrift der deutschen Orientgesellschaft.) 
gestaltet wurden. Dabei bediente sich $\mathrm{Hehn}$ indessen noch vorwiegend der rein philologischen Untersuchung. Daß z. B. das Huhn erst verhältnismäßig spät in Vorderasien und in Europa bekannt wurde, schließt Hehn daraus, daß dieses Tier im Alten Testamente nicht erwähnt wird und sich auch nicht anf den ägyptischen Wandgemälden findet, die im ïbrigen alles, was den Haushalt der alten Ägypter betrifft, ror Augen fülıren. In bezug auf Italien kommt Hehn zu dem allgemeinen Ergebnis, daß seine Pflanzenwelt unter dem Einfluß des Menschen immer mehr einen südlichen und asiatischen Charakter angenommen habe ${ }^{1}$ ). Meldet doch Plinius, daß z. B. der Kirschbaum erst durch Lncullus von der pontischen Küste nach Italien verpflanzt sei.

Die literarischen Belege und die Abbildungen von Pflanzen und Tieren finden eine wertrolle Ergänzung durch die Naturgegenstände selbst, die man in den alten Nekropolen $\ddot{A} g y p t e n s$ gefunden und in dem großen Museum von Kairo rereinigt hat. Man findet dort zahlreiche Mumien von Hunden, Krokodilen, Fischen, Vögeln besonder's dem Ibis), Spitzmäusen, Bos africanus usw. Die Insekten sind besonders durch Skarabäen vertreten. Nicht minder zahlreich sind die Pflanzenreste.

Die Ägypter gelangten auch zu chemischen Operationen, deren Ziel die Herstellung von Heilmitteln aus pflanzlichen Stoffen war. So ist bekannt geworden, daß sie in späterer Zeit zu diesem Zwecke die Destillation ansübten ${ }^{2}$ ) und sich dabei der von ilmen erfundenen Glasgefäße bedienten. In geringem Umfange fanden auch schon anorganische Stoffe, wie Eisenoxyd, Alaun usw., als Heilmittel Verwendung, so daß schon in den ältesten Zeiten ein gewisser Zusammenhang von chemischem Können mit der Pharmazie sich herausbildete ${ }^{3}$ ).

Der ägyptische Alaun galt als der beste (Plin. 35, 184). Besondere Álannwerke, die großen Gewinn abwarfen, bestanden nach Diodor $(V, 15)$ auf Lipara. Wie heute wurden mebrere Abarten unterschieden. Man benntzte Alaun nicht nur in der Heilkunde, sondern auch als Beize, zum Imprägnieren von Holz, um es vor Feuer zu schützen, zum Gerben (Plin. XXXV, 190), also zu vielen Zwecken, denen er noch jetzt dient.

1. v. Hehn, Kulturpflanzen und Haustiere in ihrem Übergange aus Asien. Berlin 1902. S. 520.

2) Gerland und Traumüller, Geschichte der physikalischen Experimentierkunst. Engelmann, Leipzig 1899. S. 9.

3) Meyer, Geschichte der Chemie. S. 16. 


\section{Die alte Kultur Süd- und Ostasiens.}

Nachdem wir das Entstehen der ersten Wurzeln von Kultur und Wissenschaft in Vorderasien und $\ddot{A}$ gypten geschildert haben, erübrigt noch eine kurze Betrachtung der in Indien und in China entstandenen Elemente. Die Bedeutung der Inder für die Entwicklung der Wissenschaften ist erst auf Grund der neueren Sanskritforschung in das rechte Licht geriickt worden, wenn auch noch manche Zweifel und Unklarheiten geblieben sind. Erst seit der Begrïndung der neueren vergleichenden Sprachforschung ist man zu der Erkenntnis gelangt, daß die Inder mit den Griechen, Römern und Germanen eines Stammes sind. Welches die Heimat des vermuteten indogermanischen Urvolkes war, wird sich wohl nie ermitteln lassen. Soviel dürfen wir.indessen annehmen, daß es sich um ein Hirtenrolk handelte, das innerhalb eines gemäßigten Klimas erstarkt war und infolgedessen zu wandern begann. Der neue Boden mußte aber nicht nur der Natur, sondern auch einer auf niedrigcr Stufe stehenden Urbevölkerung abgerungen werden. So drangen die Inder mit ihren Rossen und Rindern von Nordwesten her, einige Jahrtausende vor Beginn unserer Zeitrechnung, in die nach ihnen benannte Halbinsel ein. Zunächst setzten sie sich im Gebiete des Indus fest und drängten von hier aus die dunklen Urbewohner nach Süden und in die Gebirge zuriick.

Während der ersten Stufen, welche die Entwicklung in Indien durchlief, wird keine oder nur eine geringe Fühlung mit den Mittelmeervölkern bestanden lraben. Indes schon mit dem ersten Aufdämmern der Geschichte ist ein Verkehr Indiens mit dem Westen wie mit China nachweisbar, so daß der frïhere Glaube an die völlige Abgeschlossenheit des süd- und ostasiatischen Kultur einer anderen Auffassung hat weichen miissen. In der allerersten Zeit war es der Handel, der eine Verbindung herstellte und dabei den Secweg bevorzugte. Auf diesem Wege gelangten die Erzeugnisse Indiens nach dem Arabischen Meerbusen und von dort den Euphrat und Tigris hinauf. Selbst die Ostküste des entfernten Ägyptens unterhielt leblafte Handelsbeziehungen zu Indien. Und in späterer Zeit durchfuhren selbst römische Schiffe das Rote Meer und den Indischen Ozean, in welchem sich die Seefahrer den regelmäßigen Wechsel der Monsunwinde zunutze machten ${ }^{1}$ ).

1) Ein ausführlicher Artikel über Industrie und Handel im Altertum findet sich im 9. Bande von Paulys Reallexikon, S. 1381-1535. Der Verfasser ist Gummerus. 
Einem Austausch der Waren wird zu allen Zeiten ein Austausch des Wissens parallel gegangen sein. Ein weitcres kräftiges Ferment für eine wechselseitige Befruchtung waren ferner die Ausbreitung der Religionen und die Eroberungszüge. So entstanden später infolge des Alexanderzuges an den Grenzen Indiens griechische Königreiche, die einen regen Austausch auch geistiger Erzeugnisse zwischen den Bewohnern der Mittelmeerländer und Südasiens vermittelten. Zur römischen Kaiserzeit und während der byzantinischen Periode fand sogar ein Verkehr zwischen den indischen und den westlichen Höfen durch Gesandtschaften statt. Ja, unter Kaiser Antoninus ist sogar eine römische Gesandtschaft am chinesischen Hofe erschienen ${ }^{1}$ ).

Für die Geschichte der Wissenschaften kommt insbesondere der Einfluß in Betracht, den die Inder auf medizinischem und astronomisch-mathematischem Gebiete auf die westlich von ilınen wohnenden Völker ausgeübt haben. Besaßen doch später die Araber nicht nur in Galen, sondern nicht minder in den Indern Lehrmeister in der Anatomie und Chirurgie. Unter den Naturerzengnissen Indiens befand sich ferner mancher Stoff, der von den Bewohnern als heilkräftig erkannt und anderen Völkern übermittelt wurde. So hatten sich bei Alexander ${ }^{2}$ ) geschickte indische Ärzte eingefunden, die sich besonders auf die Heilung von Schlangenbissen verstanden. Als ein Beweis für das Alter der indischen Medizin mag auch gelten, daß die Ärzte bei den Indern in hoher Achtung standen ${ }^{3}$.

Unter den späteren astronomisch-mathematischen Schriftstellern der Inder sind besonders Aryabhatta (um 500 n. Chr.) und Brahmagupta (um $600 \mathrm{n}$. Chr.) zu nennen. Bei der Beurteilung ihrer Leistungen ist indessen zu berücksichtigen, daß in den Werken der Sanskritliteratur, die vor Aryabhatta entstanden, auch griechische Einflüsse auf die indische Wissenschaft nachweisbar sind. Hatte es doch lange den Anschein, als ob manche Lehren älterer Sanskritwerke von den Griechen stammen ${ }^{4}$ ). Doch wird neuerdings den Erzeugnissen der Sanskritliteratur eine größere Selbständigkeit zuerkannt.

1) Von den Vorstellungen der Alten über Indien handelt sehr ausführlich Wecker in Paulys Reallexik. d. klass. Altert. Bd. IX. (1914). S. 126t-1325. Die beste Darstellung der antiken Kenntnısse über Indien findet sich in der „Geographie" des Ptolemäos (s. a. spät. Stelle).
2) Nach Arrian.
3) Lassen, Indische Altertumskunde. II. 511.
4) Cantor, I. 509. 
Die ältesten Schriften der indischen Literatur sind die Vedas. In ihnen spiegelt sich das religiöse und soziale Leben der Inder wieder; sie enthalten aber auch die ersten Anfänge der Wissenschaften, die sich bei diesem merkwürdigen Volke zumeist im engsten Zusammenhange mit religiösen Gebräuchen und Empfindungen entwickelt haben. In höchst eigenartiger IVeise hat z. B. der Opferdienst die Entwicklung der indischen Mathematik beeinHlußt. Die Gestaltung der Altäre war nämlich nach der Ansicht cler Inder für den Erfolg des Opfers von der allergrößten Bedeutung. So heißt es in einer Vorschrift: „Wer die himmlische Velt zu erlangen wünscht, schichte den Altar in Gestalt eines Falken." Diese Aufgabe setzt aber eine bedeutende Kenntnis der Flächengeometrie voraus, da sämtliche Steine einer Schicht polyedrisch gestaltet und lückenlos aneinander gefügt die Figur des Falken ergeben mußten. Erhöht wurde die Schwierigkeit dadurch, daß die zweite Schicht, die gleich der ersten etwa zweihundert Steine enthielt, eine andere Anordnung aufweisen und dennoch als Ganzes die erste Schicht decken mußte. Dabei war jedes Formverhältnis ron entscheidender Wichtigkeit, da es nach der Auffassung der Inder Segen oder Unheil bringen konnte ${ }^{1}$;.

Die Schrift über die Altäre ist nach der Ansicht des Herausgebers (B ürk, s. unten) im 4. oder 5. Jahrhundert v. Chr., wenn nicht früher, verfaßt worden. Durch ilıre, beim Bau der Altäre geübte Technik sind die Inder wahrscheinlich auch mit dem Satze vom Quadrat der Hypothenuse schon vor dem 5. Jahrhundert v. Chr. bekannt geworden. Damit ist jedoch nicht etwa gesagt, da $B$ sie den allgemeinen Beweis des pythagoreischen Lehrsatzes gefunden hïtten. Wir dürfen nämlich nicht vergessen, daß auch die unmittelbare geometrische Anschauung sehr oft die Quelle neuer Wahrheiten gewesen ist. So finden wir, daß bei gewissen indischen Altären vier Quadrate (Abb. 9) sich zu einem größeren Quadrat ergänzen. Die vier Diagonalen der kleineren Quadrate

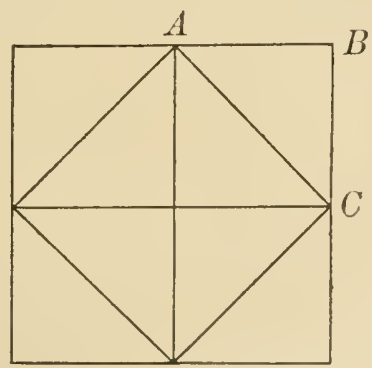

Abb. 9. Geometrische Konstruktionen der Inder. ? ergeben ein neues, über der Hypothenuse AC des gleichseitigen rechtwinkligen Dreiecks ABC crrichtetes Quadrat. Hier beweist

1) $\mathrm{Bürk}$ in der 'Zeitschrift der Deutschen morgenländisehen Gesellschaft. Bd. 55 u. 56. 
die unmittelbare Anschauung die Gültigkeit des pythagoreischen Lehrsatzes für diesen besonderen Fall. In der von Bürk veröffentlichten indischen Quelle ${ }^{1}$ ) heilit es demnach in weiterer Verallgemeinerung: „Die Diagonale eines Rechtecks bringt beides hervor, was die längere und die kiirzere Seite des Rechtecks jede für sich hervorbringen $\left.{ }^{2}\right)$."

Die früher wohl geltende Meinung, daß die indische Geometrie in der Hauptsache griechischen Ursprungs sei, kann also heute, nach der Veröffentlichung wichtiger indischer Quellen ${ }^{3}$ ), nicht mehr aufrecht erhalten werden ${ }^{4}$.

Unter den rechtwinkligen rationalen Dreiecken waren den Indern im 8. vorchristlichen Jahrhundert z. B. diejenigen bekannt, deren Seiten sich verhalten wie:

$$
\begin{aligned}
& 3: 4: 5 \\
& 5: 12: 13 \\
& 8: 15: 17 .
\end{aligned}
$$

Um einen rechten Winkel abzustecken, bediente man sich, wie in Ägypten und später in Griechenland, des Verfahrens des Seilspannens. Die Seitenlängen, welche die Inder dabei benutzten. verhielten sich in der Regel wie $15: 36: 39^{5}$ ), entsprachen also gleichfalls dem pythagoreischen Lehrsatz. Trotz alledem bleibt es wahrscheinlich, daß erst die Griechen von den zahlreichen, bekannt gewordenen Einzelfällen zu dem allgemeinen, früher dem Pythagoras zugeschriebenen, geometrischen Satz gelangt sind.

Auch für eine annähernde Quadratur des Kreises findet sich ${ }^{6}$ ) bei den alten Indern eine Regel. Handelt es sich darum, einen dem Quadrate ABCD flächengleichen Kreis zu finden, so wird $\mathrm{ME}=\mathrm{A} M$ und zwar senkrecht zu AB gezogen (Abb. 10). Zu $M G$ wird $N G=1 / 3 \mathrm{GE}$ hinzugefügt. Mit der so erhaltenen Strecke

1) Kap. 1. 4. in der Zeitschrift der Deutschen morgenländischen Gesellschaft. 56. Bd. (1902.) S. 328.

2) Die Konstruktion von Altären unter Verwendung rechtwinkliger Dreiecke, deren Seiten sich wie ganze Zahlen verhalten, geht vielleicht in das 8. vorchristliche Jahrhundert zurück. Mitteil. z. Geschichte d. Medizin u. Naturwissenschaften. 1906. S. 473.

3) Vor allem des Apastamba Sulbasutra.

4) Siehe Zeuthens Bemerkungen in der Biblioth. mathem. (3. Folge). V. $97-112$.

5) Cantor, Über die älteste indische Mathematik. Arch. f. Math. und Physik. 1904.

6. Ap. Sulb. Sutra. III. 2. Zeitschr. d. morgenl. Gesellsch. Bd. 55 и. 56. Abhandlung Bürks. 
MN als Radius wird dann der Kreis um M geschlagen. In der indischen Vorschrift heißt es: „Soviel wie (an den Ecken) verloren geht, kommt (die Segmente) hinzu."

Von jeher haben die Inder als ein besonders für die Aritlmetik beanlagtes Volk gegolten. Ist es doch ihr Verdienst, das Positionssystem und seine irrtümlich als arabisch bezeichneten Ziffern erfunden zu haben. Wie uns die Tafeln von Senkereh1) beweisen, besaßen die Babylonier ein Positionssystem, das sexagesimal war, aber die Null entbehrte. Die späteren Inder entwickelten durch Einführung der Null und der dekadischen Einheiten die heutige Positionsarithmetik, die dann dem Abendlande durch die Araber übẹrmittelt wurde.

Je mehr die archäologischen Forschungen uns mit dem Wissen des alten Orients bekannt machen, um so mehr befestigt sich die Überzeugung, daß in einer dreibis viertausend Jahre zuriickliegenden Zeit die Babylonier, die Inder und die Ägypter einen gemeinsamen Besitz an Kenntnissen besaßen. Ohne Kweifel sind jene ersten Kulturvölker

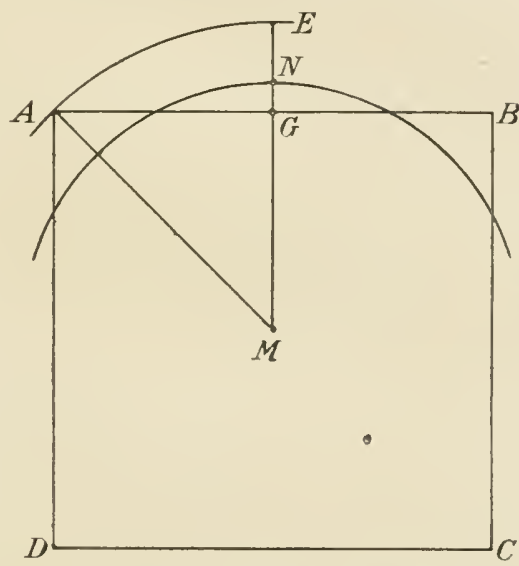

Abb. 10. Die Quadratur des Kreises bei den Indern. unabhängig roneinander in den Besitz mancher Wahrheit gelangt. Doch hat gewiß auch ein viel regerer Austausch der Kenntnisse stattgefunden als man bisher angenommen hat 2 .

Für die engen Beziehungen, die zwischen Babylon und Ägypten bestanden, fehlt es nicht an Beweisen ${ }^{3}$. Als ein Zeichen, dals der babylonische Einfluf auch nach Indien, ja selbst bis China reichte, kann die Tatsache betrachtet werden, daß die indischen und die chinesischen Quellen die Dauer des längsten Tages auf $14^{\mathrm{h}} 24^{\prime}$ angeben, ein Wert, der fuir Babylon bis auf eine Minute zutrifft $\left.{ }^{4}\right)$.

Während die wechselseitige Beeinflussung des ältesten ägyptischen, babylonischen und indischen Wissens mehr vermutet als

1) Siehe S. 19.

2) Cantor, Ưber die älteste indische Mathematik i. Arch. f. Math. u. I'hys. 8. Bd. (1904).

3) Siehe S. 6. 4) Cantor, a. a. O. S. 71. 
im einzelnen nachgewiesen werden kann, sind die Beziehungen einerseits zwischen indischer, andererseits zwischen griechischer und arabischer Wissenschaft deutlich zu erkennen. Insbesondere hat zwischen Indern, Griechen und Arabern ein Austausch mathematischer und astronomischer Kenntnisse stattgefunden. Da wir auf die Inder in späteren Abschnitten nicht mehr zurückkommen werden, so soll an dieser Stelle noch einiges über die Entwicklung, die besonders die Rechenkunst bei den für die Arithmetik so gut beanlagten Indern genommen hat, ins Auge gefaßt werden.

Unbestritten ist das Verdienst der Inder, die neuen Zahlzeichen und die Null geschaffen und das Ziffernrechnen unter Anwendung des Stellenwertes zu hoher Ausbildung gebraclit zu haben. Das Rechnen mit der Null ist schon zur Zeit des Brahmagupta in Gebrauch gewesen. Auch die Schreibweise für.die Brüche und die Bruchrechnung weichen von den heute geltenden Regeln kaum ab. Zwar fehlte der Bruchstrich, doch wurde der Zähler schon über den Nenner gestellt. Bei gemischten Brüchen kamen die

Ganzen in eine dritte, noch höhere Stufe; $2^{3 / 4}$ schrieb man z. B. 3.

Das Multiplizieren der Brüche lehrt Brahmagupta mit folgenden Worten: „Das Produkt aus den Zählern teile durch das Produkt aus den Nennern." Bei den indischen Mathematikern finden sich ferner Regeldetriaufgaben mit direktem, indirektem und zusammengesetztem Ansatz. Letztere werden in mehrere einfache Regeldetriaufgaben zerlegt. Es sind sogar besondere Kunstausdrücke für die Regeldetri-Rechnung in Gebrauch ${ }^{1}$ ).

Wie die Inder durch Einführung der Null und des Positionssystems den größten Fortschritt für die Arithmetik schufen, so erwarben sie sich für die Algebra kein geringeres Verdienst durch die Einführung der Begriffe positiv und negativ. Sogar die Erläuterung dieser Begriffe durch die Worte Schulden und Vermögen, ja ihre Erklärung durch Vorwärts- und Rückwärtsschreiten auf einer gegebenen Strecke war ihnen schon geläufig. Wollte man eine Zahl als negativ bezeichnen, so wurde ein Punkt darüber gesetzt. Selbst bei den Gleichungen wurden negative Lösungen, welche Dioplant (350 n. Chr.) noch für unstatthaft erklärte, zugelassen.

Was die arithmetischen und die geometrischen Reihen, die Quadrat- und die Kubikzahlen anbelangt, so konnten die Griechen in dieser Hinsicht von den Indern wenig lernen. Letzteres Volk

1) Tropfke, Geschichte der Elementarmathematik. Bd. I. S. 98. 
schuf jedoch die Kombinationslehre und die Anfangsgründe der Algebra. Ferner gelangte man in Indien dadurch über die Lehre von den Potenzen einen Schritt hinaus, daß man für die irrationale Quadratwurzel eine Bezeichnung einführte. An das Erheben in die 2. und die 3. Potenz sclilossen die Inder als Umkehrungen dieser Operationen das Ausziehen der Quadrat- und der Kubikwurzel. Hierbei bedienten sie sich schon der binomischen Formeln für $(a+b)^{2}$ und $(a+b)^{3}$. Ja, ihre Art, die Wurzeln zu finden, stimmte soweit mit dem heutigen Verfahren überein, daß bei ihnen selbst das Abteilen der zu radizierenden Zahl zu je zwei oder drei Stellen nicht fehlte.

Auf dem Gebiete der Algebra entwickelten die Inder vor allem die Lehre von den Gleichungen verschiedenen Grades. Für die unbekannte Größe wird ein Zeichen gebraucht. Als ein Beispiel zugleich für die poetische Form, in welche die Inder solche Aufgaben einkleideten, diene folgendes: Von einem Schwarm Bienen läßt $1 / 4$ sich auf einer Blume nieder, $2 / 3$ fliegt zu einer anderen Blume, eine Biene bleibt übrig, indem sie gleichsam durch den lieblichen Duft beider Blumen angezogen in der Luft schwebt. Sage mir, reizendes Weib, die Anzahl der Bienen.

Noch bedeutender waren die Leistungen der Inder in der Theorie der Zahlen, doch würde ein näheres Eingehen auf diese Seite der Mathematik zu weit von dem $/$ wecke dieses Buches entfernen, das die Mathematik nur insoweit berïcksichtigen will, als sie für die Entwicklung der Naturwissenschaften von Bedeutung gewesen ist. Für die Auflösung von kubischen Gleichungen findet sich bei den Indern wie bei Diophant nur ein vereinzeltes Beispiel.

Nicht uninteressant ist ein kurzer Überblick über den Umfang der indischen Arithmetik. Sie umfaßte zwanzig Operationen und acht Bestimmungen, die jedem Meister der Rechenkunst geläufig sein mußten ${ }^{1}$. $\quad$ Zu den 4 Grundrechnungsarten, dem Potenzieren und dem Wurzclziehen traten 6 Operationen mit Brüchen und 5 als einfache und zusammengesetzte Regeldetri; ferner gab es eine Regel über den Tausch. Die Bestimmungen betrafen Mischungen, Flächen- und Körperinhalte, Zinsberechnung, Schattenrechnung usw. Nach Burkhardt (Wie man vor Zeiten rechnete, Keitschr. f. d. math. u. naturw. Unterr. 1905. 1. Heft) lüßt sich annehmen, daß seit dem 5. Jahrhundert n. Chr. in Indien im wesentlichen ebenso

1) Siebe Arneth, Die Geschichte der reinen Mathematik. S. 143. 
gerechnet wurde, wie heute bei uns. Anch steht fest, daß die Araber ihre Ziffern und ihre Rechenmethode von den Indern erhalten haben.

Was man in den Sanskritwerken an geometrischen Lehren angetroffen hat, ist weniger bedeutend und nach Cantor wohl zum Teil auf alexandrinischen Ursprung, insbesondere auf Heron zurückzuführen ${ }^{1}$ ). Daron, daf die Inder mit den Kegelschnitten bekannt gewesen, findet sich nirgends eine Andeutung. Dieser Teil der Geometrie ist ausschließlich griechischen Ursprungs. Dagegen blieh es den Indern als dem vorwiegend für die Arithmetik veranlagten Volke vorbehalten, die ersten allgemeinen Sätze der Kombinationslehre zu finden, eine Errungenschaft, zu der die Griechen, soweit unsere Kenntnis reicht, nicht durchgedrungen sind.

Einen wesentlichen Fortschritt erfuhr die Trigonometrie bei den Indern, indem sie für die Sehne des Winkels deren Hälfte und somit den Sinus einfuihrten. Es war dies ein Fortschritt, den erst die Araber in seiner vollen Bedeutung erkannten und zur Geltung brachten.

Die erste indische Sinustabelle begegnet uns um 500 n. Chr. ${ }^{2}$ ). Der Kreis hat dort wie bei den Babyloniern und den Alexandrinern 360 gleiche T'eile. Jeder Teil zerfällt in 60 kleinere Abschnitte (unsere Minuten), von denen der ganze Kreis also $60 \cdot 360=21600$ enthält. Der Radius wird durch diese kleinsten Teile des Kreises gemessen. Nach einem ron den Indern für das Verhältnis der Peripherie zum Durchmesser angenommenen Werte ergab sich für den Radius die Zahl 3448. Da der Sinus, als halbe Sehne des doppelten Winkels betrachtet, für $90^{\circ}$ gleich dem Radius wird, so erscheint für $90^{\circ}$ in der Tabelle jener Wert 3448. Für sin $60^{\circ}$ wird 2978, für sin $30^{\circ}$ wird 1719 angegeben.

In bezug auf die Naturwissenschaften besaßen die Inder zwar zahlreiche Einzelkenntnisse. Zur Aufstellung naturwissenschaftlicher Lehrgebäude gelangten sie indessen ebensowenig wie die Babylonier oder die Ägypter. Diese Tat blieb vielmehr den Griechen vorbehalten. In physikalischer Hinsicht ist erwähnenswert, daß die Kenntnis des Brennglases und der Brennspiegel bei den Indern sehr weit zurückreicht. So erwähnt eins ihrer ältesten Bücher ${ }^{3}$ ), daß getrockneter Mist sich entzünde, wenn man die Sonnenstrahlen

1) Cantor, Geschichte der Mathematik. Bd. I. S. 540.

2) Sie findet sich bei Aryabhatta (geb. 476 n. Chr.), dem ältesten indischen Astronomen, dessen Schriften auf unsere Zeit gekommen sind.

3) Das Nirukta. 
mittelst eines Steines oder Glases oder auch eines Metallgefäßes darauf werfe $\left.{ }^{1}\right)$. Übrigens kannten die Griechen im Zeitalter des Aristoteles gleichfalls schon die Feuererzeugung mit Hilfe eines durchsichtigen Steines ${ }^{2}$. Auf Grund einiger Sanskritstellen hat man den alten Indern die Kenntnis des Schießpulvers zugeschrieben. So wird ein König aus dem dritten vorchristlichen Jahrhundert genannt, der "Feuerwerke" angeordnet habe. Daraus aber auf eine so frühzeitige Kenntnis der Inder zu schließen, erscheint doch rècht gewagt $\left.{ }^{3}\right)$.

Daß die so ïberaus üppige Natur eines Landes wie Indien ein frühzeitiges Emporblühen der Pflanzenkunde und einer auf ihr beruhenden Heilkunde hervorrief, ist leicht erklärlich. In der Sanskritliteratur fehlt es daher nicht an Werken, die eine große Menge von Heilmitteln, Nahrungsmitteln und Giften anführen. Es ist jedoch nur selten möglich, die Art, um die es sich handelt, zu bestimmen. Am häufigsten wird Nelumbium speciosum, eine prächtige Seerose, erwähnt. Neben den Pflanzen wurden aber auch Metalle und Chemikalien von den alten Indern zu Heilzwecken verwendet. Am ausführlichsten berichtet iiber den Stand ihrer naturwissenschaftlichen und medizinischen Kenntnisse die Ayur-Veda Susrutas. Das Werk umfaßt sechs Bücher, die sich im wesentlichen mit der Lehre von den Heilmitteln, der Anatomie, der Pathologie und der Therapie beschäftigen. Das Knochensystem des Menschen enthält nach Susrutas Aufzählung 300 Knochen. In der Schule des Susruta wurden schon Leichen zergliedert und in fließendem Wasser präpariert.

Daraus erklärt sich die erstaunliche Höhe der anatomischen Kenntnisse, welche die Inder schon im 6. Jahrhundert v. Chr. besaßen ${ }^{4}$ ). Susruta war auch schon mit dem diabetischen Zucker bekannt, während die Beobachtung, daß der diabetische Harn auffallend süß ist, in Europa erst im 17. Jahrhundert gemacht wurde $\left.{ }^{5}\right)$.

1) Rotlı, .. Indische Feuerzeuge". Zeitschrift der morgenländischen Gesellschaft. 1889.

2) Aristophanes, Wolken. v. 766 u. f. Aristophanes erzillult dort, ein Schuldner habe seinen Gläubiger dadurch geprellt, daß er die Wachstafel, welche die Forderung enthielt, mittelst einer der Linsen geschmolzen habe, die zum Erzeugen von Feuer gebrauelit würden.

3) Über die „Schießpulverfrage im alten Indien“, siehe dic Mitteilungen zur Gesch. d. Med. u. d. Naturwissensch. 1905. S. 1 u. f.

4) Hoernle, Studies in the Medicine of ancient India. Oxford 1907.

5) E. v. Lippmann, Abhandlungen und Vortrïge. 1906. 
Unter den Heilmitteln 1) erwähnt Susruta Quecksilber, Silber, Arsen, Antimon, Blei, Eisen und Kupfer. Auch Alaun und Salmiak fanden sich im Arzneischatz der alten Inder. Wann die AyurVeda entstand, ist nicht sicher bekannt. Einige legen die Zeit ihrer Entstehung weit vor Christi Geburt. Susrutas Werk erwähnt nicht weniger als 760 Heilmittel, die zum weitaus größten Teile aus dem Pflanzenreiche stammen ${ }^{2}$ ).

Wie die alten Babylonier, so operierten auch die Inder den Star. Nachrichten darüber reichen etwa bis zum Beginn unserer Zeitrechnung zurück. Die Operation wurde mit zwei Instrumenten ausgeführt. Das eine diente zum Öffnen des Augapfels; mit dem andern wurde die getrübte Linse entfernt ${ }^{3}$ ).

Weit isolierter als die indische Kultur, welche doch mit der griechischen und mit der arabischen Welt in mannigfache Berührung kam, blieb die chinesische. Nicht nur, daß China durch riesige Gebirge und weite, öde Länderstrecken von den Völkern. Vorderasiens und der Mittelmeerländer getrennt war, es fehlte auch die Rassengemeinschaft, welche die Arier Indiens mit den Persern und den westlichen Indogermanen verband. Dennoch hat schon im Altertum der Handel eine Verbindung zwischen dem äußersten Osten Asiens und dem Mittelmeer geknüpft. Diese Verbindung erfolgte durch den Seeverkehr über den Indischen Ozean. China lieferte dem Westen besonders Seide und empfing dafür Edelmetall, Glasgegenstände und Bernstein. Durch die immerweitere Ausdelnnung ihrer Eroberungszüge kamen das römische und das chinesische Reich am Kaspischen Meere einander nahe. Sogar der Einfluß der in Vorderasien entstandenen Nestorianersekte hat sich bis nach China ausgedehnt. Ein in Singanfu errichtetes Denkmal mit chinesischer und syrischer Inschrift gibt uns davon Kunde ${ }^{4}$ ). Trotzdem hat keine andere Kultur der alten Welt so wenig Einflüsse von außen erfahren und so wenig wiederum nach außen gewirkt wie diejenige Chinas, so daß dieses Land für die Entwicklung,

1) Berendes, Das Apothekenwesen, seine Entstehung und geschichtliche Entwicklung. Stuttgart 1907.

2) Ein Sanskrittext, der sich gegen den Genuß des Fleisches, der gegohrenen Getränke und gegen die geschlechtliche Liebe wendet, findet sich in der Zeitschrift der deutschen morgenländischen Gesellschaft, Jahrg. 1907, in der Übersetzung wiedergegeben.

3) S. Hirschberg, Der Starstich der Inder. Zeitschr. f. prakt. Augenheilk. Januarheft 1909 .

4) Lindner, Weltgeschichte. Bd. I. S. 413. 
welche die Wissenschaften genommen haben, kaum in Betracht kommt. Zwar hat sich das Interesse seiner Bewohner frühzeitig mathematischen und astronomischen Dingen zugewandt, ein wenn auch unvollkommenes Verfahren des Buchdrucks wurde erfunden, und eine Literatur entstand, die der arabischen an Umfang wohl gleich karn. Die gewerblichen Erzeugnisse übertrafen oft diejenigen der westlichen Völker. Dennoch war der Einfluß nach außen sehr gering. Selbst eine so wichtige Erfindung wie diejenige des Kompasses, die in China erfolgte, blieb den Mittelmeervölkern über ein Jahrtausend unbekannt.

Für das hohe Alter der Astronomie bei den Chinesen spricht die frühzeitige Erwähnung von Kometen- und Planetenkonjunktionen in ihrer Literatur. Als Europa mit der Literatur der Inder näher bekannt wurde, erstaunte man über das hohe Alter der astronomischen Tafeln dieses Volkes. Das gleiche gilt von den Chinesen. deren astronomische Literatur zu Beginn des 18. Jahrhunderts durch Jesuiten, die in China Aufnahme gefunden hatten, bekannt wurde. Es zeigte sich, daß die Astronomie dort schon um 1000 v. Chr. eine nicht geringe Höhe erreicht hatte. Indessen ist ihre weitere Entwicklung nur sehr langsam gewesen ${ }^{1}$. So geht z. B. ein. Kometenverzeichnis bis auf das Jahr 2296 v. Chr. zurück ${ }^{2}$ ). Ferner erwähnt einer der Jesuiten, welche die Chinesen mit der europäischen Astronomie bekannt machten ${ }^{3}$, eine von den Chinesen anfgezeichnete Planetenkonjunktion rom Jahre 2461 v. Chr. ${ }^{4}$ ). Es ist jedoch wahrscheinlich, daß es sich dabei nicht um eine wirkliche Beobachtung, sondern nur um eine rückwärts berechnete astronomische Erscheinung gehandelt hat. Mit dem Gnomon waren die Chinesen schon um 1100 v. Chr. bekannt. Sie ermittelten daran die Schiefe des Ekliptik, bestimmten die Daucr des Jahres zu

1) Siehe auch W. Förster, Dic Astronomie des Altertums und Mittelalters. Berlin 1876.

2) Wolff, Geschichte der Astronomie. S. 11.

3) Der Jesuitenorden, dem ja neben der Verteidigung auch die Verbreitung des katholischen Glaubens oblag, ließ sich schon im 16. Jahrhundert in den außereuropäischen Ländern nieder. In China gewann er besonderen Einfluß dadurch, daß er für die Kalenderrechnung, die dort sehr in Unordnung geraten war, eine Neuordnung auf astronomischer Grundlage schuf. Eine solche Neuordnung war deshalb sehr wichtig, weil man eine verworrene Zeitrechnung als ein ungünstiges Omen für die Verwaltung und damit die Zukunft des Staates ansah.

S. 11 .

4) Baden-Powell, History of natural philosophy. London 1834. 
$365^{1 / 4}$ Tagen 1) und kannten schon die regelmäßige Wiederkehr der Finsternisse. Es kam vor, daß man Astronomen mit dem Tode bestrafte, wenn sie eine Finsternis nicht richtig vorhergesagt hatten. Ein Fall dieser Art soll sich schon um 2000 r. Chr. zugetragen haben ${ }^{2}$ ).

Daß Ostasien auch während des Mittelalters mit der übrigen Kulturwelt Beziehungen unterbielt, beweist uns das Auftauchen alchemistischer Bestrebungen in China um $800 \mathrm{n}$. Chr. Die chinesischen Quellen lassen erkennen, daß auch die theoretischen Vorstellungen, denen die Alchemisten im Reiche der Mitte huldigten, von den A rabern stammen ${ }^{3}$ ).

1) Siehe auch H. Löschner, Über Sonnenuhren. Beiträge zu ihrer Geschichte und Konstruktion nebst Aufstellung einer Fehlertheorie. Graz 1905.

2) Mitteilungen zur Gesch. der Medizin und der Naturwissenschaften. 1908. S. 351.

3) Näheres enthält die Abhandlung R. Ehrenfelds in den Mitteilungen zur Gesch. der Medizin und der Naturwissenschaften. 1908. S. 144 u. f. 


\section{Die Entwicklung der Wissenschaften bei den Griechen bis zum Zeitalter des Aristoteles.}

Manche von den in Vorderasien und Unterägypten entstandenen Grundlagen der Wissenschaften wurden nebst anderen Kulturelementen von den Phöniziern aufgenommen, welche sie, als das wichtigste Handelsvolk der alten Welt, den übrigen Anwohnern des Mittelmeeres iiberbrachten. Bei den Griechen, die mit der am Nil und am Euphrat entstandenen Kultur später auch in unmittelbare Fïhlung kamen, fielen diese aus dem Orient stammenden Ansätze auf den fruchtbarsten Boden. Sie wurden nicht etwa nur aufgenommen, sondern als das Fundament fiir geradezu bewundernswerte Neuschöpfungen verwendet. Die Phönizier verbreiteten als das wichtigste. Mittel für jede weitere Entfaltung wissenschaftlicher Tätigkeit auch die Buchstabenschrift1), die sich aus den, Silben und ganze Wörter bezeichnenden Hieroglyphen entwickelt hatte. Erst nachdem dies geschehen, vermochte man mit klarem Bewußtsein das Abstrakte von den Dingen zu trennen und auf solche Weise zur Ausbildung systematisch geordneter Wissenschaften vorzudringen ${ }^{2}$.

Eine wichtige Rolle spielten in dieser Übermittlung der orientalischen Kulturelemente auch die Bewohner Kretas und Vorder-

1) Auch H. Winckler wendet sich in einer Abhandlung über die Bedeutung der Phönizier für die Kulturen des Mittelmeeres Zeitschr. f. Sozialwissenschaft. 1903. Bd IV. Nr. 6 u. 7) gegen die Auffassung, als ob die Phönizier die Buchstabenschrift erfunden hätten. Er ist der Ansicht, daß sich das Verständigungsmittel geistigen Lebens an dessen Mittelpunkt entwickelt haben wird und die phönizische Schrift im Anschluß an die Keilschriftliteratur entwickelt ist. Übrigens haben auch dic arischen Perser die zu monumentalen Inschriften beihehaltene Keilschrift zu ciner Buchstabenschrilt umgestaltet (L. Wilser in den Mitteil. z. Gesch. d. Med. u. Naturwissensch. 1905. S 32). Die ältesten uns erhaltenen Inschriften im griechischen Alphahet und in griechischer Sprache gehen kaum über den Anfang des 7, vorchristlichen Jahrhunderts hinaus. Siehe Beloch, Griechische Geschichte. Bd. I. 2. S. 2. 1913. 2) K. Suter, Geschichte der mathemat. Wisseuschaften. Zürich 1878. 
asiens. Auf die letzteren hat Babylonien Jahrtausende eine tiefe Wirkıng ausgeübt. In religiöser Hinsicht hat dieser Einfluß besonders stark auf das Judentum und damit weiterhin auf die Entwicklung des Christentums gewirkt.

Das Neue an der phönizischen Schrift bestand darin, daß sie für jeden Konsonanten und für jeden Vokal ein besonderes Zeichen besaß. Die ältesten in dieser Schrift verfaßten Urkunden begegnen uns um das Jahr 950.

Sobald die Griechen aus dem Dunkel der Sage in das Licht der Geschichte treten, zeigt sich uns bei ihnen das Bestreben, die Welt der Erscheinungen nicht bloß betrachtend in sich aufzunehmen, sondern sie auch in ihrem ursächlichen Zusammenhange zu begreifen. Dies geschah einmal dadurch, daß sie die Anfänge der mathematischen Erkenntnis auf die Naturvorgänge anwandten. Zum anderen aber auch, indem sie, weit über alles Maß hinaus. schreitend, sofort den letzten Grund des Geschehens zu begreifen trachteten. Und zwar erfolgten diese ersten Regungen des wissenschaftlichen Denkens nicht im eigentlichen Hellas, sondern in den ionischen Kolonien. Letztere nahmen zwischen der asiatischen Welt und dem jungfräulichen Boden Griechenlands eine vermittelnde Stellung ein. Auch hatten sie schon einige Jahrhunderte vor dem Beginn der Philosophie und der Naturwissenschaften ihre Blütezeit auf dem Gebiete der Dichtkunst erlebt.

\section{Der Beginn der griechischen Naturwissenschaft.}

Als der erste Grieche, der in den beiden soeben gekennzeichneten Richtungen wirkte, gilt Thales von Milet. Obgleich von ihm herrührende Werke nicht auf uns gekommen sind und er seine Lehren wahrscheinlich auch nur mündlich überliefert hat, sind uns doch letztere, sowie seine Entdeckungen und sein Lebensgang durch die Aufzeichnungen alter Schriftsteller hinlänglich bekannt geworden, um uns ein ungefähres Bild von Thales $\left.{ }^{1}\right)$ machen zu können.

1) Im Archiv für Geschichte der Philosophie (1902. S. 311) hat Peithmann in einer Abhandlung über die Naturphilosophie vor Sokrates neuerdings die Anschauung zu begründen versucht, daß Thales sich nicht als Philosoph, sondern nur als Astronom und Ingenieur verdient gemacht habe. Nach Peithmann hat es den Anschein, daß erst Aristoteles den Thales unverdientermaßen zu einem Philosophen gemacht hat. Die Ansicht wird nach v. Lippmann jedoch nicht allgemein anerkannt. 
Thales wurde um 640 v. Chr. geboren, wirkte also zu der Zeit, als Athen durch Solon die Grundlagen seiner Verfassung erhielt. Darin, daß Thales in Ägypten gewesen und dort mit der Priesterkaste, damals die Hüterin aller mathematischen und astronomischen Kenntnisse, in Berührung getreten sei, stimmen alle Berichte überein. „Thales, der nach Agypten ging“, so wird uns erzählt, „brachte zuerst die Geometrie nach Hellas. Vieles entdeckte er selbst, von vielem aber überlieferte er die Anfänge seinen Nachfolgern“" 1). An anderer Stelle heißt es von ihm: „Er beobachtete den Himmel, musterte die Sterne und sagte öffentlich allen Miletern vorher, daß am Tage Nacht eintreten, die Sonne sich verbergen und der Mond sich davorlegen werde 2)."

Die älteste Auffassung, die uns bezüglich der Finsternisse begegnet, ist die, daß der Sonne oder dem Monde durch irgendeine fremde Macht Gewalt angetan würde. Es erscheint zweifelhaft, ob die Babylonier schon einen wirklichen Einblick in den Vorgang besaßen. Seine natürliche Ursache erkannten wohl erst die Griechen. Nach einigen war es Anaxagoras, nach anderen waren es die Pythagoreer, denen die Astronomie diesen Fortschritt verdankte ${ }^{3}$ ).

Die Vorausbestimmung des Thales ist nicht etwa eine solche im heutigen Sinne. Sie erfolgte nämlich nicht durch Messen und Rechnen, sondern beruhte ausschließlich auf der Beobachtung derjenigen Periode, innerhalb deren die Finsternisse regelmäßig wiederkehren. Jene Periode war den Babyloniern nicht entgangen. Sie befanden sich im Besitz von Aufzeichnungen. die sich über Jahrhunderte erstreckten und einen Zeitraum von 6585 Tagen bezüglich der regelmäßigen Wiederkehr der Finsternisse erkennen ließen. Innerhalb dieses 223 Monate umfassenden Zeitraums, den die Babylonier Saros nannten ${ }^{4}$ ), kehrt nämlich der Mond fast genau in dieselbe Stellung zur Erde und zur Sonne zurïck. Allerdings machte man auch die Erfahrung, daß sich der Saros, insbeson-

1) Cantor, Geschichte der Mathematik. Leipzig 1880. Bd. I. S. 113.

2) A. a. O. S. 114 .

3) Ein Verzeichnis der von den antiken Schriftstellern erwähnten Finsternisse findet sich in Paulys Reallexikon der klass. Altertumswiss. im 6. Bande auf S. 2352-2364. Dort findet sich auch (S. 2339-2364) ein ausführlicher, von Boll verfaßter Beitrag über die Finsternisse. Die erste verbürgte Nachricht betrifft eine Mondfinsternis, die am 19. 3. 721 in Babylon beobachtet wurde.

4) Siehe oben S. 35.

Dannemann, Die Naturwissensehaften. I.:13d.:2. Aufl. 
dere für die Voraussage der Sonnenfinsternisse, nicht immer bewährte ${ }^{1}$.

Auch bei der Benennung der fünf Planeten hat sich anscheinend der sehr früh einsetzende (s. S. 30) babylonische Einfluß geltend gemacht. Die alten griechischen Namen bezeichneten nämlich Eigenschaften (Mars hieß der Feurige, Jupiter der Leuchtende usw.). Seit dem 4. vorchristlichen Jahrhundert bedient man sich dagegen folgender Namen:

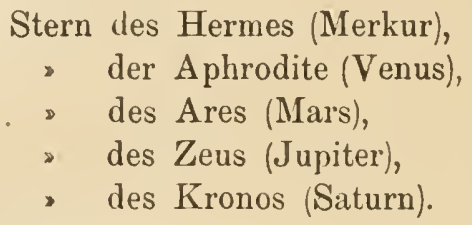

Die kurze Bezeichnung Hermes, Aphrodite usw. kam erst später auf. Es ist anzunehmen, daß hierin die Griechen den Babyloniern gefolgt sind, die gleichfalls die Planeten ilren Hauptgöttern geweiht hatten. Mit einigen Elementen des babylonischen Wissens sind nach neuerer Annahme schon die Pythagoreer bekannt gewesen ${ }^{2}$ ).

Wie unentwickelt im übrigen die astronomischen Vorstellungen der Griechen zur Zeit des Thales noch waren, geht daraus hervor, daß nach den ihm zugeschriebenen Lehren die Erde eine rom Okeanos umflossene Scheibe ist, über die sich der Himmel wie eine Kristallglocke wölbt. Unter solchen Umständen konnte noch nicht einmal von einer Kreisbewegung der Gestirne die Rede sein. In Übereinstimmung mit dieser Lehre nahm man zur Zeit des Thales an, die Sterne sänken bei ihrem Untergange in den Ozean und schwömmen in diesem am Rande der Scheibe entlang zu ihren Aufgangspunkten zurück.

Auf Thales werden ferner von den Griechen, die über die Mathematik geschrieben haben, einige der wichtigsten geometrischen Sätze zurückgeführt, so der Satz von der Gleichheit der Winkel an der Grundlinie eines gleichschenkeligen Dreiecks, sowie der Satz, daß ein Dreieck durch eine Seite und die anliegenden

1) Thales hat die am 18. Mai 603 eingetretene große Sonnenfinsteruis wahrscheinlich in $\ddot{A} g y p t e n$ beobachtet. Er konnte deshalh damit rechnen, daß etwas mehr als 18 Jahre später eine neue Finsternis stattfinden würde. Sie fand denn auch am 22. Mai 585 statt H. Diels, Antike Technik. 1914. S. 3). Siehe auch J. Zech, Astrnnomische Untersuchungen über die wichtigsten Finsternisse, welche von den Schriftstellern des Altertums erwähnt werden. Leipzig $185 ̃ 3$.

2) Neue Jahrbücher f. d. klass. Altertum. 1911. S. 5. 
Winkel bestimmt ist. Mit Hilfe dieses Satzes wurde z. B. die Entfernung der Schiffe vom Lande ermittelt.

Bezuiglich der geometrischen Kenntnisse des Thales läßt sich jedoch nicht mehr entscheiden, wieviel Eigenes und wievi l ron

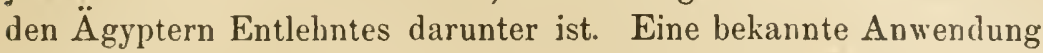
der Mathematik ist seine Schattenmessung. Es ist dies ein Verfahren, die Höhe hervorrägender Gegenstände zu bestimmen. Thales soll dadurch die Bewunderung seiner Zeitgenossen erregt hahen. Das Verfahren bestand darin ${ }^{1}$ ), daß er zu der Zeit, wenn Schatten und Höhe der Körper gleich sind, was er an einem Stock ermittelte, den Schatten des betreffenden Gegenstandes, z. B. einer Pyramide, maß, womit dann auch sofort die Höhe des Gegenstandes gefunden war.

Mit dem Gnomon, einem Werkzeug, das zur Bestimmung des Mittags aus der Schattenlänge diente, sollen die Griechen durch Anaximander von Milet,

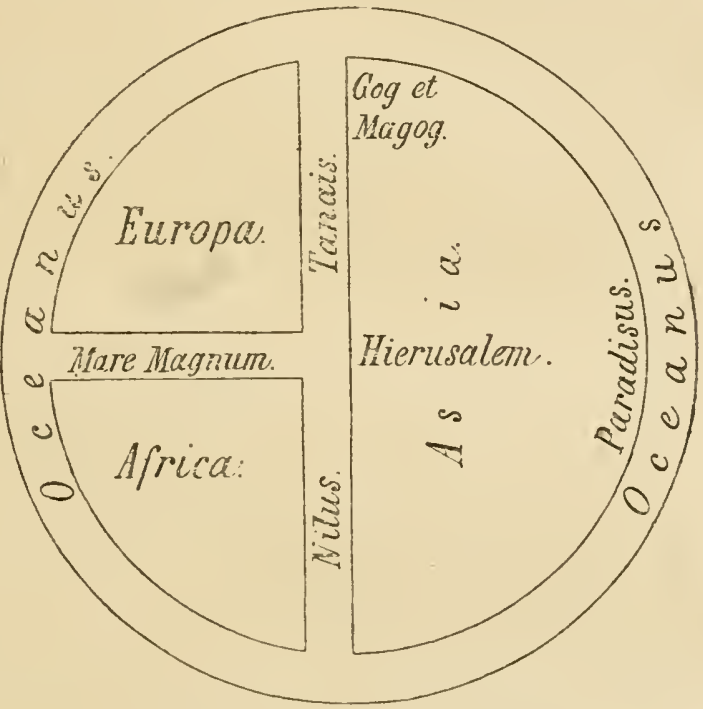

Abb. 11. Radkarte der Erde. den bedeutendsten Schüler des Thales, bekannt geworden sein. A naximander (610-546 v. Chr.) hat nach Strabon auch die erste Karte der Welt, soweit damals die Länderkenntnis reiclite, entworfen ${ }^{2}$ ).

Sein Landsmann Hekata eos (geb. um 550), der weite Reisen gemaclit hatte, soll die neue Kunst in solchem Maße entwickelt haben, daß er Erstaunen erregte. Hekataeos verfaßte eine Erdbeschreibung, der er eine Weltkarte beigab. Er gilt als der älteste griechische Geograph und der Vorgänger Herodots. Eibalten ist von den Karten jener Zeit nichts mehr. Sie glichen wahrscheinlich den Radkarten des früheren Mittelalters (Abb. 11), d. h.

1) Nach Plutarch, Vol. III, pag. 174, ed. Didot, sowie nach Plinius XXXVI. 12

2) A. Forbiger, Handbuch der alten Geographie. I. 44. 
sie waren lediglich rohe Orientierungen ohne jeden wissenschaftlichen Wert, so daß sie den Spott Herodots herausforderten.

Die Beschäftigung mit naturwissenschaftlichen Dingen, zu welcher Thales bei den Ioniern allen Nachrichten zufolge den Anstoß gab - nennt ihn doch Aristoteles den "Beginner" der philosophischen Naturforschung ${ }^{1}$ ) - rief nun auch ein Streben nach einer ursächlichen Erklärung der gesamten Erscheinungswelt hervor. Eine auf den letzten Gründen fußende Erklärung ist seitdem das Ziel der Philosophie gewesen, olne daß sie, wie es in der Natur der Sache liegt, jemals zu einer befriedigenden Lösung eines so weit gespannten Problems gelangt wäre. Was die Frage nach dem Ursprung der griechischen Philosophie anlangt, so neigt ihr hervorragendster Geschichtsschreiber, Zeller, zu der Ansicht, daß sie selbständig geworden und nicht orientalischer Herkunft sei $^{2}$ ). "Wenn es je ein Volk gegeben“, sagt Zeller, „das seine Wissenschaft selbst zu erzeugen imstande war, so waren es die Griechen".

Dem ersten Ausdruck für ihre Weltanschauung begegnen wir bei den Dichtern. Insbesondere war es der im 8. Jahrhundert v. Chr. lebende Hesiod, der in den "Werken und Tagen" die Frage nach der Weltentstehung aufwarf. Fïr Hesiod war die Weltentstehungslehre wesentlich Götterlehre. Kosmogonie und Theogonie waren in jenem Zeitalter noch zu einer in mystisches Gewand gekleideten Einheit verschmolzen. Thales und seinen unmittelbaren Nachfolgern, die sich über den Begriff des Stoffes kaum zu erheben rermochten, genügte dann die Annahme, daß alle Dinge auf einen einzigen Urstoff zurückzuführen seien. Als solcher dïnkte dem Thales nichts geeigneter als das Wasser, weil es ihm, nach seinen Eigenschaften zu urteilen, zwischen der Erde und der Luft zu stehen schien. Eine Stiitze fand diese Lehre in gewissen Beobachtungen. Wurde doch z. B. Ägypten, woher viele Anschauungen des Thales stammten, als ein Erzeugnis des Niles angesehen. Entwickelten sich nicht ferner aus der feuchten Erde die Pflanzen? Selbst als man später genauer beobachten lernte, hat jene Lehre immer wieder Anhänger gefunden. Van Helmont, ein hervorragender Forscher des 17. Jahrhunderts, war noch in ihr befangen. Erst Lavoisier und Scheele, die an der Schwelle der neuesten Zeit stehen, vermochten den Glauben

1) A ristot., Metaphys. I, 3.

2) Zeller, Die Philosophie der Griechen. Bd. I. (5. Aufl.) S. 3j. 
an die Umwandlung des Wassers in Erde, der stets wieder auf mangelhafte Beobachtungen gestützt wurde, durch einwandfreie Versuche endgültig zu widerlegen.

Das Streben nach einer Erklärung der Welt in ihrer Beziehung zum Menschen hat seit der Zeit des Thales nicht aufgehört, die hervorragendsten Geister zu beschäftigen. Hier ist es nur insofern von Belang, als die Ergebnisse des philosophischen Denkens einen Einfluß auf die weitere Entwicklung der Naturwissenschaften ausgeübt haben. Letztere steckten sich alsbald das bescheidenere, aber erreichbare Ziel, einen Einblick in den gesetzmäßigen Zusammenhang der Erscheinungen zu gewinnen. In dem Maße, wie man dieses Ziel ins Auge faßte, hat sich die Beseitigung phantastischer Auswüchse vollzogen, wie sie in der Alchemie und Astrologie z. B. zum Ausdruck kamen, und in eben demselben Maße näherte sich die Wissenschaft ihrer jetzigen Gestalt.

Mit der ionischen Naturphilosophie trat "ein neues Element in das geistige Leben der Menschheit". Es begegnen uns zum -ersten Male wissenschaftliche Persönliclıkeiten mit eigenen Überzeugungen, die durch angestrengte Geistesarbeit zu ihren Ergebnissen gelangen. Für die weitere Entwicklung echter Wissenschaft war ein solches Hervortreten der Individualität die unerläßliche Voraussetzung ${ }^{1}$ ).

Die rein philosophische Betrachtungsweise besitzt trotz der Nachteile, die ihr gegenüber der exakten Forschung innewohnen, doch unleugbar das Verdienst, die empirischen Wissenschaften ununterbrochen angeregt zu haben. Manche plilosophische Ansicht, welche das griechische Altertum entwickelte, beeinflußte bis in die neuere Zeit hinein die Naturwissenschaften. So hat sich z. B. das Bestreben, die Mannigfaltigkeit der Stoffe auf einen einzigen Urstoff zurückzuführen, bis auf unsere Tage erhalten. Zuerst wurde von den ionischen Philosophen eine der bekannten Materien, wie die Luft oder das Wasser, zu einem solchen Urstoff gestempelt. Spüter faßte Aristoteles Luft, Wasser, Erde und Feuer als die verschiedenen Erscheinungsformen eines und desselben Urprinzips auf. Infolgedessen hielt man eine Verwandlung der bekannten Stoffe ineinander für möglich. Und so war es besonders die aristotelische Philosophie, auf die sich im Mittelalter das Bemühen, unedle Metalle in edle überzuführen, stützen komnte.

1) E. Meyer, Alte Geschichte. Bd. IV. 1901. S. 199. 
Die Lehre von den Elementen ist ihrem Ursprung nach auf Empedokles aus Agrigent (um 440 v. Chr.) zurückzuführen. Für ihn waren die Urstoffe ewig, selbständig und nicht auseinander ableitbar. Durch zwei bewegende Kräfte, die Freundschaft und den Streit, den Heraklit den Vater aller Dinge nannte, wurden die Elemente gemischt und zu Dingen gestaltet. Die Entmischung sollte in der Weise erfolgen, daß die Teilchen des einen Stoffes sich unsichtbar von den Teilchen des anderen ablösen. Auf diesem Wege ließ Empedokles auch die Sinnesempfindungen entstehen $\left.{ }^{1}\right)$.

Empedokles wußte sich auch über die Naturdinge im besonderen manche zutreffende oder doch beachtenswerte Meinung zu bilden. So nahm er anstatt des Zentralfeuers, um das die Pythagoreer die Erde kreisen ließen, einen feurig-flüssigen Erdkern an, von dem die heißen Quellen und die Vulkane ihre Wärme erhalten sollten. Das unterirdische Feuer sollte ferner die Gebirge emporgehoben haben. Aus großen, auf Sizilien gefundenen Knochen schloß Empedokles auf die vorgeschichtliche Existenz eines Riesengeschlechts. Seine Ansichten entwickelte er in eineni Gedicht "Von der Natur". Leider sind davon nur wenige Bruchstücke erhalten. Diese lassen indes erkennen, dal Einpedokles auch über die Natur der Pflanze nachgedacht hat. Letztere erklärte er für beseelt. Als Zeichen der Beseelung deutete er allerdings Erscheinungen, die man heute mechanisch erklärt, wie das Erzittern, das Ausstrecken der Zweige und das kräftige Zurückschnellen gebogener Aste. Auch die Behauptung, daß die Pflanzen zweierlei Geschlecht besäßen, wird auf Empedokles zurückgeführt. Selbst die später oft wiederkehrende Lehre von den periodischen Weltumbildungen begegnet uns schon bei diesem Philosophen. Man darf deshalb ${ }^{2}$ ) aus den vorhandenen Bruchstücken altgriechischer Philosophie schließen, daß eine der wichtigsten Annahmen der neueren Geologie, die Lehre nämlich, daß unser Erdball eine Reihe von Umwandlungen erlitten, bei denen Tiere und Pflanzen untergingen, um sich in anderen Arten wieder zu erneuern, als Ahnung schon in Altertum vorhanden war ${ }^{3}$.

1. Zeller, Die Philosophie der Griechen. 5. Aufl. Bd. I. S. 769.

2) E. Meyer, Geschichte der Botanik. Bd. I (1854). S. 45.

3) Zeller, Über die griechischen Vorgänger Darwins. Abhandlungen d. kgl. Akademie d. Wissensch. zu Berlin. 1878. S. 115. 
"Der Tatsachen, auf die man sich dabei stützte", waren vielleicht nicht viele, um so schärfer war aber der Blick, der schon das Richtige traf"1).

\section{Erster Versuch einer Erklärung der Natur aus den Prinzipien der Mechanik.}

Hatte man zuerst die Stoffumwandlungen, denen man auf Schritt und Tritt begegnete, als ein Entstehen und Vergehen aufgefaßt, so waren es Philosophen, welche lehrten, daß alle Veränderung auf ein Mischen und Entmischen zurückzuführen sei, und daß dabei der Stoff selbst weder sich bilde noch vernichtet werde. Dem philosophischen Denken entsprang ferner die Vorstellung, daß der Stoff aus kleinsten Teilchen bestehe, durch deren Umlagerung jenes Mischen und Entmischen bedingt sei - beides Grundsätze, deren sich die Forschung bemächtigte, um sie als Leitsterne bei ihren, auf die denkende Erfassung der Natur gerichteten Bemülsungen zil verwerten.

Die angedeutete Durchführung der mechanischen Naturerklärung vollzog sich im Anschluß an die Lehren des Empedokles durch die Atomisten genannten Philosophen Leukipp und Demokrit. Ihre Anschauungen lassen sich in folgende Sätze fassen: Das All ist anfangslos und auf keine Weise von irgend jemandem geschaffen. Überhaupt ist alles seit ewigen Zeiten in der Notwendigkeit begründet, sowohl was war, als auch was ist und was sein wird ${ }^{2}$. Das Weltall besteht ans qualitativ gleichen Teilchen, den Atomen, die ihrer Form nach verschieden sind und ihre Lage gegeneinander ändern. Damit letzteres möglich ist, muß der Raum im übrigen leer sein. Die Atome sind ewig und unzerstörbar. Aus Nichts wird nichts. Nichts kann vernichtet werden. Jerle Veränderung besteht nur in der Verbindung und in der Trennung der Atome. Aus der Zalıl, der Gestalt, dem Zusammentreffen und der Trennung der Atome geht die Mannigfaltigkeit der Dinge hervor. Dic Vorgänge in der Natur luängen nicht von den Launen iibernatiirlicher Wesen ab, sondern sind ursächlich bedingt; nichts geschieht zufällig ${ }^{3}$ ). Die Bewegung der Atome ist seit Anbeginu vorhanden, sie hat zur Bildung umzähliger Welten gefiihrt. Außer den Atomen und dem leeren Raum gibt es nichts. Eine Schwäche

1) E. Meycr a. a. O.

2. So heißt es bei Plutarch, Strom. VII. Dox. Gr. S. 581.

3) S. auch Windelband, Dic Lehre voin Kufall. Berlin 1870. 
dieser atomistischen Lehre, die ihr auch heute noch anhaftet, liegt darin, daß nach ihr auch das Seelische aus Atomen, und zwar aus Atomen feinerer Art bestehen soll, welche die gröberen Körperatome durchdringen, sehr beweglich sind und auf diese Weise die Erscheinungen des Lebens hervorrufen. So wurden z. B. die Empfindungen des Süßen, Herben, Scharfen daraus erklärt, daß die Atome teils kugelig, teils kantig, teils zackig seien. Die Wahrnehmung, sowie überhaupt jede Wirkung der Dinge aufeinander sind nach Demokrit durch Ausströmung und Einströmung bedingt. Aus diesem Grunde mußten die Körper zwischen den Atomen Poren haben. Die Zahl der Atome ist unendlich groß und ihre Form unendlich verschieden. Qualitativ sind sie jedoch einander völlig gleich. Bei ihrer Bewegung durch den unendlichen Raum stoßen sie aufeinander. Dadurch entstehen Wirbel, aus denen die Weltkörper hervorgehen. Letztere entstehen und vergehen und sind in ihrer Zahl gleichfalls unbegrenzt. Diese Lehre von der Weltenbildung ${ }^{1}$ ) wurde im 18. Jahrhundert durch $\mathrm{Kant}$ und durch Laplace zu neuem Leben erweckt. Sie hat auch Giordano Bruno zu seinen Spekulationen über die Unendlichkeit der Welten angeregt.

Demokrit wurde um 460 v. Chr. in der ionischen Kolonie Abdera geboren und starb um 370. Er sammelte auf vielen Reisen zahlreiche Kenntnisse. "Ich habe“, sagt er, „unter allen Menschen meiner Zeit die größten Länderstrecken durchwandert, das Entfernteste erforscht, die meisten Länder gesehen und kundige Menschen gehört." Von seinen zahlreichen Schriften ist leider nur wenig erhalten geblieben. Soviel läßt sich jedoch erkennen, daß er in systematischen Werken, sowie in Einzelabhandlungen das ganze Gebiet menschlichen Wissens zu umspannen gesucht hat. Er schrieb nicht nur über Sternkunde, Medizin, Ackerbau, Technologie, Kriegskunst wie viele andere vor ihm, sondern von ihm rührt auch der erste Versuch einer wissenschaftlichen Zoologie, Botanik und Mineralogie her ${ }^{2}$. Gefördert und bereichert hat Demokrit die Wissenschaften im einzelnen kaum in erheblichem Maße. Ihn als den größten Naturforscher des Altertums zu bezeichnen, ist daher nicht berechtigt. In der Astronomie haben ihn Oenopides und Meton übertroffen. Hielt er doch an der Scheibengestalt der Erde fest, so daß er in seinen kosmischen Vorstellungen weit unter Platon

1) A. Brieger, Die Urbewegung der Atome und die Weltentstehung bei Leukipp und Demokrit. Halle 1884 .

2) E. Meyer, Alte Geschichte. Bd. V. 1902. S. 340. 
stand. Auch die Mathematik hat er trotz zahlreicher mathematischer Schriften nicht wesentlich gefördert. Trotzdem muß man bedauern, daß von seinen Werken nur geringe Bruchstïcke ${ }^{1}$ ) übrig geblieben sind. Demokrit war ohne $Z$ weifel der größte Polyhistor (d.h. kein bloßer Vielwisser) vor Aristoteles. Letzterer rübmt ron $\mathrm{ihm}$, daß er überall die natürlichen Ursachen aufgesucht und vieles früher Vernachlässigte festgestellt habe. Trotz seiner materialistischen Weltanschauung war Demokrit nach den Zeugnissen der Alten eine edle, reichbegabte, für Wahrheit und Wissenschaft begeisterte Natur.

Hatte Demokrit die ron Leukipp (um 500 v. Chr.) herrührende atomistische Lehre in ein System gebracht, so ist für ihre Weiterverbreitung besonders Epikur tätig gewesen. Während des römischen Zeitalters wurde sie dann durch Lucretius Carus (um 50 v. Chr.) in einem "Über die Natur der Dinge" betitelten Lehrgedicht ${ }^{2}$ ) dargestellt.

Am meisten Schwierigkeiten machte es diesen als Atomisten bezeichneten Philosophen, die zweckmäßige Beschaffenheit der Natur-. erzeugnisse, die auch Demokrit nach einer Stelle des Aristoteles bewundert haben soll, olnne die Mitwirkung einer Zwecktätigkeit, sondern lediglich aus der Notwendigkeit zu erklären. A ristoteles (Physik II, 8) wirft die Frage auf, „ob die Natur nur infolge einer blinden Notwendigkeit oder nach Zwecken handle"“. Falle doch auch der Regen nicht etwa, damit das Getreide wächst, sondern weil die aufsteigenden Dünste sich verdichten. Daß das Getreide dann wächst, treffe sich nur so nebenbei. .Könnte nicht", fragt Aristoteles, "dasselbe von allen Naturerzeugnissen gelten und könnten beispielsweise die Vorderzähne nicht zufïllig scharf und die Backenzähne zufällig stumpf sein. Dann wäre der Dienst, den sie uns leisten, eine unbeabsichtigte Folge dieses Zufalls und dem Zusammentreffen ähnlich, das zwischen der Verdichtung der

1) Gesammelt durch Mullach, Berlin 1843. (Völlig veraltet; s. auch Diels" "Vorsokratiker"*).

Ist auch die Zahl der authentischen Fragmente nur klein, so sind wir über Demokrits Lehren doch besser unterrichtet als über die Ansichten zahlreicher anderen Philosophen. Man hat mit Recht bemerkt, daß er eifriger ausgeschrieben als abgeschrieben wurde (F. A. I ange, Gesch. d. Materialismus. 1873. Bd. I. S. 11). Zumal durch Aristoteles und durch Lukrez sind wir mit Demokrits Anschanungen ziemlich genau bekannt. Selbst in der Überlieferung erscheinen sie als ,so klar und folgerichtig. daß sich das kleinste Bruchstück mit Leichtigkeit dem Ganzen einfügen läßl“ (Lange, a. a. O.).

2) Lucretius Carus, De rerum natura. S. an späterer Stelle dies. Buches. 
Dämpfe und dem Wachsen des Getreides besteht. Diejenigen Wesen nun, bei denen sich alles so traf, wie wenn es zu einem Zwecke entstanden wäre, blieben erhalten, dagegen ging unter und geht noch fortwährend zugrunde, was der Zufall nicht zweckmäßig gebildet hat". A ristoteles weist diese Einwendungen, die man, wie er sagt, machen könnte, zurück. Nach ihm gibt es überall einen Zweck ("ein Weswegen") in dem, was von Natur geschieht. In ihr herrsche der Zweck ebenso wie in der Kunst.

Wie sich die Atomisten die Velt ohne eine Zwecke setzende "ätigkeit entstanden dachten, ersieht man aus einigen Stellen des Lukrez, so insbesondere aus folgenden Versen ${ }^{1}$ ):

..Sage mir ferner, woher ist gekommen den Göttern das Vorbild Der zu erzeugenden Dinge, ja selbst der Begriff nur des Menschen; Daß sie wußten und sahen im Geiste, was schaffen sie wollten. Woher erhielten sie jemals von Kräften der Urstoffe Kenntnis, Was durch veränderte Ordnung sie alles zu leisten vermöchten, Hätte Natur nicht selbst eine Probe des Schaffens gegeben?

Denn gar viele der Urkörper pflegten seit ewigen Zeiten

Durch ihr eignes Gewicht und durch Stöße von außen getrieben, Sich zu bewegen und mischen auf alle nur mögliche Weise

Und zu versuchen, was sie für Verbindungen schaffen wohl könnten, IVenn sie bald so, bald anders sich zueinander gesellten.

Ist da wohl zu verwundern, daß endlich sie nun auch in solche Lage gerieten und auch in solche Bewegungen kamen, Durch die das ganze All jetzt besteht und stets sich erneuert?"

Und etwas später ${ }^{2}$ ):

..Denn nicht haben Atome nach reiflich erwogenem Plane Jedes zur richtigen Stell' sich begeben mit rechnendem Geiste, Wahrlich auch nicht durch Verträge bestimmt eines jeden Bewegung."

Den Gedanken, daß die Natur oft neue Arten schaffe, die wieder untergehen, wenn sie sich nicht erhalten können, hat nach dem Wiederaufleben der Wissenschaften zuerst Cardanus ausgesprochen ${ }^{3}$. Er tat dies in Anlehnung an die durch Lukrez ver-

1) 5. Buch. $181-194 . \quad$ 2) 5. Buch. 419 u. f.

3) Cardanus, De subtilitate. lib. XI. Cardani operum tom. III. Lugduni 1663. p. 549.) Auf diese Stelle machte mich Leopold Löwenheim aufmerksam. Siehe auch die von ihm herausgegebene Schrift: Die Wissenschaft Demokrits und ihr Einfluß auf die moderne Naturwiss. Von Louis Löweneim. Berlin 1914 . 
breiteten Lehren Demokrits und Epikurs. Es ergibt sich somit ein ununterbrochener Zusammenhang zwischen den schon im Altertum ausgesprochenen Vorahnungen der Deszendenztheorie und ihrer wissenschaftlichen Gestaltung durch Lamarck und Darwin. Übte doch die um 1715 entstandene Schrift de Maillets einen bedeutenden Einfluß auf die Entwicklung der evolutionistischen Ideen aus, der sich besonder's ein Jahrhundert später bei Lamarck bemerklich machte (s. i. IV. Bande). Wie Cardanus ist aber auch de Maillet sehr wahrscheinlich durch die aus dem Altertum stammenden Keime zur Aufstellung seiner Lehre veranlaßt worden ${ }^{1)}$.

Mag man vom philosophischen Standpunkte aus der mechanischen Welterklärung Wert beilegen oder sie für überwunden halten, man wird immer die vorurteilsfreie und konsequente Denkweise ihrer Schöpfer anerkennen müssen. Besteht doch auch heute das Bestreben der Forschung darin, Qualität auf Quantität zurïckzuführen und in der Meßbarkeit einer Erscheinung ihre Erklärung zu finden. "Wer weiß, daß erst durch diese Methode die großen Triumphe der Naturwissenschaft errungen wurden, wird die Größe des demokritischen Gedankens zu würdigen wissen. Die atomistische Theorie ist zwar ein Gewebe von Hypothesen. Und doch haben wir kein besseres Netz, um die Naturerscheinungen für unser Verständnis einzufangen"2). Die atomistische Lehre hat ein sonderbares Schicksal erlitten. Auf das Zeitalter, in dem sie entstanden war, hat sie nur einen geringen Einfluß ausgeübt. Erst 2000 Jahre später wurde sie durch Gassendi und besonders durch Dalton wieder ins Leben gerufen. Seitdem hat sie die größte wissenschaftliche Bedeutung erlangt, weil die Mechanik der Atome allen Naturerscheinungen zugrunde gelegt wurde ${ }^{3}$.

1) Über diese 'Jusammenhänge siehe auch die soeben erwähnte Schrift Löwenheims.

Üher den Einfluß, den die demokritischen Anschaungen auf die weitere Entwicklung der Wissenschaften ausgeiibt haben, wurden von Louis Löwenheim eingehende Untersuchungen angestelit. Löwenheims Arbeit ist bisher nur im Auszuge (s. S. 74 Anm. 2) veröffentlicht. Sie ist dem Verfasser nach dem Erscheinen seines Werkes durch den Sohn des verstorbenen Forschers im Manuskript zugestellt worden, um bei einer neuen Auflage berücksichtigt zu werden. Dies konnte an mehreren Stellen dieses Bandes geschehen.

2) Fr. Schultze in der Zeitschrift Kosmos. 1877. 8. u. 9. Heft.

3) Siehe auch H. C. Liepmann, Dio Mechanik der Leukipp-Demokritischen Atome. Leipzig 1885. 


\section{Der Beginn der idealistischen Weltanschauung.}

Eine weitere Tat der alten Philosophie bestand in der Aufstellung und Durchführung des Zweckbegriffs an Stelle der von den Atomisten behaupteten bewußtlosen Notwendigkeit durch Anaxagoras. Nach allem, was wir von ihm wissen, war Anaxagoras einer der bedeutendsten Philosophen des Altertums. Er wurde um 500 v. Chr. in Kleinasien geboren und siedelte nach den Perserkriegen nach Athen über, wo er zu Perikles in freundschaftliche Beziehungen trat. Anaxagoras erblickte im Nachdenken über die Natur und das Geschehen seine Aufgabe und verpflanzte diese Art des Philosophierens nach Athen, das in der Folge zum Mittelpunkt des geistigen Lebens der Alten wurde. Seine Schrift über die Natur war zur Zeit des Sokrates sehr verbreitet. Von dieser Schrift sind leider nur Fragmente erhalten geblieben 1\%

Wie Empedokles geht Anaxagoras von der Ansicht aus, daß alles Geschehen ein Gemischtwerden und eine Entmischung sei, wobei sich die Menge des Stoffes im Weltall weder mehre noch mindere. Die hierzu erforderliche bewegende Kraft erblickte er in einer vom Stoff gesonderten, freiwaltenden, selbst unbewegten Intelligenz. Diese nach Zwecken handelnde Intelligenz wird aber von ihm mehr vorausgesetzt als nachgewiesen. Daher werfen ihm Plato und Aristoteles vor, sein ",o $\tilde{v}_{s}$ "2) habe ihm zur Erklärung nur als deus ex machina gedient.

Aus dem Urzustande oder dem Chaos hat der „voũs" nach Anaxagoras als ordnendes, nicht als schaffendes Prinzip das Universum entstehen lassen. Eine Erschaffung aus dem Nichts ist eine orientalische Vorstellung, welche dem griechischen Geiste wenig zusagte und uns daher bei den griechischen Philosophen kaum begegnet. Der „voús" und die Urbestandteile der Dinge sind vielmehr von Anbeginn vorhanden. Es ist der philosophische Keim der Lehre von der Erhaltung von Stoff und Kraft, der uns hier begegnet. Der ", $\nu_{0} \tilde{u}_{s}$ "versetzte die Masse in eine Art WVirbelbewegung, welche das Gleichartige zusammenführte und das Weltall in seiner jetzigen Verfassung entstehen ließ. Die später von Kant und Laplace entwickelte Nebularhypothese besagt, wie wir sehen

1) Schaubach, Anaxagorae fragmenta. Lipsiae 1817. Mullachius, Fragm. phil. graec. Parisiis. I u. II. 1860-1867. Vor allem aber Diels' "Vorsokratiker".

2) D. h. Vernunft, hier Weltvernunft. 
werden, im Grunde dasselbe. Nur daß die Neueren diese Vorstellungen von der alten geozentrischen Ansicht loslösten und sie vom Standpunkte der koppernikanischen Lehre entwickelten. Infolge der Wirbelbewegung trennen sich nach Anaxagoras Äther, Luft, Wasser und Erde vonemander. Vom letzteren Elemente verharren einzelne Massen infolge der Wirbelbewegung im Äther, der ihnen Leuchtkraft verleiht und sie uns als Gestirne erscheinen läßt. Für diese Ansicht sprechen nach Anaxagoras die vom Himmel fallenden Meteoriten, von denen er den 423 v. Chr. in Aegospotamoi (Thrazien) gefallenen erwähnt. Er meint, dieses Eisenstück, das bei Tageslicht auf die Erde herabgefallen sei ${ }^{1}$, stamme von der Sonne, und mache es wahrscheinlich, daß letztere aus glühendem Eisen bestehe. Auch der Mond sei ein Weltkörper wie unsere Erde und besitze Berge und Täler, eine Vorahnung, deren Richtigkeit erst 2000 Jahre später durch Galilei erwiesen werden konnte ${ }^{2}$. A naxagoras teilte das Schicksal vieler aufgeklärten Geister. Er wurde im hohen Alter als Gottesleugner ins Gefängnis geworfen und nur auf die Verwendung des Perikles hin wieder in Freiheit gesetzt. Die Anklage stïtzte sich besonders darauf, daß Anaxagoras die Sonne für einen glühenden Meteorstein erklärt hatte. Ihm, wie später dem Sokrates und Aristoteles, hat das atheniensische Volk mit Undank gelohnt.

Erwies sich auch der auf Anaxagoras zuriickzuführende Begriff der Zweckmäßigkeit, der in den platonischen Ideen seine Fortbildung fand, während der späteren Entwicklungsstufen der Wissenschaft als unzureichend, so war er doch für die Naturforschung des Altertums von Bedeutung und bei dem Aufbau des das Wissen jener Zeit umfassenden, aristotelischen Lehrgebäudes das eigentlich Treibende.

Hinderlich wurde die alte Philosophie der Wissenschaft zuweilen dadurch, daß sie sich mehr dichterisch schaffend als kritisch forschend verhielt. Man war zu leicht geneigt, das Wort für das Ding und den Begriff für das eigentliche IVesen des Dinges zu nehmen. „Durch die Wörter", sagt daher Lange in seiner Geschichte des Materialismus ${ }^{3}$ ) mit Recht, „ließen Sokrates, Plato

1) Es besaß die Größe eines Mühlsteins und wird auch von Plutarch und Plinius erwähnt.

2) Anaxagoras nahm an, daß die Sonne mehrere Male so groß sei wie der Peloponnes und daß der Mond ihr an Größe etwa gleich komme. Letzterer sei wie die Erde ein Wohnsitz lebender Wesen.

3) Lange, Geschichte des Materialismus. Bd. I. S. 57. 
und Aristoteles sich täuschen. Wo ein Wort war, wurde ein Wesen vorausgesetzt. Gerechtigkeit z. B. mußte doch etwas bedeuten. Es mußte also Wesen geben, welche den Ausdrücken entsprechen."

In Platon (427-347) erreichte die griechische Philosophie ihren Höhepunkt. Sein System gipfelt darin, daß er die Idee als die Ursache und den Zweck des Geschehens betrachtet und auf diese Weise das Geistige und die Körperwelt aus einem Prinzip ableitet. Obgleich Platon wenig Eigenes auf dem Gebiete der Mathematik geschaffen hat und seine Neigung zu den Naturwissenschaften nur gering war, hat er dennoch diese beiden Wissensgebiete in nicht geringem Maße befruchtet. Groß war vor allen Dingen der persönliche Einfluß, den er als Gründer der atheniensischen Akademie auf seine Schüler ausübte. $\mathrm{Zu}$ ihnen zählten Aristoteles, Eudoxos und Herakleides Pontikos. Platon selbst wurde besonders durch die Pythagoreer angeregt, mit deren Lehren er in Grolgriechenland bekannt geworden war. Auch in $\ddot{A} g y p t e n$ ist Platon gewesen.

Seine Ansichten über die Natur entwickelt Platon in demjenigen seiner Dialoge, der den Titel „Timäos" führt. Diese Schrift ist in besonders hohem Grade durch mythische und pythagoreische Lehren beeinflußt. Nach Platon besteht die Welt nicht seit Ewigkeit, wie der fast gleichzeitig lebende Demokrit lehrte, sondern sie hat einen Beginn und einen Schöpfer. Ewig sind nur die Ideen, welche der Schöpfer, das ist das bewegende Prinzip, mit dem zunächst ungeformten Urgrund der materiellen Welt (etwa dem Chaos zu vergleichen) verbindet. Das Ergebnis ist nicht eine Unendlichkeit von Welten, sondern nur eine Welt, der die vollkommenste Gestalt, das ist die Kugelform, zukommt. Auch in den Einzelheiten weicht die platonische Auffassung in solchem Maße von der mechanischen $a b$, daß sie nicht die Grundlage der nach einer Erklärung aus mechanischen Prinzipien suchenden Naturwissenschaften werden konnte.

\section{Die Begründung der griechischen Mathematik.}

In gleichem Maße, wie die ersten philosophischen Bestrebungen anregend auf die Forschung gewirkt haben, war dies auch hinsichtlich der Mathematik der Fall. Zur vollen Erkenntnis der Wahrheit, daß nur durch die Vereinigung des mathematischen Verfahrens mit der experimentellen Forschungsweise Aussicht auf eine Lösung 
der naturwissenschaftlichen Probleme vorhanden ist, sollte jedoch erst die neuere Zeit gelangen. Es ist ein wesentlicher Mangel der Alten, welche die Mathematik wohl zu handhaben wußten, daß sie sich nicht in gleichem Maße für die Ausübung des Experiments befähigt zeigten. Mannigfache Gründe sind hierfür ins Feld geführt worden. Einer der wichtigsten bestand wohl in dem Überschätzen der reinen Geistestätigkeit gegenüber jeder Beschäftigung mit materiellen Dingen. Auch der Umstand, daß die Ausïbung gewerblichen Schaffens eines freien Mannes unwürdig galt und in die Hand der Sklaven gelegt wurde, war dem Entstehen der experimentellen Forschungsweise in hohem Grade hinderlich ${ }^{1}$ ).

Wenn wir die Entwicklung der Mathematik, die hier gleich den Ergebnissen der Philosophie nur soweit in Betracht kommt, wie sie die Naturwissenschaften beeinflußt hat, nach ihren ersten, an ägyptische und babylonische Elemente anknüpfenden Schritten weiter verfolgen, so richtet sich unser Blick von Ionien nach einem anderen Hauptsitz hellenischer Bildung, nämlich nach Großgriechenland. Hatte man den Wert der mathematischen Betrachtungsweise in Ionien überhaupt erst schätzen gelernt, so finden wir dort, bei Pythagoras und seinen Anhängern eine beträchtliche Überschätzung derselben. Wichtig ist vor allem, daß auch im übrigen Griechenland Männer auftraten, die in der denkenden Betrachtung der Welt ihre Lebensaufgabe erblickten. Als einer der ersten wird uns Pythagoras genannt. Da indes von seinem Leben fast nichts verlautet und auch keine von ihm herrührende Schrift auf uns gekommen ist, so tritt uns in Pythagoras wie in Thales eine sagenumwobene Gestalt entgegen. Ersterer galt lange als der eigentliche Begriinder der griechischen Mathematik, während für Thales und Anaximander die Mathematik als Hilfswissenschaft zur Lösung astronomischer Aufgaben in Betracht kam. Heute ist das Urteil über die Bedeutung des Pythagoras wesentlich eingeschränkt worden (s. S. 80).

1) Man darf den hier geriigten Mangel der Alten aber auch nicht ibertreiben, wie es z. B. Du Bois Reymond Kulturgeschichte und Naturwissenschaft) getan hat. Daß das Experiment auch in Altertum eise Rolle spielte, und zumal bei den Alexandrinern zu wichtigen Ergebnissen fübrte, darf nicht verkannt werden. In Mittelalter waren inshesondere die Araber bemübt, die ihnen von den Griechen übermittelten Wissenschaften durch experınentelle Untersuchungen weiter auszubanen. Sirlıe auch W. Wiedemann, Ủher das Experiment im Altertum und Mittelalter (Unterrichtsblätter für Mathem. und Naturwissenseh. 1906. Nr. 4-6). 
Pythagoras wurde um 550 v. Chr. in Samos geboren. Über die Gründung seiner Schule gehen die Nachrichten sehr auseinander. Fs läßt sich annehmen, daß er sich vorber gleich Thales in Ägypten, vielleicht auch in Babylon ${ }^{1}$ ) aufgehalten hat. Auch in diesem Falle würde es sich also um eine Verpflanzung orientalischer Wissenschaft auf den, ihrer weiteren Entwicklung besonders günstigen Boden Griechenlands gehandelt haben.

Pythagoras und seine Schüler gingen, mehr ahnend als in wirklicher Erkenntnis, von der Voraussetzung aus, daß eine durch $\mathrm{Maß}$ und Zahl bestimmte Gesetzmäßigkeit alles natürliche Geschehen beherrsche. In einseitiger Übertreibung dieses Gedankens erblickten sie dann in den Zahlen den ursächlichen Grund der Erscheinungswelt. "Den Pythagoreern," sagt Aristoteles, "ward die Mathematik zur Philosophie." Es handelte sich indessen bei ihnen mehr um bloße Zahlenmystik, als um die Pflege und Förderung exakter Wissenschaft. So bezogen sie die Sechs auf Belebung, die Sieben auf Gesundheit, die Acht auf Freundschaft usw. Diese Zahlenmystik der Pythagoreer ist zum Teil wohl auf akustische Versuche und das Nachdenken über das Wesen der Harmonie zurückzuführen. Man hatte bemerkt, daß der Ton einer Saite von bestimmter Spannung in die Oktave übergeht, wenn man die Länge der Saite auf die Hälfte herabsetzt, oder daß gleich gespannte und gleich dicke Saiten konsonierende Töne geben, wenn sich ihre Längen wie 1:2, 2:3, 3:4, 4:5 verhalten. Den Grund dieser Erscheinung suchten die Pythagoreer nun in dem geheimnisvollen Wesen der Zahlen. Auch darin kam die Vorstellung von der Bedeutung der Harmonie zum Ausdruck, daß die von der pythagoreischen Schule beeinflußte Medizin Gesundheit als die Symmetrie gewisser Qualitäten wie Warm, Kalt, Trocken, Feucht usw. betrachtete, während Krankheit in der Störung dieser Symmetrie bestehen sollte ${ }^{2}$.

Auf die Pythagoreer werden zurïckgefïhrt - wobei sich indes nicht unterscheiden läßt, was selbst gefunden und was an fremden Elementen aufgenommen wurde - die Sätze über die Winkelsumme im Dreieck, über die Kongruenz der Dreiecke, der sogenannte pythagoreische Lehrsatz, sowie die Kenntnis des goldenen Schnitts; ferner die ersten Kenntnisse der Stereometrie, insbesondere der fünf regelmäßigen Polyeder und der Kugel.

1) Cantor, Geschichte der Mathematik. 1880. Bd. I. 128 u. 158.

2) Näheres siehe bei Diels, Antike Technik, S. 21. 
Zeugnisse für geometrische Entdeckungen des Pythagoras enthält die Literatur des Altertums an etwa zwölf Stellen. Bei der Beurteilung der Zuverlässigkeit dieser Zeugnisse ist indessen zu berücksichtigen, daß die ältesten Angaben 500 Jahre, die Hauptquelle (Proklos) sogar 1000 Jahre nach Pythagoras niedergeschrieben wurden 1). Proklos, der sich auf die beiden verloren gegangenen Schriften des. Eudemos, des ältesten Geschichtsschreibers der griechischen Mathematik ${ }^{2}$, stützt, hat Pythagoras nicht für den Entdecker des Begriffes der irrationalen Größen gehalten und ihm weder die Konstruktion der regulären Körper noch die Entdeckung des pythagoreischen Lehrsatzes zugeschrieben. Auch Zeller, der Geschichtsschreiber der griechischen Philosophie, ist schon der althergebrachten Ansicht entgegengetreten, nach welcher Pythagoras selbst als Mathematiker Hervorragendes geleístet haben soll. Das Ergebnis aller neueren Nachiforschungen besteht darin, daß sich eine bestimmte Leistung auf dem Gebiete der Mathematik Pythagoras mit Sicherheit überhaupt nicht zuweisen läßt.

Die den Griechen im allgemeinen nachgerühmte Strenge der Beweisführung war bei den Pythagoreern noch wenig entwickelt. Sie verfuhren häufig noch induktiv und wußten das Allgemeine von den Einzelfällen noch nicht recht zu trennen. Immerhin kommt ihnen das Verdienst zu, daß sie die Mathematik ron den Bedürfnissen des Lebens gesondert und sie als reine Wissenschaft aufgefaßt haben ${ }^{3}$ ). Vor allem wurde die Lehre rom Dreieck durch Pythagoras und seine Schule so rollständig entwickelt, daß

1) H. Vogt, Die Geometric des Pythagoras. Siehe Bibl. math. (3. Folge 9. Bd. S. 15 u. f. Danach sind neuerdings auch Zweifel erhoben, ob Pythagoras mit der Konstruktion der fünf regulären Körper schon vertraut gewesen. Auch mit dem Begriff des Irrationalen wurden die Griechen wahrscheinlich erst viel später bekannt.

2) Die Griechen haben schon über die Entwicklung der Mathematik geschrieben. Eudeınos, ein Schüler des Aristoteles, verfaßte eine Geschichte der Astronomie und der Geometrie, die bis auf wenige, auch die erwähnten Angaben über Thales enthaltende Bruchstücke verloren gegangen ist. Ferner schrieb Theophrast von Eresos eine Geschichte der Mathematik. Sie ist leider ganz verloren gegangen (S uter, Geschichte der mathenatischen Wisseuschaften. 1873. S. 21). Die F'agmente des Eudemos wurden von L. S pengel gesammelt and herausgegeben: Eudemi fragmenta, quae supersunt. Berlin 1866. Zu erwähnen ist auch Menon. Err war gleichfalls ein Schüler des Aristoteles und schrieb eine Geschichte der Medizin. Die erhaltenen Bruchstücke veröffentlichte Diels (Suppl. Arist. III, 1. Berlin 1893.

3; Tropfke. Geschichte der Mathematik. II. S. 5.

Dannemann, Die Naturwissenschaften. 1. Bd. 2. Autl. 
Euklid, als er die mathematischen Kenntnisse der Griechen in seinen „Elementen" zusammenstellte, nur wenig hinzuzufügen brauchte. Daß die Winkel des Dreiecks zusammen zwei Rechte betragen, bewiesen die Pythagoreer, indem sie durch eine Ecke eine Parallele zur Gegenseite zogen ${ }^{1}$. Auf den nach Pythagoras benannten Satz wurde man wahrscheinlich dadurch geführt, daß man die aus Ägypten oder Babylon zu den Griechen gedrungene Erkenntnis, ein Dreieck sei rechtwinklig, wenn sich seine Seiten wie $3: 4: 5$ verhalten, mit dem arithmetischen Satze, daß $3^{2}+4^{2}$ gleich $5^{2}$ ist, zu verbinden wußte; wie denn überhaupt die Stärke der spätercn Pythagoreer in der Anwendung der Zahlenlehre auf die Geometrie bestand. Auch den Satz, daß die drei Winkelhalbierenden eines Dreiecks sich in einem Punkte schneiden, haben die Pythagoreer gekannt und zur Auffindung des dem Dreieck eingeschriebenen Kreises verwertet ${ }^{2}$ ). Eingehend haben sie sich ferner mit den regelmäßigen Polygonen und mit den fünf regelmäßigen Polyedern beschäftigt. Von letzteren waren der Würfel, das Tetraëder und das Oktaëder schon Gegenstand der orientalischen Mathematik gewesen. Das Ikosaëder und das Dodekaëder dagegen lat erst die pythagoreische Schule konstruiert. Alle fünf Körper legten die Pythagoreer ihren mystischen Welterklärungsversuchen zugrunde. Die WVelt sollte die Form des Dodekaëders besitzen, die vier übrigen regulären Körper dagegen für die Teilchen der vier Grundstoffe, Feuer, Erde, Luft und Wasser, formbestimmend sein ${ }^{3}$ ). Zu der Erkenntnis, daß es nur fünf reguläre Polyeder gibt, d. h. Körper, die von gleichen, gleichseitigen und gleichwinkligen Ebenen begrenzt sind, gelangte erst Euklid.

Wie für die Geometrie, so wurde damals auch in der Arithmetik eine Grundlage geschaffen, welche den raschen Aufschwung ermöglichte, den die Mathematik bald darauf in Griechenland erfuhr. Die Pythagoreer schufen die Begriffe der Prim- und der relativen Prim- oder teilerfremden Zahlen. Aus dem Orient übernahmen sie dann die Begriffe Quadrat- und Kubikzahl, mit denen die Babylonier schon im 3. Jahrtausend v. Chr. vertraut waren. Auch die Lehre von den Proportionen wurde von den Pythagoreern gepflegt, da die Proportionen sich für manche Aufgaben, die man heute durch Gleichungen löst, als besonders geeignet erwiesen.

1) Proclos, ed. Friedlein. S. 379.

2) Tropfke, II. 88 .

3) Nach Angaben von Platon (Timäos) und Vitruv (De architectura). Näheres siehe Tropfke. II. 400 . 
Neben der arithmetischen $(\mathrm{a}-\mathrm{b}=\mathrm{c}-\mathrm{d})$ und der geometrischen $(a: b=c: d)$ erregten auch die durch Gleichsetzung der inneren Glieder sich ergebenden stetigen Proportionen $(a-b=b-c$ und $a: b=-b: c)$ die Aufmerksamkeit der pythagoreischen Schule.

Auf den Begriff des Irrationalen wurden die Pythagoreer geführt, indem sie erkannten, daß die Diagonale und die Seite eines Quadrates kein gemeinschaftliches Maß besitzen. Die systematische Darstellung der Lehre von der Irrationalität erfolgte durch Euklid. Er dehnt sie auf mehrfache Quadratwurzeln aus, behandelt aber nur solche Ausdrücke, die sich mit Zirkel und Lineal konstruieren lassen ${ }^{1}$ ).

Einige .Jahrhunderte unausgesetzter Pflege der mathematischen Wissenschaften, mit denen sich auch die hervorragendsten unter den Philosophen, wie Platon und Aristoteles, beschäftigten, genügte dann, um in den Werken des Apollonios und des Archimedes Leistungen allerersten Ranges heranreifen zu lassen. Besonders in der Hand des letzteren wurde die Mathematik zu einem Werkzeug, mit dem schon die Bewältigung mancher physikalischen Aufgabe gelang.

In der Geschichte der griechischen Mathematik nimmt der um 440 wirkende Hippokrates von Clios eine vermittelnde Stellung zwischen der älteren Scluule der Pythagoreer und den Matbematikern des 4. Jahrhunderts v. Chr. ein. Hippokrates begrïndete eine strengere Beweisführung. Auch war er der erste, der ein mathematisches Lehrgebäude veröffentlichte ${ }^{2}$ ). Am bekanntesten ist sein Satz von den Möndchen (Lunulae Hippokratis). Er lautet: Gegeben sei ein dem Halbkreise eingeschriebenes, gleichschenkliges, rechtwinkliges Dreieck. Errichtet man dann Halbkreise ïber den Kitheten, so sind a und a, (die Lumulae) den Stücken b und b, flächengleich

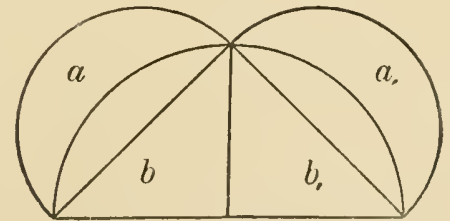

Abb. 12. Der Salz des Hippokrates. (Abb. 12). Hippokrates hat ferner bewiesen, daß sich die Kreisflächen wie die Quadrate der zugehörigen Durchmesser verhalten. Auf ihn ist wahrscheinlich auch die Exhaustionsmethode zuriickzuführen, die uns im Verfolg der weiteren Entwicklung der griechischen Mathematik noch wiederholt beschäftigen wiıd.

1) H. Vogt, Die Entdeckungsgeschichte des Irrationalen. Biblioth. mathemat. 10. Bd. S 97.

2) Siehe Paulys Reallex. d. klass. Altert. Bd. VIII. 
Der Satz über die Lunulae ist deshalb von besonderem Interesse, weil er der erste gelungene Versuch ist, eine krummlinige Figur zu quadrieren. Hippokrates ${ }^{1}$ ) glaubte sogar, durch seinen Satz der Quadratur des Kreises einen Schritt näher gekommen zu sein. Seine auf die Lösung dieses Problems hinzielenden Versuche mußten indessen schon deshalb ergebnislos bleiben, weil, wie die neuere Mathematik bewiesen hat, die wahre Quadratur des Kreises nicht möglich ist. Des Hippokrates Satz über die Lunulae war eine wichtige Verallgemeinerung des pythagoreischen Lehrsatzes. Letzterer beschränkte sich auf Quadrate. Das Hinzukommen des neuen Satzes ließ schon die Erkenntnis durchschimmern, daß, ganz allgemein, ähnliche Figuren über den Katheten zusammen einer ähnlichen Figur iiber der Hypotenuse flächengleich sind.

Für die alte Mathematik besaßen drei Probleme eine treibende Kraft, wie wir sie für die Chemie in dem Problem der Metallverwandlung kennen lernen werden. Es waren dies die Quadratur des Kreises, die Verdopplung des Würfels oder das delische Problem und die Dreiteilung eines beliebigen Winkels. Alle drei Aufgaben waren so naheliegend und schienen so einfach zu sein. Und doch haben sie, soweit sie ïberhaupt lösbar sind, den größten Mathematikern kaum überwindbare Schwierigkeiten bereitet.

Mit den Versuchen, die Quadratur des Kreises zu finden, beginnt die griechische Mathematik im 5. Jahrhundert v. Chr. reine Wissenschaft zu werden. Das Problem beschäftigt schon den Anaxagoras. Es führt bereits um jene Zeit ${ }^{2}$ ) zum Exhaustionsverfahren, das Archimedes weiter entwickelte und das als Vorstufe zur Integrationsmethode der neueren Mathematik betrachtet werden kann. Da eine vollkommene Lösung der Quadratur nicht gefunden werden konnte, so begnügte man sich bei der Exhaustionsmethode mit einer angenäherten Bestimmung. Man zeichnete in den Kreis zunächst ein Quadrat. Über den Seiten dieser Figur errichtete man die Seiten des dem Kreise eingeschriebenen Achtecks, darüber das eingeschriebene Sechszehneck und so fort, bis das schließlich erhaltene Vieleck von dem Kreise kaum noch abwich. Dieses Vieleck wurde dann nach den bekannten Verfahrungs-

1) Über Hippokrates siehe Brettschneider, Die Geometrie und die Geometer vor Euklid. Leipzig 1870.

2) Antiphon um 430 v. Chr. Siehe Cantor, Vorlesungen zur Geschichte der Mathematik. I. 172. (1880.) 
weisen der Elementarmathematik so oft in ein flächengleiches Vieleck von geringerer Seitenzahl umgeformt, bis man schließlich das dem Kreise annähernd flächengleiche Quadrat gefunden hatte. Ein derartiges konstruktives Verfahren war sehr umständlich und um so fehlerhafter, je größer die Zahl der vorgenommenen Konstruktionen war, da ja jede einzelne von dem wahren Werte mehr oder weniger abwich.

Gleichfalls im 5. Jahrh. v. Chr. tauchte das delische Problem auf. Seinen Namen soll es daher erhalten haben, daß den Deliern durch ein Orakel befohlen wurde, einem würfelförmigen Altar den doppelten räumlichen Inhalt zu geben. Das Problem, mit dem sich alle bedeutenden griechischen Mathematiker, unter ihnen auch Hippokrates von Chios und Platon beschäftigt haben, führte zunächst zum Begriff der Kubikwurzel. Ist nämlich die Kante des gegebenen Würfels a, diejenige des gesuchten $\mathrm{x}$, so ist $\mathrm{x}^{3}=2 \mathrm{a}^{3}$ und $\mathrm{x}=\mathrm{a} \sqrt[3]{2}$. Auf diesen Ausdruck kam schon Hippokrates. Während aber für die Quadratwurzeln geometrische Konstruktionen gefunden werden konnten, versagte dieser Weg zunächst bei der Kubikwurzel 1j. Die Gleichung $\mathrm{x}=\mathrm{a} \sqrt[3]{ }^{2}$ bedeutet, daß die gesuchte Seite des doppelten Würfels die erste $(\mathrm{x})$ von zwei mittleren Proportionalen ( $\mathrm{x}$ und $\mathrm{y}$ ) ist, die man in Form einer laufenden Proportion zwischen die einfache (a) und die doppeite Seite (2a) des gegebenen Würfels einschaltet. Ist nämlich

$$
\begin{aligned}
& a: x=x: y=y: 2 a, \text { so ist } \\
& \text { (1) } a: x=x: y \text { und } \\
& \text { (2) } x: y=y: 2 a \text {. }
\end{aligned}
$$

Setzen wir den aus (2) ermittelten Wert für $y$, nämlich $y=$ $V$ zax in Gleichung 1) ein, so erhalten wir $a: x=x: V 2 a x$, daraus folgt:

$$
\begin{aligned}
& x^{2}=a \sqrt{2 a x} \\
& x^{4}=a^{2} \cdot 2 a x \\
& x^{3}=2 a^{3} \\
& x=a \sqrt{ } 2 .
\end{aligned}
$$

Die Aufgabe war also gelöst, wenn es gelang den Wert $x$, ausgehend von der laufenden Proportion $a: x=x: y=y: 2 a, z u$ konstruieren. Geometrisch ist diese Proportion durch beistehende

1) Die wichtigsten Mitteilungen ïher die verschiedenen Wege, wie die Alten das delische Prohlem lïsten, verdanken wir dem Eutokios, weleher die Schriften des Archimedes kommentierte, Archimedes, ed. Heiberg, III., S. 104. 
Figur (Abb. 13) ausgedrückt: ABCD ist ein Rechteck. ACD und $\mathrm{CDE}$ sind rechtwinklige Dreiecke. Für die in der Figur mit $\mathrm{a}, \mathrm{b}, \mathrm{x}, \mathrm{y}$ bezeichneten Stücke gelten dann nach einem bekannten Satz über die Proportionalität rechtwinkliger Dreiecke die Verhältnisse $a: x=x: y$ und $\left.x: y=y: b^{1}\right)$.

Spätere Mathematiker, unter denen vor allen Platons Schüler Menächmos (etwa 350 v. Chr.) zu nennen ist, gelangten durch die Beschäftigung mit dem delisclien Problem über die Geometrie der Geraden und des Kreises hinaus zu den für die Astronomie und die Mechanik so überaus wiclıtigen, als Parabel, Ellipse und

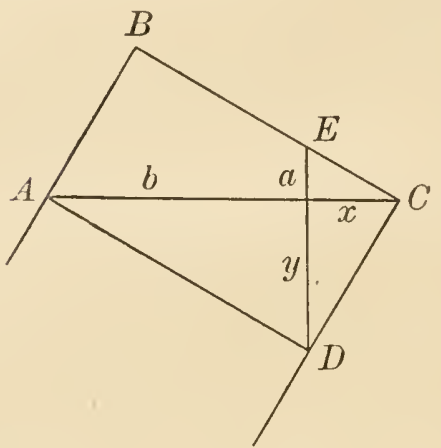

Abb. 13. Konstruktion zur Lösung des delischen Problems. Hyperbel bezeichneten Kurven.

Ausgehend von der schon Hippokrates geläufigen Proportion $a: x=x: y=y: b$, in welcher $b$ für den besonderen Fall der TVürfelverdoppeiung gleich $2 \mathrm{a}$ ist, erkannte Menächmos, daß die aus jener Proportion folgenden Ausdrücke $\mathrm{x}^{2}=\mathrm{ay}$ und $\mathrm{y}^{2}=\mathrm{bx} \quad \mathrm{zu}$ einer neuen Kurve führen. Beide Ausdrücke sind nämlich in der Form gleich und enthalten daher auch die gleiche Forderung. Ins Geometrische übersetzt bedeuten sie nämlich, an eine Gerade ein Rechteck (a y) so anzutragen ( $\pi \alpha \varrho \alpha-$ $\beta(\langle i\rangle) \varepsilon\left(\nu^{\prime}\right)$, daß der Inhalt einem Quadrate $\left(\mathrm{x}^{2}\right)$ gleich ist.

Menächmos erkannte, daß der geometrische Ort für die Schnittpunkte aller, dieser Bedingung genügenden Rechtecke eine vom Kreise abweichende krumme Linie bildet, die später wegen des Antragens ( $\pi \omega \rho \alpha \beta \sigma \lambda \eta \dot{\eta}$ ) des Rechteckes an die Gerade den Namen Parabel erhielt. Er zeigte weiter, daß sich der für die Würfelverdoppelung gesuchte Wert $\mathrm{x}$ als Schnittpunkt einer Parabel mit einer Hyperbel oder als Schnittpunkt zweier Parabeln ermitteln läßt. Doch würde ein weiteres Eingehen anf diese Konstruktionen hier zu weit führen. Jedenfalls steht fest, daß Menächmos mit einer punktweisen Konstruktion beider Kurven und mit ihren Grundeigenschaften, ja sogar mit den Asymptoten der Hyperbel

1) Diese Konstruktion, welche Eutokios in seinen Erläuterungen zu A rchimedes bringt, wird Platon zugeschrieben. Archimedes, ed. Heiberg, IU., S. 66-70. 
bekannt war $\left.{ }^{1}\right)$. Die Beziehung der von ihm untersuchten Kurven zur Kegeloberfläche hat Menächmos wahrscheinlich noch nicht erkannt, jedenfalls gelangte er zu diesen Kurven, indem er sich bemühte, für einen arithmetischen Ausdruck den zugehörigen geometrischen Ort zu bestimmen ${ }^{2}$.

Auch die Aufgabe, einen Winkel in drei gleiche Winkel zu zerlegen, führte, wie das delische Problem, auf kubische Gleichungen und höhere Kurven. So gelang es um 400 v. Chr. ${ }^{3}$ ) die Dreiteilung des Winkels mit Hilfe der Quadratrix genannten Kurve auszuführen ${ }^{4}$ ).

Die Beschäftigung mit dem delischen Problem und den Kegelschnitten führte im Verlauf der ersten Hälfte des 4 . Jahrhunderts v. Chr. auch zu einem tieferen Eindringen in die Wahrheiten der Stereometrie. Vor allem sehen wir Platon und seine Schüler auf diesem Gebiete tätig. Auf den unbefriedigenden Zustand dieser Wissenschaft wies er mit folgenden Worten hin: „Hinsichtlich der Messungen von allem, was Länge, Breite und Höhe hat, legen die Griechen eine in allen Menschen von Natur vorhandene, aber ebenso lächerliche wie schmähliche Unwissenheit an den Tag“. Platon gebührt aber auch das allgemeinere Verdienst, die mathematische Methode dadurch verbessert zu haben, daß er jeden Satz auf Vordersätze zurückführte, bis er endlich zu Axiomen und Definitionen als den, weitere Voraussetzungen entbehrenden Grundlagen der Mathematik gelangte. Auch die Erfindung des indirekten Beweisverfahrens wird Platon zugeschrieben ${ }^{5}$.

Unter den stereometrischen Sätzen, welche die platonische Schule auffand, verdienen besonders zwei hervorgehoben zu werden. Es ist das der Satz von der Raumgleichheit der Pyramide mit dem dritten Teile des Prismas von gleicher Grundfliiche und gleicher Höhe. Ferner erkannte man, daß Kugeln sich in bezug auf den Rauminhalt wie die dritten Potenzen ihrer Durchmesser verhalten ${ }^{6}$.

1) Näheres bringt die von Cautor (Bd. I. S. 199) nach Eutokios gegebene Darstellung der von Menächmos gefundenen Sätze.

2) Ging man ähnlich wie bei der Ableitung der Parabel vor, stellte aber die Bedingung, daß von den an dic Gerade anzutragenden Rechtecken stets ein

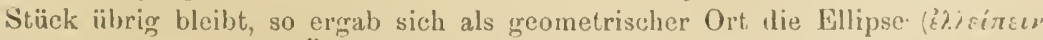
heißt übrig bleiben). Üherragten dagegen die liechtecke die Gerude, so ergab

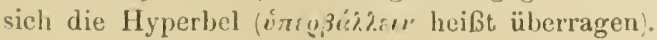

3) Hippias von Elis.

4) Näheres Cantor, I. 167.

5) Tropfke, Geschichte der Elementarmathematik. Bd. II. S. 5.

6) Beide Sätze werden Platous Sehiiler Eudoxos von Knidos zugesehrieben. 
Um jene Zeit scheint auch die Entdeckung stattgefunden zu haben, daß Ellipse, Parabel und Hyperbel wie der Kreis als Kurven auf der Kegeloberfläche (Kegelsclinitte) entstehen, wenn man Ebenen in verschiedener Neigung zur Kegelachse durch den Kegel legt ${ }^{1}$ ).

\section{Die Anfänge der griechischen Astronomie ${ }^{2}$ ).}

Nicht so erfolgreich wie auf den Gebieten der Philosophie und der Mathematik sind die Griechen während dieser Periode in der Astronomie gewesen. Die Anfänge dieser Wissenschaft verdankten sie den Sternwarten Mesopotamiens, so die Kenntnis der Ekliptik, der Tierkreiszeichen, der Planetenreihe usw. Auch das Duodezimalsowie das Sexagesimalsystem und die auf diesen Systemen beruhenden Maße gelangten iiber die ionischen Städte, welche dem babylonischen Einfluß weit geöffnet waren, nach Griechenland ${ }^{3}$ ). Große Schwierigkeiten bereitete den Griechen ihre Zeitrechnung, der sie anfangs die Bewegung des Mondes zugrunde legten. Man sah dieses Gestirn in rascher Folge einen Wechsel ron Lichtgestalten durchlaufen und gelangte dadurch zur Aufstellung des synodischen Monats, dessen Dauer 29 Tage 12 Stunden und 44 Minuten beträgt. Es ist nun sehr wahrscheinlich, daß der erste Versuch, die Rechnung nach Mond und Sonne zu regeln, zur Festsetzung eines Zeitraums von 12 Monaten zu 30 Tagen führte. Ein solcher Kalender konnte den Bedürfnissen jedoch nicht lange genügen, da er dem tatsächlichen Verlauf der himmlischen Bewegungen zu wenig entsprach. Der nächste Schritt bestand deshalb darin, daß man den Monat abwechselnd zu 29 und 30 Tagen rechnete. Dadurch wurde das Jahr aber auf 354 Tage rerkürzt. Mit diesem Zeitabschnitt rechneten die Griechen, bis Solon den bedeutenden Ausfall, den man erlitten, dadurch ausglich, daß er jeden zweiten Jahre einen vollen Monat von 30 Tagen zulegte. Auf das Jahr kamen also im Mittel $\begin{gathered}2 \cdot 354+30 \\ 2\end{gathered}=369$ Tage, was noch immer eine starke Abweichung von der wirklichen Dauer bedeutete. Einer der

1) Diese Entdeckung wird auf Aristaeos (um 320 v. Chr.), der ebenfalls der platonischen Schule angehörte, zurückgefübrt. Er soll auch das erste Werk über die Kegelschnitte geschrieben haben. Cantor I, 211.

2) Eine ausführliche Darstellung mit zahlreichen Literaturangaben enthält Paulys Realenzykl. f. d. klass. Altertum in Bd. II. (1896.) S. 1828-1862. Sie rührt von Hultseh her.

3) F. Cumont, Babylon und die griechische Astronomie. Neue Jahrbücher f. d. klass. Altertum. 1911. S. 1. 
ersten, der sich (um 460 v. Chr.) bemühte, die Kalenderrechnung durch einen besseren Ausgleich zwischen dem Mondumlauf und dem Sonnenjahr zu regeln, war der Astronom Oenopides auf Chios, zu dessen Schïlern wahrscheinlich Hippokrates von Chios zählte. Oenopides setzte 730 Mond-Monate 59 Sonnen-Jahren gleich und kam so zu einer Jahreslänge von 365,373 Tagen. Er soll auch viel zur Übermittlung der ägyptischen und babylonischen Astronomie bejgetragen und den aus gleichen Abschnitten bestehenden Tierkreis in Griechenland eingeführt haben. Auch dadurch hat er sich einen Namen gemacht, daß er die regelmäßig wiederkehrenden Nilschwellen auf kosmische Ursachen zurückführte.

Die Verwirung, in welche der Kalender der Griechen geraten war, hat ihr großer Lustspieldichter Aris tophanes ${ }^{1}$ ) dadurch verspottet, daß er den Mond über einen solch unhaltbaren Zustand sich beklagen läßt. Erst dem atheniensischen Mathematiker Meton gelang 433 v. Chr. die endgïltige Beseitigung dieses Wirrsals. Fr führte einen Zyklus ein, der 19 Jahre und imnerhalb dieses Zeitraums 125 ..volle" und 110 , ,leere" Monate umfaßte, so daß das Jahr $125 \cdot 30+110 \cdot 29$ 19 $=365,263$ Tage enthielt, während der wahre Wert des Sonnenjahres sich auf 365,242 Tage beläuft2).

Die Einteilung nach Stunden, für die sich bei Herodot noch keine besondere Bezeichnung findet, scheint erst gegen das Ende des 4. vorchristlichen Jahrhunderts in Gebrauch gekonmen zu sein. Vorher begnüigte man sich damit, daß man aus der Schattenlänge des eigenen Körpers oder eines senkrechtell Sonnenzeigers auf das Vorrücken der Tageszeit schloß ${ }^{3}$.

Zu einer annähernden Bestimmung des Sonnenjahres mußte man gelangen, sobald man zur genaueren Messung der Schattenlänge mit Hilfe des Gnomons überging. Man erkannte, daß die Mittagshöhen und damit die Tageslïngen und die Jahreszeiten innerlıalb einer Periode von 365̃ $1 / 4$ Tagen wiederkehren. Zu dieser Erkenntnis kam die Beobachtung, dali innerhalb derselben Periode

1) Aristophanes, Wolken. 615-619.

2) Es ist wahrscheinlich, daß II eton sich hierzu der 'Tabellen bediente, welche die Chaldäer Jahrhunderte vorher für die Mondbewegung und die Finsternisse entworfen hatten.

3) Das Wichtigste iiber die Hilfsınittel, welche in Altertum für die Zeitmessung zur Verfügung standen, bringt die Realenzykl. d. klass. Altertumswiss. von Pauly-Wissowa-Kroll (8. Bd. Sp. 2416-2433! in dem Beitrag ..Horologium" von $\mathrm{A}$. Rehm. 
gewisse Fixsterne nacheinander in der Nähe der auf- oder untergehenden Sonne gesehen werden. Daraus schloß man, daß die stete Änderung in der Kulmination der Sonne daher rühre, daß dieses Gestirn im Laufe eines Jahres einen zum Himmelsäquator geneigten Kreis beschreibt. Um die Neigung dieses, als Ekliptik 1) bezeichneten Kreises zu bestimmen, war es erforderlich, die größte und die geringste Mittagshöhe an einem Orte zu messen und das Mittel aus der Differenz dieser Höhen zu nehmen. Der erste Grieche, der die Schiefe der Ekliptik auf diesem Wege bestimmte, soll Anaximander gewesen sein ${ }^{2}$. Indes begegnen wir weit früheren Angaben. So fanden chinesische Astronomen schon um 1100 v. Chr. für die Schiefe der Ekliptik ziemlich richtig den Wert von $23^{\circ} 52^{\prime}$.

Hinsichtlich der Beschaffenheit des Mondes gelangte man schon frühzeitig zu der Vorstellung, daß es sich um eine freischwebende, von der Sonne beleuchtete Kugel handele. Seine Flecken wurden von einigen als Unebenlieiten, von anderen (wie A ristoteles) als Spiegelbilder unserer Erdteile und Meere aufgefaßt. Schon Anaxagoras hat sich die Frage vorgelegt, weshalb ein, der Erde so naher und vermutlich um vieles kleinerer Himmelskörper nicht zur Erde herunterfalle. Er trifft auch so ziemlich das Richtige, wenn er die Mondbewegung mit der Bewegung in einer Schleuder vergleicht, durch deren raschen Umschwung die Neigung zu fallen gleichfalls aufgehoben werde.

Während die Entdeckung der größeren Planeten aus der Veränderung ihrer Stellung zu den Fixsternen auf den ersten Blick erfolgen mußte, setzte die Auffindung des Merkur, der sich im Mittel nur um 23 Grade von der Sonne entfernt und dalier in höheren Breiten nur in der Dämmerung mit guten Augen wahrzunelımen ist, schon eine größere Aufmerksamkeit voraus. Auch der Saturn wird wegen seines langsamen Fortrückens erst verhältnismäßig spät als Wandelstern erkannt worden sein. Eine systematisch geordnete Reihe von Beobachtungen gehörte dazu, die Zeiten festzustellen, innerhalb deren die Planeten in ihre frühere Stellung zurückkelıren. So gelangte man zu der Erkenntnis, daß Jupiter in 12, Saturn dagegen erst in 30 Jahren ihren Weg anı Fixsternhimmel vollenden.

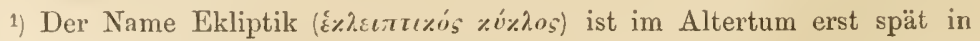
Gebrauch gekommen.

2) Um 560 v. Chr. Siehe auch Darmstädter, Handbuch der Geschichte der Naturwissenschaften. 
Größere Schwierigkeiten boten der Mars und die innerhalb der Erdbahn befindlichen Planeten Merkur und Venus dar. Da letztere beiden jedoch stets in der Nähe der Sonne erscheinen, so mußten sie der geozentrischen Vorstellung gemäß etwa dieselbe Umlaufszeit besitzen. Als Grund dieser sämtlichen Unterschiede nahm man einen verschieden großen Abstand der Himmelskörper von der im Mittelpunkte ruhend gedachten Erde an. Saturn, dessen Umlauf die längste Zeit erfordert, mußte dementsprechend auch am weitesten von der Erde entfernt sein, während der Mond, der zwölfmal in einem Jahre seinen Umlauf vollendet, als der dem Mittelpunkte am nächsten befindliche Himmelskörper galt. Man gelangte daher zu dieser Reihenfolge: Mond, Sonne, Merkur, Venus, Mars, Jupiter, Saturn.

Die Pythagoreer legten sich zuerst die Frage nach dem Verhältnis der Abstände der Planeten vor. Sie bewegten sich hierbei jedoch auf dem Gebiet der bloßen Zahlenmystik. Da sie bei ihren akustischen Untersuchungen auf einfache Beziehungen zwischen den Längen harmonisch tönender Saiten gestoßen waren, hielten sie sich für berechtigt, auch am Himmel solche einfachen Verhältnisse ohne weiteres anzunehmen. So nahm später Platon an, daß sich Mond, Sonne, Venus, Merkur, Mars, Jupiter, Saturn in Abständen von der Erde befänden, die sich wie $1: 2: 3: 4: 8: 9: 27$ verhielten 1). Durch das Obwalten solcher Beziehungen sollte dann, ähnlich wie im Reiche der Töne, eine Konsonanz entstehen. Man dachte sich nämlich, jeder Planet rufe als ein in rascher Bewegung befindlicher Körper einen 'Ton hervor, und dies verursache die Harmonie der Sphären. Über die Entfernung der Fixsterne, welche der äußersten der acht konzentrischen Sphären angehören sollten, läßt Platon nichts verlauten.

Derartige Spekulationen, so ïberflïssig sie auch nach der Entdeckung der tatsächlich obwaltenden Verhältnisse erscheinen mögen, sind für die Entwicklung der astronomischen Wissenschaft durchaus nicht ohne Belang gewesen. Sie waren es, die zu Versuchen anregten, die Richtigkeit der angenommenen Werte zu prïfen. Und wir werden sehen, auf welche Weise man in der nächstfolgenden, schon der Messung zugewandten Periode der griechischen Astronomie, der Tïsung dieser Aufgabe wäher kam.

1) Derartigen Versuchen, die Abstände der Planeten in eine mathematische Regel zu fassen, begegnet man bis ins 18. Jahrhundert (Titiussche Regel; 1766 . 
Zu allen Zeiten hat der Weg der Forschung darin bestanden, daß auf einer gewissen Stufe der Erkenntnis Hypothesen ersonnen wurden, an welche sich die weiteren Versuche behufs einer Prüfung anschlossen. Auch als später Kepler das Problem, das wir jetzt verlassen, wieder aufnahm, trat er mit der vorgefaßten Meinung an dasselbe heran, die Planeten mïßten, wie so manches in der Natur, nach einfachen Verhältnissen geordnet sein. So ist. das von den Pythagoreern aufgeworfene Problem bis in die neueste Zeit eine der fundamentalen Aufgaben geblieben, welche die Astronomie mit immer größerer Genauigkeit $\mathrm{zu}$ bewältigen strebt. Hatten die Chaldäer und die Ägypter die Himmelserscheinungen in Jahrhunderte umfassenden Beobachtungsreihen nur aufgezeichnet und dadurch das wertvollste, den Griechen zu Gebote stehende Material für eine weitere Entwicklung der Astronomie geschaffen, so ging das jüngere, der Ergründung der Ursachen mit regem Geiste zustrebende Volk zuerst zu einer Erklärung dieser Erscheinungen iiber. Einen besonderen Anreiz bot diese Aufgabe den Schülern Platons, der in seinem Timüios die Frage nach der Entstehung und der Anordnung des Weltgebäudes aufgeworfen hatte. Mehr aus philosophischen als aus deutlich erkannten astronomischen Gründen war man gleich den Pythagoreern geneigt, der Erde keine das All beherrschende, zentrale Stellung zuzuschreiben. Dieser Gedanke wurde von Platons Schüler Herakleides Pontikos weiter verfolgt und zu einer heliozentrischen Theorie erweitert, welche besonders durch Aristarch von Samos im 3. Jahrhundert r. Chr. ausgebildet wurde.

Über die Anfänge der heliozentrischen WVeltanschauung, die bis in die Schule des Pythagoras und Platons zurückreichen, haben insbesondere die Forschungen Boeckhs1) und Schiaparellis ${ }^{2}$ Licht verbreitet. Es ist früher wohl behauptet worden, ¿aß Pythagoras selbst schon die Bewegung der Erde gelehrt habe. Für die Ansicht, daß Pythagoras eine andere als die im frühen griechischen Altertum herrschende geozentrische Ansicht gelehrt habe, spricht jedoch nichts Sicheres. Dagegen müssen wir annehmen, daß die Lehre von der Kugelgestalt der Erde in der pythagoreeischen Schule schon galt, als sie in Griechenland noch

1) August Boeckh, Philolaos des Pythagoreers Lehren nebst den Bruchstücken seines Werkes. Berlin, Vossische Buchhandlung. 1819.

2) Schiaparelli, Die Vorläufer des Kopernikus im Altertum. 1873. Übersetzt von Curtze. 
unbekannt war $\left.{ }^{1}\right)$. Früher als die Erde stellte man sich den Himmel als eine Kugel vor, an deren Oberfläche die Sterne angeheftet seien. Als man jedoch bemerkte, daß der Mond, die Sonne und die Planeten an den Sternbildern vorüberziehen und die Planeten mitunter für kurze Zeit von dem Monde verdeckt werden, da konnte man sich der Erkenntnis nicht verschließen, daß die Entfernungen der Himmelskörper ron der Erde verschieden seien. Den Versuch, die Bewegung und die gegenseitige Stellung der Himmelskörper in ihrem Verhältnis zur Erde zu erklären, machten unter den Griechen zuerst die Pythagoreer. Unter ihnen war es der im 5. Jahrhundert lebende Philolaos, dem wir die ersten schriftlichen Aufzeichnungen ïber diese, für die weitere Entwicklung der Weltanschauung grundlegenden Lehren verdanken. Man hat es hier keineswegs mit bloßen Phantasiecrzeugnissen zu tun. Mit Recht sagt daher Schiaparelli: ..Das System des. Philolaos ist nicht die Frucht einer ungeordneten Einbildung, sondern es ist aus der Tendenz entstanden, die Daten der Beobachtung mit einem prästabilierten Prinzip uiber die Natur der Dinge in Übereinstimmung zu bringen" 2): Dieses Prinzip war die in der pythagoreischen Schule entstandene Lehre von der Harmonie, die überall, also auch im Kosmos, herrschen sollte.

Bei der Wichtigkeit der durch Philolaos übermittelten Lehren für das Verständnis der von Platon, ron Herakleides und Aristarch entwickelten Ansichten wollen wir an der Hand der von Boeckh herausgegebenen Bruchstücke uns ein Bild von diesen frühesten kosmologischen Vorstellungen zu machen suchen: letztere führten in ihrer weiteren Entwicklung schon im Altertum $\mathrm{zu}$ einer heliozentrischen Weltansicht.

Nach Philolaos gibt es nur eine Welt, den Kosmos, und dieser besitzt die Gestalt einer Kugel ${ }^{3}$ ). In der Mitte des Alls befindet sich das Zentralfeuer. Die Peripherie wird ron dem unbegrenzten Olymp gebildet, der seiner Natur nach ebenfalls Feuer ist, wenn wir dieses völlig farblose Feuer auch nicht wahrnehmen können. Nur durch die Sonne, die an sich ein dunkler, glasartiger Körper ist, wird das Feuer des Olymps so modifiziert, daß

1) Dies gilt z. B. von Anaxagoras, der nach der Begründung der pythagoreischen Schule lebte.

2) Schiaparelli, a. a. O. S. 7.

3) Platon erklärte im ,Timäos": ..Vom Ganzen, welches kugelförmig ist, zu behaupten, daß es einen Ort unten, den anderen oben habe, ziemt keinem Verständigen" (siehe ,Timäos", 62 u. 63). 
wir es wahrnehmen. Vielleicht ist man durch die Milchstraße zu der Annahme eines alles umschließenden feurigen Olymps geführt worden. Zwischen dem letzteren und dem Zentralfeuer bewegen sich zelın göttliche Körper, nämlich die Fixsternsphäre, die fünf Planeten, dann die Sonne, unter ihr der Mond, wie man aus den Verfinsterungen der Sonne schließen mußte, dann die Erde und endlich, dem Zentralfeuer zunächst, die Gegenerde. Während Platon im "Tinäos" die Erde als den Mittelpunkt bezeichnet, wird also bei Philolaos - und zwar zuerst - der Erde eine Bewegung zugeschrieben. Erde und Gegenerde bewegen sich in 24 Stunden um das Zentralfeuer. Daraus erklärt sich die tägliche Umdrehung des Fixsternhimmels. Die Gegenerde ist im Grunde genommen die den Bewohnern des Mittelmeeres entgegengesetzte Hemisphäre. Denken wir uns diese Hemisphäre von der den Griechen bekannten losgelöst und das Zentralfeuer, das man später in den Mittelpunkt der Erde versetzte, gleichfalls in den Weltraum hinausverlegt, so erkennen wir, daß Philolaos mit seiner Erde und Gegenerde und ihrer gleichlaufenden täglichen Bewegung um das Zentralfeuer die scheinbare tägliche Bewegung des Fixsternhimmels begreiflich gemacht lat.

Bei einer solchen Bewegung bekommen wir die Gegenerde natürlich nie zu sehen, ebensowenig wie wir die der unseren entgegengesetzte Hemisphäre von unserem Standort aus erblicken können. Indem sich die Gegenerde innerhalb der Erdbahn um das Zentralfeuer bewegt, und zwar so, daß sich die Gegenerde stets zwischen der Erde und dem Zentralfeuer befindet, bekommen wir die weit außerhalb des Systems "Zentralfeuer, Gegenerde, Erde" befindliche Sonne während dieser parallelen und konzentrisch erfolgenden Bewegung der Erde und der Gegenerde so lange nicht zu sehen, als wir uns auf der von der Sonne abgekehrten Seite befinden. Wir sind dann im Schatten der Gegenerde, die uns das Somnenlicht während der Hälfte des Tages genau so verbirgt, wie es in Wirklichkeit die aus der Vereinigung von Erde und Gegenerde hervorgehende Erdkugel tut.

Derjenige, der an Stelle der täglichen Bewegung um ein Zentralfeuer die tägliche Rotation unseres Planeten um seine Achse setzte und damit die Annahme der Gegenerde und jenes Zentrums überfliissig macbte, war Herakleides Pontikos. Herakleides ${ }^{1}$ )

1) Lr lebte etwa von 390-310 und war den Pythagoreern in mancher Hinsicht geistesverwandt. Er verfaßte zablreiche Schriften, von denen nur 
ging aber noch einen Schritt weiter, indem er die Sonne schon: als Mittelpunkt für die Bewegungen der beiden inneren Planeten, Merkur und Venus, ansprach. Diese Vorstellung hat später bekanntlich Tycho auf alle Planeten mit alleiniger Ausnahme der Erde ausgedehnt ${ }^{1}$ ).

Die Annahme, daß Merkur und Venus sich um die Sonne bewegen, entsprang der Beobachtung, daß beide Planeten sich nur wenig von der Sonne entfernen, nämlich Merkur im Mittel $23^{\circ}$, Venus höchstens $48^{\circ}$. Daher sagt auch Vitruv: "Merkur und Venus haben, da sie sich um die Sonne als Mittelpunkt ihres Laufes bewegen, ihre Stillstände und Rückläufe in die Sonnenstrahlen eingetaucht"2). Auch Platon beschäftigt sich mit diesem Problem, und zwar im "Timäos". Nach ihm setzte Gott den Mond in den ersten Kreis um die Erde, die Sonne dagegen in den zweiten Kreis. Von Merkur und Venus lieißt es dort ${ }^{3}$ ), sie seien in die Kreise gesetzt worden, "welche an Schnelligkeit sich zwar mit dem Kreislauf der Sonne gleich bewegen, jedoch eine diesem entgegengesetzte Wirksamkeit erlangt haben. Deswegen holen die Sonne, Merkur und Venus auf gleiche IVeise einander ein und werden voneinander eingeholt." Mit solchen dunklen Andeutungen war das Problem der Stillstände und Rückläufe indessen nicht gelöst. Eine Theorie, die sich diesen Erscheinungen schon besser anpaßte, gab Eudoxos durch die Annabme von "homozentrischen Sphären". Vermittelst dieser Theorie gelang es, die Bewegungen des Jupiter und des Saturn vom geozentrischen Standpunkte aus begreiflich zu machen.

Da die Hypothese des Herakleides Pontikos eine Erklärung für das Verhalten von Merkur und Venus gab, während die Theorie der homozentrischen Sphïren hier versagte, lag es nahe, zu untersuchen, ob die Hypothese des Herakleides sich nicht auf die äußeren Planeten ansdehnen ließe. So gelangte man zu dem System, das später Tycho annahm. Mond und Sonme be-

die Titel und Fragmente bekannt sind. Letztere den Titeln zuzuweisen, ist sehwierig und oft nicht möglich. Ü̉er Herakleides sithe auch Gomperz, Griechische Denker. I, 98. Systems.

1 Siche die spätere Darstellung und Abbilinung des Tychonischen

2) Vitruv, De architectura. Vou den meisten Schrift-tellern wird der Ursprung dieser Lehre den Ägyptern zugeschrieben. Koplernikus selbst kannte sie durch Martianus Capella (siehe an späterer Stelle bei Koppernikus'.

3, Platons, ,Timäos". 38. 
wegen sich danach um die Erde, während die sämtlichen Planeten gleichzeitig die Sonne umkreisen.

Alle iibrigen Gestirne betrachtete man wohl als Gesteinsmassen, welche durch die Schnelligkeit des Umschwungs erglühten. So dachten Demokrit und Anaxagoras, während andere sie für Öffnungen des Himmelsgewölbes hielten, aus denen das äußerste Element, das Feuer, hervorbrechen sollte. Später sah man die Fixsterne als Weltkörper an, die ilırem Wesen nach der Sonne und dem Monde gleich seien. Nach Herakleides Pontikos (s. vorige Seite) endlich war jedes Gestirn wie das unsere eine Welt für sich.

Daß die Fixsterne sich in verschiedener Entfernung von uns befinden könnten, vermutete man im Altertum noch kaum ${ }^{1}$ ). Es herrschte vielmehr die Vorstellung, daß sämtliche Fixsterne einer Sphäre angehörten ${ }^{2}$. Platon und Herakleides waren dagegen der Ansicht, daß das Weltall unendlich und ebenso wie jedes einzelne Gestirn beseelt sei.

Gleichzeitig mit den ersten Beobachtungen und Spekulationen über die Himmelskörper beginnt die Frage nach der Beschaffenheit unseres irdischen Wohnsitzes den forschenden Geist zu beschäftigen. Lange dauerte es, bis man sich von dem Eindruck, daß die Erde eine kreisförmige Scheibe sei, losgerungen hatte. Homer und Hesiod waren noch darin befangen. Letzterer läßt die Sonne während der Nacht im Ozean nach Osten schwimmen, wo sie sich friihmorgens wieder erhebt. Der Himmel selbst ist nach ihm ein Gewölbe von solcher Höhe, daß ein schwerer Gegenstand von dort neun Tage und neun Nächte fällt, bis er die Erde erreicht.

Die Überzengung, daß die um das Mittelmeer gelegenen Länder nur einen kleinen Teil der Erde ausmachen, hatte schon vor Aristoteles Platz gegriffen. So sagt Platon im Phaedon $^{3}$ ): ..Die Erde ist groß. Wir haben davon nur einen kleinen Teil um das Mittelmeer herum inne, während andere Menschen viele andere ähnliche Räume bewohnen." In derselben Schrift heißt es, die Erde schwebe in der reinen Himmelsluft oder dem Äther und sei, von ferne betrachtet, einem Balle ähnlich.

1. Siehe S. 93.

2) Ein ausführlicher, von Boll herrührender Beitrag über die Fixsterne findet sich in $\mathrm{Paulys}$ Realenzyklopädie f. d. klass. Altert. VI. Bd. S. 2407-2431.

3) Platons Phaedon. cap. 58. Leipzig, Wilhelm Engelmann. 1852. 


\section{Der Ursprung der Zoologie und der Botanik.}

Während die Mathematik, die Philosophie und die Astronomie bei den Griechen der voraristotelischen Zeit schon deutlich als besondere Wissenszweige hervortreten, ist dies bezüglich der Botanik und der Zoologie noch kaum der Fall. Den Pflanzen wandte man sich ans medizinischem und landwirtschaftlichem Interesse zu. So erzählt uns Theophrast, den wir als einen der frühesten botanischen Schriftsteller kennen lernen werden, von den Rhizotomen (Wurzelgräbern) und den Pharmakopolen (Arzneihändlern) der ersten griechischen Zeit. War das '/iel dieser Männer auch ein iiberwiegend praktisches und ihr Tun mit vielen abergläubischen Gebräuchen gemischt, so schufen sie doch die erste Quelle des Wissens, nämlich die empirische Grundlage, zu der dann später die Spekulation als zweites nicht weniger wichtiges Element hinzutreten mußte, um mit der Empirie vereint zu wahrer IVissenschaft heranzuwachsen $\left.{ }^{1}\right)$.

Theophrast sagt von den Rhizotomen, sie hätten vieles richtig bemerkt, vieles aber auch marktschreierisch iibertrieben. Daß sie beim Ausgraben der Wurzeln auf den Flug der Vögel und den Stand der Some achteten, erschien Theophrast als Torheit.

Die Pflanzenkenntnis der Griechen und die Zahl der den Hirten, Jägern, Landleuten und den erwähnten Rhizotomen bekannten Pflanzen waren bei einer so vielseitigen, mehrere tausend Blïtenpflanzen umfassenden Flora, wie sie Griechenland beherbergt, gewiß nicht unbedeutend. Einen Rückschluß gestattet uns der Sprachschatz jenes Zeitalters. In den homerischen Gesängen z. B. werden 63 Pflanzen erwähnt. In den hippokratischen Schriften finden sich 236 Pflanzennamen, und bei Theophrast, dem Zeitgenossen des Aristoteles, begegnen uns gar 455, unter denen nur wenige sind, die nieht der Flora Griechenlands angehören. Die ältesten fragmentarischen Aufzeichnungen ïber botanische Dinge treffen wir bei dem Philosophen Empedokles, dem Begründer der Lehre von den vier Elomenten oder, wie er sich ausdrückte, den Wurzeln der Dinge 2). Vom wissenschaftlichen Standpunkte aus sind die Ansichten, welche Empedokles über die

1) Meyer, Geschichte der Botanik. Bd. I. S. 5.

2) Ausg. v. Sturz, Vers 160-163. Seine Worte lauten: .,Jetzt zuvörderst vernimm des Alls vierfältige Wurzeln: Feuer und Wasser und Erd' und des Äther's unendliche Höhe. Daraus ward, was da war, was da sein wird, oder was nun ist."

Dannemann, Jie Naturwissenschaften. I. Bal. 2. Aufl. 
Natur der Pflanze äuBert, nicht allzu hoch einzuschätzen. Er meint, unter allen lebenden Wesen seien zuerst die Bäume aus der Erde hervorgegangen. Seiner Lebre von der Allbeseelung der Natur entspricht die Meinung, daß die Pflanzen wie die Tiere Gefühle der Lust und Unlust, ja Einsicht und Verstand besäßen. "Wisse denn, alles erhielt Anteil an Sinn und Verständnis" ist ein Wort, das man dem Philosophen zuschreibt ${ }^{1}$.

Aus der Beseelung der Pflanzen erklärte Empedokles Erscheinungen, die wir auf mechanische Ursachen zurückführen, wie das Erzittern, das Ausstrecken der Zweige gegen das Licht und das Emporschnellen herabgebogener Äste ${ }^{2}$. Auch die ersten Keime der Lehre von den Geschlechtern der Pflanzen begegnen uns bei Empedokles, wenn es sich bei ihm auch nur um eine dunkle Abnung handelte. So berichtet Aristoteles, Empedokles habe gemeint, auch die Bäume brächten Eier hervor. Und wie in dem Ei aus einem Teile das Tier entstände, das Übrige aber Nahrung sei, so entstebe auch aus einem Teile des Samens die Pflanze, das Übrige aber diene dem Keim und der ersten Wurzel als Nahrung ${ }^{3}$.

Auch anderen griechischen Philosophen werden Äußerungen iiber die Natur der Pflanzen zugeschrieben. Sie verdienen zum T'eil Erwähnung, wenn wir uns von den Vorstellungen jener Männer auch kein solch abgerundetes Bild machen können, wie von denjenigen des Empedokles. So soll auch Demokrit aus Abdera über die Pflanzen geschrieben, und einer seiner Schüler soll bemerkt haben, daß die Blätter einer im Orient wachsenden Pflanze bei der Berührung zusammenfallen. Wahrscheinlich handelt es sich um eine dort wachsende Mimosenart. Anaxagoras nennt die Sonne den Vater und die Erde die Mutter der Pflanzen. Auch soll er den Blättern das Vermögen zu atmen beigelegt haben.

In fast noch engerer Beziehung als zu den Pflanzen befand sich der Mensch zur Tierwelt. Hier fesselten ihn nicht nur die Formen, sondern auch die den seinen oft so nahe verwandten Lebensäußerungen und der innere Bau, der bei den höheren Tieren so große Übereinstimmung mit dem Bau des menschlichen Körpers darbot. Vor allem waren es die Haustiere, an denen die ersten zoologischen Kenntnisse gewonnen wurden. Beim Schlachten und Opfern gewann man einen Einblick in die Anatomie dieser Ge-

1) Meyer, Geschichte der Botanik. Bd. I. S. 51.

2) Plut. V. cap. 26.

3) Aristoteles, De gen. animalium. Bd. I. S. 23. 
schöpfe. An Haustieren besaßen die Griechen vornehmlich das Rind, das Pferd, das Schaf, die Ziege, das Sehwein und den Hund, auch wurden Hühner, Gänse, Enten und Tauben gehalten. Was die übrige Tierwelt anbetrifft, so blieben den Griechen die anthropomorphen Affen unbekannt. Dagegen kannten sie manche andere Affenart, wie die Paviane und die Makaken. Mit den großen Raubtieren wurde man besonders bekannt, nachdem Alexander und später die Römer ein Weltreich gegründet hatten. So gelangten durch Pompejus die ersten Tiger und schon um 200 v. Chr. die ersten Löwen nach Rom. Von den Waltieren war besonders der Delphin bekannt. Die Papageien erwähnt Aristoteles als indische Vögel. Außer zalılreichen Arten der Knochenfische kannte man auch die Haifische und die Rochen, zumal den elektrischen Rochen, ziemlich genau. Von den Weichtieren hatten besonders die Tintenfische die Aufmerksamkeit auf sich gezogen. Die Kenntnis ron den niederen Tieren blieb, vielleicht von den Insekten abgesehen, indessen auf einer niedrigen Stufe.

Einer der ersten, der allgemeine Betrachtungen iiber das Wesen der Tierwelt anstellte, war wieder Empedokles, mit dessen Ansichten über die Pflanzen wir uns soeben beschäftigt haben. Empedokles suchte nämlich, bei der näheren Ausführung seiner Lehre von den vier Elementen, Bestandteile des Tierkörpers, wie das Fleisch, das Blut und die Knochen, auf eine Mischung jener vier Elemente zurïckzufiihren. Vom Rückgrat der Säugetiere meinte er, es sei bei der Entstelung in einzelne Wirbel zerbrochen'1). Unter den späteren Philosophen soll besonders Demokrit Tierzergliederungen vorgenommen haben. Seine Ansichten finden bei Aristoteles oft Erwähnung und zengen mitunter von einer klaren Einsicht. Der Gegensatz zwischen Demokrit und Aristoteles geht besonders aus der Bemerkung des letzteren hervor, daß Demokrit nie rom Zwecke gesprochen habe, sondern ,alles, dessen sich die Natur bedient, auf die Notwendigkeit zuriickführe"2).

Demokrit hat seine Ansichten iiher das Wesen des Organischen in einer besonderen Schrift entwickelt. Leider ist uns nur der Titel (Über die Ursachen der Tiere) bekannt ${ }^{3}$ ).

Bei den spekulativen Neigungen der Griechen kann es nicht Wunder nehmen, daß uns schon bei den ältesten griechischen

1) Aristoteles, De part. anim. I. S. 6i40a.

2) Aristoteles, De generatione animalium. V. 8.

3) Diogenes Laertius 1X. 47. 
Philosophen Anklänge an die Deszendenztheorie begegnen ${ }^{1)}$. So lehrte Anaximander, durch die Sonnenwärme seien im Schlamme zuerst blasige Gebilde entstanden. Daraus seien dann fischartige Geschöpfe hervorgegangen. Einige von ihnen seien auf das Land gekrochen. Die so bedingte Änderung der Lebensweise habe auch zu einer Umwandlung der Gestalt geführt. Auf diese Weise sollten zunächst die landbewohnenden Tiere und endlich der Mensch entstanden sein. Von letzterem nahm man an, daß er ursprünglich einem Fische ähnlich gewesen sei. Die gleichen Ansichten hat Demokrit entwickelt. Auch Epikur betrachtete alle Geschöpfe einschließlich des Menschen als Kinder der Erde, die nur stufenweise Verschiedenheiten aufweisen.

Bei dem Römer Lucretius, der in seinem Werke „De natura rerum" im wesentlichen die Ansichten der griechischen Naturphilosophen wiedergibt. finden sich gleichfalls Anklänge an die Selektionstheorie, unter anderm auch der Gedanke, daß das Unzweckmäßige untergehe ${ }^{2}$. Derartige, gelegentlich geäußerte, später als zutreffend anerkannte Gedanken haben indessen mit der wissenschaftlichen Begründung der Deszendenztheorie nur wenig gemein. Letztere ist und bleibt eine Tat des 19. Jahrhunderts, für die in erster Linie Lamarck und Darwin in Betracht kominen.

Daß Darwin übrigens ron den deszendenztheoretischen Ansichten des Altertums, zwar ohne sie genauer zu kennen, wußte, geht aus seinen eigenen Worten hervor, in denen er ..von den auf seinen Gegenstand zu beziehenden Andeutungen in den Schriftstellern des klassischen Altertums" spricht.

1) E. Dacqué, Der Deszendenzgedanke u. seine Geschichte. München 1903.

2) Die auf Epikur und Demokrit zurückzuführenden Verse des Lucretius lauten folgendermaßen:

Denn wer nur immer sich jetzo erfreut der belebenden Lüfte,

Den hat entweder List oder Stärke beschützt oder Schnelle

Seit seiner frühesten Jugend und so sein Geschlecht stets erhalten.

Viele jedoch existieren, die unserem Schutz es verdanken,

Daß sie erhalten blieben, dem sichern Verderben entrissen.

Denen jedoch von alledem nichts die Natur hat gegeben, Daß sie aus eigener Kraft vermochten ihr Leben zu fristen, Diese sind selber zur Beute geworden. 


\section{Erste Schritte zur Begründung der griechischen Heilkunde.}

Zu den frühesten Ursachen, die zur Begrïndung der Naturwissenschaften führten, gehört auch das Bestreben, die Krankheiten des menschlichen Körpers zu heilen. Dieses Bestreben schärfte das Beobachtungsvermögen und lenkte den Blick auf die umgebende Natur, die man der Heilkunde dienstbar zu machen suchte. Bevor wir die erste Periode der Entwicklung der griechischen Wissenschaft verlassen und zu Aristoteles und seine Schule iibergehen, wollen wir daher einen kurzen Blick auf eine der wichtigsten Anwendungen der Naturwissenschaft, auf die Medizin, werfen. Es ist dies zum Verständnis des Folgenden um so wichtiger, als Aristoteles aus einer alten Ärztefamilie herrorgegangen war und bei der Errichtung eines philosophischen und naturwissenschaftlichen Lehrgebäudes zum Teil auf medizinischen Anschauungen fußte.

Aus dem Orient und Ägypten stammende Kenntnisse und Geheimlehren haben ohne Zweifel die griechische Heilkunde stark beeinflußt, ja sie bilden vielleicht die Grundlage, auf der sich die Heilkunde in Griechenland weiter entwickelte. Es blieb jedoch den Griechen vorbehalten, das Zauberwesen, das den Anfängen dieser Wissenschaft anhaftete, allmählich abzustreifen und auch hier nach unbefangener Erkenntnis und Verkniipfung der Tatsachen zu strehen ${ }^{1}$. Unter den älteren Ärzten ist besonders Alkmäion von Kroton, ein Schiiler des Pythagoras, zu nemnen ${ }^{2}$ ). Fr wird als der Begrïnder der Embryologie betrachtet und hat manche wertrolle anatomische und physiologische Beobachtung gemacht. Nach ihm wird jede Empfindung durch das Gehirn vermittelt und jede Bewegung ron dort aus geleitet. Alkmäon war der Hauptrertreter der im Einklang mit den Vorstellungen der Pythagorcer ausgebildeten Lehre, daß Gesundheit und Krankheit aus der harmonischen Mischung gewisser Qualitäten oder deren Stïrung zu erkï̈iren seien (s. S. 80). Dieser Lehre liegt die uns sogleich begegnende Anschauung von den vier Temperamenten zugrunde, die auch auf richtiger Mischung beruhen sollten.

Das wichtigste Dokument, das wir über die medizinische Wissenschaft der Griechen besitzen, ist die sog. hippoliratische Büchersammlung. Wir begegnen dieser Sammlung seit der Be-

1) E. M eyer, (ieschichte d. Altert. Bd. IV. 1901. S. 205.

2) Über die den Alkmä on betreffenden Fragmente siehe die Angabon von Meyer in seiner Geschichte des Altertums Bd. IV. 1901. S. 207. 
gründung der großen Bibliotheken in Alexandrien. Als daś Werk eines einzigen Mannes sind die hippokratischen Bücher nicht zu betrachten ${ }^{1}$ ), wenn sich auch nicht in Abrede stellen läßt, daß Hippokrates als Begrïnder der wissenschaftlichen Heilkunde, der zuerst das Zerstreute sammelte und zum Gesamtbild vereinigte, zu betrachten ist ${ }^{2}$. Außer Hippokrates ${ }^{3}$ ), der den Beinamen der Große erhielt, sind noch sechs andere Ärzte gleichen Namens aus der alten Literatur bekannt. Es kann daher nicht Wunder nehmen, wenn die Frage nach der Person des großen Hippokrates wenig geklärt ist, zumal keine zuverlässige Biographie über ihn existiert. Daß nicht Hippokrates allein der Verfasser der ihm zugeschriebenen Schriften sein kann, wird daraus geschlossen, daß sich in diesen Schriften ${ }^{4}$ ) nicht nur manche $\mathrm{Vidersprüche} \mathrm{finden,} \mathrm{sondern} \mathrm{daß} \mathrm{uns} \mathrm{darin} \mathrm{sogar}$ eine Polemik der einzelnen Verfasser gegeneinander begegnet5).

Was die Anatomie anlangt, so stützt sich das in den hippokratischen Schriften enthaltene medizinische Wissen vorzugsweise auf die Untersuchung der Tiere; doch lagen auch für den Menschen insbesondere auf dem Gebiete der Osteologie zahlreiche Beobachtungen und Erfahrungen vor. Am wenigsten waren den Alten der Bau und die Aufgabe des Nervensystems bekannt. Als besondere Ausläufer dieses Systems entdeckte man wohl zuerst den Sehnerven, den Gehörnerven und den Trigeminus. Im ïbrigen wurden die Nerven und Sehnen zunächst zusammengeworfen. Empfindung und Bewegung hielt man für immanente Fähigkeiten. Als ihre Quelle galt das "Pneuma“, das vom Gehirn aus durch die Adern zu allen Teilen des Körpers fließen sollte ${ }^{6}$ ).

1) Th. Beck, Hippokrates' Erkenntnisse. Jena 1907.

2) Platons Protagoras. Kap. III.

3) Hippokrates aus Kos lebte um 400 v. Chr.

4) Als Corpus Hippocraticum sind der Nachwelt etwa 100 griechische und 30 lateinische Schriften übermittelt worden. Mit völliger Sicherheit lassen sich nur wenige Bücher auf Hippokrates selbst zurückführen. Man hat übrigens nie alle für echt gehalten. Näheres siehe in dem sehr ausführlichen Beitrag über Hippokrates in Paulys Reallexik. d. klass. Altert. Bd. VIII (1913). S. $1801-1852$.

5) Beck, Hippokıates' Erkenntnisse. Jena 1907. Das Werk enthält außer einer Untersuchung über die Entstehung und die Bedeutung der Hippokratischen Sammlung eine Auslese der wertvollsten Stellen mit Bezugnahme auf die moderue Heilkunde.

6) Haeser, Geschichte der Medizin. Bd. I (1875). S. 141.

Nach den Ansichten, die Platon im ,Timäos" entwickelt, bewirkt das Herz die Verknïpfung der Adern. Es ist die Quelle des durch alle Glieder heftig herumgetriebenen Blutes. Zur Abkühlung des Herzens dienen die Lungen. 
Ein großer Fortschritt gegenüber der ältesten dämonologischen Auffassung der Krankheiten bestand darin, daß die hippokratischen Schriften die psychischen Störungen als Wirkungen körperlicher Krankheitszustände auffaßten. Letztere werden durch eine Störung des Gleichgewichtes zwischen den vier Flüssigkeiten (Humores) aufgefaßt, die den Körper bilden. Als solche galten das Blut, der Schleim, die gelbe und die schwarze Galle. Die Natur wird als heilbringender Faktor gewürdigt. Sie finde, heißt es von ihr, auch ohne Überlegung immer Mittel und Wege. Auch einer vernünftigen Prophylaxe wird das Wort geredet. Die Gicht wird z. B. auf Wohlleben zarïckgeführt und Mäßigkeit und Unverdrossenheit hygienisch außerordentlich hoch gewertet. Als therapeutisches Mittel wird schon die Musik empfohlen. Von der Höhe der gesamten Auffassung, die uns in den hippokratischen Schriften begegnet, zeugt der Ausspruch: Das Kennen erzeugt die Wissenschaft, das Nichtwissen den Glauben. Jedoch war man sich der Grenzen des ärztlichen Könnens wohl bewußt und erkannte an, daß der beste Arzt die Natur selbst sei. Im Einklang damit war man in erster Linie bestrebt, den natïrlichen Vorgang der Heilung zu unterstützen. An Amputationen wagte man sich noch nicht heran, da man das Unterbinden der Adern noch nicht verstand. Bekannt ist der Hippokratische Satz: „Was die Arzneimittel nicht heilen, heilt das Eisen. Was das Eisen nicht heilt, heilt das Feuer. Was endlich das Feuer nicht heilt, das ist überhaupt nicht $\mathrm{zu}$ heilen" 1 ).

Unter den hippokratischen Schriften ist diejenige „Über die Diät" in zoologischer Hinsicht wichtig. Sie enthält nämlich unter den Nahrungsmitteln eine Aufzählung von etwa 50 Tieren in absteigender Reihenfolge. Auf die Säugetiere folgen die Land- und Wasservögel, die Fische, dann die Muscheltiere und endlich die Krebse. Reptilien und Insekten werden nicht erwähnt, weil sie nicht gegessen wurden. Dieses Tiersystem, das man wohl als das "koische" bezeichnet hat (etwa 410 v. Chr.), kann als ein Vorläufer des Aristotelischen Tiersystems, das uns im nächsten Abschnitt beschäftigen soll, betrachtet werden ${ }^{2}$.

1) In der lateinischen Fassung von Schiller seimen „Räubern“ als Motto vorangestellt: Quae medicamenta non sanant, ferrum sanat. Quae ferrum non sanat, ignis sanat.

2 R. Burckliardt, Geschichte der Zoologic. S. 18. 


\section{Das aristotelische Zeitalter.}

Für das griechische Volk war mit dem vierten vorchristlichen Jahrhundert schon eine Zeit des staatlichen Niederganges angebrochen. Kunst und Philosophie hatten gleichfalls ibre Blütezeit gehabt. Die wissenschaftliche Entwicklung tritt indessen jetzt in eine Phase, welche für die Folge von nicht geringerem Einfluß als die von den Griechen auf dem Gebiete des staatlichen Lebens und der künstlerischen Betätigung geschaffenen Vorbilder sein sollte. Es ist das wissenschaftliche, auf die Erfassung des Naturganzen in seinem Zusammenhange gerichtete Streben des Menschengeistes, das uns jetzt zum ersten Male in seiner vollen Bedeutung entgegentritt. Dieses Streben rerkörpert sich in Aristoteles und seinen Schülern. Mögen auch die Vorstellungen, welche diese Männer leiteten, mit den Prinzipien der heutigen Naturforschung oft nicht vereinbar erscheinen, so kann man dennoch das Grundlegende ihrer Tätigkeit und die Bedeutung, die sie nicht nur für das Altertum und für das Mittelalter, sondern auch für die Entstehung der neueren Naturwissenschaft besitzen, nicht in Abrede stellen.

\section{Aristoteles.}

In Aristoteles begegnet uns eine der bedeutendsten Erscheinungen des Altertums, in der sich die Wissenschaft jenes Zeitraums gleichsam verkörperte $\left.{ }^{1}\right)$. Er war der Sprößling einer griechischen Ärztefamilie 2), die am mazedonischen Hofe in hohem Ansehen stand. Aristoteles wurde im Jahre 384 v. Chr. in Stagira, einer in der Nähe des Athos gelegenen griechischen Kolonie, geboren. Seine Erziehung lag, wie es damals häufiger der Fall war, in der Hand eines einzigen Mannes. Diesem b.ewahrte A ristoteles eine Dankbarkeit, wie sie später ihm selbst wieder von seinem

1) Stahr, Das Leben des Aristoteles, als I. Teil von Stahr's Aristotelia. Haile 1830.

2) Sein Vater Nikomachos war Leibarzt des Königs Amyntas von Nazedonien. 
großen Schüler Alexander erwiesen wurde. Im übrigen fehlen über die Jugend und den Entwicklungsgang des A ristoteles nähere Nachrichten. Doch darf man annehmen, daß er gemäß der in seiner Familie herrschenden Tradition für den ärztlichen Beruf bestimmt war und sich zunächst für diesen vorbereitete. Auf diesen Umstand wird vor allem der empirische Grundzug der aristotelischen Philosophie zurückzuführen sein.

War das Wissen im 5. Jahrbundert noch im Besitze weniger hervorragender Geister, so wird es im vierten immer mehr zum Gemeingut der Gebildeten. Die Literatur wuchs an Umfang und an Spezialisierung. Schon in der ersten Hälfte des 4. Jahrhunderts gab es kaum noch einen Gegenstand, über den nicht bereits Schriften erschienen wären ${ }^{1}$ ).

Der Brennpunkt des geistigen Lebens war um die Mitte des vierten vorchristlichen Jahrhunderts Athen. Hier hatte Sokrates gelehrt und Platon eine blïhende Philosophenschule gegründet. Was Wunder, daß der begiiterte und für die Wissenschaft begeisterte Jüngling seine Schritte zunächst dorthin lenkte. Im Jahre 367 trat er in die Akademie ein, an welcher Platon lehrte. Er gehörte ihr bis zu dem 347 erfolgenden Tode des Meisters ununterbrochen an. Platon soll Aristoteles seines unermüdlichen Lernens halber den Leser genannt und ihn mit einem anderen Schüler mit den Worten verglichen haben, dieser bedürfe des Sporns, Aristoteles dagegen des Zügels. Mit Recht ist Aristoteles auch später als einer der Heißigsten Gelehrten bezeichnet worden, den die Geschichte der Wissenschaft kennt ${ }^{2}$ ). Sein Ruf muf unterdessen ein hervorragender geworden sein. Es wird nämlich berichtet, daß König Philipp von Mazedonien, als er ihm im Jahre 343 die Erziehung seines im 14. Lebensjahre stehenden Sohnes übertrug, folgende Worte an Aristoteles gesclurieben lıabe: „Ich fühle mich den Göttern zu Dank verpflichtet, daß sie den Knaben zu Deiner Zeit gehoren werden ließen. Denn von Dir erzogen, hoffe ich, soll er der Nachfolge auf meinem 'Throne würdig werden." Und so wurde denn - ein Verhältnis, das einzig in der Geschichte dasteht - der bedeutendste Denker jener Zeit mit der Erziehung des größten Herrschers betraut.

Über das Erziehungswerk selbst, das nur die ersten Jahre des mazedonischen Aufenthaltes unseres Philosophen (343-340)

1) E Meyer, Gesch. d. Altertums. V. Bd. 1902. S. 338.

2) Zoller. Die Philosophie der Griechen. Bd. II, 2. s. 172. 
umfaßte, fehlen nähere Nachrichten. Auch sind die Erzählungen, daß der königliche Schüler seinem Lehrer 800 Talente 1), sowie einen ganzen Trupp Leute zum Sammeln von Naturkörpern zur Verfügung gestellt habe, mindestens iibertrieben. Soviel ist jedoch gewiß, daß Alexander wohl zu schätzen wußte, was er dem Aristoteles verdankte. Durch unverschuldete Umstände geriet letzterer gegen das Ende der Regierung Alexanders in Ungnade. Nach Ablauf eines acht Jahre umfassenden Aufenthaltes in Mazedonien, der eine Zeit des Sammelns und der Vorbereitung gewesen ist, in welcher ihn der Gedanke, eine Enzyklopädie der Wissenschaften zu verfassen, jedenfalls schon beherrscht hat, kehrte Aristoteles im Jahre 335 nach Athen zurïck.

Um eine solch umfassende wissenschaftliche Tätigkeit auszuüben, wie sie uns bei Aristoteles begegnet, waren bedeutende Mittel erforderlich. Ob ihm diese durch die Gunst der mazedonischen Könige oder aus eigenem Vermögen zur Verfügung standen, läßt sich nicht mit Sicherheit entscheiden. Sehr wahrscheinlich trafen beide Umstände zusammen und ermöglichten es dem Aristoteles, daß er, als erster unter den griechischen Philosophen, in den Besitz einer größeren Bibliothek gelangte. Die Herstellung von Büchern war damals eine mühselige und kostspielige Arbeit, und die Anzahl der Exemplare einer Schrift naturgemäß gering. Es ist daher begreiflich, daß bedeutende Summen dazu gehörten, um die Schriften seines Zeitalters sich in solchem Maße zugänglich zu machen, wie es Aristoteles verstanden hat. Allein für die Werke eines Philosophen soll er drei Talente bezahlt haben ${ }^{2}$.

In Athen hat Aristoteles im Lykeion, einem gymnastischen Spielen dienenden Gebäude der Stadt, unterrichtet. Nach der Gewohnheit des Meisters, dies im Auf- und Abwandeln zu tun, erhielt seine Schule den Namen der Peripatetiker. Während Alexander die Welt eroberte, war Aristoteles hier ein König im Reiche der Wissenschaften. Von seinen zahlreichen Schriften ist indes nur der kleinere, aber wichtigere Teil erhalten geblieben.

Die Stellung des Aristoteles in dem antimazedonisch gesinnten Athen, wo er als Fremder und wegen seiner Beziehungen zu dem verhaßten großen Könige von manchem ungern gesehen wurde, ist während seines 13 jährigen Aufenthalts in jener Stadt eine wenig angenehme gewesen. Als 323 v. Chr. die Kunde von

1) Ein Talent hatte in Reichsmünze den Wert von etwa 4700 Mark.

2) Zeller, Die Philosophie der Griechen. Bd. II, 2. S. 33. 
dem plötzlichen Tode Alexanders eintraf und von den meisten als ein Zeichen zur Befreiung vom mazedonischen Joche begrüßt wurde; erhoben sich daher zahlreiche Neider und Widersacher gegen Aristoteles. Er wurde der Lästerung der Götter geziehen, zog es aber vor, nicht eine Gerichtsverhandlung abzuwarten, sondern der ihm feindlich gesinnten Stadt den Rücken zu kehren, damit diese, wie er im Hinblick auf Sokrates sagte, sich nicht zum zweiten Male an der Philosophie versündige. Wie richtig Aristoteles seine Lage erkannt hatte, geht daraus hervor, daß der Areopag ihn bald darauf, trotz seiner Abwesenheit, zum Tode verurteilte. Aristoteles hatte sich indessen nicht weit entfernt. Er war nach Euböa ïbergesiedelt in der Erwartung, durch einen Sieg der Mazedonier iiber die Athener nach seinem langjährigen Wohnsitz zuriickgeführt zu werden. Diese Hoffnung sollte jedoch nicht in Erfüllung gehen, denn schon in dem auf das Ende Alexanders folgenden Jahre, bevor man in Griechenland die friihere Ordnung wieder hergestellt hatte, setzte der Tod seinem reichen Leben ein Ziel.

Die Schriften und die Bücher des großen Philosophen gingen zunächst in den Besitz seines Lieblingsschiilers, des Theophrast, über. Manches wird unvollendet gewesen und später ergänzt worden sein. Theophrast hinterließ die Schriften wieder einem Schüler. Anderthalb Jahrhunderte blieben sie darauf verborgen. Endlich gelangten sie, nachdem Sulla Athen erobert hatte, nach Rom, wo sie in zahlreichen Exemplaren abgeschrieben und verbreitet wurden. Daß dabei manches verunstaltet und verdorben wurde, unterliegt wohl keinem Zweifel. Die auf uns gekommenen Werke nehmen im Oktavformat fast 3800 Seiten in Anspruch $\left.{ }^{1}\right)$. Davon ist indessen ein Teil als unecht zu betrachten ${ }^{2}$ ).

Eine gänzlich unverändert gebliebene Schrift des A ristoteles gibt es sehr wahrscheinlich nicht. Auch bei einigen Hauptwerken handelt es sich wohl um Ausarbeitungen der Schïler. Dafür spricht unter anderem auch das Fehlen geines einheitlichen

1) Heller, Geschichte der Physik. Bd. I. S. 48.

2) Gedruckt wurden die Schriften des Aristoteles zuerst im Jahre 1473 in Rom, und zwar in lateinischer Übersetzung. 1493 erschien die erste gedruckte griechische Ausgabe. Augenblicklich gilt als beste die im Auftrage der Berliner $\Lambda$ kademie der Wissensehaften veranstaltete Ausgabe von Bekker. Eine griechisch-deutsche (unvollendete) Ausgabe rührt von Prantl her. Sie ersehien in Leipzig bei Wilhelm Engelmann und wurde der lier gegebenen Darstellung der aristotelisehen Lehren besonders zugrunde gelegt. 
Stiles. Andere Schriften sind bloße Entwürfe oder Zusammenstellungen von Auszügen. Dazu kommen von späteren Herausgebern herrührende Zusätze, die selten als solche kenntlich gemacht sind. Endlich fehlt es nicht an Werken, die zwar den Namen des Aristoteles tragen, die indessen als unecht oder nur zum geringen Teil als aristotelisch gelten. Unter diesen sei nur die ron Nikolaos Damaskenos im augusteischen Zeitalter herausgegebene Schrift „,̈̈ber die Pflanzen“" genannt. Über diesen Gegenstand gab es eine echte Schrift, die rerloren ging (s. S. 138). Auch eine mit Abbildungen versehene Schrift „Über die Zergliederung der Tiere" ist leider nicht auf uns gelangt.

\section{Aristoteles als Philosoph und seine Stellung zur Naturwissenschaft.}

Den breitesten Raum unter den Werken des Aristoteles nehmen seine naturwissenschaftlichen Schriften ein. Sie betreffen das gesamte Universum von den allgemeinen Bedingungen der Körperwelt und dem Weltgebäude bis herab zur Beschreibung und Zergliederung der die Erde als Tiere und Pflanzen bevölkernden Einzelwesen. Folgende Schriften naturwissenschaftlichen Inhalts sind bei der nachfolgenden Darstellung des aristotelischen Lehrgebäudes vor allem in Betracht gezogen: .., Die physikalischen Vorträge“, „Über das Weltgebäude“, „Über Entstehen und Vergehen“", „Die Meteorologie“ und „Die mechanischen Probleme“"1). Unter den rein philosophischen Werken des A ristoteles verdient wegen ihrer Bedeutung für jeden Zweig besonderer Wissenschaft das später „Organon" genannte hervorgehoben zu werden. Es sind dies die von Aristoteles zum ersten Male in ausführlicher Darstellung entwickelten Grundzüge der formalen Logik.

Des Aristoteles Verdienst um die Naturwissenschaften ist ein doppeltes. Einmal hat er das zerstreute Einzelwissen seiner Vorgänger vereinigt und der Nachwelt durch eine außerordentlich fruchtbare schriftstellerische Tätigkeit ïberliefert. Zum andern beschränkte er sich keineswegs auf eine kritiklose Kompilation dieses Wissens. Vielmehr stellte er sich die gewaltige Aufgabe, aus philosophischen Prinzipien heraus ein System aller Wissenschaften zu entwickeln. Die Philosophie, das Streben nach Welterklärung, war also der Ausgangs- und der Angelpunkt,

1. Diese Schrift ist indessen als nichtaristotelisch erlsannt. 
aus dem bei ihm die Wissenschaft erwuchs. Denken und Welt in ihrem Gegensatz und in ihrer Wechselbeziehung wollte Aristoteles begreifen und begreiflich machen. Die Philosophie, die bei Platon noch voll poetischen Schwunges gewesen, wurde bei Aristoteles nuichterne Betrachtung des Ichs mit seiner Denktätigkeit und seinen Anschauungsformen, sowie der Welt mit ihren Einzeldingen. In ihnen suchte er die Idee, welche bei Platon über und hinter den Dingen stand, sowie die Zwecke nachzuweisen. Man kann Platon den Vorwurf nicht ersparen, daß er die Wirklichkeit allzusehr vernachlässigte und an ihre Stelle ein System aus häufig inhaltsleeren Begliffen setzte, während Aristoteles sich ron der Überzeugung leiten ließ, daß wirkliche Erkenntnis nur aus der Erfahrung entspringen kann. Aristoteles fordert daher, man solle „zuerst die Erscheinungen auffassen und dann erst die Ursachen angeben".

In der Befolgung des dialektischen Verfahrens, das er meisterhaft $z$ uandhaben wußte, ist Aristoteles ein Jünger des Sokrates und des Platon. IVährend indessen die Philosophie der letzteren vorzugsweise auf dem Boden der Dialektik wurzelte, sucht Aristoteles das beobachtende Verfahren der Naturwissenschaft mit der Dialektik zu verknüpfen, was seine Lehrmeister nicht vermocht hatten. "Zwar gelang es ihm nicht, beide Elemente völlig ins Gleichgewicht zu bringen, doch hat er durch ihre Verknüpfung das Höchste unter den Griechen geleistet" 1). Sokrates und Platon latten zuerst nach den Begriffen gefragt und die oft nur aus der Betrachtung des Sprachgebrauches und der herrschenden Meinung gewonnene Erkenntnis des Begriffes dem weiteren Forschen zugrunde gelegt, während Aristoteles außer dem Begriff die bewegenden und stofflichen Ursachen ins Auge faßte. Er ist nicht nur ein scharfer Denker, sondern ein solch unermïdlicher Beobachter, daß ihm nicht selten ein übertriebener Empirismus zum Vorwurf gemacht worden ist. Die bei der Naturerklärung zu befolgenden Grundsätze finden sich bei ihm nicht zusammenhängend entwickelt, sondern in zahlreichen Einzelbemerkungen zerstreut. Aus ihnen lüßt sich folgendes entnehmen: Stets hat der Erklärung die Beobachtung vorauszugehen. Daß man die Theorie auf die Erkenntnis des Einzelnen stuitzen müsse, wird häufiger betont. Von der Beobachtung wird verlangt, daß sie sorgfältig, umfassend und vor allem frei ron jeder vorgefaßten Meinung sei. Handelt es

1) Zeller, Die P'hilosophie der Griechen. 
sich um die Beobachtungen anderer, so ist strenge Kritik anzulegen. Kurz, es begegnen uns bei A ristoteles Grundsätze, wie sie dic dem Empirismus huldigenden Philosophen der neneren Zeit, wie Bacon, kaum besser entwickelt haben. Indessen entsprach dem Wollen, wie es auch bei Bacon der Fall war, nicht das Vermögen. Es lassen sich dafür verschiedene Gründe anführen. Einmal waren die Hilfsmittel der wissenschaftlichen Forschung zur Zeit des Aristoteles noch sehr wenig entwickelt. Vor allem mangelte es auf fast allen Gebieten noch an der Möglichkeit einer schärferen Bestimmung der quantitativen Verhältnisse. A ristoteles empfindet dies schon, wo er von dèr Wärme handelt. Von einer Vervollkommnung der Sinne und der dadurch zu ermöglichenden weitgehenden Schärfung der Beobachtung besaß er aber wohl keine auch nur dunkle Ahnung. Was für die Sinne nicht existierte, galt ihm noch als nicht vorhanden $\left.{ }^{1}\right)$.

In treffender Würdigung der aristotelischen Denkweise sagt Zeller: „Da die griechische Wissenschaft mit der Spekulation angefangen hatte und die Erfahrungswissenschaften erst spät zu einiger Ausbildung gelangten, so war es natürlich, daß das dialektische Verfahren eines Sokrates und Platon einer strengeren Empirie den Rang ablief. Anch Aristoteles hält sich zunächst an dies Verfahren, ja er bringt es theoretisch und praktisch zur Vollendung. Daß die Kunst der empirischen Forschung bei ihm eine gleichmäßige Ausbildung erfahren werde, ließ sich nicht erwarten. Und ebenso lag ihm eine schärfere Unterscheidung beirler Methoden noch fern. Diese ist erst durch die höhere Entwicklung der Erfahrungswissenschaften und, von philosophischer Seite, durch die erkenntnistheoretischen Untersuchungen herbeigeführt worden, welche die neuere Zeit ins Leben gerufen hat."

Eine Reihe von Grundbegriffen oder Kategorien sind es, miter welche Aristoteles sämtliche Gegenstände der denkenden Betrachtung einzugliedern suchte. Die wichtigsten sind Substanz, Quantität, Qualität, Lage, Wirken und Leiden. Als Endzweck der gesamten Natur erschien ihm der Mensch. Im Besitz der aristotelischen Philosophie und Wissenschaftslehre hat letzterer an dieser ihm zugewiesenen Stellung zwei Jahrtausende festgehalten,

1) Ein Beispiel dafür findet sich nach Eucken in de gener. et corr. $(328,23)$. Aristoteles meint dort, wenn ein großes Quantum mit einem sehr kleinen vereinigt werde, so entstehe keine Mischung, sondern das kleinere schlüge in das größere um. So werde ein Tropfen Wein in zehntausend $\mathrm{Maß}$ Wasser geradezu zu Wasser. 
bis man den Zweckbegriff durch den Begriff der mechanischen Kausalität ersetzte und den Menschen als ein Glied in der Kette der übrigen Wesen begreifen lernte.

\section{Die Grundlehren der Mechanik bei Aristoteles.}

Wir gehen nach dieser allgemeinen Charakteristik zu dem Verhältnis über, in welchem Aristoteles zu den Einzelwissenschaften gestanden hat.

Die Bedeutung der Mathematik hat er in seinen Schriften oft hervorgehoben, doch sind eigentliche mathematische Entwicklungen in ihnen nicht enthalten. Wohl aber bieten sie manche beachtenswerte Äußerung über schwierige Begriffe, wie über den Grenzbegriff und das Unendliche. „Stetig“", sagt Aristoteles z. B., ,ist ein Ding, wenn die Grenze eines jeden von zwei aufeinander folgenden T'eilen, in der sie sich berïhren, eine und die nämliche wird." Er löste ferner das Paradoxon vom Durchlaufen unendlich vieler Raumpunkte in endlicher Zeit dadurch, daß er innerhalb der endlichen Zeit unendlich viele Zeitteilchen von unendlich kleiner Dauer annahm. Das Unendliche ist ferner für ilm nichts Wirkliches, sondern es gibt nur Endliches von beliebiger Größe und von beliebiger Kleinheit 1).

Am meisten Erfolg hatte man auf dem Gebiete der Naturwissenschaft dort anfzuweisen, wo die rasch emporblïhende Mathematik Anwendung finden kownte. Wie die ersten erfolgreichen Schritte auf dem Gebiete der Astronomie, so waren die Anfünge der Mechanik von dem Erreichen einer gewissen Stufe des mathematischen Denkens ablü̈ngig. Dem Verlauf der mechanischen Vorgänge angemessene Begriffe entwickeln sich daher weit später als das Vermögèn, die Gesetze der Mechanik anzuwenden, olme sich ihrer klar bewulit zu sein. Das letztere mulite nümlich schon bei der frühesten Ausiibung jeder gewerblichen Tätigkeit eintreten.

Mit den Grundfragen der Mechanik hat sich die griechische Philosophie schon in der vorsokratischen Zeit beschäftigt. Insbesondere wandte man sich den Problemen der Schwere und der Bewegung $\mathrm{zu}^{2}$ ). Auch daß ans der Bewegung, infolge der lamit verbundenen Reibung, Würme hervorgeht, wurde frühzeitig erkannt.

1) Eine Zusanmenstellung der auf die Mathematik bezüglichen Stellen hat schon Biancani veröffentlicht: Aristoteles loea mathematica. 1615.

2) E. Haas, Grundfragen der antiken Dynamik (Archiv f. d. Geschichte. d. Naturwiss. u. d. Technik. 1908. 1. Heft). 
Anaxagoras wollte sogar das Licht der Gestirne aus diesem Vorgange herleiten (s. S. 77).

Zu den alltäglichsten Erscheinungen, die vor allem dazu angetan sind, das Nachdenken wachzurufen, gehört die Bewegung frei fallender Körper. Diese Erscheinung, von der ausgehend später Newton zur Entdeckung des Weltgesetzes geführt wurde, faßte Aristoteles irrig auf. Bezeichnend für seine ganze Geistesrichtung ist es, daß er nicht von der Erscheinung selbst, sondern von begrifflichen Festsetzungen ansging und bei diesen stehen blieb. Er betrachtet zunächst die Bewegung in allgemeinen und unterscheidet zwei Arten derselben, die begrenzte, geradlinige, und die unbegrenzte, kreisförmige. Letztere, als die angeblich vollkommenere, schreibt er den himmlischen Körpern zu. Die geradlinige Bewegung wird aus einem entweder zum Zentrum hin oder vom Zentrum fort gerichteten Streben der Körper erklärt, und so werden die Begriffe Leichtigkeit und Schwere abgeleitet. Die erstere Eigenschaft wird der Luft und dem Fener, die zweite dem Wasser und der Erde, d. h. allen flïssigen und festen Körpern zugeschrieben. Aus diesen Erklärungen folgt nun für Aristoteles mit zwingender Notwendigkeit, daß der schwerere Körper, weil sein Streben zum Zentrum ein größeres sei, sich schneller abwärts bewegen müsse als der leichtere. Hieraus wurde dann später geschlossen, daß die Körper genau in demselben Verbältnis schneller fielen, je größer ihr Gewicht sei, so daß beispielsweise ein hundertpfündiges Stück Eisen auch hundertmal so schnell zur Erde gelange wie ein solches von einem Pfund Gewicht. Jeder, ohne Voreingenommenheit angestellte Versuch, hätte diesen Schluß als unhaltbar dartun müssen. Trotzdem blieb er, wenn schon sich hin und wieder Zweifel regten, in Geltung, bis Galilei ihn durch seine Fallversuche glänzend widerlegte.

Man kann ${ }^{1}$ ) die Unterscheidung zwischen irdischen und himmlischen, sowie zwischen natïrlichen und erzwungenen Bewegungen in erster Linie als das Hindernis ansehen, das der Entwicklung der Mechanik im Altertum und Mittelalter im Wege stand. Erst als diese Schranken fielen, war die Errichtung der neueren $\mathrm{Me}$ chanik möglich. Zu den Schwächen der antiken Mechanik rechnet auch der Umstand, daß man nicht zu einer klaren Vorstellung von dem Begriff des Beharrungsvermögens gelangte. Zwar finden sich

1) Mit Haas a. a. O. Archiv f. d. Geschichte d. Naturwiss. u. Techuik. 1908. S. 47. 
Ansätze ${ }^{1}$, doch hielten alle Physiker an der Annahme fest, ein Körper könne sich unmöglich bewegen, wenn nicht eine äußere Kraft oder die ihm innewohnende Schwere und Leichtigkeit auf ihn wirkten ${ }^{2}$ ). Den letzteren Begriff vermieden wenigstens die Atomisten, die alle Körper als schwer betrachteten.

Über den Inhalt der mechanischen Lehren des Aristoteles sei noch einiges im einzelnen mitgeteilt. Die Art der Darstellung besteht darin, daß der Philosoph an Erfahrungstatsachen eine Anzahl von Fragen anknüpft ${ }^{3}$ ), die er selten auf mathematischem Wege, wie später mit so großem Erfolge Archimedes, sondern meist, ausgehend von bestimmten Definitionen, durch dialektische Kunststücke zu lösen sucht. Den Stoff zu seinen Untersuchungen bieten ihm das Rad, der Hebel, das Ruder, die Zange, die Wage und andere bekannte Werkzeuge. Die Beantwortung der Fragen geschieht oft wieder in Frageform. So heißt es im 6. Kapitel: "Warum das an sich kleine Steuer, am Ende des Schiffes angebracht, eine so große Gewalt hat? Weil vielleicht das Steuer ein Hebel ist, die Last das Meer und der Steuermann das Bewegende".

Auffallend erscheint es Aristo teles zunächst, daß eine große Last durch eine kleine Kraft bewegt werden kann, wie beim Hebel. Die an diesem Werkzeug sich das Gleichgewicht haltenden Lasten setzt Aristoteles ganz richtig den Längen der Hebelarme umgekehrt proportional. Den Grund für dieses Gesetz findet er darin, daß die kleinere Last, ihrer größeren Entfernung vom Stützpunkt entsprechend, einen größeren Kreisbogen durchlaufen müsse. Auf den Hebel wird auch der Keil und der Tragbalken zurückgeführt. Letzteres geschieht (Abb. 14) durch folgende Erörterung: "Zwei Leute tragen auf einer Stange AB eine Last G. "Warum, fragt

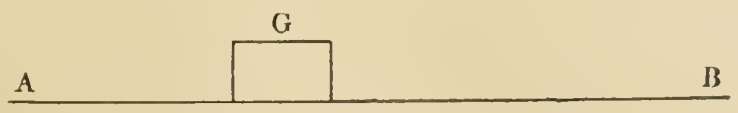

Abb. 14. Der Tragbalken bei Aristoteles.

A ris toteles, wird der am stärksten gedrückt, dem $\mathrm{G}$ am nächsten ist? A B sagt er darauf, wird hier gebraucht wie ein Hebel. Der G nächste Träger bei $\mathrm{A}$ ist das Bewegte, der andere Träger bei

1) Besonders bei Plutarch und bei Lukrez.

2) $\mathrm{H}$ aas a. a. O. S. 44.

3) Daher lautet der Titel des Werkes auch "Quaestiones mechanicae". bannemann, Dle Naturwissensehaften. I. Bd. ?. Aufl. 
$B$ ist das Bewegende. Und je weiter dieser von der Last entfernt ist, desto leichter bewegt er." Den einarmigen Hebel hat Aristoteles nicht als eine besondere Art betrachtet.

Ein wichtiger Abschnitt des aristotelischen Werkes ist auch derjenige, der den Satz vom Parallelogramm der Bewegungen enthält. "Tenn etwas", heißt es dort, „nach irgendeinem Verbältnis bewegt wird, so daß es eine Linie durchlaufen muß, so wird diese Gerade die Diagonale einer Figur sein, welche durch die nach dem gegebenen Verhältnis zusammengesetzten Linien bestimmt wird. Sei zum Beispiel das Verhältnis der Bewegung dasjenige, welches A B zu AC hat. Es werde also $\mathrm{A}$ nach $\mathrm{B}$ getrieben, $\mathrm{AB}$ aber nach CG. Ebenso gelangt in derselben Zeit A nach D, in welcher AD nach $\mathrm{EF}$ gelangt. Ist dann das Verhältnis

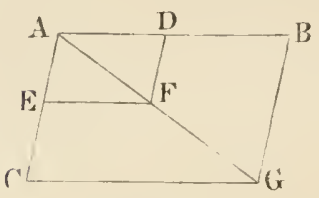

Abb. 15.

Der Satz vom Parallelogramm der Bewegungen. der Bewegung in letzterem Falle dasselbe, d. h. verhält sich $\mathrm{AD}: \mathrm{AE}$ wie $\mathrm{AB}: \mathrm{AC}$, so ist das kleine Parallelogramm dem größeren ähnlich; und es wird folglich die Diagonale $\mathrm{AF}$ in die Diagonale $\mathrm{AG}$ fallen. Hieraus wird also offenbar, daß ein auf der Diagonale nach zwei Richtungen bewegter Gegenstand notwendig in dem Verhältnis der Seiten bewegt wird. Ändern dagegen zwei Bewegungen in jedem Augenblick ihr Verbältnis, so kann der Körper unmöglich eine geradlinige, sondern er muß eine krummlinige Bewegung durchlaufen." Auch der Satz, daß die Bewegung im Kreise aus zwei Bewegungen, die nach dem Mittelpunkt und in der Richtung der Tangente erfolgen, zusammengesetzt gedacht werden kann, ist auf Aristoteles zurückzuführen. Ferner hat sich Aristoteles mit dem Problem des Stoßes beschäftigt, das erst durch W allis, Wren und Huygens seine Lösung finden sollte. Er stellt nämlich die Frage, weshalb ein geringer Stoß auf einen Keil viel ausrichten könne, während ein gegen den gleichen Keil ausgeübter Druck nur wenig leiste ${ }^{1}$ ).

In exakt-wissenschaftlicher Hinsicht sind dem Aristoteles noch zwei Verdienste zuzuschreiben. Einmal war er wohl einer der ersten, der seine Erörterungen durch Zeichnungen zu unterstützen suchte. Ferner befindet sich bei ihm der Keim zu dem Gedanken, die in Beziehung zu setzenden Größen mit Buchstaben zu bezeichnen.

1) Mechanische Probleme. Ausg. von Poselger 1881. S. 34. 


\section{Die Anfänge der Akustik und der Optik.}

Ein anderes Gebiet, das sich gleichfalls schon im Altertum der exakten Behandlung zugänglich erwies, war die Akustik. So hatten z. B. die Pythagoreer erkannt, daß die Längen von gleich dicken und in gleichem Maße gespannten Saiten, wenn sich Konsonanzen ergeben sollen, in einem einfachen Verhältnis stehen müssen. Dieses Verhältnis fanden sie für die Oktave gleich 1:2. Und zwar geschah dies mit Hilfe eines Monochords. Der Apparat besaß die Einrichtung, daß eine Saite über einen Steg geführt und durch Gewichte beliebig gespannt werden konnte. In dieser Vorrichtung begegnet uns der erste Apparat, vermittelst dessen auf experimentellem Wege ein Naturgesetz gefunden wurde. Auch bei Aristoteles finden wir einige zutreffende Vorstellungen über akustische Vorgänge. Aristoteles schreibt z. B. der Luft die vermittelnde Rolle bei den Scliallerscheinungen zu und führt die letzteren auf Schwingungen zurück, die sich bis zu unserem Ohre fortpflanzen. „Ein Ton“, sagt er, „entsteht nicht dadurch, daß der tönende Körper der Luft, wie einige glauben, eine gewisse Form einprïigt, sondern dadurch, daß er die Luft auf eine angemessene Weise in Bewegung setzt. Die Luft wird dabei zusammengedriickt und auseinandergezogen und durch die Stöße des tönenden Körpers immer wieder fortgestoßen, so daß sich der Schall nach allen Richtungen ausbreitet." Auch das Echo wurde von Aristoteles ganz richtig als ein Reflex erkannt.

Die gleiche Anschauung, die er sich vom Scliall gebildet, übertrug Aristoteles auf das Gebiet der Optik. Vor ihm hatte sich die wunderliche Vorstellung entwickelt, das Sehen sei eine Art Tasten, bei dem das Auge sich aktiv verhalte und sozusagen Fühlfäden nach den Körpern hin erstrecke. Nach den ältesten Ansichten ist das Auge sogar feuriger Natur. Auch bei den Inderm begegnen wir dieser Meinung. So schreibt Susruta der Linse, die hïufig als das Hauptorgan des Auges betraclitet wurde, ewiges Feuer $\mathrm{zu}^{1}{ }^{1}$. In Übereinstimmung damit betrachteten die ältesten griechischen Plilosophen, wie die Pythagoreer, das Sehen als eine heiße Ausdünstung, die vom Auge nach dem wahrgenommenen Gegenstande strömen sollte.

1) Haas, Antike Liclittheorien (Archiv für Geschichte d. Philos. 20. Bd. 1907. 3. Heft. 
Aristoteles wendet dagegen ein ${ }^{1}$, daß man dann auch während der Nacht zum Sehen befähigt sein müsse. Ähnlich wie beim Schall die Luft zur Übermittlung erforderlich sei, setze auch die Lichtempfindung zwischen dem Auge und dem gesehenen Gegenstande ein Medium voraus, das die Wirkung zu übertragen vermöge. Das Innere des Auges ist ferner nach Aristoteles deshalb durchsichtig, weil sich der Sitz des Sehvermögens auf der hinteren Seite befinde. Auch an eine Erklärung der Farben wagt sich Aristoteles. Sie sollen aus der Mischung von Weiß und Schwarz, die er als Grunlfarben bezeichnet, hervorgehen, ein Gedanke, der später oft wiederkebrte. Er wendet sich dann gegen die Annahme, die Farben seien Ausflüsse der farbigen Körper. „Man muß nicht annehmen, " fügt er hinzu, "daß alles durch Berührung empfunden wird. Sondern es ist besser zu sagen, die Empfindung des Sehens erfolge durch eine Bewegung des Mittels zwischen dem Auge und dem Gesehenen." Es begegnet uns also hier schon im Keime der Widerstreit zwischen der Emanations- und der Vibrationstheorie, der sich durch das 17. und 18. Jahrhundert hindurchzog und erst im 19. entschieden wurde ${ }^{2}$. Trotz mancher Unrichtigkeiten, die sich bei Aristoteles finden, hat kaum ein anderer Denker des Altertums solch klare Vorstellungen iiber optische Dinge entwickelt, wie er. Daher kniipft selbst Goethe in seiner Schrift "Zur Farbenlehre" wieder an ihn an und gibt dort eine Darstellung der aristotelischen Ansichten über das Licht und die Farben ${ }^{3}$ ).

Erwähnt sei noch, daß die von den Atomisten (Leukipp, Demokrit) geschaffenen optischen Vorstellungen einen Rückschritt bedeuteten. Die Atomisten fielen eigentlich in die alten Vorstellungen zurück. Sie kehrten das Verhältnis aber un und ließen Abbilder der Dinge von den Gegenständen sich loslösen und ins Auge strömen. Mit beiden Anscliauungen brach Aristoteles, indem er die Bedeutung des Mediums für den Vorgang des Sehens erkannte. Im Mittelalter glaubte man von jeder physikalischen Erklärung absehen zu dürfen, da die Seele keiner äußeren Beihilfe bedürfe ${ }^{4}$ ). Man nahm vielmehr beim Sehen eine

1) Aristoteles, Über die Sinne. Kap. II.

2) Wilde, Über die Optik der Griechen. Berlin 1832.

3) Die aristotelische Schrilt über die Farben gilt allerdings nach neueren Untersuchungen als unecht.

4) Haas, a. a. O. S. 386.

Platon hatte die Lehre von den Sehstrahlen und den Abbildern zu einer Theorie der Zusammenstrahlung (Synergie) verschmolzen. 
unvermittelte Fernwirkung an und schuf damit einen Begriff, der lange dazu dienen mußte, einen aus mechanischen Prinżipien nicht zu erklärenden Vorgang wenigstens mit einem Worte zu verbinden.

Obgleich die Beschäftigung mit Fragen der Mechanik, der Optik und der Akustik ganz besonders zu wissenschaftlichen Beobachtungen und zu Versuchen anregt, finden wir bei Aristoteles, wie fast überall im Altertum, nur geringe Ansätze nach dieser Richtung. Stets wird an die Meinungen früherer angeknüpft, darauf werden Tatsachen der gewöhnlichen Erfahrung herangezogen und daraus auf dialektischem Wege, unter Gedankensprïngen und logischen Kunstgriffen, ein Ergebnis gewonnen, das sich dem herrschenden System anpaßt, oft aber auch auf eine bloße Worterklärung hinausläuft. Das Ergebnis der so geübten Spekulation sucht Aristoteles mitunter wieder durch neue Beispiele aus der Erfahrung zu stiitzen. Das Unzulängliche seines Verfahrens scheint ihm indessen manchmal selbst zum Bewuftsein gekommen zu sein. So sagt er an einer Stelle: "Noch sind die Erscheinungen nicht hinreichend erforscht. Wenn sie es aber dereinst sein werden, ist der Beobachtung mehr zu trauen, als der Spekulation und letzterer nur insoweit, als sie mit den Erscheinungen Übereinstimmendes ergibt."

\section{Das Himmelsgebäude nach Aristoteles.}

Auf dem Gebiete der Astronomie hat Aristoteles den soeben erwähnten Grundsatz, den im übrigen erst die neuere Naturforschung zur vollen Geltung brachte, auch hin und wieder befolgt ${ }^{1}$ ). Andererseits verleugnet er in seinem, ron diesem Gebiete handeluden Werke an manchen Stellen die an ihm gewohnte Denkart nicht. So bemüht er sich, aus Vernunftgriinden darzutun, daß es nur ein Himmelsgewölbe geben könne und daß das Universum ohne Ursprung und unvergängtich sei. Selır klar ist seine Zusammenstellung der Gründe für die Kugelgestalt der Erde. Der betreffende Abschnitt möge hier in etwas freierer Wiedergabe fölgen 2): „Daß die Erde eine Kugel ist, ergibt sich auch aus der Sinneswahrnehmung. Bei den Mondfinsternissen ist nämlich die abgrenzende Linie, welche der Schatten der Erde zeigt, immer gekrümmt. Ferner ist durch das Erscheinen der Sterne nicht bloß augenfällig, daß die Erde rund ist, sondern auch, daß sie nicht

1) Wolff, Geschichte der Astronomie, S. 42.

2) Nach der Ausgabe von Prantl. 
eben groß sein kann. Wenn wir nämlich nur eine geringe Ortsveränderung gegen Süden oder Norden vornehmen, so zeigen die Sterne über unserem Haupte eine große Veränderung, denn einige

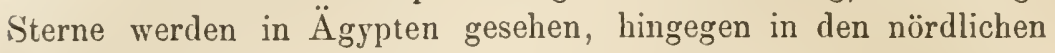
Ländern nicht. Und diejenigen Sterne, welche in den nördlichen Gegenden immerwährend am Himmel stehen, gehen in den südlichen unter. Folglich ist die Erde nicht nur kugelförmig, sondern auch nicht groß, denn sonst würde sich bei einer nur so geringen Ortsveränderung nicht die beschriebene Erscheinung zeigen. Es ist daher nicht unglaublich, daß die Gegend um die Säulen des Herkules mit jener ron Indien zusammenhängt und daß es auf diese Weise nur ein Meer gibt. Ferner behaupten die Mathematiker, daß der Umfang der Erde etwa 400000 Stadien betrage. Auch daraus würde folgen, daß die Erde nicht nur kugelförmig, sondern im Vergleich zu den übrigen Gestirnen nicht groß ist."

Gleichzeitig mit der Lehre von der Kugelgestalt der Erde entstand die Vorstellung, daß es Antipoden geben müsse. Schon die Pythagoreer sollen dies angenommen haben ${ }^{1}$. Als der "Erfinder" des Wortes Antipoden wird Platon genannt. Daß die Erde in ihrem ganzen Umfange bewohnt sei, wird indessen nicht etwa als Tatsache, sondern nur als nicht zu umgehende Annahme hingestellt.

Von eigener Beobachtung eines seltenen astronomischen Ereignisses zeugt folgende Stelle, die gleichfalls im Wortlaute mitgeteilt sei ${ }^{2}$ ): "Wir haben nämlich gesehen, wie der Mond einmal halbkreisförmig war und unter dem Mars vorüberging. Letzterer verschwand an der dunklen Hälfte des Mondes und kam an der beleuchteten wieder hervor. In gleicher Weise berichten solches, auch bezüglich der übrigen Gestirne, diejenigen, die schon seit einer sehr langen Reihe von Jahren Beobachtungen angestellt haben, nämlich die Ägypter und die Babylonier, von denen wir viele beglaubigte Nachrichten betreffs eines jeden Gestirns besitzen."

Die Kugelform legt Aristoteles nicht nur der Erde, sondewn auch dem Himmelsgewölbe bei. Letzteres müsse notwendig kugelförmig sein, denn die Kugel sei sowohl für das Wesen des Universums die am meisten ansprechende, als auch von Natur aus

1) Nach Diog. Laertius VIII, 26, der aber wenig zuverlässig ist.

2. Nach der Übersetzung von Prantl, Aristoteles' vier Bücher über das Himmelsgebäude. Leipzig 1857. Verlag von W. Engelmann. S. 180-181. 
die ursprünglich erste Form 1). Für die Welt nimmt Aristoteles räumliche Begrenzung an. Die Gestirne seien aus Äther gebildet, dessen Bewegung die kreisförmige sei, während den irdischen Elementen die geradlinige zukomme. Die fünf Planeten, die Sonne und der Mond sollen, wie schon Eudoxos behauptet, jeder in seiner eigenen Sphäre bewegt werden. An diesen Sphären, unter denen man sich konzentrische, die im Mittelpunkte ruhende Erde umgebende Kugelschalen vorstellte, sind diese sieben Weltkörper befestigt, während die Fixsterne eine gemeinsame Sphäre hesitzen und ihre gegenseitige Lage innerhalb dieser Sphäre nicht ïndern.

Astrologische Vorstellungen kommen in den Schriften des Aristoteles nicht vor. $Z$ war hatte Platon die Ansicht vertreten, daß die Gestirne göttliche Wesen seien. Aristoteles teilte diese Ansicht, sowie die Lehre von der Sterndeutung jedoch nicht, wenn auch den Griechen damals schon die astronomischen und die astrologischen Lehren der Chaldäer bekannt waren. Auch Eudoxos, der sich zur Zeit Platons eingehend mit der Astronomie befaßte, verhielt sich diesen Lehren gegenüber ablehnend. Erst in der späteren, als hellenistisch bezeichneten Periode wurde die Astrologie zu einer herrschenden geistigen Strömung.

Um die Ungleichheiten in der Bewegung der Planeten zu erklären, hatte schon Eudoxos, der Begründer der Theorie der homozentrischen Sphären, für jeden Wandelstern mehrere Sphären eingeführt. Für jedes dieser Gestirne mußte, da es wie die Fixsterne auf- und unterging, eine der Fixsternbewegung entsprechende Sphäre angenommen werden. Eine zweite, deren größter Kreis in die Ekliptik fiel, bewegte den Planeten dann entgegengesetzt zur täglichen Drehung, also von West nach Ost, in einer Zeit, innerhalb welcher der Planet den Tierkreis durchläuft. Weitere Sphären waren zur Erklärung der Stillstände und der zeitweiligen Rückwärtsbewegung von Ost nach West nötig. Eür den Mond und für die Sonne waren gleichfalls zwei Sphären nicht ausreichend. Im ganzen benötigte Eudoxos zur Darstellung der Bewegungen der Himmelskörper 27 Sphären. Zu diesen fügte Kalippos 7 und Aristoteles noch 22 weitere hinzu. Dadurch wurde der Mechanisıus so verwickelt, daß man ihn endlich aufgab und durch die Epizyklentheorie ersetzte.

1) De coelo II, 4. 
Eine Rekonstruktion der Anschauungen des Eudoxos verdanken wir Schiaparelli1). Es handelt sich bei der Annahme der Sphären um keine mystischen Ungereimtheiten, sondern um eine kinetische Hilfsvorstellung zur möglichst genauen Beschreibung der beobachteten Vorgänge. Man darf bei der Beurteilung älterer Hypothesen nie vergessen, daß auch unsere modernen Theorien im Grunde genommen solche Hilfsvorstellungen sind, die mit dem Fortschreiten der Wissenschaft oft durch neue Vorstellungen verdrängt werden. Man darf ferner wohl annehmen, daß Eudoxos selbst seine Hilfsvorstellung als das betrachtete, was sie war, und daß erst Spätere seinen homozentrischen Splärren Wirklichkeit beigemessen haben. Bezeichnend ist auch der Ausdruck, der bei den alten Schriftstellern oft wiederkehrt, daß man für die Bewegung der Himmelskörper Theorien aufgestellt habe, „um die Erscheinungen zu retten", d. h. sie mit einer, den Verstand befriedigenden, kinetischen Darstellung in Einklang zu bringen. Hielt man an dem Grundsatz fest, am Himmel seien nur gleichmäßige und kreisförmige Bewegungen möglich, so boten die Sphärentheorie und später die Epizyklentheorie eine Lösung der den alten Astronomen gestellten Aufgabe, die dem damaligen Stande des Wissens entsprach.

Die Vorstellung, die Erde und der Himmel seien kugelförmig, führte schon im Altertum zur Verfertigung von Globen. Zuerst begegnen uns Himmelsgloben. Ein solcher ist uns in dem „Farnesischen Globus" erhalten geblieben. Er wird im Nationalmuseum zu Neapel aufbewahrt und bildet die Marmorkugel, welche der "Farnesische Atlas" trägt. Dieser Globus ist vermutlich eine Nachbildung einer von Eudoxos hergestellten Sphäre. Auf dem Farnesischen Globus sind die Sternbilder in reliefartiger Darstellung gemeißelt. Nach der Lage des Frühlingspunktes zu urteilen, stammt das Kunstwerk aus dem 3. vorchristlichen Jahrhundert. Später haben die Araber, unter Benutzung der griechischen Sternverzeichnisse, in der Anfertigung von Himmelsgloben Hervorragendes geleistet. Von solchen aus dem 13. Jahrhundert stammenden Globen sind mehrere erhalten ${ }^{2}$. Die Verfertigung von Erdgloben kam erst im Zeitalter der Entdeckungen auf, als sich der geographische Gesichtskreis über die gesamte Erde auszudehnen

1) Schiaparelli, Le sfere omocentriche di Eudosso, di Calippo e d'Aristotele. Mailand 1876; deutsch von Horn. Abhandl. z. Gesch. d. Math. 1. Heft.

2) Siehe Wolff, Geschichte der Astronomie. S. 195. 
begann ${ }^{1}$. Die von den Himmelskörpern ausgehende Wärme und ihr Licht führt Aristoteles darauf zurïck, daß "die Luft unterhalb der Sphäre erhitzt wird". „Denn," fügt er hinzu, „, von Natur aus versetzt Bewegung sowohl Hölzer als auch Steine urd Eisen in Feuerhitze 2)." Aber nicht nur die Erde und das Himmelsgewölbe sind nach Aristoteles kugelförmig, sondern er legt diese Form den Gestirnen ganz allgemein bei ${ }^{3}$ ). Die Ansicht, letztere müßten eine Art Spbärenmusik erzeugen, kann er nicht teilen. Denn übermäBiges Geräusch, meint er, zerstöre selbst die widerstandsfähigsten Körper ${ }^{4}$ ). Bei der Erklärung des Flimmerns fällt er in die an anderer Stelle von ihm bestrittene Sehtheorie zurück. Er meint nämlich, die Planeten besäßen ein ruhiges Licht, weil sie nahe seien und der "Blick sie deshalb in seiner vollen Kraft erreiche". „Hingegen auf die Fixsterne gerichtet," fährt er fort, „wankt der Blick wegen der Länge des Abstandes, daher flimmern die am Himmel fest eingefügten Sterne, die Planeten aber nicht $\left.{ }^{5}\right)^{6}$

Was endlich die Kometen anbetrifft, so rechnete A ristoteles sie nicht zu den Himmelskörpern, sondern er hielt sie für Gebilde der irdischen Atmosphäre. Welchen Wert man dieser Meinung beilegte und wie sehr die Kometen das allgemeine Interesse fesselten, geht daraus hervor, daß noch am Ende des 17. Jahrhunderts in manchen IJändern kein Professor angestellt wurde, wenn er nicht öffentlich erklärte, daß er außer mit den übrigen Grundsätzen des Aristoteles auch mit dessen Ansichten über die Kometen einverstanden sei 6 ).

Bis auf Aristoteles zurückzuverfolgen ist auch eine andere Lehre (orientalischen Ursprungs), die in ihren letzten Konsequenzen las paradoxeste Erzeugnis des menschlichen Geistes darstellt, die Lehre von der steten Wiederkehr ${ }^{7}$ ). Aristoteles spricht an einigen Stellen seiner Werke den Gedanken aus, ähnlich der Bewegung der Gestirne vollziehe sich alles irdische Geschehen periodisch in stetem Kreislauf. So finde z. B. auch ein steter Wechsel zwischen

1) Siehe Martin Behain, 1492.

2) De coelo II, 7 .

3) De coclo II, 8.

4) De coelo II, 9 .

5) De coelo II, 8.

ט) Kaiser, Der Sternenhimmel. Berlin 1800.

7) $\mathrm{DaB} \mathrm{Nietzsche} \mathrm{dieser} \mathrm{ri \pi oxıŕorc \sigma \iota s} \mathrm{genannten} \mathrm{Lehro} \mathrm{einen} \mathrm{beson-}$ deren Wert beilegte, ist bekaunt genug. 
Meer und Land statt1). Spätere Philosophen, so die Stoiker, waren schon, wie später Nietzsche, in maßloser Übertreibung eines an sich richtigen Gedankens, auf die sonderbare Lehre gekommen, $d a B$ in großen Weltperioden in steter Folge selbst das Einzelwesen in seiner ganz bestimmten Individualität, z. B. ein bestimmtes Dorf, ein Sokrates usw. mit allen gleichzeitigen Wesen, Dingen und Erscheinungen wiederkehren müsse ${ }^{2}$. Erklärlich wird dieser Irrgang des menschlichen Geistes daraus, daß für die Gestirne, denen man einen maßgebenden Einfluß auf alles Werden und Vergehen zuschrieb, eine Rückkehr in die Anfangsstellung angenommen wurde. Sobald diese erreicht sei, sollten sich alle Geschehnisse in der gleichen Folge von neuem abspielen. Man unternahm es sogar, auf Grund der vorhandenen Beobachtungen die Rückkehr der Planeten in dasselbe Ortsverhältnis zu berechnen. Aristarch hatte dafül einen Zeitablauf von 2484 Jahren angenommen. Andere hatten Jahrmillionen herausgerechnet. Unter den Neueren hat sich selbst Tycho mit der Berechnung dieses ,annus mundanus" genannten Zeitraumes befaßt und 25816 Jahre gefunden. Ganz aufgegeben wurde dieser Gedanke wohl erst, als man erkannte, daß die Zahl der Planeten weit größer ist, als bisher angenommen war.

$\mathrm{Zu}$ den astronomischen Grundlagen der Lehre von der steten Wiederkehr ist auch Hipparchs Entdeckung der Präzession der Nachtgleichen zu rechnen. Sie führte gleichfalls auf eine Periode von etwa 25000 Jahren, die als platonisches Jahr bezeichnet wurde. (Siehe a. spät. Stelle.)

Außer den astronomischen kommen auch geophysische Grundlagen für diese Lehre in Betracht, indem man die regelmäßige Wiederkehr gewaltiger Überflutungen oder auch von Perioden gesteigerter vulkanischer Tätigkeit voraussetzte. Gewöhnlich wurden diese Ereignisse in der Art miteinander verbunden, daß man die irdischen Katastrophen an die periodisch wiederkehrenden astronomischen Erscheinungen knüpfte ${ }^{3}$ ).

Um die regelmäßige Wiederkehr der Überflutungen zu erklären, dachte man sich entweder die Erde von Adern und Spalten

1) E. v. Lasaulx, Die Geologie der Griechen und Römer. München 1851. S. 32.

2) Auch im Neuen Testament findet sich ein Anklang an diese Lehre (Apostelgeschichte 3. 21).

3) S. G ünther, Die antike Apokatastasis. Sitzungsber. d. k. bayer. Akad. d. Wissensch. math. phys. Kl, 1916. S. 83-111. 
durchzogen, die das Wasser in sich aufnehmen und sich wieder leeren sollten, oder man nahm an, daB sich in den oberen Schichten der Atmosphäre die Luft in Wasser verwandele. $\mathrm{Zu}$ den Anhängern dieser Auffassung gehörte Aristoteles, der sich mit den meteorologischen Erscheinungen eingehend beschäftigte.

\section{Die Grundzüge der physischen Erdkunde und der Geologie.}

In seinen vier Büchern über die Meteorologio beschreibt und erörtert Aristoteles das Auftreten der Kometen und der Sternschnuppen, welche er als Erzeugnisse unserer Atmosphäre betrachtet, die Gestalt und die Höhe der Wolken, die Bildung von Tau, Eis, Schnee, die Entstehung der Winde und des Gewitters usw.

Im ersten Buche ${ }^{1)}$ spricht Aristoteles von Erscheinungen. die wohl nur dahin gedeutet werden können, daß es sich um das Nordlicht handelt. Er erzählt, daß man in klaren Nächten mitunter Schlünde erblicke, die blutigrote Fackeln hinauszuschleudern schienen. Die Erscheinung mache den Eindruck, als ob sie von einem weit entfernten Brande herruilhre. Weniger bestimmt lassen sich einige bei Plinius und Seneca vorkommende Stellen auf das Nordlicht deuten.

Erdbeben werden nach Aristoteles durch eingeschlossene Luft erzeugt. Sehr ausführlich wird vom Regenbogen gehandelt. Aristoteles sucht diese Erscheinung einzig aus der Reflexion des Lichtes abzuleiten. Die Wassertröpfchen, meint er, seien Spiegelchen, die indessen infolge ihrer Kleinheit nicht die Form, sondern nur die Farbe des lenchtenden Gegenstandes, gemischt mit ihrer eigenen Farbe, zurückwürfen. Dem Regenbogen werden nur die drei Farben rot, grün und violett zugeschrieben. Doch zeige sich zwischen rot und grïn eine fahle Farbe (das Gelb). Auch die Beziehung des Regenbogens zur Sonnenhöhe wird erörtert und es wird erwähnt, daß es um Mittag im Sommer in Griechenland keinen Regenbogen gebe. Den Mondregenbogen, sagt Aristoteles, habe or in 50 Jahren nur zweimal beobachtet. Die Erscheinung sei so selten, weil sie nur bei Vollmond eintrete. Auch der künstliche Regenbogen, der sich im zerstäubten Wasser zeigt, findet Erwähnung. 
Die ersten geologischen Vorstellungen begegneten uns schon bei Thales und bei Empedokles (s. S. 70). Bei dem mit vielen Teilen der Erde bekannt gewordenen Demokrit hatten diese Vorstellungen eine erstaunliche Höhe erreicht. Man kann das aus der auf Demokrit zuriickgehenden Darstellung schließen, welche Aristoteles über die geologischen Vorgänge gibt. Seine (Worte lauten 1): "Nicht immer sind dieselben Orte der Erde feucht oder trocken, sondern sie verändern sich je nach dem Entstehen und dem Verschwinden der Flüsse. Ebenso verändert sich das Verhältnis des festen Landes zum Meere. Wo festes Land ist, da wird Meer, und wo jetzt Meer ist, da entsteht wiederum festes Land ${ }^{2}$ ). Man muß annehmen, daß dies periodenweise geschieht ${ }^{3}$ ).

Da die ganze natürliche Entstehung eines Landes allmählich und in Zeiträumen vor sich geht, die im Vergleich mit unserem Leben außerordentlich lang sind, so bemerken wir nichts davon ${ }^{4}$.

$\ddot{A}$ gypten z. B. scheint immer trockner geworden zu sein. Das ganze Land muß wohl als eine Anschwemmung des Niles betrachtet werden. Ähnlich verhält es sich mit Argos. Vor alters war diese Landschaft sumpfig und fast unbewohnt. Heute dagegen ist sie angebaut. Was von dieser engbegrenzten Gegend gilt, das geschieht auch bei ganzen Ländern. Einige nehmen an, daß die Ursache solcher Vorgänge eine Veränderung des ganzen Himmelsgebäudes ist, als sei dies dem Wechsel unterworfen. Oder man behauptet, das Meer nehme ab, indem es austrockne. Dabei übersieht man, daß gleichzeitig Teile der Erde trocken werden, während das Meer andere überflutet $\left.{ }^{5}\right)$."

1) Arist., Meteor. 1, 14.

2) Ähnliche Anschauungen entwickelten auch Strabon und Eratosthenes. S. a. spät. Stelle. Strabon knüpfte seine Theorien an seine Kenntnis der vulkanischen Erscheinungen an, während Eratosthenes von der Beobachtung von Versteinerungen im Innern der Kontinente ausging.

3) Die Begründung, die Aristoteles hierfür gibt, sei übergangen. Er spricht von der Blütezeit und dem Alter der einzelnen Teile der Erdoberfläche.

4) Aristoteles führt dann des Näheren aus, weshalb die Erinnerung an solche Vorgänge selbst im Gedächtnis der Völker, die vor dem eindringenden Meere zurückwichen oder in neuentstandene Länder einwanderten, nicht festgehalten worden ist.

5) Barthélemy St. Hilaire erklärt diese Darlegungen des Aristoteles in der Vorrede zu seinem Werke „Météorologie d'Aristote". Paris 1863, für geradezu bewunderungswürdig. 
Die Annahme, daß die Menge des Meeres geringer werde und das Meer schließlich ganz verschwinden müsse, rührt von Demokrit her. Letzterer ist $\mathrm{zu}$ dem großartigen Gedanken, daß die Konfiguration der Erdoberfläche sich im Lauf der geologischen Perioden ändere, schon vor Aristoteles gelangt $\left.{ }^{1}\right)$. Auch die Ansicht, daß die geologischen Änderungen auf kosmologische Ursachen zurückzuführen seien, rührt von Demokrit her. Aristoteles verwirft sie, weil er den Himmel als den Ort des unveränderlichen Seins betrachtet. Wir sehen aus alledem, daß Demokrits Naturauffassung in vielem höher steht als diejenige des Aristoteles und sich der unseren nähert, denn die Einwirkung kosmischer Vorgänge auf die säkularen Änderungen der Erdoberfläche wird heute nicht mehr in Abrede gestellt. Ferner entspricht Demokrits Annahme einer steten Verringerung der auf der Erde befindlichen Wassermenge den heutigen geologischen Vorstellungen. Das Ende dieses Vorgangs würde darin bestehen, daß alles Wasser durch die Verwitterung und andere Veränderungen der Gesteine gebunden ist.

Daß das Meer nicht etwa dadurch verschwindet, daß es sich durch die Sonne in Dampf verwandelt, war Demokrit ganz klar, denn er wußte, daß das Wasser des Meeres immer wieder in Gestalt von Regen auf die Erde herabfällt. Dies ist aus seiner Erklärung der Nilüberschwemmungen ersichtlich ${ }^{2}$ ).

Es ist anzunehmen, daß Demokrits ganz klare Lehre vom Kreislauf des Wassers der von Aristoteles gegebenen Dar-

1) Ovid hat diesen Gedanken in seinen "Metamorphosen" in poetischer Form zum Ausdruck gebracht (XV,260 u. f.). Es heißt dort:

260 So auch hat gar oft sich gewendet der Gegenden Schicksal.

Ich sah selber als Meer, was fester und trockener Boden

Vormals war; ich sah aus Wogen gewordene Länder.

Fern ab lagen vorn Mcer in der See einheimische Muscheln,

265 Und man entdeckte sogar auf Gebirgshöhen Anker der Vorzeit.

Was erst Ebene war, das schuf der Gewässer Herabsturz

Um zum Tal, und der Berg ward niedergeschwemmt in die Fläche.

Vordem sumpfiges Land ist lechzend von trockenem Sande,

269 Während von stehendem Sumpf feucht ist, was früher gedürstet.

Zu 265: Pomponius Mela berichtet, im Innern Numidiens seien „Reste von Schnecken, von den Fluten abgeschliffenes und von Strandsteinen nicht unterscheidbares Gestein, in Felsen haftende Auker (?), sowie andere Zeichen dafür gefunden worden, daß einst das Meer bis in diese Gegend gereicht habe".

2) Diodori bibliotheca historica I, 39. Dieser Darstellung der geologischen Ansichten Demokrits ist die oben erwähnte Schrift Löwenheims (siehe S. 75) zugrunde gelegt. 
stellung zugrunde gelegen hat. Sie lautet: ..Einige behaupten, daß die Fliisse nicht allein in das Meer fließen, sondern auch aus demselben." Das Wasser des Meeres verdampfe und steige nach oben. Dort werde es durch Abkuihlung wieder verdichtet und falle infolgedessen wieder zur Erde herunter ${ }^{1}$ ).

Für das Entstehen der ersten geologischen Anschauungen ist der Umstand von großer Bedeutung gewesen, daß das Land, in dem das älteste Kulturvolk der Ägypter wohnte, alle Anzeichen dafür darbot, daß es sich in langsamer, stetiger Änderung befindet. Die Erinnerungen und Aufzeichnungen der Ägypter umfaßten einen Zeitraum von Jahrtausenden, der wohl erkennen ließ, daß sich das Land am unteren Lauf des Niles fortgesetzt nach Norden ausdehnte 2). Die salzigen Seen auf der Landenge von Suez konnten kaum anders denn als Überbleibsel des Meeres gedeutet werden. Auf das allmähliche Emportauchen Ägyptens aus dem Meere wiesen auch die in seinen gebirgigen Teilen sich findenden Versteinerungen hin. Trotzdem ist es erstaunlich, daß man auf Grund von einer immerhin nur geringen Summe von Beobachtungen im Altertum schon zu einer so klaren Einsicht in die geologischen Vorgänge gelangt ist, wie sie uns bei Eratosthenes, bei Aristoteles, der allerdings nur berichtet, und ganz besonders bei Demokrit begegnet. Es läßt sich nicht verkennen, daß diese antiken Anfänge der geologischen Wissenschaft auf ihre eigentliche Begründung im 16. und 17. Jahrhundert von nicht geringem Einfluß gewesen sind, wie an späterer Stelle gezeigt werden soll. Dieser Einfluß geht so weit, daß zwischen den am klarsten von Demokrit entwickelten Lehren des Altertums eine besonders durch Aristoteles vermittelte Wirkung auf die Geologie der Neuzeit nachzuweisen ist.

1) Aristoteles bemerkt an dieser Stelle, daß er es lächerlich finde, wenn einige annehmen, die Sonne werde durch die feuchten Dünste ernährt und mache deswegen ihren Umlauf, da ihr nicht immer dieselben Orte die Nahrung liefern könnten.

2. So sagt Plutarch: „Die Insel Pharos, die einst eine Tagfahrt von Ägypten entfernt war, ist jetzt ein Teil des Landes. Sie bewegte sich aber nicht an das Land heran, sondern das dazwischen liegende Neer wich vor dem, festes Land bildenden Flusse zurück." Weiter bemerkt Plutarch: ,Ägypten war nämlich ein Meer. Daher findet man noch jetzt viele Muscheln in den Schächten und auf den Bergen. Alle Quellen und Brunnen haben salziges und bitteres Wasser als Rest des ehemaligen Meeres“* (Plutarch, „Über Isis und Osiris", herausgegeben von Parthey, Berlin 1850. S. 70 u. 71). 


\section{Die vier aristotelischen Elemente.}

Am Schlusse seiner "Meteorologie“ handelt Aristoteles von den vier Elementen. Ausführlichere Darlegungen über diesen Gegenstand enthält die Schrift über "Entstehen und Vergehen". Daß nur vier Elemente möglich seien, beweist A ristoteles auf spekulativem Wege. Seine Ausführungen sind für die Beurteilung der aristotelischen Denkweise so bezeichnend, daß wir auf sie etwas näher eingehen wollen \%)

Es gibt, meint er, vier Grundempfindungen: warm, kalt, feucht und trocken. Diese Empfindungen werden paarweise vereint wahrgenommen. Mathematisch betrachtet, können sich sechs solcher Vereinigungen (sechs Kombinationen zu zwei) bilden. Doch sind zwei als sich widersprechend unmöglich, nämlich die Vereinigung warm und kalt und die Vereinigung feucht und trocken. Es bleiben folglich nur vier Gegensätze bestehen, und dementsprechend sind nur vier Elemente möglich. Dem Gegensatz kalt und trocken entspricht die Erde, kalt und feucht das Wasser, warm und feucht die Luft, warm und trocken das Feuer. Durch die Mischung dieser vier Elemente entstehen nun nach Aristoteles sämtliche irdischen Stoffe 2). Ferner kommt jedem Element sein bestimmter "natürlicher" Ort zu, gegen den hin es sich bewegt.

Die Materie setzt A ristoteles als gegeben voraus. Sie kann nicht etwa aus dem Nichts entstehen, auch sich nicht vermehren oder sich vermindern $\left.{ }^{3}\right)$. Sie ist vielmehr nur der Veränderung fähig. Veränderungen werden dadurch hervorgerufen, daß Un-

1) Auch Platon entwickelte schon die Lehre von den vier Jlementen, sowie Ansichten über die Stoffe, aus denen sich die Mineralien, die Pflanzen und die Tiere zusammensetzen. Alchemistische Vorstellungen begegnen uns bei $\mathrm{Plat}$ on und bei Aristoteles noch nicht, dennoch sind ihre Lehren von der Natur der Stoffe von großem Einfluß auf die Entstehmg der Alchemie rewesen. Näheres hierüber enthält die Abhand.ung O. E. v. Lippmanns, Chemısches und Physikalisches aus Platon Journal für praktische Chemie, Bd. 76. S. 513 u. f.). Siehe auch v. Lippmanns Abliandlungen und Vorträge zur Gresch. d. Naturwiss. Bd. II, Leipzig 1913.

2) Von den chemischen Kenntnissen des Aristoteles und seinen Vorstellungen handelt E. v. Lippmann im Archiv für die Gesch. der Naturwiss. u. d. Technik. 1910. Bd. 2. S. 235-300.

3) Nach der "Physik", nach „Entstehen und Vergehen" und der Sehrift "Über das Himmelsgrebäude". Die betreffenden Stellen lıat O. E. v. Lippmann im zweiten Bande des Archivs für die Gesch. d. Naturwissenseh. u. d. Technik zusammengestellt. Dort findet man auf S. 235-300 eine große Zahl weiterer, die Hauptgedanken des Aristoteles wiedergebender Zitate. 
gleichartiges oder Gegensätzliches aufeinander wirkt. Dies setzt Berührung voraus. Letztere braucht nicht immer eine unmittelbare zu sein. Es kann vielmehr auch eine Vermittlung durch eine Zwischensubstanz stattfinden, von der jeder Teil den zunächst liegenden in Bewegung setzt. In letzter Linie beruht jede Veränderung, einerlei ob sie qualitativ oder quantitativ ist, auf Bewegungen. Ist ein Körper einmal in Bewegung, so ist kein Grund denkbar, daß er stillstehen sollte, wenn er keinen Widerstand findet. Indes auch das Ruhende widerstrebt und verharrt an seinem Orte ${ }^{1}$ ).

In all diesen Sätzen begegnen uns schon Keime und Vorahnungen, die sich später ganz oder teilweise bewahrheiten sollten. Der Andeutung des Gesetzes von der Erhaltung der Materie trat auch schon eine Vorahnung des Energiegesetzes zur Seite. Sie begegnet uns in dem Ausspruch; daß die in der Natur vorhandene Bewegung weder entstehen noch vergehen könne ${ }^{2}$. Man darf indessen nicht außer Acht lassen, daß Aristoteles mitunter rein zufällig das Richtige trifft. So, wenn er sagt, die Luft bestehe aus zwei Bestandteilen. In der Nähe des Erdbodens herrsche nämlich ein feuchter und kühler, in der Höhe dagegen ein trockner und warmer ror.

Für das Entstehen gibt es nach Aristoteles drei Ursachen, den Stoff, als das dem Werden zugrunde Liegende, die Form als Zweck und die Bewegung als Veranlassung. Die den Stoff gestaltende Form ist nach Aristoteles für die Lebewesen mit dem, was wir Seele nemnen, einerlei. Die Artunterschiede der Seele sollen die Stufenreihe der Lebewesen bestimmen. Die niedrigste

1) Mechanische Probleme. S. 9 u. 32. Die in dieser Schrift entwickelten allgemeinen Ansichten entsprechen denjenigen der älteren peripatetischen Schule. Trotzdem wird die Schrift nicht für echt aristotelisch gehalten, weil die Probleme und Lösungen im einzelnen auf praktische Anwendungen hinzielen. Dies gilt nämlich als unaristotelisch und entspricht mehr der Richtung Stratons, der nach dem Tode des Theophrast die Leitung der pei ipatetischen Schule übernommen hatte. Über grundlegende kritische und erklärende Ausgaben siehe Paulys Reallex. der klass. Altertumswiss. II. Bd. (1896) S. 1012-10555 (Aristoteles).

2) "Physik" VIII, 1 und ,Metaphysik" XII, 6.

Man darf solche Vorahnungen nicht zu hoch einschätzen, vor allem aber sie nicht den neuzeitlichen Ërgebnissen wissenschaftlicher Forschung als gleichwertig zur Seite stellen. Andererseits läßt sich auch nicht in Abrede stellen, daß sie häutig durch die Jahrbunderte hindurch anregend und befruchtend gewirkt haben. Man vergleiche z. B. hierzu die Beziehungen des Koppernikus zu den alten Schriftstellern. 
Seelenstufe ist die regetative. Sie beschränkt sich auf die Nahrungsaufnahme und die Fortpflanzung und ist in den Pflanzen wirksam. Die Tierseele ist außerdem der Empfindung fähig, zu welcher bei dem Menschen noch die Vernunft hinzutritt. Der Mensch selbst erscheint dem Aristoteles als Zweck und Mittelpunkt der ganzen Schöpfung. In ihm gelangt das göttliche Empfinden zum Bewußtsein 1). Die Seele ist indessen für Aristoteles nichts für sich Bestehendes. Sondern sie ist an den Stoff gebunden, ohne selbst körperlich zu sein. Sie ist es, welche aus dem Stoff den Leib aufbaut und bewirkt, daß letzterer zweckmäßig eingerichtet ist.

Die Lehre von den vier Elementen genügte schon den Hippokratikern und auch Platon, um daraus die Entstehung der Krankheiten abzuleiten. Da der Körper aus Erde, Feuer, Luft und Wasser zusammengesetzt sei, so müsse ein Zuviel oder Zuwenig von einem dieser Grundstoffe, sowie eine Veränderung ihres Sitzes Aufruhr, d. h. Krankheit, zur Folge haben.

Auch Aristoteles führt einige Krankheiten auf ein Übermaß an Feuchtigkeit, andere auf ein Zuviel an Wärme zurück. In den Lungen häufen sich nach ihm mit zunehmendem Alter erdige Bestandteile an, durch die das Feuer endlich erlischt und der Tod eintritt.

Die Elemente sind bei A ristoteles nicht etwa Grundstoffe im heutigen Sinne. Andererseits verwirft er aber auch den Hylozoismus der jonischen Naturphilosophen (ndaß nur Eines, z. B. Luft, das Sämtliche sei, ist nicht möglich"“)2). A ristoteles ist der Ansicht, daß es „eine Substanz der sinnlich wahrnehmbaren Körper "gibt, die aber immer mit einer Gegensätzlichkeit verbunden ist, aus welcher die sogenannten Elemente entstehen“3).

\section{Die Begründung der Zoologie.}

IVährend die Mathematik und die Astronomie schon vor dem Auftreten des Aristoteles die ersten Stufen ihrer Entwicklung zurückgelegt hatten und in zielbewußter "Weise die Lösung bestimmter Aufgaben anstrebten, war das Gleiche bezüglich der beschreibenden Naturwissenschaften noch nicht der Fall. Zwar waren die Grundlagen auch auf diesem Gebiete wie auf dem-

1) Aristoteles, Politik. I, 8.

2) Aristoteles, Zwei Bücher über Entstehen und Vergehen. Übersetzung von Prantl. Leipzig, W. Engelmann. 180̄7. S. 451.

3) A. a. O. S. 437.

Dannemann, Die Naturwissenschaften. J. Bal. 2. Aufl. 
jenigen der Astronomie in der sich unmittelbar aufdrängenden Beobachtung gegeben. Dem Aristoteles und seiner Schule blieb indes die erste denkende Erfassung und die systematische Gestaltung der noch wenig zusammenhängenden naturgeschichtlichen Einzelkenntnisse vorbehalten.

Das wichtigste zoologische Werk des Aristoteles ist seine Tierkunde ${ }^{1}$. Es ist ein grundlegendes Werk und das bedeutendste zoologische Buch des Altertums. Es enthält nicht nur Beschreibungen der Tiere, sondern es geht auch auf den Bau und die Verrichtungen der Organe, sowie auf die Entwicklung und die Lebensweise ein. Eine kurze Betrachtung möge uns eine Probe ron dem Wissen des Aristoteles und der Art, wie er seinen Gegenstand behandelt, bieten. Begonnen wird mit der Beschreibung des menschlichen Körpers. Zur Erforschung der imneren Organe mußte jedoch das Tier dienen, da man sich noch nicht an die Zergliederung menschlicher Leichen heranwagte. Die anatomischen Kenntnisse des Aristoteles sind infolgedessen noch gering.

Das Herz, von dem er sagt, es enthalte von allen Eingeweiden allein Blut, ist ihm auch allein das Organ, in dem das Blut bereitet wird 2). Vom Herzen aus läßt er diese Flüssigkeit sich durch den ganzen Körper verbreiten, ohne jedoch damit die Vorstellung von einem Kreislauf zu verbinden $\left.{ }^{3}\right)$. Das Blut ist ihm ferner der Träger der dem Menschen eingepflanzten Wärme. Die Aufgabe der Atmung soll darin bestehen, diese Wärme auf das richtige Maß herabzumindern. Man darf sich nicht wundern, daß die Anschauungen des Aristoteles noch so weit von dę heute als richtig erkannten und jedermann geläufigen abweichen. Denn

1) Aristoteles' Tierkunde, kritisch berichtigter Text mit deutscher Übersetzung, sachlicher und sprachlicher Erklärung und vollständigem Index ron H. A ubert und Fr. Wimmer. 2 Bände. Mit 7 lithograph. Tafeln. Gr. 8. Leipzig, Verlag von Wilh. Engelmann. 1868.

2) Aristoteles, Teile der Tiere. III, 4.

3) Als Probe für die Art, wie Aristoteles die anatomischen Verhältnisse betrachtet, möge folgende Stelle aus seiner Schrift über die Teile der Tiere dienen (Aristoteles, Vier Bücher über die Teile der Tiere. Griechisch und Deutsch; herausgegeben von Franzius. Leipzig, W. Engelmann. 185̃3):

..Da das Blut eine Flüssigkeit ist, so muß notwendig ein Gefäß da sein, für welchen Zweck die Natur die Adern bildete. Für diese muß notwendig ein einziger Anfang sein. Denn, wenn es sein kann, ist einer besser als viele. Das Herz aber ist der Anfang der Adern, denn sie entspringen offenbar aus diesem, nicht aber gehen sie durch das Herz hindurch, und dessen Beschaffenheit als eines verwandten Teiles ist aderartig." 
gerade die Erforschung der Vorgänge, die sich in den Lebewesen abspielen, hat den späteren Jahrhunderten die größten Schwierigkeiten gemacht, so daß wir selbst zurzeit noch kaum zu einem befriedigenden Einblick in den Zusammenhang dieser Vorgänge gelangt sind. Die Aufdeckung eines solchen Zusammenhanges ist nämlich vor allem ron den Fortschritten der Chemie und der Physik abhängig gewesen, Wissenschaften, die zur Zeit des Aristoteles erst im Keime vorhanden waren. So konnte, um hier nur eins zu erwähnen, der Vorgang der Atmung und der Entstehung tierischer Wärme erst richtig gedeutet werden, nachdem man die Zusammensetzung und die Rolle der atmosphärischen Luft erkannt hatte. Und dies geschah erst gegen das Ende des 18. Jahrhunderts, an der Schwelle des letzten Abschnittes der Geschichte der Naturwissenschaften. Es ist Verdienst genug, daß Aristoteles die Fragen nach den Verrichtungen, sowie nach der Entwicklung der organischen Wesen ${ }^{1}$ ) gestellt und dadurch späteren Geschlechtern den Anlaß geboten hat, die Erforschung dieser Dinge weiter zu betreiben. So ist die Entwicklung des Hühnchens im Ei ein Problem, das schon Aristoteles beschäftigte. Die eingehendere Untersuchung wurde indes erst 2000 Jahre später wieder aufgenommen und erst in neuester Zeit, auf Grund der Vervollkommnung aller Hilfsmittel, zu einem gewissen Abschluß gefülırt.

Mit Recht mag es dagegen Verwunderung erregen, daß A ristoteles nicht nur die niederen, sondern selbst höber entwickelte Tiere durch Urzeugung entstehen ließ. Es begegnet uns auch hier wieder ein Problem, das wir durch den Verlauf der Jahrhunderte in seinen Wandlungen verfolgen werden, bis es endlich im neuesten Zeitalter seine Lösung gefunden hat. Zwar ist es begreiflich, wenn Aristoteles Lüuse aus Fleisch und Wanzen aus tierischen Feuchtigkeiten herleitet. Man höre aber, welch sonderbare Vorstellungen er sich über die Entstehung der Aale gebildet hat: „Sie legen", sagt er $\left.{ }^{2}\right)$, „keine Eier. Und man hat noch nie in ihnen einen der Fortpflanzung dienenden T'eil entdecken können. Es gibt sumpfige 'Teiche, in denen sie wieder entstehen, wenn auch das Wasser und der Schlamm herausgeschafft sind, sobald diese Teiche wieder durch den Regen gefiillt werden.

1) Aristoteles, 5 Biicher vou der Zeugung und Entwicklung der Tiere, übersetzt und erklärt von H. A ubert und Fr. Wimmer. Leipzig, Verlag von W. Engelmann. 1860.

2. Nach einem von O. Lenz in seiner Zoologie der Griechen und Rümer mitgeteilten Auszug. S. dort S. 5̃19. 
Die Aale gehen nämlich aus Regenwürmern hervor, die sich von selbst aus dem Schlamme bilden." Zur Entschuldigung mag es demgegeniiber dienen, daß die Fortpflanzung der Aale bis in die neueste Zeit hinein ein dunkles Gebiet der Zoologie gewesen ist.

Keineswegs nahm aber Aristoteles die Urzeugung für die niederen Tiere als den einzigen Weg der Entstehung an. So sagt er von den Insekten ausdrücklich, sie zeugten, entständen aber auch spontan. Die Urzeugung war ihm und späteren Zoologen ein Glaubenssatz, um aus der Verlegenheit, in die man häufig durch Unkenntnis der obwaltenden Verhältnisse geraten war, herauszukommen. Über den Vorgang der Entwicklung selbst läßt Aristoteles sich in seiner Schrift über die Zeugung und Entwicklung der Tiere mit folgenden zutreffenden Worten aus: „Entweder entstehen alle Teile des Tieres auf einmal; oder sie entstehen nacheinander wie die Maschen eines Netzes. Daß letzteres geschieht, ist deutlich. Denn man sieht, daß manche Teile schon vorhanden sind, andere aber noch nicht. Es ist unzweifelhaft, daß man sie nicht nur etwa ihrer Kleinheit wegen nicht sieht. Obgleich die Lunge nämlich einen größeren Umfang hat als das Herz, so zeigt sie sich doch später als dieses ${ }^{1}$ "“.

Beziiglich der anatomischen Kenntnisse des Aristoteles sei hervorgehoben, daß er die schneckenförmige Gestalt des inneren Ohres und die Verbindung zwischen dem Gehörorgan und der Mundhöhle kannte. Vom Innern des Auges, sagt er, es bestehe aus einer Flüssigkeit, welche das Sehen vermittle. Um diese sei eine schwarze und außerhalb der letzteren eine weiße Haut vorhanden. Beim Gehirn unterscheidet er die stärkere, dem Schädel anliegende Haut von der schwächeren, welche das Gehirn unmittelbar umschließt ${ }^{2}$ ).

Auch die Drüsen der Verdaungsorgane hat Aristoteles im ganzen richtig beschrieben und sie sogar bei einigen Wirbellosen gekannt. Ferner hat er seine Schriften durch Zeichnungen erläutert und soll hierin vorbildlich gewesen sein. Andererseits wußte Aristoteles Nerven und Sehnen noch nicht scharf genug zu unterscheiden. Die Bedentung der Muskeln war ihm noch nicht bekannt. Er führte vielmehr die Bewegungen der Glieder

1) Lenz, a. a. O. S. 137.

2) Zwischen der von Aristoteles erwähnten harten und weichen Haut (dura und pia mater) befindet sich noch die sehr zarte Spinnwebenhaut (Arachnoïdea). 
auf die Tätigkeit der Sehnen zurück und betrachtete das Fleisch als das Organ für die Empfindung.

Es sind etwa 500 Tierformen, die Aristoteles in den auf uns gelangten Schriften erwähnt; doch lassen sich diese Formen nicht sämtlich identifizieren. So werden zwar mehrere Arten von Vierhändern unterschieden, mit den menschenähnlichen Affen war man zur Zeit des Aristoteles jedoch noch nicht bekannt ${ }^{1}$ ). Auch wußte man sehr wenig von den niederen Tieren. Doch bewältigt und beherrscht Aristoteles die ihm bekannten Formen, - und das ist sein wesentlichstes Verdienst -, indem er sie in ein der Natur entsprechendes, wissensehaftliches System gliedert, das erst lurch Cuvier im Beginn des 19. Jalırhunderts eine wesentliche Verbesserung gefunden hat. Es erscheint deshalb gerechtfertigt, auf diesen ersten und auch gleich so wohlgelungenen Versuch eines natürlichen Systems der Tiere etwas näher einzugehen.

Zunächst teilte Aristoteles das gesamte Tierreich in Bluttiere und Blutlose. Ging er auch hierbei von der unrichtigen Annahme aus, dals die rote Farbe ein notwendiges Kennzeichen des Blutes sei, so decken sich doch tatsächlich seine beiden großen Gruppen, wie wir aus ihrer weiteren Einteilung erkennen, mit unseren heutigen Wirbeltieren und Wirbellosen. Die Bhuttiere zerfallen bei Aristoteles in lebendig gebärende Vierfüßler (Säugetiere), Vögel, eierlegende Vierfüßler (unsere heutigen Klassen der Reptilien und Amphibien, zu denen er ganz richtig trotz des Fehlens der Gliedmaßen, wegen ihrer sonstigen Beschaffenheit, die Schlangen rechnet) und in die von den Fischen scharf abgesonderten Waltiere. Fuir letztere gibt er an, daß sie durch Lungen atmen und lebendig gebären. „Die lebendig gebärenden Vierfüßler", sagt A ristoteles, „sind fast alle dicht behaart. Sie sind ferner entweder vielzehig wie der Löwe, der Hund und der Panther, oder zweihufig wie Schaf, Ziege und Hirsch. Oder sie besitzen nur einen Huf wie das Pferd. Den Tieren, welche Hörner tragen, hat die Natur meist zwei Hufe verlichen. Ein Einhufer mit Hörnern ist uns niemals zu Gesicht gekommen. Auch im Gebiß weichen die Tiere untereinander und von Menschen vielfach ab. Zälıne besitzen alle lebendig gebärenden Vierfüßler. Und zwar haben sie in beiden Kiefern entweder zusammenläingende

1) S. Günther, Geschichte der antiken Naturwissenschaft. Handbuch der klass. Altertuınswissensch. 13d. V. 1. Abt. S. 100. Sellst den Elefanten, der bald darauf zu Kriegszwecken in die Mittelmeerländer eingeführt wurde, kannte Aristoteles nur vom Hörensagen (Beloch, Griech. Geschichte). 
Zahnreihen oder unterbrochene. Allen Hörnertragenden fehlen nämlich die Vorderzähne im Oberkiefer. Doch gibt es auch Arten mit unvollkommenen Zahnreihen ohme Hörner, wie das Kamel. Manche haben Hauzähne, z. B. der Eber. Ferner gibt es Tiere mit Reißzähnen, wie der Löwe, Panther und Hund. Hauzähne und Hörner zugleich besitzt kein Tier. Auch kommen nicht Reißzähne neben Hauzähnen und Hörnern vor."

Obgleich Aristoteles hier manche Mitteilungen und Verallgemeinerungen ïber die Zühne und den Bau der Füße bei den Säugetieren macht, gelangt er doch nicht etwa zur Aufstellung von Ordnungen oder Unterordnungen im heutigen Sinne. Bei den Vögeln indessen unterscheidet er die Ordnung der Raubvögel von den Ordnungen der Schwimm- und der Stelzrögel. Besonders gekennzeichnet wird die Gruppe der Vögel noch durch folgende Bemerkungen: „Sie allein unter allen Tieren sind zweibeinig wie der Mensch, sie haben weder Hünde noch Vorderfüße, sondern Flügel. Das sind Organe, welche dieser Tierklasse eigentümlich sind. Alle haben mehrspaltige Füße. In der Regel sind die Zehen getrennt. Bei den Schwimmrögeln aber sind die gegliederten, deutlich gesonderten Zehen durch Schwimmhäute verbunden. Die Vögel, welche hoch fliegen, haben sämtlich vier Zehen, von denen meistens drei nach rorn und eine nach hinten gestellt sind. Einige haben zwei nach vorn und zwei nach hinten gerichtete Zehen..

Für seine fünfte und letzte Gruppe, die Fische nämlich, hebt er das Vorhandensein von Kiemen und Flossen hervor ${ }^{1}$ ). Auch ist ihm bekannt, daß nicht nur die Waltiere, sondern auch gewisse Haie lebendige Junge zur Welt bringen. Ja, er zeigt sich nit Verhältnissen in der Entwicklung der Haie vertraut, welche erst in neuerer Zeit ihre Bestätigung gefunden haben. So erzählt er, daß es unter den Haien eierlegende und lebendig gebärende gäbe, und unter den letzteren auch solche, bei denen der Fötus mit dem Uterus wie bei den Säugetieren durch einen Mutterkuchen verbunden sei (s. Abb. 16). Diese Tatsache wurde erst im 19. Jahrhundert durch Johannes Müller an Mustela laevis wieder entdeckt ${ }^{2}$ ).

Unter den Blutlosen (Wirbellosen) gelten ihm als die entwickeltsten die Kopffüßler (Tintenfische), mit deren Bau und

1) Er unterscheidet Knorpelfische (Haie) und Grätenfische.

2. Vgl. J. Müller, Über den glatten Hai des Aristoteles. Alhandl. der Berliner Akademie. 1840. 
Lebensweise er sich eingehend befaßt. "Sie besitzen", sagt er, „Füße, die sich am Kopf befinden, einen Mantel, der das Innere umschließt, und Flossen rings um den Mantel. Es sind acht mit Saugnäpfen versehene Füße vorhanden. Einige Arten, wie die Sepien, haben außerdem zwei lange Fangarme. Mit diesen ergreifen sie die Nahrung und fuihren sie zum Maule. Bei Sturm befestigen sie diese Arme wie Anker an einem Felsen und lassen sich so von den Wogen hin und hertreiben. Auf die Füße folgt bei allen der Kopf, in dessen Mitte sich das mit zwei Zähnen versehene Maul befindet. Dariiber liegen die großen Augen, und

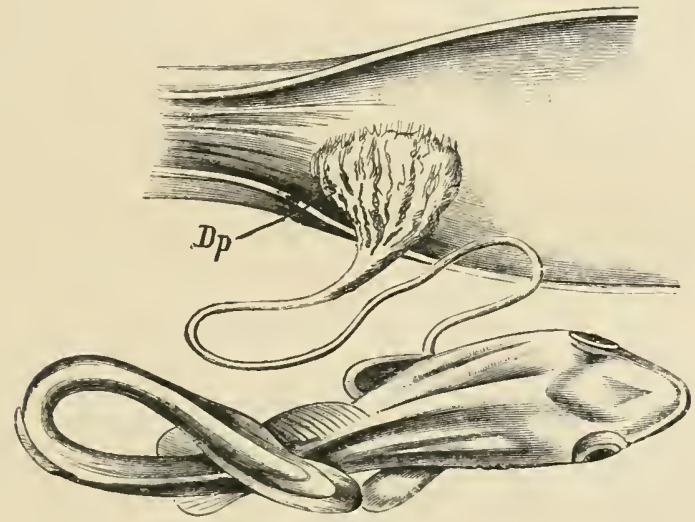

Abb. 16. Der Embryo des glatten Hais des Aristoteles. Dp, der Mutterkuchen in Verbindung mit dem Uterus ${ }^{1}$.

zwischen diesen eine knorpelige Masse, welche das Gehirn einschließt."

Dann folgen die Krebse, von Aristoteles Weichschalige genannt. Die dritte Gruppe bilden die Kerbtiere. Aristotele. begreift darunter sämtliche Tiere mit geringeltem Körper, alsu nicht nur die Insekten, sondern auch die Spinnen, die Tausendfüßler und die Gliederwürmer. Er hebt hervor, daß der Körper aller Insekten in drei Abschnitte zerfällt, den Kopf, den Körperteil, welcher Magen und Darm enthält, und drittens den dazwischen liegenden Abschnitt, dem bei anderen Tieren Brust und Rïcken entspreelıen. .Außer den Augen“, fährt Aristoteles fort, „haben die Insekten kein dentliches Sinnesorgan. Manche besitzen einen Stachel, der sich entweder innerhalb des Körpers hefindet, wie bei den Bienen und

1) Claus, Lehrbuch der Zoologie. 1883. S. 677. 
Wespen, oder außerhalb, wie beim Skorpion 1. Letzterer ist allein unter allen Insekten lang geschwänzt; ferner besitzt er Scheren. Einige Insekten haben über den Augen Fühler, z. B. die Schmetterlinge und die Käfer. Im Innern findet sich ein Darm, der in der Regel bis zum After gerade verlüuft, mitunter aber auch gewunden ist."

Bei den Insekten fesseln Aristoteles besonders der Bau und die Lebensweise der Honigbiene. Er erwähnt, daß sie das Bienenbrot an den Schenkeln einträgt und den Honig in ihre Zellen speit. Er erzählt von dem Bau der Waben, den Maden und Puppen und kennt die Herkunft, sowie die Rolle, die das sogenannte Vorwachs besitzt, so daß wir vor Swammerdam, welcher durch die Anwendung des Mikroskops und durch die Befolgung der Grundsätze der neueren Naturforschung zu einem weit tieferen Einblick befähigt war, kaum eine gleich gute Schilderung dieses wichtigen Insektes antreffen.

Die vierte Gruppe, ausgezeichnet durch harte Schalen, die einen weichen ungegliederten Körper umschließen, bilden die Schnecken und die Muscheln, die von Aristoteles als Schaltiere zusammengefaßt werden. Der fünften und letzten Gruppe, den Seewalzen, Seesternen und Schwämmen, wird eine vermittelnde Stellung zwischen dem Tier- und Pflanzenreiche zugewiesen.

Viele Betrachtungen, die Aristoteles in seinen zoologischen Schriften anstellt, lassen erkennen, daß er, wenn auch vom teleologischen Standpunkt, doch schon ron dem Gedanken geleitet wird, den die neuere Biologie als Erhaltungsmäßigkeit bezeichnet. Das Wort soll ausdrücken, daß Lebensweise, Aufenthaltsort und Einrichtung eines Tieres einander entsprechen. Nicht minder stehen aber die einzelnen Organe zueinander und zum Gesamtbau in einem gewissen Verhältnis, das Cuvier, der größte Zoologe der Neuzeit, als die Korrelation der Organe bezeichnet hat. In welchem Maße Cuvier und die neuere Biologie hierin mit Aristoteles übereinstimmen, lassen z. B. dessen Betrachtungen über die Zähne erkennen. Sie lauten 2): „Die Zähne haben die Tiere im allgemeinen zur Zerkleinerung der Nahrung, dann aber auch als Waffen zu Angriff und Abwehr. Von denen, die sie zu Schutz und Trutz besitzen,

1) Der Name Insekten, welcher heute die sechsfüßigen Arthropoden bezeichnet, wurde von Aristoteles in viel weiterem Sinne gebraucht; er rechnete auch die Spinnentiere, sowie die Tausendfüßler und Eingeweidewürmer, kurz alle Geschöpfe mit Einschnitten rings um den Körper, zu den Insekten.

2) Im dritten Buch der Schrift „Über die Teile der Tiere". 
haben einige Haner wie der Eber, andere scharf ineinander greifende Zähne. Die Stärke dieser Tiere beruht auf ihren Zähnen. Diese miissen also scharf sein und zweckmäßig ineinander greifen, damit sie sich nicht durch gegenseitige Reibung abstumpfen. Ferner haben die spitzzähnigen ein weit geschlitztes Maul. Da nämlich ihre Wehr im Beißen besteht, haben sie ein weites Maul nötig, denn sie werden mit um so mehr Zähnen und um so stärker beißen, je weiter das Maul geschlitzt ist ${ }^{1}$.."

Auch ïber die Ernährung der Tiere wie uiber diejenige der Pflanzen hatte sich Aristoteles schon Vorstellungen gebildet, die viel Zutreffendes enthalten. Sämtliche Bestandteile des Körpers läßt er durch die Umwandlung der aufgenommenen Nahrungsmittel entstehen ${ }^{2}$. Für einzelne Substanzen wie das Fett, die Galle usw. gebe es wahrscheinlich auch bestimmte Nährstoffe. Diese sollen aus dem Blute durch die Wandungen der Adern hindurchsickern und auf diese Weise an den Ort gelangen, wo sie abgeschieden werden. Das Fett entstehe aus mehliger und siißer Nahrung, die sich leicht in Fett unwandele. Als die wichtigste Ausscheidung des Blutes betrachtet Aristoteles den Samen. Er enthalte neben Wasser und Erde vor allem den warmen, lebenerregenden Luftgeist, das Pneuma (s. S. 102). Wie sich die Erde in ein Mineral verwandeln könne, so verwandele die im Samen enthaltene Erde sich in einen Menschen. Tiere mit starken Knochen läßt Aristoteles aus einem besonders erdhaltigen Samen hervorgehen. Seele und Körper dor Lebewesen bilden nach ihm eine Einheit, allerdings nur in dem Sinne, daß der Körper das Organ der Seele ist $\left.{ }^{3}\right)$. Dafür spreche auch, daß manche Tiere, die man zerschneide, in jedem ihrer Teile weiterleben.

1) H. Stadler zieht einen Vergleich mit dieser Betrachtungsweise des Aristoteles und derjenigen moderner Biologen (Biologie und Teleologie, in den neuen Jahrbüclıern für das klass. Altert. 1910. S. 147). Als Beispiel führt er folgende Stelle aus dem Lehrbuch der Zoologie von Schmeil an: „Schließt die Katze das Maul, so greifen die Zühne des Oberkiefers dicht an denen des Unterkiefers entlang. Da die Zälne aneinander vorbeigleiten, reiben sich ihre Kronen nicht $a b$, sie bleiben also stets scharf und schneidend, wie dies für ein Raubtier notwendig ist. Wenn die Katze gähnt, sieht man, daß ilır Maul weit gespalten ist. Sic vermag daher ihre Zähne ticf in das Opfer ein-

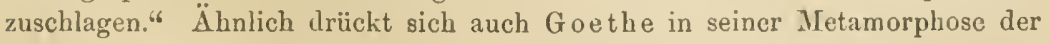
Tiere aus 'siehe Dannemann, Aus der Werkstatt großer Forscher, 3. Aufl. W. Engelmann 1908. S. 4).

2) Tierkunde I, 69 .

3) De anima. I, 4 u. 5 . 


\section{Aristoteles über die Pflanzen.}

In seinem Bestreben, das gesamte Wissen seiner Zeit vom Standpunkte des Philosophen zu sammeln, zu prüfen und systematisch zu gliedern, konnte Aristoteles auch an der Pflanzenwelt nicht achtitos vorübergehen. Leider ist indessen seine diesem Gegenstande gewidmete "Theorie der Pflanzen" verloren gegangen. Was wir an Ansichten des Aristoteles ïber die Natur der Pflanzen kennen, sind vereinzelte, aber immerhin zahlreiche $\ddot{A} u ß e r u n g e n ~ d e s$ Philosophen, die sich in seinen übrigen Werken zerstreut finden ${ }^{1}$ ). Von besonderem Interesse ist, was Aristoteles uiber die Verwandtschaft der Tiere mit den Pflanzen sagt ${ }^{2}$. Die Natur geht allmählich vom Unbeseelten zum Beseelten über. Auf die unbeseelten Dinge läßt sie zunächst die Pflanzen folgen. Unter diesen unterscheide sich die eine von der anderen darin, daß sie teils mehr, teils weniger Anteil am Leben zeige. Vergleiche man die Pflanzen mit den leblosen Dingen, so seien erstere wie beseelt, dagegen erscheine die Pflanze im Vergleich zum Tiere wie unbeseelt. Und doch sei der Übergang zwischen Pflanze und Tier ununterbrochen. Denn bei einigen Wesen des Meeres könne man zweifeln, ob sie Tiere oder Pflanzen seien. Auch über die Teilbarkeit der Pflanzen und der Tiere stellt Aristoteles Betrachtungen an ${ }^{3}$. "Nimmt man von einer Zahl“, sagt er, „eine Zahl weg, so bleibt eine andere Zahl. Die Pflanzen dagegen und viele Tiere bleiben bestehen, wenn man sie teilt." Die niederen Tiere und die Pflanzen stimmen, wie Aristoteles richtig hervorhebt, eben darin überein, daß ihnen die Einheit der Organisation fehlt. Infolgedessen können abgetrennte Teile des Organismus fortleben und sich zu selbständigen Wesen entwickeln ${ }^{4}$ ). Auch darin seien sie einander ähnlich, daß bei beiden der Hauptzweck die Fortpflanzung sei und alle Einrichtungen sich auf diesen Zweck zurückführen ließen.

Auch ïber die Ernährung der Pflanzen hat Aristoteles nachgedacht. Die Wurzein nennt er ein Analogon des Mundes, da

1) Eine Sammlung dieser Fragmente aristotelischer Pflanzenkunde gab Wimmer heraus. Fr. Wimmer, phytologiae Aristotelicae fragmenta. Breslau 1838. Eine Übersetzung dieser Fragmente findet sich in E. Meyer, Geschichte der Botanik, Bd. I. S. 94 u. f.

2) Histor. animal VIII. cap. 1.

3) De anima. cap. 6 .

4) De part. animal. 4, 5. 
beide die Nahrung eimmehmen $\left.{ }^{1}\right)$. Die Erde enthalte eine für die Pflanze zubereitete Nahrung und diene ihr sozusagen als Bauch, während die Tiere gleichsam die Erde als Inhalt des Darms in sich trügen, aus dem sie, wie die Pflanzen mit den Wurzeln, mit etwas Ähnlichem die Nahrung aufnehmen müßten ${ }^{2}$. W Wem füllt bei dieser originellen, im Grunde aber richtigen Auffassung des Philosophen nicht die so treffende Benennung der Darmzotten als innere Wurzeln des Tieres ein? Ein ähnliches Verhältnis, wie für die Ernährung von Tier und Pflanze, nimmt Aristoteles für die Entwicklung an. Er sagt nämlich: "Wie sich die Gewächse des Bodens bedienen, so bedienen sich die Embryonen des Uterus" 3 ).

Was die Entstehung anbetrifft, so wird auch für die Pflanzen angenommen, daß sie entweder aus Samen oder von selbst entständen. Letzteres geschehe, wenn die Erde oder Pflanzenteile faulten. Was endlich die Sexualität anlangt, so meint A ristoteles, bei den Pflanzen sei das Männliche und das Weibliche nicht getrennt; sie zeugten daher aus sich selbst. Das Gleiche finde gewissermaßen bei den Tieren statt. Denn wenn sie zeugen wollten, so werde sozusagen ein Tier aus zweien. Die Tiere seien somit gleichsam Pflanzen, in denen das Männliche und das Weibliche voneinander geschieden sei. Aus den zerstreuten Bemerkungen des Aristoteles erkennen wir somit, daß das Nachdenken über botanische Dinge rege geworden war und manche wertvolle $\mathrm{Be}-$ obachtung und Verallgemeinerung vorlag. Der erste, dem wir ein zusammenhängendes Werk ïber die Pflanzen verdanken, ist denn auch ein Schüler des großen Philosophen, Theophrast. Dieser nimmt der Botanik gegenüber eine ähnliche Bedeutung ein, wie sie Aristoteles für die Zoologie besitzt.

\section{Theophrast begründet die Botanik.}

Über das Leben des Theoplirast sind wir besonders durch Diogenes Laertios und durch Plutarch unterrichtet. Doch sind seine Lebensumstände wenig bekannt und durch Sagen und Übertreibungen verdunkelt. Theophrast wurde 371 v. Chr. zu Eresos auf der Insel Lesbos geboren. Er widmete sich der Philosophic. Und zwar schloB er sich zuerst an die Atomisten (Len-

1) De animalibus II. cap. 1.

2) De part. animal. 1I. cap. 3 .

3) Politic. VII. cap. 16. 
kipp), dann an Platon und schließlich an Aristoteles an. Theophrast nannte man ihn seiner Beredsamkeit wegen ${ }^{1}$.

Nach dem Tode des Aristoteles, dessen Lieblingsschüler und langjähriger Freund er war, übernahm Theophrast die Führung der von Aristoteles in Athen gegründeten Philosophenschule, die er zur höchsten Bliite brachte. Theophrast genoß in Athen das größte Ansehen. Sein Ruhm drang auch ins Ausland, so daß Ptolemäos der Lagide ihn nach Alexandrien zu ziehen suchte. Wie selı man Theophrast in seinem Vaterlande schätzte, geht auch aus folgender Erzählung hervor. Theophrast wurde des Mangels an Religion beschuldigt. Man gab indessen dieser Klage nicht nur keine Folge, sondern es fehlte nicht viel, daß der Kläger selbst in den Anklagezustand gesetzt wurde ${ }^{2}$.

War Theophrast auch nicht an schöpferischer Kraft mit Aristoteles zu vergleichen, so überragte er ihn durch den Umfang seiner naturwissenschaftlichen Einzelkenntnisse. Auf die Beobachtung zahlreicher Einzelfälle, wodurch man allein zur Bildung richtiger Begriffe gelangen könne, legte er den größten Wert. Wo Theophrast nur fremde Beobachtungen zu Gebote stehen, verhält er sich durchaus kritisch und macht aus etwaigem Zweifel kein Hehl. Sein Fleiß war unermüdlich und begleitete ihn bis ins höchste Alter. Sterbend klagte er noch im Hinblick auf das Aufhören seiner wissenschaftlichen Tätigkeit über die Kürze des menschlichen Lebens ${ }^{3}$ ). Das Altertum pries auch seine Umgangsformen. Cicero läßt ihn sagen, die rauhe Tugend allein mache keineswegs die Glückseligkeit aus. Er galt ferner als einer der berleutendsten Redner,-der vortrefflich und wohlberechnet seine Worte mit seinen Gebärden und seinem Mienenspiel in Einklang zu bringen wußte.

1) Diogenes Laert. 5, 38, 51.

Diogenes Laertios schrieb im 3. Jahrhundert n. Chr. ,Zehn Bücher über das Leben, die Lehren und Aussprüche der in der Philosophie berühmten Männer". Das Werk ist indessen nur oberflächlich und wenig zuverlässig.

Von Plutarch rührt eine Schrift her, die unter dem Titel ,Über die Meinungen der Philosophen" bekannt ist. Wahrscheinlich ist das Vorhandene nur ein Auszug einer Schrift des Plutarch.

Trotz ihrer Unvollkommenheiten sind die erwähnten Schriften wichtige Quellen, weil sie über manches berichten, was anderweitig nicht mehr festgestellt werden kann.

2) Diogenes 39, 37.

3) Cicero, tuscul. disput. 3. 28. 
Von einem ganz ungewöhnlichen Fleiße legt anch die Zahl seiner Schriften Zeugnis $a b^{1}$ ). Leider sind die wichtigsten verloren gegangen. Sie erstreckten sich auf Mathematik, Astronomie, Botanik, Mineralogie und alle Teile des von Aristoteles gegründeten philosophischen Systems. Theophrast starb 286 v. Chr. Er ist also 85 Jahre alt geworden. Seiner Schule soll er einen Pflanzengarten und eine Halle, in welcher der Unterricht stattfiniden sollte, vermacht haben ${ }^{2}$ ).

Außer dem botanischen Hauptwerk, dessen neun Bücher vollständig auf uns gekommen sind, und mit dessen Inhalt wir uns im nachfolgenden in der Hauptsache bekannt machen wollen, verfaßte Theophrast noch eine Schrift "Von den Ursachen der Pflanzen“. Sie ist leider mur unvollständig vorhanden. Die Schrift von den Ursachen der Pflanzen ( $\pi \varepsilon Q i$ qutũy cicicu) verhielt sich zur Geschichte der Pflanzen ähnlich wie die mehr philosophischen zu den beschreibenden Büchern, die Aristoteles über die Tierkunde verfaßt hatte ${ }^{3}$ ).

Vor Aristoteles hatte man sich den Gewächsen, soweit sie nicht dem unmittelbaren Unterhalt von Mensch und Tier dienten, vorzugsweise aus medizinischem Interesse zugewandt. Das Sammeln der Pflanzen und ihre Verarbeitung zu heilkräftigen Säften wurde berufsmäßig von den schon erwähnten Rhizotomen (Wurzelschneidern) betrieben. Es waren dies die Vorläufer unserer heutigen Pharmazeuten. Jetzt wandte sich das wissenschaftliche Interesse neben der Tierwelt auch dem Pflanzenreiche zu. Wemn wir von der verloren gegangenen Schrift des Aristoteles ïber die Theorie der Pflanzen absehen, lieferte Theophrast die erste, eingehende Bearbeitung der den Griechen bekannten Gewächse unter Berücksichtigung ihrer Lebensbedingungen, sowie der allgemeinen Morphologie. Die Schrift, auf die wir jetzt näher eingehen wollen, fiihrt den Titel: Naturgeschichte der Gewächse ${ }^{4}$ ).

W as beim Lesen dieses Buches zunächst auffällt, ist das Fehlen genauer Beschreibungen, die erst später in immer höherem Grade

1) Diogenes führt 227 Titel an.

2) Zeller, Philos. der Griechen. II. 2. S. 642.

3) Über die Schriften des Theophrast siehe auch W. Christ, Griechische Literaturgeschichte. Nördlingen 1889. S. 435 u. f.

4) Theophrast, Naturgeschichte der Gewächse, iibersetzt und erläutert von K. Sprengel. 1822. Die Hauptausgabe seiner Werke rührt von Wimmer her. Breslau und Leipzig 1842-1862. Theophrasti Eresii Opera, quae supersunt, omnia. - 'Theophrast fußt auf Schriften anderer, die jedoch nicht auf uns gelangt sind. 
als das nächstliegende Ziel der botanischen Wissenschaft erkannt wurden. Oft fehlt eine Beschreibung der zur Besprechung gelangenden Pflanze ganz, da Theophrast sie als den Lesern hinreichend bekannt voraussetzt. In anderen Fällen beschränkt er sich darauf, angenfällige Eigentümlichkeiten hervorzuheben, so daß es später oft schwer, ja manchmal unmöglich gewesen ist, selbst nachdem man die Elora Griechenlands genauer kennen gelernt hatte, die Identität der einzelnen Pflanzen festzustellen. Als gegen den Ausgang des Mittelalters die Botanik eine Weiterentwicklung erfuhr, war man zunächst in der Vorstellung befangen, alle Pflanzen, über welche die Alten, insbesondere der später zu erwäbnende Dioskurides geschrieben, seien auch im westlichen Europa zu finden. Erst nachdem man sich lange in dieser Richtung abgemült und nur in wenigen Fällen etwas erreicht hatte, weil man der geographischen Verbreitung der Gewächse noch nicht die gebührende Beachtung schenkte, ging man zur möglichst genauen Beschreibung der Pflanzen über. So entstanden die Kräuterbiicher der ersten neueren Botaniker. Die Schwierigkeit, die ron den Alten beschriebenen Pflanzen zu identifizieren, wurde noch durch den Umstand vergrößert, daß sich die Flora der in Betracht kommenden Länder im Laufe der Jahrtausende durch Wanderungen, durch klimatische Änderungen und ganz besonders durch die Einwirkung des Menschen ge:̈ndert hatte ${ }^{1}$ ).

Das den Griechen zur Zeit des Theophrast floristisch hekannt gewordene Gebiet war ein sehr beträchtliches. War man doch durch die Züge Alexanders des Großen auch mit Persien, Baktrien und Indien bekannt geworden, während man schon vorher

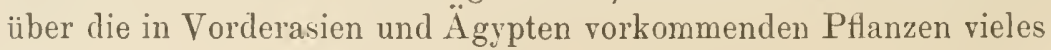
erfahren hatte. Allerdings lernten die Griechen auf ihren Eroberungszügen die Naturkörper zunächst mehr im Vorübergehen kennen und achteten fast nur auf das, was auf den fremden Märkten ihr Erstaunen hervorrief 2 ).

Ein neues Licht haben die Untersuchungen Bretzls auf die botanischen Ergebnisse des Alexanderzuges geworfen ${ }^{3}$. Das grie-

1: Eine Untersuchung über die einigermaßen sicher zu bestimmenden Pflanzen des Theophrast findet sich in Sprengels Geschichte der Botanik. I. S. $58-90$.

2) Strabon sagt von den Nachrichten der Griechen über Indien: Was sie sahen, erkannten sie nur auf den Feldzügen im Vorbeigehen. Buch 15. Ausgabe von Grosskurd. Bd. III. S. 108.

3) H. Bretzl, Botanische Forschungen des Alexanderzuges. Mit 11 Abb. 
chische Heer wurde von Gelehrten begleitet. Ihre Aufzeichnungen bildeten einen Teil dessen, was man heute das "Generalstabswerk" über den indischen Feldzug nennen würde. Dieses Werk ist leider verloren, doch sind Auszüge in Theophrasts Geschichte der Pflanzen ${ }^{1)}$ iibergegangen. Von den fremden Vegetationsbildern, welche Theophrast genauer schildert und mit der Vegetation der Länder des östlichen Mittelmeeres vergleicht, ist vor allem die Mangroveformation des persischen Golfes zu nemmen. Theophrast gibt eine genaue Beschreibung der eigenartigen Pflanzen jener Formation. Er schildert die Lebensweise der Mangrovegewächse, die auf Stelzenwurzeln weit über das Meeresufer linauswachsen, so richtig, daß neuere Reisende, wie Schweinfurth, seine Angaben nur bestätigen konnten. Einen "Glanzpunkt“ nennt Bretzl die Beschreibung, welche Theophrast vom indischen Feigenbaum gegeben, der mit seinen, von den $\ddot{A}$ sten her in die Erde eindringenden, Stützwurzeln einem Walde gleicht. Daß es sich bei den Stiitzen, welche die fast horizontal sich ausbreitenden Äste in den Boden hinabsenden, um eigentliche Wurzeln handelt, erkannte schon Theophrast, wie er auch das Bambusrohr als eine Schilfart erkennt und das vom Rande her einreißende Blatt der Banane sehr zutreffend mit den Schwungfedern eines Vogels vergleicht.

Wahrscheinlich sind die Griechen auch mit der Baumwolle erst nach den Zügen Alexanders genauer bekannt geworden, während in $\ddot{A g y p t e n}$ die Baumwollweberei schon früh anzutreffen war. Durch die Beobachtungen, die man auf dem Alexanderzuge anstellte, wurden die Griechen auch mit der Tatsache vertraut, daß gewisse Pflanzen Bewegungen ausführen, wie man sie bisher nur bei den Tieren kannte. Es handelt sich um die periodischen Bewegungen der Blattfiedern von Tamarindus indica. Diese Bewegungen werden in ihren einzelnen Stadien so genau beschrieben, daß sie bis zum Beginn der neueren physiologischen Untersuchungen über diesen Gegenstand die beste Schilderung sind, die wir über den Pflanzenschlaf besitzen. Die betreffende Stelle lautet bei Theophrast2;: „Der Baum besitzt zahlreiche Fiederblättchen. Sic legen sich während der Nacht leise zusammen. Bei Sonnenaufgang öffnen sie sich, und um Mittag entfaltet sich der Baum völlig. Am Nachmittage ziehen sich die Blïttchen allmählich wieder zusammen und

und 4 Karten. Gedruckt mit Unterstützung der Kgl. Gesellschaft der Wissenschaften zu Göttingen. Lcipzig, B. G. Teubner. 1903. 412 Seiten.

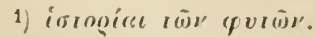

2) Hist. plant. IV. 7, 8. Siehe Bretzl a. a. O. S. 121. 
in der Nacht schließt sich die Pflanze wieder. Man sagt dort zu Lande, sie schlafe."

Dadurch, daß die Griechen die Pflanzenwelt vom Mittelmeerbecken bis in die tropischen Gebiete Asiens kennen lernten, wurden sie nicht nur mit gewissen Grundtatsachen der Pflanzengeographie, sondern auch schon mit einigen wichtigen, pflanzengeographischen Gesetzen bekannt, so daß es nicht ganz zutreffend ist, die Anfänge dieser Wissenschaft auf A. r. Humboldt zurückzuführen. Die Erscheinung, daß die Flora ihren Charakter mit der Erhebung des Bodens iiber das Meer ändert, hatten die Griechen schon in ihrer Heimat beobachtet. Sie hatten dort bemerkt, daß sich an die Mittelmeerflora mit ihren immergrïnen Gewächsen zunächst eine Laubwaldregion, darüber Nadelholzwälder und noch höher hinauf eine Region anschloß, die wir heute als alpin bezeichnen wïrden. Die gleiche Erscheinung nahmen sie noch deutlicher wahr, als sie an den Fuß der Berge gelangten, die Indien vom Rumpf des asiatischen Kontinentes trennen. Dort herrschte noch die tropische Flora mit ihren Palmen und Bananen in reicher Fülle. Unmittelbar darüber erblickten die Griechen Pflanzen, die sie an diejenigen der Mittelmeerländer erinnerten. Dann folgten wieder Laubhölzer, Nadelhölzer und alpine Pflanzen. Einen ähnlichen Wechsel der Flora nahmen sie wahr, als sie die Pflanzen nördlicher Landstriche mit denen südlicher verglichen. Dieser Vergleich drängte sich ihnen nicht nur in Europa, sondern auch in Asien auf. Auch hier fanden sie in den nördlicher gelegenen Teilen die mächtigen dunklen Nadelholzwaldungen wieder, die sie als charakteristisch fuir das mittlere Europa betrachtet hatten.

In Theophrasts "Geschichte der Pflanzen" überwiegt das praktische Interesse häufig das wissenschaftliche. Die Beschreibung gewisser technischer Verrichtungen, wie der Gewinnung ron Holzkohle, Pech, Harz und Spezereien, ferner der Verwendung der Holzarten, insbesondere aber der Wirkung von Pflanzen auf den menschlichen Körper, nehmen dementsprechend einen breiten Raum ein ${ }^{1}$. Aber auch von der geographischen Verbreitung, den Krankheiten, der Lebensdauer, dem Einfluß des Klimas, sowie der Ernährung der Pflanzen ist die Rede. Daß dabei zu einer Zeit, in der man kaum beobachten, geschweige denn mit Pflanzen experimentieren gelernt hatte, manche irrtümliche Ansicht aus-

1) Die Wirkung der Pflanzen auf den Menschen wird im 9. Buch geschildert, das aber gerade in diesen Teilen unecht ist H. Stadler, Neue Jahrbücher f. d. klass. Altertum. 1911. S. 86). 
gesprochen wird, ist leicht begreiflich. So führt Theophrast die Erscheinung, daß die Bäume, wenn sie dicht gedrängt stehen, keinen kräftigen Wuchs aufweisen, sondern dünn und lang werden, nicht auf den Einfluß des Lichtes, sondern auf Mangel an Nahrung zurück. An Krankheiten der Pflanzen erwähnt er den Wurmstich, den Rost des Getreides und den Honigtau. Letzteren leitet er aus einem zu großen Feuchtigkeitsgehalt der Pflanzen ab, während es sich in der Tat um Ausscheidungen von Blattläusen handelt. Als eine Wirkung des Klimas betrachtet Theophrast die Erscheinung, daß in heißen Ländern der jälrliche Laubfall bei Pflanzen unterbleibt, die in den Mittelmeerländern ihr Laub im Winter verlieren. Dies sei z. B. bei dem Feigenbaum und dem Weinstock der Fall ${ }^{1}$ ).

Als Ernährungsorgane werden nicht nur die Wurzeln, sondern auch die Blätter betrachtet. Die Ernährung soll auf beiden Flächen durch Einsaugung vor sich gehen. Das Wachstum der Blätter und das Ansetzen der Früchte stehen, wie Theophrast sehr richtig bemerkt, in solchem Verhältnis, daß, wenn der eine Vorgang stattfindet, der andere zurückgehalten wird ${ }^{2}$ ). Auch die Möglichkeit, daß sich die eine Pflanzenart in eine andere umwandele, ein häufig wiederkehrender Irrtum, wird bei Theophrast erörtert. So sagt er: „Die wilde Minze soll sich in Gartenminze umändern, auch soll sich der Weizen in Lolch verwandeln." Von der Sexualität der Pflanzen vermochte er sich ebensowenig wie das übrige Altertum eine klare Vorstellung zu machen. Doch erwähnt er, daß man bei den Dattelpalmen das Ansetzen von Früchten dadurch fördere, daß man die stauberzeugenden $Z$ weige über die fruchttragenden hänge:

„Manche Bäume“, sagt er, „werfen ihre Früchte vor der Reife ab, wogegen man auch Anstalten trifft. Bei den Datteln besteht das Hilfsmittel darin, daß man die männliche Blüte der weiblichen nähert, denn jene macht, daß die Früchte dauern und reif werden. Es geschieht dies aber auf folgende Weise: Blüht die männliche Pflanze, so schneidet man die Blütenscheide ab und schüttelt sie mit dem Staube auf die weibliche Frucht. Wird diese so behandelt, so dauert sie aus und fällt nicht ab." Anknüpfend an diese und ähnliche Beobachtungen der Alten begründete in der neueren Zeit Camerarius die Lehre von der Sexualität der Pflanzen.

1) Gesch. der Pflanzen. 1, 5.

2) Von den Ursachen der Pflanzen. 2, 14.

Dannemann, Die Naturwissenschaften. I. Bd. 2. Autl. 
Ein Verdienst erwarb sich Theophrast auch durch die begriffliche Bestimmung, sowie die Morphologie der wichtigsten Pflanzenorgane. Z. B. begegnet uns bei ihm der Begriff des gefiederten Blattes, das man bis dahin für einen Zweig gehalten hatte. Dagegen gelang es ihm nicht, eine naturgenäße Einteilung des Pflanzenreichs zu schaffen und damit das zu leisten, was Aristoteles für die Zoologie getan. Theophrast unterscheidet Bäume, Sträucher, Stauden und Kräuter und spricht innerhalb dieser vier Gruppen wieder von zahmen und wilden Pflanzen. So überschreibt er z. B. ein Kapitel: „Von den wilden Bäumen“, während er ein anderes mit den Worten beginnt: "Jetzt soll von den Gewächsen der Flüsse, Sümpfe und Teiche die Rede sein." Immerhin werden bei seiner Einteilung der Kräuter mitunter natürliche Gruppen angedeutet. Endlich verdanken wir dem Theophrast auch eine Reile wertvoller Mitteilungen über den Bau und die Entwicklung der Pflanzen. Sie erscheinen ihm als lebende Wesen, welche als Voraussetzungen des Lebens Wärme und Feuchtigkeit in sich bergen. Daher ist er auch bemüht, eine Ähnlichkeit im Bau der Pflanzen und der Tiere nachzuweisen. Als innere Teile der Pflanzen unterscheidet er Rinde, Holz und Mark. Diese Teile seien aus Fasern, Adern, Fleisch und Saft gebildet. Das Fleisch entspricht dem, was wir heute als Parenchym oder Grundgewebe bezeichnen. Die Fasern sind dagegen die Gefäßbündel. Theophrast bemerkt sogar, daß sie mitunter regelmäßig angeordnet, bei anderen Pflanzen, wie den Gräsern und Palmen, dagegen unregelmäßig im. Fleisch (Grundgewebe) zerstreut seien.

Auch über die Entwicklung der Pflanzen finden sich bei Theophrast einige Beobachtungen. Er weist darauf hin, daß der Keim sowohl Wurzel als Stamm enthält11), und daß die Wurzel zuerst aus dem Samen hervorbricht. Darauf entwickle sich der Stamm, dessen erste Blätter durch einfachere Gestalt von den späteren abwichen. Treffend wird ferner bemerkt, daß das Winklige und die Gliederung mit dem Fortschreiten der Entwicklung zunehmen 2). Daß uns die Botanik bei Theophrast sofort als eine ziemlich entwickelte Wissenschaft entgegentritt, darf uns nicht in Erstaunen setzen, denn ohne Zweifel komnte Theophrast auf Vorgänger fußen, die er zum Teil auch erwähnt ${ }^{3}$. Neben

1) Gesch. d. Pflanzen. 8, 2. S. 153.

2) O. Warburg, Berichte der Deutsch. bot. Gesellschaft XIX (1901).

3) Ursache d. Pflanzen. I. 5, 5. 
Theophrast wären zwar noch einige Mitglieder der peripatetischen Schule zu nennen, die sich mit Botanik beschäftigt haben. Da sich aber nicht viel mehr als ihre Namen und die Titel ihrer Schriften erhielten, wollen wir uns mit dem weiteren Schicksal der botanischen Wissenschaft erst wieder befassen, wenn sie uns bei den Römern von neuem begegnen wird.

Wie für die Tiere so sahen die Griechen auch für die Pflanzen, als eine besondere Art der Vermehrung, die Urzeugung an. Man nahm sie nicht nur für kleinere Pflanzen, sondern mitunter selbst für Bäume in Anspruch. Theophrast war dieser Ansicht gegeniiber indes schon skeptisch. Er suchte angebliche Fälle von Urzeugung auf die Verbreitung der Samen durch Regengiisse, Vögel, Überschwemmungen oder durch den Wind zurückzuführen. Auch darauf weist er hin, daß manche Samen ihrer geringen Größe wegen leicht übersehen werden. Die Fortpflanzung durch Samen erklärt er für die gewöhnliche. Der Pflanzensamen sei dem tierischen Ei zu vergleichen. Beide enthielten die erste Nahrung des Keimes in sich. Daß aber Urzeugung insbesondere bei kleineren Pflanzen vorkomme, stellt er nicht in Abrede. Er nimmt vielmehr an, daß Pflanzen sowolsl wie Tiere bei der Zersetzung von Stoffen unter dem Einfluß von Feuchtigkeit und Wärne entstehen können.

\section{Theophrast als der Begründer der Mineralogie.}

Auch die dritte der beschreibenden Naturwissenschaften, die Mineralogie, fand ihre erste Bearbeitung in demselben Zeitalter, in welchem die Zoologie und die Botanik ins Leben gerufen wurden. Dies geschah gleichfalls durch Theophrast, und zwar in seinem Werke "Über die Steine" ${ }^{1}$ ). Jedoch handelt es sich hier in noch höherem Grade wie in der Botanik um eine Zusammenstellung von chemischen und mineralogischen Einzelkenntnissen, in deren Besitz man durch die Ausiibung hüttemmännischer Prozesse gelangt war. Mit dem Eisen war man schon in der mykenischen Zeit bekannt. Obgleich Griechenland reich an Eisenerz war, benutzte man das Metall anfangs nur zu Schmuckgegenstäuden (z. B. zu Ringen). Nachdem man es härten gelernt hatte, diente es auch zur Herstellung von Waffen. Bei Homer ist meist von Bronze die Rede, doch wird das Eisen auch öfters erwähnt ${ }^{2}$.

1) IIepi hif(1) . Theophrasti Eresii Opera. Griechisch und lateinisch von $\mathbf{F}$. Wimmer.

2) Beloch, Griechische Geschichte. I, 1. S 212. 
Auch das Silbererz des Laurions wurde seit recht frühen Zeiten abgebaut. Die dortigen Bergwerke besaßen ausgedehnte Schächte und Stollen mit Holzzimmerung. Ihre reichen Erträgnisse ermöglichten es Athen, zur Abwehr der Perser, Rüstungen von einem Umfange zu betreiben, wie sie sich ein solch kleiner Staat sonst schwerlich hätte auferlegen können. Es handelte sich am Laurion um silberhaltige Bleierze, aus denen man zunächst, wie es noch heute geschieht, durch Rösten und darauffolgendes Niederschmelzen das rohe Blei gewann. Ein der Treibarbeit entsprechendes Verfahren lieferte dann, infolge der Oxydation des Bleies zu Glätte, das Silber $)$.

Theophrast hebt bei der Besprechung der Mineralien herror, daß sie sich besonders in der Farbe und im Gewichte unterscheiden. Zu den Mineralien rechnet er auch die Korallen, die im Meere entständen. Ferner erwähnt er ein Mineral, das wie der Bernstein Holz, indessen auch Erz und Eisen anziehe. Theophrast nennt es Lynkurion. Es ist nicht aufgeklärt, welchen Stoff er damit gemeint hat. Manchen Mineralien wurden auch heilkräftige Wirkungen zugeschrieben. So wurde der Rauch von Gagat, einer sehr bituminösen Braunkohle, eingeatmet, um epileptische Anfälle zu bekämpfen. Malachitpulver diente als Mittel gegen gewisse Erkrankungen der Augen usw. 2).

Als dasjenige Volk, das als erstes in den Mittelmeerländern Bergbau betrieben haben soll, werden seit alters die Phönizier bezeichnet. Sie waren es, die in dem an Erzen reichsten Lande des alten Europas, in Spanien, den Metallreichtum durch Betriebe größeren Umfangs aufschlossen. In der griechischen Literatur ist von Bergwerken zuerst bei Herodot die Rede. Bei Homer findet sich jedenfalls noch keine Andeutung ${ }^{3}$ ).

Genauere Kenntnis über den Bergbau im Altertum hat man erhalten, seitdem man den Betrieb verlassener alter Bergwerke in Spanien und am Laurion wieder aufnahm. Es geschah dies um

1) Bö ckh, Abhandlungen der Berliner Akademie. 1814/15. S. 104. Die von den Athenern aufgehäuften Schlacken enthalten noch $10 \%$ Blei und $0,004 \%$ Silber; sie werden neuerdings wieder auf diese beiden Metalle verarbeitet. (Siehe Dammer, Handbuch der chemischen Technologie. 18950. II. Band. S. 549.)

2) H. Fühner, Beiträge zur Geschichte der Edelsteinmedizin. Berichte der Deutschen pharmazeutischen Gesellschaft. 1901. S. 435 u. f. 1902. S. 86 u. f. Siebe auch Lenz, Mineralogie der alten Griechen und Römer. 1861.

3) Siehe das Reallexikon der indogermanischen Altertumskunde von O. Schrader unter, „Bergwerk". 
die Mitte des 19. Jahrhunderts. Am Laurion hat man zallireiche Tagebaue und Stollen, sowie an 2000 Schächte wieder aufgedeckt. Man fand auch die Geräte, welche die Alten beim Bergbau benutzten, z. B. Grubenlampen, eiserne Hämmer, Meißel, Brechstangen usw. Die Schächte gehen bis über hundert Meter in die Tiefe. Ein weiteres Eindringen wird die Ansammlung von Grubenwasser verhindert haben. Auch in Ton geformte Nachbildungen, die sich auf den Betrieb beziehen, bat man ausgegraben. Diese archäologischen Funde ergänzen die erhaltene Literatur in solchem Maße, daß wir uns von dem bis in das 7. vorchristliche Jahrhundert zurückreichenden Bergbau und Hüttenbetrieb der Athener ein zutreffendes und deutliches Bild machen können ${ }^{1}$ ).

\section{Einfluß und Dauer des aristotelischen Lehrgebäudes.}

Wir haben uns in diesem Abschnitt insbesondere ein Bild von den Leistungen des Aristoteles und desjenigen, der vor allem auf dem Gebiete der Naturwissenschaften in seine Fubtapfen trat, des Theophrast, gemacht. Beror wir uns dem alexandrinischen Zeitalter zuwenden, sei noch ein Wort über die Bedeutung des Aristoteles gesagt. Sein Einfluß hat sich auf 2000 Jabre erstreckt, und jedes Zeitalter hat, wenn auch in sehr verschiedener Weise, zu ihm, wie zu der griechischen Philosophie und Naturwissenschaft überhaupt, Stellung nehmen müssen. Die Schätzung, welche sie gefunden haben, ist eine recht wechselnde gewesen, je nach dem Standpunkt, den dic Beurteiler einnahmen. Während des größten Teiles des Mittelalters galt Aristoteles als unanfechitbare Autorität. Noch Dante erkennt ihn voll an und nennt ihn ,il maestro di color che sanno" 2). Der Ansturm, der sich zu Beginn der neucren Zeit gegen Aristoteles erhob, betraf weniger ihn selbst als seine mittelalterlichen Anhänger und Ausleger, die manchen eigenen Irrtum durch seine Autorität zu decken suchten.

Ein scharfer Gegensatz zu Aristoteles entstand erst mit dem immer konsequenter werdenden Bemühen, die Natur aus inechanischen Prinzipien zu erklïren, unter Beseitigung des Zweck-

1) C. v. Ernst, Über den Bergbau im Laurion. Berg- und Hüttenmännisches Jahrbuch der k. k. Bergakademien zu Leoben und Pribram. 1902. Die Ablandlung stützt sich auf das Gutachten Cordellas, der Jahrzehnte lang die Wiederaufnahme und den Betrieb der Bergwerke des Laurions leitete.

2 Der Meister derjenigen, die Wissenschaft treilien. 
begriffs, der in der aristotelischen Philosophie dasjenige ist, um das sich alles dreht. Aufs Schärfste verurteilt wurde demgemäß Aristoteles im Jahrhundert der Aufklärung, der Zeit der französischen Materialisten und des l'homme machine. Es gehörte damals zum guten Ton, von den nutzlosen Hirngespinsten des Aristoteles zu reden, ohne seine Schriften gelesen zu haben. Eine Ausnahme bildete damals Curier, der ihm für seine Leistungen auf zoologischem Gebiete geradezu Bewunderung zollte. Mit der Überwindung des reinen Materialismus durch das erneute Emporblühen der Philosophie stellte sich ein Rüickschlag ein. Es war vor allem Hegel1), der den großen Stagiriten wieder anerkannte: .Aristoteles ist," sagt $\mathrm{Hegel}$, „in die ganze Masse des realen Universums eingedrungen und hat ihre Zerstreuung dem Begriffe untergeordnet." Ziehen wir von diesem Ausspruch Hegels soviel ab, daß wir für die Tat das Wollen setzen, so ist die Bedeutung des Aristoteles richtig erfaßit. In ihm begegnet uns ein Mensch, der sich die Erklärung des Weltganzen und der Natur im einzelnen zum Ziele machte und diese Aufgabe in umfassender Weise zu lösen suchte. Ihn dabei an dem Maßstabe des modernen Naturforschers zu messen, wie es in England $\left.{ }^{2}\right)$ geschehen, ist nicht gerecht.

Durch Aristoteles wurde zum ersten Male ein Lehrgebäude errichtet, das die Ergebnisse der Beobachtung und der Erfahrung, zwar unter allzu starker Hervorhebung bloßer Denkbegriffe, indes unter Vermeidung religiöser, mystischer und nationaler Vorurteile, umfaßt. In diesem allgemein wissenschaftlichen Grundzug liegt die Bedeutung und die treibende Kraft seiner Lehre. Das war es, was Aristoteles die Wirkung für alle Zeiten und auf alle Völker sicherte.

Ganz abgesehen von dieser allgemeinen Bedeutung des A ristoteles wird man zugeben müssen, daß in seinen Werken eine Menge von Einzelkenntnissen zusammengestellt und gesichtet sind. Mit Recht nennen daher die Herausgeber ${ }^{3}$ ) der 'Tierkunde des Aristoteles dieses bedeutendste naturwissenschaftliche Werk des Altertums eine „Biologie der gesamten Tierwelt, gegründet auf eine große Menge ron Einzelkenntnissen, belebt durch den groß-

1) Auch in der neuesten Phase der Biologie begegnet uns eine Wiederbelebung aristotelischer Gedanken. Siehe an späterer Stelle (Bd. IV).

2: J. Tyndal1, Religion und Wissenschaft. Autorisierte Übersetzung. Hamburg 1874.

3. A ubert und Wimmer. 
artigen Gedanken, alles tierische Leben als einen Teil des Weltalls in allen seinen unendlichen Abwandlungen $\mathrm{zu}$ einem einheitlichen Gemälde zusammenzufassen, und erfüllt von der Weltanschauung, für die Gesetze des natürlichen Geschehens einen vernünftigen Endzweck vorauszusetzen."

Auch für die Entstehung der Geschichte der Wissenschaften als einer besonderen Disziplin ist Aristoteles grundlegend gewesen. Er war es, der z. B. Eudemos zur Abfassung seiner Geschichte der Mathematik anregte (s. S. 81) und andere seiner Schüler veranlaßte, dasselbe für die Heilkunde und die Physik zu unternehmen. 


\section{Das alexandrinische Zeitalter.}

Wir haben uns in den ersten Abschnitten diejenige Periode in ihren Grundzügen vergegenwärtigt, in der die Keime der Naturwissenschaften entstanden, eine Periode, die in der zusammenfassenden, systematisierenden Tätigkeit des Aristoteles ihren Höhepunkt erreichte. Frühzeitig traten uns geistige Regungen iu den ionischen Kolonien entgegen, wo die Berührung des Griechentums mit der älteren, orientalischen Kultur besonders innig war. Zu Hauptsitzen der Wissenschaft wurden darauf Athen und die blühenden Städte Unteritaliens, dort durch Aristoteles und seine Schule, hier durch die Pythagoreer.

Wie Alexander durch gewaltige Machtentfaltung die Welt, so batte Aristoteles das gesamte Wissen seiner Zeit zu umspannen gesucht. Zu einer dauernden Beherrschung der übrigen Völker waren die Griechen indessen nicht imstande. Mit dem T'ode des großen Eroberers zerfiel auch sein Reich. Anders gestalteten sich die Dinge auf dem Gebiete der Wissenschaft. Hier kann wohl von einer das Altertum überdauernden Herrschaft der Griechen die Rede sein. Sie wurden die Lehrer der alten Völker, während Rom die Rolle der Weltbeherrscherin zufiel.

Bei den Griechen hatte die persönliche Eigenart eine bisher unerreichte Bedêtung erlangt, doch war die Schaffenskraft dieses Volkes nicht mehr clie frühere, nachdem es seine politische Selbständigkeit verloren hatte. Zwar machte sich diese Schwächung mehr auf dem Gebiete der Kunst, vor allem auf dem der Dichtkunst, und weniger auf dem Gebiete der Wissenschaften bemerkbar. Doch zeigte sich hier eine andere, eigenartige Erscheinung. Während des nationalen und wirtschaftlichen Niederganges, der im Mutterlande selbst, schon im dritten Jahrhundert, eintrat, wurde nämlich das gelehrte Griechentum kosmopolitisch. Der Hauptsitz griechischer Weisheit wurde gleichzeitig von Athen nach Alexandrien verlegt, das durch seine günstige Lage, seinen Reichtum, sowie durch das Interesse, das die ägyptischen Herrscher 
bekundeten, besonders geeignet war, die weitere Pflege der Wissenschaften zu übernehmen.

Sehr eng gestalteten sich seit der Hellenisierung Vorderasiens auch die schon seit Jahrhunderten vorhandenen Beziehungen der griechischen zur babylonischen Wissenschaft. Die Griechen rechneten sich den Besuch der Tempelschulen Babylons geradezu als Ehre an. Besonders rege war dieser Verkehr unter der Herrschaft der Seleukiden und der Ptolemäer.

Die Herrschaft über Agypten war nach dem Tode Alexanders (323 v. Chr.) in die Hände des Ptolemäos Lagi ïbergegangen. Dieser Fürst, dessen Geschlecht den ägyptischen Thron inne hatte, bis im Jahre 30 v. Chr. das Land römische Provinz wurde, zog viele griechische Gelehrte, insbesondere aus Athen, an seinen Hof. Er wurde dadurch der Begründer der alexandrinischen Akademie, die berufen war, die Wissenschaft durch eine Reihe von Jahrhunderten zu fördern und sie für die nachfolgenden Zeiten zu erhalten. Die äußeren Einrichtungen für jene gelehrte Körperschaft fanden ihre Vollendung durch Ptolemäos Philadelphos. Letzterer errichtete ein prächtiges Gebäude, das den Gelehrten Wohnungen und Räume zur Ausübung ihrer Tätigkeit bot. Auch grïndete er die beriihmte alexandrinische Bibliothek. In einem in der Nähe des Königsschlosses gelegenen Garten wurden Tiere aus den tropischen Regionen Afrikas, darunter auch riesige Schlangen, unterhalten.

Der dritte Ptolemäos, welcher den Beinamen Euergetes führte (247-222 v. Chr.), hat der Bibliothek den Bücherschatz hinzugefiigt, den einst Aristoteles und Theophrast besaßen ${ }^{1}$ ). In späteren Zeiten umfaßte die große Bibliothek des alexandrinischen Museums etwa 400000 Rollen. Dazu kam noch eine zweite Büchersammlung im Serapeion. Bei der Belagerung Alexandriens durch Cäsar (47 v. Chr.) wurden die dort befindlichen Bïcherschätze, die Cäsar nach Rom zu schaffen beabsichtigte, teilweise zerstört. Später wurden sie durch Einverleibung der perganienischen Bibliothek um 200000 Rollen bereichert 2).

Fast sämtliche Gelehrte der alten Zeit, ron denen noch die Rede sein wird, gehörten entweder der alexandrinischen Aka-

1. Cantor, Vorlesungen über Geschichte der Mathematik. Bd. I. S. 223. Leipzig 1880.

2) Genaueres über die alexandrinische Bibliothek und die übrigen Bibliotheken des Altertums findet man in Paulys Reallexikon d. klass. Altertums. Bi. III (1899). S. 405 u. f. 
demie an, oder standen mit ihr in mehr oder weniger enger Fiihlung. Im allgemeinen ist das Wirken dieser Männer indes nicht mehr grundlegend, sondern auf die Erhaltung und die Fortentwicklung aller während des Altertums gewonnenen Ansätze gerichtet gewesen. Ihre Arbeiten betrafen dementsprechend nicht nur die Mathematik und die Naturwissenschaften, sondern das ganze Gebiet des damaligen Wissens, von der Philosophie und anderen Gebieten des reinen Denkens bis zı der Beschäftigung mit den konkretesten Dingen, gehörte zu ihrem Bereich. Häufig beschränkten sie sich auf bloßes Kommentieren der vorhandenen Schriften, wie es bezüglich der Zoologie und der Botanik der Fall war. Wo aber das deduktive Verfahren Anwendung finden konnte, wie auf dem Gebiete der reinen Mathematik, fand eine Fortentwicklung der übermittelten Keime statt. Auch einige Teilgebiete der Physil erfuhren eine namhafte Förderung. Vor allem gilt dies von der Physik der Gase. In der späteren alexandrinischen Zeit begegnen uns endlich die Anfänge der Alchemie und somit die Wurzeln der chemischen Wissenschaft.

Als Mathematiker sind unter den Mitgliedern der alexandrinischen Akademie besonders Euklid, Apollonios und Diophant zu nennen. Als Astronomen wirkten Hipparch und Ptolemäos, während die Phrsik durch Ktesibios und Heron gefördert wurde.

\section{Die Begründung eines Systems der Mathematik.}

Z u den frühesten Mitgliedern der alexandrinischen Schule gehört Euklid (Eukleides), dessen Name eng mit der Geschichte der Mathematik verbunden ist, einer Wissenschaft, die nicht etwa erst in der neueren Zeit, sondern auch schon im Altertum in hohem Grade das Emporblïhen der Naturwissenschaften bedingt hat. Die Lebensumstände Euklids sind wenig bekannt. Beziiglich seines Geburtsortes, sowie seines Studienganges schwanken die Angaben $\left.{ }^{1}\right)$. Sicher ist, daß Euklid zu Beginn der Ptolemäerzeit, also um 300 v. Chr., in Alexandrien gelebt hat. Dem Ptolemäos Lagi gegenüber, der das mathematische Studium erleichtert zu sehen wïnschte, soll er den bekannten Ausspruch: „Es gibt keinen Königsweg zur Mathematik!" getan haben.

Unter den auf uns gekommenen Werken Euklids nehmen die :Elemente" den ersten Platz ein. Sie wurden wegen ihrer

1) Euklid ist oft mit einem Zeitgenossen Platons, Euklid von Megara, verwechselt worden. 
Vollständigkeit und ihrer strengen Beweisfïhrung in solchem Grade als mustergiiltig anerkannt, daß sie bis in die neneste Zeit hinein sehr oft dem Anfangsunterricht zugrunde gelegt wurden.. In seine "Elemente" hat Euklid im wesentlichen das damals bekannte mathematische Wissen aufgenommen und es, wo dies noch nicht geschehen war, auf strenge Beweise gestiutzt. Das Werk umfaßt die Geometrie der Ebene und des Raumes und geht anch auf die Lehre von den Zahlen, als der Grundlage allen Messens, ein.

Eine genauere Inhaltsangabe der 13 Bücher, in welche die "Elemente" Euklids zerfallen, findet sich bei Cantor (Gesch. d. Mathematik Bd. I. S. 221-252) 1). Das 1. Buch handelt von den Linien, Dreiecken und Parallelogrammen. Den Abschluß bildet der pythagoreische Lehrsatz. Das 2. Buch gipfelt in der Aufgabe, für jede gegebene, geradlinige Figur ein gleich großes Quadrat $\mathrm{zu}$ zeichnen. Im folgenden Buch wird dann die Lehre vom Kreise behandelt. Das vierte handelt von den ein- und umgeschriebenen Vielecken. Die Konstruktion des Fünfecks macht die Anwendung des goldenen Schnitts erforderlich. Das 6. Buch ist dadurch besonders fesselnd, daß uns darin die erste Lösung einer Maximum-Aufgabe begegnet. Es wird nämlich gezeigt, daß $x(a-x)$ seinen größten Wert erhält, wenn $\mathrm{x}=\frac{\mathrm{a}}{2}$ wird.

Im 7., 8. und 9. Buche findet sich die Lehre von den Zahlen. Begonnen wird mit teilerfremden Zahlen und solchen, die ein gemeinsames Maß besitzen. Die Auffindung geschieht wie heute durch fortgesetzte Teilung des letztmaligen Divisors durch den erhaltenen Rest. Ferner werden die Proportionen und die Primzahlen untersucht und z. B. bewiesen, daß es unendlich viele Primzahlen gibt. Damn lehrt Euklid die Summierung der geometrischen Reihe und befaßt sich mit Untersuchungen iiber irrationale Zahlen. Das 12. Buch handelt von der Pyramide, dem Kegel, dem Zylinder und der Kugel. Euklid läßt den Zylinder durch Drehung eines Rechtecks um eine feststehende Seite und den Kegel, sowie die Kugel duch eine entsprechende Drehung eines Dreiecks bzw. eines Halbkreises entstehen. Er erwälnnt zwar, dafi sich die Inhalte von Kugeln wie die Kuben ihrer Durchmesser verhalten, den Inhalt der Kugel vermochte jedoch erst Arehimedes zu bestimmen. Auch findet sich bei Euklid schon die Bemerkung, dißß man durch den

1. Vgl. auch Cantor, Euklid unả sein Jainhuntert Leipzig 1867!. Eine neuere Ausgabe sämtlicher. Werke likklids rülrt von Heiberg und Menge her (Leipzig 1883-1896). 
schrägen Schnitt eines Zylinders oder eines Kegels eine wie ein Schild aussehende Kurve (die Ellipse) erhalte 1).

Das 13. Buch endlich handelt von den Polyedern, die sich aus regelmäßigen Vielecken bilden lassen. Es schließt mit der Bemerkung, daß es nur fünf regelmäßige Polyeder geben könne, nämlich das Tetraeder, das Oktaeder und das Ikosaeder, die von Dreiecken begrenzt sind, den Würfel und das von Fünfecken eingeschlosisene Dodekaeder ${ }^{2}$ ).

Die Klarheit und die strenge Form der Beweisführung, die Euklid geschaffen, sind den späteren griechischen Mathematikern eigen geblieben. Doch fehlt ihnen meist noch der Sinn für eine allgemeinere Fassung der Probleme. Soviel Fälle bezüglich der Lage von Linien in einer Aufgabe möglich sind, soviel Probleme waren auch für die griechische Mathematik vorhanden ${ }^{3}$ ). Daher sehen wir oft ihre hervorragendsten Schöpfer sämtliche, mitunter sehr zahlreichen Fälle eines Problems erledigen, ohne durch eine Erweiterung der Begriffe zu allgemeineren Sätzen zu gelangen. Daß der neueren Mathematik in dieser Hinsicht gelang, was der griechischen versagt blieb, liegt daran, daß erst in der viel später entstehenden Verknüpfung der Geometrie mit der Algebra ein Mittel zur allgemeineren Lösung mathematischer Aufgaben gewonnen wurde.

Die Bedeutung der Euklidischen "Elemente" wird durch folgende Worte treffend gekennzeichnet: „Was der Alexandriner Euklid um 300 vor Beginn unserer Zeitrechnung schrieb, ist auch heute in Form und Inhalt der eiserne Bestand der Schulmathematik. Nur wenig Zusätze sind dem Euklidischen System eingegliedert worden. Stolzer als ein Denkmal von Stein, schärfer und reiner in der Linienführung als irgend ein Kunstwerk, hat es sich der Jetztzeit erhalten. Was der junge Grieche durchdenken, lernen und üben mußte, das arbeitet mit gleicher Andacht heute der strebsame Schüler durch $\left.{ }^{4}\right) . "$

Euklid hatte das mathematische Wissen seiner Zeit in ein System gebracht5). Er hatte zwar viel Eigenes hinzugefügt. Der

1) Heiberg, Euklidstudien. S. 88.

2) Siehe die merkwürdige Anwendung, die später Kepler von den fünf regelmäßigen Körpern zur Begründung eiuer astronomischen Lehre machte.

3) H. Hankel, Die Entwicklung der Mathematik in den letzten Jahrhunderten.

4) Tropfke, Gesch. d. Elementarmath. Bd. II. S. 3.

5) Mehrere Handschriften enthalten noch ein 14. und 15. Buch. Sie werden 
weitere Ausbau und die Erschließung neuer Gebiete erfolgte jedoch durch Archimedes. In ihm begegnet uns der genialste Mathematiker des Altertums. Zwischen Aristoteles, dem Hauptrepräsentanten des vorigen Zeitabschnitts, und Archimedes liegt ein Zeitraum von etwa hundert Jahren. Dieser Zeitraum ist geschichtlich dadurch von Bedeutung, daß seit dem Eroberungszuge Alexanders der Orient mit den Völkern des Mittelmeeres in die engste Fühlung kam, während gleichzeitig ein neues Reich, dasjenige der Römer, zunächst das westliche Mittelmeerbecken, später aber die gesamte alte Kulturwelt zu umfassen strebte. Eine ähnliche Expansivkraft entfaltete auf dem Gebiete der Kunst und der Wissenschaft das Griechentum, das iiberall, im fernen Orient, in Ägypten, in Italien, ja selbst an den Küsten des westlichen Mittelmeeres seine Stützpunkte fand. Griechentum und Römerherrschaft sollten dann im Verlaufe der nächsten Jahrhunderte die Bindemittel abgeben, welche die so verschiedenartigen Völker Südeuropas, Vorderasiens und Nordafrikas bis zu einem gewissen Grade zu einer staatlichen, geistigen und Handelsgemeinschaft verband, einer Gemeinschaft, welche den Boden für die so überraschend schnelle, alles bezwingende Ausbreitung des Christentums bereiten half.

\section{Das Leben und die Bedeutung des Archimedes.}

Bevor wir uns mit dem weiteren Ausbau der reinen und der angewandten Mathematik durch Archimedes beschäftigen, wollen wir uns in aller Kürze die bisherige Entwicklung der Mathematik vergegenwärtigen und dann einen Blick auf die Lebensverhältnisse des großen Mathematikers werfen.

Überwog im 4. Jahrhundert v. Chr. noch der philosophierende, auf die Entwicklung von umfassenden Lehrsystemen gerichtete Grundzug des griechischen Geistes, so tritt uns in dem auf Alexander den Großen folgenden Zeitabschnitt mehr die Richtung auf das Empirische und Nützliche, in Verbindung mit einer raschen Entwicklung der Mathematik und einer Beschränkung der Spekulation auf ein bescheideneres Maß, entgegen. Neben den Forderungen des praktischen Lebens (Handel, Vermessungen usw.)

indessen nicht Euklid, sondern Hypsikles von Alexandria (um 150-120) zugeschrieben. Wahrscheinlich rührt aber nur das erste Buch von ihm her. Beide handeln von den regelmäßigen Körpern. Näheres siehe bei Cantor, Gesch. d. Math. I (1907). S. 358. 
waren es drei Probleme der reinen Wissenschaft, welche die Mathematik bei den Griechen schon vor Archimedes ${ }^{1}$ ) auf eine ungewöhnliche Höhe gebracht hatten. Es waren dies die Quadratur des Kreises, die Würfelverdoppelung und die Dreiteilung des Winkels. So hatten die vergeblichen Versuche, den Kreis zu quadrieren, Hippokrates zur Auffindung des Satzes geführt, der noch jetzt unter dem Namen der Lunulae (kleine Monde) Hippokratis bekannt ist. Hippokrates ${ }^{2}$ hatte mit Hilfe des erweiterten pythagoreischen Lehrsatzes bewiesen, daß sich zwei von krummen Linien begrenzte Flächen auf ein aus geraden Linien gebildetes Flächenstück zurïckführen lassen ${ }^{3}$ ). Die Würfelverdoppelung oder das Delische Problem forderte, die Seite (a) eines Wiirfels zu finden, der doppelt so groß ist wie ein gegebener Wiirfel. Anders ausgedriickt, wenn $\mathrm{x}^{3}=2 \mathrm{a}^{2}$ gegeben ist, soll $\mathrm{x}$ durch Konstruktion gefunden werden. Das Bemühen, dies Problem zu lösen, wurde durch die Auffindung einer Anzall newer Kurven (Cissoide, Konchoide, Kegelschnitte) belohnt. Auch das Problem der Dreiteilung des Winkels führte zur Auffindung neuer, bestimmte Eigenschaften aufweisender und auf Grund derselben konstruierbarer, krummer Linien. Eine Zusammenfassung der mathematischen Kenntnisse der Griechen erfolgte durch Euklid, von dem zu Beginn des vorigen Abschnitts die Rede gewesen ist.

Über Archimedes ist wenig Zuverlässiges bekannt. Er wurde um 287 v. Chr. in Syrakus geboren, gehört also in die für Sizilien so bewegte Zeit der großen Entscheidungskämpfe, welche Rom und Karthago um die Weltherrschaft fiihrten. Die Geschichtschreiber dieser Periode, Livius, Polybios und Plutarch, sind es auch, denen wir die meisten Nachrichten über Archimedes verdanken. Was diese und andere über ihn erzäblen, setzt sich indessen zum großen Teil aus Anekdoten zusammen, mit denen das Altertum das Leben seiner beriihmten Männer, insbesondere seiner hervorragenden Denker, auszuschmücken liebte. Archimedes war nach Plutar $\mathrm{ch}^{4}$ ) ein Verwandter Hierons II., des Tyrannen ron Syrakus. Sein Vater war Astronom und machte ihn sehr früh mit astronomischen Be-

1) Einen ausführlichen Beitrag über Archimedes bringt $\mathrm{Hultsch}$ in Paulys Realenzykl. d. klass. Altert. Bd. II (1896). S. 507.

2) Hippokrates stammte aus Chios. Er lebte in der zweiten Hälfte des 5. vorchristlichen Jahrhunderts in Athen.

3) Siehe S. 83.

4) Nach Cantor (Gesch. d. Mathem. Bd. I. S. 253) ist es wahrscheinlich, daB er von niederer Abkunft war. 
obachtungen vertraut. Archimedes lebte, ohne ein öffentliches Amt zu bekleiden, ganz der Wissenschaft. Eine Zeitlang hielt er sich in $\ddot{g} g y p t e n$ auf. Dort war nach dem Tode Alexanders des Großen in der alexandrinischen Akademie, zu der man Archimedeś rechnen kann, eine Stätte hellenischer Weisheit emporgebliiht, die berufen war, in den nachfolgenden Jahrhunderten die Fackel der Wissenschaft hochzuhalten. Die alexandrinische Schule soll deshalb auch noch in einem späteren Abschnitt Gegenstand der Betrachtung sein. In Alexandrien zählte Archimedes zu den Schülern des Mathematikers Konon. Diesem soll Archimedes auch nach seiner Rückkehr nach Syrakus, wo er den

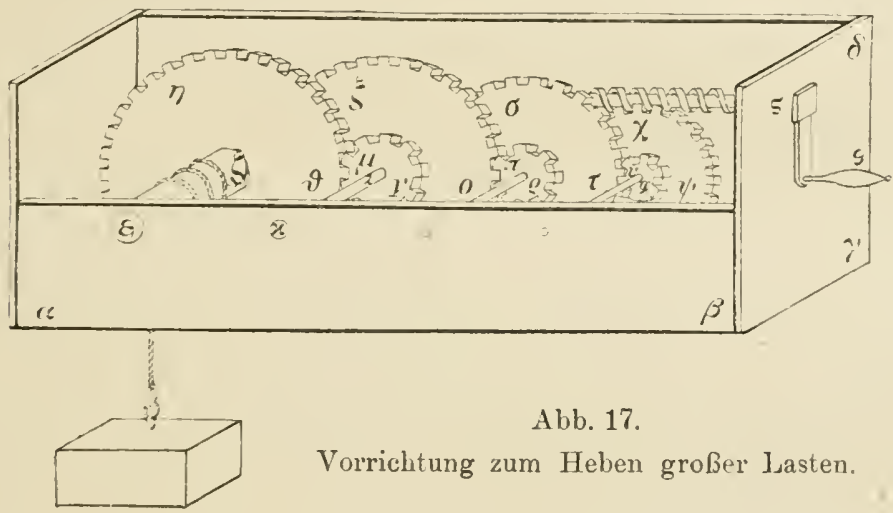

größten Teil seines Lebens zubrachte, Schriften zur Durchsicht geschickt haben, auch stand er mit ihm in regelmäfigem brieflichen Verkehr. Seine Beziehungen zu den syrakusanischen Machthabern veranlaßten ihn, sein außerordentliches Geschick in mechanischen Dingen auf die Vervollkommnung der Schleuderwerkzeuge und anderer Kriegsgeräte zu verwenden. Die Alten schrieben Archimedes die Erfindung zahlreicher Maschinen zu. Unter diesen werden der Flaschenzug und die Archimedische Schraube genannt. Letztere findet noch leute in Ägypten zum Bewässern der dem Nil benachbarten Ländereien Verwendung. Bei manchen Angaben, insbesondere denjenigen, die sich auf die ron Archimedes geleitete Verteidigung seiner Vaterstalt beziehen, ist es nicht leicht, Wahrheit und Irrtum voneinander zu scheiden. A rchimedes dürfte z. B. wohl selbst die Wirkung der Brennspiegel besser gekannt haben als die späteren Schriftsteller, die ilum das Unmögliche zuschrieben, er habe die Schiffe der Belagerer mit Brenn- 
spiegeln in Brand gesetzt. Es wird ferner erzählt, Hieron habe ihn aufgefordert, vermittelst einer geringen Kraft eine große Last zu bewegen. Dies habe Archimedes zur Erfindung des Flaschenzuges geführt, mit dem er dann vor den Augen des erstaunten Königs eine schwer beladene Triëre ohne Anstrengung an das Land zog. Vielleicht hat Archimedes auch zu diesem Zwecke die Schraube ohne Ende in Verbindung mit einer Zahnradübersetzung benutzt1), einen Apparat, den uns die vorstehende $\mathrm{Ab}$ bildung vorführt.

Große Bewunderung erregte ferner eine Art Planetarium, das Archimedes konstruierte. Im Mittelpunkt befand sich die Erde. Mond, Sonne und Planeten wurden durch einen, wahrscheinlich hydraulisch betriebenen, Mechanismus um den Zentralkörper herumgeführt. Cicero erwähnt diēses Kunstwerk, das als Vorbild für die im Mittelalter (z. B. an der Uhr des Straßburger Münsters) entstandenen Planetarien diente ${ }^{2}$ ).

Ausführlicher lauten die Berichte über die letzten Lebensjahre des Archimedes, da sie in die Zeit der Belagerung von Syrakus fallen. Hierbei hat Archimedes, den Nachrichten der Geschichtschreiber ${ }^{3}$ ) zufolge, eine wichtige Rolle gespielt und schließlich ein trauriges Ende gefunden. Auch bezüglich der über diese Begebenheit auf uns gelangten Nachrichten sind Wahrheit und Dichtung vermengt. Der zweite punische Krieg, der über das Schicksal Siziliens entscheiden sollte, hatte im Jahre 218 v. Chr. mit einem Siegeslauf Hannibals begonnen, wie ihn die Welt seit den Tagen Alexanders nicht gesehen. Bald jedoch wandte sich das Glück, und während Hannibal sich nur durch geschickte Züge in Italien zu 'ıalten wußte, brachten die Römer eine Stadt Siziliens nach der andern zu Fall, bis sich endlich die ganze Insel in ihren Händen befand. Am meisten Schwierigkeiten bereitete dem römischen Feldherrn Marcellus die Stadt Syrakus. Daß sie viele

1) W. Schmidt, Aus der antiken Mechanik (Jahrbuch für das klassische Altertum). Bd. 13 (1904). S. 329.

Die Abbildung (Abb. 17 S. 159) ist der Heronausgabe von Schmidt entnommen (Op. II, 1. Fig. 62 .

2) O. Spie B, Archimedes von Syrakus. Mitteilungen zur Geschichte der Mediz. u. Naturwiss. III. Bd. S. 230.

Siehe auch Cicero, De rep. I, 14 und die Abhandlung von F. Hultsch, Über den Himmelsglobus des Archimedes, in Schlömilchs Zeitschr. H. XXII. A. 106-108.

3) Polybios, Geschichte. Übersetzt von Haakh. Stuttgart 1868. 8. Buch. Kapitel 5-9. Plutarchos: Marcellus 14-19. 
Monate der Belagerung zu trotzen vermochte, wird ror allem den Verteidigungsmaßregeln des Archimedes zugeschrieben. Wurfmaschinen von ganz hervorragender Wirkung und Treffsicherheit, die nach Plutarch Steinblöcke ron Zentnerschwere anf große Entfernung schleuderten, schreckten die Stürmenden zurück. Dem Angriff der Flotte suchte man mit Feuerbränden zu begegnen. Spätere Berichterstatter haben daraus die erwähnte, völlig unglaubwiirdige Erzählung gemacht, Archimedes habe die Schiffe der Belagerer mit Hilfe ron Hohlspiegeln in Brand gesetzt.

Als endlich die Römer Syrakus einnahmen und die Soldaten, voll Wut über die erlittenen Mühsale und Verluste, ein furchtbares Gemetzel anstellten, zählte Archimedes zu den Opfern. Über sein Ende, das Marcellus sehr betrübt haben soll, lauten die Berichte verschieden. Am bekanntesten ist die Erzählung, Archimedes sei, in Nachdenken über ein mathematisches Problem versunken, ron einem römischen Soldaten niedergestoßen worden. Seine letzten Worte sollen .Noli turbare circulos meos" gelautet haben. Das Grab des Gelehrten wurde mit einem Stein geschmückt, in den die von dem Zylinder eingeschlossene Kugel eingemeißelt war. So soll Archimedes es selbst gewünscht haben, ein Zeichen, welchen Wert er auf seine Entdeckung legte, daß der Inhalt der Kungel zum Inhalt des umschließenden $/$ ylinders sich wie 2:3 rerhält. Dieses Grabmal, das Marcellus errichten ließ, wurde später von Cicero in einem sehr vernachlässigten $\mathrm{Zu}$ stande wieder aufgefunden und der Vergessenheit entrissen $\left.{ }^{1}\right)$.

Seine Bewunderung für den größten Mathematiker des Altertums hat Cicero in die Worte gekleidet, Archimedes habe mehr

1) Cicero erzählt diese Begebenheit (Tusculanae disputationes V. 23, mit folgenden Worten: „Als ich in Sizilien Quästor war, fand ich das Grab des Archimedes, das die Syrakusaner selbst nicht kannten. Mir waren nämlich einige kleine Verse in der Erinnerung, die man auf dem Grabmal eingemeißelt hatte. Die Verse weisen darauf hin, daß sich an dem oberen Teile des Monumentes eine Kugel mit einem Zylinder befindet. Nun bemerkte ich unter den vielen Gräbern, die sich vor dem nach Agrigent führenden Tor befinden, eine kleine Säule, die nur wenig aus dem Gestrüpp hervorragte und auf der sich das Bild einer Kugel mit einem Zylinder befand. Sogleich sagte ich zu den Syrakusanern, von denen mich die vornehmsten begleiteten, dies sei das gesuchte Grabmal. Wir ließen den Platz mit Hacken erschließen und säubern. Darauf erschien auf der Vorderseite des Sockels jene Inschrift. Die vornehmste und einst so gelehrte Stadt Großgriechenlands besäße also keine Kenntnis von dem Grabe ihres größten Denkers, wenn nicht ein Fremder es ihren Bürgern gezeigt hätte.* 
Genie besessen, als mit der menschlichen Natur verträglich zu sein scheine 1). An Vielseitigkeit und Genialität kann ihm unter den Neueren vielleicht nur Gauß an die Seite gestellt werden ${ }^{2}$.

Die Probleme, welche etwa 100 Jahre nach Aristoteles den Archimedes beschäftigten, betrafen insbesondere das Gebiet der Statik. Sie wurden nach echt naturwissenschaftlichem Verfahren, d. h. gestützt auf Versuche und mathematische Ableitung und deshalb mit dem besten Erfolge, behandelt. Seine Werke sind daher als das hervorragendste Erzeugnis des griechischen Geistes auf exaktem Gebiete zu bezeichnen. Es scheint kein Zufall zu sein, daß diese Werke nicht in dem vorwiegend der Kunst und der Philosophie zugewandten Mutterlande, sondern in Großgriechenland entstanden sind, wo der Handel blïhte und eine gewisse, die forschende Tätigkeit begünstigende Nüchternheit des Verstandes vorherrschte.

\section{Die griechische Mathematik erreicht in Archimedes und in Apollonios ihren Höhepunkt.}

Die wissenschaftliche Bedeutung des Archimedes ${ }^{3}$ ) ist in gleicher Weise auf den Gebieten der reinen Mathematik und der Mechanik zu suchen. Außer dem soeben erwähnten, wichtigen Satze iiber den Inhalt der Kugel und des sie umschließenden Zylinders, deren Oberflächenverhältnis er gleichfalls auffand, lieferte Archimedes eine Arbeit über die Kreismessung, die eine Berechnung der Kahl $\pi$ enthält. Diese Arbeit ist, sowohl nach ihrer Bedeutung für die Entwicklung der Geometrie, als auch für die Geschichte der Rechenkunst, von Wichtigkeit. Sein Verfahren ist das in der elementaren Geometrie noch jetzt gelehrte. Ausgehend von dem Satze, daß der Umfang des Kreises kleiner als der Umfang des unschriebenen und größer als derjenige des eingeschriebenen regel-

1) De republica I, 22 .

2) So urteilt auch H. Diels in dem A rchimedes gewidmeten Abschnitt seines Buches ...Antike Technik".

3) A r chimedes' von Syrakus vorhandene Werke. Aus dem Griechischen übersetzt und mit erläuternden und kritischen Anmerkungen begleitet von Ernst Nizze. Stralsund 1824. Eine neuere Archimedesausgabe rührt von Heiberg her. Sie erschien im Jahre 1880: J. L. Heiberg, Archimedis opera omnia cum comentariis Eutocii. Leipzig, bei B. G. Teubner. Eine neue erweiterte Ausgabe erfolgte 1910.

Eutokios, der einen Teil der Archimedischen Schriften kommentierte, lebte zur Zeit Justinians (um $550 \mathrm{n}$. Chr.). 
mäßigen Vielecks ist, berechnet Archimedes als Grenzwerte für $\pi$ die Zahlen 3,141 und 3,142. Es sind dies die Werte, die sich für den Umfang des ein- und umgeschriebenen regelmäßigen 96-Ecks ergeben. Das erwähnte Verfahren wird als Exhaustionsverfahren bezeichnet, könnte aber auch die Integrationsmethode der alten Mathematik genannt werden. Aus dem Bestreben, bei derartigen Aufgaben die Grenzwerte beliebig nahe zu rücken, ohne dazu umständliche, zeitraubende Berechnungen nötig zu haben, ist im 17. Jahrhundert die Infinitesimalrechnung erwachsen.

Auch mit isoperimetrischen Problemen, d. h. Aufgaben, bei denen es sich um die Bestimmung größter oder kleinster Werte handelt, beschäftigte sich schon das Altertum. So war schon vor Aristoteles bekannt, daß der Kreis unter allen Flächen gleichen Umfangs den größten Flächeninhalt und die Kugel unter allen Körpern von gleicher Oberfläche den größten Rauminhalt besitzt ').

Das Exhaustionsverfahren wurde von den Alten nicht nur auf krummlinige Figuren, sondern auch auf Flächen und auf Rammgebilde angewandt. Das Verfahren lief stets darauf hinaus, den Unterschied zwischen der zu messenden Linie, Fläche oder Raumgröße und den diesen Formen sich nähernden, leicht zu berechnenden Hilfsgebilden immer kleiner zu machen. Man erhielt eine noch größere Sicherheit, wenn man zwei Hilfsgebilde, z. B. das ein- und umgeschriebene Polygon beim Kreise, wählte und auf diese Weise zwei Grenzwerte für die zn messende Größe ermittelte. Was den Inhalt des Kreises anbetrifft, so bewies Archimedes, daß er gleich demjenigen eines rechtwinkeligen Dreiecks ist, dessen eine Kathete gleich dem Halbmesser und dessen andere gleich dem Unfang des Kreises ist.

Die Behandlung ebener Figuren wurde von Archimedes jedoch iiber das Gebiet der elementaren Mathematik hinausgeführt, indem er den Inhalt der Parabel und der Ellipse berechnen lehrte und die Eigenschaften von Kurven höherer Ordnung, wie der Spiralen, ermittelte. Mit Hilfe der soeben besprochenen Exhaustionsmethode wies Archimedes z. B. nach, daß das Parabelsegnent ${ }_{4,3}^{4}$ eines Dreiecks von gleicher Grundlinie und Höhe beträgt. Für die Ellipse zeigte er, daß sich ihre Flaiche zur Fläche eines mit der großen Achse als Durchmesser geschlagenen Kreises wie die kleine Achse zur großen Achse verhält usw. Die merkwiirdigste

1) Nach Simplicius. Siche auch die Abhandlung von W. Schmidt über Isoperimetrie im Altertum (Bibl. math. 1901. S. 5). 
Schrift über die Kurven ist sein Buch von den Schneckenlinien. Die nach ihm als archimedische Spirale bezeichnete Schneckenlinie definiert er mit folgenden Worten: „Wenn eine gerade Linie in einer Ebene um einen ihrer Endpunkte, der unbeweglich bleibt, nit gleichförmiger Geschwindigkeit sich dreht, und wenn gleichzeitig in der bewegten Linie ein Punkt rom unbewegten Endpunkte aus sich gleichförmig bewegt, so beschreibt dieser Punkt eine Schneckenlinie." Eine derartige, zuerst bei Hippias anzutreffende Verbindung von zwei bestimmt gekennzeichneten Bewegungen stellte eine nicht geringe Bereicherung der Wissenschaft dar $^{1}{ }^{1}$.

Auch gelang es Archimedes, durch ein ähnliches Verfahren, wie er es beim Kreise und bei der Parabel anwandte, die Quadratur der Schneckenlinie zu finden. Sogar das Tangentenproblem vermochte er für diese Kurve zu lösen, indem er zeigte, wie die Berührungslinie an irgend einen ihrer Punkte gezogen werden kann.

Daß Archimedes sich schon einer Methode bediente, die in ihrem Wesen unserem heutigen Integrationsverfahren entsprach, läßt sich noch deutlicher, als aus den hier besprochenen Werken, aus der vor kurzem durch Heiberg entdeckten Methodenlehre (Ephodion) ersehen ${ }^{2}$. Es hat den Anschein, als ob Archimedes die im Ephodion enthaltene Infinitesimalmethode gewissermaßen nur zu seinem Privatgebrauch entwickelt hätte, weil die Anwendung der Unendlichkeitsbegriffe bei den Mathematikern, welche die Einwände der Philosophen fürchteten, verpönt war. Als vollgültig wurde für die lier in Betracht kommenden Problene nur das Exhaustionsverfahren angesehen. In dieses kleidete Archimedes, offenbar der herrschenden Schule zuliebe, Sätze, die er zunächst ausgehend von der Mechanik oder mit Hilfe seiner Infinitesimalmethode gefunden hatte. Als Beispiel dafür verdient der Satz vom Zylinder-

1) Hippias von Elis lebte um 420 v. Chr. Seine unter dem Namen der Quadratrix bekannte Linie ließ Hippias durch die Verbindung einer drehenden mit einer fortschreitenden Bewegung entstehen. Mit Hilfe dieser Linie hoffte man zur Quadratur des Kreises zu gelangen. Näheres bei Cantor, Gesch. d. Math. I (1907). S. 197.

2) Heiberg entdeckte sie in einem in Konstantinopel aufbewahrten Palimpsest und veröffentlichte sie in der Zeitschrift „Hermes". Berlin 1907. S. 235 u. f.

In der neuen Archimedesausgabe von Heiberg (1913) findet sich die "Methodenlehre" mit lateinischer Übersetzung (Bd. II. S. 427). Eine deutsche Übersetzung veröffentlichte Heiberg mit Zeuthen in der Bibl. mathem. III. Folge. VII (1907). S. 322 u. f. 
huf genannt zu werden 1). Für diesen gibt Archimedes einen mechanischen Beweis, einen Beweis nach dem Exhaustionsverfahren und einen solchen mit Hilfe seiner jetzt bekannt gewordenen Infinitesimalmethode. Letztere bestand darin, daß er die Flächen auf Gerade und die Körper auf Flächen zurückführte, wie es unter den neueren Mathematikern zuerst Cavalieri getan. Erläutert wird die neue Methode unter anderem an dem Satz vom Flächeninhalt des Parabelsegments und an melnreren Sïtzen über Volumund Schwerpunktsbestimmungen.

Ein Buch des Archimedes über das Siebeneck im Kreise und ein anderes über die Berührung von Kreisen sind leider verlorengegangen. Von herrorragender Wichtigkeit sind die erhalten gebliebenen archimedischen Schriften iiber die Kugel und den Zylinder. Es wird darin bewiesen, daß die Kugeloberfläche dem Vierfachen ihres größten Kreises gleich ist $\left(O=4 x^{2} \pi\right)$. Ferner wird die Oberfläche der Kalotte oder des Kugelabschnittes bereclinet. Und endlich wird gezeigt, daß ein Zylinder, der zur Grundfliiche einen größten Kreis der Kugel, zur Höhe aber den Durchmesser der Kugel hat, mit anderen Worten, daß ein der Kugel umschriebener Zylinder seinem Inhalt nach sich zur Kugel selbst wie 3:2 verhält. Die Oberfläche dieses Zylinders fand Archimedes gleich dem Anderthalbfachen der Kugeloberfläche. Die betreffende Figur hat nicht nur auf seinem Grabstein Platz gefunden. Sie erhielt sich auch auf Münzen der Stadt Syrakus.

Seine Untersuchungen über die Kugel führten Archimedes endlich noch auf die Rotationskörper, welche durch die Umdrehung von Kegelschnitten entstehen, seine Konoide und Splä̈roide. Auch in diesen Fällen bediente er sich der Exhaustionsmethode, indem er die zu kubierenden Körper in Scheiben von gleicher Dicke zerlegte und die ein- und umgeschriebenen Zylinder summierte. Die erhaltenen Summen stellen Grenzwerte dar, die sich dem zu ermittelnden Rauminhalt um so mehr nähern, je geringer der Abstand der Schnitte ist.

Über die Kegelschnitte hatte schon Euklid geschrieben. Doch hat sich um die Begründung dieses Gegenstandes keiner unter den alexandrinischen Mathematikern ein so großes Verdienst erworben wie Apollonios von Pergä. Er war ein Zeitgenosse von Archimedes und Eratosthenes. Seine Werke entstanden in der Zeit von 240-200 v. Chr. Erhalten ist nur das bedeu- 
tendste, als xur'xú (Kegelschnitte) bezeichnete Werk. In diesem zeigte Apollonios, daß die als Ellipse, Parabel und Hyperbel bezeichneten Kurven auf der Oberfläche eines Kegels entstehen, wenn durch letzteren Ebenen gelegt werden. Auch das schwierige Gebiet der Asymptoten, die sich den Asten der Hyperbel nähern, ohne sie zu schneiden, hat Apollonios erschlossen. Seine acht Bücher über die Kegelschnitte ${ }^{1}$ ) erregten nicht nur bei den Zeitgenossen, sondern auch bei den späteren Geschlechtern die größte Bewunderung, wenn auch von einigen Verkleinerern dem Apollonios mit Unrecht vorgeworfen wurde, daß er sich zu sehr auf die von Euklid und Archimedes geschaffenen, indes verlorengegangenen Vorarbeiten iiber diesen Gegenstand gestützt habe 2). Besteht doch eine grundlegende Neuerung des Apollonios schon darin, daß er sich nicht wie seine Vorgänger auf den geraden Kegel beschränkte, sondern nachwies, daß alle Schnitte auch an dem schiefen Kegel hervorgebracht werden können. Auch war er der erste, welcher an den Kegelschnitten die Mehrzahl derjenigen Eigenschaften nachwies, die man heute aus den Gleichungen dieser Kurven ableitet. Der Inhalt seines Werkes ist der Hauptsache nach folgender. Zunächst wird der Kegel als die Oberfläche definiert, welche durch eine Linie entsteht, wenn man sie in einer Kreisperipherie herumführt, während diese Linie zugleich durch einen festen, außerhalb der Ebene des Kreises liegenden Punkt geht. Jeder Schnitt, welcher durch den festen Punkt geht, erzeugt ein Dreieck. Liegt in der Schnittebene auch die Verbindungsgrade zwischen dem Mittelpunkt des Kreises und dem festen Punkt, welcher die Spitze des Kegels bildet, so nennt man das entstandene Dreieck, weil es jene Verbindungsgrade oder die Achse enthält, ein Achsendreieck. Neue Schnittebenen liefern dann, je nach ihrer Richtung, die verschiedenen Kegelschnittkurven auf der Oberfläche des Kegels. Es werden sodann Betrachtungen über konjungierte

1) Des Apollonios Schrift über die Kegelschnitte wurde 1861 in deutscher Bearbeitung von $\mathrm{H}$. Balsam herausgegeben. Die in der Ursprache erhaltenen Schriften gab Heiberg heraus (Leipzig 1891-1893). Das Werk üljer die Kegelschnitte umfaßt 8 Bücher. Die ersten vier sind in der Ursprache, Buch 5-7 in arabischer Übersetzung erhalten. Das achte dagegen ist verlorengegangen. Eine gute Bearbeitung rührt von dem englischen Astronomen Halley her (1710), der das Werk unter Beifügung des griechischen Textes, soweit er vorhanden war, ins Lateinische übersetzte und verlorengegangene Teile zu rekonstruieren suchte.

2) Die ersten Ansätze zur Erforschung der Kegelschnitte finden sich schon bei dem im 4. Jahrhundert v. Chr. Iebenden Menächmos. 
Durchmesser, über die Tangente an irgendeinen Punkt des Kegelschnittes, sowie über die Asymptoten der Hyperbel angestellt. Eingehend wird auch von denjenigen Punkten gehandelt, die wir heute als die Brennpunkte der Kegelschnitte bezeichnen. Bewiesen wird der wichtige Satz iiber die Gleichheit der Winkel, welche die Normallinie mit den beiden Brennstrahlen des Berührungspunktes bildet, sowie auch der Satz von der Konstanz der Summe, bzw. der Differenz der Brennstrahlen. Die betreffenden Abschnitte des Werkes enthalten also fast sämtliche grundlegenden Sätze der Lehre von den Kegelschnitten.

Auf dem Satz, daß die Summe der Brennstrahlen gleich der großen Achse ist $\left(r+r^{\prime}=2 a\right)$, beruht bekanntlich die gebräuchliche Fadenkonstruktion der Ellipse. Dies Verfahren findet sich jedoch noch nicht bei Apollonios, sondern es kam erst weit später auf. Hinsichtlich der Hyperbel sei bemerkt, daß man vor Apollonios die Zusammensetzung der Kurve aus zwei Asten nicht kannte, sondern die Untersuchungen immer nur an einem Ast anstellte. Apollonios selbst führte den zweiten Ast noch unter einem besonderen Namen auf. Die Quadratur der Hyperbel gelang den alten Mathematikern nicht. Sie erfolgte erst, als im 17. Jahrhundert neuere, die höhere Mathematik ausmachende Methoden gefunden waren.

Den Höhepunkt des Werkes bildet das Buch, das von größten und kleinsten Werten handelt, die in Verbindung mit den Kegelschnitten auftreten 1). Insbesondere sind es Untersuchungen über die längsten und kürzesten Linien, die von irgendeinem Punkte der Ebene an einen Kegelschnitt gezogen werden können.

Infinitesimalbetrachtungen, die sich schon bei Euklid und Archimedes finden, vermochten die Alten noch nicht zu einer allgemeinen Methode zu erweitern. Die alte Mathematik hat vielmehr in den Werken des Archimedes und des Apollonios das erreicht, was ohne den Besitz der Infinitesimalmethode und des analytischen Kalkuls, die erst im 16. und 17. Jahrhundert zu allgemeinerer Anwendung gelangten, zu erreichen möglich war ${ }^{2}$ ). Mit der Lehre von den Kegelschnitten wurde für die spätere Entwicklung der Astronomie und der Mechanik eine wichtige Grundlage

1 Has 5. Buch.

2) Daß Archimedes bei Volum- und Flächenbestinnungen sich schom einer den Verfahren Cavalieris entsprechenden Infinitesimalmethode bediente, und zwar neben den üblichen Beweisverfahren, hat die Entdeckung des "Ephodion" bewiesen (s. S. 164). 
geschaffen. Das gleiche gilt auch von der Trigonometrie, die aus den Bedürfnissen der Astronomie entsprang und von den späteren Alexandrinern begründet wurde. Wie wir später sehen werden, konnte Aristarch, als er den Sonnenabstand aus gegebenen Stiicken eines Dreiecks ohne die Hilfsmittel der Trigonometrie berechnete, die gesuchte Größe nur auf umständlichem Wege durch Näherungswerte bestimmen.

Anhangsweise séi hier noch eine Schrift des Archimedes erwähnt, die früher viel gelesen wurde und auch heute noch Beachtung verdient. Es ist dies seine "Sandesrechnung“. Zum Verständnis der in dieser Schrift gelösten Aufgabe müssen wir vorausschicken, daß die Griechen etwas unserem heutigen Ziffernsystem Entsprechendes noch nicht besaßen. Die Zahlen wurden durch Buchstaben bezeichnet. Größere Zahlen zu schreiben, war daher sehr unbequem, weil man das Prinzip des Stellenwertes, das erst durch Vermittlung der Araber aus dem Orient nach Europa gelangte, noch nicht kannte und auch noch kein Zeichen für die Null besal\}. Es ist erstaunlich, wie weit es die Alten trotzdem in der Arithmetik gebracht haben. Wagte sich Archimedes doch sogar an die geometrische Reihe $1,1 / 4,1 / 16,1 / 64 \ldots$, deren Summe er gleich $4 / 3$ fand. Sie diente ihm bei der Berechnung der Fläche des Parabelabschnittes. Auch vermochte er es schon, schwierige Quadratwurzeln zu berechnen ${ }^{1}$ ).

In der Sandesrechnung ${ }^{2}$ ) wird gezeigt, daß sich jede, noch so große Menge durch eine Zahl ausdrücken läßt. Indem Archimedes die Abmessungen der aristarchischen Fixsternsphäre zugrunde legt, berechnet er, wieviel Sandkörner von bestimmter Größe darin Platz finden können. Die meisten Sternkundigen verstanden zur Zeit des Archimedes unter dem Ausdruck Welt eine Kugel, deren Zentrum der Mittelpunkt der Erde und deren Radius eine gerade Linie zwischen den Mittelpunkten von Erde und Sonne ist. In seiner Schrift „Wider die Sternkundigen“, so erzählt uns Archimedes, suchte nun Aristarch von Samos zu beweisen, daß die Welt ein Vielfaches der oben bezeichneten Kugel ist. Er sei zu der Annahme gelangt, die Fixsterne samt der Sonne seien unbeweglich, die Erde aber werde in einer Kreislinie um die Sonne, die inmitten der Erdbahn stehe, herumgeführt. „Der Durchmesser der Fixsternkugel möge sich“, sagt Archimedes, „zu dem-

1) Tropfke, Geschichte der Elementarmathematik. I. S. 253.

2) Eine gekürzte Wiedergabe enthält Dannemann, Aus der Werkstatt großer Forscher. Verlag von Wilhelm Engelmann. Leipzig 1908. S. 10. 
jenigen der Welt (in dem zuerst erwähnten Sinne) verhalten, wie der letztere zum Durchmesser der Erde." Er behauptet dann, wenn es auch eine Sandkugel gäbe von der Größe dieser aristarchischen Fixsternsphäre, so lasse sich doch eine Zahl angeben, deren Größe selbst die Menge der Körner in der gedachten Kugel übertreffe. Nach einigen Voraussetzungen iiber den Umfang der Erde, das Größenverhältnis von Erde und Somne, aus dem, nach Bestimmung des scheinbaren Sonnendurchmessers, die Entfernung der Somme zu 10000 Erdhalbmessern ermittelt wird, berechnet Archimedes die Zahl der Sandkörner, die innerhalb der Fixsternsphäre Platz finden, auf $10^{63}$ oder 1000 Dezillionen.

\section{Archimedes entwickelt die Prinzipien der Mechanik.}

An hervorragenden Mathematikern besaß das Altertum keinen Mangel. Wir brauchen neben Archimedes nur Euklid und Apollonios zu nennen. Es gab aber niemanden bis in die nevere Periode der Geschichte der Wissenschaften, der ähnliche Leistungen auf dem Gebiete der Mechanik vollbracht hätte wie Archimedes. Letzterer muß als der Hauptbegründer dieser Wissenschaft bezeichnet werden. Es sind die wichtigsten Sätze vom Hebel, vom Schwerpunkt und aus der Hydrostatik, die uns bei Archimedes, zum ersten Male klar ausgedrïckt, begegnen. Die Gesetze vom gleicharmigen Hebel spricht Archimedes in folgenden Worten ans:

a) Gleich schwere Größen, in ungleichen Entfernungen wirkend, sind nicht im Gleichgewicht, sondern die in der größeren Entfernung wirkende sinkt.

b) Ungleich schwere Größen sind, bei gleichen Entfernungen, nicht im Gleichgewicht, sondern die schwerere wird sinken.

c) Wenn ungleich schwere Größen in ungleichen Entfernungen im Gleichgewicht sind, so befindet sich die schwerere in der kleineren Entfernung.

d) Ungleiche Gewichte stehen im Gleichgewicht, sobald sie ihren Entfernungen umgekehrt proportional sind.

An den letzten, das Hebelgesetz zum Ausdruck bringenden Satz knüpft sich das Archimedes zugeschriebene Wort: „Gib mir einen Ort, wo ich mich hinstellen kann, und ich will die Erde bewegen 11 ."

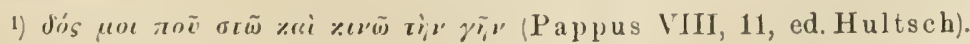


Die Schwerpunktsbestimmungen dehnt Archimedes im zweiten Teile der Abhandlung vom Gleicligewicht ${ }^{1}$ ) sogar auf das Parabelsegment aus, nachdem er zuvor die Quadratur der Parabel gelehrt hat. In den Büchern, die von den schwimmenden Körpern handeln, leitet er aus den Grundeigenschaften der Flüssigkeiten, nämlich der leichten Verschiebbarkeit ihrer Teilchen und der Druckfortpflanzung, eine Reihe von Sätzen $a b$, von denen die wichtigsten folgendermaßen lauten:

a) Die Oberfläche einer jeden zusammenhängenden Flüssigkeit im Zustande der Ruhe ist sphärisch, und ihr Mittelpunkt fällt mit dem Mittelpunkt der Erde zusammen.

b) Feste Körper, die bei gleichem Rauminhalt einerlei Gewicht mit einer Flïssigkeit haben. sinken, in diese eingetaucht, so weit ein, daß nichts von ihnen über die Oberfäche der Flüssigkeit hervorragt.

c) Jeder feste Körper, der leichter ist als eine Flüssigkeit und in diese eingetancht wird, sinkt so tief, daß die Masse der Flüssigkeit, die dem eingesunkenen Teil an Volumen gleich ist, ebensoviel wiegt wie der ganze Körper.

d) Wenn Körper, die leichter sind als eine Fliissigkeit, in diese eingetaucht werden, so erheben sie sich wieder mit einer Kraft, die gleich ist dem Gewichte des dem Körper gleichen Volumens Flüssigkeit, vermindert um das Gewicht des Körpers selbst.

e) Feste Körper, die bei gleichem Rauminhalt schwerer als eine Flüssigkeit sind und in diese eingetancht werden, sinken, solange sie noch tiefer kommen können, und werden in der Flüssigkeit um so viel leichter, wie das Gewicht einer Masse Flüssigkeit von der Größe des eingetauchten Körpers beträgt.

Das zuletzt erwähnte Gesetz, das archimedische Prinzip, ist für die Mechanik der Flïssigkeiten von derselben fundamentalen Bedentung wie das Hebelgesetz für die Mechanik der festen Körper ${ }^{2}$ ). Auf das nach ihm benannte hydrostatische Prinzip soll Archimedes nach der Erzählung des Vitruv ${ }^{3}$ ) durch einen besonderen Anlaß gekommen sein. Danach hatte Hieron aus einer abgewogenen Menge Gold einen Kranz anfertigen lassen. Als man ihm nun hinterbrachte, daß ein Teil des Goldes unterschlagen und durch

1. Archimedes' Werke. Ausgabe von Nizze. S. $26 \mathrm{ff}$.

2. Die erwähnten hydrostatischen Grundgesetze finden sich in Archimedes' erstem Buch von den schwimmenden Körpern. Siehe die Archimedesausgabe von $\mathrm{N}$ izze. S. 225-228.

3) Vitruvius, de architectura IX. Übersetzt von V. Reber. Stuttgart 1865 . 
Silber ersetzt worden sei, wurde Archimedes zu Rate gezogen, um den Betrug nachzuweisen. "Dieser, eifrig damit beschäftigt," fährt Vitruv fort, „kam zufällig in ein Bad. Als er dort in die gefüllte Wanne stieg, bemerkte er, daß das Wasser in gleichem Maße austrat, in welchem er seinen Körper in die Wanne niederließ. Sobald er auf den Grund dieser Erscheinung gekommen war, verweilte er nicht länger, sondern sprang, von Freude getrieben, aus dem Bad und rief, nackend seinem Hause zulaufend, mit lauter Stimme: Eügr

Die Lösung des von Hieron gestellten Problems, der sogenannten Kronenrechnung, erzählt Vitruv mit folgenden Worten: „Dann soll Archimedes, von jener Entdeckung ausgehend, zwei Klumpen von demselben Gewicht, das der Kranz besaß, den einen von Gold, den andern von Silber, hergestellt haben. Hierauf füllte er ein weites Gefäß bis zum obersten Rande mit Wasser und senkte dann den Silberklumpen hinein, worauf das Wasser in gleichem Maße ausfloß, wie der Klumpen in das Gefäß getaucht wurde. Nachdem er den Klumpen wieder herausgenommen hatte, füllte er das Wasser um so viel wieder auf, als es weniger geworden war, und maß dabei die zugegebene Menge. Daraus ergab sich, welches Gewicht Silber einem bestimmten Rauminlalt Wasser entspricht. Nachdem er dies erforscht hatte, senkte er den Goldklumpen in das volle Gefäß und füllte das verdrüngte Wasser vermittelst eines Hohlmaßes nach. Es ergab sich, daß diesmal von dem Wasser um soviel weniger abgeflossen war, wie der Goldklumpen einen minder großen Rauminhalt besaß als ein Silberklumpen von gleichem Gewicht. Nachdem er hierauf das Gefäß abermals gefüllt und den Kranz selbst in das Wasser gesenkt hatte, fand er, daß mehr Wasser bei dem Kranze als bei dem gleichschweren Goldklumpen abfloß, und entzifferte aus dem, was mehr bei dem Kranze abfloß, die Beimischung an Silber und machte so die Unterschlagung offenbar."

In weiteren Verlaufe seiner Abhandlung über das Schwimmen untersucht Archimedes die Stabilität gewisser schwimmender Körper, wie des Kugelabschnitts und des parabolischen Konoids. wobei es ilhm offenbar mehr auf eine Betätigung seines mathematischen Geschicks als auf eine Bereicherung der Mechanik ankam.

Auch mit Schwerpunktsbestimmungen befaßte sich A rchimedes. So war ihm bekannt, daß der Punkt, in welchem sich zwei Seitenhalbierende treffen, der Schwerpunkt des Dreiecks ist. Überhaupt erweisen sich die mathematischen Hilfsmittel des Archimedes den ihn beschäftigenden mechanischen Problemen gegenüber als der 
iiberlegene Teil, während in der neueren Periode mitunter das umgekehrte Verhältnis obwaltete, so daß der von Leibniz herrührende Ausspruch: "Wer in die Werke des Archimedes eindringt, wird die Entdeckungen der Neueren weniger bewundern" wohl gerechtfertigt erscheint.

\section{Fortschritte der Optik und Akustik.}

Durch die bedeutenden Fortschritte der Mathematik wurden vor allem die Physik, die Astronomie und die mathematische Geographie gefördert. Die ältesten Ansichten iiber den Schall und

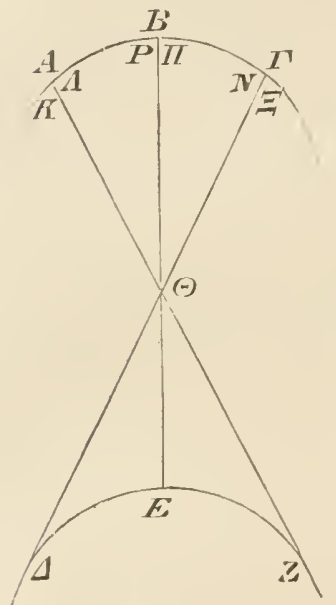

Abb. 18.

Das Verhalten des Hohlspiegels nach Euklid ${ }^{4}$ ). iiber das Licht haben wir bei den Pythagoreern und bei Aristoteles kennen gelernt. Den Alexandrinern, die ja besonders zur Zusammenfassung des Wissens neigten, verdanken wir die erste zusammenfassende Bearbeitung der Optik. Diese Bearbeitung wird dem Euklid zugeschrieben. Sie erfolgte in zwei Buichern, der "Optik" und der "Katoptrik", und ist wohl der erste Versuch, die Geometrie, unter Benutzung des Satzes ron der geradlinigen Fortpflanzung des Lichtes und des Reflexionsgesetzes, auf die Erklärung der scheinbaren Größe, der Gestalt, der Spiegelung und anderer optischen Erscheinungen anzuwenden ${ }^{1}$. Von Interesse ist der Satz ${ }^{2}$, daß , von Hohlspiegeln, welche gegen die Sonne gehalten werden, Feuer erzeugt wird“. Doch wird irrtümlich behauptet, die Entzündung erfolge im Krümmungsmittelpunkt.

Euklid sucht dies geometrisch durch obige Figur ${ }^{3}$ ) (Abb. 18) darzutun und bemerkt zu seiner Konstruktion: .,Alle Strahlen, die ron der Sonne $(\angle E Z)$ aus durch das Zentrum $\Theta$ des Spiegels $(A B \Gamma)$

1) Euklids Optik und Katoptrik wurde 1557 zu Paris griechisch und lateinisch herausgegeben. Eine neuere Ausgabe von Gregory erschien im Jahre 1703. Die Hauptausgabe rührt von Heiberg und Menge her. Bibl. Teubn. 1883.

2) 30. Theorem der Katoptrik Euklids.

3) Euklids Optik und Katoptrik findet sich im 7. Bande der Gesamtausgabe von Heiberg und Menge.

4) Gesamtausgabe Bd. 7. S. 343. Siehe auch die Abhandlung von Würschmidt in den Commemoration Essays, Oxford 1914. 
gehen, fallen in das Zentrum $\Theta$ zuriick. Durch diese Strahlen wird daher im Zentrum die Sonnenwärme gesammelt und infolgedessen ein dort befindlicher Körper entziindet." Die Annahme, daß die Sonnenstrahlen parallel in den Hohlspiegel fallen, hätte Euklid zur Auffindung des richtigen Verhältnisses leiten müssen. Den Irrtum Euklids erkannte schon Apollonios ${ }^{1}$.

Die Spiegelung an Konkar- und Konvexspiegeln wird von Euklid dahin erläutert, daß an ihnen, wie an ebenen Spiegeln, die Strahlen unter gleichen Winkeln zurückgeworfen werden. Zur Erläuterung dient folgende Abbildung ${ }^{2}$. Auch mit einem der be-
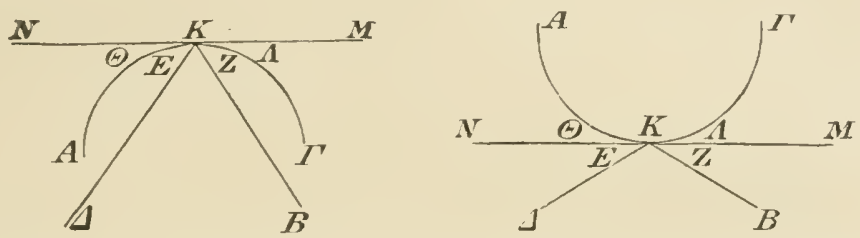

Abb. 19. Die Spiegelung an einem Konkav- (links) und an einem Konvex-Spiegel rechts; nach der Darstellung Euklids.

kanntesten Versuche iiber die Brechung des Lichtes war Euklid schon vertraut. Er berichtet darüber mit folgenden (Worten ${ }^{3}$ ): "Legt man einen Gegenstand auf den Boden eines Gefäßes und schiebt letzteres so weit zurück, daß der Gegenstand eben verschwindet, so wird dieser wieder sichtbar, wenn wir Wasser in das Gefäß gießen."

Wie die Geometrie ron gewissen Grundsätzen ausgeht, die sich auf wenige Axiome zuriickführen lassen, so geht auch die Optik Euklids von einer Anzahl - es sind acht - Grunderfahrungen aus, aus denen Euklid seine Theoreme durch geometrische Konstruktion ableitet. Die wiclitigsten der von Euklid hervorgehobenen optischen Grundtatsachen sind die folgenden: Die Lichtstrahlen ${ }^{4}$ ) sind gerade Linien. Die von den Strahlen eingeschlossene Figur ist ein Kegel, dessen Spitze im Auge liegt, während der Grundfläche dieses Kegels die Umgrenzung des gesehenen Gegenstandes entspricht. Unter größerenı Winkel geselıene Gegen-

1) E. Wiedemann, Über das Experiment in Altertum und Mittelalter (Vortrag).

2) Gesamtausgabe Bd. 7.

3) 7. Erfahrungssatz der Katoptrik.

4) Eigentlich müßte man Sehstrahlen sagen, da nach der Vorstellung Fuklids die Strahlen aus dem Auge kommen. 
stände erscheinen größer als unter kleinerem Winkel gesehene, oder die scheinbare Größe eines Gegenstandes hängt von dem Sehwinkel ab.

Auch in der Katoptrik wird von bestiminten Erfahrungssätzen - es sind deren 7 - ausgegangen. Aus ihnen werden etwa 30 Theoreme abgeleitet.

Höchstwahrscheinlich sind die optischen Schriften Euklids in sehr verdorbener Gestalt auf uns gekommen. Sie waren indes trotz mancher Mängel und Unrichtigkeiten bis zur Zeit Keplers, der die Optik um ein Bedeutendes förderte, allgemein im Gebrauch.

Auch mit akustischen Problemen hat man sich in Alexandrien befaßt. Hatten die Pythagoreer die Erscheinung der Konsonanz und Dissonanz von Tönen einfach als Tatsache hingenommen, so finden wir bei Euklid zum ersten Male das Bestreben, sich von der Ursache dieser merkwürdigen Erscheinung Rechenschaft zu geben. Dissonanz ist für ihn die Unfähigkeit der Töne, sich zu mischen, wodurch der Klang für das Gehör rauh werde, während konsonierende Töne sich zu mischen vermöchten. Euklid kommt damit vorahnend der später gegebenen Erklärung nabe 1).

\section{Die Grundlagen der wissenschaftlichen Erdkunde.}

Im engsten Zusammenhange mit dem Fortschreiten der gesamten Kultur, der politischen Entwicklung und den übrigen Wissenschaften erreichte in diesem Zeitalter die Erdkunde eine Höhe, die sie bis zum Beginn der Neuzeit nicht überschritten hat. Vor allem kommt für das alexandrinische Zeitalter in Betracht, daß das Verkehrs- und Nachrichtenwesen den damaligen Gelehrten schon ausgedehnte Reisen und weitreichende Erkundigungen gestattete. Die Bekanntschaft mit dem fernen Osten wurde der wissenschaftlichen Erdkunde durch den Alexanderzug erschlossen. Daß die auf diesem Zuge gesammelten Erfahrungen die Grundlagen der Pflanzengeographie entstehen ließen, haben wir schon an frïherer Stelle gesehen. Afrika wurde seit der Ptolemäerzeit immer weiter von Ägypten aus erschlossen. Nach Norden hatte sich der geographische Gesichtskreis fast bis zum Lande der Mitternachtssonve erweitert.

Mit den nördlichen Ländern Europas wurde das Altertum besonders durch die Reisen des Massiliers Pytheas, eines Zeit-

1) Von Smith und Helmholtz. 
genossen Alexanders des Großen, bekannt. Pytheas unternahm eine Forschungsreise bis zur Nordspitze Britanniens. Die frühere Annahme, er sei bis nach Island vorgedrungen, hat man nicht aufrechterhalten können. Jedenfalls brachte er aber Kunde ron der Erscheinung, daß im hohen Norden in der Mittsommerzeit die Sonne nicht untergehe. Im Zusammenhange damit erwähnt er das sagenhafte Thule ${ }^{1}$ ).

Der geographische Gesichtskreis der Alten hat sich also von der südlichen Halbkugel bis zum nördlichen Polarkreis erstreckt 2 . Die Ergebnisse der alten Forschungsreisen waren besonders wertvoll, wo es sich, wie bei Pytheas, um einen Mann handelte, der mit physikalischen und astronomischen Kenntnissen ausgerüstet war. Leider sind eigene Schriften von Py theas nicht erbalten und die ron ihm gewomnenen Ergebnisse nur zum geringen Teil durch Fragmente bei anderen Schriftstellern bekanntgeworden ${ }^{3}$ ).

Verarbeitet wurde das reiche, durch die Ziige Alexanders und durch Entdeckungsreisen gleich derjenigen des Pytheas gewonnene Material durch Dikaiarchos, einen Schüler des Aristoteles, und etwa ein halbes Jahrhundert später am umfassendsten durch Eratosthenes. Dikäarch schätzte die Breite der den Alten bekannten Welt ron Meroë bis zum Polarkreis auf 40000 Stadien. (Die Länge des attischen Stadiums belief sich auf 177,6 Meter.) Die Längenausdehnung von den Säulen des Herkules (der Straße von Gibraltar) bis zur Mïndung des Ganges wurde von ihm auf 60000 Stadien veranschlagt 4 ).

Nach Dikäarch (350-290) sollten die Säulen des Herkules, die Straße ron Messina, die peloponnesische Halbinsel, die Südküste Kleinasiens und Indien auf dem nämlichen Breitenkreise liegen und dieser sollte die Ökumene, d. h. den als bewohnt angenommenen Teil der Erde, etwa halbieren. Die Orientierungsfehler, die Dikäarch bei der Feststellung dieser Linie beging, waren also nicht unerheblich.

1) Nach Stadler handelt es sich hier nicht um eine Insel, sondern um Skandinavien (Jahrbücher f. d. klass. Altert. 1911. S. 86. Auch Island oder die Shetlandsinseln galten wohl für Thule. Siehe Peschels Geschichte der Erdkunde. 1877. S. 2.

2) Genaucre Angaben über die rüumliche Begrenzung der griechischen und der römischen Erdkunde enthält der erste Abschnitt von Peschels Geschichte der Erdkunde.

3) Die von ihm erhaltenen Fragmente gab M. Fuhr heraus. Darmstadt 1841.

4) Beloch, Griechische Geschichte. Bd. III. 1. Abt. S. 476 (1904). 
Von Dikäarch rühren auch die ersten Höhenbestimmungen her, die über bloße Schätzungen hinausgingen. Anfangs hatten die Alten iibertriebene Vorstellungen von der Höhe der Gebirge. So ließ Aristoteles die Höhen des Kaukasusgebirges noch 4 Stunden, nachdem die Sonne für den Fuß des Gebirges untergegangen war, in ihrem Lichte glänzen, und Plinius schätzte die Alpen zehnmal zu hoch ${ }^{1}$. Er hätte eine solche Übertreibung vermeiden können, wenn er die Werte mehr beachtet hätte, die Dikäarch und nach ihm Eratosthenes schon für bedeutende Höhen ermittelt hatte. So bestimmte Dikäarch die Höhe des Pelion (1620 Meter) und die Höhe von Akrokorinth (575 Meter) ammähernd richtig. Als allgemeines Ergebnis hob er schon hervor, daß solche Werte im Vergleich zum Durchmesser der Erde verschwindend klein seien. Dikäarch ist wohl als der Begründer der mathematischen Erdkunde bezeichnet worden ${ }^{2}$ ). Dieser Ehrentitel bleibt indessen besser dem etwa ein halbes Jahrhundert nach ihm lebenden Eratosthenes vorbehalten.

Eratosthenes wurde 275 v. Chr. in Kyrene geboren. Ptolemäos III Euergetes berief ihn nach Alexandria und ernannte ihn zum Bibliothekar der großen alexandrinischen Bibliothek. Des Eratosthenes Hauptwerk war seine ..Erdbeschreibung “; das erste wissenschaftliche Werk über Geographie, das indes nur aus Bruchstücken bei Strabon bekannt ist ${ }^{3}$ ). Es zerfiel in drei Bücher. Das erste handelte von der physikalischen, das zweite von der mathematischen Geographie, während das dritte die Chorographie, d. h. die Beschreibung der einzelnen Länder, enthielt. Außerdem hat Eratosthenes auch auf den Gebieten der Astronomie Hervorragendes geleistet. Vorhanden ist ferner ein Brief, in dem er sich mit dem berühmten delischen Problem der Verdoppelung des Würfels beschäftigt. Auch eine Regel zur Auffindung der Primzahlen rührt von ihm her. Im Jahre 220 v. Chr. soll Erato-

1) Plin. lib. II. cap. 6j. Plinius verweist an dieser Stelle auch auf die Angaben Dikäarchs.

Aus der Angabe des Aristoteles würde sich für den Kaukasus eine Höhe von etwa $70000 \mathrm{~m}$ ergeben haben.

2) A. Gercke und E. Norden, Einleitung in die Altertumswissenschaft. II. Bd. S. 314. B. G. Teubner. 1912.

3) Siehe Bernhardy, Eratosthenica, Berlin 1822, eine Sammlung von Bruchstücken der Schriften des Eratosthenes. Eratosthenes starb um 194 v. Chr. Bernhardys Schrift ist veraltet. Doch fehlt eine neuere zusammenhängende Darstellung aller Fragmente. Ferner H. Berger, Die geographischen Fragmente des Eratosthenes. Leipzig 1880. 
sthenes in Alexandrien Armillen ${ }^{1}$ ) aufgestellt und damit den Abstand der Wendekreise zu ${ }^{11} /$ ss des Kreisumfanges, das sind 47,7 Bogengrade, ermittelt haben.

Nachdem man erkannt hatte, daß die Erde die Gestalt einer Kugel besitzt, lag der Gedanke nahe, die Größe dieser Kugel zu bestimmen. Der Ruhm, den richtigen Weg zu einer solchen Messung eingeschlagen und auf ihm ein, im Verhältnis zu den vorhandenen Mitteln annähernd richtiges, Ergebnis gefunden zu haben, gebübrt gleichfalls dem Eratosthenes ${ }^{2}$.

Bei größerer Ausdehnung der Reisen mußte es den Alten auffallen, daß die täglichen Kreise, welche bekannte Sterne beschreiben, nicht überall die gleiche Neigung zur Ebene des Horizontes besitzen. Insbesondere konnte ihnen dies nicht lange bezüglich der Sonne verborgen bleiben. So wußte Eratosthenes, daß dies Gestirn zur Zeit der Sommersonnenwende im siidlichen Ägypten mittags durch den Zenit geht, während es in Alexandrien an diesem Tage einen siidlich rom Zenit gelegenen Punkt durchläuft. Infolgedessen zeigte der Gnomon an dem Mittag jenes Tages in Syene ${ }^{3}$ ) keinen Schatten. Anknuipfend an diese, ihm bekannte Tatsache, ging Eratosthenes

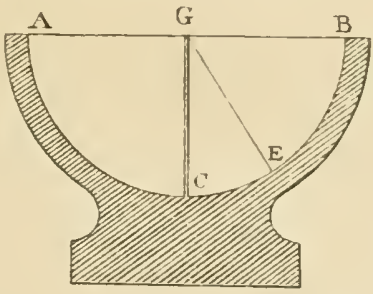

Abb. 20. Das zum Messen der Sonnenhöhe dienende Instrument der Alten 5 . bei der Lösung seiner Aufgabe von einigen Voraussetzungen aus, die zwar nicht ganz zutreffend sind, der Wahrheit aber doch so nahe kommen, daß bei dem nur rohen Verfahren, um das es sich hier handelt, das Ergebnis dadurch nicht wesentlich beeinflußt wird. Zunächst war dies die Annahme, daß die Erde eine vollkommene Kugel sei. Ferner, daß die genannten Städte auf demselben Meridian gelegen seien, während sie in Wahrheit einen Längenunterschied von mehreren Graden 4) aufweisen.

In A (Abb. 20) befindet sich das Instrument, das die Alten bei der Bestimmung der Sonnenhöhe gewöhnlich benutzten. Es

1) Siehe S. 180.

2) Siehe auch Günther, Die Erdmessung des Eratosthenes (in der Deutschen Rundschau für Geographie und Statistik. III. Band).

3) Am ersten Nilkatarakt, fast unter dem nördlichen Wendekreis gelegen (das heutige Assuan).

4) Alexandria liegt um $3^{\circ} 14^{\prime}$ westlich von Syene.

5) Das Skaphium. Siehe Schaubach, Geschichte der griechischen Astronomie. Tab. III. Fig. 2.

Dannemann, Die Naturwissenschafteu. 1. Bd. 2. Aut. 
war dies eine halbkugelige Höhlung, aus deren Mitte sich ein Gnomon ( $G \mathrm{C}$ ) erhob. Dieses Werkzeug wurde so aufgestellt, daB der Gnomon senkrecht zum Horizonte stand, also die Verlängerung des Erdradius bildete. Der Winkel EDA (Abb. 21) ließ sich auf einer Gradeinteilung ablesen. Er war gleich dem zu messenden Bogen A B des Meridians (siehe Abb. 21). Eratosthenes fand nun E D A gleich $1 / 50$ des Kreisumfanges oder gleich $7^{\circ} 12^{\prime}$. Er schätzte ferner die Strecke Syene-Alexandrien auf 5000 Stadien. Genauere Landesvermessungen gab es nämlich nur für das untere Ägypten, so daß Eratosthenes auf die Angabe von Reisenden angewiesen war, welche die Entfernungen in Tagesmärschen aufgezeichnet hatten ${ }^{1}$ ). Der Umfang der Erde ergab sich somit gleich

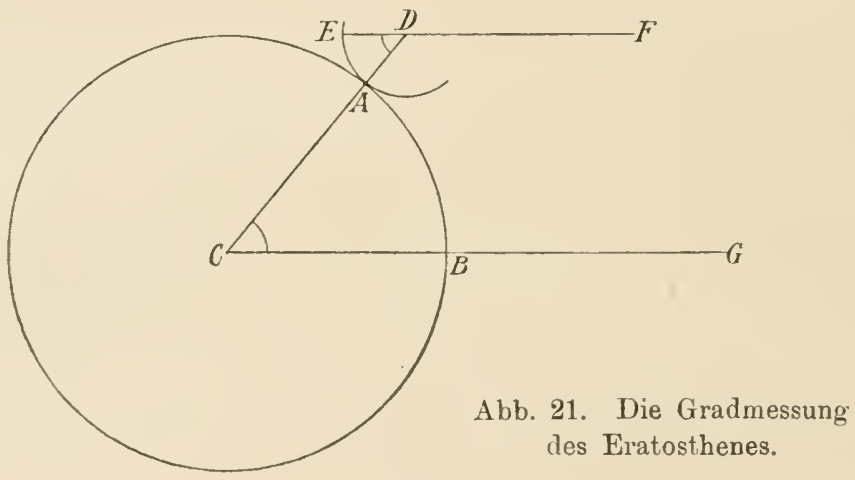

$5000 \times 50=250000$ Stadien, eine Größe, die sich in heutigem Maße auf etwa 45000 Kilometer beläuft, während der wahre Wert 40000 Kilometer beträgt \%). Diese wissenschaftliche Tat des Eratosthenes erregte die Bewunderung des Altertums, das nur in den besprochenen Messungen des Aristarch etwas Ahnliches aufzuweisen hatte.

Das Nächstliegende wäre nun gewesen, die Gradmessung auf einem nicht lediglich abgeschätzten; sondern genauer gemessenen Teil des Meridians zu wiederholen. Eine solche Untersuchung gelangte jedoch erst viel später zur Ausführung.

1) S Cantor, Bd. I. S. 283.

2) Näheres siehe bei Lepsius, Das Stadium und die Gradmessung des Eratosthenes auf Grundlage der ägyptischen Maße, in der Zeitschrift für ägyptische Sprache u. Altertumskunde. 1877. 1. Heft. S. 3-8. Nach Lepsius kann es keinem Zweifel unterliegen, daß das Stadium des Eratosthenes eine Länge von 180 Metern besaß. A. a. O. S. 7. Dies war die Länge des griechischen Stadiums. Das ägyptische Stadium belief sich auf 179 Meter. 
Wie Dikäarch, so hat auch Eratosthenes die Messung der. Erdoberfläche durch die Bestimmung der sie überragenden Höhen zu ergänzen gesucht. Eratosthenes verfubr dabei wie Dikäarch auf trigonometrischem Wege und gelangte zu dem Ergebnis, daß es sich bei den höchsten von ihm gemessenen Berghöhen um Werte ron etwa 10 Stadien handele.

\section{Die Anfänge der heliozentrischen Lehre.}

Daß schon während der ersten Periode der alexandrinischen Akademie die Astronomie zur Wissenschaft heranreifte, indem sie sich von der Spekulation der messenden Beobachtung zuwandte, ersehen wir vor allem aus den im dritten vorchristlichen Jahrhundert entstandenen Arbeiten der Alexandriner Aristyllos und Timocharis, sowie des mit der alexandrinischen Schule in enger Fühlung stehenden Aristarchos ron Samos. Dem letzteren gebührt das Verdienst, die heliozentrische Theorie in voller Klarheit entwickelt zu haben. Daran, daß die Erde im Mittelpunkt der Welt ruhe, haben zuerst die Pythagoreer gezweifelt. Unter ihnen entwickelte Philolaos eine Theorie ${ }^{1}$ ), nach der sich die Erde innerhalb eines Tages um ein Zentralfeuer drehe. Auf diese Weise wurde die tägliche Bewegung des Himmels als eine nur scheinbare erklärt. Sobald man das Zentralfeuer in die Mitte der Erdkugel verlegte, hatte man den einen Bestandteil der koppernikanischen Lehre, nämlich die Drehung unseres Weltkörpers um seine Achse, schon vorweggenommen.

Der Kern dieser Lehre, die Umlaufsbewegung der Erde und der ïbrigen Planeten um die Sonne, läßt sich heute in seiner allmählichen Entwicklung zurückverfolgen. Den Ausgang bilden die Peobachtungen an Venus und Merkur. Sie führten, wie wir sahen ${ }^{2}$, zu der Lehre des Herakleides Pontikos, nach welcher diese Himmelskörper um die Sonne kreisen. Von dieser Lehre, die

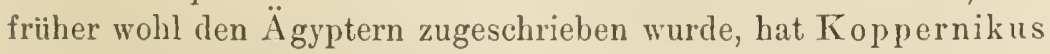
nach seinen eigenen Worten sehr wohl gewußt. Von lier aus konnte man leicht zu einer richtigen Auffassung des Weltsystems gelangen, wenn man die Sonne als Mittelpunkt der Bahnen auch der übrigen Planeten betrachtete. Sieht man von den heute schwer sicherzustellenden Spekulationen der Pythagoreer ab, 
so war es vor allem Aristarch, der die heliozentrische Weltansicht mit voller Klarheit aussprach. Ihn soll die Überzeugung, daß die Sonne weit größer als die Erde und der Mond sei, zur Aufstellung seines Systems geführt haben. Auch ohne eine Kenntnis der Gesetze der Dynamik fühlte Aristarch sozusagen durch, daß es ungereimt sei, den Umlauf eines gewaltigen Weltkörpers um einen im Verhältnis winzig kleinen anzunehmen. Koppernikus fügte zu diesem Grund noch den hinzu, daß die Sonne als Leuchte der Welt auch in deren Mitte gehöre ${ }^{1}$ ).

Bis zum Ende der ersten, etwa bis Aristoteles reichenden Periode der griechischen Astronomie hatte die Spekulation überwuchert. Zum Glück traten jedoch in der alexandrinischen Schule, und im Zusammenhange mit dieser, Männer auf, die sich mit nüchternem Sinne der Erforschung der Himmelserscheinungen zuwandten. Die Astronomie ging damit von den durch mangelhafte Beobachtung gestützten Philosophemen zum messenden Verfahren . über und erhob sich dadurch auf die Stufe einer Wissenschaft im strengen Sinne des Wortes. Als diejenigen unter den Griechen, die zuerst diesen $W$ eg beschritten haben, sind die Alexandriner Aristyll und Timocharis und vor allem der schon erwähnte Aristarch von Samos zu nennen. Mit der Forschertätigkeit dieser Männer heben zwei Probleme an, die seitdem den menschlichen Geist beschäftigt haben und mit immer größerer Schärfe ihrer Lösung zugeführt worden sind. Es sind dies die Topographie des Fixsternhimmels, d. h. die genaue Bestimmung möglichst vieler Sternörter, sowie die Ermittelung der Abmessungen der Erde und unseres Planetensystems, zunächst der Entfernung der Sonne und des Mondes. In welchem Maße die Ägypter und ganz besonders die Chaldäer den alexandrinischen Astronomen durch das Sammeln eines reichen, sich über lange Zeiträume erstreckenden Beobachtungsmaterials vorgearbeitet hatten, wurde an früherer Stelle dargetan.

Aristyll und Timocharis, die ihre Beobachtungen um das Jahr 300 v. Chr. anstellten, bedienten sich der Armillen, d. h. geteilter Kreise, von denen der eine in der Ebene des Äquators lag, während der andere um die Weltachse gedreht werden konnte. Mit Hilfe dieses Apparates bestimmten sie die Lage einzelner Sterne, indem sie ihre Deklination oder den Bogenabstand vom Äquator bis auf Bruchteile von Graden ermittelten und gleichzeitig den Ort der

1) Koppernikus, De revolutionibus I, 10. 
Sterne auf den Frühlingspunkt bezogen. Das von ihnen herrührende Verzeichnis, das bis auf wenige Angaben verlorengegangen ist, gab 170 Jahre später Hipparch die Möglichkeit, das Vorrücken der Nachtgleichen zu entdecken $\left.{ }^{1}\right)$. Timocharis bediente sich bei seinen astronomischen Beobachtungen auch der Stundenangaben. Die (babylonische) Zwölfteilung des Tages läßt sich bei den Griechen nicht vor Alexander dem Großen nachweisen ${ }^{2}$. Vorher richtete man sich im praktischen Leben nach der Länge des eigenen Schattens und verabredete z. B. eine $\mathrm{Zu}$ sammenkunft für die Tageszeit, wann der Schatten 6 oder 8 Fuß lang sei.

Über die Größenverhältnisse des Planetensystems hat Aristarch die ersten Untersuchungen angestellt. Er war ohne Zweifel einer der bedeutendsten Astronomen seiner Zeit. Von seinem Leben ist indessen keine nähere Kunde auf uns gelangt. Aristarch wurde um das Jahr 270 v. Chr. in Samos geboren. Das einzige, was von seinen Schriften erhalten blieb, sind Teile einer Abhandlung, die von der Größe und den Entfernungen des Mondes und (ler Sonne handelt ${ }^{3}$ ). Die Abstände dieser Weltkörper von der Erde verhalten sich nach Aristarch etwa wie 1:19, während das wahre Verhältnis annähernd 1:400 ist. Zu seinem Ergebnis gelangte Aristarch durch folgende Überlegung. Erscheint von einem Punkte $\mathrm{E}$ der Erde (siehe Abb. 22) der Mond genau zur

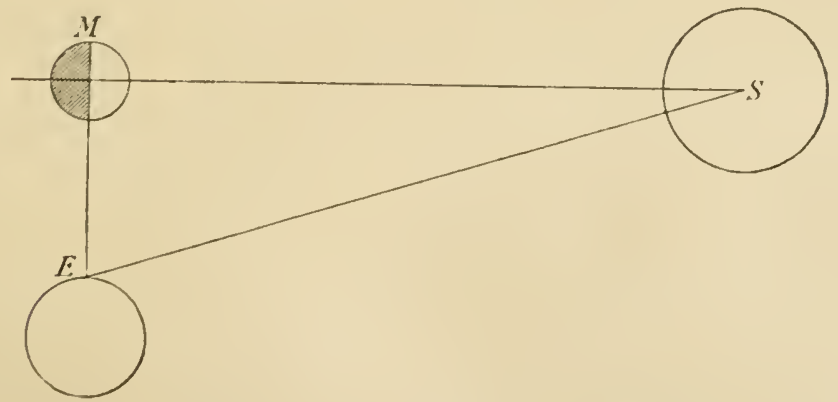

Abb. 22. Aristarchs Verfahren, die Entfernung des Mondes und der Sonne zu bestimmen.

Hälfte von der Sonne beleuchtet, so bildet jener Punkt E mit den Mittelpunkten des Mondes und der Sonne ein rechtwinkliges

1) Siehe an späterer Stelle dieses Bandes.

2) G. Bilfinger, Die antiken Stundenangaben. Stuttgart 1888. S. 74.

3) Aristarchos, Über die Größen und Entfernungen der Sonne und 
Dreieck, in welchem der Abstand des Mondes eine Kathete (M E) und die Entfernung der Sonne die Hypotenuse (ES) ist. Der Winkel bei $\mathrm{E}$ mißt nun wach A ristarch $87^{\circ}$, während er in Wahrheit viel weniger von einem Rechten abweicht und sich auf $89^{\circ} 50^{\prime}$ beläuft. Das gesuchte Verhältnis, das Aristarch auf mühsame Weise in die Grenzen 1:18 und 1:20 einschloß, ist gleich dem Cosinus des Winkels bei $\mathrm{E}$, unter dem beide Weltkörper in dem angegebenen Falle von der Erde aus gesehen werden (E M : E S, siehe Abb. 22).

Auch die Raumverhältnisse der Weltkörper berechnete Aristarch. So fand er, daß der Mond etwa 25 (statt 48) mal so klein, die Sonne dagegen 300 (statt 1300000 ) mal so grol, wie die Erde sei ${ }^{1}$ ).

Der Weg, auf dem Aristarch seine Aufgabe zu lösen suchte, ist, theoretisch genommen, zwar richtig. Daß sich trotzdem ein Resultat ergab, das von dem heute gültigen Wert in solch erheblichem Maße abwich, ist aus mehreren Umständen zu erklären. Einmal war man zu jener Zeit noch nicht imstande, solch kleine Winkelunterschiede wie diejenigen, um die es sich hier handelt, zu messen. Zum andern aber besitzt die gesuchte Grenze zwischen dem belenchteten und dem dunklen Teile des Mondes keine hinlängliche Schärfe. Immerhin verdiente Aristarch in vollem Maße die Anerkennung, die ihm das Altertum dieser Bestimmung wegent zollte. Daß Aristarch die beliozentrische Theorie $1 \frac{1}{2}$ Jahrtausende vor Koppernikus klar aussprach, geht auch aus einer Äußerung des Archimedes hervor. Sie lautet: „Aristarch gelangt zu der Annahme, die Fixsterne samt der Sonne seien unbeweglich. Die Erde aber werde in einer Kreislinie um die Sonne, die in der Mitte der Erdbahn stehe, herumgeführt2)."

$\mathrm{Zu}$ den Vorläufern des Koppernikus ist auch der Pythagoreer Niketas zu rechnen. Auf ihn führt Koppernikus selbst die Anregung zurück, die ihn veranlaßte, den geozentrischen Stand-

des Mondes. Übersetzt und erläutert von A. Nokk. Als Beilage zu dem Freiburger Lyzeumsprogramm von 1854.

Aristarchs Schrift wurde durch eine 1488 erschienene lateinische Übersetzung bekannt. Den griechischen Text hat erst 1688 Wallis nach einem Manuskript veröffentlicht. Erneut wurde der griechische Text dann 18506 durch E. Nizze herausgegeben. Eine Ausgabe des griechischen Textes mit deutscher Übersetzung wird von $K$. Manitius vorbereitet.

1) Aristarch, Über die Größen usw., Lehrsatz 15-18.

2) Des Archimedes Sandesrechnung (Dannemann, Aus der Werkstatt großer Forscher. S. 13). 
punkt aufzugeben. Von der Lehre des Niketas gibt uns eine kurze Bemerkung Kunde, die sich bei Cicero findet und auf die sich später Koppernikus berufen hat. Sie lautet: „Niketas aus Syrakus nimmt an, wie Theophrast erzählt, daß der Himmel, die Sonne, der Mond und die Sterne stillstehen, und daß sich außer der Erde nichts im Weltall bewegt. Die Erde dreht sich um eine Achse. Dadurch scheint sich der Himmel zu bewegen." Ohne Zweifel ist dies ein deutliches Zengnis dafür, daß man im frïhen Altertum, wenn auch nur vereinzelt, den Versuch gemacht hat, die scheinbare tägliche Umdrehung des Himmels aus einer Rotation der Erde zu erklären. Auch auf Plutarch konnte sich Koppernikus berufen, da Plutarch in seiner Schrift "Von den Meinungen der Philosophen" die astronomischen Lehren des Philolaos und des Herakleides Pontikos erwähnt sowie an anderer Stelle auch auf die Ansichten Aristarchs bezug genommen hat.

\section{Fortschritte der messenden Astronomie.}

Die bedeutendste Förderung während des vorchristlichen $\mathrm{Ab}$ schnittes des alexandrinischen Zeitalters erfuhr die Astronomie durch Hipparch. Seine wissenschaftliche Tätigkeit fällt etwa in die Zeit von $160-125$ v. Chr. Von seinem Leben ist wenig bekannt. Er lebte in Rhodos, hielt sich wahrscheinlich aber auch in Ägypten auf ${ }^{1}$ ). Hipparch erleichterte die Arbeit des Astronomen vor allem dadurch, daß er als trigonometrisches Hilfsmittel eine Sehnentafel schuf. Sie enthielt für die Winkel im Kreise den Wert der zugehörigen Sehnen, in Teilen des Halbmessers ausgedriickt. Die Berechnung war sehr mïhsam. Sie geschah, indern man von den Sehnen der Winkel $120^{\circ}, 90^{\circ}, 72^{\circ}, 60^{\circ}, 36^{\circ}$ ausging. Diese Sehnen ließen sich als Seiten des regelmäßigen 3-, 4-, 5-, 6- und 10-Ecks leicht in Teilen des Radius ausdrücken. Mit Hilfe des Pythagoreischen Lehrsatzes und eines Hilfssatzes

1) Über Hipparch handelt ein Artikel von A. Relim in der Realenzyklopädie des klassischen Altertuıns von Pauly-Wissowa-Kroll. 8. Bd. Sp. 1666-1681.

Hipparchs ..Geographisehe Fraginente* wurden vou H. Berger gesammelt und bearbeitet; eine weitere Sammlung von Fragmenten liegt bisher nicht vor. Daß sich wissenschaftliche Bedeutung wohl mit astrologischen Vorstellungen vereinigen läßt, hat $H i p p a r c h$ ähnlich wie später $K e p l e r$ bewiesen. Im Original erhalten ist von Hipparch nur ein Jugendwerk von

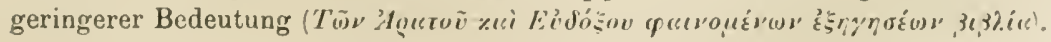


bestimmte man dann die Sehnen von halben Bogen, sowie die Sehnen von Bogensummen und Bogendifferenzen und gelangte so zu einer Tafel ron zahlreichen Bogen nebst den entsprechenden Sehnen. Anfangs wies diese Tafel bedeutende Lücken auf, die man indessen durch Interpolation nach und nach ausfüllte. Erst von Ptolemäos wurden die Sehnen aller Winkel, nach halben Graden fortschreitend, mit hinreichender Genauigkeit bestimmt. Seine Tafel, die einen wesentlichen Teil des $1 \frac{1}{2}$. Jahrtausende die Astronomie beherrschenden Ptolemäischen Werkes ausmachte, hat während jenes langen Zeitraumes den Astronomen an Stelle unserer heutigen trigonometrischen Tabellen große Dienste geleistet.

Ptolemäos teilte den Radius in 60 Teile und führte diese Teilung sexagesimal weiter. Die Sehnen wurden dann für die verschiedenen Winkel in Sechzigsteln des Radius ausgedrückt. So wurden feststehende Verhältnisse gewonnen, da die absolute Größe des Radius und der Sehnen nicht in Betracht kam. Es kam auch vor, daß Ptolemäos mitunter statt der ganzen die halben Sehnen benutzte, doch blieb die konsequente Durchführung dieser Maßregel, die ja die Einführung der Sinusfunktion bedeutet haben würde, den Indern vorbehalten.

Die Trigonometrie beschränkte sich bei den Alten auf das rechtwinklige Dreieck. Die Ausdehnung der trigonometrischen Funktionen auf Winkel von $90^{\circ}-180^{\circ}$ erfolgte erst durch die Araber, die auch die Trigonometrie des schiefwinkligen Dreiecks begründeten ${ }^{1}$. Kamen solche Dreiecke für die alten Astronomen in Betracht, so wurden sie in rechtwinklige Dreiecke, die man berechnen konnte, zerlegt.

Aus den Fortschritten, welche die Mathematik im alexandrinischen Zeitalter erfuhr, zog unter allen Wissenschaften die Astronomie auch weiterhin den größten Nutzen. Es begann für sie die Periode der systematischen, messenden Beobachtungen. Und wenn das Ergebnis auch noch nicht in der allgemeinen Annahme des wahren Weltsystems bestand, so gelangte man doch zur klaren Auffassung vieler, nur vermöge exakter Messung wahrnehmbarer Erscheinungen. Vor allem ist hier Hipparch zu nennen, der für die Astronomie dieselbe Bedeutung besitzt, die Aristoteles hinsichtlich der Zoologie und Archimedes in bezug auf die Mechanik zugeschrieben werden muß.

1) J. Tropfke, Geschichte der Elementarmathematik. Bd. II. S. 223. 
Während der ersten Entwicklungsstadien der Astronomie hatte man sich darauf beschränkt, die Stellung der wichtigeren Fixsterne dadurch festzulegen, daß man am Himmel gewisse Figuren einzeichnete. Mitunter brachten diese Sternbilder auch äußerliche Äbnlichkeiten zum Ausdruck, wie z. B. beim Wagen.

In die Blütezeit der alexandrinischen Schule fällt nun der Versuch einer genaueren, durch Winkelmessung ermittelten Ortsbestimmung der wichtigsten Fixsterne. Man bezog ibre Stellungen auf die Punkte, in denen die Ekliptik den Himmelsäquator schneidet, und bestimmte bei einer größeren Anzahl auch den Abstand rom Aquator bis auf Teile cines Grades. Ein solches, von Aristyll und Timocharis herrührendes Fixsternverzeichnis, das etwa 150 Angaben umfaßte, befand sich in den Händen des Hipparch, als plötzlich, im Jahre 134 v. Chr., ein seltenes astronomisches Ereignis, nämlich das Auftreten eines neuen Sternes erster Größe, eintrat 1). Bot aber die Fixsternregion, die Aristoteles als den Ort des unwandelbaren Seins bezeichnet hatte, derartige plötzliche Veränderungen dar, so mußte sich in den Astronomen der Wunsch nach einer genauen Topographie des Himmels regen, um auf solche Weise späteren Zeiten eine stete Kontrolle zu ermöglichen. In den auf jenes Ereignis folgenden Jahren bestimmte deshalb Hipparch etwa tausend Sternörter ${ }^{2}$. Hipparch löste dadurch nicht nur die gestellte Aufgabe, sondern er machte außerdem die wichtige Entdeckung, daß der Frühlings- und der Herbstpunkt ihre Lage langsam ändern. Für einen der hervorragendsten Sterne des Tierkreises, die Spica in der Jungfrau nämlich, ergab sich, daß er $6^{\circ}$ vom Herbstpunkte entfernt war, während der 170 Jahre früher gemessene Abstand $8^{\circ}$ betrug. Die Breite der Fixsterne war dagegen unverändert geblieben. Dieses Vorrücken der Aquinoktialpunkte ${ }^{3}$ ) glaubte Hipparch aus seinen und den

1. Der neue Stern trat, wie auch aus chinesischen Berichten hervorgeht, in Sternbilde des Skorpions auf.

2) F. Boll, Die Sternkataloge des Hipparch und des Ptolemäos (Bibl. math. Jahrg. 1901. S. 185). Nach Boll umfaßte Hipparchs Katalog 850 Sterne.

3) Die Erscheinung erklärt sich daraus, daß die Erdachse innerhalb eines Zeitraums von etwa 26000 Jahren einen Kegelmantel beschreibt. Infolgedessen ändert der Himmelsäquator, der sich als eine Projektion des Erdäquators darstellt, gleichfalls seine Lage innerhalb derselben Periode. Der Vorgang wird als Präzession oder Vorrücken der Nachtgleichen bezeichnet, weil dabei der Frühlings- und der Herbstpunkt langsam ihren Ort im Sinne der täglichen Umdrehung ändern. 
älteren Beobachtungen auf mindestens einen Grad für ein Jahrlundert, also auf 36" für das Jahr ansetzen zu dürfen, während es in Wahrheit 50 " beträgt.

Die Arbeiten, in denen Hipparch von der Präzession der Nachtgleichen handelt, sind leider bis auf dasjenige, was der „Almagest": darüber bringt, verlorengegangen. Nach Tannery beläuft sich der von Hipparch gefundene Betrag des Vorriickens auf $1^{\circ} 23^{\prime} 25^{\prime \prime}$ für das Jahrhundert'1). Auf die Entdeckung der Präzession gründet sich die Vorstellung ron einem 26000 Jahre umfassenden Zeitraum (dem platonischen Jahr), der mit der Lehre von der steten Wiederkehr in Beziehung gebracht wurde. Auf diese Lehre abzielende Andeutungen finden sich schon bei Platon, später auch bei Cicero, Seneca und anderen Schriftstellern des Altertums. Die Vorstellung, daß die Natur einem regelmäßig wiederkehrenden Wechsel unterliegt, hatte ja auch manches für sich. Die Kirchenväter verhielten sich jedoch ihr gegenüber ablehnend, weil sie den christlichen Vorstellungen nicht entsprach. Unter den Arabern finden sich dagegen wieder Anhänger der Lehre von der steten Wiederkehr ${ }^{2}$.

Auch daß sich die Erde in der Sonnennähe schneller bewegt als in der Sonnenferne, wurde von Hipparch beobachtet, wenn er auch diese Berwegung auf unser Zentralgestirn übertrug, an dem sie ja scheinbar rorsichgeht. Da man im Altertum an der aristotelischen Voraussetzung festhielt, daß die Bewegung der Himmelskörper gleichförmig und in Kreisen erfolge, so erklärte Hipparch die beobachtete Erscheinung aus der Epizyklentheorie, indem er die Sonne einen Kreis durchlaufen ließ, dessen Mittelpunkt sich auf einem größeren, um die Erde gespannten Kreise fortbewegen sollte.

Die genauere Erforschung der scheinbaren Sonnenbewegung führte Hipparch ferner zu der Entdeckung, daß die Länge des Jahres, d. h. der Zeit zwischen zwei Durchgängen des Sonnenzentrums durch den Frühlingspunkt, nicht, wie vor ihm angenommen, $365^{1 / 4}$ Tage beträgt, sondern daß sie etwas kuirzer ist $\left.{ }^{3}\right)$.

1) Mitteilungen zur Gesch. d. Mediz. u. d. Naturwissenschaften. Nr. 53 (1913). S. 431.

2) Siehe auch S. 121 dieses Bandes.

3) Hipparch nahm die Dauer des tropischen Jahres zu 365 Tagen 5 Stunden $55^{\prime}$ an, während sie in Wahrheit 365 Tage 5 Stunden 48' 51" beträgt. 
Eine schärfere Bestimmung der Mond- und der Planetenbewegungen, wie sie am Himmelsgewölbe vorsichzugehen scheinen, hat Hipparch gleichfalls in Angriff genommen. Die Lösung dieser Aufgabe gelang jedoch erst melrere Jahrhunderte später dem Ptolemäos, dessen Bedeutung für die astronomische Wissenschaft späterer Würdigung vorbehalten bleibt.

Auch das durch die Zahlenmystik der Pythagoreer angeregte, schon ron Aristarch belandelte Problem, die Entfernungen und die Größe der Himmelskörper zu bestimmen, beschäftigte Hipparch. Behufs der Lösung dieser Aufgabe führte er den Begriff der Parallaxe ein. Man versteht darunter den Winkel, unter dem der Erdhalbmesser von dem Gestirne aus erscheint, dessen Abstand gemessen werden soll. Hipparchs Bestimmungen ergaben für die Entfernung des Mondes 59 Erdhalbmesser. Dieser Wert kommt der Wahrheit ziemlich nahe1), während die ron Hipparch herrïhrenden Werte für die Entfernung und die Größe der Sonne von der Wirklichkeit erheblich abweichen.

Die wichtigsten Lehren der antiken Astronomie wurden nach dem von Hipparch gewonnenen Standpunkte ron Geminos zusammengestellt. Geminos aus Rhodos lebte um $70 \mathrm{v}$. Chr. in

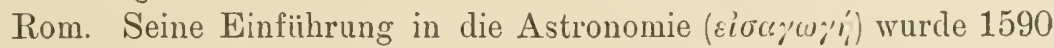
unter dem Titel Elementa astronomiae herausgegeben $\left.{ }^{2}\right)$. Sie zeugt von großer Sachkunde, ist frei von allem hergebrachten Aberglauben, kurz, durchaus wissenschaftlich gehalten. Einen entschieden ablehnenden Standpunkt nimmt Geminos manchen herrschenden Lehren gegenüber ein. So spricht er sich z. B. dahin aus, daß die Hitze des Sommers nicht von dem Hundsstern (Sirius) ablü̈nge, sondern in dem Stande der Sonne ihre Ursache habe. Für Geminos liegen ferner die Fixsterne nicht sämtlich in einer Sphäre. Ihre Entfernung von der Erde werde wohl sehr verschicden sein. Es fehle uns nur an einem Mittel, diese Verschiedenheit wahrzunehmen. Das Werk des Geminos hat späteren Zeiten als wertrolle Quelle für die antike Astronomie gedient.

1) Die mittlere Entfernung zwischen den Mittelpunkten von Mond und Erde beträgt 60,27 Halbmesser des Erdäquators oder $38+400 \mathrm{~km}$.

2) Durch den in Jever geborenen Hildericus. Eine spätere Ausgabe besorgte 1819 Halma im Anschluß an seine Ptolemäosausgabe. 


\section{Die Anfänge der wissenschaftlichen Kartographie.}

Die geschilderten Fortschritte der Astronomie trugen dazu bei, daß auch die Geographie immer mehr einen wissenschaftlichen Grundzug erhielt. Dies sprach sich vor allem darin aus, daß man sich der astronomischen Ortsbestimmung zu bedienen anfing. Anfangs waren die geographischen Karten bloße Itinerarien, d. h. sie wurden auf Grund der von den Reisenden angegebenen Wegelängen und der eingeschlagenen Himmelsrichtung entworfen. Während Eratosthenes bei seiner Bearbeitung der Länderkunde sich auf

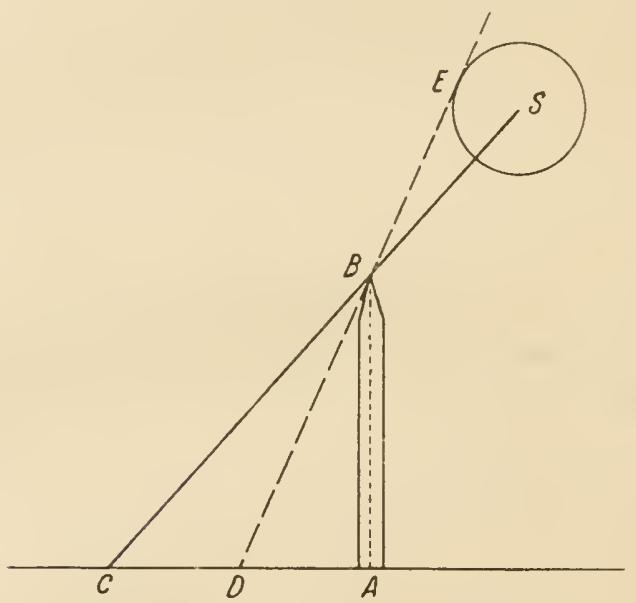

Abb. 23. Breitenbestimmung mit dem Gnomon. die Angabe der Polhöhe eines Ortes oder einer Landschaft beschränkte, führte Hipparch die Bestimmung nach geographischer Länge und Breite ein. Um die Breite eines Ortes zu finden, brauchte man nur die Höhe der Sonne um Mittag während der Zeit der Tag- und Nachtgleiche zu ermitteln und den so erhaltenen Winkel von $90^{\circ}$ abzuziehen. Dazu bediente man sich des Gnomons. Bei diesen Messungen, die bis auf 1-2 Bogenminuten genau erfolgten, begingen die alten Astronomen einen Fehler von 16 Bogenminuten, ein Wert, der dem Halbmesser der Sonne gleichkommt. Den Ursprung dieses Fehlers erläutert $\mathrm{Abb}$. 23. Sie läßt erkennen, daß aus dem Schatten als Höhenwinkel der Winkel BDA resultiert, während die wahre Sonnenhöhe BCA ist1). Hipparch teilte den $\ddot{A} q u a t o r$ in 360 Grade. Als Anfangsmeridian wählte er denjenigen, welcher die Insel Rhodos schneidet, da er hier einen Teil seiner Beobachtungen angestellt hatte. Während die Breite, nachdem man ihren Zusammenhang mit der Polhöhe erkannt, leicht bestimmt werden konnte, machte die Feststellung der Länge

1) Genaueres über diese Messungen siehe in Peschels Geschichte der Erdkunde. München 1877. S. 43-45. 
Schwierigkeiten. Diese wurden noch im Zeitalter Newtons lebhaft empfunden und erst durch die immer weiter gehende Ver- vollkommnung der Chronometer gehoben. Auch Hipparch brachte eine Art von chronometrischem Verfahren in Vorschlag. Unter der Voraussetzung, daß der Eintritt einer Himmelserscheinung, z. B. der Beginn einer Mondfinsternis, von allen Bewohnern eines Erdteils in demselben Augenblick gesehen wird, sollte die Zeit des Eintritts für verschiedene Orte festgestellt und aus dem Unterschied der Ortszeiten der Unterschied der Längen berechnet werden.
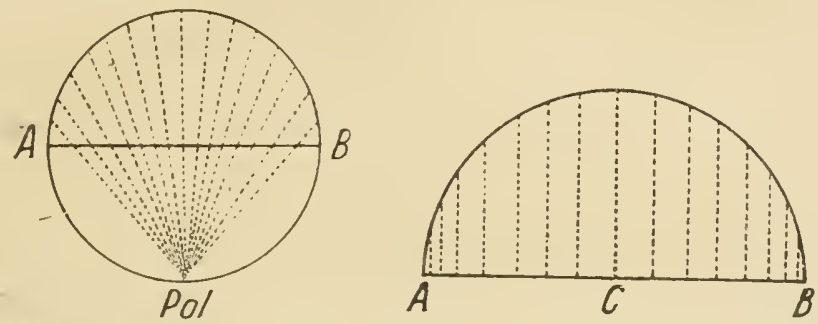

Abb. 24. Stereographisehe und orthographische Projektion.

Für die kartographisclıe Darstellung bediente sich Hipparch zur Abbildung des Himmels der stereographischen 1), zur Abbildung von Ländern meist der orthographischen Projektion. Bei der ersten Projektionsart wird eine Ebene zwischen das Auge und die abzubildende krumme Fläche gebracht. Jeder Strahl, der einen Punkt der letzteren mit dem Auge verbindet, schneidet jene Ebene. Infolgedessen projizieren sich die Punkte der krummen Fläche in der Weise auf die Ebene, daß das Auge von dem Bilde auf der Ebene denselben Eindruck bekommt, den es von der krummen Fläche, z. B. der Halbkugel des Himmels, erhäit. Bei der orthographischen Projektion dagegen wird von jedem Punkte der darzustellenden krummen Fläche eine Senkrechte auf die Projektionsebene gefällt. Das Bild auf dieser macht also den Eindruck, den die krumme Fläclıe einem weit entfernten Auge bietet.

\section{Die Begründung einer Physik der Gase und der Flüssigkeiten.}

Während die Astronomie und die Geographie sich mächtig entwickelten und im 2. Jahrhundert nach dem Beginn der christ-

1) Die stereographische Projektion wurde auch von $\mathrm{P}$ tole mäos empfohlen. Ob Hipparch sie kannte, ist nach Hoppe nicht sicher. 
lichen Zeitrechnung innerhalb derselben alexandrinischen Akademie durch Ptolemäos eine zweite Blütezeit erlebten, schien die wissenschaftliche Mechanik nach den hoffnungsvollen Anfängen, die man dem Archimedes rerdankte, zum Stillstande verurteilt zu sein, obgleich sich auch diese Wissenschaft für die Anwendung des durch die Mathematik gebotenen, deduktiven Verfahrens so sehr eignete. Abgesehen von der Schwerpunktsbestimmung körperlicher Gebilde - Archimedes hatte sich hierbei auf Flächen beschränkt - machte die theoretische Mechanik kaum wesentliche Fortschritte. Jene Bestimmungen rühren von Pappos von Alexandrien her, der im 4. nachchristlichen Jahrhundert lebte und somit einer späteren Periode angehört.

Pappos befaßte sich nach dem Vorbilde des Archimedes auch mit der Untersuchung von Rotationskörpern und kam dabei auf einen wichtigen allgemeinen Satz, der später unter dem Namen der Guldinschen Regel bekannt geworden ist. Pappos fand nämlich, daß der Inhalt eines Rotationskörpers aus der Fläche der sich drehenden Figur und dem von ihrem Schwerpunkt beschriebenen Kreise berechnet werden kann. Diese Regel wurde im Laufe der Jahrhunderte vergessen und von Guldin (1577-1643), nach dem sie heute die Guldinsche Regel genannt wird, von neuem gefunden.

Weit mehr als um die Fortbildung der theoretischen hat man sich während der alexandrinischen Zeit um die der praktischen Mechanik bemüht. Man versah z. B. die Wasseruhren mit einer Zeigervorrichtung und erfand die Feuerspritze $\left.{ }^{1}\right)$. Diese besa $B$, nach einem im 18. Jahrluundert aufgefundenen, aus der römischen Kaiserzeit herstammenden Exemplar ${ }^{2}$ ) zu urteilen, schon im Altertum eine im wesentlichen der heutigen entsprechende Einrichtung. (Abb. 25.)

Auch gewann man damals einige Kenntnis von der Natur der Gase und der Dämpfe. Besonders verdient um dieses Gebiet machte sich Heron von Alexandrien, dessen Name noch heute in einem bekannten Apparat unserer physikalischen Sammlungen, dem Heronsball, fortlebt ${ }^{3}$ ). Herons Tätigkeit fällt vielleicht um das Jahr 100 v. Chr. Doch ist die Frage, welchem Zeitalter er

1) Die Erfindung der Feuerspritze wird dem Ktesibios (um 150 v. Chr.) zugeschrieben. Siehe Vitruvius, De architectura $X, 7$.

2) 1795 in der Nähe von Civitavecchia ausgegraben.

3) Einen sehr ausführlichen Artikel über Heron enthält Paulys Realenzyklopädie f. d. klass. Altert. Bd. VIII (1913. S. 992-1080. 
eigentlich angehört hat, noch immer nicht mit Bestimmtheit gelöst. Näheres über diese ..Heronische Frage" enthält die Einleitung der unten erwähnten Ausgabe der Werke Herons (s. S. 192 Anm. 4). Sein Verdienst bestand darin, daß er zahlreiche Erfindungen der alten Physiker und Techniker zusammenstellte und dadurch die Entwicklung, welche die Physik seit dem 16. Jahrhundert nahm, in hohem Grade befruchtete. Von eigenen Erfindungen Herons ist in seinen Schriften kaum die Rede. Seine "Pneumatik“ ist das erste auf uns gelangte Werk ${ }^{1}$, das sich mit Versuchen iiber

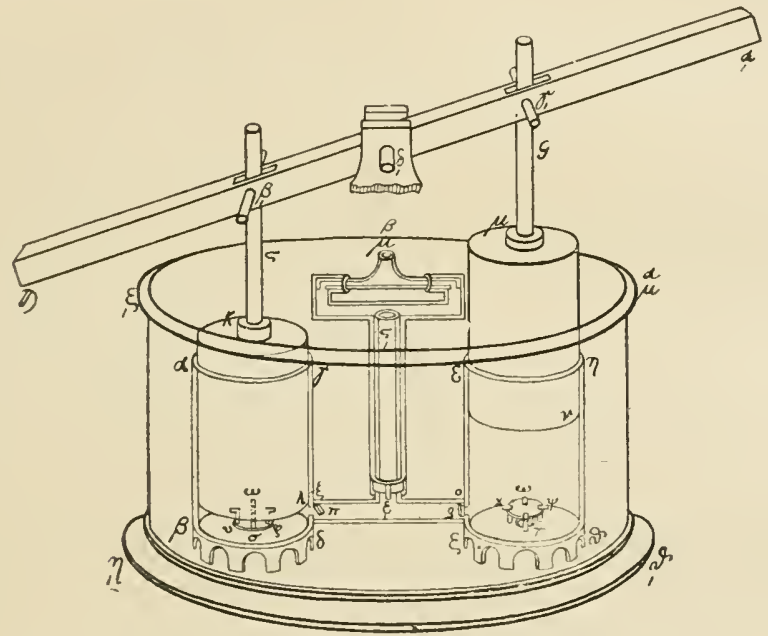

Abb. 25. Die Feuerspritze nach Heron.

die Eigenschaften der Luft und der gespannten Dämpfe :beschäftigt. Daß Heron auf diesem Gebiete zahlreiche Vorgänger besaß, ist daraus ersichtlich, daß er seine "Pneumatil" mit folgenden Worten beginnt: „Die Beschäftigung mit Luft- und Wasserkünsten ist von den alten Philosophen und Mathematikern hoch geschïtzt worden. Es ist daher notwendig, das seit alters darüber Bekannte in gehörige Ordnung zu bringen....

1) Herons von Alexandria Pneumatica et Automata. Griechisch und leutsch herausgegeben von Wilhelm Sehmidt. Teubner, Leipzig 1899.

Herons "Pneumatik" wurde 1575 durch Commandinus aus den Griechischen ins Lateinische iibersetzt und im Druck herausgegeben (Heronis Alexandrini Spiritualium liber. A Federico Commandino Urbinate. Ex Graeco nuper in Latinum conversus. Urbini 1575). Der Urtext wurde zuerst. 1693 von Thévenot veröffentlicht. 
Unter den Vorläufern Herons ist als einer der frühesten, der uns bekanntgeworden ist, Ktesibios von Alexandrien zu nennen (um 140 v. Chr.).

Letzterer fand einen Nachahmer in Philon von Byzanz. Bei ihm findet sich schon die Beschreibung des Heronsballs, der also eigentlich als Philonsball bezeichnet werden müßte ${ }^{1}$. Auch das Thermoskop begegnet uns schon bei Philon2). Philons „Pneumatik" und Herons "Mechanik" waren bis vor kurzem nur in spärlichen Fragmenten bekannt. Da entdeckte man, daß arabische Übersetzungen der griechischen Texte existieren. So wurde man ${ }^{3}$ ) 1894 mit der "Mechanik" Herons und 1897 mit der "Pneumatik" des Philon von Byzanz bekannt. Die Gesamtausgabe der Werke Herons ist für die Geschichte der Mathematik sowie der reinen und der angewandten Naturwissenschaften von großer Bedeutung. Das Automatenwerk Herons ist auch kunstgeschichtlich von Wichtigkeit, da es manchen Aufschluß iiber die antiken Bühneneinrichtungen gibt $\left.{ }^{4}\right)$. Heron beschreibt in seiner "Pneumatik“ eine große Anzahl von Apparaten, welche durch erwärmte Luft oder Dampf in Bewegung gesetzt werden. Die Abbildungen, von denen wir einige hier wiedergeben, rïhren nicht von Heron selbst, sondern von einem späteren Herausgeber her ${ }^{5}$ ).

Handelt es sich zum Teil auch um physikalische Spielereien, so begegnet uns doch manches, was den Anstoß zu späteren Erfindungen gegeben hat. Insbesondere gilt dies von einem Apparat, bei dem der Dampf in derselben Weise einen Körper in drehende Bewegung versetzt, wie es das ausströmende Wasser bei den Reaktionsrädern bewirkt. Die Maschine Herons (Abb. 26) besteht aus einem Kessel, von dem zwei senkrechte Röhren ausgehen. Zwischen ihnen befindet sich eine drehbare Halbkugel mit zwei Ansätzen, aus welchen der in die Halbkugel geleitete Dampf

1) W. Schmidt, Aus der antiken Mechanik. Neue Jahrbücher für das klassische Altertum. Bd. 13 (1904). S. 329.

2) W. Schmidt, Die Geschichte des Thermoskops (Abhandl. z. Gesch. d. Mathem. Bd. VIII. S. 161-173).

3) Durch Carra de Vaux. Dieser gilt jedoch als wenig zuverlässig.

4) Heronis Alexandrini Opera quae supersunt omnia. Leipzig, B. G. Teubner. Bd. I: Druckwerke und Automatentheater, griechisch und deutsch herausgegeben von W.Schmidt. 1899. Bd. II: Herons Mechanik und Katoptrik, herausgegeben und erläutert von L. Nix und W. Schmidt. 1901. Bd. III: Herons Vermessungslehre und Dioptra, griechisch und deutsch von H. Schoene. 1903.

5) Baldo v. Urbino. 
in tangentialer Richtung entweicht. Dadurch wird die Kugel in Drehung versetzt.

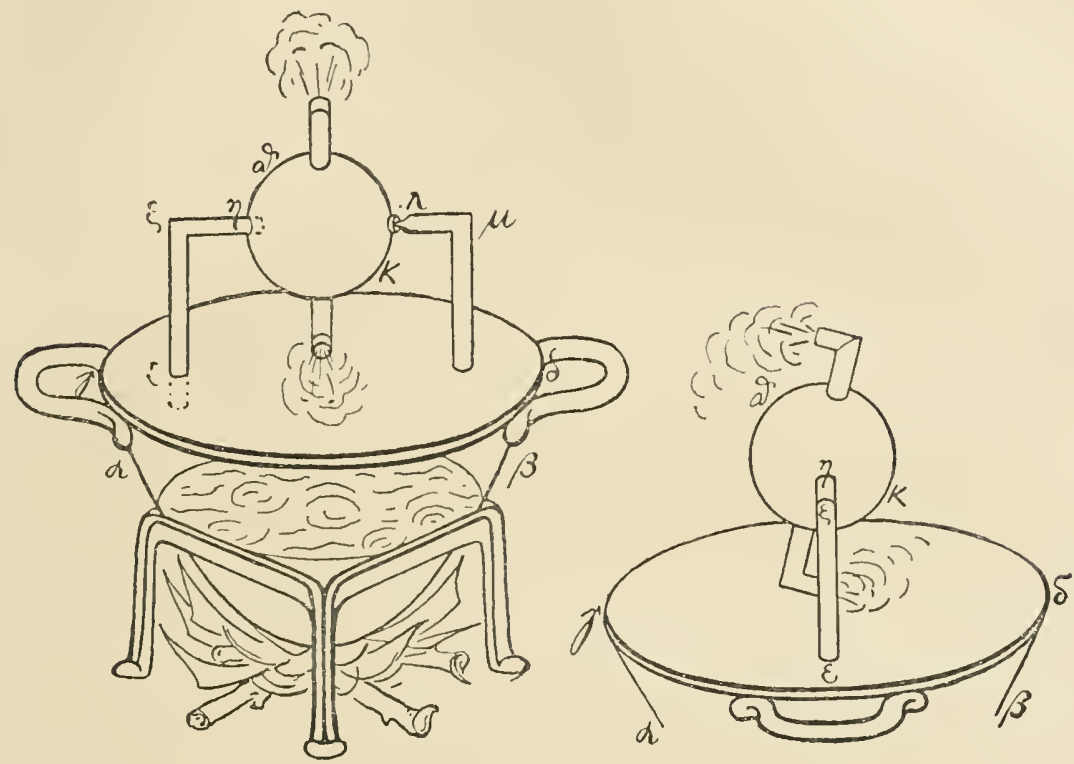

Abl. 26. Heron verwendet den Dampf zum Betriebe einer maschinellen Einrichtung.

Den nach ihm benannten Ball in folgender Weise: „In die Öffnung eines Gefäßes wird eine Röhre eingelötet, die fast bis auf den Boden reicht und in eine enge Mündung ausläuft. Durch eine seitliche Öffnung gießen wir Wasser in das Gefäß. Darauf blasen wir in diese Öffnung hinein, während wir auf die enge Mündung der senkrechten Röhre den Finger legen. Schließen wir dlann die seitliche Öffnung und nehmen wir den Finger von der senkreehten Röhre fort, so wird in ihr das Wasser durch die hineingeblasene, zusammengeprelite Luft emporgetricben." (s. Abb. 27) beschreibt Heron

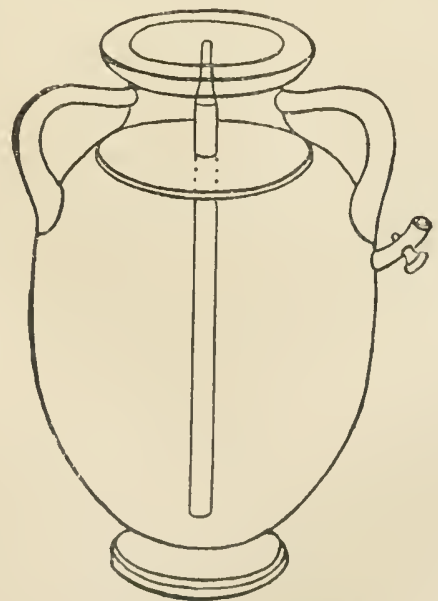

Alb. 27. Der Heronsball. 
Endlich sei hier noch Herons Abbildung des Hebers wiedergegeben (s. Abb. 28). „Befindet sich“, sagt Heron in seiner Erläuterung dieses Apparates, „die Hebermündung in gleicher Höhe mit dem Wasserspiegel, so wird der Heber, obgleich er voll Wasser ist, nicht fließen, sondern gefüllt bleiben. Es ist nämlich, wie bei einer Wage, das Wasser in diesem Falle im Gleichgewicht, indem es bestrebt ist, auf der Seite $\vartheta \beta$ sich zu heben und auf Seite $\beta \gamma$ sich zu senken. Ist aber die äußere Mündung des Hebers niedriger

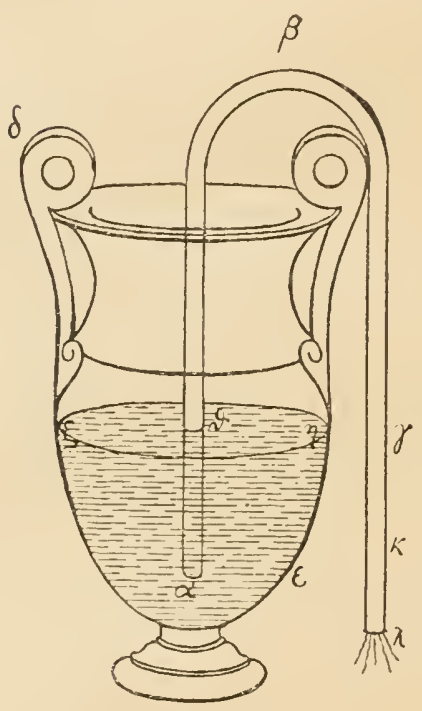

Abb. 28. Herons Abbildung eines Hebers. als der Wasserspiegel, so fließt das Wasser aus, da das in dem $\mathrm{Ab}$ schnitte $\% \beta$ befindliche Wasser, das scliwerer ist als das in $\beta \gamma$, letzteres iiberwältigt und anzieht."

Was die Natur der Luft betrifft, so meint Heron, daß sie aus Teilchen bestehe, die wie die Körnchen des Sandes durch leere Zwischenräume getrennt seien. Dies beweise zumal der Umstand, daß sich noch Luft in eine Kugel zu der darin vorhandenen füllen lasse, was darauf beruhe, daß die neuen Luftteilchen an Stelle der leeren Räume treten. Wolle man annehmen, die Luft fülle den rorhandenen Raum ganz aus, so wiirde eine Kugel beim Hineinbringen einer weiteren Luftmenge platzen müssen. Gäbe es keine Vakua, fügt Heron noch hinzu, so könnten weder Licht noch Wärme durch Wasser oder andere Flüssigkeiten dringen. Wenn nämlich die Flïssigkeit keine Poren lätte, die Strahlen also mit Gewalt ins Wrasser drängen, so müßten volle Gefäße überlaufen ${ }^{1}$. Jeder Körper besteht deshalb, nach Heron, aus kleinen Teilchen und dazwischen befindlichen leeren Räumen. Ein kontinuierliches Vakuum sei dagegen ohne Mitwirkung einer äußeren Kraft nicht möglich 2). Daß die Iuft ein Körper ist, beweist Heron, indem er ein leeres Gefäß umgeliehrt ins Wasser taucht. Auch bemerkt er, die Luft habe eine eigentïmliche Spannkraft, indem sie sich, wie

1) Ausgabe von Schmidt. S. 24.

2 Ausgahe von Schmidt. S. 29. 
ein trockener Schwamm, nach dem Zusammendriicken wieder ausdehne.

$\mathrm{Zu}$ welch überraschenden Kunststücken man diese Kenntnisse $z u$ verwerten wußte, zeigt uns die, durch nebenstehende Abbildung (29) erläuterte, auf der Ausdehnung und der Zusammenziehung der Luft beruhende Vorrichtung.

Wird auf dem Altar $\mathrm{E}$ ein Feuer angezündet, so treibt die erwärmte Luft infolge ihrer Ausdehnung das Wasser, das sich in der Kugel $\mathrm{P}$ befindet, in das aufgehängte, mit einem Drelıwerk rerbundene Gefäß M. Letzteres sinkt infolge seiner Gewichtszunahme und öffnet die Tür. Nach dem Erkalten der Luft strömt das Wasser durch die Röhre $\mathrm{L}$ nach $\mathrm{P}$ zurück, und die Tür wird durch das Gegengewicht D geschlossen, während das Gefäß $M$ in seine frühere Lage zurückkehrt.

Sowohl eine Beschreibung in Herons "Pneumatica", als auch die archäologischen Funde liefern den Beweis, daß man im spä-

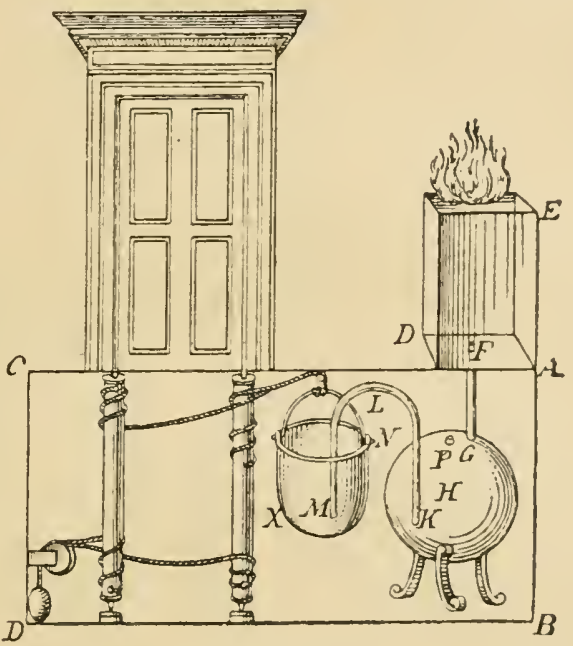

Abb. 29.

Herons Automat zum Öffnen der Tempel ${ }^{1}$. teren Altertum schon Orgeln mit Klaviaturen besaß, die man wie unsere heutigen Orgeln und Klaviere benutzte (Abb. 30). Sie wurden durch Wasser betrieben, mit dessen Hilfe man die Luft in einem Kasten zusammenpreßte (Wasserorgel oder hydraulus). Eine aus Ton verfertigte Orgel wurde ror einiger Zeit in Karthago aufgefunden. Sie läßt außer den Einrichtungen, die zur Herstellung des Luftstromes dienen, drei Reilıen von Orgelpfeifen und eine Klaviatur erkennen ${ }^{2}$.

1) Heronis Alexandrini spiritualium liber. Amstelodami 1680. Siehe anch Macl, Die Prinzipien der Wärmelelıe. Leipzig 1896. S. 5.

") Das ..Klavier" der alten Römer (Mitteil. zur Geschichte d. Medizin u. Naturwiss. 1905. S. 342, Der Bau der Wasservrgeln bat sich wälrend des Mittelalters im ostrümisehen Reich erhalten, so daß die Konstruktion nicht, wie man früher annahm, gegen den Ausgang des Mittelalters von neuem entdeckt werilen mußte. 
Heron bringt ferner eine Beschreibung der Feuerspritze, deren Rekonstruktion in Abb. 25 wiedergegeben wurde (s. S. 191). Seine Beschreibung lautet: „Es seien $\alpha \beta \gamma \delta$ und $\varepsilon \zeta \eta \vartheta$ zwei bronzene Stiefel, deren Inneres für zwei Kolben ausgedrechselt ist. Die Kolben müssen luftdicht in die Stiefel passen. Letztere seien durch das an beiden Euden offene Rohr $\xi \circ \delta \zeta$ miteinander verbunden. Außerhalb der Stiefel, aber innerhalb dieses Rohres, sollen

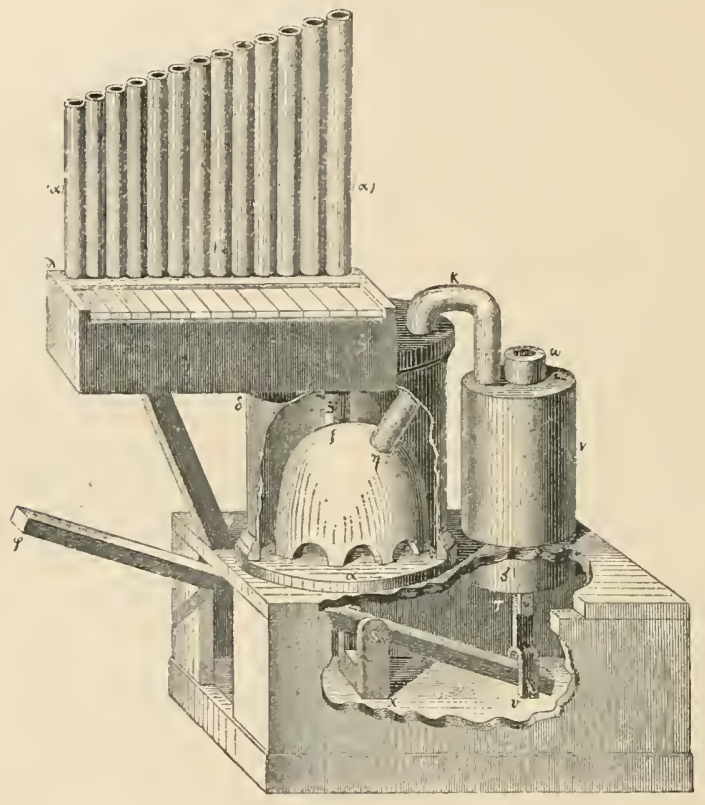

Abb. 30. Wasserorgel oder hydraulus.

Klappenventile $\pi$ und $\varrho$ derart angebracht sein, daß sie sich nach der Außenseite öffnen können. Die Stiefel sollen auch auf dem Boden runde Löcher haben, die mit kleinen, geschliffenen Scheibchen bedeckt werden. Letztere sind durch Stifte und Häkchen so angebracht, daß sie sich wohl auf- und abbewegen, aber sich nicht von den Öffnungen seitlich entfernen können. Mit den Kolben seien Kolbenstangen und ein Querbalken verbunden. Mit dem Rohre, das die beiden Stiefel verbindet, stehe ein vertikales Steigrohr in Verbindung. Dieses verzweige sich bei s zu einem Doppelarm, der zu einer drehbaren Mündung führt 1)." Die beschriebene

1) Schmidt, a. a. O. S. 133. 
Vorrichtung stimmt also mit der heutigen Feuerspritze überein, nur daß der Windkessel fehlt.

Ein Teil der zahlreichen, in Herons "Pneumatica" beschriebenen Versuche stammt von Philon von Byzanz, der gleich Heron ein Schüler des Ktesibios war. Da einige von diesen Versuchen eine grundlegende Bedeutung haben, so seien sie hier angeführt. So stellte Philon ein Thermoskop her, das auf der Ausdehnung der Luft durch die Wärme beruhte. In eine Bleikugel a wurde das doppelt gebogene Rohr b (s. Abb. 31) luftdicht eingefügt. Das andere Ende des Rohres mündete unter Wasser. Brachte man die Bleikugel in die Sonne, so strömte die Luft durch $b$ aus. Wurde dagegen die Bleikugel abgekühlt, so gelangte Wasser durch $b$ in die Kugel a ${ }^{1}$.

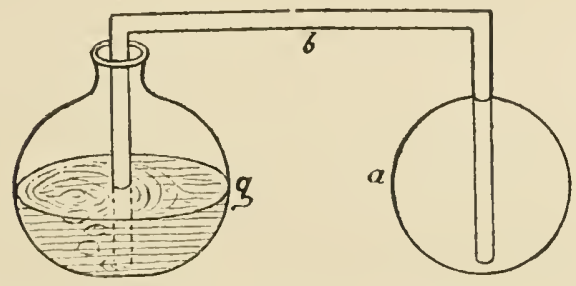

Abb. 31. Philons Thermoskop.

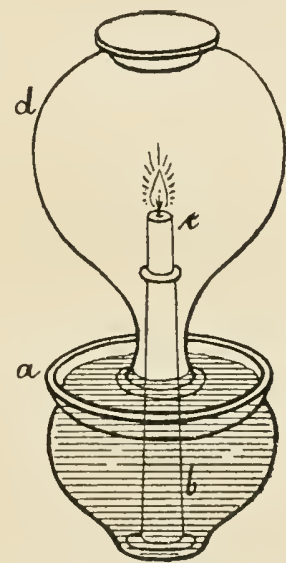

Abb. 32. Philons Saugkerze.

Die Abbildung 32 zeigt ims Philons Saugkerze. In dem Gefäße a befindet sich Wasser und eine brennende Kerze. Über diese wird d gestülpt ${ }^{2}$. "Man wird", sagt Philon, „bald das Wasser aufwärtssteigen sehen. Dies geschieht, weil die in d enthaltene Luft durch die Bewegung des Feuers verfliichtigt wird. Das Wasser steigt empor, je nach der Quantität Luft, welche verflüchtigt wird." Daß stets nur eine gewisse Menge Luft verschwindet, entging also der Beobachtung des alten Physikers. Immerhin begegnet uns hier schon derselbe Versucl, den im 18. Jahrhundert Scheele und andere anstellten, um zu beweisen, daß die Luft aus zwei verschiedenen Gasen zusammengesetzt ist.

1) Heronis Alexandrini opera, ed. Schmidt. S. 475.

2) Ausgabe von Schmidt. Abb. 115. 


\section{Weitere Fortschritte der Mechanik.}

Heron hat auch über die Mechanik der festen Körper ein Werk geschrieben, das lange als verloren galt und nur anszugsweise durch den späteren Alexandriner Pappos (um $300 \mathrm{n}$. Chr.) erhalten geblieben ist1). Wie Pappos mitteilt, hat Heron in diesem Werk die fünf Potenzen behandelt, nämlich den Hebel, das Rad an der Welle, den Keil, die Schraube und den Flaschenzug.

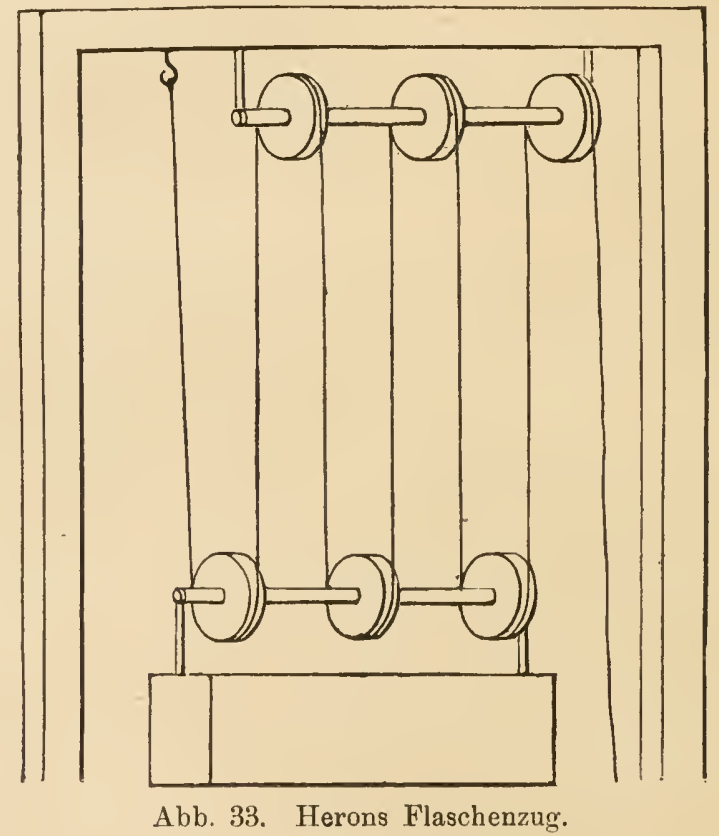

So wird, um ein Beispiel zu bringen, der Flaschenzug mit folgenden Worten beschrieben: „Wenn wir eine Last aufziehen wollen, so müssen wir an einem daran gebundenen Seil mit einer Kraft ziehen, welche der Last gleich ist. Wenn wir aber das eine Ende des Seils an einem festen Ort anbinden und das andere Ende um eine an der Last befestigte Rolle legen, so werden wir die Last leichter bewegen. Und wenn wir an dem festen Ort eine zweite Rolle anbringen und das Seil auch um diese legen, werden wir die Last

1) Pappi Alexandrini collectionis lib. VIII, ed. F. Hultsch. Berlin 1878. Über die vor kurzem entdeckte arabische Bearbeitung der Mechanik Herons siehe die folgende Seite. 
noch leichter bewegen. Aber wir bringen nicht die einzelnen Rollen an dem festen Ort, sondern, um ihre Achse drehbar, in einem hölzernen Gehäuse an, das wir eine Flasche nennen, und binden diese Flasche mit einem Seile an den festen Ort. Diejenigen Rollen, die mit der Last verbunden werden sollen, schließen. wir in eine andere, der ersten gleiche Flasche ein ${ }^{1}$. Je zallreicher die Rollen, desto leichter läßt sich die Last heben." An anderer Stelle löst Heron die Aufgabe, durch Zahnradübertragungen vermöge der Kraft 5 die Last 1000 zu heben (s. Abb. 17)2).

Durch eine ähnliche Übertragung finden wir schon bei Heron das Prinzip des Taxameters gelöst. Seine Einrichtung ist aus Abb. $3 t$ ersichtlich. An der Nabe des Rades befindet sich ein Stift, der das horizontale, mit 8 Speichen versehene Rad EZ jedesmal um eine Speiche weiter dreht. Einer Umdrehung des Rades EZ entspricht eine Fortbewegung des über $\mathrm{E} Z$ befindlichen /aahnrades um einen Zahn. Die Übertragung erfolgt durch das Schneckengewinde üiber EZ. Diese Übertragung wiederholt sich so oft, daß eine Umdrehung des letzten Zeigers mehrere tausend Umdrehungen des Wagenrades oder auch direkt den zuriickgelegten Weg in Stadien anzeigt $\mathbf{t}$ ).

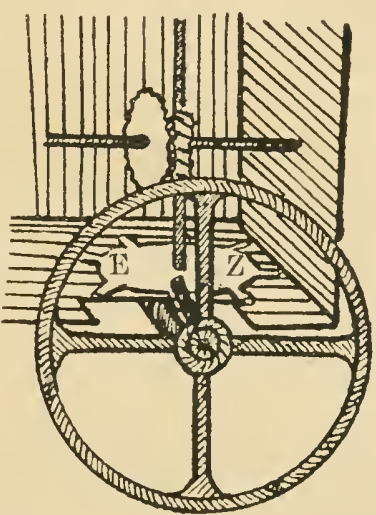

Abb. 34. Herons Wegmesser.3).

Neuerdings ist die Mechanik Herons nach einer arabischen Handschrift in französischer Übersetzung herausgegeben worden ${ }^{5}$ ). Heron bringt nicht nur die Beschreibung und die Theorie der fünf einfachen Maschinen, sondern er beschäftigt sich auch eingehend mit Schwerpunktsbestimmungen. So findet er den Schwer-

1) Ausgrabe von Schmidt. Bd. II. S. 102.

2) Papp. Kap. X. Heron, Opera omnia, Ausgalse v. Schinidt. Bd. II. 1. Teil. S. 259.

3 Diels, Ant. Teclınik, Abb. 28.

4 Näheres über derartige antike Automaten enthält Diels' Antike T'echnik in 3. Alsschnitt. Iseipzig, B. G. Teubner. 1914.

5) Von Carra de Vaux im .Journal asiatique $\mathrm{X}, 1-2$. Von dem griechischen Text sind nur einige Fragmente vorhanden. Bd. II der Opera omnia (Ausg. r. Sehmidt) enthält die Übersetzung der Mechanik nach der arabischen Bearbeitung dieser Suhrift Herons. Die Katoptrik wurde nach einem lateinischen T'ext überset». 
punkt des Dreiecks als den Schnittpunkt der Mitteltransversalen, die sich im Verhältnis 2:1 teilen. Um den Schwerpunkt des unregelmäBigen Vierecks zu finden, zerlegt er es durch eine Diagonale in zwei Dreiecke, verbindet deren Schwerpunkte und teilt dann diese Verbindungslinie im umgekehrten Verhältnis der Gewichte dieser Dreiecke.

Beim Hebel und beim Flaschenzug untersucht Heron das Verhältnis des Kraftweges zum Lastwege oder das der Zeiten, welche die Last, je nach dem Kraftgewinn, zum Emporsteigen auf eine bestimmte Höhe gebraucht. Er gelangt dabei zu dem Gesetz, das wir heute als die goldene Regel der Mechanik bezeichnen. Die Fassung, welche er diesem Gesetz gibt, lautet: „Das Verhältnis der Zeiten ist gleich dem umgekehrten Verhältnis der bewegenden Kräfte ${ }^{1}$." Nicht so klar ist Heron die Theorie der Schraube und des Keiles geworden. Hier vermag er das Verhältnis von Kraft zu Last nicht anzugeben. Es rührt dies daher, daß er Keil und Schraube nicht auf die schiefe Ebene zuriickfiilırt, sondern sich vergeblich abmüht, sie aus der Hebelwirkung zu erklären. Die schiefe Ebene wird von ihm nicht zu den einfachen Maschinen gerechnet und gleichfalls in ihrer Wirkung noch nicht richtig erkannt ${ }^{2}$ ).

\section{Die wissenschaftlichen Grundlagen der Vermessungskunde.}

Eine besondere Würdigung verdienen noch Herons Bemühungen um die Ausgestaltung der Feldmeßkunst. Heron verfaßte eine Schrift "Über die Dioptra“"3). Es ist das ein Meßapparat, in dem wir das Urbild des heutigen Theodolithen erblicken müssen. Eine Rekonstrulition des interessanten Instrumentes ist in nebenstehender Abbildung wiedergegeben ${ }^{4}$ ). Die Hauptteile waren die auf dem Stativ ruhende Platte $A B$ und das Zahnrad $\Gamma \Delta$, welches

1) Journal asiatique IX, 2. S. 264 u. f.

2) Eine gute Übersicht über das physikalische Wissen Herons bietet die Programmabhandlung von F. Kna $\mathrm{ff}$, Sophiengymnasium, Berlin. Ostern 1900.

3) Der griechische Text wurde 1858 von Venturi und Vincent mit französischer Übersetzung herausgegeben, und zwar in den Notices et extraits des manuscrits de la libliothèque impériale XIX, 2. Paris 185̃8. Dioptra heißt etwa Sehrohr oder Instrument zum Visieren durch zwei sich gegenüberstehende Öfrnungen (siehe die Abb. 35).

4) Sie rührt von Hermann Schöne her und wurde im Jahrbuch des Kaiserl. deutschen archäolog. Institutes (Bd. XIV. 1899. Heft 3) veröffentlicht. 
durch die Archimedische Schraube $E Z$ in Bewegung gesetzt wurde und dadurch eine Drehung des ganzen Instrumentes um eine vertikale Achse ermöglichte. Eine zweite Archimedische Schraube befand sich iiber $K \Lambda$. Man erkennt, daß sie die Aufgabe hatte, vermittelst des vertikal gestellten, halbkreisförmigen Zahnrades die oberste, mit dem Visierlineal versehene Platte um eine horizontale Achse zu drehen. Da die Platte nicht unmittelbar auf dem halbkreisförmigen Zahnrade aufsa $\beta$, sondern an eine rechteckige Fortsetzung des letzteren angeschlossen war, so konnte die Drehung um die horizontale Achse vermittelst der oberen Archimedischen Schraube so lange fortgesetzt werden, bis die große Platte eine senkrechte Stellung eingenommen hatte. Es ließ sich somit jeder Horizontal- und jeder Höhen winkel mit Hilfe dieses Apparates messen, so daß die Dioptra zur Lüsung von Auf-

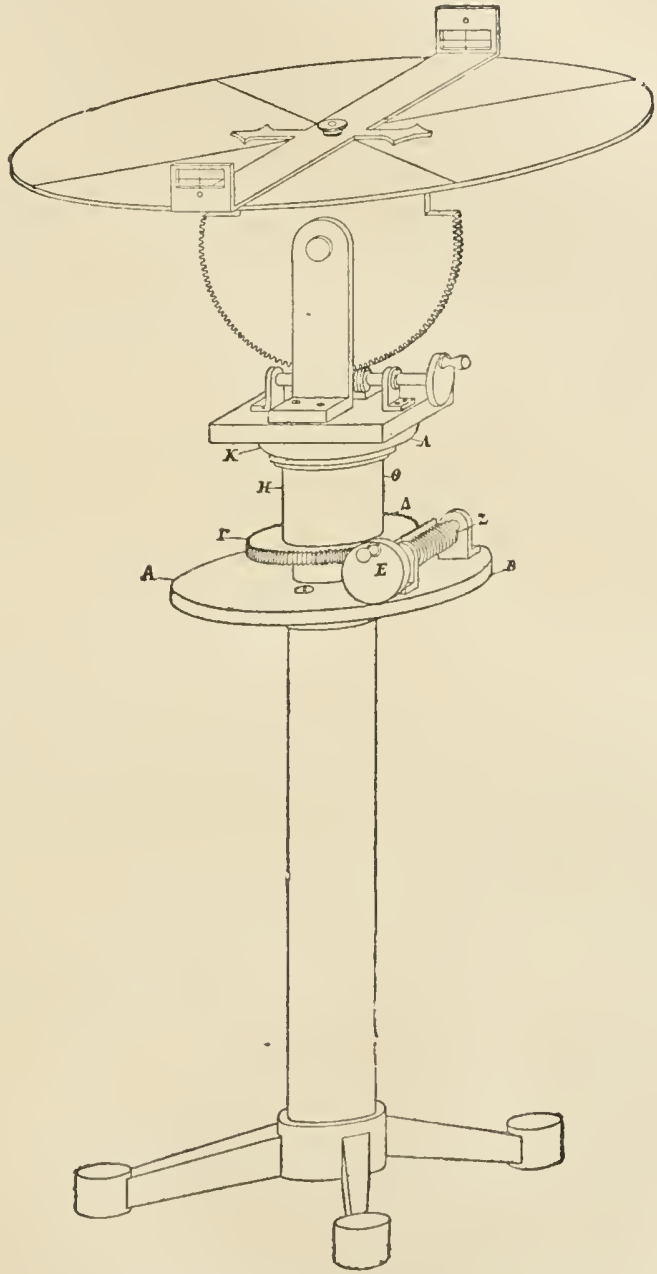

Ab\}. 35. Herons Winkelmeßapparat. galen der Feldmeßkunst vortrefflich geeignet war. Die Einstellungen wurden durch Wasserwage und Bleisenkel vermittelt. Ferner besaß das Diopterlineal, um auch kleinere Winkel noch ablesen zu können, eine bedeutende Lïnge.

Von den zahlreichen Aufgahen, für welche Heron in seiner Schrift das einzuschlagende Meß- und Berechnungsverfahren an- 
gibt, seien hier nur einige erwähnt. Die wichtigste Aufgabe war die Aufnahme eines Feldes ron beliebiger Umgrenzung. Heron verfuhr clabei wie folgt: Zunächst wurde ein großes Rechteck so abgesteckt, daß es innerhalb der Umgrenzung lag (siehe Abb. 36). Dann wurde für viele Punkte der Umgrenzung der senkrechte Abstand ron der zugewandten Seite des großen Rechtecks gemessen. Auf diese Weise wurde der außerhalb des Rechtecks liegende Teil des zu messenden Feldes in kleinere Abschnitte von möglichst regelmäßiger Form zerlegt, deren Flächeninhalt leicht annähernd ausgemessen werden konnte.

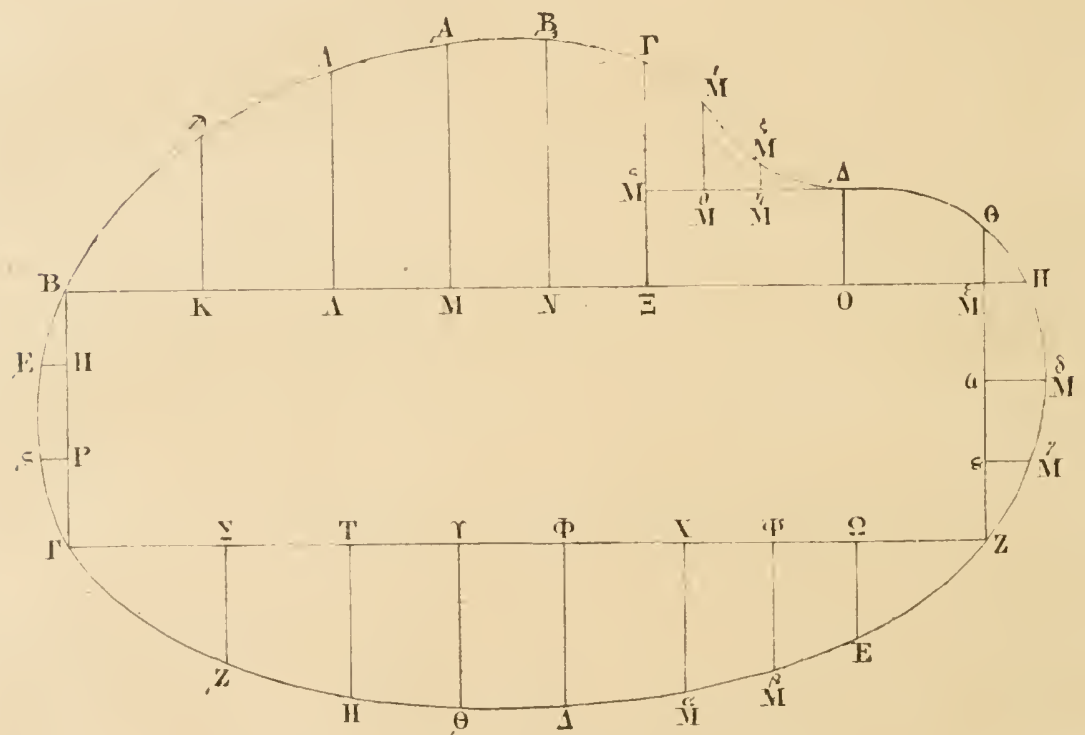

Abl. 36. Herons Vermessung eines Feldes.

Ein Blick auf die Abbildung lehrt uns, daß Heron hier mit rechtwinkligen Koordinaten arbeitet, und daß er die umgrenzende Linie recht genau in den Plan einzeichnen kounte, wenn er nur recht viele Senkrechte von den Punkten der Linie aus nach den Rechteckseiten errichtete und ausmaß.

Weiter zeigt Heron, wie man die Breite eines Flusses ermittelt, ohne ihn zu überschreiten. In einem andern Abschnitt wird die Aufgabe gelöst, ein Feld mit Hilfe eines Planes wieder abzustecken, wenn die Umfriedigung mit Ausnahme weniger Grenzsteine rerlorengegangen ist $\left.{ }^{1}\right)$. Ein Abschnitt (30) entwickelt die

1 Siehe Abschn. 25 des Heronschen Werkes sowie Cantor, Geschichte der Mathematik. Bd. I. S. 324. 
Heronsche Formel für die Fläche eines Dreiecks, dessen drei Seiten gegeben sind. Sie lautet:

$$
\Delta=\sqrt{\frac{a+b+c}{2} \cdot \frac{a+b-c}{2} \cdot \frac{a+c-b}{2} \cdot b+c-a}
$$

Ob Heron diese Formel selbst gefunden oder anderen entlehnt hat, ist nicht bekannt. Auch weiß man nicht, wie groß sein Anteil an der Konstruktion der Dioptra ist. Sicherlich bestand die Feldmeßkunst in Ägypten schon Jahrtausende vor Heron. Doch waren ihre Regeln zum Teil recht mangelhaft, so daß man ${ }^{1}$ ) annimmt, daß Heron, auf den Arbeiten seiner Vorgänger fußend, ein amtliches, zahlreiche Verbesserungen aufweisendes Lehrbuch der Feldmeßkunst lieferte. Dieses hat dann auch den Römern als Handbuch gedient. Stand doch bei diesem Volke die Vermessungskunde, wie bei dem praktischen Grundzuge der Römer nicht anders $\mathrm{zu}$ erwarten ist, in hoher Blüte. Wie hätte sich z. B. die Anlage ausgedehnter Wasserleitungen ermöglichen lassen, wenn die Kunst des Nivellierens, für welche man sich ebenfalls der Dioptra bediente, den Römern nicht geläufig gewesen wäre.

Während der griechische Text der „Dioptra“ schon seit 1858 bekannt ist, entdeckte man erst 1896 Herons "Metrika“, ein Werk, das seit dem 6. Jahrhundert verschollen war. Die "Metrika” Herons ${ }^{2}$ ) stellen ein Handbuch dar, das eine Anweisung zur Teilung und Berechnung von Flächen enthält, während die "Dioptra“"3) Herons die Beschreibung der wichtigsten geodätischen Hilfsmittel und eine Anzahl ron Aufgabenbeispielen lieferte.

Zu den Aufgaben, deren Lösung Heron bringt, gehört außer den Nivellierungen auch die Absteckung von Geraden zwischen zwei Punkten, von denen der eine nicht vom andern aus gesehen werden kann. Die Aufgabe war schon im Altertum praktisch wichtig, z. B. wenn es galt, einen Tunnel durch einen Berg zu graben. Daß dic alten Ingenienre schon Tunnelbauten ron betrïchtlicher Länge ausführten, beweist dic im Jahre 1884 erfolgte Freilegung eines Tunnels von etwa $1000 \mathrm{~m}$ Länge durch den Kastroberg (auf Samos).

1, Siehe Cantor, Gesehichte der Mathematik. I (1907). S. 382 u. f.

2) Heronis Alexandrini Opera, quae supersunt omnia. Ausgabe von Schmidt. Bd. I-III. I Leipzig 1889, 1900, 1903. Die ..Metrika* finden sich im III. Bande; sie wurden von R. Schöne 1896 entdeckt.

3, Siehe S. 200 . Anm. 3. 
Wie Heron die Aufgabe löste, einen Berg zu durchstechen, wenn die Miindungspunlite des Durchsticlss gegeben sind, zeigt uns Abb. 37. Wir sehen, daß er sich auch hierbei wieder eines Systems von rechtwinkligen Koordinaten bediente.

Heron schließt seine Darstellung mit den zuversichtlichen Worten: "Wird der Tunnel auf diese Weise hergestellt, so werden sich die Arbeiter von beiden Seiten treffen."

Der Tunnel durch den Kastroberg ist durch deutsche Forschungen wieder entdeckt worden. Er hatte den Zweck, eine jenseits des Berges befindliche Quelle mit der Stadt zu verbinden.

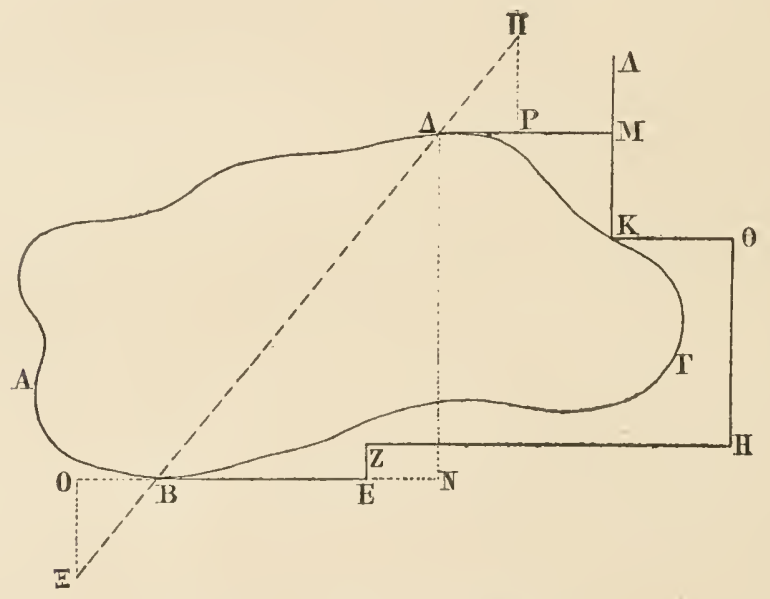

Abb. 37. Herons Tunnelaufgabe.

Diese Anlage, die Herodot als ein Wunderwerk preist, entstand zur Zeit des Polykrates. Sie verdient auch deshalb Bewunderung, weil die Arbeit ja ohne die modernen Sprengmittel geleistet werden mußte $\left.{ }^{1}\right)$.

Ein weiteres Beispiel für den Tunnelbau der Alten bietet der noch jetzt vorlandene Abfluß (Enissar) des Albaner Sees. Dieser Abflußkanal ist ein Stollen von $1200 \mathrm{~m}$ Länge. Seine Breite beträgt $1 \frac{1}{2} \mathrm{~m}$, seine Höhe $\left.2-3 \mathrm{~m}^{2}\right)$. Als eine Ingenieurarbeit größeren Umfangs ist aus der griechischen Geschichte die Trockenlegung des Kopaissees unter Alexander dem Großen zu erwähnen $\left.{ }^{3}\right)$.

1. Diels, Antike Technik. S. 9.

2) E. Merkel, Die Ingenieurtechnik in Altertum. 1899. S. 151.

3) F. Zink, Die Entwicklung der Entwässerungen mit offenen Gräben 
Bei Heron begegnen uns auch die ersten Anweisungen darüber, wie man sich beim Bergbau unter der Erde zu orientieren hat. Aus diesen Anfängen hat sich, besonders seit dem Zeitalter Agricolas, des Begründers der neueren Mineralogie (16. Jahrhundert), die Markscheidekunst entwickelt.

Durch Herons Schriften wird man am besten mit dem konkreten Messen und Rechnen seiner Zeit und mit den damals gebräuchlichen Maßen bekannt. Für das kaufmännische Rechnen fehlt es leider an einer ähnlichen Überlieferung $\left.{ }^{1}\right)$. Doch be-

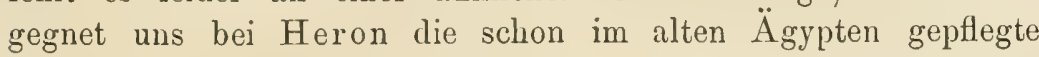
Verteilungs- und Gesellschaftsrechnung. Bekannt ist beispielsweise Herons Brunnenaufgabe. Es wird darin nach der Zeit gefragt, innerhalb deren durch mehrere Röhren ein Behälter mit Wasser gefüllt werden kann, wenn man die Füllzeit für jede einzelne Röbre kennt.

Heron hat auch eine Katoptrik geschrieben. Sie läßt uns erkennen, daß schon im Altertum die Ansicht bestand, daß die Natur nichts vergeblich tue. Von diesem Prinzip ausgehend, wurde die gradlinige Ausbreitung des Lichtes erklärt. Die gleiche Betrachtungsweise leitete Heron bei dem Nachweise, daß der Weg, den das einfallende und das reflektierte Licht zuriicklegt, nur dann ein Minimum ist, wenn der Einfallswinkel gleich dem Reflexionswinkel ist 2).

\section{Naturbeschreibung und Heilkunde im alexandrinischen Zeitalter.}

Bei der Beurteilung der Schriften eines Ptolemïos, Euklid und Heron läßt es sich schwer entscheiden, was diese Männer auf den von ilınen behandelten Gebieten Eigenes, Neues geschaffen, und was sie ibren Zeitgenossen und Vorgängern entlehnt haben. Es kann indessen auch gar nicht die Aufgabe der hier gebotenen, zusammenhängenden Darstellung einer Geschichte der Wissenschaften sein, im einzelnen Prioritiitsansprüche gegeneinander abzuwägen. Diese, in der Regel wenig fruchtbringende Aufgabe muß

und Drainagen von den ältesten Zeiten bis zur Gegenwart. - Drainierungsanlagen mit T'onrühren wurden in Babylonien schon um 1900 v. Chr. hergestellt.

1) Tropfke, Geschichte der Elementarmathematik. Bd. I. S. 98.

2) Haas, Antike Lichttheorien, im Archiv für Geschichte d. Philosophie. 20. Bd. (1907). S. 356 . 
der listorischen Einzelforschung überlassen bleiben, eine Einschränkung, die hier auch gleich für die Behandlung späterer Perioden der Wissenschaft gemacht sei. Für uns ist es viel wichtiger, in den jeweiligen Stand der Kenntnisse einzudringen und den logischen Zusammenhang, die bedingenden Ursachen aufzuweisen. Für diesen Zweck war die etwas ausführlichere Darstellung, die wir den genannten drei alexandrinischen Gelehrten gewidmet haben, von Wert.

Während die Astronomie, die Mathematik und einige Zweige der Physik von den Alexandrinern sehr gepflegt und gefördert wurden, wandten sie den beschreibenden Naturwissenschaften eine geringere Anteilnahme zu. Vielleicht ist dies in der kommentatorischen Gelehrsamkeit der Alexandriner begruindet. Bestand doch ihre Hauptaufgabe darin, Handschriften zu vergleichen, zu erläutern und zu ergänzen. So sagt Plinius ron ihnen: „In den Schulen sitzen und Vorträge anhören, war angenehmer, als durch Einöden zu gehen und Tag für Tag neue Pflanzen zu suchen 1)." Als selbständige Wissenschaft hörte die Botanik auf. Sie bestand in der alexandrinischen Schule nur noch als ein Zweig der Heilkunde, als Heilmittellehre, weiter. Es war deshalb von Bedeutung für die Entwicklung der Botanik, daß auch die Geographen dieses Zeitalters der Pflanzenwelt ihre Aufmerksamkeit zuwandten. Vor allem ist hier Strabon als der größte unter den Geographen der spätalexandrinischen Schule zu nennen. Wenn dieser Mann auch nicht selbst Pflanzenkenner war, so nahm er doch die Pflanzenund die Tierwelt als Gegenstand seiner Wissenschaft mit Recht in Anspruch, so daß seit Strabons Auftreten die Bedeutung der Botanik für die allgemeine Erdkunde stets gewürdigt worden ist.

In höherem Maße als die Botanik wurde die Anatomie bei den Alexandrinern gepflegt: An erster Stelle sind hier Herophilos (um 300 v. Chr.) und Erasistratos ${ }^{2}$ ) (um 280 v. Chr.) zu nennen. Von Herophilos, einem der bedeutendsten Ärzte des Altertums ${ }^{3}$ ), riihrt die erste eingehendere Untersuchung des Auges her, während Erasistratos die blutführenden Venen von den, nach damaliger Ansicht, mit Pneuma gefüllten Arterien unterschied.

1) Meyer, Geschicbte der Botanik. Bd. I. S. 215.

2) Einen ausführlichen Beitrag über Erasistratos enthält Paulys Realenzyklopädie f. d. klass. Altertum. Bd. VI (1909). S. 333. Er rührt von Wellmann ber.

3) Wie Diels (Antike Technik, S. 24) angibt, maß Herophilos den Puls seiner Kranken mit Hilfe einer Taschenwasseruhr. 
Erasistratos war auch nahe daran, den Kreislauf des Blutes zu erkennen. Er scheiterte nur an dem soeben erwähnten Irrtum, daß die Arterien das Pneuma (den Luftgeist) enthielten. Andererseits erkannte er ganz richtig das Herz als den Ausgangspunkt der Gefäße, sowie das Gehirn als die Ursprungsstelle der Nerven. Vor allem wurde die Anatomie dadurch auf eine sichere Grundlage gestellt, daß man die Sehnen von den Nerven unterschied und letztere als die Organe der Empfindung sowie die Muskeln als die Werkzeuge der Bewegung kennenlernte. Allerdings waren die Alexandriner in ihren Mitteln nicht sehr wählerisch, da sie selbst vor Vivisektionen an Menschen nicht zurückscheuten $\left.{ }^{1}\right)$.

1) Haeser, Geschichte der Medizin. Bd. I. S. 233. 


\section{Die Naturwissenschaften bei den Römern.}

Weit später als in Griechenland und in dem von Griechen bewohnten Siiden Italiens entwickelte sich eine höhere geistige Kultur in Mittelitalien. Die Hauptmasse der Berölkerung dieses Teiles der Apenninenhalbinsel war in vorgeschichtlichen Zeiten, als ein den Hellenen und Kelten verwandtes Volk, über die Alpen eingedrungen. Sie war dort zunächst mit den Etruskern, einem Volk, dessen Abstammung zweifelhaft ist, in Berührung getreten. Erst weit später machte sich der Einfluß der in Süditalien bestehenden griechischen Ansiedelungen auf die mittelitalischen Völkerschaften geltend. Es geschah dies erst, nachdem letztere unter der Fïhrung Roms eine staatliche Einigung erfahren hatten.

Während man sich in den unserer Zeitrechnung vorangehenden Jahrhunderten in der Stille des alexandrinischen Gelehrtentempels die Welt zu erkennen mühte, hatte man sie von Mittelitalien aus durch die Gewalt der Waffen unterjocht. Giriechenland war schon länger als ein Jahrhundert römische Provinz, als im Jahre 30 v. Chr. Agypten dasselbe Schicksal ereilte. Die politische Umgestaltung dieses Landes vollzog sich jedoch allmählich, da der römische Einfluß sich schon lange vor jenem Zeitpunkt in stetig wachsendem Maße geltendgemacht hatte. Diese Umgestaltung war daher auch für die Wissenschaften nicht von solch einschneidender Bedeutung, wie später das Hereinbrechen entfesselter, barbarischer Horden. In dem Maße nämlich, wie die Römer das dem Osten sein geistiges Grepräge verleihende Griechenland politisch überwanden, nahmen sie den Inhalt der griechischen Bildung in sich auf. Sie wurden die Herren, aber zugleich die Schüler der Griechen. Auch aus den reichen literarischen Schöpfungen der Semiten und der Ägypter vermochten die Römer zu schöpfen ${ }^{1}$ ). Meister sind sie auf dem Gebiete der Kunst und Wissenschaft indessen nicht geworden. Weit mehr entsprach ihrem ganzen Sinne sowie ihren Bedürfnissen eine Fortentwicklung der Technik. Auf diesem Felde

1) Lindner, Weltgeschichte. Bd. I. S. 26. 
haben sie, wie rlie großartigen Überreste ihrer Werke noch heute bezeugen, die Griechen zweifelsohne übertroffen. Doch erfuhr die wissenschaftliche Grundlage der Technik, die Mechanik nämlich, durch die Römer keinen wesentlichen Fortschritt. Wurde auch während der Kaiserzeit Rom, nachdem es zum politischen Mittelpunkt der Welt geworden, neben Alexandria mehr und melır zu einem Sitz der W Wissenschaften, so kann man doch von einem römischen Zeitalter der letzteren nicht sprechen. Dariiber, sich die Elemente 'der griechischen Bildung anzueignen, sind die Römer kaum hinausgekommen, während in dem römisch gewordenen Alexandria ein nener, bedeutender Aufschwung die ersten Jahrhunderte unserer Zeitrechnung ausfüllt.

Als der Hellenismus etwa um die Zeit des zweiten punischen Krieges das römische Geistesleben zu durchdringen begann, hatte die römische Literatur noch keine Schöpfung von einiger Bedeutung aufzuweisen. Ein mit wissenschaftlichen Dingen sich befassendes Prosaschrifttum fehlte ihr bis zu dem angegebenen Zeitpunkt noch fast gänzlich. Was auf diesem Gebiete vorhanden war, betraf lediglich die Grundlagen des Rechtswesens, die Führung von Chroniken, den Kultus und dic engeren Bedürfnisse des praktischen Lebens. Vom größten Einfluß auf die Literatur des römischen Volkes wurde seine Berïhrung mit den Griechen, zunächst mit den Kolonien Süditaliens und später mit dem griechischen Mutterlande. Eingeleitet wurde die Berührung zwischen Römer- und Griechentum durch den Handel. Zu einer innigeren Durchdringung kam es jedoch erst durch den kriegerischen Zusammenstoß, der die römischen Heere in die griechischen Kolonien und nach Hellas führte und umgekehrt zahlreiche Griechen sowie griechische Kunst- und Wissensschätze nach Rom gelangen ließ. Diese Umwälzungen begannen in 3. vorchristlichen Jahrhundert mit dem tarentinischen (282-272) und dem ersten punischen Kriege (264-241). Um 200 folgte die Besiegung Makedoniens, und wenige Jahrzehnte später wurde durch Aemilius Paulus dem einst dem römischen an Umfang und Bedeutung gleichen makedonischen Reiche durch die Schlacht bei Pydna (168 v. Chr.) ein Ende bereitet. Z/ahlreiche Geiseln, zumeist vornehmen und gebildeten hellenischen Familien entsprossen, kamen infolge dieses Sieges nach Rom. Eins der wertvollsten Beutestiicke, welche der Sieger heimbrachte, war die Bibliothek des makedonischen Königs. Infolge dieser Geschehnisse bildete sich in Rom ein stetig wachsender Kreis von Freunden griechischer Bildung, die voll Bewunde- 
rung den Vorträgen nach Rom gewanderter Rhetoren und Philosophen lauschten. Aus dieser geistigen Verbrïderung trat mit immer größerer Deutlichkeit das Bestreben hervor, durch die Vereinigung der realen römischen Macht mit dem Inhalt des griechischen Geisteslebens innerhalb eines einzigen Staatsgebildes ein von den bisherigen engen nationalen Schranken befreites Weltbiirgertum entstehen zu lassen.

Unter den Männern, die sich gegen diese Entwicklung stemmten, ohne sie jedoch nur im geringsten hemmen zu können, ist besonders Marcus Portius Cato zu nennen. Dem Haß, mit dem er in jeder Sitzung des Senats die Zerstörung Karthagos forderte, kam seine Erbitterung gegen griechische Bildung und griechisches Geistesleben gleich. Aus dieser Stellungnahme erwuchsen Catos "Unterweisungen“, ein Werk, das eine Art Enzyklopädie darstellte und zeigen sollte, daß die ältere römische Literatur es mit der besonders ihrer Neuheit wegen so hoch eingeschätzten griechischen wohl aufnehmen könne. Von Catos „Unterweisungen" sind nur einige Fragmente erhalten geblieben. Dagegen besitzen wir in seinem Buche uiber die Landwirtschaft (De agricultura) das älteste auf unsere Zeit gekommene Werk des lateinischen Prosaschrifttums. Es ist eine der wichtigsten Quellen für die an späterer Stelle ausführlich zu besprechende "Naturgeschichte" des Plinius gewesen.

Von dem die Hellenen beherrschenden Streben, im Einzelnen das Allgemeine, die Idee zu finden, gingen die Römer später zu einem mehr empirischen, oft unkritischen Beobachten des Außerlichen ïber und gelangten auf diesem Wege mitunter zu Plattheiten, wie sie uns bei Cicero begegnen, der da meinte, die Naturwissenschaft suche entweder nach Dingen, die niemand wissen könne, oder nach solchen, die niemand zu wissen brauche. Es sind manche Vermutungen darüber ausgesprochen worden, weshalb die Römer das von den Griechen begonnene Werk nicht fortgesetzt haben, so daß auf die Begründung der Wissenschaften unmittelbar ihr weiterer Ausbau gefolgt wäre. Die einen erblicken die Ursache dieser Erscheinung in dem Fehlen der experimentellen Forschungsweise, obgleich doch, wie wir sahen, die Ansätze zu einer solchen in der Blütezeit der alexandrinischen Periode wohl vorhanden waren. Andere meinen, die Römer, welche zwar die berufenen Erben der Griechen gewesen seien, hätten bei ihrer Aufgabe, die Welt zuerst zu erobern und sie dann zu beherrschen, weder Zeit noch Simn für die Beschäftigung nit wissenschaftlichen 
Dingen gehabt. Auch den Mangel an Werkzeugen für die wissenschaftliche Arbeit, wie sie die neuere Zeit in Fülle hervorbrachte, hat man dafür verantwortlich machen wollen, daß die Wissenschaft nach ihrer Begründung zunächst keine wesentlichen Fortschritte aufwies.

Die Einflüsse, welche die in Frage stehenden sowie ähnliche Erscheinungen in der Entwicklung der Zivilisation und des Geisteslebens herbeigeführt haben, sind für uns, die wir solch entlegene Zeiten durch ein sehr getrübtes Medium erblicken, nicht mehr scharf erkennbar. Jedenfalls haben hier nicht nur eine oder einige der genannten Ursachen mitgespielt, sondern es hat ein 'Zusammenwirken zahlreicher Umstände stattgefunden. Die natïrlichen Anlagen, die auch bei nahe verwandten Völkern nicht immer die gleichen sind, sowie die Macht der politischen und der religiösen Verhältnisse werden jedenfalls hierbei in erster Linie den Ausschlag gegeben haben. So war ${ }^{1)}$ "die ganze Geistesanlage der Römer nach wesentlich anderen Gebieten gerichtet als dem der reinen Wissenschaft". Und selbst als Rom Weltreich geworden, betonte Cicero, daß die griechischen Mathematiker auf dem Gebiete der reinen Geometrie das Glänzendste geleistet, während sich die Römer nur auf die Ausïbung des Rechnens und des Ausmessens beschränkt hätten $\left.{ }^{2}\right)$.

\section{Meßkunst und Astronomie bei den Römern.}

'Die Römer hielten die Feldmeßkunst für wenigstens eben so alt wie Rom. Sie wurde zuerst von Priestern ausgeübt, um das zu den Tempeln gehörende Land abzugrenzen. In der Kaiserzeit war die Feldmeßkunst sehr entwickelt. Wer sie ausüben wollte, muBte eine Schule durchmachen und eine Prüfung ablegen ${ }^{3}$.

Die ersten Kenntnisse in der Feldmeßkunst verdankten die Römer sehr wahrscheinlich den Etruskern. Als Meßapparat benutzten sie ein Winkelkreuz, das aus zwei in der horizontalen Ebene sich schneidenden Linealen bestand. Eine Abbildung dieses Apparates wurde auf dem Grabe eines römischen Feldmessers gefunden ${ }^{4}$. An den Enden der Lineale befanden sich Lote. Die

1) Nach einem Ausspruch Cantors (Geseh. d. Math. Bd. I. S. 45).

2) Cicero, Tuseul. disput. Lib. I. 2, 5 .

3) Siehe Cantor, Röm. Agrimensoren. Leipzig 1875.

4) Die betreffende Grabschrift wurde im XIV. Bande der II. Serie der Abhandlungen der 'l'uriner Akademic veröfientlicht. 
alten Italer vermochten mit Hilfe dieses Instrumentes, der Groma, und der Meßstange schon die Breite eines Flusses von einem Ufer aus zu bestimmen, ohne den Fluß zu ïberschreiten. Für diese Aufgabe war sogar eine bestimmte Bezeichnung im Gebrauch ${ }^{1}$ ). Das erwähnte, von den Römern benutzte Winkelmeßinstrument

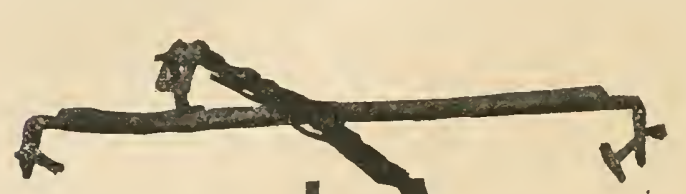
haben neuere Ausgrabungen ans Licht gebracht. Die nebenstehende Abbildung 38 stellt ein bei der

Abb. 38.

Der Meßapparat der Römer.

Limesforschung ${ }^{2}$ ) entdecktes Exemplar dar. Die Abbildung 39 zeigt uns eine Rekonstruktion. Das Instru-

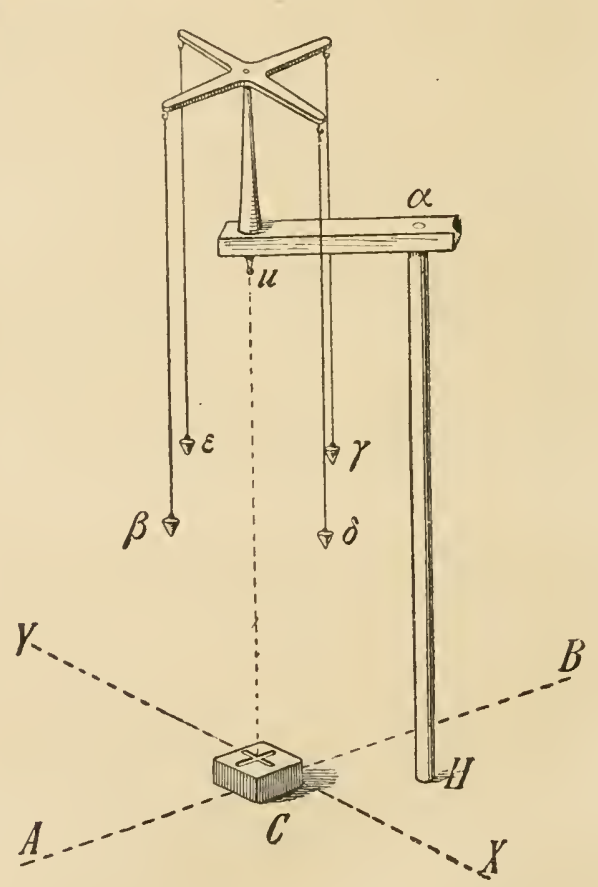

Abb. 39. Die Rekonstruktion der Groma. ment ${ }^{3}$ ) der Römer bedeutet gegen Herons Dioptra einen Rückschritt. Sie benutzten es zur Festlegung der Nord-Süd-Linie und

1) Siehe Cantor, Bd. I. S. 456.

2) In der Nähe von Regensburg.

3) Näheres siehe bei Schmidt, Neue Jahrbücher f. d. klassische Altertum. Bd. 13 (1904). S. 329. Ferner Bibl. math. 3. Folge. 4. Bd. Die Frage, ob die römischen Feldmesser von Heron abhängig waren, wird von $\mathrm{Schmidt}$ außer Betracht gelassen. 
zum Abstecken rechter Winkel. Als Nivellierlineal bedienten sie sich einer Art Kanalwage. Besonders fand die Groma Verwendung, wenn es sich darum handelte, eine Niederlassung oder eine Flur durch ein System rechtwinklig sich schneidender Wege einzuteilen.

Einen Aufschwung erfuhr die Mathematik zur Zeit Cäsars. Es zeigten sich die Anfänge einer eigenen mathematischen Literatur, wie denn auch Cäsar selbst als Schriftsteller auf mathematischem Gebiete tätig gewesen ist. Hat doch Plinius ein von Cäsar verfaßtes und „De astris“ betiteltes Werk vielfach als Quelle für das XVIII. Buch seiner "Naturgeschichte“ benutzt. Cäsar hatte sich zwei große Aufgaben auf dem Gebiete der angewandten Mathematik gestellt. Er wollte den in die größte Verwirrung geratenen römischen Kalender verbessern und eine Vermessung des ganzen römischen Reiches ins Werk setzen.

Bis zum Jahre 46 v. Chr. hatte man in Rom nach Mondjahren gerechnet und durch ziemlich regelloses Einschieben von Schaltmonaten den Kalender den Jahreszeiten anzupassen gesucht. Dẹr Fehler war indessen schließlich so groß geworden, daß um die Zeit Cäsars der Tag der Frühlingsnachtgleiche 85 Tage vor die wirkliche Nachtgleiche, also mitten in den Winter fiel. Nach der Rückkelır von dem ägyptischen Feldzug (47 v. Chr.) regelte Cäsar den Kalender unter Mitwirkung des alexandrinischen Astronomen Sosigenes. Es gelangte die Zeitrechnung zur Einführung, von der uns das Dekret von Kanopus schon Kunde gibt $\left.{ }^{1}\right)$. Das Jahr wurde nämlich in der Folge zu 365 Tagen gerechnet und im 4. Jahre, jedesmal vor dem 24. Februar, dem dies sextus ante calendas Martis, ein Tag als bissextus (daher auch annus bissextilis) eingeschaltet.

Die von Cäsar geplante Vermessung des römischen Reiches ist wahrscheinlich auch durch alexandrinische Gelelurte angeregt worden. Die Verpachtung der Provinzen, die Heereszüge und die Ausdehnung der Kriegs- und Handelsflotte ließen diese Arbeit als dringend erforderlich erscheinen. Da Cäsar indessen vorzeitig durch Mörderhand hinweggerafft wurde, blieb die Ausführung dem Augustus vorbehalten. Die Vermessung, welche der Augustus nahestehende Feldherr und Staatsmann Agrippa leitete, wurde nach fast dreißigjähriger Arbeit im .Jahre 20 v. Chr. beendet und besaß für Italien, Griechenland und $\ddot{A} g y p t e n$ einen ziemlich hohen

1) Siehe S. 4 dieses Bandes. 
Grad von Genauigkeit, während andere Länder nur durch Leute, die man Dimensoren nannte, ausgeschritten wurden. Ihr Ergebnis war eine gewaltige Karte, welche in einer für diesen Zweck errichteten Säulenhalle „der Welt die Welt als Schauspiel“ darbot ${ }^{1}$ ). Neuerdings sind Zweifel darüber entstanden, ob diese auch wohl nach Agrippa benannte Karte auf Grund genauerer Messungen entworfen wurde. Indessen, selbst wenn es unentschieden bleibt, welchen Wert die Karte besessen, so ist Agrippas Unternehmen

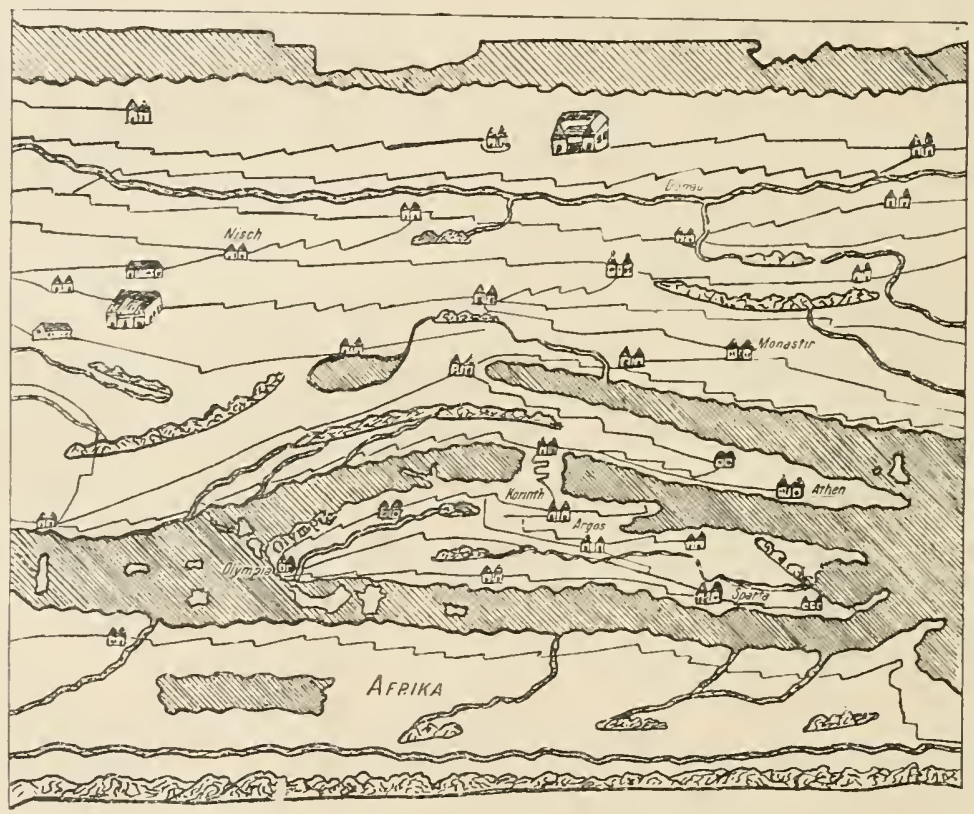

Abb. 40. Peutingers Karte (Balkanhalbinsel:

doch ohne Zweifel das Vorbild für spätere, den orbis terrarum umfassende Karten gewesen. Von diesen ist noch heute ein Exemplar erhalten, das offenbar für strategische $\mathrm{Zwecke}$ gedient hat. Es ist unter dem Namen der Tabula Peutingeriana bekannt, enthält die Heerstraßen für das ganze römische Reich und befindet sich in Wien 2). Abb. 40 zeigt den Teil, der die Balkanhalbinsel darstellt.

1) Plinius, Hist. nat. III. 2.

2) Ihr früherer Besitzer hieß Peutinger. Er lebte im Anfang des 16. Jahrhunderts in Augsburg und erhielt die Karte von Konrad Celtes, der sie 1500 aufgefunden hatte. Entworfen wurde die Karte im Jahre 375 n. Chr. Celtes war einer der bedeutendsten Humanisten Deutschlands. Er bevorzugte die Realien des Altertums gegenüber den literarischen Erzeugnissen. 
Die ganze Karte (Abb, 40 stellt ein Stück aus der Mitte dar), besteht aus einer Rolle von 11 Pergamentblättern und ist etwa $7 \mathrm{~m}$ lang und $0,3 \mathrm{~m}$ hoch. Die eigentiimliche Verzerrung in der Richtung Ost-West ist aus der Rollenform zu erklären. Bei dem Entwurf trat nämlich offenbar der kartographische Gesichtspunkt hinter dem rein praktischen, eine bequeme Übersicht über die Wege zu haben, zurïck. Durch die hakenförmigen Unterbrechungen der Wege (Itinerarien) sind die Stationen angedeutet. Ihre Entfermungen sind durch Zahlen bezeichnet. Meist handelt es sich um römische Meilen, das sind 1000 Schritte (milia passuum) oder $\left.1482 \mathrm{~m}^{1}\right)$.

Mit astronomischen Dingen haben sich die Römer erst verhältnismäßig spät und meist nur aus praktischen Gründen beschäftigt. Mit den Sonnenuhren wurden sie ${ }^{2}$ ) erst um die Mitte des 3. vorchristlichen Jahrhunderts, mit den Wasseruhren etwa cin Jahrhundert später bekannt, während die Chaldäer sich der Sonnenuhren schon 750 v. Chr. bedienten $\left.{ }^{3}\right)$.

\section{Die Pflege der, ,Ingenieurmechanik“.}

Wie die Mathematik und die Astronomie, so wurde anch die Mechanik bei den Römern weniger ihrer selbst, als ihres praktischen Nutzens wegen gepflegt. Es erwuchs ein Gebiet, das die Bezeichnung Ingenieurkunst oder Ingenieurmechanik verdient und bei den Römern zu hoher Bliite gedieh ${ }^{\dagger}$.

Einen guten Einblick in die Ingenieurmechanik der Römer erhält man durch das den wenig zutreffenden Titel „Über die Architektur" tragende Werk Vitrurs ${ }^{5}$. M. Vitruvius Pollio lebte zur Zeit des Augustus. Er befaßte sich besonders mit dem Bau von Kriegsmaschinen und wurde von Augustus mit der Leitung des Bauwesens betraut. Eine kurze Inhaltsangabe des Werkes von Vitruv möge uns den damaligen Stand des Wissens erläutern.

1) Eine neuerc Ausgabe del Karte mit Erläuterungen rührt von K. Miller her. Stuttgart 1916.

2) Plinius, VII. 60. Siehe anch Bilfinger, Die antiken Stundenangaben. Stuttgart 1888. S. 75.

3) II. Iı̈sschner, Üher Sonmenuhren. Beitrïge zu ihrer Geschichte und Konstruktion. Graz 190ว. Das Buch enthält zahlreiche Quellenangaben.

4) C. Merkel, Die Ingenieurmechanik im Altertum. Mit 261 Abbild. Springer, Berlin 1903.

5) Vitruvius, Zehn Bücher über die Arehitektur. Übersetzt von Reber. Stuttgart 1865 . 
Vitruv beginnt damit, daß er für den Ingenieur eine vielseitige wissenschaftliche Ausbildung verlangt. Er soll nicht nur in der Mathematik bewandert, sondern auch mit den Grundzügen des Rechtes und mit der Heilkunde vertraut sein. Komme doch letztere schon in Frage, wenn es sich um die Wahl passender und gesunder Bauplätze handle.

Sehr zutreffend ist auch, was Vitruv über das Verhältnis zwischen Theorie und Praxis sagt: „Diejenigen, die ohne Wissenschaft nur nach mechanischer Fertigkeit strebten, haben sich durch ihre Arbeiten niemals maßgebenden

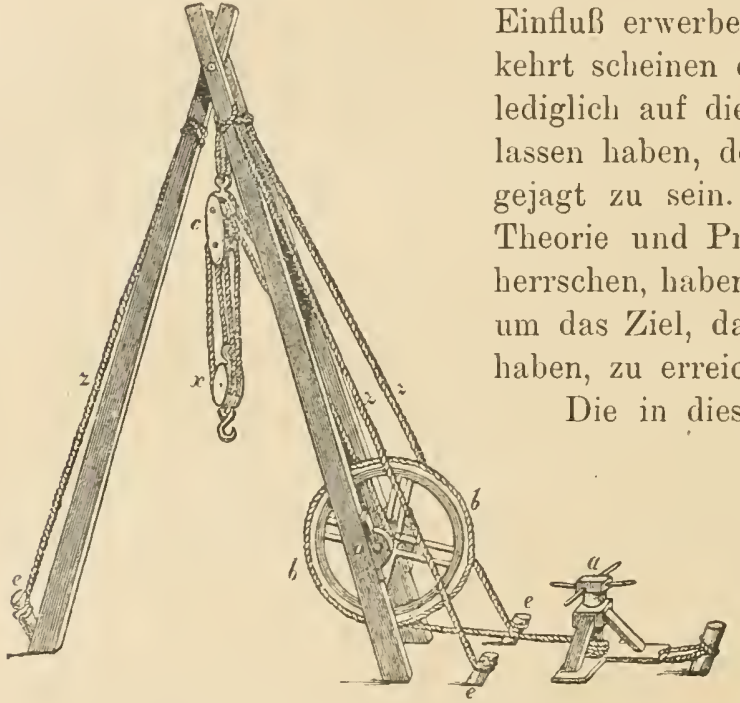

Abb. 41. Römisches Hebezeug ${ }^{2}$. Finflu erion können. Umgekehrt scheinen diejenigen, die sich lediglich auf die Wissenschaft verdem Schatten nachgejagt zu sein. Nur die, welche Praxis gründlich beherrschen, haben die volle Rüstung, um das Ziel, das sie sich gesteckt

Worten ausgesprochene Mahnung gilt bis auf den heutigen Tag $\left.{ }^{1}\right)$.

Im zweiten Buche bespricht Vitruv die Baumaterialien. Geschildert wird das Brennen und das Löschen des Kalkes. Auch die Puzzolanerde, die mit Kalk vermischt für Wasserbauten Verwendung fand, wird erwälnnt. Dann folgen Angaben über den Bau von Häusern, Tempeln, Bädern usw. In einem Abschnitte über die Wandmalerei werden als geeignete Farben Zinnober, Kupfergrün und Ocker genannt. Das achte Buch handelt von den Quellen und der Anlage von Wasserleitungen. Erwähnung finden

1) Beherzigenswert sind die Worte, welche Diels an sie knüpft, wenn er sagt, es sei der Archimedische Punkt der Pädagogik, in der Jugend weltoffene Anschaumng und praktische Fertigkeit, verbunden mit Wissen und wissenschaftlicher Einsicht, zu wecken Antike Technik, 1914. S. 32:.

2) Terquem. Isa science romaine à l'époque d'Auguste. Paris 1885. S. 75 . Fig. 9 . 
auch bittere Quellen und Erdölquellen sowie der Asphaltsee bei Babylon, welcher das Bindematerial für die dortigen Bauten lieferte. Im neunten Buche ist besonders von physikalischen und astronomischen Dingen die Rede, während das letzte ron Pumpwerken, Feuerspritzen und anderen Maschinen handelt. Von den praktisch-plyysikalischen Instrumenten ist die Schnellwage, die auch heute noch den Namen der römischen Wage führt, wohl dasjenige, das die Römer selbständig erfunden haben und schon in der altrömischen Zeit anwandten ${ }^{1}$ ). Abb. 42 zeigt uns zwei in Pompeji entdeckte Schnellwagen. Sie werden, wie die Mehrzahl der in Pompeji gemachten Funde, im Nationalmuseum in Neapel aufberahrt. Die Erfindung der römischen Wage reicht mindestens bis in das 3. Jahrhundert v. Chr. zuriick. Das Laufgewicht wurde sehr oft kiinstlerisch gestaltet, indem man diesem Teil der Wage die Form einer Frucht (Granatapfel) oder einer Büste (Merkur) gab.

Die Leistungen der Römer gingen auf den Gebieten der Architektur und der Ingenieurkunst (Briickenbau, Schiffsbau, Anlage ron Wasserleitungen, Heerstraßen, kriegstechnischen Arbeiten) jedenfalls über das rein handwerksmäßige Schaffen hinaus. Diese Teistungen setzen nämlich wissenschaftlich und praktisch vorgebildete Architekten und

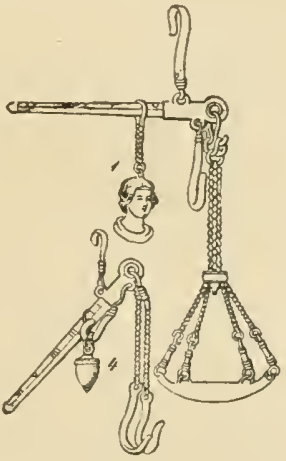

Ahl). 42. Römische

Schnellwagen. Ingenieure voraus. Besondere Schulen, wie sie für Philosophie, Rhetorik, Jurisprudenz und Medizin bestanden, gab es für die Ingenieure zwar nicht. Wer das Ingenieurfach ergreifen wollte, wurde in jugendlichem Alter einem Fachmann in die Lehre gegeben. Voraussetzung fuir die Erlernung der Ingenieurkunst waren Kenntnisse in der Mathematik, der Optik, der Astronomie. der Geschichte und im Rechtswesen. Während der Kaiserzeit wirkten in Rom neben den Lehrern für Rhetorik, Heilkunde usw. auch solche, die in der Mechanik und in der Architektur unterrichteten. Fïr Gehalt und Lehrsäle sorgte der Staat. Auch befreite er wohl die Väter, die ihre Sölne die Ingenieurkunst erlernen lassen wollten, von der Zalılung der Stenern. Die gleiche Vergünstigung erhielten Ingenieure, die sich als Lehrer in

1 Gerland und Traumüller, Geschichte der physikalischen Experimentierkunst. S. 56. Jeipzig 1899. W. Engelmann. 
ihrem Fache anszeichneten. Wie sehr man die Bedeutung der Ingenieure zu würdigen wußte, beweist folgende Stelle aus einem Briefe, den Kaiser Konstantin (323-337) an einen seiner Statthalter richtete. Sie lautet: ., Wir brauchen möglichst viele Ingenieure. Da es an solchen mangelt, veranlasse zu diesem Studium Personen, die ungefähr 18 Jahre alt sind und die zur allgemeinen Bildung nötigen Wissenschaften bereits kennengelernt haben. Befreie die Eltern von den Stenern und gewähre den Schïlern ausreichende Mittel ${ }^{1}$.."

Die Mechanik hatte also, wo es sich um praktische Anwendungen handelte, zur Zeit der Alexandriner und der Römerherrschaft schon manche Frucht gezeitigt. Anders stand es um die Mechanik als wissenschaftliche Disziplin. Welch unvollkommene Vorstellungen in mechanischen Dingen die meisten Schriftsteller des Altertums hegten, davon läßt sich manches Beispiel nachweisen. So erzählt Plinius folgende Fabel ron dem Schiffshalter (Echineis remora), einem Fisch des Mittelmeeres, der eine Anzahl Saugnäpfe auf der Stirn trägt, mit denen er sich an Schiffen und anderen Gegenständen festhält: „Mögen die Stïrme wüten und die Wogen rasen, dieses kleine Geschöpf spottet ihrer Wut, zähmt ihre Kraft und zwingt ein Schiff zu stehen, während kein Tau und kein Anker dazu imstande sind. Und zwar hemmt es den Ansturm und bezwingt es die Elemente nicht durch eigene Arbeit oder Gegenwirkung, sondern einzig und allein dadurch, daß es sich anhängt.“

Eine solche Unklarheit herrschte also bezüglich eines so einfachen mechanischen Begriffes, daß ein Schriftsteller wie Plinius, lange nachdem die ersten erfolgreichen Schritte auf dem Gebiete der Mechanik durch Archimedes getan waren, derartige Fabeln ohne Widerspruch aufnahm. Hierin zeigt sich aber anch, daß Archimedes auf das physikalische Denken der auf ihn folgenden Jahrhunderte einen nur geringen Einfluß ausgeiibt hat. Das volle Verständnis für seine Werke sowie die Fähigkeit, an das von ihm Geleistete anzukniipfen und darauf weiterzubanen, scheint in den nächsten anderthalb Jahrtansenden mit geringen Ausnahmen gefehlt zu haben.

1) C. Köhne, Die Ausbildung der Ingenieure in der römischen Kaiserzeit. Mitteil. z. Gesch. d. Medizin u. d. Naturw. 1907. S. 17. 


\section{Die Literatur während der Kaiserzeit.}

Die Citeratur eines Volkes ist stets nicht nur von seiner Eigenart und fremden Einflüssen, sondern auch ron dem Gange der politischen Entwicklung in hohem Grade abhängig gewesen. Diese Abhängigkeit war im Altertum weit größer als in der Neuzeit, in der das geistige Leben weniger an nationale Schranken gebunden ist und die Freiheit der Einzelpersönlichkeit erheblich zugenommen hat. Wie im alten Athen, in Alexandria und in anderen wissenschaftlichen Mittelpunkten, so war auch im kaiserlichen Rom die Stellung, welche das Oberhaupt des Staates zu Kunst und Wissenschaft einnahm, für das Gedeihen dieser Gebiete von großer Bedeutung. Schon Augustus, der die kaiserliche Gewalt begründete, brachte der Literatur Interesse und Verständnis entgegen. Hat er sich doch selbst als Dichter und als Prosaschriftsteller versucht. Augustus wußte anch in vollem Maße zu würdigen, daß die Literatur der staatlichen Macht, von der sie abhängt, entweder dienstbar gemacht oder durch eine verkehrte Behandlung in einen Gegensatz zur Staatsgewalt gebracht werden kann, wodurch die letztere stets mehr oder minder Abbruch erleidet.

Auf die reiche Entfaltung der römischen Literatur im Augusteischen Zeitalter folgten unter der Herrschaft des finsteren Tiberius und des dem Cäsarenwahn rerfallenen Caligula Jahrzehnte, die weniger günstig waren. Der lähmende Druck, der damals auf allen Kreisen lastete, machte sich auch auf dem Gebiete des geistigen Schaffens fühlbar. Err wich erst, als nach dem Tode Neros mit Vespasian ein milder Herrscher den Kaiserthron bestieg, auf den ihm - leider nur für wenige Jahre - sein Soln Titus folgte. Plinius stand zu beiden in naher Beziehung, insbesondere zu Titus. Zwar ist dieser erst in dem Jahre zur Regierung gekommen, in dem Plinius starb. Doch hat Titus schon bei IJebzeiten seines Vaters wie im Staats- so auch im wissenschaftlichen Leben einen bedeutenden Einfluß ausgeübt. Während Vespasian noch in erster Linie Kriegsmann war, hatte sich 'Titus mit der gelehrten Bildung seines Zeitalters schon in dem Maße befreundet, daß er, wie Plinius berichtet, ein Gedicht iiber das Erscheinen eines Kometen verfaßte.

Ein Erzeugnis dieses für die Jiteratur so günstigen '/eitalters der Kaiser aus dem Hause der Flavier ist die .Naturgeschichte“ des Plinius. Sie ist das umfassendste Denkmal, das wir von den naturwissenschaftlichen Kenntnissen der Römer besitzen und ent- 
hält zahlreiche Angaben, die olnne die gewissenhaften Aufzeichnungen des Plinius verlorengegangen wären. Sie wurde, wie aus der Vorrede zu entnehmen ist, im 77. oder 78. Jahre n. Chr. vollendet.

\section{Plinius.}

Cajus Plinius Secundus Major wurde im Jahre 23 n. Chr. zu Como geboren. Er empfing den Beinamen Major (der Altere), um ihn von seinem gleichfalls als Schriftsteller bekanntgewordenen Neffen gleichen Namens, der den Zusatz Minor (der Jüngere) erhielt, zn unterscheiden. Plinius kam frülzeitig nach Rom, wo er sich den Pomponius Mela zum Vorbild erkor. Dieser hatte es verstanden, mit einer verantwortungsvollen amtlichen Tätigkeit eine große Vorliebe zum literarischen Schaffen zu verbinden. Hierin ist ihm Plinius gefolgt. Gleich Pomponius Mela war er militärischer Befehlshaber. Von Vespasian wurde er häufig als Berater zu den Regierungsgeschäften herangezogen. In jüngeren Jahren hat ihn der Kriegsdienst auch nach Germanien geführt. Obgleich er liöhere Amter bekleidete und stets im Drange der Geschäfte lebte, fand Plinius doch Muße, das Wissen seiner Zeit in einem Sammelwerke zu umspannen. In der an Titus gerichteten Widmung sagt er von seinem Unternehmen: „Der Weg, den ich wandeln werde, ist unbetreten; keiner von uns, keiner von den Griechen hat es unternommen, allein das Ganze der Natur zu behandeln. Gelingt mir mein Unternehmen nicht, so ist es doch großartig und schön, danach gestrebt zu haben."

Die "Naturgeschichte" wird um $77 \mathrm{n}$. Chr. ziemlich abgeschlossen gewesen sein. Da ihr Verfasser bald darauf plötzlich aus seiner Tätigkeit herausgerissen wurde, so erfolgte die Heransgabe durch seinen Neffen, den schon erwähnten Plinius Secundus Minor. Offenbar hat dieser nur wenig an dem Werk geändert. Er nennt es ${ }^{1}$ ) ein ,weitläufiges gelehrtes Werk, das nicht minder mannigfaltig wie die Natur selbst ist".

Bekannt ist das tragische Ende des Plinius. Als er sich im Jahre $79 \mathrm{n}$. Chr. in der Nähe von Neapel aufhielt, begann plötzlich jener furchtbare Ausbruch des Vesurs, durch den Herculanum und Pompeji vernichtet wurden. Der unerschrockene Römer ließ sich nicht abhalten, der Stätte des Verderbens zuzueilen; mag ihn nun Pflichtgefühl oder Wilßbegierde dazu getrieben haben. Nach

1) Epistol. III, 5. 
der Landung ist er dann der Wut der entfesselten Elemente zum Opfer gefallen.

Die Katastrophe selbst hat der juingere Plinius in einem an den Geschichtsschreiber Tacitus gerichteten Briefe geschildert. Aus diesem mögen einige Stellen hier Platz finden:

"Du bittest mich, dir den Tod meines Oheims zu schildern, eines Mannes, der das Glück hatte, große Taten zu vollbringen und herrliche Bücher zu schreiben. Ein wunderbares Geschick fügte es, daß er beim Untergange einer herrlichen Landschaft den Tod fand. Sein Andenken wird jedoch ewig leben.

Mein Onkel befand sich mit der Flotte, die er als Admiral befehligte, bei Misenum. Am 22. August meldete man ihm, daß sich eine Wolke von ungewöhnlicher Gestalt zeige. Sie hatte das Aussehen einer Pinie, deren Stamm sich himmelhoch erhebt und deren Zweige sich schirmartig ausbreiten. Mit dem Eifer eines Naturforschers, der etwas zu untersuchen wünscht, befahl mein Oheim, sogleich ein Schiff zur Abfahrt bereit zu machen. Noch bevor er es bestiegen, erhielt er einen am Fuße des Vesurs geschriebenen Brief, in dem er um Hilfe gebeten wurde. Infolgedessen mußte die ganze Flotte auslaufen. Mein Oheim steuerte auf dem Admiralsschiff kühn der Gefahr entgegen und beobachtete vom Verdeck aus den Verlauf der furchtbaren Erscheinung. Gleichzeitig diktierte er seine Beobachtungen einem Schreiber. Als man sich der Unglücksstätte näherte, fiel die Asche immer dichter und heißer auf die Schiffe. Sogar Stücke von Bimsstein und Lava mengten sich darunter. Man landete in Stabiae. Unterdessen wurde es Nacht. Vom Vesuv brachen die Flammen hoch empor. Gleichzeitig bebte die Erde, so daß das Haus, in dem sich Plinius mit seiner Begleitung auflielt, ins Wanken geriet. Man verließ das Haus, nachdem sich jeder zum Schutze gegen den Steinregen ein Kissen über den Kopf gebunden hatte. Als man dem Schwefelqualm und der Feuersglut zu cntkommen suchte, sank Plinius plötzlich crschöpft nieder. Einmal gelang es ihm noch, sich mit Hilfe zweier Sklaven wieder aufzurichten. Dann brach er sterbend zusammen."

Auch über die Persönlichkeit und die Arbeitsweise seines Onkels lat der jüngere Plinius einiges mitgeteilt1). Was ihn danach auszeichnete, war ein unglaublicher Fleiß. Er schlief nur wenig und aß auch nur wenig, und zwar nach der Sitte der Vaiter

1) Epistol. HI, 5. 
ganz einfach. Auch auf seinen Reisen studierte er unermiidlich. Dabei hatte er seinen Schreiber stets neben sich.

Die literarische Fruchtbarkeit des Plinius war eine ganz ungewöhnliche. Außer der "Naturgeschichte" liat er noch eine Reilue anderer Werke geschrieben, die indessen verlorengegangen oder nur in Fragmenten, d. h. als Bestandteile anderer Werke, erhalten geblieben sind. So verfaßte Plinius während seines Aufenthaltes in Germanien ein Werk, das von den Kriegen handelt, welche die Römer auf germanischem Boden geführt haben.

\section{Die Quellen des Plinius.}

Aus nicht weniger als 2000 Werken hat Plinius den Stoff für seine "Naturgeschichte" geschöpft. Seine Leistung verdient um so größere Anerkennung, als er nur die Stunden, die ihm die Geschäfte ührig ließen, also besonders, wie er selbst erzählt, die Nacht, auf sein Werk verwenden konnte. Ohne Plinius würden wir von manchen Schriften keine Kenntnis besitzen. Andererseits muß aber betont werden, daß Plinius sich nicht auf die Stufe selbständigen Forschens und Denkens erhebt. Er bringt sogar manches, was er offenbar nicht einmal richtig verstanden hat. Oft wird Wahres und Falsches von ihm miteinander vermengt. Man gewinnt den Eindruck, daß Plinius sein Wissen weniger aus der Natur, sondern vorzugsweise aus. Biichern geschöpft hat, was bei einem Manne, der schon einen Spaziergang als Zeitvergeudung betrachtete, nicht wundernehmen kann.

Das Verzeichnis der Quellen, aus denen Plinius nach seiner Angabe schöpfte, umfaßt 146 römische und 327 fremde Schriftsteller. Unter diesen befinden sich viele, deren Schriften ganz verlorengegangen sind und von denen man auch nicht einmal die Namen wiißte, wenn Plinius sie nicht unter seinen Gewährsmännern aufzählte.

Unter den römischen Schriftstellern, auf welchen Plinius fußt, ist vor allem Marcus Terentius Varro (116-27 v. Chr.) zu nennen. Er hat eine ganze Anzahl von Wissenschaften enzyklopädisch bearbeitet. Seine Schriften sind das Vorbild für die im Mittelalter so häufig anzutreffenden Werke über die „sieben freien Künste" gewesen ${ }^{1}$ ). Wie Cato, so bemühte sich auch Varro, den alten Wissensschatz zu sammeln und ihn der ein- 
dringenden griechischen Literatur gegenüber in seiner Selbständigkeit und in seinem wahren Werte hervortreten zu lassen. Unter den Varronischen Schriften, die Plinius benutzt hat, ist vor allem das Werk ïber die Landwirtschaft zu nennen (Rerum l'usticarum libri III. Varro handelt darin rom Ackerban, von der Viehzucht, den Bienen, den Fischen und dem Wild. Wenn sich Varro auch an Cato (s. S. 210 anlehnt, so entwickelt er doch uiberall ein sicheres, auf reicher Erfahrung und umspannendem Wissen gegründetes Urteil. Von besonderem Interesse ist eine Stelle ${ }^{1}$ ), in der man eine Art Vorwegnahme der Bazillentheorie erblicken kann. Varro vermutet nämlich, in sumpfigen Gegenden entstünden Lebewesen, die so winzig seien, daß man sie nicht sehen könne. Diese Geschöpfe sollen nach ihm durch den Mund und die Nase in den Körper eindringen und schwere Krankheiten verursachen.

Der Wert solcher mit unseren heutigen Anschauungen sich teilweise deckenden Vorstellungen wird von philologischer Seite oft überschätzt. Varros Meinung ist für die Begründung der modernen Bazillentheorie sicherlich belanglos gewesen, eben so wenig wie die Ansichten Epikurs2) Lamarck oder Darwin zur Aufstellung ihrer Theorien veranlaßten. Trotzdem haben divinatorische Eingebungen, wie sie uns in der Entwicklung der Wissenschaften so oft begegnen, ein Anrecht darauf, in der Geschichte des menschlichen Geistes genannt zu werden. Thr Wert ist unbestritten. Nur darf man sie in ihrer Bedeutung nicht derart iiberschätzen, daß man sie mit sicheren neuzeitlichen Forschungsergebnissen in Parallele zu stellen sucht.

Unter den medizinischen Schriftstellern, die Plinius den Stoff für seine der Heilkunde gewidmeten Bücher geliefert haben, ist neben Hippokrates, Erasistratos und vielen anderen besonders Cornelius Celsus (etwa $35 \mathrm{r}$. Chr. bis etwa $45 \mathrm{n}$. Chr.) zu nennen. Ähnlich wie Varro und schon lange ror ihm Cato suchte Celsus das Wissen seiner Zeit in einer Enzyklopädie zusammenzufassen. Sie erhielt den Titel „Artes“. Erhalten geblieben ist nur der Teil, der von der Heilkunde handelt. Auf diesem Gebiete vermochte es Celsus, ohne selbst Arzt zu sein, auf Grund von Erfahrungen eigene Anschauungen zu entwickeln. Als griechische Quellen hat Celsus neben den Hippokratischen

1) Rerum rustic. libri tres. 1. 12, 2.

$\because$ Siche S. 100 dieses Bandes. 
hauptsächlich die alexandrinischen Schriften benutzt. Mit diesen und den Schriften Galens hat man das medizinische Buch des Celsus auf eine Linie zu stellen ${ }^{1}$. Es behandelt in klarer, schmuckloser Darstellung zunächst die Lebensweise, darauf die Krankheiten und endlich deren Heilung durch Arzneien und chirurgische Eingriffe ${ }^{2}$ ). So beschreibt Celsus das Verfahren des Unterbindens, das die Hippokratischen Schriften noch nicht erwähnen, wenn man auch schon sehr früh blutstillende Mittel, die verklebend oder zusammenziehend wirkten, benutzte. Derartige Mittel finden nämlich schon bei Homer Erwähnung ${ }^{3}$ ).

Sehr zutreffend hat Celsus unter anderem die Krankheiten der Leber und des Magens beschrieben. Das von ihm bei diesen Krankheiten empfohlene Heilverfahren und seine Begründung auf diätetischen Regeln ist selbst heute noch von Wert").

Einer etwas späteren Zeit als Celsus gehört Asklepiades an. Er war hellenischer Herkunft5) und lebte im Anfang des 1. Jahrhunderts v. Chr. in Rom. Asklepiades wirkte dort zuerst als Lehrer der Beredsamkeit. Später erwarb er sich als Arzt große Anerkennung. Er wird als der Erfinder der Tracheotomie genannt. Anklänge an die moderne Zellentheorie enthält seine Lehre, daß die Lebewesen aus einer sehr großen Zahl von Körperchen zusammengesetzt seien. Sie sollten sich in steter Bewegung und Veränderung befinden und beim Menschen durch ihr Verhalten und ihre Beschaffenheit Gesundsein und Krankheit bedingen.

Auch den als Schöpfer der Äneïde bekannten Virgil erwähnt Plinius als Quelle für eine Anzahl seiner Bücher. In einer "Georgika" genannten Dichtung schildert und preist nämlich Virgil das Leben auf dem Lande. In der Hauptsache handeln die "Georgika" vom Ackerbau, der Baumpllege, der Viehzucht und

1) Haeser, Lehrbuch der Gesch. d. Medizin. Jena 1875. 1. Bd. S. $25 t$.

2) Cornelius Celsus, Über die Grundfragen der Medizin, als 3. Band von Voigtländers Quellenbüchern herausgegeben von Dr. 'T'h. MeyerSteineg. Celsus war kein Arzt, wenn er auch eins der besten medizinischen Werke geschrieben hat. Er wurde wahrscheinlich in Verona geboren und starb in Rom.

3) Siehe Heeger, Zur Geschichte der Blutstillung im Altertum und Mittelalter (Wiener klin. Wochenschrift 1910. S. 1006 u. 1079). Über Parés Verfahren der Arterienunterbindung siehe später.

4) Pron, Les maladies de l'estomac et du foie et levir traitement dans Celse. La France Médic. 1910. S. 374.

5, Seine Vaterstadt war Prusa in Bithynien. 
der Imkerei. Das Leben der Bienen wird anschaulich und in der fesselnden Sprache des Dichters geschildert.

Von den zahlreichen ausländischen Schriftstellern, die Plinius als seine Quellen nennt, seien hier nur folgende genannt: Thales, Aristoteles, Theophrast, Demokrit, Hipparch, Herophilos, Eudoxos, Pytheas, Juba usw. Juba war nach Besiegung seines Vaters als Geisel aus Numidien nach Rom gekommen. Dort widmete er sich ganz den Wissenschaften. Auch Plutarch und andere Schriftsteller gehen häufig auf Juba zurück, von dessen Schriften nur noch Fragmente erhalten sind.

Die Frage nach den Quellen, die Plinius benutzte, hat eine umfangreiche Literatur hervorgerufen. Insbesondere hat man das Verhältnis eingehend erörtert, in dem Plinius zu Aristoteles, zu Cato und zu Varro steht1).

Als Schriftsteller, dem besonders die Rolle eines Vermittlers zwischen Plinius und der griechischen Literatur zuzuschreiben ist, wird Juba betrachtet. Letzterer ging auf Aristoteles und Theophrast zurïck und hatte für Plinius hinsichtlich der griechischen Literatur etwa die Bedeutung, die Varro für ihn beziiglich der römischen besaß.

Gebricht der "Naturgeschichte" des Plinius auch die Einheitlichkeit des Aufbaues, so ist doch eine vom Allgemeinen zum Einzelnen fortschreitende Gliederung des Stoffes nicht zu verkennen. Plinius beginnt seine Darstellung mit der Schilderung des Weltgebäudes sowie den Erscheinungen, die uns das Luftmeer und die Oberfläche der Erde im allgemeinen darbieten. Darauf folgt das Wesentlichste aus der Geographie und der Völkerkunde. Im Anschluß daran werden die Tiere, beginnend mit den Säugctieren und schließend mit den Insekten, behandelt. Es folgen die Bücher über die Pflanzen sowie über die dem Pflanzenreich entstammenden Heilmittel und ihre Wirkungen. Den Schluß bilden die Bücher mineralogischen Inhalts. Den Edelsteinen sowie den Mineralfarben sind je ein besonderes Buch gewidmet. In den letzten Büchern wird die Verwendung der Metalle und der Gesteine zu künstlerischen Zwecken eingehend unter Aufzïhllung zahlreicher hervorragender Kunstwerke geschildert ${ }^{2}$ ).

1) Montigny, Qnaestiones in Plinii nat. list. de animalibus libros. 1814, und Müntzer, Beitrüge zur Quellenkritik der Naturgesch. des Plinius. 1897.

2) In einem Plinius gewidmeten Bande der .,Klassiker der Naturwissenschaft und Technik", die bei Eugen Diederichs in Jena er'scheinen, habe ich dasjenige aus der, Naturgesehichte" zusammengestellt, was besonders geeignet 
Unter den Geographen, auf die sich Plinius stützte, ist vor allem Pomponius Mela, ein Zeitgenosse des Kaisers Claudius, zu nennen. Seine „Chorographie“ (Ortskunde) entstand wahrscheinlich um das Jahr $43 \mathrm{n}$. Chr. Sie ist das älteste römische Werk über Geographie, das uns erhalten geblieben ist 1\%. Pomponius beschreibt, den Küsten folgend, die Länder und enthält über die mathematische Geographie, mit der Plinius sein Werk anhebt, fast nichts.

\section{Die ,Naturgeschichte“" des Plinius.}

Wir gehen jetzt zu Plinius selbst über. In seiner ..Naturgeschichte", die 37 Buicher umfaßt, stellt er sich die Aufgabe, das in den zahlreichen erwähnten Quellen zerstreute Wissen seiner Zeit zu sammeln und zu sichten. Durch die miiherolle Lösung dieser Aufgabe hat er sich ein großes Verdienst erworben, wenn er auch oft kritiklos zusammenträgt und den Stoff nicht immer beherrscht. So hält er beispielsweise die fabelhaftesten Nachrichten über afrikanische Völker für erwälnenswert. Er berichtet von einem dieser Volksstämme, seine Angehörigen besäßen keine Köpfe, sondern trïgen Mund und Augen auf der Brust. Der Grundgedanke, welcher das Werk durchzieht, ist der, daß die Natur des Menschen wegen alles erzeugt zu haben scheine. Die beschriebenen Naturkörper werden daher kanm als solche, sondern rorzugsweise in ihrer Beziehung zum Menschen betrachtet ${ }^{2}$. Über den Menschen selbst spricht er sich in folgenden, fuir ihn charakteristischen Worten aus: ..Die anderen Tiere fühlen sich sogleich im Besitz ihres Wesens. Nur der Mensch kann nichts ohne Unterweisung. Er allein kennt Ehrgeiz, Habsucht, sorgt für sein Grab, ja sogar für die Zukunft nach seinem Tode. Keinem Geschöpf raubt die Angst so die Besinnung. Bei keinem wird die Wut heftiger. Alle anderen Tiere leben mit ihresgleichen in Frieden. Die Löwen kämpfen trotz ihrer Wildheit nicht gegeneinander, ebensowenig

ist, von dem wissenschaftlichen Geist des Altertums, soweit er sich in Plinius spiegelt, und den Errungenschaften jener Zeit ein Bild zu geben. Die Herausgabe ist durch den Krieg verzögert worden, wird aber voraussichtlich im nächsten Jahre erfolgen.

1) Eine Handschrift, nach der die übrigen angefertigt wurden, findet sich im Vatikan. Ein ron Dr. H. Philipp herrührender Auszug erschien als 11. und 31. Band von Voigtländers Quellenbüchern.

2. Als Beispiel diene der 6. Abschnitt ron Dannemann, Aus der Werkstatt großer Forscher. Leipzig, W. Engelmann. 1908. 
die Seeungeheuer. Aber fürwahr, dem Menschen schafft das größte Leid der Mensch" 1).

Daß Plinius übrigens sich des öfteren auch mit den Gegenständen selbst bekannt machte und sich eine eigene Meinung bildete, geht aus verschiedenen Stellen seines Werkes hervor. Manches ron den Dingen, über die er berichtet, wird ihm auch das vielgestaltige Leben der Kaiserzeit ganz ron selbst aufgedrängt haben. Gar manches Tier, das er beschreibt, wurde zur Befriedigung der Schaulust, für die Arena oder für den Gaumen aus den entferntesten Teilen des Orbis antiquus nach der Welthauptstadt gebracht. Ähnlich stand es mit den Pflanzen. Erzählt doch Plinius von einem botanischen Garten ${ }^{2}$, den ein römischer Gelehrter unterhielt, um die Wirkungen der Kräuter kennen zu lernen. Unter seiner Anleitung ist Plinius mit zahlreichen heilkrïftigen Pflanzen bekannt geworden.

$\mathrm{Zu}$ der Lehre von der Kugelgestalt der Erde ist die Ansicht getreten, daß das Menschengeschlecht riel weiter verbreitet sei, als man frïher glaubte, ja, daß es Gegenfüßler geben miisse. "Die Wissenschaft und die Meinung des großen Haufens", sagt Plinius ${ }^{3}$ ), „befinden sich in gewaltigem Widerspruch. Jener zufolge wird die Erde ringsum von Menschen bewohnt, so daß sie mit den Füßen gegeneinander stehen und den Himmel alle gleichmäßig über dem Scheitel haben. Nach der anderen Meinung fragt man, weshalb denn die Antipoden nicht abfielen. Als ob nicht die Gegenfrage zur Hand wäre, warum jene sich nicht verwundern, dal wir nicht abfallen. Am meisten aber sträubt sich der große Haufe, wenn man ihm glaublich machen will, daß auch das Wasser gewölbt sei. Und doch ist nichts augenfälliger, denn iiberall bilden hängende Tropfen sich zu kleinen Kugeln."

Aus der Tatsache, daß der längste Tag in Alexandrien 14, in Italien 15 und in Britannien 17 Stunden hat, folgert Plinius, daß die dem Pol benachbarten Lünder im Sommer 24 Stunden Tag, zur Zeit des Wintersolstitiums dagegen eben so lange Nacht hahen müssen"). Bei Plinius finden wir unter den Beweisen für die Krïmmung der Erdoberfläche auch die Erscheinung angefïhrt,

1) Plinius, VIl. 1.

2) Einen ausführlichun Artikel über Gartenbau im allgemeinen enthält P'aulys Realenzyklopädie f. d. klass. Altert. im VII. Banrle auf S. 768-841.

3) Plinius, Naturgeschichte. II. 65.

1) Plinius, Naturgeschichte. II. 75. 
daß auf dem Meere zuerst der Mast der Schiffe und erst später der Rumpf sichtbar wird.

Während zur Zeit der römischen Weltherrschaft die Lehre von der Kugelgestalt der Erde zu einem Gemeingut der Gebildeten geworden war, hat man vereinzelt auch schon eine richtige Auffassung vom Verhältnis der Sonne zu den Planeten gehegt. Infolgedessen blieben die bei den Griechen entstandenen Keime der heliozentrischen Lehre bei den späteren Schriftstellern nicht unbeachtet. Koppernikus konnte seine Lehre daher unmittelbar an die aus dem Altertum überlieferten Anschauungen anknüpfen ${ }^{1}$ ).

Dem Monde und sogar den Fixsternen, denen wir heute keine nachweisbaren Einflüsse auf irdische Vorgänge beimessen, schrieben die Römer, wie wir aus der "Naturgeschichte" des Plinius ersehen, solche zu. So heißt es dort ${ }^{2}$ ): „Daß beim Aufgang des Hundes der Einfluß dieses Gestirns auf die Erde in der weitesten Ausdehnung empfunden wird, wer wüßte das nicht? Bei seinem Aufgang schäunt das Meer, der Wein wird unruhig in den Kellern und die Sümpfe beginnen zu gären." Daß der Mond bei der Erregung von Ebbe und Flut eine wichtige Rolle spielt, hatte man wohl erkannt, doch erklärte man diese Erscheinung in einem durchaus mystischen Sinne, indem man den Mond als das Gestirn des Odems ansah. Daher sollten sich bei der Annäherung des Mondes alle Körper füllen. Plinius behauptet sogar, daß bei zunehmendem Monde die Muscheln größer würden. Ja, auch das Blut im menschlichen Körper mehre und mindere sich wie das Licht dieses Gestirnes ${ }^{3}$. „Ebbe und Flut des Meeres“, sagt Plinius, „haben bei aller Abwechslung doch ihre Ursache nur in der Sonne und in dem Monde. Indessen treten die Gezeiten nie wieder zu derselben Stunde ein wie am Tage zuvor, weil sie dem gierigen Gestirn, das alle Tage an einer anderen Stelle aufgeht, gewissermaßen dienstbar sind. Bei Vollmond ist die Flut am heftigsten. Auch tritt die Flut zwei Stunden später ein, als sich der Mond aus der Mittagslinie abwärts senkt, da die Wirkungen aller Erscheinungen am Himmel erst später zur Erde gelangen, als die Erscheinungen selbst stattfinden. Die offene, große Fläche des Meeres empfindet die Macht des weithin wirkenden

1) Koppernikus erwähnt, er habe bei Cicero und Plutarch gelesen, da $B$ die heliozentrische Lehre im Altertum Anhänger gefunden habe. Copernicus, De revolutionibus (A usg. v. Curtze). S. 6.

2) Plinius, Naturgeschichte. II. 40.

3) A. a. O. II: 99. 
Gestirns nachdrücklicher als engbegrenzte Räume. Daher werden weder Seen noch Fliisse auf solche Weise in Bewegung versetzt 1)."

Die Zahl der Sterne, welche die Astronomen mit Namen bezeichnet hatten, gibt Plinius auf $1600 \mathrm{an}^{2}$ ). Sie sollen aus dem das All umgebenden Feuer entstanden sein und werden nach ihm von der belebenden, alle Räume durchdringenden Luft, die sich dem Feuer am nächsten befindet, in der Schwebe gehalten. Von der Luft getragen, ruht die Erde, verbunden mit dem Wasser als viertem Element, im Raume. Zwischen der Erde und dem Himmelsgewölbe schweben der Mond, die Sonne und die fünf Planeten. Ihrer Bewegung wegen wiirden diese wohl Irrsterne genannt, obgleich keine weniger irrten als gerade sie.

Das ist in großen Zügen das Weltbild, das sich das Altertum gebildet. In dieser Vorstellung gab es keinen Raum mehr für die anthropomorphen Götter der früheren Zeit, an denen das Volk unter der Führung der Priester festhielt. Ein unüberwindlicher Zwiespalt zwischen Wissen und Glauben war somit auch im Altertum das Ergebnis der ganzen geistigen Entwicklung. Dem Fortschreiten der Erkenntnis hat sich indessen stets der religiöse Glaube anzupassen gesucht. So hat im Altertum der Gang der Wissenschaft einer neuen, monotheistischen Gestaltung der Religion vorgearbeitet. Hatten in dem gewonnenen Weltbilde die vielen Gottheiten der frïheren Zeit keinen Raum mehr, so mußte, wie Plinius es ausdrückt, die Welt selbst als Gottheit gelten. Dem pantheistischen Standpunkte des Plinius entspricht seine Auffassung, daß, wenn man von einer Gottheit rede, damit nur die Natur gemeint sein kïnne. Von der Auffassung, die Welt sei ein Ganzes, zu dem Glauben, daß die Welt zwar nicht Gott selbst, wohl aber die Kundgebung eines einzigen Gottes sei, war aber nur ein Schritt. Und dieser führte in dem Zeitalter, von dem wir handeln, zur Begründung des Monotheismus. Weil der alte Götterglaube für den Gebildeten ïberwunden war, fehlte es an einem innerlichen Verhültnis zwischen Gott-Natur und dem Menschen. Daher das Unbefriedigte und der pessimistische Grundzug, welcher der christlichen Religion in jener Zeit den geeignetsten Boden bereitete. Bezeichnet es doch Plinius als den einrigen Trost gegenüber der Unvollkommenheit des Daseins, daß der Mensch diesem Dasein jederzeit freiwillig entsagen könne.

1) A. a. O. II. 97.

2) A. a. U. XI. 3. 
Auf dem Gebiete der beschreibenden Naturwissenschaften finden wir bei Plinius einen Rückgang gegen Aristoteles und Theophrast. Nanche zoologische Mitteilung älterer Schriftsteller, die Aristoteles in das Grebiet der Fabel verwiesen hatte, nimmt Plinius unbedenklich wieder auf. Von einem systematischen Aufbau der Zoologie und der Botanik ist bei ihm nicht die Rede. Bezüglich der letzteren bleibt er weit hinter Theophrast zuriick, da er bei der Einteilung der Pflanzen den reinen Nützlichkeitsstandpunkt vertritt. Er unterscheidet nämlich Arzneipflanzen, Spezereien usw. Eine richtige Auffassung finden wir hingegen bei Plinius bezüglich derjenigen Tiere, die Aristoteles "Blutlose" genannt hatte. „Daß die Insekten kein Blut haben“, sagt er, "gebe ich zu, doch besitzen sie dafür eine gewisse Lebensfeuchtigkeit, die für sie Blut ist."

Seine der Botanik gewidmeten Bücher beginnen mit den Bäumen. Nicht etwa, daß er in ihnen die höchste Stufe pflanzlicher Organisation erblickt hätte, sondern weil sie zuerst die einfachsten Bedürfnisse des Menschen befriedigten. Zunächst bespricht er (12. und 13. Buch) die bemerkenswerteren fremden Bäume nach ihrem geographischen Vorkommen. Dann handelt er vom Weinstock, vom Ölbaum und von den Obstbäumen. Ein Buch ist den Zierpflanzen und den Bienenpflanzen gewidmet. Letztere unterscheidet er in empfehlenswerte und in solche, die den Honig verderben.

Am ansfïhrlichsten werden die Arzneipflanzen behandelt. Plinius ist dabei von dem Gedanken durchdrungen, daß auch das unscheinlarste Kraut seine, wenn auch oft noch verborgenen, Heilkräfte haben müsse. Wie hier, so ist auch an den übrigen Stellen der ..Naturgeschichte" der leitende Gedanke der; daß die Natur alles um des Menschen willen erzeugt habe. Das Nützlichkeitsprinzip beherrscht also die Darstellung, die dementsprechend oft recht trocken ist und nicht selten auf eine bloße Aufzählung hinausläuft. Stellenweise erhebt sie sich jedoch auch zu rhetorischem Schwung, zumal wo Plinius seine stoische Weltanschauung durchblicken läßt oder, wo er sich als laudator temporis acti, d. h. als Lobredner auf die gute alte Zeit, zu erkennen gibt.

Die Hauptquelle für die botanischen Kenntnisse des Plinius ist Theophrast. So entnahm er z. B. Theophrast die Schilderung der indischen Pflanzenwelt. Doch geschah es ohne tieferes Urteil und Verständnis. Das Feine und Exakte ist zumeist ver- 
wischt und kaum merklich hebt sich bei Plinius dieser Teil aus der Menge der übrigen Einzelheiten $a b^{1}$ ). Eigene Beobachtungen kann Plinius in Anbetracht seiner oben erwähnten Lebensweise nicht oft gemacht haben. Wenn er gelegentlich in seinem Werke von Erfahrungen spricht, so ist damit wohl in den meisten Fällen ihm miindlich zuteil gewordene Auskunft gemeint. Die Zahl der bei Plinius vorkommenden Pflanzen ist eine recht beträchtliche. Sie beläuft sich anf nahezu tausend, etwa das Doppelte der bei Dioskurides aufgezählten Arten ${ }^{2}$. Es entspricht das zwar dem enzyklopädischen Grundsatz des Plinius, verdient aber immerhin Beachtung, wenn wir bedenken, daß Linné den Pflanzenreichtum der ganzen Erde auf nur 10000 Arten schätzte.

Auch über die Wirkung, welche die "Naturgeschichte" des Plinius auf die Nachwelt ausgeübt, und iiber die Würdigung, die das Werk erfahren hat, mögen hier einige Bemerkungen Platz finden. Hatte doch die "Naturgeschichte" für die gesamten nachchristlichen Jahrhunderte bis zum Wiederaufleben der Wissenschaften eine Bedentung wie nur wenige Biicher. Sie war die wichtigste Quelle für jede Belehrung ïber naturwissenschaftliche und viele andere Dinge. Dies dauerte so lange, bis man das eigene Beobachten und Forschen höher als Autorität und Biicherweisheit einschätzen lernte und damit die Grundlagen für einen Neubau der Naturwissenschaften zu schaffen begann.

Daß die Elemente des alten Wissens nicht nur manches wertvolle Stiick fuir diesen Neubau lieferten, sondern auch durch ihre Unzulänglichkeit den Anstol zur Weiterentwicklung gegeben haben, wird bei der Beurteilung der antiken Schriften oft vergessen. Daher rührt es, dak das Urteil jo nach der Stellung, die man einnimmt, außerordentlich schwankend und widerspruchsroll ist. Lis gilt das ron Plinius nicht minder wie ron Theophrast, Aristoteles und viele andere. Man hat sie bald hoch gepriesen, bald herabgesetzt, selten aber sie nach Gel,uihr gewürdigt.

Selbst ein Curier und ein Buffon, Forscher, die zu den bedeutendsten der Nenzeit zïhlen, haben Plinius ilne Anerkennung nicht versagt. So schreibt Buffon in seiner großen "Naturgeschichte", der er ein Wort des Plinius voranstellt, iiber diesen: .Sein Werk umfaßt nicht nur die Tliere, die Pflanzen und die

1. Nach II. Bretzl, Die hotanisehen Forsehungen des Alexanderzuges. Leipzig 1903. Siehe auch S. 142 dieses Bandes.

2) E. Mcyer, Geschichte der Botanik. 4 Bände. 185 \& 
Mineralien, sondern auch die Erd- und Himmelskunde, die Medizin, die Entwicklung des Handels und der Künste, kurz alle Wissenschaften. Erstaunlich ist, wie bewandert Plinius sich auf allen Gebieten zeigt. Erhabenheit der Gedanken und Schönheit des Ausdrucks vereinigen sich bei ihm mit tiefer Gelehrsamkeit."

Auch A. v. Humboldt, der uns im 2. Bande seines "Kosmos" eine Geschichte der physischen Weltanschauung hinterließ, hat für Plinius Worte der Anerkennung. Er bezeichnet die "Naturgeschichte", dem das Altertum nichts Ähnliches an die Seite zu stellen habe, als das großartige Unternehmen einer Weltbeschreibung. Trotz aller Mängel des Werkes habe dem Verfasser ein einziges großes Bild vorgeschwebt. Man möchte hinzufügen, daß Plinius für seine Zeit das versucht hat, was v. Humboldt im "Kosmos" anstrebte. Und wenn Plinius selbst sein Werk als eine Enzyklopädie bezeichnete, so ist zu bedenken, daß dieses Wort seit dem Altertum seine Bedeutung gewechselt hat. Es bedeutete nämlich etwa soviel wie „Vollkreis und Inbegriff der allgemeinen Wissenschaften"1), während man heute eine Art Wörter- und Nachschlagebuch darunter versteht. Neuere geschicbtliche Darstellungen, deren Verfasser die "Naturgeschichte" vielleicht nicht einmal genauer kennen, haben Plinius mitunter als enzyklopädischen Vielschreiber und geistlosen Kompilator abgetan. Dabei verfielen sie selbst in den Fehler, zu Nachbetern der absprechenden Urteile zu werden, die um die Mitte des 19. Jahrhunderts über das Altertum und seine Schriftsteller (besonders ron naturwissenschaftlicher Seite) in Umlauf gesetzt wurden. Heute ist dagegen eine sachlichere Würdigung der geschichtlichen Entwicklung im Entstehen begriffen, so daß man es wohl allgemein ablehnen würde, wenn jemand Plinius oder Aristoteles an dem Maße eines neueren Forschers messen wollte. Um den richtigen Maßstab zu gewinnen, müssen wir sie aus der Zeit, die sie erzeugt hat, zu verstehen suchen und ihre Werke mit denen der nämlichen oder einer noch naheliegenden Periode vergleichen. Dabei richtet sich der Blick zunächst auf die christliche und die arabische Literatur des Mittelalters. Und wenn man die "Naturgeschichte" des Plinius mit einem Erzeugnis jener Literatur, das das gleiche Ziel verfolgt, z. B. mit dem „Buch der Natur" des Konrad Megenberg, vergleicht, dann erscheint das Werk des Römers in einer ganz anderen und vor allem in der richtigen Beleuchtung.

1) v. Humbold t, Kosmos. Bd. II. 1847. S. 230. 
Der Anerkennung, die man der "Naturgeschichte“ des Plinius während des ganzen Mittelalters zollte, entspricht es, daß aus diesem Zeitraum eine große Zahl ron Handschriften - es sind nicht weniger als zweihundert - auf uns gelangt sind. Von den älteren ist allerdings keine einzige vollständig. Sie sind sogar oft sehr fragmentarisch. Sämtliche neueren Handschriften lassen iibrigens erkennen, daß sie auf einen Archetyp (d. h. die nämliche alte Vorlage) zurückzuführen sind.

\section{Fortschritte der Anatomie und der Heilkunde.}

Fïr die Beschäftigung mit den Tieren und den Pflanzen waren bei den Römern, wie in der alexandrinischen Akademie, an erster Stelle medizinische und landwirtschaftliche Gesichtspunkte maßgebend. Wichtig war es auch, daß man sich ïber die Bedenken hinwegsetzte, die bis dahin von einem Eindringen in den Bau und die Verrichtungen des menschlichen Körpers abgehalten hatten. Schon bald nach Aristoteles, dessen anatomisches Wissen, wie wir sahen, wenigstens in bezug auf den Menschen, noch gering war, unterschied man Arterien und Venen. Auch bemerkte man, daß ihre Verzweigungen dicht nebeneinander liegen. Da man die Arterien jedoch beim Zerschneiden des toten Körpers leer fand, so glaubte man, daß es ihre Aufgabe sei, im lebenden Organismus Luft zu fiihren. Zu einer $\mathrm{zwar}$ noch mit vielen Unrichtigkeiten durchsetzten Vorstellung von der Bewegung des Blutes, deren wahren Verlauf erst Harvey im 17. Jahrhundert erkannte, kam der römische Arzt Galen') (131-201 n. Chr.). Galen wurde in Pergamon geboren. Er empfing seine Ausbildung in Griechenland, übte aber die ärztliche Kunst in Rom aus (von 164-201 n. Chr.) und hielt dort auch Vorlesungen über Anatomie, für die cr schätzenswerte Beiträge auf Grund zootomischer Untersuchungen lieferte.

Galen erkannte die Anatomie und die Physiologie als die Grundlagen der Heilkunde und bemiihte sich schon, physiologische Fragen auf experimentellem Wege zu entscheiden ${ }^{2}$. Die Bewegung des Blutes schildert er folgendermaßen, wobei wir uns der heutigen

1) Galen fußte hesonders auf Lrasistratos, einem der bedeutendsten Anatomen der vorchristichen Zeit (geh. $280 \mathrm{v}$. Chr.), der auch den Bau des Gehirns untersucht haben soll. Sein Zeitgenosse Herophilos lieferte eine genaue Beschreibung des Auges.

2) A. Hirseh, Geschichte d. Medizin. S. 10. 
Bezeichnungweise bedienen wollen 1\%: "Durch die Venen gelangt das Blut zum rechten Teile des Herzens. Mittels der Wärme des Herzens werden die noch brauchbaren Teile ron den unbranchbaren geschieden. Die letzteren werden durch die Lungenarterie zu den Lungen geführt und beim Ausatmen entfernt, während gleichzeitig die Lungen Pnemma aus der Atmosphäre anziehen 2). Das Pneuma gelangt durch die Lungenvenen zum linken Herzen, verbindet sich hier mit dem Blut, das durch die Herzscheidewand treten sollte, und wird alsdann durch die Aorta in alle Teile des Körpers und endlich wieder in die Venen zurüickgeführt."

Von dem großen Kreislauf des Blutes hatte Galen ${ }^{3}$ ) also schon eine Vorstellung, während ihm unbekannt blieb, däß die ganze Masse des Blutes nach Vollendung dieses Kreislaufs durch die Lungen getrieben wird. An die Stelle einer richtigen Auffassung von der Rolle des Luftsanerstoffs, die erst durch die fortschreitende Einsicht in den chemischen Prozeß ermöglicht wurde, tritt bei Galen die Annahme des mystischen Pneumas. Darunter dachte man sich nicht die Luft selbst, sondern ein ihr innewohnendes, belebendes Prinzip.

Über die Fortschritte, welche die Anatomie zur 'Zeit der Römerherrschaft erfahren, gibt uns das Werk Galens die beste Auskunft4). Es verdient auch deshalb besondere Beachtung, weil es die einzige ausführliche, aus dem Altertum vorhandene Dar-

1) H. Haeser, Lehrbuch d. Gesch. d. Medizin. Jena 1853. Bd. I. S. 154.

2) Galen meint, daß man den belebenden Bestandteil der Luft, den er als Pneuma bezeichnet, später noch entdecken werde.

3) Galen war ein außerordentlich fruchtbarer und vielseitiger Schriftsteller. Man kennt nach Christ, Geschichte der griech. Literatur, S. 630) mehr als 350 Gralensche Schriften, von denen 118 echte und $4 \check{\text { zweifelhafte }}$ erhalten sind. Die meisten sind medizinischen Inhalts. Geschätzt war vor

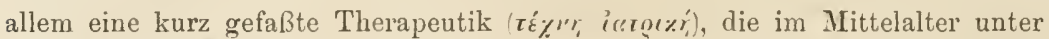
dem Namen ... Hikrotechnikum" bekannt war. Außerdem hat Galen auch Schriften philosophischen und grammatischen Inhalts verfaßt, z. B. Kommentare zu Platons .Timaeos", zu Aristoteles und zu Theophrast. Die Hauptausgabe der Galenschen Schriften ist die Aldina 1525; ed. Chartrier, Paris 1679. Eine ausfuhrliche Darstellung der Bedeutung Galens enthält Paulys Realenzyklopädie des klass. Altert. Bd. VII. S. 578-591.

4) Galenos. Sieben Bücher Anatomie des Galen. INITOMIKIN ETXEIPUIEQY BIB JION $\overrightarrow{-}-\overrightarrow{E I}$. Zum ersten Male veröffentlicht nach den Handschriften einer arabischen Übersetzung des 9. Jahrh. n. Chr., ins Deutsche übertragen und kommentiert ron Dr. med. Max Simon. I. Band: Arabischer Text. Einleitung zum Sprachgebrauch, Glossar mit 2 Faksimiletafeln. LXXXI u. 362 S. gr. $8^{0}$ u. 2 Tafeln. II. Band: Deutscher 
stellung der Anatomie ist. Galen beginnt mit der Anatomie des Gehirns und der daraus entspringenden Nervenpaare. Es folgt die Beschreibung des Auges, der Zunge und der Lippen. Die Bewegung wird aus dem Verhalten der Muskeln erklärt, von denen Galen angibt, daß sie sich zusammenziehen und wieder erschlaffen ${ }^{1}$. Zu sehr wichtigen physiologischen Ergebnissen gelangte Galen, weil er sich als einer der ersten des vivisektorischen Versuchs bediente. So finden wir in seinem Buche die Wirkungen geschildert, welche das Durchschneiden des Glossopharyngeus (Zungenschlundkopfnerv), des Seh- und des Gehörnerven zur Folge hat. Besonders fesselnd sind die an dem Zungenschlundkopfnerven rorgenommenen Experimente. Galen erwähnt, daß sich auf jeder Seite der Zunge zwei Nerren befinden. Schneide man das eine Paar durch, so sei die ganze Zunge der willkürlichen Bewegung beraubt, während die Durchschneidung nur eines dieser Nerven nur die Hälfte der Zunge lähme2). Das zweite Nervenpaar, sagt Galen weiter, rereinige sich nicht mit den Muskeln, sondern verteile sich in der Decke der Zunge und vermittle die Empfindung. „Der Nerv bringt die Geschmacksempfindung vom Gehirn herab", heißt es bei ihm.

Hervorzuheben ist auch Galens Beschreibung des Lidhebemuskels und ganz besonders seine anatomische Untersuchung der

Text. Kommentar, Einleitung zur Anatomie des Galen. Sach- und Namenregister. - Leipzig, J. C. Hinrichs, 1906. LXVIII u. 366 S. gr. $8^{0}$.

Die ersten 8 Bücher von Galens Anatomie und ein Stiick des 9. Buches sind im griechischen Urtext bekannt. In ihnen werden die Gliedmaßen, Kopf, Hals, Rumpf, die Organe der Verdauung und die Atmungswerkzenge beschrieben. Das 9.-15. Buch, die Simon nach der arabischen Handschrift herausgegeben hat, waren bisher so gut wie unbekannt. Das 9. Buch bringt die Beschreibung des Gehirns. Im 10. werden die Augen, die Zunge und die Speiseröhre, im 11. der Kehlkopf, im 12. die Geschlechtsorgane beschrieben. Buch 13 handelt von den Gefäßen, Buch 14 und 1 jon den Nerven. Es handelt sich in diesen sieben Büchern fast überall um eigene anatomische Untersuchungen am lebenden und toten Tiere, wobei stets auf den Menschen bezuggenommen wird. An manchen Stellen wird der berülımte alexandrinische Anatom Erasistratos zitiert. Ausdrücklich wird gefordert, dab jeder, der über Anatomie liest, es nicht versïumen solle, die einzelnen Dinge am Tierkörper mit eigenen Augen anzuschen.

1) Bd. II der Ausgabe von Simon. S. 45.

2 Bil. II der Ausgabe von Simon. S. 94.

Der häufig anzutreffende '/usatz Klaudios zu Galenos ist nicht berechtigt. Der große Arzt ist nicht $\mathrm{K}$ laudios $\mathrm{Galenos,}$ sondern nur Galenos zu hènennen. Siehe Mitteil. zur Gesch. d. Med. u. d. Naturwissenschaft. 1902. S. 3. 
Nerven und Muskeln des Kehlkopfs, eine Untersuchung, bei der es ihm vor allem auf die Feststellung des Wesens der Stimmbildung ankam.

Ein Buch Galens handelt ron den Venen und den Arterien, ein zweites von den Fortpflanzungsorganen. Auch der Fötus mit seinen Hïllen und die Plazenta (Mutterkuchen) werden beschrieben.

Ist es für die Entwicklung der Medizin von großer Bedeutung, daß ein Galen in einem umfassenden Lehrgebäude das Ganze der griechischen Heilkunde zur Darstellung brachte, so ist es von rein wis-enschaftlichem Standpunlit das Verfahren Galens, das unser höchstes Interesse beansprucht. War er es doch, der

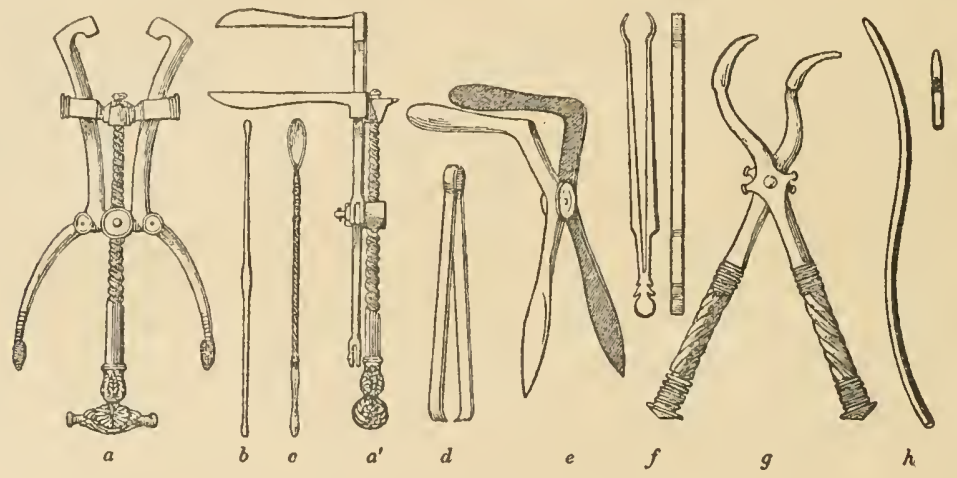

Abb. 43. Chirurgische Instrumente.

zuerst in größerem Umfange durch seine an lebenden Tieren ausgeführten Untersuchungen sich der Erforschung der Verrichtungen des Organismus zuwandte. Mit Recht verdient deslualb Galen als der Begründer der experimentellen Physiologie bezeichnet zu werden ${ }^{1}$. In welchem Grade die Heilkunde schon durch die Leistungen der Mechaniker gefördert wurde, zeigen uns die aus dem Altertum erhaltenen ärztlichen Bestecke (Abb. 43). Erwähnt sei noch, daß Galen, wie Jahrhunderte vor ihm die Verfasser der hippokratischen Schriften, auf die hygienisch-diätetsche Seite der Heilkunde großen Wert legte. Galen hat eingehend seine Ansichten ïber die Wirkung der Luft und der Nahrungsmittel ent-

1) H. Haeser, Geschiche der Medizin. Bd. I (1875̌). S. 364.

Unter anderem hat $\mathrm{G}$ alen schon versucht, sich eine Vorstellung von dem Sitz der einzelnen Funktionen des Gehiıns zu machen, indem er die Gehirumasse schichtfnweise abtrug. Siehe Falk, Galens Lehre vom Nervensystem. Leipzig 1871. 
wickelt und auch Schlaf und Wachen, Ruhe, Bewegung und Gemütszustände vom ärztlichen Standpunkte aus gewürdigt. In dieser prophylaktischen Richtung folgte ihm im Mittelalter die Schule von Salerno ${ }^{1}$.

Erst dadurch, daß Galen zu einem im ganzen'richtigen Verständnis des TVesens der Muskeln, Selnnen und Nerven gelangte, wurde die Heilkunde auf die Stufe einer Wissenschaft emporgehoben. Vor allem war es die Chirurgie, die aus der gewonnenen Einsicht in den anatomischen Bau des Körpers Nutzen zog. Die Zoologie und die Botanik büßten dagegen im Vergleich zu der Behandlung, die Aristoteles und Theophrast diesen Gebieten angedeihen ließen, an Wissenschaftlichkeit ein und wurden nur noch mit Rücksicht auf d:s medizinische Bedürfnis gefördert. So entst.ınd, kurz bevor Plinius schrieb, die Arzneimittellehre des 1)ioskurides2). In ihr finden wir etwa 600 Pflinzen erwähnt, die indes so oberfächlich beschrieben sind, daß es meist schwer hält, die Arten sicher zu erkennen.

Bei den Bearbeitern der Schriften des Dioskurides finden wir nämlich als einen Grundzug, der uns bei alten naturwissenschaftlichen Schriftstellern des Mittelalters begegnet, daß man dem Wort eine fast größere Bedeutung zuschrieb als dem Dinge selbst. Genaue Überlieferung der Nimen, möglichst vollständige Aufzählung der Synonyme, der volkstümlichen und der Geheimbezeichnungen nehmen in jenen Schriften den ersten Platz ein. $\mathrm{Ja}_{\mathrm{a}}$, es gab Schriftsteller, deren Hauptgegenstand die Nomenklatur der Pflinzen und im Anschluß diran angestellte Betrachtungen iiber Besonderheiten der Grammatik und der Synonymik war ${ }^{3}$ ). Die Botanik beriicksichtigte Dioskurides nur insoweit, als es

1) Näheres siche Gerster-Braunfels, Abriß der Geschichte der Jatrohygiene vom Altertum durchs dentsche Mittelalter bis zur Neuzeit.

2) Dioskorides lebte im 1. Jahrundert n. Chr. Die authentische Namensform ist Dioskurides; Dioskorides ist aber die allgemein übliche. Er war Grieche und besuchte als Arat im Gefolge römischer Heere viele Länder. Seine Werke wurden griechisch und lateinisch von Sprengel herausgegehen. Leipzig 1829. (Diese Ausgabe ist völlig üherholt durch die neuere von Wellmann.) Sie sind in vielen Handschriften erhalten. Berühmt ist der mit Abbildungen versehene Kodex der Wiener Bibliotlek aus dem 6. Jahrhundert, der in konstantinopel für Maximilian II. erworben wurde. (Siehe W. Christ, Geschichte der griechischen Literatur. München 1889. S. 629.) Zu beachten ist auch der Artikel üher Dioskorides von M. Wellmann in Pauly-Wissowas Realenzyklopädie. V. 1131.

3) E. M e yer, Geschichte der Botanik. Bd. II. S. 113. 
sein Zweck erforderte. Die bei manchem seiner Vorgänger übliche alphabetische Anordnung der Pflanzen verwarf er, um sie nach ilım natürlich erscheinenden Gruppen zusammenzustellen. Doch begegnete ihm dabei mancher Mißgriff. Freilich ist es schwer, zu entscheiden, was er selbst gefunden und was er seinen Vorgängern entlehnt hat.

Das Werk des Dioskurides blieb für das gesamte Mittelalter und noch dariiber hinaus von großer Bedeutung. „Was einer späteren Zeit", sagt Meyer in seiner Geschichte der Botanik 1), „Linnés Systema naturae wurde, das war für jene Zeit die Arzneimittellehre des Dioskurides; unr mit dem Unterschiede, daß man auf Linnés Werk fortzubauen nicht lange säumte, auf dem des Dioskurides dagegen wie auf einem Ruhekissen schlummerte." Indessen galt Dioskurides nicht nur für das Mittelalter als unanfechtbare Autorität auf dem erwähnten Gebiete, sondern noch die Begriunder der neueren Botanik knïpften im Anfange des 16. Jahrhunderts vielfach an ihn an. Sie waren dabei von dem Bemiihen geleitet, die von Dioskurides beschriebenen Pflanzen wieder aufzufinden, wodurch die Liebe zur Natur zu neuem Lehen erweckt wurde.

Während die Griechen sich auf dem Gebiete der Pflanzenkunde mehr als Theoretiker erwiesen, haben die Römer, ihrem auf das Nützliche gerichteten Sinne entsprechend, vorzugsweise die angewandte Botanik gefördert ${ }^{2}$. Eine Anregung dazu empfingen sie ron den Karthagern. Dort entstand schon im 6. Jahrhundert v. Chr., also lange vor den griechischen Georgikern, Magos Werk über die Laandwirtschaft, das der römische Senat später ins Lateinische übersetzen ließ. Die Bedeutung der Karthager auf diesem Gebiete ist wohl auf ihre Abhängigkeit von der phönizischen Kultur zuriickzuführen ${ }^{3}$ ). Der Simn für die Pflanzenkunde wurde bei den Römern auch dadurch gefördert, daß sie sich mit besonderer Vorliebe dem Gartenbau zuwandten. So kamen bei ihnen auch die Fensterbeete auf, welche die jungen Pflanzen vor Kälte schützten, aber durch ihre Marienglasscheiben die Sonnenstrahlen hindurchließen ${ }^{4}$.

1) Bd. II. S. 94.

2) O. Warburg, Geschichte der angewandten Botanik (Berichte der Deutsch. bot. Gesellsch. XIX [1901]. S. 159).

3) Warburg, a. a. O. - Das Wichtigste über den Ackerbau bei den alten Völkern enthält der Artikel „Ackerbau* in Paulys Realenzyklopädie der klass. Altertumswiss, 1894. S. 261 u. f.

4) Seneca erwähnt solche Beete als neuere Erfindung. 
Berühmt waren die Gärten, welche Kaiser Hadrian bei seinem Landsitz in Tibur, dem heutigen Tivoli, unterhielt. Auch die Landsitze, mit denen die römischen Großen die felsigen Gestade des Mittelmeers umsäumten, erhielten reichen gärtnerischen Schmuck. Die römischen Gärten wiesen jedoch auch manche Künsteleien auf, so daß sich Stimmen erhoben, die, wie z. B. Horaz, die Riickkehr zur Natur predigten.

Eins der besten Werke über die Landwirtschaft verfaßte M. Portius Cato, der durch sein Bemühen, die Römer zur Einfachheit und Sittenreinheit zurückzufuihren, bekannt gewordene Kensor. Das Werk') beginnt mit dem Lobe des Landbaues und enthält Vorschriften über die Obstzucht, den Anbau des Getreides und die Pflege anderer niitzlicher Gewächse2). Wir haben es schon als eine der Quellen, aus denen Plinius schöpfte, gewiirdigt.

\section{Die Botanik als Hilfswissenschaft der Heilkunde.}

Vom medizinischen Standpunkte aus hat sich auch der als Anatom und Arzt zu großer Berühntheit gelangte Galen mit den Pflanzen beschäftigt. Auf seinen Reisen, die ihn nach Griechenland, Kleinasien, Agypten und Palästina führten, bemühte er sich, alle Pflanzen, denen man Heilwirkungen zuschrieb, an ihrem natuirlichen Standorte zu beobachten und zu sammeln. Welchen Wert man diesem Gegenstande beimaß, geht auch daraus hervor, daß die römischen Kaiser jener Zeit Kräntersammler auf Kreta unterhiclten, weil die Arzneipflanzen dieser Insel besonders hoch geschïtzt waren. Galen bekïmpte diese Meinung und vertrat die Ansiclit, daß Italien ebenso wirksame Arzneipflanzen beherberge.

Durch manchen archïologischen Fund ist unsere '/eit mit den Pflanzen selbst bekannt geworden, mit denen sich das Altertum beschäftigte. $/ / u$ jenen, wolche die Mumiensärge Agyptens lieferten, sind vor allem die pflanzlichen Reste getreten, die bei der Ausgrahung Pompejis zutage gefördert wurden. Sie sind im

1) Cato, De re rustica. Eine treflliche Ausgabe rührt von Keil (1892) her. Cato starb $149 \mathrm{v}$. Chr.

2) Auch Marcus Terentius Varro, der zur Zeit Ciceros lebte, schrieb ein Buch über die Landwirtschaft. Näheres siehe unter den Quellen des Plinius. Varrus ..De re rustica: wurdr 1884 gleiehfalls vou Keil herausgegehen. 
Nationalmuseum in Neapel aufbewahrt und zum Teil so gut erhalten, daß sie identifiziert werden konnten 1 ).

Ein besonderes Interesse, das mitunter selbst gekrönte Häupter beherrschte, wandte man im Altertum der Erforschung giftiger Pflanzen zu. König Attalos von Pergamon, so erzählt uns Plutarch2), baute giftige Gewächse, wie Bilsenkraut, Nieswurz, Schierling, Sturmhut, und machte ein besonderes Studinm daraus, ihre Säfte kennen zu lernen und zu sammeln. Überhaupt wetteiferte Pergamon eine Zeitlang in der Pflege der Wissenschaften mit Alexandrien.

\section{Die römische Naturauffassung bei Lukrez und Seneca.}

Außer Plinius sind insbesondere noch zwei andere römische Schriftsteller zu nemnen, die über die Naturwissenschaften geschrieben haben, Lukrez und Seneca. Lucretius Carus (er starb 55 v. Chr.) hat seine naturphilosophischen, auf Epikur zurückgreifenden Anschauungen in einem Lehrgedicht entwickelt, das manche beachtenswerte Stelle enthält. Es führt den Titel „De rerum natura“, wurde unter den literarischen Erzeugnissen der voraugusteischen Zeit hoch geschätzt und ist sowohl der Form als dem Inhalt nach griechischen Mustern entlehnt. Als seine Quellen nennt Lukrez neben Empedokles, dem ,herrlichsten Schatz des gabenreichen sizilischen Eilands", vor allem Epikur. Aus den Schriften dieses Mannes, welcher "die anderen Weisen überstrahle wie die Sonne die Sterne verdunkle, habe er die goldenen Worte entnommen", welche uns sein Lehrgedicht biete. Eine dankbare Aufgabe für einen Dichter war es wohl kaum, die mechanische Weltanschauung poetisch zu entwickeln. Um so mehr verdient die Art,

1) L. Wittmack, Die in Pompeji gefundenen pflanzlichen Reste. Englers Botanische Jahrbücher. 33. Bd. (1903). S. 38-63. Identifiziert wurden unter anderem: Allium Cepa, Amygdalus communis, Castanea vesca, Corylus Avellana, Iuglans regia, Lens esculenta, Olea europaea, Panicum italicum, Panicum miliaceum, Phoenix dactylifera, Pinus Picea, Pisum sativum, Prunus persica, 'Triticum vulgare, Vicia Faba, Vitis vinifera.

Es handelt sich bei diesen Resten um Samen und Früchte.

Auf den Wandgemälden Pompejis sind etwa 50 Pflanzen dargestellt, die sich identifizieren ließen, während dies bei manchen nicht möglich war. Comes, Darstellung der Pflanzen in den Malereien von Pompeji. Stuttgart 1895.

2) Plutarch, Vita Demetrii. 
wie Lukrez sie löste und durch die er den Kranz der Musen davontrug, unsere Bewunderung. Es ist nicht nur die Schönheit der Gleichnisse und die lebensvolle Schilderung gewaltiger Naturerscheinungen, die uns in seinem Werke fesselt, sondern vor allem die Genialität der auf der Ablehnung alles Götter- und Aberglaubens beruhenden Lebensauffassung. Bezüglich seiner Auffassung der Naturvorgänge $\left.{ }^{1}\right)$ müssen wir uns hier auf einige Andeutungen beschränken.

Nichts entsteht aus nichts, sagt Lukrez mit Demokrit und Epikur, wenn selbst die Götter es wollten. Sondern die Natur erzeugt stets das eine aus dem andern. Die Dinge läßt Lukrez aus unendlich feinen Teilchen bestehen. Sonst sei z. B. das allmähliche Dïnnerwerden der im Gebrauch befindlichen, metallenen Gegenstände ganz unerklärlich. Da bei absoluter Raumerfüllung Bewegung unmöglich sei, so müsse man annehmen, die Teilchen seien nicht dicht zusammengedrängt, sondern durch leere Zwischenräume geschieden. Alles sei ferner schwer. Im leeren Raume müsse selbst die Flamme schwer sein. Ihr Emporsteigen sei dadurch bedingt, daß der Lufthauch sie trotz ihrer natürlichen Schwere in die Höhe treibe, wie ja auch das schwere Holz im Wasser emporschnelle. Schall, Licht und Wärme sind für Lukrez körperliche Ausflüsse. Sonderbar ist seine, dem Epikur entlehnte Bildertheorie. Wir nehmen nach ihr die Dinge wahr, indem sich dünne Häutchen von ihrer Oberfläche lösen und durch die Lüfte zu unserem Auge schwimmen. Die magnetischen Erscheinungen werden gleichfalls aus der Annahme erklärt, daß feine Teilchen von dem Magneten ausströmen. Selbst den Blitz läßt Lukrez aus glatten und winzigen Teilchen bestehen.

Eine Andeutung des Gesetzes von der Erhaltung des Stoffes und der Kraft kann man in folgenden Zeilen erblicken:

„Denn er (der Stoff) vermehrt sich nie, noch rermindert er sich durch Zerstörung,

Ferner war die Bewegung, die jetzt in den Urelementen Herrscht, schon von jeher da, und so wird sie auch kïnftig noch da sein. -

Denn kein Platz ist vorhanden, nach welchem die Teile des Urstoffs

1) Vergil widmete Lukrez die Worte: „Felix, qui potuit rerum cognoscere causas", ein Ausspruch, der später auf Newton angewandt wurde. Siehe Vergils Georgica II, 490.

Dannemann, Die Naturwissensehaften. I. Bd. 2. Auf. 
Könnten entfliehen, kein Platz, von wo aus erneuerte Kräfte Brächen herein, die Natur und Bewegung der Dinge zu ändern 1$). *$

Interessant ist, wie Lukrez das Verhältnis von Empfindung und Materie erörtert. Er schreibt die Empfindung nämlich nicht den Atomen, sondern nur ihrer Zusammenfassung zu. Denn, so meint er, die Menschenatome könnten doch nicht weinen und lachen. Indem er das tut, erhebt sich Lukrez iiber den krassen Materialismus der demokritischen Lehre. Des weiteren bringt er bemerkenswerte Anschauungen iiber Gegenstände der physikalischen Geographie. So erklärt er den gleichmäßigen Bestand des Meeres als eine Folge des Kreislaufs des Wassers. Nach seiner Annahme gelangt das Wasser aus dem Meere auf unterirdischem Wege in die Gebirge zuriick? ) und speist dort unter Abgabe des Salzgehaltes die Quellen. Die Erdheben werden darauf zurïckgeführt, daß die Erde mit Höhlungen, Strömen, Sümpfen und geborstenem Gestein ausgefüllt sei. Durch den Einsturz der Höhlen entständen Erschütterungen, die man als Erdbeben hezeichne.

Nicht minder merkwürdig als die Schrift des Lukrez sind $\left(\mathrm{die}^{3}\right)$ "Quaestiones naturales" des römischen Dichters und Philosophen Seneca, der im Jahre $65 \mathrm{n}$. Chr. starb.

Seneca meint, das Gesicht sei der triigerischste Sinn, da z. B. ein Ruder im Wasser wie gebrochen erscheine. Den Regenbogen hält er für das Spiegelbild der Sonne, denn einige Spiegel, sagt er, sind so beschaffen, daß sie die Gegenstände zu einer entsetzlichen Größe ausdehnen. Bei Seneca findet sich auch die einzige Stelle, welche darauf hindeutet, daß die Alten das Prisma gekannt und das Spektrum beobachtet haben. Seneca sagt nämlich, wenn man Glasstücke mit mehreren Kanten anfertige und die Sonnenstrahlen auf sie fallen lasse, so erblicke man die Farben des Regenbogens. Er erwähnt ferner mit Wasser gefüllte Glaskugeln und ihre Eigenschaft, dahinter befindliche Gegenstände vergrößert zu zeigen ${ }^{4}$. Dafür, daß die Römer mit den optischen Eigenschaften geschliffener Gläser bekannt waren, soll auch eine Angabe des Plinius sprechen. Es heißt dort, daß N'ero sich eines Smaragds bediente,

1) Lucretius. Deutsch von Max Seydel. München, R. Oldenbourg, 1881. 2. Gesang, V. 258 u. f.

2) Nach Vitruv dagegen werden die Quellen durch das in den Boden sickernde Regenwasser gespeist.

3) allerdings wohl vielfach interpolierten.

4) Quaest. natur. 1, 6. 
um besser sehen zu können. Dieser Stein sei konkay und dadurch geeignet gewesen, , die Sehstrahlen zu sammeln"1). Man hat auch bei Ausgrabungen (so in Pompeji) linsenfürmig geschliffene Gläser gefunden und nimmt an, daß sie als Brennglüser gedient haben. Auch bei den Ausgrabungen in Ninive hat man eine plankonvexe Linse aus Bergkristall entdeckt, die angeblich auch optischen Zwecken gedient hat ${ }^{2}$.

Der Schall ist für Seneca ein Druck der Luft. Er begegnet sich in dieser, annähernd das Richtige treffenden Anschauung mit Titruv, der im Gegensatz zu dem, alles als Ausfliisse auffassenden Lukrez den Schall als eine Lufterschütterung betrachtet. Diese Erschütterung läßt Vitruv ähnlich entstehen, wie sich durch einen Stein in Wasser die Wellenkreise bilden. Nur entständen die Wellen beim Schall nicht allein in der Fläche, sondern sie dehnten sich auch in die Breite und in die Höhe (somit kugelförmig) aus.

Im 3. Buche findet sich ein Anklang an den als Apokatastasis bezeichneten periodischen Wechsel. Die Erde sollte danach ${ }^{3}$ ) verbrennen, wenn alle Wandelsterne im Krebse zusammenkämen und somit eine gerade Tinie bildeten. Dagegen würde eine allgemeine Überschwemmung eintreten, wenn sich diese Konstellation im Steinbock wiederhole.

Die Höhe der Naturanschauung Senecas zeigt sich besonders in den Ansichten, die er über die Kometen entwickelt $\left.{ }^{4}\right)$. Seine Zeitgenossen, sagt er, seien der Meinung, die Kometen entständen aus verdichteter Luft. Er aber halte sie für, ,ewige WVerke der Natur", und zwar deshalb, weil auch ihnen ein Kreislauf eigen sei.

Von Beobachtungsgabe und Scharfsinn zeugen auch die Ansichten, die Seneca ïber die geologischen Erscheinungen entwickelt. Die Erdbeben werden teils auf den Einsturz von Höhlıngen des Erdinnern, teils auf dort angesammelte Gase zurïckgefïhrt. Die Vulkane stellen die Verbindung zwischen der Oberflïche und dem glutflüssigen Erdimern her. Unter den Vulkanen, welche Seneca aufzählt, findet der Vesur keine Erwähnung, während Strabo ihn wegen der in seiner Nähe sich findenden Schlacken als einen erloschenen Vulkan betrachtete. Nanche Bemerkungen Senecas über die lösende und die abtragendc Tätigkeit des

1) Plinius, Hist. nat. 37, 5. Diese Stelle ist jedoch unklar und ihre Deutung nur unsicher.

2) Poggendorffs Ergänzungsband 4. S. 452.

3) Nach einer Mitteilung des Berosos.

1 Seneca, Quaestiones VII. 22 u. 23. 
Wassers und die Bildung von Ablagerungen stimmen mit den neueren geologischen Anschauungen gut überein und "verraten durchweg ein gesundes Urteil"1). Auch Vitruv äußert in seiner Schrift „De architectura" die Ansicht, daß in der Nähe des Vesuvs das Innere der Erde glühend sein müsse. Er schließt dies daraus, daß bei Bajae heiße Dämpfe aus dem Boden entweichen. Vitruv erwähnt ferner auf Grund der Überlieferungen, daß die Glut des Erdinnern in alten Zeiten Ausbrüche des Vesuvs veranlaßt habe, daher rühre auch wohl der Bimsstein in der Nähe von Pompeji, der infolge der Hitze aus einem anderen Steine entstanden sei. Vitruv erwähnt auch, daß es Quellen gäbe, die vermöge ihrer Säure Blasensteine aufzulösen vermöchten, wie der Essig die Eierschalen löse ${ }^{2}$ ).

\section{Chemische Kenntnisse und ihre Anwendungen.}

Über die mineralogischen und die chemischen Kenntnisse der Römer erfahren wir manches durch Plinius $\left.{ }^{3}\right)$. Eingehender befaßt sich dieser mit dem Glase. Er schildert seine Herstellung aus Sand, Soda (Nitrum) und Muschelschalen ${ }^{4}$ ). Auch ist ihm bekannt, daß man mit Kugeln aus Glas oder Kristall sowie mit kugeligen, mit Wasser gefüllten Glasgefäßen in der Sonne Hitze erzeugen kann ${ }^{5}$ ). Die Römer stellten sogar Treibhäuser mit gläsernen Wänden her, um auf diese Weise frühzeitig frisches Gemüse $\mathrm{zu}$ erhalten. Aus Glas verfertigte Spiegel finden gleichfalls schon bei Plinius Erwähnung. Neuere Ausgrabungen haben solche auch zutage gefördert. Der Belag dieser antiken Spiegel besteht bald aus reinem Blei ${ }^{6}$ ), bald aus anderen Metallen.

Auch über die wichtigsten Farbstoffe und ihre Verwendung berichtet Plinius. Er erwähnt den Krapp und den Indigo, mit denen man die Wolle färbte. Wie man in Indien den Indigo ge-

1) A. v. Zittel, Geschichte der Geologie und Paläontologie. 1899. S. 10.

2) Vitruv, De architectura 8,3.

3) Die chemischen Kenntnisse des Plinius in E. v. Lippmanns Abhandlungen u. Vorträge zur Geschichte der Naturwissenschaften. Leipzig 1906. Im 2. Bande der Abhandlungen und Vorträge von Lippmanns (Leipzig 1913) findet sich in der zweiten Abteilung Wichtiges über die chemischen und physikalischen Kenntnisse der Griechen zusammengestellt.

4) Plinius 36,64 .

5) Plinius 36, 66 u. 67.

6) Jahresbericht über die Fortschr. d. klass. Altertumswiss. 1902. Bd. III. S. 26-82 (Stadlers Bericht). 
winnt, ist ihm indessen nicht bekannt. Am weitesten hatten es in der Kunst zu färben nach Plinius die Ägypter gebracht. Er erzählt von ihnen, daß sie die Stoffe ror dem Färben mit besonderen Flüssigkeiten (Beizen) behandelten.

Plinius kannte auch schon die Seife. Er erzählt, daß sie von den Galliern und den Germanen durch Kochen von Talg mit Pflanzenasche hergestellt werde. Wahrscheinlich wurde die Aschenlauge durch Zusatz von Kalk kaustisch gemacht ${ }^{1}$ ).

Mancherlei über die chemischen Kenntnisse zur Zeit der Römerherrschaft erfabren wir auch durch die um $75 \mathrm{n}$. Chr. entstandene Arzneimittellehre des Dioskurides. So spricht dieser vom Verzinnen von Kesseln 2). Daß gewisse Mineralien beim Übergießen mit Essig Gas entwickeln, war im Altertum bekannt. Plinius knüpft daran die Bemerkung, der Essig sei stärker als das Feuer, denn er bezwinge Felsen, die dem Feuer Widerstand leisteten $\left.{ }^{3}\right)$.

1) E. v. Meyer, Geschichte der Chemie. 1914. S. 17.

2) E. v. Lippmann, Alhandlungen u. Vorträge z. Gesch. d. Naturwissenschaften. Leipzig 1906. S. 56.

3) Die bekannten Erzählungen über das „Auflösen" der glühend gemachten Felsen mit Essig durch Hannibal, u. dgl., gehen jedoch nach v. Lippmann auf die rein abergläubische Vorstellung zurück, daß der Essig von äußerster Kälte sei und daß deshalb das Zusammentreffen dieses Extrems mit der Glut des Feuers auch ganz außergewöhnliche Wirkungen bedinge. 


\section{Der Ausgang der antiken Wissenschaft.}

In die Zeit der römischen Weltherrschaft fällt eine nochmalige Bliiteperiode der alexandrinischen Akademie. Die mit ihr verbundene große Bibliothek war zwar im Jahre 47 v. Chr. zum größten Teile vermichtet worden. Als Ersatz dafür gelangten zahlreiche Rollen der pergamenischen Bibliothek nach Alexandrien (s. S. 153). Eine zweite kleinere Bibliothek befand sich dort im Serapeion. Sie wurde gegen das Ende des 4. Jahrhunderts bei einem von den Christen hervorgerufenen Aufstand zerstört. Trotzdem blieb Alexandrien noch lange iiber das 4. nachchristliche Jahrhundert hinaus die bedeutendste Hochschule des Orients ${ }^{1}$ ).

\section{Das ptolemäische Weltsystem.}

Als ruhmvollster Name unter den alexandrinischen Gelehrten der nachchristlichen Jahrhunderte leuchtet uns derjenige des Ptolemäos entgegen. Mit seinen Verdiensten um die Fortentwicklung der Astronomie und der Geographie haben wir uns zunächst zu beschäftigen.

Ptolemäos lebte im 2. Jahrhundert n. Clir. in Alexandrien. Er hat sich als Mathematiker, Astronom, Physiker und Geograph die größten Verdienste erworben. Wahrscheinlich ist er in Ptolemais in Oberägypten geboren. Im übrigen ist über sein Leben fast nichts bekannt. Ptolemäos hat zahlreiche Schriften verfaßt, die zum Teil im Original, zum Teil in arabischer oder in lateinischer Sprache erhalten geblieben sind. Die wichtigsten sind die .,Erdbeschreibung", der "Almagest" (das astronomische Hauptwerk) und die "Optik". Das Weltsystem des Aristarch war zwar ein gliicklicher Einfall gewesen; die heliozentrische Auffassung allein vermochte jedoch

1) Über die alexandrinischen Bücherschätze und deren Schicksale siehe anch Ritschel, Breslau 1838, sowie F. Schemmel, Die Hochschule von Alexandrien im 4. u. 5. Jahrh. n. Chr. Neue Jahrbïcher f. d. klass. Altertum. 1909. S. 438. Nach der dort gegebenen Darstellung wurde die große Bibliothek mit ihren 400000 Bänden erst 272 n. Chr. zerstört. 
noch nicht, der genaueren Beschreibung der sich am Himmel abspielenden Vorgänge eine sichere Grundlage zu bieten. Dies System konnte daher im Altertum keine allgemeine Geltung finden, zumal es an den mechanischen Begriffen fehlte, welche damit in Einklang gebracht werden mußten. So erhob Ptolemäos den später auch Koppernikus und Galilei gegenüber gemachten, ron letzterem aber entkräfteten Einwand, daß eine Drehung der Erde um ihre Achse die Ablenkung eines senkrecht in die Höhe geworfenen Körpers zur Folge haben müßte. Ferner galt der von Aristoteles herrührende Satz, daß die Bewegungen der Himmelskörper, weil die letzteren göttlich und ewig seien, gleichmäßig und im Kreise vor sich gehen müßten, dem Ptolemäos, wie dem gesamten Altertum, als eine unumstößliche Wahrheit. Zwar hatte es den Anschein, als ob sjich die Planeten, sowie die Sonne und der Mond am Fixsternhimmel bald schmeller, bald langsamer bewegten; erstere schienen sogar zeitweilig stillzustehen und sich bald ror-, bald rïckwärts zu bewegen.

Die Unregelmäßigkeit der jälılichen Sonnenbewegung machte sich dem Ptolemäos vor allem darin bemerkbar, daß die Sonne 178 Tage und 18 Stunden gebraucht, um im Verlaufe des Winterhalbjahres rom Herbstpunkt zum Frühlingspunkt zu gelangen, während sie die andere Hälfte der Ekliptik, also den Weg vom Frühlings- zum Herbstpunkt, in weit längerer Zeit, nämlich in 186 Tagen und 11 Stunden, zuruicklegt 1). Diese als die erste Ungleichheit bezeichnete Unregelmäßigkeit entspringt, wie wir heute wissen, daraus, daß die Himmelskörper sich nicht in Kreisen, sondern in Ellipsen bewegen. Die zweite Ungleichheit, die nur bei den Planeten auftritt, wird dadurch herrorgerufen, dab wir unsere Beobachtungen von der Erde aus anstellen, die sich ihrerseits wieder um die Sonne bewegt. Dieser Umstand ist es, der die scheinbaren Stillstände und Rückgänge der Planeten verursacht. Auch daß an dem Monde eine als Evektion bezeichnete Ungleichheit in die Erscheinung tritt, bemerkte Ptolemä̈os schon ${ }^{2}$. Wir führen sie heute auf Störungen zuriick, welche die Mondbewegung dureh die Sonne erleidet. Sie ist die bedeutendste unter den Unregelmäßigkeiten der Mondbewegung und erreicht einen Betrag ron mehr als einem Girarl.

1) Johannes Frischauf, Grundriß der theoretischen Astronomie und Iler Geschichte der Planetentheorien. 2. Auflage. Leipzig 1903. S. 104. Die Intlerung der Gesehwindigkeit der scheinbaren Sonnenbewegung erklärt sieh daraus, daß die Erde im Winter der Sonne näher ist als in Somner.

2) Frischauf, a. a. O. S. 103. 
Schon Platon hatte es als die wichtigste Aufgabe der Astronomie bezeichnet, die beobachteten, scheinbar unregelmäßigen Bewegungen auf gleichförmige zurückzuführen, da, wie er sagte, keine Ursache dafür vorhanden sei, daß die himmlischen Körper sich anders als gleichförmig bewegen sollten. Der erste, der eine Lösung der von Platon gestellten Aufgabe versuchte, war sein Schüler Eudoxos von Knidos. Er bediente sich dazu der Theorie der homozentrischen Sphären; und es gelang ihm so, die zweite Ungleichheit als ein gesetzmäßig bestimmtes Bewegungsphänomen darzustellen. Nach Eudoxos ist jeder Planet auf einer rotierenden Sphäre befestigt. Die Pole dieser Sphäre liegen in einer zweiten Sphäre, die ebenfalls um eine Achse rotiert. Es kam nun darauf an, die Geschwindigkeiten jener Sphären und die Lage ihrer Achsen so zu wählen, daß dadurch dem tatsächlichen Verlauf der Erscheinungen möglichst Rechnung getragen wurde. Zu diesem Zwwecke mußten für den Mond und für die Sonne je drei und für jeden Planeten vier Sphären angenommen werden. Am besten gelang es auf diese Weise, die Bewegungen der entfernteren Planeten Saturn und Jupiter gewissermaßen in eine Regel $z u$ fassen. Die größten Schwierigkeiten bereitete der Mars, an dem später Tycho und Kepler den wahren Ablauf der Planetenbewegungen nach endlosen Mühen entdecken sollten.

Um die Theorie mit den Erscheinungen in besseren Einklang zu bringen, wurde später die Zahl der Sphären noch vermehrt1). Einen anderen Weg schlugen Hipparch und Ptolemäos ein. Sie benutzten zur Auflösung der ersten Ungleichheit exzentrische Kreise und zur Bewältigung der zweiten Ungleichheit den Epizykel 2). Hipparch erklärte die Erscheinung, daß die Sonne auf ihrer jährlichen Bahn eine größte und eine geringste Geschwindigkeit annimmt, indem er die Erde aus dem Mittelpunkt rückte und die Sonne um sie in gleichförmiger Bewegung einen exzentrischen Kreis beschreiben ließ. Die Größe der Exzentrizität ließ sich nun leicht so wählen, daß damit dem Verlauf der Erscheinungen Rechnung getragen wurde. Die Annahme von exzentrischen Kreisen hatte aber nicht einmal die Bewegung des Mondes, geschweige denn diejenige der Planeten zu erklären vermocht. Ptolemäos griff deshalb einen Gedanken auf, den der Mathematiker Apollonios geäußert hatte, und nahm zwei oder mehr Krreisbewegungen

1) Durch Kalippos.

2) Der exzentrische, mit dem Epizykel verbundene Kreis wurde als der deferierende Kreis bezeichnet. 
zu Hilfe. Zur Erklärung diene Abb. 44. Es sei E die Erde, um die mit einem Radius $\mathrm{R}=\mathrm{Mm}$ ein exzentrischer Kreis gezogen ist. Auf letzterem bewegt sich indes nicht der in Frage kommende Himmelskörper, sondern der Mittelpunkt der Kreisbahn p q t s, in der erst der Planet mit gleichförmiger Geschwindigkeit sich bewegt. Diese Kreisbahn wird der Epizykel, die Theorie daher die Epizyklentheorie genannt. Es ist ersichtlich, daß der Himmelskörper, von der Erde gesehen, sich in p rascher bewegt als in $t$, wo seine Bewegung derjenigen des Epizykels entgegengesetzt ist. Auch ist klar, daß trotz der gleichförmig gedachten Bewegung, mit deren Annahme der Forderung Platons Genüge geleistet war, scheinbare Stillstände und Rückgänge eintreten können. Es kam nur darauf an, das Verhältnis von $r$ und ME zu R, sowie die Umlaufszeiten um $M$ und $m$ so zu wählen, daß dem Verlauf der Erscheinungen durch die hypothetischen Bewegungen Genüge geleistet war und erstere aus den angenommenen Verhältnissen berechnet werden konnten. Stimmten dann die Berechnungen mit neuen, auf Grund der Rechumng angestellten Beobachtungen nicht überein, so führte

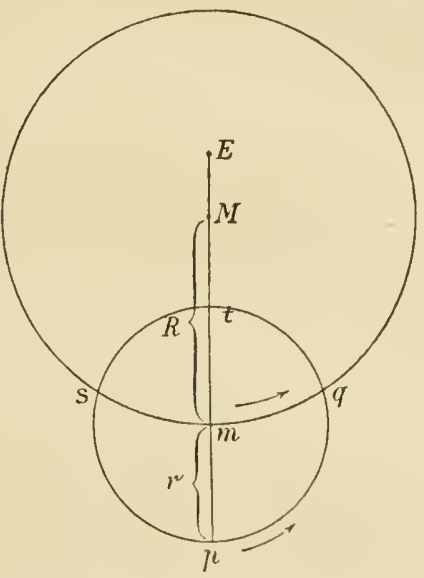

Abb. 44. Zur Erläuterung der Epizyklentheorie. man einen dritten Epizykel ein, dessen Mittelpunkt den Kreis p q t s beschrieb. Durch eine Verknuipfung derartiger Kreisbewegungen läßt sich offenbar jede, nach einem bestimmten Gesetze auf beliebiger Bahn ablaufende Bewegung darstellen.

Ptolemäos wandte die Epizyklentheorie zunächst auf die Erklärung der Mondhewegung an. Daß die Entfernung des Mondes von der Erde beträchtlichen Schwankungen unterworfen ist, liatte sich ihm aus der 'latsache ergeben, daß der scheinbare Durchmesser des Mondes nach seinen Beobaclitungen zwischen $31^{1 / 3}$ und $351 / 3$ Minuten schwankt. A ristoteles hatte also recht, wemn er behauptete, „daß derselbe Diskus, bei sich gleichblcibender Entfernung vom Auge, den Mond bald bedecke, bald nicht".

Un die Ungleichliciten des Mondumlaufes zu erklären, ließ Ptolemäos das Gestirn einen Epizykel beschreiben, der sich innerhalb eines Zeitraumes vollziehen sollte, in welchem der Mond 
zu demselben Endpunkte seiner großen Bahnachse zuriickkehrt. Der Mittelpunkt dieses Epizykels umlief die Erde in einem Kreislauf, der gegen die Ekliptik, der Neigung der Mondbahn entsprechend, schief gerichtet war. Die Zeitdauer dieses Kreislaufs währte bis zur Riickkehr zu den Knoten, den Punkten, in denen die Ekliptik und die Mondbahn sich schneiden. Auf diese Weise erzielte Ptolemäos, daß sich Rechnung und Beobachtung, wenigstens für den damaligen Stand der astronomischen Wissenschaft, in etwa deckten.

Dasselbe Ziel suchte Ptolemäos bezüglich der Planetenbewegung unter Zuhilfenahme der Epizyklen und der exzentrischen Kreise zu erreichen. Doch waren die Schwierigkeiten hier fast noch größer.

So lange man die Epizyklentheorie als bloße Hilfshypothese ansah und benutzte, ließ sich gegen sie nichts einwenden. Wir bedienen uns noch hente zur Beschreibung von Naturvorgängen mancher Fiktionen, die dem Fortschritt der Erkeuntnis nur dann gefährlich werden, wenn wir uns daran gewöhnen, in ihnen den wahren Grund der Erscheinungen zu erblicken. Erinnert sei nur an die Annahme magnetischer und elektrischer Fluida, an deren wirkliches Vorhandensein kein Physiker glaubt, obgleich sie einer elementaren Beschreibung der magnetischen und der elektrischen Vorgänge zugrunde gelegt werden. Mit der zunehmenden Kompliziertheit solcher Hypothesen wird indes ihre Anwendung immer mehr erschwert. So trug schon aus dieser Ursache die Epizyklentheorie den Keim des Todes in sich, wenn auch ihre Herrschaft noch lange danern sollte. Denn selbst Koppernikus war, nachdem er die Sonne, wie er sich ausdrückt, auf ihren königlichen Thron in die Mitte der sie umkreisenden Gestirne gesetzt hatte, sofort gezwungen, sich der Epizykel wieder als Hilfskonstruktion zu bedienen, weil er an der Vorstellung einer lkreisförmigen Bewegung der Planeten festhielt.

Zwar kam bei Annahme der heliozentrischen Lehre die sogenannte zweite Ungleichheit in Fortfall, da sie ja daraus entsprang, daß man die Erde als den Mittelpunkt der Bewegungen betrachtete. Anders stand es mit der ersten Ungleichheit, welche daraus hervorgeht, daß die Himmelskörper sich nicht in Kreisen, sondern in Ellipsen bewegen. Da Koppernikus an die Möglichkeit einer anderen als der kreisförmigen Bewegung noch gar nicht dachte, so blieb ihm zur Erklärung der ersten Ungleichheit nichts anderes übrig, als auf sie die Epizyklentheorie anzuwenden. Das 
astronomische und das trigonometrische Wissen seiner Zeit legte Ptolemäos, nachdem es durch ihn eine beträchtliche Vermehrung erfahren, in einem Lehrbuche nieder, das von den Arabern Almagest1) genannt wurde und dem gesamten Mittelalter in astronomischer Hinsicht als ein Evangelium galt.

Das Bedürfnis nach einer Verbesserung der von Ptolemäos mitgeteilten Planetentafeln machte sich schon im Mittelalter geltend. Um das Jahr 1250 berief daher König Alfons von Kastilien eine Anzahl Gelehrter, welche nene astronomische Tafeln, die sogenannten alfonsinischen, entwarfen, die einen wesentlichen Fortschritt gegeniiber denjenigen des Ptolemäos bedeuteten. An der Epizyklentheorie wurde indes trotz ihrer wachsenden Kompliziertheit nicht geriittelt, was Alfons zu dem Ausspruch veranlaßt haben soll, die Welt wäre einfacher geworden, wenn Gott ihn bei ihrer Erschaffung zu Rate gezogen hätte.

Außer der vorstehend skizzierten, dem damaligen Standpunkte der Astronomie geniigenden Epizyklentheorie finden wir im Almagest die schon von den älteren alexandrinischen Astronomen sowie von Hipparch in Angriff genommene Bestimmung der Fixsternörter fortgesetzt 2). Das von Ptolemäos entworfene Verzeichnis ${ }^{3}$ ) umfaßt 1022 Sterne, die nach ihrer Lage innerhalb der von den Griechen angenommenen Sternbilder, sowie nach Länge und Breite bestimmt sind.

Auch die Untersuchung der von Hipparch entdeckten und ihrer Größe nach gleich etwa einem Grad für das Jahrhundert an-

1) Aus dem arabischen Artikel uud dem ersten Wurt des griechisehen

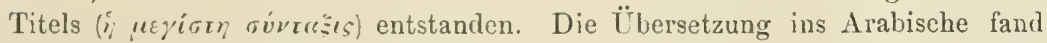
spätestens um 827 statt. Seit dem 12. Jahrhundert wurde der Almagest wiederholt ins Lateinische übertragen. Eine ungenügende Ausgal)e des griechisehen Textes nelst einer Übersetzung ins Französische veranstaltete $\mathrm{Halma}$ (2 Bde., Paris 1813-1816). Eine griechisch-lateinische Ausgabe besorgten Wilberg und Grashof, Essen 1833-1815. Unter den neueren Schriftstellern, die den Almagest zugänglich gemacht laben, ist neben Heiberg besonders Manitius $z u$ nennen (Des Claudius Ptolemaeus Handbuch der Astronomic. Aus dem (iriechischen übersetzt und mit erklärenden Anmerkungen verselıen von $\mathrm{K}$ ar Manitius. Leipzig 1912. B. G. Teubner.

2) Die Kahl der mit bloßem Auge sichtbaren Fixsterne beläuft sich auf 4-5000. Hipparch stellte das erste wissensehaftliche Fixsternverzeichnis mit Angahe der Positionen und der Größenverhältnisse aul.

3) Es bildet das 7. Buch des Almagest und wurde 1795, übersetzt und erläutert, heransgegeben von J. E. Bude: J. E. Bode, Claudius Ptolemäus' Beobachtung und Beschreibung der fiestirne. Berlin 1795. 
gegebenen Präzession der Tag- und Nachtgleichen wurde von Ptolemäos wieder aufgenommen. Eine Bestätigung dieser Erscheinung war nämlich sehr wichtig, da Hipparch sich nur auf die wenig genauen Beobachtungen der älteren Alexandriner stützen konnte.

Bevor wir die Schilderung der astronomischen Verdienste des Ptolemäos beenden, sei noch einiges aus dem Inhalt des Almagest mitgeteilt, woraus sich der Ștandpunkt, den die Sternkunde in Alexandrien erreicht hatte, ermessen läßt. Die Erde ist eine Kugel. Sie befindet sich in der Mitte des Himmels, kann aber im Vergleich zu den Himmelsräumen nur als ein Punkt betrachtet werden. Während die Erde unbeweglich feststeht, bewegen sich die Gestirne in kreisförmigen Bahnen. Dies sind die Sätze, welche an der Spitze des Werkes stehen. Die Länge des Jalıres wird im Almagest zu 365 Tagen 5 Stunden und 55 Minuten angegeben. Die Erde ist $39 \mathrm{mal}$ so groß wie der Mond, während die Sonne den Mond 6600 mal an Größe übertreffen sollte. Bezüglich der Entfernungen wird angegeben, daß der Mond 59, die Somne dagegen 1210 Erdhalbmesser von uns entfernt sei.

Die Abstände der Gestirne von der Erde regeln sich nach Ptolemäos folgendermaßen: Auf den Mond folgt zunächst Merkur, dann Venus und darauf die Sonne. Die weitere Reihenfolge ist Mars, Jupiter und Saturn. Auf diese sieben Wandelsterne, deren Zahl erst durch Herschels Entdeckung des Uranus vermehrt wurde, folgen die Fixsterne.

An die Beschreibung dieses seinen Namen tragenden Weltsystems schließt sich eine Darstellung der Grundzüge der ebenen und der sphärischen Trigonometrie, der wichtigsten Hilfswissenschaft der Astronomen.

\section{Hilfswissenschaften der Astronomie.}

Die astronomischen Leistungen des Ptolemäos wurden dadurch ermöglicht, daß die beiden wichtigsten Hilfswissenschaften der Astronomie, die Mathematik und die Meßliunde, bedeutende Fortschritte aufzuweisen hatten. Die wichtigste Vorarbeit auf dem Gebiete der Mathematik lieferte der Astronom Menelaos von Alexandrien, dessen Sternbeobachtungen im Almagest Erwähnung finden. Menelaos verfaßte ein Werk über die Berechnung der Sehnen, das verloren ging, und ein zweites, "Sphärik“ genannt, welches die Grundzüge der sphärischen Trigonometrie entwickelte, 
indessen nur in Übersetzungen bekannt geworden ist $\left.{ }^{1}\right)$. Menelaos bringt schon den Satz, daß in jedem sphärischen Dreieck die Summe der drei Winkel größer als zwei Rechte ist. Er zeigt, daß gleichen Seiten desselben sphärischen Dreiecks gleiche, ungleichen Seiten ungleiche IVinkel gegenüberliegen, und zwar den größeren Seiten die größeren Winkel. Sein Werk enthält die wichtigsten Sätze ïber die Kongruenz sphärischer Dreiecke, ferner diejenigen Sätze iiber Transversalen im ebenen und im sphärischen Dreieck, die man noch jetzt als die Sütze des Menelaos bezeichnet. Ptolemäos vollendete, was Hipparch und Menelaos auf dem Gebiete der ebenen und der sphärischen Trigonometrie begonnen hatten. Er gab dieser Wissenschaft für den astronomischen Gebrauch eine Form, die sich, wie seine Lehre, länger als ein Jahrtausend erhalten hat.

Als der letzte unter den großen Mathematikern des Altertums ist Diophant von Alexandrien zu nennen. Dieser schrieb ein Werk über Arithmetik, das etwa zur Hälfte erhalten geblieben ist ${ }^{2}$ ). Er

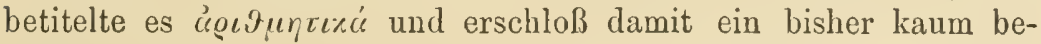
tretenes Gebiet.

Bei Diophant begegnen uns schon gewisse Zeichen und Abkürzungen, während vor ihm die Rechnungen zumeist nur durch Worte auseinandergesetzt wurden und höchstens gewisse Fachaus drücke (wie bei den alten Ägyptern) wiederkehren. Für die Unbekannte (unser x) gebrauchte Diophant z. B. das Sigma, $s$, den einzigen griechischen Buchstaben, der keine bestimmte Zahl bedeutete.

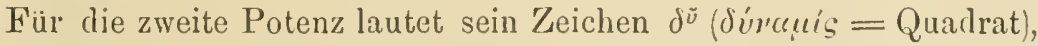
für die dritte $\%^{\tilde{v}}\left(\% v^{\prime} \beta\right) s=W$ ürfel). Für die sechste Potenz schrieb Diophant $\varkappa^{\tilde{v}} x^{\tilde{v}}$. Höhere Potenzen kommen bei ihm nicht vor. Für die Subtraktion verwendet er ein besonderes Zeichen ( $h=$ umgekehrtes $\psi$ ). Zu addierende Größen dagegen werden ohne ein Zeichen nebeneinander gestellt. Selbst ein Gleichheitszeichen ( $\iota$ als Abkürzung von iso $\iota$, gleich) fehlt nicht'3). Diese Beispiele zeigen zur Genüge, daß uns bei Diophant schon ein Verfahren bergegnet, das seine hervorragenden Erfolge erklärlich macht. Ein wesentlicher Mangel der diophantischen Algebra besteht darin, daß sie den Gegensatz von positiv und negativ noch

1) Die beste Ausgabe rührt von Halley her. Sie ersehien in Oxford im Jahre 1758 .

2) Eine lateinische Übersetzung von Xylander (Basel 1575) vormittelte zuerst die Kenntnis von Diophants Werken.

3) M. Cantor, Geschichte der Mathematik. Bd. I. S. 402. 
niclit kennt. Dies hat darin seinen Grund, daß Diophant nur Differenzen bildet, bei welchen der Minuend größer als der Subtrahend ist. Eine größere Zahl von einer kleineren abzuziehen, die algebraische Operation, die ja zum Begriff der negativen Zahl geführt hat, erschien ihm als etwas Unmögliches. Führte die Lösung einer Gleichung auf negative Werte, so erklärte Diophant einen derartigen Fall für unzulässig. Eine Rolle spielte diese Beschränkung besonders bei der Auflösung quadratischer Gleichungen, mit der Diophant sich sehr vertraut zeigt. Bei ihm begegnet uns auch die erste kubische Gleichung. Doch bleibt der Fall vereinzelt. Auch ließ sich die betreffende Gleichung auf einen niedrigeren Grad reduzieren 1). Diophant gibt die Lösung, ohne jedoch sein Verfahren anzudeuten.

Was Diophant vor allem auszeichnet, ist die Art, in der er sich bei fast allen Problemen von den Einzelfällen loslöst und sich zur allgemeineren Betrachtung erhebt.

Die Stellung, die Diophant in der Entwicklung der Wissenschaften einnimmt, ist infolgedessen eine ganz einzigartige. Einmal treten uns seine Schöpfungen, die von allem, was vor ihnen liegt, so sehr verschieden sind, ganz unvermittelt entgegen. „Eine ganz andere Luft weht in den Schriften dieses Arithmetikers als in denjenigen der klassischen Geometer" 2). Und wie es an nachweisbaren Vorstufen und Vorläufern fehlt, so mangelt es in dem auf Diophant folgenden Jahrtausend auch an Mathematikern, die das von ihm Begonnene fortgesetzt hätten. Erst zu Beginn der neueren Periode vermochte man an Diophant anzuknüpfen und eine höhere Mathematik zu schaffen, deren wichtigstes Element, wie bei Diophant, allgemeine Zahlen, für sich betrachtet und in ihrer Beziehung zu geometrischen und physikalischen Größen, sind.

Diophant lebte vermutlich im 3. nachchristlichen Jalırhundert, jedenfalls ist aber sein Werk später als die Schriften des Ptolemäos verfaßt. Auf die Entwicklung der alten Astronomie hat es keinen Einfluß ausgeübt ${ }^{3}$ ).

Die Förderung, welche die Meßkunde bei den Vorgängern des Ptolemäos erfahren hatte, wußte dieser sich nicht weniger als

1) Diophant, lib. VI. 19. Näheres siehe Cantor', I. S. 407.

2) H. Hankel, Die Entwicklung der Mathematik in den letzten Jahrhunderten. S. 10 .

3) Die erste brauchbare Ausgabe rührt von Halley her. Sie erschien in Oxford im Jahre 1758. 
die mathematischen Fortschritte zunutze zu machen. Im Jugendzeitalter der Astronomie wird man wohl die Entfernungen am Himmelsgewölbe nach Mondbreiten abgeschätzt und dabei wahrscheinlich zwei um ein Scharnier drehbare Stäbe, in deren Treffpunkt sich das Auge des Beobachters befand, gebraucht haben. Die Alexandriner benutzten zwei Arten von Winkelmeßinstrumenten. Bei der einen kam eine geradlinige, bei der anderen die Kreisteilung in Anwendung. Zur ersten Art gehört das parallaktische Lineal, auch Regula Ptolemaica genannt, das Ptolemäos im Almagest beschreibt. Es besteht aus einem lotrecht und drehbar aufgestellten Stabe, um dessen oberen Endpunkt sich ein gleich langer Stab mit Dioptern, zum Anvisieren des Gestirnes, bewegen ließ. Am unteren Ende des senkrechten Stabes war ein dritter drehbarer Stab mit Längseinteilung angebracht. Dieser Stab ließ sich in einer Rille des Diopterlineals verschieben. Bef jeder Höhenmessung konnte die Lage des Diopterlineals auf der Gradeinteilung des zweiten beweglichen Lineals abgelesen und da-

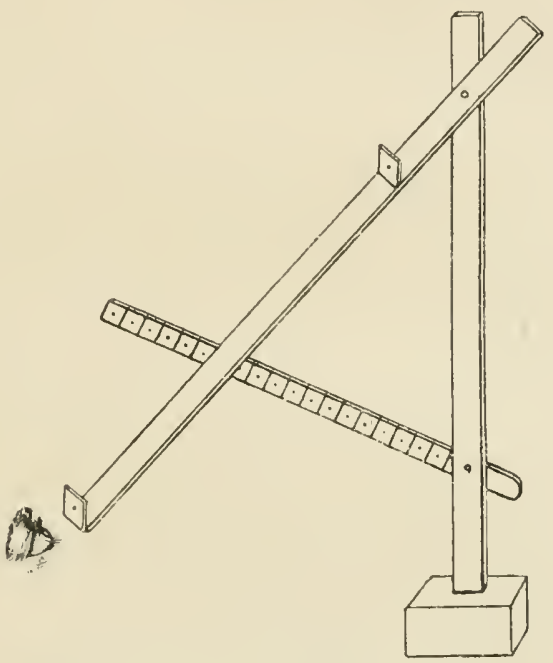

Abb. 45. Das parallaktische Lineal. nach der entsprechende Winkel aus der Sehnentafel entnommen werden.

Indessen bediente sich Ptolemäos nach dem Beispiel von Aristyll und Timocharis (300 v. Chr.) auch der mit Gradeinteilung versehenen, miteinander verbundenen Kreise, der sogenamnten Armillen. Eratosthenes hatte 220 v. Chr. in Alexandrien Armillen von bedeutender Größe errichtet und rermittelst dieser Instrumente den Abstand der Wendekreise zu ${ }^{11} / 83$ des Kreisumfanges bestimmt. Eine der von Ptolemäos benutzten Armillen zeigt uns die Abbildung 461) auf S. 256. Sie bestand aus einem ans Kupfer oder Bronze rerfertigten Ring, der in 360 Grade geteilt war. Der Ring war in senkrechter Lage auf einer Säule errichtet 
und fiel mit dem Meridian zusammen. Diesem Ringe war ein zweiter drehbarer Ring mit zwei diametral gegenüber befindlichen Vorsprüngen eingepaßt. Wollte man z. B. die Mittagshöhe der Sonne messen, so wurde der innere Ring gedreht, bis der Schatten des einen Vorsprunges auf den anderen Vorsprung fiel. Eine Armillarsphäre (Ringkugel) bestand aus zwei festverbundenen, rechtwinklig zueinander stehenden Kreisen, von denen der eine in der Ebene des Meridians, der andere in der Ebene des Himmelsäquators lag. In dem Meridiankreis war ein dritter Kreis drehbar angebracht, dessen Drehachse

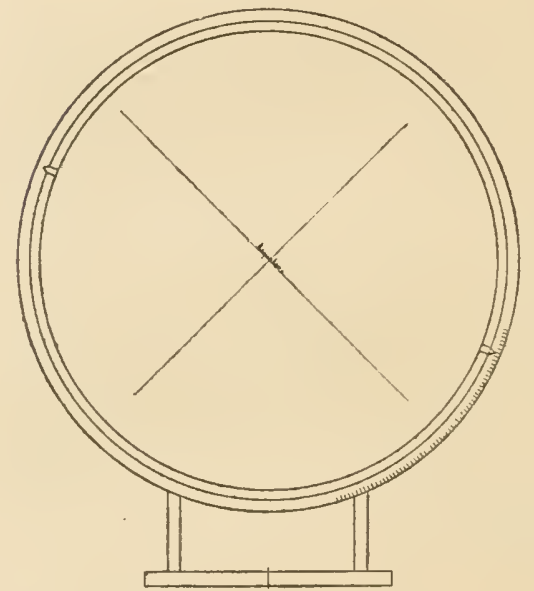

Abb. 46. Solstitial-Armille des Ptolemäos. Schematische Skizze nach dem Almagest. mit der Weltachse zusammenfiel. In diesem dritten Kreise befand sich, konzentrisch und verschiebbar, ein vierter. Durch Diopter wurde ein Anvisieren ermöglicht, während Gradeinteilungen ein Ablesen der Deklination und des Stundenwinkels gestatteten. Dem Instrument lag also der Gedanke zugrunde, die an der Himmelskugel erkannten Kreise und Kreisbewegungen im kleinen nachzubilden. Zum Messen von Winkeln diente auch wohl der astronomische Ring oder das Astrolabium 1).

Es bestand aus zwei konzentrischen, gegeneinander verschiebbaren Ringen, die mit je zwei gegenüberstehenden Dioptern versehen waren. Wollte man Horizontalwinkel messen, so wurde der Ring hingelegt. Handelte es sich um das Messen von Höhenwinkeln, so hing man ihn auf.

Außer den Armillen benutzte Ptolemäos, wie die chaldäischen Astronomen, auch aus Stein verfertigte Mauerquadranten, die in der Ebene des Meridians errichtet waren.

1) D. h. Sternfasser. Über noch vorhandene Astrolabien gibt der Bericht über die Ausstellung im South Kensington Museum (Berlin 1877. S. 394 u. f.) Auskunft.

Nach dem Almagest $(V, 1)$ war das von Ptolemäos benutzte Astrolab eine Art Armillarsphäre, da es aus einem System teils fester, teils beweglicher, mit Absehen (Dioptern) versehener Ringe bestand. 
Wir erkemnen, daß schon bei den frihesten astronomischen Beobachtungen der Forscher wesentlich auf die Geschicklichkeit des Mechanikers angewiesen war. Die Entwicklung der Astronomie ist daher mit der steten Vervollkommnung und mit der wachsenden Genauigkeit der Meßwerkzeuge Hand in Hand gegangen 1). Schon die Herstellung der Ringinstrumente, welche die Alexandriner benutzten, erforderte eine hervorragende Fertigkeit. "Noch jetzt", so lautet das Urteil eines herrorragenden Kenners der Präzisionsmechanik, „würde nur von einen geschickten, mit einer Drehbank ausgerüsteten Arbeiter die auch nur für primitive Beobachtungen genügende Genauigkeit solcher Meßinstrumente zu erwarten sein“2).

Die für die Astronomie gleich wichtige Zeitbestimmung erfolgte, wie es schon bei den Chaldäern geschah, durch Wassermessung. Schon im 5. Jahrhundert r. Chr. begnügte man sich nicht mehr mit einer Abschätzung der Tagesstunden aus der Länge des Scliattens, sondern man baute Wasseruhren (Klepsydren). Ja sogar solche mit Weckrorrichtung begegnen uns schon im 4. vorchristlichen Jahrhundert ${ }^{3}$ ). Die hierbei Verwendung findenden Instrumente vervollkommnete der um $270 \mathrm{v}$. Chr. lebende Alexandriner Ktesibios, der anch als der Erfinder der Feuerspritze, der Wasserorgeln usw. genanut wird, und der in Heron einen Fortsetzer seiner Arbeiten fand. Damit die Öffnung, durch welche das Wasser bei seinen Uhren strömte, unverändert blieb, stellte Ktesibios diese Öffnung nicht in geröhnlichem Metall, sondern in Gold oder Edelstein her. Ferner sorgte er für ein konstantes Niveau des Wassers in dem Abflulgefüß, damit in gleichen Zeiten stets gleiche Mengen ansströmten. Mitunter wurden durch das ausströmende Wasser Gegenstände gehoben, die ihre Bewegung wieder auf ein Räder- oder Zeigerwerk übertrugen.

\section{Fortschritte der Geographie.}

Vie durch Hipparch, so crfuhr auch durch Ptolemäos die Geographie eine bedentende Förderung. Das von letzterem

1 Irn einzelnen liat dies neuerdings Repsold dargetan. S. S. 256.

2) Repsold, a. a. O. S. 6.

3) Diels, Antike Technik. S. 25. In dem noch erhaltenen Turm der Winde in Athen befand sich cine Wasserulır, während aufen eine Sonnenuhr und eine Wetterfahne angebraeht waren. Unter dem Gesinso sind die acht Hauptwinde allegorisch dargestellt. Auf sie zeigt der Pfeil der Wetterfahno je nach der Richtung des herrschenclen Windes

I) annemann, Die Naturwissenschaften. I. Ba. 2. Aun. 
um 140 n. Chr. geschaffene Lehrbuch 1) dieser Wissenschaft genoß, gleich dem Almagest, bis gegen das Ende des Mittelalters eine unbestrittene Herrschaft. Durch beide Schriften ist Ptolemäos einer der großen Lehrer für alle Zeiten geworden, da an den "Almagest" und die ..Geographie" die großen Entdeckungen anknüpften, welche die Neuzeit auf astronomischem und geographischem Gebiete gemacht hat. Wie der "Almagest", so enthält auch die "Geographie" eine erstaunliche Fülle von Tatsachen. Nicht weniger als 5000 Punkte des damals bekannten Teiles der Erdoberfläche werden nämlich in der "Geographie" nach Länge und Breite angegeben. Und zwar sind nicht nur Städte, sondern auch Flußmündungen, Berge und andere bemerkenswerte Orte berücksichtigt. Die Ermittelung der Breite geschah mit einer solchen Genauigkeit, daß die nach P tol e mä os' Angaben entworfenen Karten in meridionaler Richtung nur geringe Verzerrungen aufweisen. Ptolemäos selbst hat Anleitungen für die Ortsbestimmung und das Entwerfen von Karten gegeben. Die den alten Handschriften seiner Geographie beigegebenen Karten 10 über Europa, 5 iber Afrika und 12 über Asien) entstammen indessen erst dem 6. Jahrhundert, wenn sie anch zweifellos auf antike Torlagen zurückgehen. „Sie sind", sagt Ritter ${ }^{2}$, die Grundlage aller neveren Landkarten geworden. Ohne sie würden die unserigen schwerlich ihren jetzigen Grad von Vollkommenheit erlangt haben."

Das bei den Alten übliche Verfahren der Lüngenbestimmung wurde schon erörtert ${ }^{3}$ ). Es lieferte sehr unvollkommene Ergebnisse ${ }^{4}$. Auch wechselte man schon im Altertum mit der Lage des Nullmeridians. So rechnete Ptolemäos nicht nach dem durch die Insel Rhodos gezogenen Meridian, sondern er verlegte den Anfang der Zählung nach den ,glücklichen Inseln“ des äußersten Westens. Diese Einrichtung bot den Vorzug, daß fuir die in Betracht kommenden Gegenden der Erde die Unter-

1) Herausgegeben ron Nobbe. 3 Bde., Leipzig 1843-1845. Eine deutsche Übersetzung findet sich in 1. Bande der ..alten Geographie" von Georgii (Stuttgart 1838) auf dem Titel als Anhang angekündigt, ist aber nie erschienen. Eine Übersetzung der Kapitel 21-24 findet sich im Jahresbericht des Kgl. Gymnasiums zu Chemnitz von 1909. Sie rührt von Th. Schöne hex.

2) C. Ritter, Geschichte der Erdkunde u, d. Entdeckungen. Berlin 1861.

3) Siehe S. 189.

4) So hatte Marinus die Längenausdehnung der den Alten bekannten Welt (von den glückseligen Inseln bis zur Südostküste Chinas) auf $225^{\circ}$ angegeben. Ptolemäos beschränkte diese Ausdehnung auf $180^{\circ}$. Ihr tatsächlicher $W$ ert ist $140^{\circ}$. 
scheidung zwischen westlicher und östlicher Länge in Wegfall kam.

Bei der kartographischen Darstellung des ihm bekannten Teiles der Erdoberfläche konnte Ptolemäos ihre Krümmung nicht mehr unberücksichtigt lassen. Es galt daher, eine Methode zu benutzen, welche 'Teile einer Kugelfläche in der Ebene zu zeichnen ermöglichte. Diese Aufgabe löste Ptolemäos, indem er eine Projektionsart empfahl, die grundlegend für die weitere Entwicklung der Kartographie gewesen ist.

Marinus von Tyrus, der Vorgänger des Ptolemäos, hatte die Parallel- und die Längenkreise sämtlich als gerade Linien und die letzteren parallel zueinander gezeichnet. Die Längengrade wurden dadurch für die nördlichen Gegenden der Erde viel zu groß, was Ptolemäos durch sein Projektionsverfahren zu vermeiden suchte. Ptolemäos erläutert es mit folgenden Worten: „Es wird richtig sein, zwar die Meridiane als gerade Linien zu zeichnen, die Breitengrade dagegen als Stiicke von Ḱreisen, die um ein und dasselbe Zentrum gezogen sind. Dieses wird senkrecht über den Nordpol gedacht. Von dort ans wird man die Meridiane als gerade Linien zeichnen müssen, damit die annähernde Ähnlichkeit mit der Kugelfläche gesichert wird. Dies geschieht dadurch, daß die Meridiane senkrecht zu den Breitenkreisen bleiben und in dem gemeinsamen Pole zusammenlaufen" 1 ).

Während der mathematische Teil der Erdkunde infolge der bedeutenden Fortschritte der Astronomie sehr gefördert wurde, blieb auch die physische Erdkunde nicht zurück. Von großem Einfluß war hier die Erweiterung des Gesichtskreises durch die römischen Eroberungszüge und der dadurch bedingte kosmopolitische Zug, welcher die gesamte Erde als Wohnsitz des Menschen aufzufassen lehrte. Insbesondere spricht sich dieser Zug in Strabon aus, von dessen Erdbeschreibung Humboldt²) sagt, sie übertreffe an Mannigfaltigkeit und Großartigkeit alle geographischen Arbeiten

1) Siehe die Abhandlung von Th. Schöne über „Die Gradnetze des Ptolcuäos im ersten Buche seiner Geographie." Chemnit\% 1909 (Programmbeilage des Kgl. Gymnasiums).

2) Strabons Erdbeschreibung, übersetzt von Forbiger, Stuttgart 1856-1862. Line neuere Ausgabe veranstaltete Meineke, Leipzig 1866.

Siche A. v. Humboldt, Examen critique de l'histuire de la géographie. I. 152-10̃4. Strabon war griechiseher Abstammung, lebte indes meist in Rom. Er wurde 63 v. Chr. geboren nnd lernte einen großen 'leil des römischen Weltreichs durch eigene Ansehaunng kennen; or schrieb in griechiseher Sprache. 
des Altertums. Strabon läßt Inseln und ganze Kontinente, in Übereinstimmung mit den Ansichten der heutigen Geologen, durch vulkanische Kräfte emporgehoben werden. "Nicht nur kleine Inseln können gehoben werden“, heißt es bei Strabon"), „sondern auch große, ja selbst Festland". Von Sizilien sagt er, man möchte es „nicht für ein Bruchstück Italiens halten, sondern vermuten, es sei durch das Feuer des Ätna aus der Tiefe emporgehoben worden". Doch erörtert Strabon auch die Möglichkeit, daß Sizilien durch ein Erdbeben von Italien getrennt worden sei. Als Beweis, daß Inseln auf vulkanischem Wege entstehen, führt er an, daß sich im Jahre 196 v. Chr. in der Nähe von Thera, dem heutigen Santorin, unter Feuererscheinung eine Insel von 12 Stadien Umfang erhoben habe. Wie Sizilien, so betrachtete Strabon auch Capri und andere der Küste benachbarte Inseln als frühere Teile des Festlandes, während inmitten des Meeres gelegene Inseln, wie jene Neubildung in der Nähe Theras, durch vulkanische Tätigkeit entstanden sein sollten.

Bei Strabon begegnet uns übrigens auch zuerst die Ansicht, daß die Vulkane Sicherheitsventile der Erde seien. Die Alten wollten nämlich beobachtet haben, daß Sizilien in Zeiten einer erhöhten Tätigkeit der in der Nähe dieser Insel liegenden Vulkane

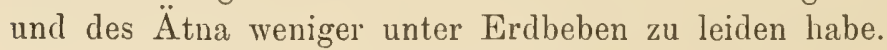

Auch die Versteinerungen werden von Strabon richtig gedeutet. So tritt er bei der Besprechung der linsenförmigen Nummuliten des Kalksteins, aus dem die Pyramiden von Gizeh erbaut sind, der Meinung entgegen, daß es sich hier um erbärtete Überreste von den Speisen der Erbauer handeln könne. Schon Eratosthenes habe erwähnt, daß Tausende von Stadien vom Meere entfernt Schnecken und Muscheln gefunden würden ${ }^{2}$ ). Man müsse daher annehmen, daß einst große Teile des Festlandes für eine gewisse Zeit überschwemmt gewesen und dann wieder trocken geworden seien. Der Boden des Meeres sei ferner uneben wie die Oberfläche des Landes und das Meer infolgedessen von verschiedener Tiefe.

Als Beweis für eine außerordentliche, in historischer Zeit erfolgte Verschiebung der Meeresküste erwähnt Strabon von einer früheren Seestadt südlich der Pomündung, daß sie 90 Stadien vom Ufer entfernt liege. Seit jener Zeit ist diese Küste bekanntlich

1) Im 3. Abschnitt seines I. Buches.

2) Eratosthenes erblickte auch in den Salzseen der Landenge von Suez den Beweis dafür, daß diese Landenge früher vom Meere bedeckt war. 
um einen weiteren erheblichen Betrag meerwärts hinausgeschoben worden, so daß Ravenna, das z. B. zur Zeit Strabous noch Seestadt war, jetzt sieben Kilometer von der Küste entfernt liegt.

Strabón besitzt auch bezüglich der erodierenden Tätigkeit des Wassers, der Ursache von Ebbe und Flut, sowie der Abnahme der Temperatur mit der Erhebung richtige Vorstellungen. Er ahnt sogar das Vorhandensein einer zweiten Kontinentalmasse neben der von Europa, Asien und Afrika gebildeten, wenn er sagt: „Es ist wohl möglich, daß in demselben gemäßigten Erdgürtel, welcher durch das Atlantische Meer geht, außer der ron uns bewohnten Welt noch eine andere oder selbst mehrere liegen." Columbus ließ sich dagegen von der Vorstellung leiten, daß eine Fahrt nach Westen unmittelbar zu den östlichen Gestaden des asiatischen Festlandes führen müsse.

Auch bei den Römern war man auf dem Gebiete der physikalischen Geographie gegen den Ausgang des Altertums zu ziemlich klaren Vorstellungen gelangt. So rerdankt man dem Vitruvius $\left.{ }^{1}\right)$ eine im ganzen richtige Theorie der Quellenbildung nebst einer darauf beruhenden Anweisung zur Auffindung von Quellen, während Seneca2) die durch das Wasser auf der Erdoberfläche hervorgerufenen Veränderungen recht gut schildert und die Springfluten darauf zuriickführt, daß bei ihnen außer dem Monde auch die Sonne zur Wirkung gelangt.

Nicht gering waren ferner die Kenntnisse auf dem Gebiete der Länderkunde während der letzten Jahrhunderte vor Beginn unserer Zeitrechnung. Was die Kenntnis der einzelnen Länder anbelangt, so ergänzt die Erdbeschreibung Strabons in glïcklicher Weise diejenige des Ptolemäos. Strabon hat mehr die europäischen, Ptolemäos dagegen mehr die asiatischen Länder berücksichtigt. Nur in bezug auf das nördliche und östliche Germanien ist der Bericht des Ptolemäos wieder als der reichhaltigere zu bezeichnen. „Ptolemäios eröffnete“, sagt Ranke ${ }^{3}$ ), "durch seine Beschreibung der Länder jenseits des Rheines und der Donau gleichsam eine neue Welt." Er zerstörte ferner den Wahn, daß das Kaspische Mcer in das Weltmeer miinde und

1) Vitruvius, De architectura VIII, 1.

2) Seneca, Naturales quaestiones III, 5 und 28. Seneca, römischer Dichter und Plilosoph, lebte von $4 \mathrm{v}$. Chr. bis $65 \mathrm{n}$. Chr. Eine Ühersetzung seiner Werke veranstalteten Moser und P'auly, Stuttgart 1828-185̃o. Eine nenere Ausgabe rïhrt von $\mathrm{H}$ a ase her ('Teubner, 1893 und 1895).

3) L. v. Ranke, Weltgeschichte III, 313. 
wies die Abgeschlossenheit jenes Beckens nach. Seine Darstellung stützte Ptolemäos besonders auf die geographischen Kenntnisse der Phönizier und auf die Berichte, welche ihm der Karawanenhandel zuführte. Auch die Züge Alexanders, die gewaltige Ausdehnung der Römerherrschaft, sowie die Reisen, welche die damaligen Geographen im Gefolge der Heere, der Statthalter und Gesandtschaften unternahmen, hatten eine Fuille von Material geliefert. So wußte man z. B. über Indien zur Zeit des Ptolemäos viel mehr als zur Zeit Mercators am Schlusse des 16. Jahrhunderts ${ }^{1}$.

Nach Herodots Erzählung $(I V, 42)$ ließ der ägyptische König Necho um 600 v. Chr. phönizische Schiffer vom Roten Meere aus Afrika umsegeln und durch die Straße von Gibraltar nach Ägypten zurïckkehren. Die Fahrt soll 3 Jahre gedauert haben. Herodots Erzählung ist oft angezweifelt worden. Soviel ist indes gewiß, daß im Altertum der Äquator überschritten wurde. Denn die Schiffer sagten aus, bei ihrer Fahrt um Lybien herum nach Westen habe die Sonne um Mittag zur rechten Hand, also im Norden, gestanden. Herodot fügt dieser Angabe hinzu, er könne das nicht glauben; vielleicht gäbe es andere, die es glauben könnten. Diese Erzählung Herodots hat man als einen Beweis dafür betrachtet, daß die Fahrt wirklich stattgefunden hat ${ }^{2}$.

Die Quelle, aus welcher Ptolemäos bei der Abfassung seiner, acht Bücher umfassenden, Geographie besonders schöpfte, waren die Reiseberichte des Marinus aus Tyrus ${ }^{3}$ ). In den phönizischen Häfen besaß man auf Grund des ausgedehnten Handels, der von dort aus getrieben wurde, eine ausgedehnte Kenntnis aller von phönizischen Schiffen besuchten Länder, Inseln und Meere. Nach diesem Material entwarf Marinus eine Karte, die sich unter dem Namen der Tyrischen Weltkarte in der Bibliothek zu Alexandrien befand.

Die Längen- und die Breitengrade waren bei Marinus gerade Linien, die sich unter rechten Winkeln schnitten. Für den damals bekannten Teil der Erde (30.-40. Breitengrad) ergab diese Projektionsart, die man wohl als die "platte" bezeichnet, ein Netz von Rechtecken. Für den Äquator als mittleren Breitengrad würde das Netz aus Quadraten bestanden haben.

1) O. Peschel, Geschichte der Erdkunde. S. 12.

2) C. Ritter, Gesch. der Erdkunde und Entdeckungen. Berlin 1861.

3) Marinus aus Tyrus lebte im 2. Jahrhundert n. Chr. kurz vor Ptolemäos. Er bemühte sich, für jeden Ort die Länge und die Breite festzustellen. 
Marinus von Tyrus wurde durch seine Plattkarte der Begründer der mathematischen Geographie. Er ging von einem Gradkreuz aus, das er aus dem Meridian und dem Breitenparallel von Rhodos $\left(36^{\circ}\right)$ bildete und zu einem Netz rechtwinklig sich schneidender Linien erweiterte.

Ptolemäos sagt von Marinus, auf dessen Arbeiten er sich besonders stützt, dieser habe einen so großen Reichtum an Nachrichten der Alten und der Neueren zusammengebracht und so viele Reiseberichte und Werke berücksichtigt, wie keiner seiner Vorgänger. Dementsprechend sind auch die Angaben, die Ptolemäos von den asiatischen Ländern macht, weit reichhaltiger als diejenigen, welche durch die römischen Geographen auf uns gekommen sind. So nennt Ptolemäos viele Städte, Flüsse und Berge der Insel Ceylon (Taprobane), von der Plinius kaum etwas zu erzählen weiß. Ptolemäos kennt auch die Sundainseln. Vorderindien ist ihm so gut bekannt, daß er von 39 Orten nicht nur die Lage, sondern auch die Dauer des längsten Tages nach genaueren Beobachtungen angibt. Die Flïsse und Berge Indiens, die er nennt, sind den Europäern bis ins 16. Jahrhundert hinein unbekannt geblieben.

Die geographischen Kenntnisse der Phönizier, auf denen Ptolemälos fußte, erstreckten sich also keineswegs nur auf die Meere und die Kiisten, sondern auch auf das Innere der Kontinente. Sogar der Weg iiber Land rom Euphrat über Baktrien und ein holes Gebirge, das sich bis nach China erstrecke, wird beschrieben ${ }^{1}$.

\section{Weitere Fortschritte der Physik.}

Wir haben die Fortschritte, welche die Astronomie und die mit ihr emporblühende Geographie in den ersten nachchristlichen Jahrhunderten erlebten, als die wichtigsten wissenschaftlichen Ereignisse an die Spitze dieses Zeitraumes gestellt. Es gilt jetzt, der Naturlehre und der Naturbeschreibung, die weniger hervortreten, eine kurze Darstellung zu widmen. Dic Mechanik hatte in der vorchristlichen Zeit in Archimedes und in Heron ihren Hiihepunkt erreicht. Als ihr Hauptvertreter während des jetzt zu

1) Dic in den auf uns gekrmmenen Handsehriften ,der Geographie* enthaltenen Karten rühren allerdings nicht von Ptolemäos selbst, sondern vou einen jüngeren Zeitgenossen her, der die vorlandenen Karten einer Durchsicht unil Verhesserung unterzog. 
schildernden Zeitraumes ist der Alexandriner Pappos zu nennen, der sich auch um die Weiterbildung der Mathematik verdient gemacht hat. Pappos lebte gegen das Ende des 3. Jahrhunderts n. Chr. Sein auf uns geliommenes Werk besteht aus 8 Bïchern und führt den Namen ..Die Sammlung“ 1). Besonders das letzte Buch bringt geometrisch begründete Lehren der Mechanik, wie die Lehre rom Schwerpunkt und von der schiefen Ebene. Es behandelt auch die Aufgabe, eine gegebene Last durch eine gegebene Kraft mit Hilfe ron Zahnrädern zu bewegen, deren Durchmesser in gewissen Terhältnissen stehen. Das 7. Buch des Pappos enthält jenen wichtigen Satz, der unter dem Namen der Guldinschen Regel erst im 17. Jahrhundert wieder allgemeiner bekannt wurde, den Satz nämlich, daß der Inhalt eines Rotationskörpers gleich dem Produkt aus der rotierenden Fläche und dem Wege ihres Schwerpunktes ist. Erwähnt sei ferner noch, daß sich bei Pappos in solch ausgedehntem Maße die Verwendung ron Buchstaben zur Bezeichnung allgemeiner Zahlen findet, wie bei keinem Schriftsteller vor ihm, so daf uns bei Pappos schon die Elemente der Buchstabenrechnung begegnen.

Von der Förderung der Optik und der Akustik während der ersten Bliitezeit der alexandrinischen Schule wurde an früherer Stelle gehandelt. Bemerkenswert ist, daß die Optik auch während der zweiten Blïtezeit erheblich gefördert wurde. Und zwar geschah dies durch denselben $\mathrm{P}$ tolemäos, dessen Verdienste auf dem Gebiete der Astronomie und der Geographie wir soeben als so hervorragend anerkannt haben ${ }^{2}$. Wir finden nämlich bei Ptolemäos einen der merkwürdigsten Ansätze zu der dem Altertum im übrigen nur wenig geläufigen induktiven Behandlung einer physikalischen Erscheinung.

Es handelt sich um die Ablenkung, die ein Lichtstrahl beim Übergange aus einem Mittel in ein zweites ron anderer Dichte erfährt, während das Licht sich in ein- und derselben Substanz

1) Eine Ausgabe mit lateinischer Übersetzung gab Fr. Hultsch heraus. Berlin 1875-1875. Im Jahre 1871 erschien das VII. und VIII. Buch mit deutscher Übersetzung von Gerhardt.

2) Über die eigentümlichen Schicksale der ,Optik“ des Ptolemäos berichtet Wilde in seiner Gesch chte der Op'ik, Ld. I. S. 51 u. f. Danach war das Werk Roger Bacon, Regiomontan und auch noch zu Anfang des 17. Jahrhunderts bekannt. Dann galt es lange als verloren, bis es ror einigen Jahrzehnten in einer lateinischen Übersetzung aus dem Arabischen wiederentdeckt wurde. Eine kritisclie Ausgabe besolgte Gilberto Govi: L'ottica di Claudio Tolemeo. Torino 1885. 
geradlinig fortpflanzt. Selbst der frühesten Beobachtung konnte es nicht entgehen, daß diese Brechung um so größer ist, je schräger das Licht die Grenzfläche zwischen beiden Mitteln trifft. Der erste Schritt auf dem Wege des induktiven Verfahrens mußte darin bestehen, daß man die Erscheinung messend verfolgte und für eine Reihe von Einfallswinkeln die Größe der entsprechenden Brechungswinkel durch den Versuch bestimmte. Letzteres geschah durch Ptolemäos. Nit einem für diesen Zweck verfertigten Werkzeug maß er für die Einfallswinkel von $10^{\circ}, 20^{\circ}, 30^{\circ}$ usw. die zugehörigen Brechungswinkel. Sein Apparat bestand aus einer Scheibe, die in Grade geteilt war und bis zum Mittelpunkt in Wasser tauchte (Abb. 47). Das Verfahren war folgendes: Ein Lichtstrahl BC wurde durch eine Marke B des iiber dem Wasserspiegel $\mathrm{MN}$ befindlichen Scheibenstiickes nach dem Mittelpunkte C der Scheibe geleitet. An dieser Stelle fand beim Eintritt in das Wasser die Brechung statt. Der gebrochene Strahl CD setzte seinen Weg unter Wasser fort, bis er den Unfang der Scheibe in einem auf der Grarleinteilung abzulesenden

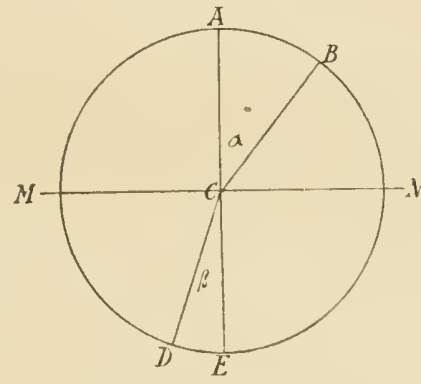

Abb. 47. Ptolemäos mißt die Brechungswinkel. Punkt D wieder traf. Die Werte, welche Ptolemäos auf solche Weise erhielt, sind in folgender Tabelle zusammengestellt:

Einfa!lswinkel $(\alpha)$ Brechungswinkel $(\beta)$

\begin{tabular}{|c|c|c|c|}
\hline $10^{\circ}$ & $8^{\circ}$ & (stat & t $\left.\quad 7^{\circ} 29^{\prime}\right)$ \\
\hline $20^{\circ}$ & $15^{\circ} 30^{\prime}$ & ( & $\left.14^{\circ} 51^{\prime}\right)$ \\
\hline $30^{\circ}$ & $22^{\circ} 30^{\prime}$ & 1 & $22^{\circ}-1$ \\
\hline $40^{\circ}$ & $29^{\circ}$ & , & $\left.28^{\circ} 49^{\prime}\right)$ \\
\hline $50^{\circ}$ & $35^{\circ}$ & ( & $\left.34^{\circ} \quad 3^{\prime}\right)$ \\
\hline $60^{\circ}$ & $40^{\circ} 30^{\prime}$ & ( ) & $\left.40^{\circ} 30^{\prime}\right)$ \\
\hline $0^{\circ}$ & $45^{\circ} 50^{\prime}$ & l & $\left.44^{\circ} 48^{\prime}\right)$ \\
\hline$)^{\circ}$ & $50^{\circ}$ & , & $47^{\circ} 36$ \\
\hline
\end{tabular}

Der Brechungsexponent für den Übergang des Lichtes aus Luft in Wasser ergilst sich daraus gleich 1,31, wïhrend dieser Wert nach neueren Messungen 1,33 beträgt ${ }^{1}$ ). Das Ergebuis war

1) Die Werte in Klammern sinl aus dem Rreclungsindex $\mathrm{n}=1.3335$ berechnet (nach .J. Hirschberg. Zeitschr. f. P'sychologie u. Pliysiologie der Sinnesorgane. XVI, S. 331, 
also im Hinblick auf die Art des Verfahrens recht genau, ein Beweis, daß eins der wichtigsten Erfordernisse der exakten Forschung, die Schärfe der Messung nämlich, dem $\mathrm{P}$ tolemäos nicht mangelte.

Ptolemäos benutzte sein Ergebnis auch zur Erklärung einer astronomischen Erscheinung. Er schloß nämlich, daß der Lichtstrahl auch beim Durchgange durch die Atmospliäre eine Brechung erleidet, die vom Zenith nach dem Horizont allmählich zunimmt und unter dem Namen der atmosphärischen Refraktion bekannt ist. Diese Refralition machte sich ihm z. B. dadurch bemerklich, daß er die Poldistanz eines Gestirnes beim Auf- und Untergang kleiner fand als zur Zeit der oberen Kulmination.

Nach dem Messen besteht der nächste Schritt auf dem Wege des induktiven Verfahrens in dem Auffinden einer gesetzmäßigen Beziehung zwischen den gegebenen und den gefundenen Größen. Ptolemäos hat auch diesen Schritt auf dem Gebiete der Physik zu machen versucht. Wenn es ihm auch nicht gelang, die gefundenen Beziehungen auf einen mathematischen Ausdruck zuriickzuführen, so sprach er doch das Grundgesetz der Dioptrik dabin aus, daß der Lichtstrahl beim Übergange aus einem dünneren in ein dichteres Mittel zum Einfallslote hin gebrochen wird. Er findet es sogar wahrscheinlich, daß für je zwei Stoffe stets ein bestimmtes Verhältnis zwischen dem Einfalls- und Brechungswinkel obwaltet.

Nachdem das Problem der Brechung soweit gefördert war, hat es lange geruht. Zwar beschäftigte es die gerade auf dem Gebiete der Optik sehr tätigen Araber ${ }^{1}$ ). Doch gelangten diese nicht wesentlich ïber Ptolemäos hinaus. Auch Johann Kepler hat sich damit befaßt, indem er nach einem später zu beschreibenden Verfahren Messungen iiber die Brechung anstellte und den Begriff des Grenzwinkels einführte. Seine Lösung fand das Problem indes erst im 17. Jahrhundert durch Snellius, den wir als den Entdecker des Brechungsgesetzes kennen lernen werden.

Erwähnung verdient anch des Damianos Schrift über die Optik2). Über die Lebensumstände Damians ist niclits Näheres bekannt. Seine Schrift über die Optik ist jedenfalls später als diejenige des Ptolemäos verfaßt. Eigentümlich ist die Begründung, welche Damian ïber die optischen Ansichten der Griechen Bandes.

1) Alhazen im 7. Buche seiner Optik. Siehe an späterer Stelle dieses

2 Sie wurde griechisch und deutsch von R. Schöne herausgegeben (Berlin 1897). 
bringt. Es sollen hier deshalb einige Stellen in freier Übersetzung Platz finden:

„Die Gestalt unserer Augen, die nicht wie die übrigen Sinneswerkzenge hohl und dadurch für die Aufnahme von irgend etwas eingerichtet, sondern kugelförmig sind, beweist, daß eine Ausstrahlung von uns ausgeht. Daß diese Ausstrahlung Licht ist, das zeigen die von den Augen aufleuchtenden Blitze. Bei den Nachttieren erscheinen die Augen bei Nacht sogar leuchtend. Noch deutlicher wird diese Ansicht, wenn wir die Gleichartigkeit unseres Sehorgans mit der Sonne dargelegt haben werden.

Da die Sehstrahlen, die ron unserem Auge ausgehen, möglichst schnell zu dem sichtbaren Gegenstande gelangen sollen, so müssen sie sich in gerader Linie bewegen. Und ferner, wenn sie davon möglichst viel erfassen sollen, werden sie in Kreisform darauf losgehen. Denn alles was den lebenden Wesen nützlich ist, pflegt die Natur zu tun. Um die sichtbaren Gegenstände in Kreisform zu treffen, müssen die Sehstrallen entweder die Gestalt eines Zylinders oder eines Kegels haben. Ein Zylinder kann nicht in Betracht kommen, weil dann nicht Gegenstände erfaßt werden könnten, die größer als das Auge sind. Die Sehstrahlen haben daher die Gestalt eines Kegels.

Die geradlinige Fortbewegung des Sehstrahls, seine Zurïckwerfung und seine in große Entfernung reichende und zeitlos sich vollziehende Fortbewegung: Dies alles kann man auch an den Sonnenstrahlen beobachten. Auch vermag unser Sehstrahl durch diejenigen Gegenstände, durch welche die Sonnenstrahlen hindurchdringen, wie Glas und Wasser, gleichfalls seinen Weg zu nelimen."

Nach der Betrachtung der Fortschritte, die sich besonders unter der Mitwirkung des Ptolemäos auf dem Gebiete der Astronomie, der Geographie und der Physik vollzogen, wollen wir uns in großen Züigen den Besitz vergegenwärtigen, iiber den das Altertum während der römisch-alexandrinischen Periode in den übrigen Zweigen der Naturwissenschaften verfiigte.

Während die Mechanik, die Optik und die Akustik ihre Grundlagen erhielten, blieb man auf den Gebieten der Wärme, des Magnetismus und der Elektrizität bei einigen rohen Beobachtungen und dunklen Deutungen stehen. Der Magnetstein und seine Eigenschaft, das Eisen anzuziehen, waren schon dem frïhesten griechischen Altertum bekannt. Da man der Scele das Vermögen, 
etwas zu bewegen, zuschrieb, glaubte man, daß der Magnet, ähnlich wie das Tier und die Pflanze, beseelt sei ${ }^{1}$ ).

Auch die Eigenschaft des Magneten, durch andere Stoffe hindurch zu wirken, konnte nicht lange verborgen bleiben. So erzählt Lukrez, der in seinem Werke „De rerum natura“ die magnetischen Erscheinungen mit behaglicher Breite schildert: „Ich sah eiserne Spän' aufkochen und wallen in ehernen Schalen, wenn der magnetische Stein denselbigen untergelegt ward“2). Auch die bei Uneingeweihten das größte Staunen erregenden, schon Platon bekannten Ketten, welche aus eisernen, magnetisch gemachten Ringen bestanden, die nicht ineinander griffen, sondern sich nur berührten, beschreibt Lukrez. Er wagt sich sogar an eine Erklärung der magnetischen Erscheinungen. Wie ron manchen Körpern, so sollen auch vom Magneten Teilchen ausströmen, welche die benachbarte Luft zurückdrängen. Infolgedessen "stürzen urplötzlich des Eisens Stoffe sich hin nach lem Leeren, und also geschieht es"3. Daß der Magnet zwei Pole besitzt, und zwischen diesen eine Indifferenzzone liegt, scheint den Alten entgangen zu sein 4). Auch die Richtkraft kannten sie nicht, während die Chinesen mit ihr schon vor Beginn unserer Zeitrechnung vertraut waren.

Die Grunderscheinung der Reibungselektrizität ist den alten Völkern jedenfalls bekannt geworden, sobald sie durch den Handel in den Besitz des Bernsteins gelangten, da dieser in besonders auffallender Weise nach dem Reiben leichte Körperchen anzieht. So sagt Plinius: "Übrigens zieht Bernstein, wenn er durch Reiben mit den Fingern Lebenswärme erhalten hat, trockene Blätter, Spreu und Bast gerade so an wie der Magnet das Eisen“5).

1) So heißt es bei Aristoteles (de anima I. 2): „Auch Thales scheint die Seele für etwas Bewegendes gehalten zu haben, da er von dem Magneten sagt, daß.er eine Seele besitze, weil er das Eisen bewegt."

2) Lukrez VI, v. 1043-1044. Lukrez lebte von 98 bis 55 v. Chr. Seine aus sechs Büchern lestehende Schrift, ,De rerum natura" befaßt sich mit den Grundlehren der Physik, der Psychologie und der Ethik. Von den Ausgaben sei hier diejenige Lachmanns eiwähnt. 4. Aufl. Berlin 1871. Eine Übersetzung rührt von Seydel Miinchen 1881) her.

3. Lukrez VI, v. $1005-1006$.

4) Eingrehend lerichtet äber die Kenntnisse der Alten auf dem Gebiete der magnetischen und elektrischen Ersthe nunqen unter Auführung zahlreicher Literatur-tellen A.v. Urbanitzky im 34 Bande der Elektrotechnischen Bibliothek. Wien, A. Hartlebens Vellag, 1887.

5) Plinius, Naturgeschichte, Buch 37, Kap. 12. 
Den Bernstein nannten die Alten Elektrum. Aus diesem Worte ist die Bezeichnung „Elektrizität" für die am Bernstein zuerst beobachtete Eigenschaft entstanden.

Auch an anderen Stoffen scheinen die Alten jene Eigenschaft gelegentlich bemerkt zu haben 1), doch ahnten sie keinen Zusammenhang zwischen ihr und dem Gewitter. Zwar erblickten die Philosophen in dem Blitz und dem Donner nicht mehr, wie das in den Anschauungen einer lieidnischen Naturreligion befangene Volk, das Geschoß und die Stimme des Zeus. Man war aber anch noch weit entfernt ron einer richtigen Deutung der Erscheinung. Anaximander z. B. hielt den Blitz für die in den Wolken verdichtete Luft, die plötzlich mit Geräusch hervorbreche.

Plinius spricht rom Blitz und rom Donner mit folgenden Worten: „Bricht der Wind aus einer größeren Höhlung einer herabgedriickten Wolke hervor, so nennt man ihn Orkan. Hat sich der. Wind in dem Augenblicke, in dem er die Wolke durchbrach, entzündet, so ist er ein Blitz. Daß man den Blitz eher sieht, als man den Donner hört, obgleicb sie zugleich entstehen, ist gewill nicht zu verwundern, da das Licht schneller ist als der Schall. Blitz und Donner erfolgen gleichzeitig, so hat es die Natur geordnet" 2).

Auch mit den stillen elektrischen Entladungen, die man als Elmsfeuer bezeichnet, waren die Alten wohl bekannt. Plinius beschreibt die Erscheinung folgendermaßen: „Es entstehen sogar auch Sterne zu Wasser und zu Lande. Ich selbst sah bei dem näclitlichen Wachtdienst der Soldaten auf den Speeren außerhalb des Walles einen Lichtschein ron dieser Gestalt haften. Auch auf die Rahen und andere Teile der Schiffe setzen sich dergleichen Sterne mit einem eigentümlichen, vernehmbaren Ton, wobei sie, wie Vögel, ihren Sitz oft wechseln"3).

Aus manchen Literaturstellen und antiken Einrichtungen (vergoldete Spitzen ron Tempeln, mit Kupfer beschlagene Stangen) glaubte man schließen zu diirfen, daß die alten Völker schon Blitzableiter verwendet hätten. Aus der Kritik des vorhandenen Materials ergibt sich jedocl, daß ron einer bewußten Anwendung von Blitzableitern vor Benjamin Franklin nicht die Rede sein kann ${ }^{4}$ ).

1) So erwähnt 'T'heophrast in seinem Buche über die Steine einen Edelstein, welcher durch Reiben elektrisch werde.

2) Plinius, Naturgeschichte, Buch 2, Kap. 50 u. 55.

3) Plinius, Naturgeschichte, Buch 2, Kap. 37.

4) R. Hennig im Archiv f. Gesch. d. Naturw. u. Technik. Bd. II. Heft 1. 
Auch das Phänomen der tierischen Elektrizität war den Alten wohl bekannt. Es entzog sich aber gleichfalls ihrer Einsicht. Gelang doch eine Erklärung der atmosphärischen Erscheinungen aus den Gesetzen der Reibungselektrizität erst im 18. Jahrhundert, während ein Verständnis der Gesetze der tierischen Elektrizität erst in der nevesten Periode, nach der Entdeckung des Galvanismus, anbrach. ..Dem Zitterrochen steht ein gefährliches Gift zu Gebote", schreibt der griechische Verfasser eines im 2. Jahrhundert n. Chr. entstandenen Werkes ${ }^{1}$, , ,von Natur ist er schwach und so langsam, daß es aussieht, als kömne er nur kriechen. Er besitzt auf jeder Seite ein Gewebe, das denjenigen, der es berührt, sogleich jeder Kraft beraubt, sein Blut erstarren macht und seine Glieder lähmt.* Plinius ahnt schon, daß man es hier mit einem Vorgang ganz eigener Art zu tun hat, wenn er sagt 2): „Der Zitterrochen lähmt selbst aus der Ferne, sobald er nur mit der Lanze berührt wird, den stärksten Arm. Man ersieht daraus, daß es unsichtbare Kräfte gibt." Daß auch der menschliche Körper wie die Lanze diese eigentuimliche Wirkung fortzuleiten vermag, ist zwar eine Entdeckung der neueren Zeit, doch erwälnt ein anderer Schriftsteller des Altertums, daß schon Erschïtterung eintritt, wenn man Wasser aus einem Gefäß, in dem sich ein Zitterrochen befindet, auf die Hand oder den Fuß gieße ${ }^{3}$.

Die Heilkunde versäumte nicht, aus dieser merkwürdigen Erscheinung Nutzen zu ziehen. So finden wir bei Galen berichtet, daß er einem an Kopfschnerzen leidenden Menschen einen lebenden Zitterrochen genähert, und daß dieser sich als schmerzstillendes Mittel erwiesen habet). Avicenna (Ibn Sina), der arabische Bearbeiter der Schriften Galens, wiederholt diese Angabe.

\section{Die Anfänge der Chemie.}

Erfreute sich die Physik im Altertum wenigstens auf einigen ihrer Gebiete schon einer wissenschaftlichen Behandlung, so war dies bezüglich der Chemie noch nicht der Fall. Hier konnte ein Einblick in das Wesen der Erscheinungen nur auf Grund zahlreicher, zielbewußter Versuche erlangt werden, und einer solchen

1) Oppian, de piscat. 2. 43.

2) Plinius, 32, 1 u. 2.

3) Aelian, 9, 14.

4, Galeni opera, ed. C. S. Kühne. Bd. XII. S. 36 . 
Forschungsrichtung erwies sich die ältere Periode wenig geneigt. Was wir iiber die Anfänge der Chemie berichten können, ist, daß man durch die Heilkunde und durch die Gewerbe, insbesondere den Huittenbetrieb, allmählich mit einer Anzahl ron chemischen Vorgängen bekannt wurde, ohne daß es gelang, eine Verknüpfung dieser Vorgänge unter sich oder mit anderen Gruppen von Erscheinungen zu finden. Alle Erklärungen, die man für die stofflichen Veränderungen aufstellte, hatten nur den Wert bloßer Philosopheme, zu deren Prïfung man noch keine Mittel besaß.

Den größten Einfluß auf die weitere Beschäftigung mit chemischen Dingen hat wohl jene Lehre gehabt, welche die Welt auf einen einzigen Urstoff zuriickführte, der sich den Sinnen in vier Erscheinungsformen, als Feuer, Erde, Luft und Wasser, offenbaren sollte. Im Einklang mit dieser Lehre stand auch das gegen den Ausgang des Altertums auftretende Bestreben, unedle Metalle in edle zu verwandeln; ein Problem, das während des ganzen Mittelalters als Ziel und Zweck der Chemie betrachtet wurde.

Die Kenntnis und die Verwendung der Metalle war in Altertum schon eine recht ausgedehnte. Blei z. B., das gleich dem Eisen sich nur selten als solches findet und aus Bleiglanz dargestellt wurde, fand schon im alten Rom zu Wasserleitungsröhren Verwendung. Zinn und Zink waren nicht in reinem Zustande, sondern nur als Bestandteile von Legierungen bekannt. Diese wurden erhalten, indem man Zinnstein oder den zinkhaltigen Galmei den Kupfererzen bei ihrer Verhiittung zusetzte. Auch die Gewinnung des Quecksilbers durch Erhitzen ron Zinnober mit Eisen war schon dem Altertum gcläufig.

Die Darstellung ron chemischen Prïparaten, soweit sic nicht durch bloße Oxydation entstehen, war kaum möglich, so lange man sich nicht im Besitze der Mineralsäuren befand. Mit ihrer Darstellung waren die Alten jedoch noch nicht vertraut. Die einzige ihnen bekannte Süure war eine organische, die Essigsïure.

Die Tatsache, daß Marmor und Kalkstein beim Glihhen eine neue Substanz liefern, die, mit Wasser in Verbindung gebracht, ein vorziigliches Baumaterial abgibt, wußte man indes wohl zu rerwerten. In der spitteren Römerzeit finden wir auch Zement iu Anwendung, ohne den manches gewaltige Bauwerk nicht ausführbar gewesen wäre. Auch dals der gebrannte Kalk dic Soda iitzender macht, war schon im Altertum bekannt 1). Dagegen blieb

1) Meyer, Gesch. d. Chemie. s. 1 ti. 
die chemische Natur gasförmiger Substanzen in Dunkel gehüllt. Zwar bemerkte man, daß bei der Gärung und an manchen Stellen der Erde ein Gas auftritt, das zur Atmung nicht geeignet ist. Es kam jedoch niemandem in den Sinn, in dieser Luftart ein ron der natürlichen Luft verschiedenes Gas zu erkennen.

Einen gewaltigen Anstoß zur Beschäftigung mit stofflichen Veränderungen rief der Gedanke hervor, durch geeignete Behandlung könne aus unedlen Metallen Edelmetall gewonnen werden. Eine gewissermaßen theoretische Grundlage fand dieses Streben in den Lehren des Platon und des Aristoteles. Das alchemistische Problem begegnet uns schon in den ersten Jahrhunderten n. Chr. in Agypten bei Gelehrten der alexandrinischen Schule. Es stiitzte sich auf die, während einer langen vorhergehenden Periode rein empirisch erworbenen, nicht unbeträchtlichen Kenntnisse über die Metalle, ihre Gewinnung und ihre wichtigsten Legierungen.

Auch für die Folgezeit kann man wohl sagen, daß die Geschichte der Alchemie und diejenige der Metallurgie im wesentlichen zusammenfallen ${ }^{\dagger}$. Die Ägypter unterschieden nach Lepsius in ihren Inschriften acht mineralische Erzengnisse, die sie für besonders wertvoll hielten. Es waren vor allem das Gold, die als Elektrum bezeichnete Legierung ron Gold und Silber, das Silber und der Lapis lazuli.

Bei den ersten Alchemisten spielte das Blei eine große Rolle. Da man aus dem Rohblei Silber abzuscheiden vermochte, glaubte man, das Blei sei für die Erzeugung ron anderen Metallen hervorragend geeignet. Zinn findet sich zwar in den Bronzen der alten Ägypter. Wahrscheinlich kannten sie das reine Zinn aber nicht 2\%. Auch das Quecksilber, das seiner merkwürdigen Eigenschaften wegen bei den Alchemisten die größte Rolle spielte, war den alten Ägyptern wohl noch nicht bekannt. Es kam erst bei den Griechen und Römern in Gebrauch. Plinius nennt es eine beständige Flïssigkeit und ein Gift für alles ${ }^{3}$ ).

Nachdem durch lange Zeiträume chemische, ror allem metallurgische Einzelkenntnisse gesammelt waren, begegnet uns bald nach Beginn der christlichen Zeitrechnung die bestimmte, als Alchemie

1) Siehe auch Berthelot, Les origines de l'Alchimie. Paris 1885. Berthelot gilt als einseitig und durch neuere Forschungen, vor allem die v. Lippmanns, überholt.

2) Neuerdings hat man Gegenstände aus ziemlich reinem Zinn in ägyptischen Gräbern gefunden.

3) Liquor aeternus, venenum rerum omnium. 
bezeichnete Richtung, deren Ziel die Umwandlung unedler Stoffe in edle Metalle war. Die älteste ägyptische Handschrift, die uns davon Kenntnis gibt, stammt aus dem 3. Jahrhundert n. Chr. Die Alchemie tritt uns darin in Verbindung mit der Astrologie entgegen. Darauf deutet auch hin, daß dem Gold die Sonne, dem Silber der Mond und den iibrigen Metallen die Planeten entsprachen.

Aus der Beobachtung, daß man durch Zusammenschmelzen unedler Metalle dem Golde und dem Silber ähnliche Legierungen erhält, daß aus Rohblei durch geeignete Behandlung wirkliches Silber und aus Amalgam Gold abgeschieden werden kann, hatte sich nämlich die Annahme von der Möglichkeit, unedle Metalle in edle zu verwandeln, gebildet. Bei dem Mangel an Einsicht in den chemischen Prozeß lielt man die genannten Vorgänge für wirkliche Umwandlungen der Stoffe. Da man nun durch Verbesserung der hüttenmännischen Betriebe eine größere Ausbeute erzielte, so lag der Gedanke nahe, ob nicht durch geeignete Behandlung das gesamte Rohmaterial in edles Metall verwandelt werden könne. Die Periode, in welcher die Erforschung stofflicher Veränderungen von diesem Bestreben geleitet wurde, hat man als das Zeitalter der Alchemie bezeichnet.

Die ersten alchemistischen Regungen begegneten uns schon bei den Alexandrinern. Aus dem 3. nachchristlichen Jahrhundert sind nämlich Schriften alexandrinischen Ursprungs bekannt geworden, die sich mit dem Problem der Metallveredelung beschäftigen ${ }^{1}$ ). Von den Gelehrten des unterjochten Ägyptens und den nestorianischen Schulen Vorderasiens ging zweifelsohne für die Araber der Antrieb aus, sich mit dem gleichen Problem zu befassen. Schon das Wort Chemie deutet vielleicht darauf hin. Es ist nämlich gleichlautend mit einer alten Benennung $\ddot{\text { gyptens. }}$ Wie Plutarch berichtet, haben die Bewohner dieses Land der

1. Der Urtext dieser Schriften nebst französischer Übersetzung wurde von Berthelot in den Jahren 1887 und 1888 unter dem Titel ,Collection des anciens alchimistes grecs" veröffentlicht.

Berthelot (Die Chemie im Altertum u. Mittelalter. Deutsch von Kalliwoda und Strunz. 1909. S. 5) hat 'Texte griechischer Chemiker, sowie diejenigen von syrischen und arabischen veröffentlicht und zugänglich gemacht, darunter auch Handschriften, die bis dahin in den Bibliotheken von Paris, London und Leyden vergraljen und vergessen waren.

Etwas anders, wie auf dieser Seite angegeben, stellt sich der Beginn der Alchemie nach v. Lippmann dar. Näheres darüber siehe im Anlange und in v. Lippmanns, Alchemie". 
schwarzen Farbe seines Erdreichs wegen chêmi genannt. Auch die Bezeichnung "schwarze Kunst" würde dadurch vielleicht ihre Erklärung finden.

Nach neueren philologischen Untersuchungen ist diese $\mathrm{Ab}$ leitung zweifelhaft geworden. Man ist heute geneigt, mit Zosimos, einem alchemistischen Schriftsteller des 4. nachchristlichen Jahrhunderts, das Wort Chemie ron Chemes abzuleiten, den Zosimos als den Verfasser des ersten chemischen Buches bezeichnet. Eine dritte Auffassung geht dahin, daß das Wort zúuc, welches „Metallguß" bedeutet, das Stammwort für .Chemie“ sei ${ }^{1}$. Bei diesem Stande der ganzen Frage wird man sich also wohl dahin entscheiden miissen, daß der Ursprung des Wortes Chemie völlig dunkel ist.

Die alexandrinischen Gelehrten, sowie anch später die Araber, die sich mit chemischen Vorgängen befaßten, ließen sich in ihren Anschauungen ron den Theorien leiten, die Platon und Aristoteles über die Natur der Materie entwickelt hatten.

Die praktische Grundlage, auf der sich die Alchemie erhob, war neben der lrüttenmännischen Gewinnıng der Metalle, vor allem die Verarbeitung der Edelmetalle zu Schmuckgegenstïnden. In dieser Industrie regte sich seit den frühesten Zeiten das Bestreben, Minderwertiges an die Stelle von Wertvollem zu setzen und auf diese Weise den Käufer zu übervorteilen. Man erreichte dies entweder dadurch, daß man dem Golde und dem Silber andere Metalle beimengte oder daß man Metalle und Legierungen oberflächlich färbte, um ihnen ein dem Golde oder dem Silber ähnliches Aussehen zu verleihen. Als ein Mittel dieser Art diente zum Beispiel die Verbindung des Arsens mit dem Schwefel, die in der Mineralogie noch heute den Namen Auripigment führt. Anch das Quecksilber, mit dem man in Kleinasien und durch den von den Karthagern in Spanien betriebenen Bergbau bekannt wurde, fand zur Herstellung von Legierungen und oberflächlichen Veränderungen schon lange vor dem Beginn der christlichen Zeitrechnung Verwendung. Wenn man all diese Praktiken, an die sich bald gewisse Vorstellungen und Spekulationen anschlossen, schon mit dem Namen Chemie belegen will, so geht die chemische Wissenschaft in ihren Anfüngen bis tief ins Altertum zurück. Das Bekanntwerden mit Stoffen, welche die Metalle oberflächlich veränderten, führte ganz von selbst zum Suchen nach einem, die gewünschten Verände-

1) Diels, Antike Technik. S. 111. 
rungen hervorrufenden Universalmittel. So entstand die Lehre vom „Stein der Weisen“, dem man, ohne ihn gefunden zu haben, später immer neue Wirkungen beilegte, insbesondere diejenige, Krankheiten $\mathrm{zu}$ heilen und das Leben zu verlängern 1).

Eine wichtige Rolle spielte bei jenen Veränderungen das Quecksilber. Es ist begreiflich, daß ein so sonderbares Metall bei seiner Entdeckung angestaunt wurde und die Phantasie erregte. Welch universelle Bedeutung man dem Quecksilber zuschrieb, beweist die Stelle eines Briefes aus dem 4. nachchristlichen Jahrhundert 2). Sie lautet: „Was ich lernen möchte, lehre es mich. Das ist das Werk, das Du kannst, die Transmutation. Das Quecksilber nimmt doch auf jede Art das Aussehen aller Körper an. Es bleicht alle Körper und zieht ihre Seelen an, nimmt sie durch Sieden in sich und bemäclitigt sich ihrer. Ist es doch dazu geeignet, weil es in sich selbst die Prinzipien alles Flüssigen enthält. Wenn es die Transmutation durchgemacht hat, bereitet es alle Farbenwechsel vor. Es bildet den feststehenden Grund, während doch die Farben keine eigentliche Grundlage haben. Das Quecksilber wird, indem es seinen eigenen Grund verliert, ein abänderungsfähiges Etwas, und zwar abänderungsfähig durch die auf die metallischen Körper ausgeuibten Behandlungen."

Die hellenistischen Schriftsteller nennen als den Begriinder der Alchemie den Hermes Trismegistos (den Dreimalgrößten) ${ }^{3}$ ). Es ist das eine durchaus mystische, auch wohl mit einem der ägyptischen Hauptgötter (Ptah, Thot) identifizierte Persönlichkeit. Dem Hermes wurden zahllose Werke (20000 und meln) zugeschrieben. Ausdrücke wie hermetische Kunst, hermetischer Verschluß, hermetische Bücher erinnern noch heute an ihn. Auch Tafeln wurden auf Hermes zuriickgefuihrt. Unter ihnen trug die berühmteste die Überschrift: De operatione solis, d. l., vom Machen der Sonne (des Goldes). Von dem mystischen lnhalt dieser im Mittelalter hochgeschätzten Tafel geben folgende 'Zeilen eine Vorstellung: „Wie alle Dinge wurden aus Einem, so sind auch alle Dinge geboren aus diesem einen Dinge. Sein Vater ist die Sonne, seine Mutter der Mond. Der Wind trug es in seinem Bauche.

1) Siche die hiervon abweichende Meinung v. Lippmanns in dessen "Alchemie".

2) Berthelot a. a. O. S. 20.

3, Einen Beitrag über Hermes 'Trismegistos enthält Paulys Realenzyklopädic d. klass. Altert. im VIII. Bande auf S. 792-822. 
Seine Nährerin ist die Erde. Du scheide das Erdige vom Feurigen, die dunstartigen Teile von den dichten, so gewinnst du das Rühmlichste der ganzen Welt" 1).

Bestimmtere, wenn auch nur spärliche Überreste werden auf einen alexandrinischen Schriftsteller namens Zosimos zurückgeführt. Er war in Panopolis (Oberägypten) geboren und lebte um 300 n. Chr. Zosimos ist ohne Zweifel auf die Entwicklung der Alchemie von großem Einfluß gewesen. In einem umfangreichen Werke stellte er die Kenntnisse seiner Vorgänger und seine eigenen Erfahrungen zusammen. Doch handelt es sich zumeist um kaum verständliche, in mystischen Ausdriicken nieder-

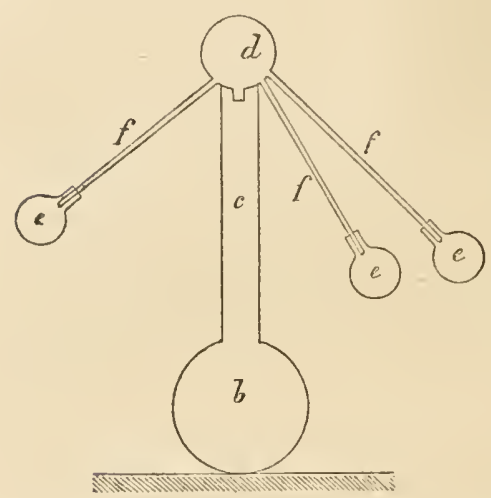

Abb. 48. Von Zosimos geschilderter Destillierapparat. gelegte Rezepte. Nach Zosimos waren diese Rezepte in Agypten entstanden. Sie befanden sich im Besitz der Priesterschaft und wurden auf das strengste geheimgehalten. Wer in die alchemistische Kunst eindringen wollte, mußte eine Reihe von sittlichen Vorbedingungen erfüllen. Er mußte reinen Sinnes und frei von Habgier sein. Er mußte sich ferner aus tiefster Seele in seinen Gegenstand versenken können 2). Erfolg hatte nur, wer nach Erkenntnis strebte, nicht aber der Ungelehrte oder gar derjenige, der von unlauterer Gesinnung erfüllt war. Eine weitere Vorbedingung bestand darin, daß man "die richtige Zeit und die glücklichen Augenblicke" wählte. Um sie herbeizuführen, waren nicht nur Beschwörungen, Zaubermittel und Gebete, sondern auch die Mitwirkung der Planeten erforderlich.

Jene Werke des Zosimos, die in Bruchstuicken durch syrische Manuskripte bekannt geworden sind, enthalten manches über die von den Alchemisten benutzten Apparate, wie Öfen, Destilliervorrichtungen usw.

Was die planetarischen Einflüsse betrifft, so stützt sich Zosimos besonders auf Hermes Trismegistos. Die wirksamste

1) Kopp, Beiträge zur Geschichte der Alchemie. S. 377.

2) Berthelot, Collection des anciens alchemistes grecs. Paris 1888. 
Sphäre sollte diejenige des Merkur sein, weil der Schattenkegel der Erde gerade bis zu ihm reiche ${ }^{1}$ ).

An einer Stelle beschreibt Zosimos, wie sich erhitztes Quecksilber und Schwefel zu Zinnober vereinigen, der zunächst eine schwarze Masse bilde, die erst beim Sublimieren rot werde. Wird Zinnober mit gewissen Zutaten in einem geschlossenen Gefäß erhitzt, so steigt aus dem Zinnober das Quecksilber als "Silberwasser" oder "göttliches Wasser" empor. Es ist ein furchtbar giftiges, in der Hitze nicht festzuhaltendes Pneuma, das beim Abkühlen seinen „flüchtigen Schwung“ verliert und sich an dem Deckel des Gefäßes in Form von Tropfen festsetzt ${ }^{2}$.

Die von Zosimos im Anschluß an Hermes entwickelte Lehre von dem Einfluß der Planeten auf das Gelingen des ,heiligen Werkes" findet sich im 5. Jahrhundert bei dem Neuplatoniker Olympiodor zu einem System entwickelt ${ }^{3}$ ). Er schrieb nämlich jedes von den sieben Metallen den den Alten gleichfalls nur in der heiligen Siebenzahl bekannten Planeten zu. Das Gold entsprach bei ihm der Sonne, das

Silber dem Monde,
Kupfer der Venus,
Eisen dem Mars,
Zinn dem Jupiter,
Quecksilber dem Merkur,
Blei dem Saturn.

Das Gestirn sowie das entsprechende Metall erhielten dasselbe Zeichen ${ }^{4}$. Diese mystischen Beziehungen zwischen der Alchemie und der Astrologie wurden später von den Arabern mit Vorliebe weiter gepflegt.

Man hat sich bemüht, durch archäologische Nachforschungen in Ägypten Stätten nachzuweisen, wo man chemische Prozesse

1) Berthelot, Collection des anciens alchemistes grecs. II. 272 u. 274.

2) Berthelot, Collect. II. 276.

3) Eine ihm zugeschriebene Ahhandlung führt den Titel: „Der alexandrinische Philosoph über Zosimos, Hermes und die Philosophen.“

4) In ähnlicher Weise wurden die 12 Edelsteine, die man untersehied, den 12 Tierkreisbildern zugeteilt. „Alle irdisehen Dinge und alles irdisehe Geschehen waren in himmlischen Vorlildern vorgezeichnet" (MI. Berthelot, Die Chemie im Altertum u. Mittelalter. Deutsch von Kalliwoda u Strunz. 1909. XV). Nach E. v. Lippmann sind manche der von Berthelot herrührenden Angaben einseitig und uuzuverlässig. Siehe v. Lippmanns "Alehemiv". 
ausuibte, sozusagen die Laboratorien jenes ersten alchemistischen Zeitalters und die in diesen Stätten zur Anwendung kommenden Gerätschaften. Der Erfolg ist bisher nur ein geringer gewesen. So beschreibt Berthelot nach den Angaben Masperos eine Stätte, die an eine Grabkammer stößt und die, nach allen Anzeichen zu urteilen, während des 6. Jahrhunderts unserer Zeitrechnung als Laboratorium gedient hat. Die Wände jener Stätte waren angeräuchert, und am Boden befand sich ein Herd aus Bronze und allerlei Gerät aus Bronze, Alabaster und anderen Mineralien.

Unter den noch vorhandenen Überresten der alchemistischen Literatur sind vor allem die Schriften, die fälschlich unter dem Namen Demokrits gehen, und zwei in Theben in Ägypten aufgefundene Papyrusurkunden zu nennen.

Das Werk des Pseudo-Demokrit ist ursprünglich wohl um 200 v. Chr. in Ägypten entstanden; es enthielt eine Zusammenfassung des gesamten chemisch-technischen Wissens jener Zeit ${ }^{1}$ ), aber noch nicht Alchemistisches (nach v. Lippmann). Unter den aus dieser Quelle stammenden Bearbeitungen ist vor allem ein umfangreiches Werk zu nennen, das sich „Demokrits Physik und Mystik" betitelt. Was davon auf uns gekommen ist, erweist sich als lückenhaft und entstellt. Der Neuzeit wurden die pseudodemokritischen Lehren genaner erst im 16. Jahrhundert bekannt 2).

Aus den erhaltenen Fragmenten geht hervor, daß ..Demokrits Physik und Mystik" besonders über Gold, Silber, Perlen, Edelsteine und Purpur handelte. Ein Beispiel möge uns einen Begriff von dem Inhalt geben. Es lautet $\left.{ }^{3}\right)$ : "Nimm Quecksilber, fixiere es mit Magnesia. Wirf die weiße Erde auf Kupfer. Wirfst du gelbes Silber darauf, so erhältst du Gold. Die Natur besiegt die Natur."

Der demokritische Spruch:

Eine Natur vergewaltigt die andere,

Eine Natur besiegt die andere

ist für die Goldmacherkunst durch alle Jahrhunderte das Leitwort geblieben.

1) Die in syrischer Sprache übermittelten Lehren Demokrits sind in einigen in England befindlichen Nanuskripten vorhanden. Näheres darüber siehe in E. v. Lippmanns Entstehung und Ausbreitung der Alchemie. Berlin 1919. S. 40 u. f.

2) E. v. Lippmann, Alchemie. S. 31 .

3) Ausführlicher bei E. v. Lippmann, Alchemie. S. 32. 
Ein ganz neues Licht haben die Papyrusfunde der thebanischen Ausgrabungen auf die Vorgeschichte der Alchemie geworfen. Diese Funde wurden 1828 beim Aufdecken eines Grabes gemacht. Sie gelangten mit zahlreichen anderen Papyrusrollen nach Europa, fanden aber erst nenerdings Beachtung. Die in Leyden befindliche Urkunde wurde 1885 und die Stockholmer 1913 veröffentlicht. Beide Papyri stammen aus dem 3. Jahrhundert n. Chr. und enthalten im wesentlichen Vorschriften, welche die Verfälschung der edlen Metalle, das Färben mit Purpur und Waid (Isatis tinctoria), sowie die Edelsteine und Perlen betreffen. So enthält der Stockholmer Papyrus Anweisungen, den Perlen den verloren

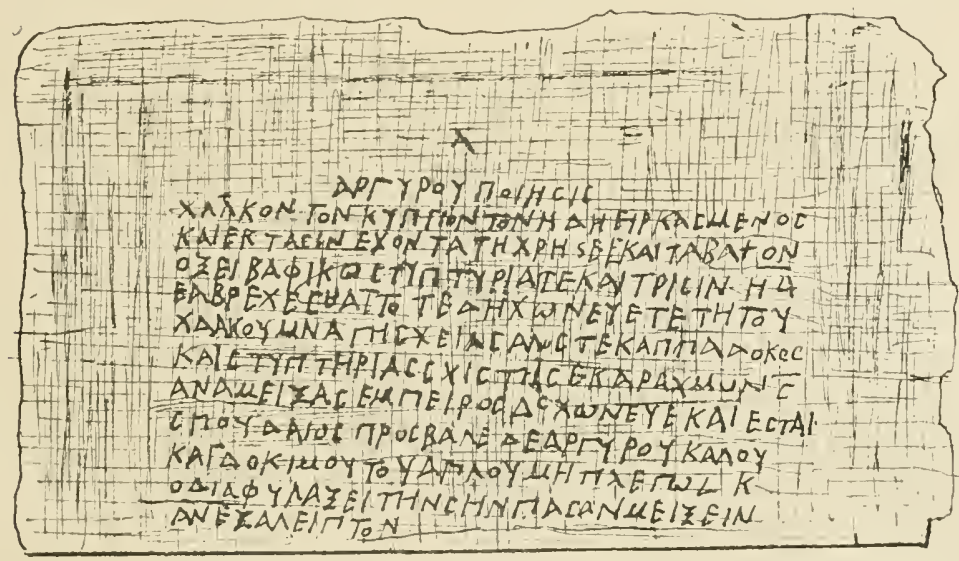

Abb. 49. Eine Probe aus dem Stockholmer Papyrus.

gegangenen Glanz wiederzugeben. Andere Vorschriften betreffen die Anfertigung ron Perlen aus Glimmer und anderem minderwertigen Material. Sie werden als .,besser als die echten“ angepriesen.

Von der Herstellung goldähnlicher Legierungen handeh Rezepte, denen nachgeriihmt wird, daß selbst Fachmänner iiber die Herkunft des Erzeugnisses getäuscht wiirden ${ }^{1}$ ). Die erste Seite des berühmten Stockholmer Papyrus ist in Abb. 49 teilweise wiedergegeben. Sic betrifft, wic aus der Überschrift hervorgelıt, die Dar-

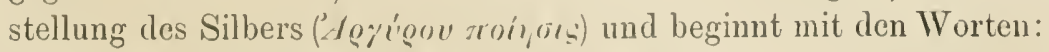

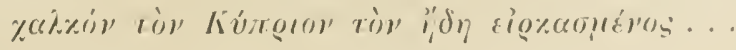

1) Stockholmer Papyrus (Ausg. V. LAfgererant\%). S. 4. 
Die Übersetzung der hier gebotenen Textprobe lautet folgendermaßen:

„Schön bearbeitetes und abgeputztes Kupfer tauche in ein scharfes Alaunbad und lab es drei Tage darin erweichen. Dann schmilz es zusammen mit einer Mine $(=43,6 \mathrm{~g})$ Erz aus chiischer Erde, nachdem Du kapadokisches Salz und kristallinischen Alaun zu 200 Drachmen ${ }^{1}$ ) beigemischt hast. Schmilz es sorgsam, und es wird kostbar sein. Dazu gib nicht mehr als 20 Drachmen schönen und reinen Silbers; das wird die ganze Mischung unlöslich erhalten."

Den Ausgangspunkt für die Legierungen bildet meist das Kupfer. Es wird durch Arsen-, Blei- oder Zinnverbindungen zu Silber geweißt (der Vorgang wird $\lambda \varepsilon \dot{v} \varkappa(u \sigma \iota s$ genannt). Die oberflächliche Vergoldung des Kupfers erfolgt durch Quecksilber (Feuervergoldung). Auch die im Mittelalter wieder anzutreffende Vorschrift, Blattgold in Eiweiß zu verteilen und mit dieser Tinte Manuskripte anzufertigen, findet sich unter den Rezepten.

Wieder andere Abschnitte betreffen die Vermehrung (Verdoppelung, Verdreifachung) des Silbers ${ }^{2}$.

Die Ausführungen über Farbstoffe und Färberei, die sich im Stockholmer Papyrus befinden, lassen den hohen Stand erkennen, den die chemische Technik dieser Gebiete schon im Altertum erreicht hatte. Die zum Fürben bestimmte Wolle wird durch Waschen und Kochen unter Zusatz von Seifenwurzel, Kalkwasser oder Sodalösung gereinigt. Dann wird die Wolle gebeizt, wozu in der Hauptsache Alaun oder alaunhaltige Mineralien genommen werden. Die Farbstoffe wie auch die iibrigen Materialien werden vor dem Gebrauch geprüft. Und zwar prïft man das Aussehen, das Verhalten beim Zerreiben, zu Lösungsmitteln usw. Endlich folgt die Auflösung, die Erzielung bestimmter Nuancen und das Färben selbst. Gefärbt wird fast nur Wolle, und zwar mit syrischem Kermes (Scharlach), Krapp, Schöllkraut und Purpur. Die Indigo enthaltende Waidpflanze diente zum Blaufärben. Durch geeignete Mischungen ron Waid und Kermes erzielte man täuschende Nachahmungen ron Purpur. Die betreffende Vorschrift

1) Eine Drachme $=41 / 2 \mathrm{~g}$.

2) Eine genaue Analyse des Inhalts beider Papyri gibt E. v. Lippmann in seiner Alchemie auf S. 1-26. Nach Diels, Antike Technik S. 21, läuft die Vermehrung der Metalle nicht etwa lediglich auf Betrug, sondern ursprünglich auf dic Vorstellung hinaus, daß das Metall sich ähnlich vermehren lassen müsse wie ein in die Erde gepflanztes Samenkorn. 
schließt mit den Worten: „Du wirst sehen, der Purpur wird unbeschreiblich schön."

$\mathrm{Zu}$ den wenigen Vorgängern, welehe die Verfasser des Leydener und des Stockholmer Papyrus flüchtig anführen, gehört auch der oben erwähnte Pseudo-Demokritos.

Die Anfänge der Chemie lassen schon zwei Einflüsse erkennen, die ihre Entwicklung bis in die neuere Zeit bestimmt laben. Es war dies erstens das Bestreben, die entdeckten Tatsachen und ersonnenen Verfahrungsweisen geheim zu lialten, und zweitens die Verknüpfung dieses Gebietes mit Magie und Mystik. Erklärlich wird dies daraus, daß die chemischen Vorgänge in ganz besonderem Maße den Charakter des Rätselhaften und WVunderbaren tragen und erst nach langem Forschen wissenschaftlich erfaßbar wurden. Ferner handelte es sich um Gebiete, auf denen Gewinnsucht, Aberglaube und Betrug seit alters eine große Rolle spielten. Begegnet uns doch die Verwendung gold- und silber:ihnlicher Legierungen zu Zwecken der Falschmünzerei schon im frühen Altertum.

Die Geheimhaltung der Vorschriften wird schon im Stockholmer Papyrus verlangt und die so viel spätere Mappae clavicula stellt den Eid der Geheimhaltung sogar an die Spitze. Durch die Geheimhaltung wollte der Chemiker nicht nur seine Kenntnisse, sondern vor allem auch sich selbst persönlich schützen. Drohten ihm doch Anfeindungen von der Kirche, von den Regierenden und der besonders abergläubischen Masse. Wie die Chemie seit den Tagen der Renaissance aus diesen Fesseln befreit und in der Neuzeit zu einer führenden Stellung auf dem Gebiet der Wissenschaften und der Technik emporgehoben wurde, soll Gegenstand der späteren Betrachtungen sein.

\section{Der Übergang vom Altertum zum Mittelalter.}

Mit der zweiten Blüteperiode der alexandrinischen Schule und dem mehr kommentierenden Verhalten, das die Folgezeit den Naturwissenschaften entgegenbrachte, ist die Entwicklung, welche diese Wissenschaften in Altertum erfuliren, beenclet. Es trat nunmehr eine lange /eit des Stillstandes, ja des Verlustes an manchem erworbenen Besitz ein, die sich etwa mit demjenigen Zeitraum deckt, den man in der Weltgeschichte als das Mittelalter bezeichnet. Erst im 13. Tahrhundert mehren sich, abgesehen von vereinzelten, insbesondere bei den Syrorn und den Arabern 
anzutreffenden Bestrebungen, auf die wir näher eingehen werden, die Anzeichen, die auf ein Wiederaufleben der Wissenschaften schließen lassen. Und erst, nachdem man das Studium der alten Literatur auf allen Gebieten aufgenommen, nachdem in Italien und den benachbarten Ländern im 15. und 16. Jahrhundert die Kunst geblüht, nachdem endlich der geographische Gesichtskreis sich über die ganze Erde ausgedehnt, sowie die allgemeine Kultur sich beträchtlich gehoben hatte, sehen wir mit dem Anfange des 17. Jahrhunderts eine neue Bliite der Naturwissenschaften anheben, welche dem geistigen Leben der letztverflossenen Jahrhunderte den Stempel aufgedriickt hat. Ja, dieser neue Aufschwung ist so eng mit der gesamten Kultur unseres '/eitalters verknüpft, daß ein abermaliger Verfall der Wissenschaften zugleich das Ende dieser Kultur bedeuten würde. Man hat viel nach den Gründen der Erscheinung gesucht, daß die Wissenschaft und die Kultur des Altertums untergegangen sind und das menschliche Geschlecht während eines Zeitraums von tausend Jahren fast dem Stillstande verfallen war. Ist doch unsere Zeit von dem Gefühl beherrscht, daß sich die Menschheit auf der Bahn, die sie seit dem Ausgang des Mittelalters eingeschlagen hat, in einem unaufhaltsamen Fortschritt zu weiterer Erkenntnis und höherer Gesittung befindet. Ein wichtiger Grund, der diesem Gefühle Sicherheit verleiht, besteht darin, daß die neuere Wissenschaft eine gewaltige Technik ins Leben rief, wie sie das Altertum, während dessen das gewerbliche Schaffen wesentlich auf der Stufe eines noch nicht von wissenschaftlichen Grundsätzen durchdrungenen Handwerks verblieb, nicht kannte. Dadurch, daß sich in der Neuzeit der Mensch auf dem Wege des experimentellen Verfahrens zum Herren der Naturkräfte machte, erfuhr die Wissenschaft eine weit innigere Verschmelzung mit der gesamten Kultur, als dies im Altertum der Fall gewesen.

Es hat nicht an Verkleinerern der wissenschaftlichen Leistungen des Altertums gefehlt I). Man darf jedoch nicht vergessen,

1) So sagt H. v. Mohl in einer 1863 gebaltenen Rede von den Alten: ..Sie blieben in den Naturwissenschaften auf einer durchaus kindlichen Stufe und bieten ein Beispiel dafür, daß der höchste philosophische Scharfsinn unfähig ist, in den Naturwissenschaften etwas zu leisten, wenn er sich nicht auf die genaue Erforschung der Körper stützt." Wie Mohl, so urteilten die meisten Naturforscher während des größten Teiles des 19. Jahrhunderts. Erst in den letzten Jahrzehnten, nachdem der Sinn für die Geschichte der Wissenschaften bei ihren Vertretern lebendiger wurde, ist man anderer Ansicht geworden. Und der ganze Gang unserer bisherigen Betrachtung hat zur Genüge 
daß im Altertum mangels jedweder Vorarbeit iiberall erst die Grundlagen geschaffen werden mußten. Mag man auch zugeben, daß die Alten auf den Gebieten der Mathematik, der Dichtkunst und der Philosophie mehr leisteten als auf demjenigen der Naturwissenschaften, so kann sie deshalb doch kein Vorwurf treffen. Ihre Beobachtungen konnten nicht weiter gehen, als die unbewaffneten Sinne reichen. Und das bloße Nachdenken auf Grund einer nur oberflïchlichen, nicht durch besondere Hilfsmittel geschärften Beobachtung, sowie der Mangel einer induktiven Forschungsweise mußten auf manchen Irrweg führen. Eine rühmliche Ausnahme machten wieder die Araber, unter denen sich auch bedeutende Experimentatoren befanden. Erst als gegen das Ende des Mittelalters allgemeiner das Bewußtsein durchbrach, .daß bloßes Spekulieren nichts helfe, daß nicht nur die Tatsachen, sondern auch ihre Grïnde erkundet werden mïßten“, erstand eine im modernen Sinne ausgeübte Forschung ').

Es ist ferner zu bedenken, daß es im Altertum an einem folgerichtig durchgeführten Verfahren der wissenschaftlichen Forschung noch gebrach. Ihr Wesen ist damit noch lange nicht erschöpft, daß man von der Erfahrung ausgeht, wie es im Altertum schon viele forderten. Es besteht vielmehr darin, daß der Forscher seine Vorstellungen, die aus der Untersuchung der Erfahrungswelt entspringen, unausgesetzt und möglichst vollkommen den Tatsachen anzupassen sucht. Den Alten fehlte es nicht an solchen Vorstellungen, wohl aber fehlte es noch an der Einsicht, daß nur der unausgesetzte Vergleich der Ideen mit den Erscheinungen, die Abänderung der Idee, ihre deduktive Gestaltung, ilır Ersatz durch eine neue Vorstellung, wenn die alte nicht genügt, das Wesen der Naturwissenschaft ausmachen. Hat sich doch gerade das Festhalten an einer Idee einem Vorurteil zuliebe als das größte Hemmnis für den Fortschritt erwiesen.

Die erwähnten Mängel des Altertums gehören zu den Ursachen, dals politische und religiösc Umwälzungen von solchem Umfang eintraten, wie sie der neueren Kulturwelt, der vielleicht andere Gefahren drohen, hoffentlich erspart bleiben werden. Es war der durch eine jahrhundertlange Zersetzung vorbereitete, durch den Ansturm der germanischen Stämme herbeigeführte Zerfall des

gezeigt, daß ein Urteil, wie dasjenige v. Mohls, in seiner Allgemeinheit wenigstens, nicht zontrifft.

1) Lindner, Weltgeschichte. 1. 34. 
Römerreiches, sowie die Überwindung des Heidentums - oder der angesichts der Unhaltbarkeit des Götterglaubens eingetretenen Indifferenz - durch das Christentum und den Islam. Von diesen wirkte das erstere mehr innerlich, indes nachhaltiger, während der Islam, das Feuer und das Schwert mit dem Bekehrungseifer ${ }^{1}$ ) verbindend, unmittelbar in die Geschicke eines großen Teiles der Welt eingriff. Mit dem zunächst zersetzenden Wirken all dieser Einflïsse beginnt für die allgemeine Geschichte wie für die Geschichte der Wissenschaften das Mittelalter, dem wir uns jetzt zuwenden wollen.

1) Dieser richtete sich nur gegen die Heiden, nicht aber gegen Christen, Juden und Parsen (Bem. von E. Wiedemann). 


\section{Der Verfall der Wissenschaften zu Beginn des Mittelalters.}

Der tiefste Eingriff, den die Entwicklung der allgemeinen Kultur und der Wissenschaft erlitt, bestand in der Vernichtung des römischen Weltreichs durch die germanischen Völker. Die meisten Städte wurden zerstört. An die Stelle des Städtewesens, das in Griechenland und in Italien zu hoher Blüte gelangt war und allein die feineren, auf Kunst und Wissenschaft gerichteten Kräfte zu entwickeln vermochte, trat wieder eine mehr ländliche, den geistigen Bestrebungen abholde Lebensweise. Die Bevölkerung der Städte, wie diejenige der Mittelmeerländer im allgemeinen, verminderte sich trotz des Zuflusses von neuen, erobernd einbrechenden Völkermassen. Unermeßlich waren auch die Verluste an den seit Jahrhunderten aufgespeicherten Schätzen der Kunst und Wissenschaft. Hatte doch Rom z. B. zu Beginn des 5. nachchristlichen Jahrhunderts, von den ältesten Zeiten abgesehen, noch nie einen Feind in seinen Mauern beherbergt. Zwar hatten blutige Kämpfe in seinen Straßen getobt, doch waren Verwüstung und Plünderung bis dahin von Rom ferngehalten worden. Das erste Ereignis dieser Art erfolgte durch Alarich und seine Westgoten im Jahre 410. „Ungehener war der Eindruck auf die Zeitgenossen. Die römische Welt zuckte von Riesenschmerz überwältigt zusammen" 1). Auf diese erste Verwüstung folgten andere, weit schlimmere. Nicht nur Rom, sondern auch andere Zentren der geistigen und kiinstlerischen Bestrebungen wurden von solchen Ereignissen heimgesucht. Unter diesen Verlü̈ltnissen war der Zerfall des gewaltigen römischen Weltreichs unausbleiblich. Der Historiker, der es liebt, seinen Einteilungen in die Augen springende Ereignisse zugrunde zu legen, lïßt daher das Mittelalter mit dem Eintritt der Völkerwanderung oder mit der Errichtung der ersten germanischen Herrschaft auf italischem

1) Lindner, Weltgeschichte seit der Vülkerwanderung. 1. 96. 
Boden beginnen. In der Geschichte der Wissenschaften hat man wohl nach älnlichen, epochemachenden Ereignissen gesucht und die Auflösung der Philosophenschule zu Athen oder die Erobermng Alexandriens durch die Araber im Jahre 642 als solche betrachtet (so Heller in seiner Gesch. der Physik). Man darf jedoch nicht vergessen, daß auf diesem Gebiet die Ereignisse geräuschlos vor sich gehen, daß es wohl von den Katastrophen der Weltgeschichte beeinflußt wird, aber niemals den Charakter einer ruhigen Entwicklung verleugnet.

Der Geist der zweiten alexandrinischen Blüteperiode war um das Jahr 600 längst erloschen. Die alexandrinischen Gelehrten verstanden die alten Schätze, von denen das meiste schon vernichtet war, kaum noch zu hüten. Seitlem moralische Fänle auf der einen und das der Welt mit ihrem Wissen abgewandte Christentum auf der anderen Seite das Leben immer mehr durchdrangen, also schon eine ganze Reihe von Jahrzehnten vor dem endgültigen Siege des germanischen Elementes, fanden auch in Rom die Wissenschaften nicht mehr die frühere Pflege. Rom und Alexandrien wurden Hauptsitze der christlichen Kirche. Und diese kehrte sich, da es ihr Ziel war, die antiken Elemente zu überwinden und neue an deren Stelle zu setzen, in mißverstandener Auslegung der heiligen Schriften auch gegen die antike Wissenschaft. Das Verhältnis der Seele zu Gott und gar nichts anderes sollte erkannt werden; dies allein hielt man für erkennbar. Der Verstand dagegen galt als machtlos. Nur die durch Gottes Gnade geschehene Offenbarung sollte imstande sein, die Menschen zu erleuchten $\left.{ }^{1}\right)$. „Forschung“, sagt Tertullian²), „ist nach dem Evangelium nicht mehr vonnöten". Und Eusebius meint von den Naturforschern seiner Zeit: „Nicht aus Unkenntnis der Dinge, die sie bewundern, sondern aus Verachtung ihrer nutzlosen Arbeit denken wir gering von ihrem Gegenstande und wenden unsere Seele der Beschäftigung mit besseren Dingen zu." Konnten doch diese Kirchenväter der ältesten christlichen Zeit selbst Meinungen heidnischer Philosophen für ihre Ansicht ins Feld führen, wie diejenige des Sokrates, der die menschliche Seele mit ihren inneren Zuständen für den einzigen, des Nachdenkens würdigen Gegenstand erklärt hatte.

Mit einem wahren Ingrimm wandten sich die ersten christlichen Gelehrten gegen den von Leukipp, Demokrit und Epi-

1) K. Lasswitz, Geschichte der Atomistik. Bd. I. S. 12.

2) Tertullian, De praescr. haeretic. cap. 7. 
kur herrïhrenden Versuch einer mechanischen Welterklärung. „Es wäre mir besser", ruft Augustinus aus, „ich hätte den Namen Demokrits nie vernommen!" Die Atomisten werden als blinde und bedauernswerte Menschen bezeichnet. Besonders eifert gegen sie der alexandrinische Bischof Dionysios der Große in seiner Schrift „Über die Natur" 1). Die Mitteilungen, welche Dionysios iiber die Lehren der Atomisten macht, dienen trotz ihrer polemischen Richtung als wertvolle Quelle über diesen wichtigen Abschnitt der griechischen Philosophie.

Dionys bekämpft die Atomisten vor allem, indem er die Zweckmäßigkeit der Welt betont und für das Kunstwerk, als das sie dem Menschen erscheint, in Gott den Künstler und Schöpfer erblickt. Kann doch nicht einmal, so etwa lauten einige seiner Ausfuihrungen, ein Kleid oder ein Hans von selbst entstehen, sondern es bedarf dazu einer geregelten Leitung. Und nun soll das große, aus Erde und Himmel bestehende Haus, der Kosmos, die Ordnung selbst, aus dem Chaos geworden sein. Zu den Gestirnen übergehend, sagt er: „Aber wenn auch jene Elenden es nicht wollen, so ist es doch, wie die Gerechten glauben, der große Gott, der sie gemacht hat und durch seine Worte ihre Bahn leitet." Weder der Bau der menschlichen Organe und ihr Zusammenwirken, noch weniger aber die geistige Tätigkeit sind, wie Dionys ausführt, mit der Atomenlehre vereinbar. Der Philosoph könne seine Vernunft doch nicht von den vernunftlosen Atomen erhalten haben.

Während Dionys der mechanischen Naturerklärung gegenüber den Standpunkt des eifernden Theologen einnimmt und mit Gründen ficht, die sich der wissenschaftlichen Erörterung entziehen, erhebt Lactantius gegen die atomistische Lehre physikalische und philosophische Einwürfe. Lactantius fragt, woher denn jene Teilchen stammen sollten und wie sich ihr Dasein beweisen lasse, da niemand sie gesehen oder gefiihlt habe. Aber, selbst das Vorhandensein der Atome zugegeben, würden diese leichten und runden Teilchen doch keinen Zusammenhang äußern und feste Körper bilden können. Wolle man, un dieser Schwierigkeit zu begegnen, den Atomen Ecken und Haken beilegen, so habe

1) Bedeutende Fragmente dieser Schrift sind als Bestandteile der Werke von Eusebius anf uns gekommen Ausgabe von Dindorf, Leipzig 1867. Bd. II. S. 321). Jine Übersetzung dieser Fragmente enthïlt: Georg Roch, Die Sehrift des alexandrinisehen Bisehofs Dionysios des Großen "Üher die Natur". Leipzig $188 \%$. 
man keine Atome mehr, da solche Herrorragungen doch abgetrennt werden könnten. Das Bemühen, die Gesetzmäßigkeit des Geschehens zu erklären oder es auch nur zu verfolgen, wurde abgelelint. Und dieser Standpunkt, den die Kirche einnahm, hat sich, mit wenigen Zugeständnissen an die Fortschritte der Wissenschaft, durch lange Zeiträume in ihr erhalten. „Je mehri) die Macht der christlichen Lehre fortschreitet, um so mehr schwindet das Verständnis für die kausale Erklärungsweise. Das Wunder reicht überall aus. WVas also sollen die Bemühungen, Erklärungen aufzufinden?:6

Dies Verhalten, das die Kirchenlehrer der naturwissenschaftlichen Erklärungs- und Betrachtungsweise gegenüber einnahmen, ist bei dem Ansehen, das ihre Schriften bis in die neuere Zeit genossen haben, für die weitere Entwicklung von schlimmen Folgen gewesen. Es erregte auch sehr oft den Fanatismus der Menge, die sich keineswegs mit dem Streit der Meinungen begnügte, sondern nicht nur gegen die Wissenschaft, sondern auch gegen ihre Denkmäler und Schätze zu Felde zog. So wurde z. B., lange bevor die Araber Alexandrien einnahmen, in dieser Stadt, unter der Führung eines christlichen Patriarchen, die wertrolle Bibliothek des Serapeions den Flammen überliefert. Schon im 3. Jahrhundert hatte ein Patriarch die Gelehrten der alexandrinischen Akademie vertrieben. Unter Kaiser Julian durften sie zurückkehren. Indessen unter Theodosios begann die Verfolgung von neuem. Damals war es, daß der Patriarch Theophilos sich von dem Kaiser die Erlaubnis erwirkte, das Serapeion zerstören zu dürfen. Mit dem gleichen Unverstand, wie gegen die weltliche Wissenschaft, verfuhren die ersten Bekenner des neuen Glaubens auch gegen die ron den Alten iiberlieferte Heilkunde. Krankheit wurde mit Gebet und Beschwörung bekämpft oder gar als eine Strafe Gottes betrachtet, in die man sich willenlos fügen müsse, während glückliche Heilungen als Teufelswerk galten.

Sogar die Lehre ron der Kugelgestalt der Erde, eine Lehre, die auf ein Alter von Jahrhunderten zurïckblicken konnte und die allein die geographische Ortsbestimmung ermöglicht hatte, ging im Mittelalter, nachdem Kirchenväter wie Lactantius sie verdammt hatten, verloren oder wurde wenigstens durch mystische Vorstellungen verdunkelt. So begegnen wir der Ansicht, daß die Erde

1) So sagt Lasswitz in seiner trefflichen Darstellung der Atomistik im Mittelalter K. Lasswitz, Gesch. d. Atomistik. Bd. I. S. 29). 
ein Hügel sei, um den sich die Sonne im Laufe eines Tages bewege. Augustin sprach sich gegen die Existenz von Antipoden aus, weil ein Geschlecht dieser Art in der heiligen Schrift unter den Abkömmlingen Adams nicht aufgefuihrt werde. Bei Rhabanus Maurus besitzt die Erde eine radförmige Gestalt und wird rom Ozean umflossen. Welcher Rückschritt gegenüber den Astronomen der alexandrinischen Schule! Befanden sich die Gelehrten des frühen Mittelalters mit ihrer $\mathrm{V}$ eltauffassung doch fast wieder auf dem nairen Standpunkt, den Hesiod im 8. Jalırhundert v. Chr. einnahm. Erst seit dem 8. nachchristlichen Jahrhundert etwa schrieb man der Erde die Gestalt einer Kugel zu. In einer Hinsicht wirkten die Kirchenväter übrigens auch Gutes. Sie verhielten sich nämlich im allgemeinen den astrologischen Lehren gegenüber, die während der Kaiserzeit das astronomische Wissen verdunkelt hatten, ablehnend. Dies geschah zwar weniger aus wissenschaftlicher Überzeugung, sondern weil es frevelhaft sei, Menschen- und Völkerschicksal aus den Sternen erkennen zu wollen $\left.{ }^{1}\right)$.

In demselben Maße bildungsfeindlich wie die ersten Christen, wenn auch aus anderen Grïnden, verhielt sich die zweite Macht, die von der Welt auf den Trümmern der Antike Besitz ergriffen hatte, das Germanentum. Seine Träger waren Volksstämme, die erst von dem Augenblicke an, in dem sie mit der alten Kultur in Berührung kamen, in das Licht der Geschichte traten. Ihnen galten nicht nur die zivilisierten Bewohner des südlichen Europas, sondern auch deren Geisteserzeugnisse zunächst als feindliche Mächte. So erzählt Prokop von den Goten, die nach den langen Wirren der Völkerwanderung in Italien zuerst wieder geordnete Verhältnisse schufen, sie seien der Ansicht gewesen, daB derjenige, der die Rute des Lehrers gefürchtet, keinem Schwert und keinem Speer mehr festen Blickes begegnen könne.

Bedenkt man nun, daß diese beiden Mächte, das Christentum und das Germanentum, das eine geistig, das andere physisch, ron dem abendländischen Teil der alten Welt Besitz ergriffen, während bald darauf im Morgenlande der Islam mit ähnlichen Tendenzen ins Leben trat, so läßt es sich begreifen, daß die im Altertum gegründete Wissenschaft in dem Geistesleben des Mittelalters zu-

1) Nach v. Lippmann bestritten die Kirchenväter, daß die Sterne die Ereignisse bewirken. Daß letatere dagegen durch die Bewegungen der Gestirne angezeigt würden, hielt man wohl für möglich.

Uanuemann, Die Naturwisenschaften. I. Ba. 2. Aufl. 
nächst keinen Platz fand. Man wird vielmehr darüber staunen, daß diese Wissenschaft Kraft genug besaß, nicht gänzlich unterzugehen, sondern unter der Asche fortzuglimmen, bis sie, seit dem 13. Jahrhundert etwa, von neuem entfacht wurde.

Einer Fortentwicklung der vom Altertum geschaffenen Anfänge wirkte nicht nur das geschilderte Streben entgegen, welches dem Christentum und dem Germanentum zu Beginn ihres Auftretens innewohnte, es brach auch eine Summe von Geschehnissen über die alte Welt herein, die an Furchtbarkeit nicht ihresgleichen hatten und das südliche Europa in einen Trümmerhaufen verwandelten, so daß dort der Wohlstand, der doch bis zu einem gewissen Grade die Vorbedingung aller Kunst und Wissenschaft ist, vernichtet wurde.

Während sich das oströmische Reich einer gewissen Beständigkeit erfreute, wurde der Westen ein Spielball der germanischen Stämme. Auf die Verwüstung durch die Goten folgte der Einfall der Vandalen, die überall Ruinen als die Spur ihrer Züge zurückließen. "Sie zerstörten alles", berichtet der Chronist von ihnen, „was sie fanden. Die Pest konnte nicht verheerender sein. Auch wütete eine fürchterliche Hungersnot, so daß die Überlebenden die Körper der Gestorbenen verzehrten." Es klingt kaum glaublich, wenn uns die Geschichtsschreiber jener Zeiten erzählen, daß man Festungen durch den Leichengeruch zur Übergabe zwang, indem man die Gefangenen vor den Wällen niedermetzelte.

Fast zur selben Zeit, als die Vandalen Rom plünderten, wurde Oberitalien durch die Hunnen verwüstet, deren Zug durch die von Aëtius gewonnene Schlacht bei Châlons nach Süden abgelenkt worden war. Nach diesen völkermordenden Kriegen nahmen todbringende Seuchen von dem aus vielen Wunden blutenden Europa Besitz. Vielleicht war infolge der vorhergegangenen Ereignisse eine allgemeine Schwächung der europäischen Menschbeit eingetreten und dadurch der Pest der Boden bereitet worden. Zum ersten Male hatte diese Geißel unter Marc Aurel ihren Zug durch das römische Reich gehalten und weit mehr Opfer gefordert, als die Seuchen der Neuzeit. Nach dem von Prokop, dem Geheimschreiber Belisars, hinterlassenen Bericht wütete sie volle 50 Jahre im ganzen römischen Reiche dermaßen, daß in Italien stellenweise die Weinstöcke und das Getreide vermoderten, weil es an Arbeitskräften fehlte.

Allmählich erhoben sich indes aus der Verworrenheit und der Verwüstung, welche die ersten Jahrhunderte des Mittelalters 
kennzeichnen und das Erlahmen des wissenschaftlichen Geistes begreiflich erscheinen lassen, gefestigte Verhältnisse. Rom war dadurch, daß es im 5. Jahrhundert in den Besitz der kirchlichen Vorherrschaft gelangt war, wieder, wenn auch in anderem Sime als im Altertum, zum geachteten Mittelpunkt des Abendlandes und die römische Sprache zur Weltsprache geworden. Benedikt von Nursia hatte im Anfang des 6. Jahrhunderts das Klosterwesen in Westeuropa begründet. Der Gedanke, sich um der Erfüllung religiöser Pflichten willen von der Welt zurückzuziehen, ist orientalischen Ursprungs und schon dem Heidentum des Orients geläufig. Er ergriff mit besonderer Macht die ersten Christen, welche die Satzungen der neuen Religion mit den Forderungen und Schwierigkeiten des Lebens nicht in Einklang zu bringen vermochten. So sehen wir bald nach der Ausbreitung des Christentums Tausende sich in entlegene Teile Syriens und Ägyptens zurückziehen. Es entstand ein von bestimmten Regeln abhängiges Mönchstum, das für jene Zeiten eine berechtigte Erscheinung war und die Erhaltung der geistigen Kultur begünstigte. Schon um die Mitte des 4. Jahrhunderts verbreitete sich das Mönchswesen besonders durch den Bischof Basilius den Großen in Kleinasien und auf der Balkanhalbinsel. Bald fand es auch im weströmischen Reiche Eingang, wo namentlich Augustinus für diese Form des religiösen Lebens den Boden bereitet hatte. Benedikt von Nursia gebührt das Verdienst, daß er zuerst die umherschweifenden, zuchtlosen, dem Mönchstum ergebenen Scharen zun Zusammenleben und zu geordneter Tätigkeit zwang. Die Beschäftigung mit den Wissenschaften bezeichnete er als eine der wichtigsten Pflichten seines Ordens. „Den Klöstern“, sagt Lindner 1), "verdanken wir alles oder das weitaus meiste, was von antik-lateinischen Schriften und selbst von den alten germanischen auf uns gekommen ist, sie haben den Rückweg zum Altertum offen gehalten."

Zwar, das Studium der nicht philosophischen Schriften des Altertums wurde von den kirchlichen Machthabern nur ungern gesehen. So begegnet uns um 1200 ein Verbot 2), welches den Mönchen das Lesen naturwissenschaftlicher Schriften als sündhaft untersagte. Im ganzen war jedoch die Tätigkeit der Orden auf die

1) Lindner, Weltgeschichte. Bd. I. S. 305.

2) Lrlassen auf der Kirchenversammlung zu Paris vom Jahre 1209. Siehe auch v. Humboldts Kosmos II. S. 31, sowic die bezügliche Anmerkung. 
Erhaltung der alten Schriftwerke und die Ausbreitung der Bildung gerichtet, so daß die Benediktiner mit Recht den Wahlspruch „Ex scholis omnis nostra salus" führten.

Auch im politischen Leben Italiens machte die Brandung, welche dort Jahrhunderte gewütet, endlich einer ruhigen Entwicklung Platz. Während der ersten Hälfte des 6. Jahrhunderts herrschten hier die Ostgoten. Unter ihrem großen König The oderich (475-526), der eine Verschmelzung des germanischen mit dem römischen Element herbeizuführen suchte, erlebte das Land sogar einen kurzen Aufschwung. Der wissenschaftliche Sinn wurde von neuem lebendig, die Schulen blühten und die Gelehrten wurden wieder geachtet ${ }^{1}$ ). In diesem Zeitraum verdienen besonders Cassiodor und Boëthius Erwähnung.

Cassiodor wurde in Süditalien geboren und war um 500 Theoderichs Geheimschreiber und Ratgeber. Nach der Besiegung der Ostgoten durch die Byzantiner zog er sich in die klösterliche Einsamkeit zurück. Durch ihn und Benedikt von Nursia, der im Jahre 529 das Kloster zu Monte Cassino bei Neapel gestiftet hatte, wurde an Stelle der früheren Beschaulichkeit der Mönche rege Tätigkeit als oberster Grundsatz hingestellt. Unermiidlich wurden in schöner Schrift die im Besitze der Klöster befindlichen Werke auf Pergament übertragen und so neben manchem Wertlosen doch auch das Wertvolle der Nachwelt erhalten. Cassiodor selbst empfiehlt das Abschreiben von Büchern den Mönchen als die verdienstlichste Arbeit. Seine letzte Schrift verfaßte er im 93. Lebensjahre. Er hinterließ 12 Bücher Briefe ${ }^{2}$ ) und eine Enzyklopädie ${ }^{3}$ ) der sogenannten sieben freien Künste (Grammatik, Rhetorik, Dialektik, Arithmetik, Musik, Geometrie und Astronomie). Indessen handelt es sich für ihn nicht um eine ausführliche Darstellung dieser Wissenszweige, sondern mehr um eine Aufzählung derjenigen griechischen und lateinischen Schriftsteller, deren Studium dem Anfänger zu empfehlen sei.

Das Urbild derartiger, im Mittelalter so häufigen Sammelwerke über die freien Künste rührt von Marcus Terentius Varro her, der im 1. Jahrhundert v. Chr. lebte und neun Wissenschaften enzyklopädisch behandelte ${ }^{4}$ ). Außer den genannten hatte

1) Libri, Histoire des sciences mathématiques en Italie. Bd. I. S. 82.

2) Variarum (epistolarum) libri XII.

3) De artibus ac disciplinis liberalium literarum.

4) Siehe den Abschnitt über die Quellen des Plinius, S. 222 dies. Bds. 
er nämlich auch die Medizin und die Baukunst in Betracht gezogen.

Der in einer Geschichte der Wissenschaften Erwähnung verdienende Genosse Cassiodors war der aus altem römischen $\mathrm{Ge}$ schlecht entstammende Boëthius. Nachdem er in seiner Vaterstadt die höchsten Ämter bekleidet, fiel er in Ungnade und wurde nach längerer Gefangenschaft enthauptet. Im Kerker entstand seine berühmte Schrift "Über die Tröstungen der Philosophie", ein Werk, das in viele Sprachen übersetzt wurde $\left.{ }^{1}\right)$. Boëthius machte das Studium der griechischen Schriftsteller wieder zugänglich, indem er sie in das Lateinische übersetzte und erläuterte. Cassiodor, der Geschichtsschreiber der Ostgotenzeit, hat der Nachwelt eine Stelle aus einem Briefe Theoderichs an Boëthius aufbewahrt, welche den König wie den Empfänger in gleicher Weise ehrt. "In deinen Übertragungen", heißt es in diesem Schreiben, „wird die Astronomie des Ptolemäos, sowie die Geometrie des Euklid lateinisch gelesen. Platon, der Erforscher göttlicher Dinge, und Aristoteles, der Logiker, streiten in der Sprache Roms. Auch Archimedes, den Mechaniker, hast du lateinisch wiedergegeben. Welche Wissenschaften und Künste auch das fruchtbare Griechenland erzeugte, Rom empfing sie in vaterländischer Sprache durch deine Vermittlung" 2).

Lieblingsgebiete des Boëthius waren die Musik und die Akustik. Er stellte zahlreiche Versuche mit dem Monochord und mit Pfeifen an und schrieb ein Werk über die Musik ${ }^{3}$, in dem manche klare Anschauung entwickelt ist. Wichtiger ist dieses Buch dadurch, daß wir uns nach ihm eine gewisse Vorstellung von der Tonkunst des Altertums und des früheren Mittelalters machen können. Auch der Astronomie und der Physik brachten die gebildeteren Goten, geschichtlichen Berichten zufolge, ein großes Interesse entgegen.

Leider sollte dieser hoffnungsvolle Ansatz, den der italische Boden gezeitigt, noch in der Blüte geknickt werden. Ebenso rasch, wie das Ostgotenreich emporgekommen war, wurde es durch die furchtbaren Kriege, welche der oströmische Kaiser gegen die Ostgoten führte, wieder hinweggefegt. Zehn Jahre später fiel das verwüstete Italion in dic Hände der Langobarden. Einen ähn-

1) De consolatione philosophiae. Herausgeg. von Heiper 1871.

2) Cassiodorus, Varia I. 45.

3) Bö̈thius, Fünf Bücher über Musik. Deutsch von Oscar Paul, Leipzig 1880. 
lichen Aufschwung, wie zur Zeit der Ostgoten, hat es unter der, Jahrhunderte davernden Herrschaft dieses Volkes nicht wieder erlebt. Doch fand in dieser verhältnismäßig ruhigen Zeit eine allmähliche Verschmelzung des germanischen Elementes mit dem römischen statt, wodurch die Vorbedingung für eine höhere Kultur geschaffen wurde.

Neben Cassiodor und Boëthius rerdient für dieses Zeitalter der Bischof Isidor von Sevilla erwähnt zu werden. Er wurde im Jahre 570 in Cartagena geboren und starb 636. In einem, aus 20 Büchern bestehenden Werk, das den Titel „Origines" (die Ursprünge) führt, gab er, wie es Cassiodor und Martianus Capella getan, eine Art Enzyklopädie der Wissenschaften lieraus. Die "Origines" berücksichtigen nicht nur die freien Künste, das Trivium (Grammatik, Rhetorik und Dialektik) und das Quadrivium (Arithmetik, Musik, Geometrie und Astronomie), sondern auch die Medizin, die Naturgeschichte, die Geographie usw. Das Werk verdrängte die Enzyklopädien des Cassiodor und des Martianus Capella und war neben Plinius und Aristoteles bis gegen das Ende des Mittelalters für alle späteren Sammelwerke die wichtigste Fundgrube. Es führt auch wohl den Titel „Die Etymologien" (Libri originum seu etymologiarum). Dementsprechend finden wir für alle Gegenstände die Etymologien des Namens an die Spitze gestellt, ja oft allein gegeben. In den meisten Fällen waren die Wortableitungen jedoch sehr willkürlich und wertlos.

Männer, wie die Genannten, haben das Vorhandene nicht vermehrt, sondern, wie Plinius, als literarische Sammler gewirkt. Als solche sind sie aber für die Erhaltung des Wissens und des wissenschaftlichen Interesses für das ganze Mittelalter von Bedeutung gewesen. Fast allen lag daran, die Beschäftigung mit den Wissenschaften in weitere Kreise zu tragen, indem sie für die Verbreitung und Verbesserung des Schulwesens wirkten. Das ist nicht nur Cassiodor und Rhabanus Maurus, sondern auch Isidor von Sevilla nachzurühmen.

Wie die Klöster zu Mittelpunkten literarischer Beschäftigung wurden, so fand in ihnen auch, zumal in den sich erst der Kultur erschließenden germanischen Ländern, die Heilkunde eine Stätte. Die Mönche bereiteten Arzneien nicht nur für ihren eigenen $\mathrm{Ge}-$ brauch, sondern auch für die Bewohner der Umgegend. Die heilbringenden Kräuter wurden in besonderen Gärten im Schutze der Klostermauern gezogen. Genauere Angaben besitzt man ïber 
den Kräutergarten des Klosters St. Gallen, aus dem schon im 9. Jahrhundert die benachbarten Dörfer mit Arzneien versorgt wurden. Von den zahlreichen Kräutern, die man in St. Gallen zu diesem Zwecke zog, seien beispielsweise Salbei, Raute, Minze und Fenchel genannt. Ein selbständiges Apothekenwesen entwickelte sich im germanischen Kulturbereich erst im späteren Mittelalter 1). Im Altertum hatte der Arzt die Arzneien in der Regel selbst bereitet.

1) Siehe an späterer Stelle dieses Bandes. 


\section{Das arabische Zeitalter.}

Ein neuer Anlaß zur Beschäftigung mit der Wissenschaft des Altertums sollte im Abendlande nicht mehr, wie zur Zeit Theoderichs, auf eigenem Boden ersprießen, sondern von einem orientalischen Volke ausgehen, das bis dahin kaum eine Rolle gespielt hatte. Diese Erscheinung ist eine der merkwïrdigsten, die uns in der Entwicklung der Wissenschaften begegnet, weshalb wir ihr eine etwas eingehendere Betrachtung schenken müssen. Während das Christentum die abendländischen Völker durchdrang, bemächtigte sich der Islam des gesamten Orients. Die Ausbreitung der neuen Lehre erfolgte durch Feuer und Schwert und ging Hand in Hand mit der Errichtung eines Weltreiches durch die Araber. Auch die letzteren traten, wie die ersten Bekenner des Christentums, den vorhandenen Bildungselementen zunächst feindlich gegenüber. Von fanatischem Eifer verblendet, soll der Kalif Omar dem arabischen Feldherm, der Alexandrien eroberte, den Befehl zur Vernichtung der noch vorhandenen Bücherschätze mit den Worten gegeben haben: „Wenn diese Bücher das enthalten, was im Koran steht, so sind sie unnuitz, wenn sie etwas anderes enthalten, so sind sie schädlich. Sie sind deshalb in beiden Fällen zu verbrennen."

Nach anderen Nachrichten ${ }^{1}$ ) soll dieses Wort bei der Eroberung Persiens gefallen sein. Bei diesem Ausspruch und manchen anderen, geschichtlichen Persönlichkeiten zugeschriebenen Worten ist der Nachweis, daß es sich um eine verbürgte $\ddot{A} u ß e r u n g$ han-

1) Ich verdanke darüber Herrn Prof. E. Wiedemann folgende Bemerkung: Es scheint, als ob ein Ereignis, das sich in Persien abgespielt hat, auf Ägypten übertragen wurde. Ibn Khaldun, ein arabischer Historiker, bemerkt: Wir wissen, daß die Mohammedaner bei der Eroberung Persiens eine Unzahl von Büchern vorfanden und daß ihr Feldherr Saad Ibn Abi Waggâs beim Kalifen $\mathrm{O}$ mar anfragte, ob diese Bücher mit der Beute an die Gläubigen zu verteilen seien. Omar antwortete: „Wirf sie ins Wasser. Enthalten sie etwas, was zur Wahrheit führt, so haben wir von Gott, was uns noch besser dahin leitet. Enthalten sie aber Falsches, so sind wir derselben ledig. " Infolge dieses Befehles vernichtete man die Bücher durch Wasser oder Feuer. 
delt, in vielen Fällen nicht zu erbringen. Wenn sie trotzdem, wie beispielsweise Galileis Wort: „Und sie bewegt sich doch“, in der Geschichte der Wissenschaften Erwähnung finden, so geschieht dies, weil sie häufig Personen, Zeitverhältnisse oder geistige Strömungen vortrefflich kennzeichnen.

Wie groß der Verlust an Bücherschätzen infolge der von den Arabern zu Beginn ihres Auftretens bewiesenen Zerstörungswut gewesen ist, läßt sich nicht mehr ermessen. Diese Verluste begannen übrigens in Alexandria schon weit früher, nämlich zur Zeit der Belagerung durch Julius Caesar. Unter Kleopatra wurden sie jedoch durch die Erwerbung der pergamenischen Bibliothek ausgeglichen. Die Zerstörung des Serapeions fand unter Theodosios statt. Es wurde jedoch soviel gerettet, daß eine neue Bibliothek gegründet werden konnte. Mit den etwa noch vorhanden gewesenen Überresten an literarischen Schätzen scheinen dann die Araber bei der Eroberung Alexandriens nicht allzu glimpflich umgegangen $z u$ sein, wenn auch die Nachrichten über den von ihnen bewiesenen Vandalismus olnne Zweifel stark ïbertrieben sind $\left.{ }^{1}\right)$. Im allgemeinen waren die Bekenner des Islams nämlich duldsamer als die Christen. Während letztere die Unterworfenen zur Bekehrung zwangen und keine Religion neben der christlichen anerkannten, war der Islam mehr darauf bedacht, zu herrschen. Die Christen behielten unter dieser Herrschaft ihre Glaubensfreiheit, ja selbst ihre Kirehen und Klöster. Der Islam ließ den unterworfenen Völkern mehr ihre Eigenart. Auch behielten die von ihm unterjochten Städte als Mittelpunkte des geistigen Lebens und eines größeren Wohlstandes ihre Bedeutung, während das Abendland durch die Germanen einer mehr ländlichen, naturalwirtschaftlichen Lebensweise anheimfiel. Die Kultur des Morgenlandes erlitt daher durch den Islam in ihrer Entwicklung keine solch gewaltsame Unterbrechung, wie sie das Abendland erfulır. Die morgenländische Kultur des Mittelalters verdient auch die Bezeichnung einer arabischen weniger ihrer Eigenart wegen als dem Unstande, dal die Sprache der Araber die herrschende wurde. Mit dieser Erkenntnis fïllt auch die Paradoxie, die darin liegen würde, wenn man einem bis dahin unbekannten Nomadenvolke alle Schöpfungen, welche der Orient im Mittelalter herrorbrachte, zuschreiben wollte.

1) Genaueres über das wechselnde Schicksal der in Alexandrien aufbewahrten Bücherschätze siehe bei Ritschl, S. 188, Amm.1. 
Die Araber verstanden es vortrefflich, dasjenige, was die unterjochten Völker an Kulturelementen besaßen, zu sammeln und zu sichten. Nachdem sie in der kurzen Zeit vom Auftreten Mohammeds bis zum Beginn des 8. Jahrhunderts Syrien, Palästina, Ägypten, Persien, Nordafrika und Spanien erobert hatten, nahmen sie die Bildungselemente, die sie in diesen Ländern vorfanden, in sich auf, um sie später den abendländischen Völkern zu übermitteln. Den letzteren blieb es vorbehalten, auf diesen Grundlagen erfolgreich weiter zu bauen, was die Araber nur in bescheidenem Maße vermocht hatten. Es ist ein Verdienst der arabischen Literatur, wichtige Teile der griechischen Wissenschaft erhalten und sie durch das Dunkel des Mittelalters in die nenere Zeit hiniiber gerettet $\mathrm{zu}$ haben.

Nach dem Untergange der alten Kultur wurden die Wissenschaften in Syrien und Persien in griechisch-christlichen und jiidischen Schulen gepflegt. Als die Araber diese Länder eroberten, fanden sie dort. ein reiches geistiges Leben vor $\left.{ }^{1}\right)$. Wahrscheinlich ist aber bei dem ersten Anprall die ältere Literatur jener Länder zum Teil vernichtet worden, so daß man sich bei dem erwachenden Interesse für wissenschaftliche Dinge veranlaßt sah, auf die griechischen Originale zurückzugehen, woraus sich z. B. das später zu erwähnende Verhalten des Kalifen Al Mamîn erklärt 2). Mit dem Übersetzen ging das Kommentieren Hand in Hand. So soll Ibn Sina (Avicenna, 980-1037) die Schriften des Aristoteles in 20 Bänden kommentiert haben. Seine Arbeit ging verloren, doch blieb sein Kommentar zu den aristotelischen Schriften über die Tiere in lateinischer Übersetzung (von Michael Scotus) erhalten.

Trotz aller Verfolgungen, denen die griechische Wissenschaft ausgesetzt gewesen, fanden sich also im Orient doch noch zahlreiche, wertrolle Überreste. Vor allem war es die zur Zeit der Eroberungskriege der Araber in Syrien und Persien verbreitete christliche Sekte der Nestorianer, die sich um die Erhaltung dieser Überreste ein großes Verdienst erworben hatte ${ }^{3}$ ). Seit dem

1) Wüstenfeld, Die Akademien der Araber und ihre Lehrer. Göttingen 1837.

2) S. 304 .

3) Die Nestorianer waren um 450 aus dem byzantinischen Reich vertrieben worden. Durch sie wurden die Araber mit den syrischen Übersetzungen astrologischer und alchemistischer Schriften bekannt. Eine selbständige alchemistische Literatur als Fortsetzung der griechischen und syrischen 
Zeitalter Alexanders hatten sich viele Griechen in den bedeutenderen Städten Syriens und Persiens niedergelassen und ihr Wissen und ihre Sprache in Vorderasien verbreitet. Mit dem Griechentum berührte sich dort alsbald das jüdische Element. Beide wurden nach Beginn unserer Zeitrechnung durch die Ausbreitung des christlichen Glaubens noch enger verbunden. Der den Griechen eigene Drang, überall, wo sie in fremden Ländern sich niederließen, als Lehrer ihrer neuen Landsleute aufutreten, empfing dadurch eine neue Anregung. Die Schulen wurden christlich, behielten aber ihre Richtung auf die Pflege und Verbreitung der weltlichen Wissenschaft, getreu dem Geiste des Griechentums, bei.

Als Sitz einer Akademie sei Edessa erwähnt. Dort entstand auch eine bedeutende Bibliothek. Vom 5. Jahrhundert etwa an wurden die Werke des Aristoteles, sowie griechische Schriften über Medizin, Mathematik, Astronomie usw. ins Syrische übertragen. Die Syrer sind als die unmittelbaren Schüler der Griechen zu betrachten. Eine nennenswerte Förderung der Wissenschaften scheint durch die Syrer aber nicht stattgefunden zu baben. Ihr Hauptverdienst besteht darin, daß sie die Kenntnisse und Anschauungen der Alten den Arabern übermittelten. Die in Mesopotamien entstandenen Nestorianerschulen blühten rom 5 . bis ins 11. Jahrhundert. Und hier war es, wo die Elemente der antiken Wissenschaft, darunter auch diejenigen der Alchemie, den Arabern bekannt wurden, durch die sie dann nach Spanien und darauf zu den übrigen Ländern Europas gelangten. Durch die Beschäftigung mit chemischen Vorgängen sind die syrischen Gelehrten Mesopotamiens viellcicht auf die Erfindung des sogenannten griechischen Feuers gelangt, das seit dem Ende des 7. Jahrhunderts bei Belagerungen und in Seeschlachten benutzt wurde $\left.{ }^{1}\right)$.

Das griechische Feuer wurde im Jahre 678 durch cinen Syrer in Konstantinopel eingefiihrt und bestand vermutlich aus einer Mischung von leichtflüchtigen Erdölen, Asphalt und gebranntem Kalk. Letzterer bewirkte, daß sich die Masse beim Zusammen-

schufen die Araber wohl erst während der Herrschaft der Abbasiden (750-1258). Man kann wohl mit E. v. Lippmann (Alchemie S. 357) annehmen, daß die Araber, sobald sie auf das Treiben der Goldmacher aufmerksam wurden, sich der Alchemie nicht aus wissenschaftlichem Interesse zuwandten, sondern weil sie durch die Aussicht auf Gewinn dazu verlockt wurden.

1) Mr. Berthelot, Die Chemie im Altertum und im Mittelalter. Herausgegeben von E. Kalliwoda und F. Strunz. Teipzig und Wien 1909. Ber. thelots Buch ist nach E. v. Lippmann zum Teil wenig zuverlässig. 
treffen mit Wasser entziindete. Die Verwendung von Salpeter zu Zündsätzen, Raketen usw. ist hingegen erst weit später anzusetzen $\left.{ }^{1}\right)$.

Von den syrischen Handschriften, die sich mit chemischen Dingen beschäftigen, sind noch melırere erhalten und durch Berthelot ihrem Inhalt nach bekannt geworden. Es gehört dahin eine Aufzählung ${ }^{2}$ ) der Metalle, der sieben Erden, der zwölf als Amulette dienenden Steine und einer Anzahl zum Färben des Glases dienender Mineralien. Als Amulette, denen man Zauberkräfte zuschrieb, galten z. B. der Amethyst (gegen Trunkenheit) und der Bernstein (gegen die Gelbsucht). Eine zweite syrische Handschrift ${ }^{3}$ ) kann als das älteste methodische Buch über Chemie betrachtet werden. Seine Abschnitte sind iiberschrieben: Die Bearbeitung des Kupfers, des Quecksilbers, des Bleies, des Eisens usw. Die syrische Alchemie besteht in der Hauptsache aus der Übersetzung griechischer Quellenschriften. In der erwähnten Aufzählung finden sich dem Namen jedes Metalls der Name eines bestimmten Planeten und einer bestimmten Gottheit beigefügt.

Dogmatische Streitigkeiten riefen einen Gegensatz zwischen den syrischen, an der Lehre des Bischofs Nestorios ${ }^{4}$ ) festhaltenden Christen und der Hierarchie von Alexandrien und Byzanz hervor. Die Bedrückung, welche die in Syrien an den Schulen wirkenden Gelehrten infolgedessen erfuhren, veranlaßte diese Männer, sich in den persischen Christengemeinden, und zwar besonders in Mesopotamien, niederzulassen und dort im 5. Jahrhundert neue Pflanzstätten zu griinden ${ }^{5}$ ). Dadurch wurden die Nestorianer die Vermittler zwischen dem Osten und dem Westen der alten Welt. Die in Indien entstandenen Wissénselemente fanden nämlich in Persien Eingang und wurden später den Arabern und durch sie Europa übermittelt.

Als in Bagdad unter Almansur das Kalifat allen Glanz des Morgenlandes um sich verbreitete, wurden die Nestorianer, sowie

1) Siehe v. Lippmann, Über das Feuerbuch des Marcus Graecus in der "Alchemie". 1919. S. 477 u. f.

2) Das Manuskript befindet sich im Britischen Museum. Näheres siehe in v. Lippmanns, Alchemie“.

3) Sie befindet sich in Cambridge. Siehe Berthelot a. a. O.S. 43.

4) Nestorios war in Syrien geboren. Er war ein Anhänger des Anastasios, dessen Lehre für Ketzerei erklärt wurde.

5) Unter diesen ist die Schule zu Nisibis zu nennen und die Akademie von Dschondisabur, die bereits im 6. Jahrhundert in hoher Blüte stand. 
andere griechische Gelehrte an den Hof gezogen und damit betraut, die in ihrem Besitz befindlichen Wissensschätze ins Arabische zu übertragen. Die mohammedanischen Machthaber scheint dabei zuerst mehr eine Art von Sammeleifer als ein Verständnis für die Bedeutung des Errungenen geleitet zu haben. So wird z. B. berichtet, daß Harun al Raschid, der zur Zeit Karls des Großen lebende Kalif aus dem Hause des Omejaden, sich von den griechischen Kaisern alles ausgebeten habe, was ihr Land an philosophischen Werken besaß. Die Stellung, welche die Araber, diesen Werken gegenüber einnahmen, war zunächst die blinde Achtung gegenüber der Autorität. Wie der Koran in der Religion und im Leben, so dienten die vorhandenen, insbesondere die griechischen Vorbilder ihnen als unbedingte Richtschnur für das Studium der Wissenschaften. Bei diesem Grundzug ihres Wesens war zwar ein wesentlicher Fortschritt nicht zu erwarten, doch hatte die von ihnen geübte Überschätzung das Gute im Gefolge, daß ihre Literatur in erster Linie der Erhaltung der gewonnenen Geistesschätze diente. Darauf und weniger auf dem Inhalt an eigenen Gedanken beruht die weltgeschichtliche Bedeutung der arabischen Literatur ${ }^{1}$.

Die Begierde, Bücher zu sammeln, war in den Ländern, in denen die arabische Kultur aufblühte, allgemein. So gab es in Bagdad angeblich über hundert Buchhandlungen, und viele Privatleute besaßen größere Bibliotheken. Es entstanden sogar gelehrte Gesellschaften, wie sie uns im Abendlande erst mit dem Wiederaufleben der Wissenschaften zu Beginn der neueren Zeit begegnen. Auch der Mittelstand war in den Städten bemüht, sich die Elemente der Bildung anzueignen, für deren Ausbreitung Schulen sorgten. Während in Rom zur Kaiserzeit etwa 30 öffentliche Bibliotheken vorhanden waren, bestanden in Bagdad deren weit mehr. Die Lehrer, die an den mohammedanischen Schulen wirkten, wurden vom Staate besoldet. Legten sic ihrem Vortrage auch meist Bücher zugrunde, so gestaltete sich der Unterricht, der meist das theologische und das juristische Gebiet betraf, doch zu einem belehrenden Gespräch mit den Schülern. Er befand sich also auf einer hohen Stufe. Als weiteres Ausbildungsmittel waren ausgedehnte Studienreisen üblich. Solche Reisen gaben wieder den Anlaß zur Entstehung vortrefflicher geographischer Werke. Mit offenem Blicke schildern ihre Verfasser nicht nur die topographischen, sondern auch die klimatologischen Verhiälnisse der besuchten

1) Meyer, Geschichte der Botanik. Bil. IIJ. S. 107. 
Länder, sowie ihre Erzeugnisse. Ja, wir besitzen arabische Berichte, die uns sogar über den Zustand von Mainz, Fulda und anderen deutschen Städten des frühen Mittelalters wertvolle Aufschlüsse geben.

Auch das Interesse für mechanische Dinge war bei den Arabern nicht gering. So übersandte, wie Einhard berichtet, Harun al Raschid Karl dem Großen unter den zur Krönungsfeier bestimmten Geschenken eine Wasseruhr, die ein Zeigerwerk besa $ß$ und die Stunden dadurch ankündete, daß eine Metallkugel in ein aus Erz gefertigtes Becken fiel ${ }^{1}$ ).

Tatsache ist, daß die Präzisionsmechanik bei den Arabern einen hohen Grad der Ausbildung erreicht hatte und daß sie bei der Herstellung .von verschiedenen Arten der Wasseruhren „ein fabelhaftes Talent an den Tag legten")2.

Nicht minder groß war die Vorliebe, welche der Sohn und Nachfolger Haruns, der Kalif Al Mamûn, für die Wissenschaft bekundete. Er errichtete in Bagdad eine Sternwarte und gründete in zahlreichen Städten seines Reiches Schulen und Bibliotheken. Hatte schon Harun eigene Übersetzer angestellt, so gründete sein Nachfolger zu diesem Zwecke ein förmliches Institut, zu dem eine große Anzahl, der verschiedenen Sprachen kundiger, Gelehrten vereinigt wurden. In Syrien, Armenien und Ägypten wurden durch besondere Abgesandte Bücher aufgekauft. Vor allem übertrug. man sämtliche Werke des Aristoteles und des Galen. Auch Euklid, Ptolemäos und Hippokrates lernte man kennen. Selbst aus dem Persischen und dem Indischen wurde eifrig übersetzt. Nach einem erfolgreichen Kriege gegen den byzantinischen Kaiser legte Al-Mamûn letzterem die Bedingung auf, ihm von sämtlichen, in den Bibliotheken des griechischen Reiches befindlichen Werken je ein Exemplar zu überlassen, damit diese Werke ins Arabische übertragen würden. Darunter befand sich auch das oben erwähnte astronomische Hauptwerk des Ptolemäos, das in der Folge Almagest genannt wurde.

1) Heller, Geschichte der Physik. 1882. Bd. I. S. 160.

2) Über die Zeiteinteilung und den Ubrenbau der Araber haben E. Wiedemann und F. Hauser eine sehr ausführliche Darstellung gegeben: Über die Uhren im Bereich der islamischen Kultur. E. Harras, Halle 1915. 272 S. - Nach Wiedemann und Hauser ist Einhards Erzählung nicht ganz zutreffend. 


\section{Mathematische Geographie und Astronomie bei den Arabern.}

Die Araber haben oft bewiesen, daß sie sich den Alten gegenüber nicht bloß rezeptiv verhalten wollten. So wurde z. B. die Messung eines Breitengrades zur Bestimmung des Erdumfanges unter Al Mamûn wieder vorgenommen und zwar, ohne daß man sich an das von den Griechen geschaffene Verfahren klammerte ${ }^{1}$ ), Ein wesentlicher Fortschritt dem Eratosthenes gegenüber lag bei diesem Unternehmen nänilich darin, daß die zugrunde gelegte Strecke nicht in Tagereisen ausgedrückt, sondern in der Richtung des Meridians mit Hilfe der Meßschnur ausgemessen wurde. Man fand die Länge des Grades gleich 56 und bei einer zweiten Messung gleich $562 / 3$ arabischen Meilen ${ }^{2}$ ) oder gleich etwa 113040 m, woraus sich der Erdumfang zu $40700 \mathrm{~m}$ berechnet.

Albiruni (um 1000) berichtet über das eingeschlagene Verfahren mit folgenden Worten ${ }^{3}$ ): „Man wähle einen Ort in einer ebenen Wüste und bestimme dessen Breite. Dann ziehe man die Mittagslinie und schreite längs derselben nach dem Polarstern. Miß den Weg in Ellen. Dann miß die Breite des zweiten Ortes. Ziehe die Breite des ersten davon ab und divi-

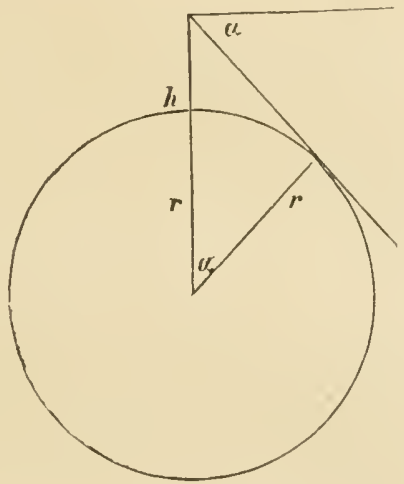

Abb. 50. Albirunis Bestimmung des Erdumfanges.

diere die Differenz durch den Abstand der Orte in Parasangen. Das Resultat, multipliziert mit 360, ergibt den Umfang der Erde in Parasangen."

Von Interesse ist ein zweites Verfahren, das Albiruni zur Ermittlung des Erdumfanges anwandte. Es besteht darin, daß man einen hohen Berg besteigt, der sich in der Nähe des Meeres befindet, und von hier aus durch Beobachtung des Somnenunterganges den Winkel $u$, d. h. die Depression (Abb. 50) bestimmt. Albiruni zeigt dann weiter, wie man aus diesem Winkel und der

1 S. Günther, Studien zur Geschichte der mathematischen und physikalischen Geographie. 1877. S. 59.

2) Peschel, Geschichte der Erdkunde. 1877. S. 122.

3) E. Wiedemann, Bestimmungen des Erdumfanges von Al Beruni (Archiv für Gesehichte der Naturwiss, u. der Technik). I. Bd. (1908). S. 66. 
Höhe des Berges den Radius der Erde durch trigonometrische Rechnung ermittelt. Eine solche Bestimmung hat or wirklich ausgefuihrt. Er hat in Indien einen Berg, der 652 Ellen über das Meer emporragt, bestiegen und den Winkel gemessen, den die nach dem Horizont gerichtete Sehlinie mit der Horizontalen auf dem Gipfel bildet. Dieser Winkel wurde mit Hilfe des Astrolabs gefunden und belief sich auf $34^{\prime}$. Aus diesem Werte und der Höhe des Berges wurde der Radius und die Länge eines Grades berechnet. Die Berechnung ergab für den Umfang der Erde etwa 5600 Meilen ${ }^{1}$, das sind $41550 \mathrm{~km}$.

Auf Befehl des Al Mamûn, der die erwähnte Gradmessung in der Nähe des Roten Meeres anstellen ließ, wurde auch die Schiefe der Ekliptik mit großer Genauigkeit ermittelt. Der gefundene Wert belief sich auf $23^{\circ} 35^{\prime}$. Heute beträgt er $23^{\circ} 27^{\prime}$. Die Änderung beläuft sich also in einem Jahrhundert auf etwa $48^{\prime \prime}$.

Die Astronomie fand bei den Arabern eine zusammenfassende Bearbeitung durch den unter Al Mamûn lebenden Alfragani oder Alfergani. Dem Werk, das Melanchthon 1537 unter dem Titel „Alfragani rudimenta astronomiae" aus dem Nachlaß Regiomontans herausgab, lag zwar der Almagest zugrunde, es zeigt aber, daß sein Verfasser ein fleißiger Astronom war, der die Methoden seiner Vorgänger zu verbessern suchte. Auch beschrieb Alfragani die zu seiner Zeit gebrauchten astronomischen Instrumente. Er stellte seine Beobachtungen auf der von Al Mamûn errichteten Sternwarte an und wurde dabei häufig von dem Kalifen unterstützt.

Alfragani wurde weit übertroffen durch den etwa ein Jahrhundert später lebenden Al Battani (Albategnius haben ihn seine Übersetzer genannt). Al Battani war prinzlichen Geblütes und hat sich nicht nur um die Astronomie, sondern auch um die Einführung der trigonometrischen Funktionen große Verdienste erworben. Seine Beobachtungen, die er etwa von 880—910 anstellte, wurden von den Arabern als die genauesten gepriesen. Albattani hat viele Angaben des Ptolemäos nachgepriuft und verbessert. Das von ihm verfaßte Werk "Über die Bewegung der Sterne“ erschien in lateinischer Übersetzung und mit Zusätzen Regiomontans im Jahre 1537. Aus diesem Werke ist die Bezeichnung Sinus, für das Verhältnis der halben Sehne zum Radius, in die mathematische Literatur aller Völker übergegangen. Die mit

1) E. Wiedemann a. a. O. S. 69. 
der Anwendung der ganzen Sehnen verknüpfte rechnerische Unbequemlichkeit, welche der Almagest aufwies, kam damit in Fortfall. Die trigonometrischen Sätze nehmen ferner bei Albattani mehr den Charakter für die Rechnung bestimmter Formeln an. Aus $\frac{\sin \alpha}{\cos \alpha}=\mathrm{D}$ wird $\sin \alpha=\frac{\mathrm{D}}{\sqrt{1+\mathrm{D}^{2}}}$ berechnet und $\alpha$ dann in den Sinustafeln aufgefunden. Auch der Bruch $\frac{\cos \alpha}{\sin \alpha}$ wird einer Rechnung zugrunde gelegt. Bedeutet nämlich a die Höhe der Sonne über dem Horizont und ist $h$ die Höhe eines Schattenmessers, 1 die Länge des Schattens, dann ist $\frac{\mathrm{l}}{\mathrm{h}}=\frac{\cos \alpha}{\sin \alpha}=\operatorname{ctg} \alpha$; oder $\mathrm{l}=\mathrm{b} \operatorname{cotg} \alpha$.

Albattani berechnete danach die Länge von 1 bei einer bestimmten Höhe von $\mathrm{h}(=12)$ für $\alpha=1^{\circ}, 2^{\circ}, 3^{\circ}$

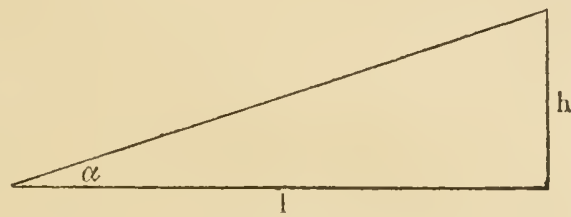

Abb. 51. Trigonometrische Berechnungen. usw. Er erhielt auf diese Weise eine kleine Tabelle für die Kotangenten der ganzen Winkel.

Die Trigonometrie erscheint als eines der Gebiete, das die Araber nicht nur wegen ihrer Beziehung zur Astronomie, sondern auch seiner selbst wegen mit Vorliebe angebaut haben. Auf die Tangensfunktion mußte schon Albattani kommen, als er denStab h horizontal in der W and A B befestigte und das Verhältnis der Schattenlänge $1 \mathrm{zu}$ der Länge des Stabes h zur Bestimmung des Winkels a benutzte. Daß sich die Tangensfunktion zur Berechnung von Dreiecken vorzüglich eignet, wurde bald nach Albattani erkannt1).

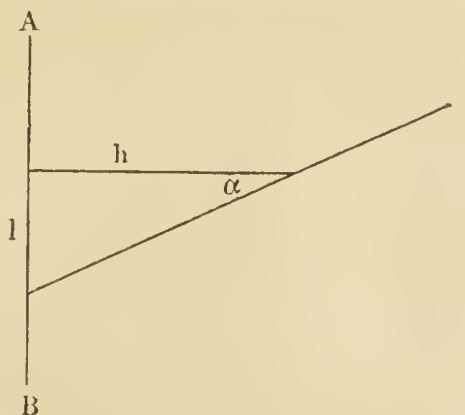

Abb. 52. Einführung der Tangensfunktion.

Thren Höhepunkt erreichte die Trigonometrie der Araber um 1250 in dem Werke "Über die Figur der Schneidenden“. Es wird darin das rechtwinklige und, ausgehend vom Sinussatz, das schiefwinklige Dreieck behandelt. Auch die Trigonometrie des schief-

1) Abul Wafa $(940-998)$. Siehe v. Braunmühl, Vorlesungen über Goschichte der Trigonometrie. S. 55. 
winkligen sphärischen Dreiecks wird in dem genannten Werke in den Grundzügen entwickelt. Der weitere Ausbau der Trigonometrie, vor allem die Formulierung des so wichtigen Cosinussatzes erfolgte erst einige hundert Jahre später, als im Abendlande die Wissenschaften wieder auflebten, durch Regiomontan.

Wir haben an früherer Stelle den hohen Grad von Kunstfertigkeit erwähnt, den die alexandrinischen Mechaniker bei der Herstellung astronomischer Meßinstrumente, insbesondere der Astrolabien, bewiesen. In dieser Kunst war die praktische Astronomie der Araber derjenigen der Griechen mindestens ebenbürtig, wenn nicht gar überlegen $\left.{ }^{1}\right)$. Neben den ringförmigen Astrolabien benutzten die Araber als Meßwerkzeuge auch Quadranten und Halbkreise, ferner parallaktische Lineale und Instrumente, welche die trigonometrischen Funktionen, wie den Sinus und den Sinus versus, anzeigten 2). Die Einführung dieser Funktionen in die Astronomie ist an den Namen Al Battanis (Albategnius) geknüpft, der in den Jahren 882--910 seine Beobachtungen anstellte und Tabellen entwarf $\left.{ }^{3}\right)$. Auf Grund der astronomischen Beobachtungen der arabischen Sternwarten in Damaskus und Bagdad wurde eine Revision der ptolemäischen Tafeln vorgenommen ${ }^{4}$ ).

Die Blüte der arabischen Wissenschaft war keine kurze, wie man hin und wieder behauptet hat, denn ein Jahrhundert später begegnen wir wieder einem hervorragenden Astronomen Ibn Junis (gestorben 1008), der in Kairo auf Befehl des Kalifen Al Hâkim wertvolle astronomische Tafeln über die Bewegung der Sonne, des Mondes und der Planeten anfertigte. Auch dort stand den Astronomen eine mit großer Freigebigkeit eingerichtete Sternwarte zu Gebote. Auf Grund der Sternverzeichnisse verstand man es, rortreffliche Himmelsgloben aus Silber oder Kupfer anzufertigen, von denen einige erhalten geblieben sind. Eine weitgehende Genauigkeit der Winkelmessung suchte man dadurch zu erreichen, daß man den mit der Gradeinteilung versehenen Instrumenten gewaltige Dimensionen gab. So soll ein in Bagdad aufgestellter Sextant, mit dem man im Jahre 992 die Schiefe der Ekliptik

1) Repsold, Zur Geschichte der astronomischen Meßwerkzeuge. Leipzig 1908. S. 11.

2) Sédillot, Mémoire sur les instrumens astronomiques des Arabes. Paris 1841.

3) C. Brockelmann, Geschichte der arabischen Literatur. 1898/1902. Bd. I. S. 222.

4 C. Brockelmann, Bd. I. S. 220. 
maß, einen Radius von 58 Fuß gehabt und einzelne Sekunden angezeigt haben. Auch das Verfahren, zum Messen der Kulmination bestimmte Instrumente fest im Meridian aufzustellen, indem man Mauerquadranten errichtete, treffen wir bei den Arabern. Sogar ein Instrument mit einem Horizontalkreis, über dem zwei Quadranten drehbar angebracht waren, findet man bei ihnen in Gebrauch. Dieses Instrument, dem später Tychos Azimutalquadrant im wesentlichen entsprach, ermöglichte es, von zwei Gestirnen gleichzeitig Azimut und Höhe zu bestimmen. Jene „drehenden Quadranten" der Araber und Tychos Instrument sind grundlegend für die Konstruktion des heutigen Theodoliten gewesen.

Die Astronomie, die immer mehr in Astrologie ausartete, die Mathematik und die auf geometrischer Grundlage beruhende Optik, ferner auch die Chemie in ihrem ersten, von mystischen Vorstellungen durchwebten Gewande, waren die Gebiete, denen sich die Araber mit Vorliebe zuwandten. Auf diesen haben sie, zumal was die, wenn auch nicht ihrem Ursprunge, so doch ilhrer ersten Entwicklung nach vorwiegend arabische Wissenschaft der Chemie betrifft, anerkennenswerte Leistungen aufzuweisen.

Eine Anregung zur Beschäftigung mit der Mathematik empfingen die Araber nicht nur durch die griechischen Schriften, die von einem vorzugsweise für die Geometrie veranlagten Volke herrührten, sondern in nicht geringerem Maße von den Indern, die sich durch ihre rechnerische Begabung anszeichneten. Von den letzteren erhielten sie, soweit die vorliegenden, noch mangelhaften Angaben zu schließen gestatten, vermutlich auch das auf dem Stellenwert beruhende Ziffernsystem, das wir noch heute als das arabische bezeichnen, weil die Araber es den abendländischen Völkern übermittelt haben. Auch die Algebra, soweit sie indischen Ursprungs ist, erfuhr durch die Araber eine wesentliche Fortbildung.

Von den griechischen Mathematikern ist Euklid für die Entwicklung der Mathematik bei den Arabern von großem Einfluß3 gewesen. Zur Weiterentwicklung der Arithmetik wurden sie besonders durch die Übernahme des indischen Ziffernsystems angeregt. Die indischen Zahlzeichen verbreiteten sich übrigens schon sehr früh von Alexandrien aus nach Rom ${ }^{1}$ ).

Bevor wir auf die Weiterentwicklung der Mathematik durch die Araber wäher eingehen, sei noch erwähnt, daß gegen den Aus-

1) C. Brockelmann, Gesch. d. arabischen Literatur. Bd. I (1898). S. 210. 
gang des Mittelalters das westliche Europa, wahrscheinlich gleichfalls durch Vermittlung dieses Volkes, in den Besitz der in Ostasien erfundenen Bussole und sehr wahrscheinlich auch des Schießpulvers gelangt ist. Eine Nachricht über die Bussole begegnet uns in einer chinesischen Schrift aus dem 2. Jahrhundert n. Chr. Dort wird der Magnet als ein Stein bezeichnet, mit dem man der Nadel Richtung gebe ${ }^{1}$. Ferner ist nachgewiesen, daß die Chinesen schon im 12. Jahrhundert n. Chr. mit der Erscheinung der magnetischen Deklination bekannt waren. Die betreffende Stelle der chinesischen Literatur lautet ${ }^{2}$ : „Wenn man die Spitze einer Nadel mit dem Magnetstein bestreicht, so zeigt sie nach Süden, jedoch nicht genau, sondern etwas nach Osten. Die Abweichung beträgt etwa $1 / 24$ des Kreisumfanges (also etwa 15\%)."

Daß die Bussole durch den Schiffer Flavio Gioja aus Amalfi erfunden oder in Europa bekannt geworden sei, hat sich als eine der vielen, in der Geschichte der Wissenschaften vorkommenden Legenden erwiesen. Es unterliegt keinem Zweifel, daß man mit dem Gebrauche der Magnetnadel in Europa lange vor dem im 14. Jahrhundert lebenden Gioja bekannt war. So erwähnt ein provenzalisches, im 12. Jahrhundert entstandenes Buch ${ }^{3}$ ), daß der Schiffer, wenn er weder Mond noch Sterne sehen könne, sich nach der Magnetnadel richte. Auch in einer um 1180 entstandenen Schrift ${ }^{4}$ ) heißt es, die Eisennadel erlange durch die Berührung mit

\section{1) Klaproth, Sur l'invention de la Boussole. 1834.}

Neuere Untersuchungen verlegen die chinesischen Angaben über den Kompaß bis ins 4. Jahrhundert v. Chr. zurück. Siehe E. Gerland, Der Kompaß bei den Arabern und im christlichen Mittelaiter. Die Chinesen benutzten den Kompaß zuerst bei Landreisen; auf Seereisen wurde er wohl nicht vor dem 3. Jahrhundert n. Chr. gebraucht.

2) Heller, Geschichte der Physik. Bd. I. S. 210.

3) La Bible von Guyot de Provins.

4) Von Alexander Neckam. Die betreffende Stelle lautet: „Nautae enim mare legentes, cum beneficium claritatis solis in tempore nubilo non sentiunt, aut etiam cum caligine nocturnarum tenebrarum mundus obvolvitur, et ignorant in quem mundi cardinem prova tendat, acum super magnetem ponunt, quae circulariter circumvolvitur usque dum ejus motu cessante cuspis ipsius septentrionalem plagam respiciat." Siehe Hellmann, Die Anfänge der magnetischen Beobachtungen. Zeitschrift der Gesellschaft für Erdkunde zu Berlin. Bd. 32. Berlin 1907. In der Übersetzung lantet die Stelle: „Wenn die Seeleute bei nebligem Wetter die Sonne nicht sehen oder bei Nacht nicht wissen, nach welcher Himmelsrichtung das Schiff sich bewegt, so bringen sie eine Nadel über einem Magneten an. Diese dreht sich so lange, bis ihre Spitze, nachdem die Nadel zur Ruhe gekommen ist, nach Norden zeigt." 
dem Magneten die Fähigkeit, nach Norden zu zeigen, was für den Schiffer wichtig sei. Gioja gebührt vielleicht das Verdienst, daß er die Nadel mit der Windrose verbunden und damit für den Gebrauch geeigneter gemacht hat 1 ). Ob die Bussole in Europa selbständig erfunden ist oder durch die Vermittlung der Araber von Ostasien nach dort gelangte, ließ sich bisher nicht mit Sicherheit nachweisen. Letztere Annahme ist aber bei dem regen Handelsverkehr, den die Länder des Islams mit Indien und China unterhielten, die wahrscheinlichere ${ }^{2}$ ).

Interessant ist auch, wie sich die Anbringung der Magnetnadel allmählich immer praktischer gestaltete. Zuerst ließ man die Nadel schwimmen. So heißt es an einer Stelle ${ }^{3}$ ) in dem 1232 verfaßten „Buche des Schatzes der Kaufleute in Kenntnis der Steine“: „Wenn die Nacht so dunkel ist, daß die Kapitäne keinen Stern wahrnehmen können, um sich zu orientieren, so füllen sie ein Gefäß mit Wasser und stellen dieses im Innern des Schiffes, gegen den Wind geschützt, auf; damn nehmen sie eine Nadel und stecken sie in einen Strohhalm, derart, daß beide ein Kreuz bilden. Dieses werfen sie auf das in dem erwähnten Gefäß befindliche Wasser und lassen es auf dessen Oberfläche schwimmen. Hierauf nehmen sie einen Magneten, nähern ihn der Wasseroberfläche und geben ihrer Hand eine Drehung. Dabei dreht sich die Nadel auf der Wasseroberfläche; dann ziehen sie ihre Hände plötzlich und rasch zurück, worauf die Nadel nach zwei Punkten, nämlich Nord und Süd, zeigt."

Die nächste Verbesserung bestand darin, daß man den Magneten auf einer Nadel schweben ließ. Die Verbindung des Magneten mit der Windrose, die man auf solche Weise beweglich machte, erfolgte wahrscheinlich im 14. Jahrhundert. Seine Vollendung erhielt der Kompaß, als ihn Cardanus (im 16. Jahrhundert) mit der nach ihm benannten Aufhängung versah 4).

1) A. Breusing, Flavio Gioja und der Schiftskompaß. In der Zeitschr. d. Gesellsch. f. Erdkunde zu Berlin. Bd. IV. 1869.

2) Siehe E. Wiedemann, Zur Geschichte des Kompasses bei den Arabern. Verhandl. d. Deutschen physik. Gesellschaft zu Berlin. 1907. Bd. 9. S. 764-773. Wiedemann gibt darin unter anderem eine Stelle ans dem Jabre 1232 an, aus der hervorgeht, da $B$ man dem Eisen durch Reiben mit dem Magnetstein die Eigenschaft gab, sich in die Nord-Südrichtung einzustellen.

3) Nach der Übersetzung von E. Wiedemann.

4) Von den Verbesserungen, welche der Kompaß in der neuesten Zeit erfuhr, wird an späterer Stelle die Rede sein. 
Wie mit der Bussole verhält es sich wahrscheinlich auch mit dem Schießpulver, das in China weit früher als in Europa bekannt war. Die älteste Nachricht, welche die europäische Literatur über das Pulver aufweist, enthält wohl das Manuskript des Marcus Graecus 1). Es gibt an, man solle Schwefel, Kolophonium oder Kohle und Salpeter zusammenreiben und mit dieser Mischung lange Röhren füllen. Zünde man die Mischung dann an, so flögen die Röhren in die Luft oder sie würden mit donnerähnlichem Knall zerplatzen.

Nach M.Graecus wurden 1 Teil Kolophonium, 1 Teil Schwefel, 6 Teile Salpeter gepulvert, mit Öl gebunden und dann in ein Rohr gefüllt. Nach einer anderen dort mitgeteilten Vorschrift wurden 1 Teil Schwefel, 2 Teile Linden- oder Weidenkohle und 6 Teile Salpeter gepulvert und zur Füllung einer Art Rakete benutzt, um "fliegendes Feuer" herzustellen 2). Derartige Raketen wurden auch gegen feindliche Schiffe geschlendert, um sie in Brand zu stecken ${ }^{3}$ ).

\section{Die Rechenkunst der Araber.}

Zur Beschäftigung mit der Mathematik gelangten die Araber dadurch, daß ihnen die Schriften der Griechen und der Inder bekannt wurden. Ptolemäos und Euklid, Apollonios, Heron und Diophant wurden in zahlreichen arabischen Übersetzungen verbreitet4). Welche Rolle hierbei christlich-griechische Schulen spielten, die unter dem Einfluß der Sekte der Nestorianer in Syrien entstanden waren, haben wir schon erwähnt. Im 8. Jahrhundert gelangte ein Auszug aus dem Werke des Inders Bramagupta nach Bagdad. Dieser Auszüg wurde um 820 durch Mohammed ibn Musa Alchwarizmi einer Umarbeitung unterzogen.

1) Das Manuskript befindet sich in Paris.

2) Marcus Graecus, Liber ignium. Berthelot, Chimie au moyen âge. Bd. I. S. 108.

3) Näheres darüber siehe bei Diels, Antike Technik. S. 97 u. f. Die obige nach Diels, der wieder Berthelot gefolgt ist, gegebene Darstellung wird von E. v. Lippmann bestritten. (Siehe dessen Abhandlungen und Vorträge Bd. I.) Nach v. Lippmann ist Marcus Graecus' Schrift erst um 1250 verfaßt. Siehe auch die neueste Schrift von $R$ uska über diesen Gegenstand. Näheres siehe im Anhang des vorliegenden Bandes und in v. Lippmanns, ,Alchemie“ S. 477 u. f.

4) So pflegte Ibn al Haitam (Alhazen) in jedem Jahre den Euklid und den Almagest abzuschreiben, um von dem Erlös zu leben. Siehe E. Wiedemann, Ibn al Haitam, ein arabischer Gelehrter. Leipzig 1906. S. 152. 
Ibn Musa (ben Musa), der bekannteste arabische Mathematiker, lebte unter Al Mamûn. Er war nicht nur an der Herausgabe indischer Werke, sondern auch an einer Neubearbeitung der ptolemäischen Tafeln, sowie an der erwähnten arabischen Gradmessung beteiligt ${ }^{1}$ ) Ferner schrieb Ibn Musa über die Rechenkunst und die Algebra. Ein Übersetzer des Buches über die Rechenkunst hat aus Alchwarizmi den Namen Algorithmus gemacht, der noch jetzt für jedes zur Regel gewordene Rechnungsverfahren benutzt wird.

Den Ziffern wird von Ibn Musa nach indischem Vorbild ein Stellenwert beigelegt. Übersteigt beim Addieren die Summe der Ziffern 9, so sollen die Zehner der folgenden Stelle zngerechnet und an der ursprünglichen Stelle nur das geschrieben werden, was unter 10 ïbrig ist. „Bleibt nichts iibrig“, fährt Ibn Musa fort, .,so setze den Kreis (die Null), damit die Stelle nicht leer sei. Der Kreis muß sie einnehmen, damit nicht durch das Leersein die Zahl der Stellen vermindert und die zweite für die erste gehalten wird" 2 ).

Ibn Musas Werk iiber die "Algebra“ ist das erste, das diese Bezeichnung trägt. Das Wort Algebra bedeutet soviel wie Ergänzung und bezieht sich auf die Auflösung der Gleichungen. Das Verfahren der Ergänzung (Algebr) besteht darin, daß man, um die negativen Glieder aus einer Gleichung zu entfernen, auf beiden Seiten die gleichen, positiven Werte hinzufügt.

Das Buch war weniger für den wissenschaftlichen als für den praktischen Gebrauch bestimmt. Dies geht auch aus folgenden Worten hervor, mit denen Ibn Musa sein Buch einleitet: „Die Liebe zu den Wissenschaften, durch die Gott den Al Mamûn, den Beherrscher der Gliiubigen, ausgezeichnet hat, und seine Freundlichkeit gegen die Gelehrten haben mich ermuntert, ein kurzes Werk über Rechnungen durch Ergänzung und Reduktion zu schreiben. Hierbei beschränke ich mich auf das Leichteste und das, was die Menschen am meisten bei Teilungen, Erbschaften, Handelsgeschäften, Ausmessung von Ländereien usw. gebrauchen."

Ibn Musa unterscheidet sechs Arten von Gleichungen, dic in heutiger Schreibweise folgendermaßen lauten würden:

1) Die Übersetzung wurde 1857 in der Bibliothek zu Cambridge entdeekt und bildet das I. Heft der von dem Fürsten Boueampagni herausgegebenen Trattati d'aritmetica.

2) Trattati d'aritmetica I. 8 . 


$$
\begin{gathered}
b x=c \\
a x^{2}=c \\
x^{2}+b x=c \\
x^{2}=b x+c \\
x^{2}+c=b x \\
a x^{2}=b x
\end{gathered}
$$

Für die Gleichung $\mathrm{x}^{2}+\mathrm{c}=\mathrm{bx}$ gibt er die Lösung:

$$
\mathrm{x}=\frac{\mathrm{b}}{2} \pm \sqrt{\left(\frac{\mathrm{b}}{2}\right)^{2}-\mathrm{c}} \text {. }
$$

Er erwähnt, daß die Aufgabe für den Fall, daß $c>\left(\frac{b}{2}\right)^{2}$ unmöglich sei. Auch die Regel de tri, und zwar nach indischen Mustern, ist in dem Werke behandelt, das nicht nur für die arabische, sondern auch für die Enwicklung der abendländischen Mathematik von großer Wichtigkeit gewesen ist.

\section{Die Ausbreitung der arabischen Wissenschaft.}

Nach der Eroberung Spaniens errichteten die Araber das Kalifat zu Cordova, das für den westlichen Teil ihres Reiches eine ähnliche Bedeutung erhielt, wie sie Bagdad für den Osten besaß. Handel und Gewerbe gelangten zu hoher Blüte. Prächtige Bauten entstanden. Neue Pflanzen, ror allem die Dattelpalme, wurden verbreitet. In Spanien war es, wo die Beriihrung der abendländischen Christenheit mit der Wissenschaft des Islams vorzugsweise stattfand. Von hier erfolgte die Wiederbelebung der gelehrten Studien in den christlichen Ländern, die im 9. und 10. Jahrhundert die griechischen Schriftsteller in arabischer Übersetzung und kommentiert von arabischen Gelehrten, wie Avicenṇa und Averroes, kennen lernten.

Avicenna (Ibn Sina lautet sein arabischer Name) lebte von 980-1037 in Persien. Als Philosoph schließt er sich an Alfarabi an, welcher die platonische und die aristotelische Philosophie zu übermitteln gesucht und der Astrologie diejenige Form gegeben hat, die sie durch das ganze Mittelalter behielt ${ }^{1}$ ). Avicenna befaßte sich besonders mit der Medizin. Was seine Zeit

1) Alfarabi verfaßte eine enzyklopädische Darstellung der Wissenschaften, die arabisch und in lateinischen Übersetzungen erhalten ist (De scientiis). Näheres enthält die Abhandlung von E. Wiedemann, Beiträge zur Geschichte der Naturwissenschaften. XI. Erlangen 1907. (Sitzungsberichte der physikalisch-medizinischen Sozietät in Erlangen. 39. Bd.) 
auf diesen Gebieten an Kenntnissenbesaß, vereinigte er in einem großen Werk, dem Kanon ").

Die Bedeutung des Averroes (Ibn Roschd, 1120-1198) besteht vor allem darin, daß er die Werke des Aristoteles dem arabischen und christlichen Mittelalter zugänglich machte. Seine Verehrung für diesen Philosophen war so groß, daß er behauptete, die Welt sei erst durch die Geburt des Arịstoteles vollständig geworden. Trotzdem kann man Averroes eine gewisse Selbstständigkeit bei seinem Philosophieren nicht absprechen ${ }^{2}$ ). Seine ganze Naturauffassung trägt einen, man könnte fast sagen, modernen Grundzug. Gott und die Materie sind danach ewig. Eine Schöpfung aus dem Nichts, die beliebte Vorstellung orientalischchristlicher Mystik, ist undenkbar. Das Geistige ist dasjenige, was die Materie bewegt und ihre Form bestimmt. Auch die menschliche Seele ist nichts anderes als die formbestimmende Kraft unseres Seins. Daß die Kirche solche Lehren als ketzerisch verwarf, läßt sich wohl denken. Es ist sogar wahrscheinlich, daß man die Naturanschauung des Averroes, weil sie mit den physikalischen Lehren des Aristoteles verknïpft wurde, durch das zeitweilige Verbot der physikalischen Schriften dieses Philosophen zu bekämpfen suchte.

Für die hohe Blüte der Wissenschaft unter der westarabischen Herrschaft spricht auch, daß in Cordova um das Jahr 900 eine hohe Schule mit einer Bibliothek von mehreren hunderttausend Bänden entstand. Ähnliches wurde in anderen, unter der naaurischen Herrschaft durch Handel und Wohlstand emporblühenden Plätzen, wie Granada, Toledo und Salamanka, geschaffen. Aus allen Teilen des übrigen Westeuropas zogen Wißbegierige an diese Stätten, denen man daheim nichts an die Seite zu stellen hatte. Nachdem die Araber in Siiditalien Fuß gefaßt hatten, wußte der hochsinnige Staufenkaiser Friedrich II. auch dort arabische Weisheit wohl zu schätzen. Auf seine Anregung wurde der Almagest nach einer arabischen Handschrift ins Lateinische übersetzt. Den Naturwissenschaften wandte diescr Kaiser, gleichfalls auf arabischen Quellen, jedoch auch auf eigenen Beobachtungen.fußend, ein großes Interesse zu. So entstand sein Werk über die Jagd mit Vögehn, in dem er an manchen Stellen den zoologischen Betrachtungen

1) Dieser erschien, ins Lateinische übersetzt, im Druck zuerst in Venedig im Jahre 1493.

2) E. Renan, Averroes et l'Averroisme. Paris 1852. 
eine anatomische Begründung zu geben wußte $\left.{ }^{1}\right)$. Das Buch enthält eine gute Beschreibung des Vogelskeletts, sowie eine Anatomie der Eingeweide. Es handelt ron den mechanischen Bedingungen des Fliegens, den Wanderungen der Vögel usw. Die Anleitung zur anatomischen Untersuchung des Vogels verdankte der Kaiser wohl den Gelehrten der medizinischen Schule zu Salerno.

Friedrich II. soll auch als erster Herrscher die Zerlegung menschlicher Leichen gestattet haben, weil er von der Überzeugung durchdrungen war, daß nur dadurch eine Förderung der Heilkunde zu erwarten sei.

\section{Optik und Mechanik bei den Arabern.}

Wie schon erwähnt, wurde neben der Mathematik und der Astronomie besonders die auf geometrischer Grundlage beruhende Optik von den Arabern gepflegt. Das auf diesem Gebiete teils gesammelte, teils erworbene Wissen ist uns am vollständigsten in dem Werke des im 11. Jahrhundert in Spanien lebenden Physikers Alhazen (Ibn al Haitam) übermittelt worden ${ }^{2}$ ). Dieses Werk stand in hohem Ansehen und verdient es, daß wir uns mit seinem Inhalt etwas eingehender beschäftigen, um uns einen Begriff von den damaligen Kenntnissen zu verschaffen. Zunächst handelt Alhazen von dem Organ des Sehens. Zwar hatten sich schon die Alexandriner mit dem Bau des Auges befaßt. Die Beschreibung, die uns Alhazen liefert, ist jedoch die erste, die den Namen einer anatomischen rerdient. Die noch heute gebräuchlichen Bezeichnungen für die Hauptteile des Auges, wie Humor vitreus (Glaskörper), Cornea (Hornhaut), Retina (Netzhaut) usw. gehen auf Alhazens Optik zurïck.

1) Reliqua librorum Friderici II. imperatoris de arte venandi cum avibus. Ed. J. G. Schneider. T. I. II. Lipsiae 1788/89. Siehe auch Carus, Geschichte der Zoologie. Nünchen 1872. S. 206, und Burkhardt, Geschichte der Zoologie. Leipzig 1907. S. 45.

2) Opticae thesaurus Alhazeni Arabis libri VII, nunc primum editi a Frederico Risnero. Basileae 1572. Vergleiche auch Schnaase, Die Optik Alhazens. Programm des Friedrichs-Gymnasiums zu Stargard. 1889. Alhazens vollständiger Name lautet Abû Alî Muhammed ben el Hasan ibn el Haitam el Basri. Eine arabische, mit Abbildungen versehene Handschrift seines Werkes wird in Leyden aufbewahrt. Risners Übersetzung ist eine gekürzte, indes getreue Wiedergabe des Originals.

Über eine spätere arabische Bearbeitung von Alhazens Optik hat E. Wiedemann ausführlich berichtet. Siehe das Archiv f. d. Geschichte d. Naturwiss. u. d. Technik. 1912. S. 1-53. 
Das Verhältnis von Linse und Netzhaut in seiner Bedeutung für das Zustandekommen des Bildes zu erkennen, blieb allerdings späteren Untersuchungen vorbehalten. Wie aus der beistehenden, der Ausgabe Risners entnommenen Abbildung ersichtlich ist, verlegte Alhazen die Linse in die Mitte des Auges. Dorthin sollten alle, die vordere Wölbung des Auges senkrecht treffenden Strahlen gelangen. Nur diese Strahlen vermitteln nach seiner Annahme das deutliche Sehen und werden von der Linse empfunden $\left.{ }^{1}\right)$. Die Gesamtheit dieser Strahlen bildet die Sehpyramide. Ihre Spitze liegt also im Mittelpunkte des Auges, während ihre Grundfläche die Oberfläche"des gesehenen Gegenstandes ist.

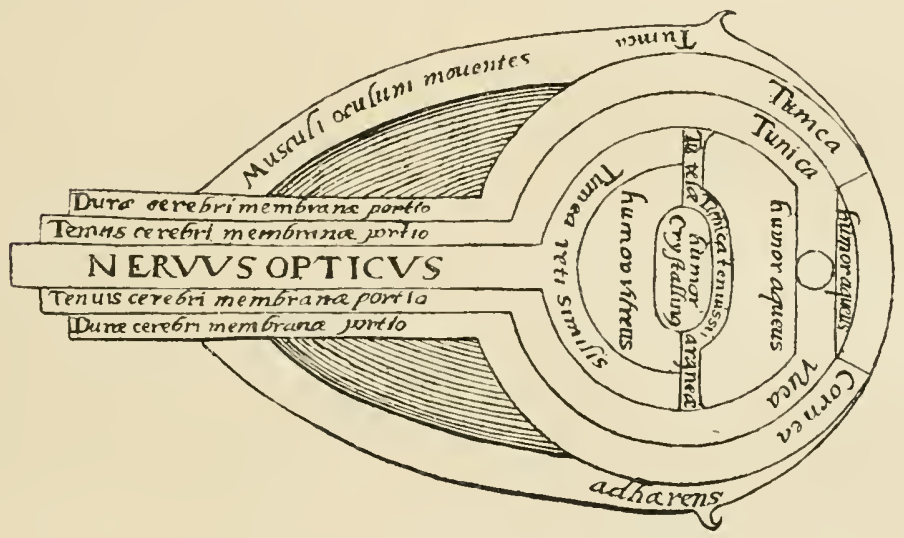

Abb. 53. Alhazens Darstellung des Auges.

Im 2. Buche werden die 22 Eigenschaften untersucht, welche das Auge an den Körpern unterscheide, nämlich Licht, Farbe, Entfernung, Gestalt, Größe, Zahl, Bewegung, Ruhe, Durchsichtigkeit usw.

Das Licht braucht nach Alhazens Annahme zu seiner Fortpflanzung Zeit. Auch den optischen Täuschungen widmet er eine Betrachtung ${ }^{2}$ ).

In der Behandlung der Reflexion und der Brechung, denen das Werk der Hauptsache nach gewidmet ist, zeigt sich ein Fort-

1) Diese Ansicht begründet er fälschlich damit, daß die Zerstörung der Linse cine Vernichtung der Sehkraft zur Folge habe, während die Verletzungen anderer Teile des Auges seiner Meinung nach eine solche Wirkung nicht hervorbringen.

2) Im 3. Buche seiner Optik. 
schritt den Griechen gegenüber 1 \%. Nicht nur ebene, sondern auch sphärische, zylindrische und konische Konkav- und Konvexspiegel werden zur Erzeugung von Bildern herangezogen und Lage und Größe der letzteren bestimmt. Für sämtliche untersuchten Spiegel fand Alhazen das Reflexionsgesetz bestätigt. Er kennt die Lage des Brennpunktes, den Euklid noch in den Krümmungsmittelpunkt verlegt hatte. Auch mit der Tatsache, daß nicht alle Strahlen in einem und demselben Punkte vereinigt werden, zeigt sich Alhazen vertraut. Seine Messungen an der Brennkugel führten zu dem Ergebnis, daß bei jeder glatten, durchsichtigen Kugel aus Glas oder einer ähnlichen Masse die Strahlen in einer Entfernung von der Kugel vereinigt werden, die etwa ein Viertel des Durchmessers beträgt. Selbst die Eigenschaft des Rotationsparaboloids, die vom Brennpunkte ausgehenden Strahlen parallel zu reflektieren, wird erörtert. In Alhazens Optik ${ }^{2}$ ) wird ferner auf die Erscheinung hingewiesen, daß ein aus durchsichtigem Material verfertigtes Kugelsegment die Gegenstände größer erscheinen läßt.

Hatte Ptolemäos gefunden, daß jedem Einfallswinkel ein bestimmter Brechungswinkel entspricht, so fügte Alhazen die Erkenntnis hinzu, daß der einfallende und der gebrochene Strahl mit dem Einfallslot in einer Ebene liegen. Die ältere Annahme, daß

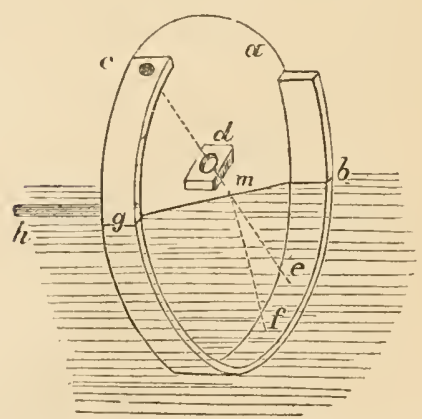

Abb. 54. Alhazen untersucht die Brechung. das Verhältnis zwischen dem Einfallsund dem Brechungswinkel ein konstantes sei, erkennt Alhazen nur für kleine Werte als richtig an. Bei seinen Untersuchungen über die Brechung des Lichtes bediente er sich eines Apparates, der dem von Ptolemäos (siehe S. 265்) benutzten entspricht. Er nahm eine kreisförmige Scheibe aus Kupfer, die einen Rand mit Gradeinteilung besaß (siehe Abb. 54). In dem Rande befand sich eine Öffnung c. Eine zweite Öffnung (d) war in einer nahe der Mitte der Scheibe gelegenen Platte angebracht. Dieser Apparat wurde bis zum Mittelpunkt in die Flüssigkeit getaucht. Fiel dann ein Lichtstrahl durch die beiden Öffnungen $\mathrm{c}$ und $d$, so traf er die Flüssigkeit im Mittelpunkt der

1) Siehe auch Schnaases ,Alhazen" in den Schriften der Danziger Gesellschaft. N. Folge. Bd. VII. S. 140.

2). Optic. Thes. VII. 48. 
Scheibe, auf deren Rand der Einfallswinkel und der Brechungswinkel abgelesen werden konnten.

Aus der Spiegelung und der Brechung erklärt Allazen einige wichtige astronomische Erscheinungen. So wird die Dämmerung auf die Reflexion des Lichtes zurückgeführt. Die Tatsache, daß die Dämmerung nur so lange dauert, bis die Sonne sich $19^{\circ}$ unter dem Horizont befindet, gibt Alhazen ein Mittel an die Hand, die Höhe unserer Atmosphäre zu bestimmen ${ }^{1}$ ). Es sei M, so führt er aus, die äußerste Luftschicht, welche den Strahl SM noch zu reflektieren vermag, und A der Ort des Beobachters. Der Winkel HMS, den der Sonnenstrahl S M mit dem Horizont bildet, beträgt dann $19^{\circ}$. Nach dem Reflexionsgesetz ist nun $女 \mathrm{BMC}$ $=\varnothing \mathrm{AMC}$. Da ferner die Summe der drei

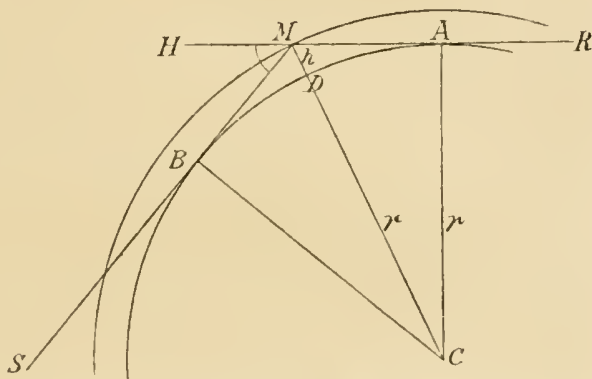

Abb. 55. Alhazen bestimmt die Höhe der Atmosphäre.

Winkel bei $\mathrm{M}=180^{\circ}$ ist, só ergibt sich für den Winkel AMC der Wert $\frac{180^{\circ}-19^{\circ}}{2}=80^{\circ} 30^{\prime}$. Da die Seite $\mathrm{AC}=\mathrm{r}$ bekannt ist, so ist das rechtwinklige Dreieck A CM bestimmt. Die gesuchte Höhe ergibt sich, wenn man aus den gegebenen Stücken die Hypotenuse $\mathrm{MC}$ berechnet $\left(\mathrm{MC}=\mathrm{r}: \sin 80^{\circ} 30^{\prime}\right)$ und davon $\mathrm{r}$ abzieht. $\mathrm{MD}=\mathrm{h}$ ist also $=\left(\mathrm{r}: \sin 80^{\circ} 30^{\prime}\right)-\mathrm{r}$. Diese Größe beträgt nach der Berechnung Alhazens 52000 Schritt (5-6 Meilen), während wir dafür 10 Meilen annehmen 2).

Gegen diese Berechnung läßt sich ein Einwand erheben, den Alhazen selbst schon hätte machen können. Er wußte nämlich, daß ein Lichtstrahl, der schräg in die Atmosphäre einfällt, keine gerade Linie beschreibt, sondern, da er auf immer dichtere, das Licht in wachsendem Maße brechende Schichten trifft, einen krummen Weg nimmt. Diese, mit dem Namen der astronomischen Refraktion bezeichnete Erscheinung war schon dem Ptolemäos bekannt. Man führte sie im Altertum jedoch nicht auf die zu-

1) In einem Anhange zum Optic. Thesaur.

2) Alhazen nalim den Erdumfang gleich 4800 (statt 5400) Meilen an. 
nehmende Dichte der Atmosphäre, sondern auf die in ihr enthaltenen Dünste zurück. Das Funkeln der Sterne rührt nach Alhazen von raschen Änderungen in der Atmosphäre her, während die Erscheinung, daß Mond und Sonne in der Nähe des Horizontes abgeplattet erscheinen, aus der astronomischen Refraktion erklärt wird.

Außer der "Optik" gibt es auch eine kleinere Abhandlung Alhazens, in der er von der Durchsichtigkeit und über die Natur des Lichtes handelt. Sie beginnt mit folgenden Worten ${ }^{1}$ ): „Die Behandlung des, Was' des Lichtes gehört zu den Naturwissenschaften. Aber die Behandlung des, Wie', der Strahlung des Lichtes, bedarf der mathematischen Wissenschaften wegen der Linien, auf denen sich das Licht ausbreitet. Ebenso verhält es sich mit den durchsichtigen Körpern, in die das Licht eindringt. Die Behandlung des, Was' ihrer Durchsichtigkeit gehört zu den Naturwissenschaften und die Behandlung des, Wie', der Ausbreitung des Lichtes in ihnen, zu den mathematischen Wissenschaften." Von Interesse sind auch die in dieser Schrift entwickelten Ansichten über den Grad der Durchsichtigkeit, für die es nach Allazen keine Grenzen gibt.

Durch Alhazen wurde man besonders auf die vergrößernde Kraft gläserner Kugelsegmente aufmerksam ${ }^{2}$. Es ist sehr wohl möglich, daß sein Hinweis auf die Herstellung von Brillen geführt hat. Wenn sich Alhazen auch auf die antiken Optiker stiitzt, so ragt er über Ptolemäos als den letzten und bedeutendsten, den wir erwähnt haben, doch hinaus. Während die frühere $\mathrm{Ge}$ schichtsschreibung Alhazen nur gering einschätzte ${ }^{3}$ ), ist sein Verdienst und die Selbständigkeit, die er in vielen Teilen seiner Schriften zeigt, durch die neuere Forschung gewürdigt worden ${ }^{4}$.

Neben der Optik wurde auch die Mechanik von den Arabern gepflegt. So begegnen uns bei ihnen genauere Bestimmungen der spezifischen Gewichte. Eine aus dem 12. Jahrhundert herrührende Tabelle ${ }^{5}$ ) enthält folgende Werte:

1) Zeitschr. d. morgenl. Gesellsch. 1882. Baarmann, „Über das Licht" von Ibn al Haitam.

2) Optic. Thesaur. VII. 48. Siehe auch Schnaase, "Alhazen", in den Schriften der Danziger Natf. Gesellschaft. N. Folge. Bd. VII. S. 140.

3) Montucla z. B.

4) Besonders durch Schnaase und E. Wiedemann.

5) Die Tabelle findet sich bei Al Khazini her, der im Jahre 1137 ein die ,Wage der Weisheit" betiteltes Buch verfaßte. Siehe Wiedemanns Annalen. Bd. 20. S. 539. 


\begin{tabular}{|c|c|c|c|c|c|c|}
\hline Gold & 19,05 & (statt & 19,26 & nach & neuerer & Bestimmung) \\
\hline Quecksilber & 13,56 & 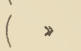 & 13,59 & » & » & , \\
\hline Kupfer & 8,66 & » & 8,85 & ע & > & , \\
\hline Blei & 11,32 & * & 11,35 & , & » & , \\
\hline Seewasser & 1,041 & » & 1,027 & » & , & , \\
\hline Blut & 1,033 & » & 1,045 & » & » & » \\
\hline
\end{tabular}

Die Bestimmungen erfolgten vermittelst der Wage oder eines Gefäßes, das die von einer gewogenen Menge des zu untersuchenden Körpers verdrängte Menge Wassers zu finden gestattet. Für Flüssigkeiten bediente man sich des Aräometers, das schon die späteren Alexandriner zu diesem Zwecke benutzten ${ }^{1}$.

Die Wägungen waren schon recht genau. Bei einem Gesamtgewicht von mehr als zwei Kilogramm wurden noch $0,06 \mathrm{~g}$ angezeigt ${ }^{2}$ ).

Diese Leistungen der Araber verdienen um so mehr Bewunderung, wenn man bedenkt, daß zur selben Zeit das christliche Abendland meist noch von scholastischen Zänkereien erfüllt war. So befindet sich z. B. in dem Hauptwerk des Thomas von Aquino ${ }^{3}$ ) unter mehreren hundert Kapiteln nur ein einziges, das von den „natürlichen Wirkungen der Dinge" handelt, während sich eine ganze Anzahl mit der Nahrung, der Verdauung und dem Schlaf der Engel beschäftigen. Derselbe Thomas von Aquino, den die Scholastiker als ihren großen Meister verehrten, erklärte das Streben nach Erkenntnis der Dinge für Sünde, soweit es nicht auf die Erkenntnis Gottes abziele ${ }^{4}$ ).

\section{Die Chemie im arabischen Zeitalter.}

Große Verdienste haben sich die Araber auch um die Entwicklung der Chemie erworben. Zwar wurde man schon lange vor ihnen durch liüttenmännisches und gewerbliches Schaffen mit einer Reihe stofflicher Veränderungen vertraut. Auch empfingen zweifelsohne die Araber die erste Anregung zu ihrer Beschäftigung mit der Chemie in Syrien, Mesopotamien und Ägypten, wo man

1) Näheres siehe Gerland und Traumüller, Geschichte ler physikalischen Experimentierkunst. Leipzig, Wilh. Engelmanu. 1899. S. 71 u. f.

2) W. Wiedemann, Über das Experiment im Altertum und Mittelalter (Vortrag).

3) Starb 1274.

4) Summa theologiae. Venet. 1593. 'T. XI. p. 407. 
zahlreiche Erfahrungen gesammelt hatte. Bei den späteren Alexandrinern und den Arabern finden wir indes die Beschäftigung mit den stofflichen Veränderungen losgelöst von den alltäglichen Nützlichkeitszwecken und in den Dienst eines Strebens gestellt, das einen Ansporn verlieh, wie es kein rein wissenschaftliches Interesse in höherem Grade vermocht hätte.

Zahlreiche, aus dem Orient stammende, chemische Kenntnisse gelangten durch die Araber nach Spanien. Von hier aus wurden sie dem christlichen Abendlande übermittelt, wo sie einen besonders gïnstigen Boden fanden. Seit dem 13. Jahrbundert stand infolgedessen die alchemistische Kunst in Frankreich, in Deutschland und in England in Blüte. Eine nicht geringe Zahl von Kenntnissen, die sich auf das Verhalten und die Verarbeitung der Metalle beziehen, war zweifelsohne im Abendlande selbst aus dem Altertum ins Mittelalter hinüber gerettet worden. Man darf daher die Rolle, welche die Araber gespielt haben, auch nicht zu hoch einschätzen. So existiert noch heute ein Manuskript aus der Zeit Karls des Großen 1), das den Titel "Compositiones ad tingenda“ führt und Vorschriften über das Färben von Mosaiken und Häuten, über das Vergolden, das Löten usw. enthält. Unter den Manuskripten des 10. Jahrhunderts ist man ferner mit einem größeren Werke über Färberei (Mappae clavicula) bekannt geworden, das nach Berthelot keine Spur von arabischer Beeinflussung zeigt. Die Vorschriften, welche diese abendländischen Schriften des Mittelalters enthalten, sind vielmehr oft wörtlich den griechischen Alchemisten entnommen. Die Mappae clavicula enthält nämlich Vorschriften, die mit solchen der kürzlich bekannt gewordenen antiken chemischen Urkunden (des Leydener und des Stockholmer Papyrus, s. S. 279) wörtlich übereinstimmen. Die frühere Meinung, daß man es in der Alchemie ausschließlich mit einer Schöpfung der Araber $\mathrm{zu}$ tun habe, hat sich somit als unhaltbar erwiesen. Trotzdem ist das Verdienst der Araber auf dem Gebiete der Alchemie nicht gering einzuschätzen. Sie haben diese $\mathrm{W}$ issenschaft, wie sie ibnen aus dem Altertum überkommen war, nicht nur erhalten und verbreitet, sie haben sie auch fortgeführt und wesentlich bereichert.

Bereits im 8. und 9. Jahrhundert erlangte die arabische Literatur über Alchemie einen bedeutenden Umfang. Etwas später laben die schon erwähnten arabischen Gelehrten (s. S. 312) Alfarabi und Avicenna neben vielem anderen auch über Alchemie

1) In der Bibliothek zu Lucca. Siehe Berthelot a. a. O. S. 28. 
geschrieben. A vicenna, den spätere Alchemisten als einen ihrer Gewährsmänner ausgaben, erklärte, Gold und Silber entständen unter dem Einfluß des Mondes und der Sonne aus den Dünsten der Erde mit allen ihren besonderen Eigenschaften, die kein Mensch künstlich nachzuahmen vermöge. Auch den astrologischen Lehren gegenüber hat sich Avicenna skeptisch verhalten ${ }^{1}$ ).

Über die chemischen Einzelkenntnisse der Araber erfahren wir manches aus dem um 975 von Abu Mansur verfaßten „Buch der pharmakologischen Grundsätze“2). A bu Mansur erwähnt z. B. die Anwendung des Gipsverbandes bei Knochenbrüchen, ein Verfahren, das die neuere Medizin erst im 19. Jahrhundert wieder aufnahm. Trinkbares Wasser, heißt es an einer anderen Stelle des Buches, läßt sich durch Destillation von Meerwasser in ähnlicher Weise bereiten, wie man Rosenwasser destilliert.

Hatte man die Schwefelverbindungen des Arsens (Realgar und Auripigment) schon im Altertum nnterschieden, so bringt uns das Buch A bu Mansurs eine der ersten Nachrichten iiber den weißen Arsenik. Die Arsenikverbindungen werden als fliichtig und giftig, aber als heilkräftig bezeichnet. Das Gleiche wird beim Quecksilber hervorgehoben, das in Form von Salbe gegen Ungeziefer empfohlen wird. Die mineralischen Säuren finden dagegen bei Abu Mansur noch keine Erwähnung. Es ist daher wohl anzunehmen, daß sie zu seiner Zeit noch nicht dargestellt waren. Die Salpetersäure und das Königswasser begegnen uns in der Literatur des Mittelalters zuerst im 13. Jahrhundert ${ }^{3}$ ). Diese chemischen Agentien können auch nicht viel früher bekannt geworden sein, weil der Salpeter dem Altertum unbekannt war und erst um 1200 durch die Araber als "Salz von China" nach Europa gelangte. In China selbst ist dieses Salz zu explosiven Mischungen wahrscheinlich nicht schon vor Beginn unserer Zeitrechnung, sondern erst viel später angewendet worden 4 ).

Durch die Araber wurde auch der Anban des Zuckerrohrs von Indien nach den westlichen Kulturländern verbreitet. Das

1) E. v. Lippmann, Alchemie. S. 405.

2) Eine Übersetzung ersehien in den .,Historischen Studien“, Jahrg. 1893.

Einen Auszug brachte E. v. Lippmann unter der Überschrift „Chemie vor tausend Jahren" in der Zeitschrift f". angewandte Chemie. 1901. H. 26; siehe auch dessen Abhandlungen und Vorträge.

3) Näheres siehe bei E. v. Lippmann, Abhandlungen und Vorträge zur Geschichte der Naturwissenschaften. Leipzig 1906. S. 139.

4) F. v. Isippmann a. a. O. S. 132 .

Da nnemann, Die Naturwissensehaften. I. Bul. 2. Aufl. 
Zuckerrohr hatte man durch den Zug Alexanders des Großen kennen gelernt. Die Bereitung des festen Zuckers wurde erst mehrere hundert Jahre n. Chr. erfunden ${ }^{1}$ ). Seit etwa $750 \mathrm{n}$. Cbr. wurde das Zuckerrohr in Ägypten angebaut. Bald nach der Entdeckung Amerikas wurde es nach St. Domingo verpflanzt. So sehen wir, wie die Ausbreitung einer Pflanze, die uns eine der wichtigsten organischen Verbindungen liefert, aufs engste mit dem Gange der geschichtlichen Ereignisse verknüpft ist.

Technisch und wissenschaftlich von großer Wichtigkeit, aber auch von unheilvollen Folgen war die früher den arabischen Chemikern und Ärzten zugeschriebene Entdeckung, daß sich durch Destillation aus dem Wein der berauschende Stoff dieses Getränkes absondern läßt. Später nannte man ihn Al-kohol und nahm ihn zum größten Unsegen für die Menschheit unter die Arzneimittel auf $\left.{ }^{2}\right)$. Insbesondere wurde der Alkohol als Vorbeugungsmittel gegen die großen Seuchen (Pest, schwarzer Tod) betrachtet, die im Mittelalter Europa heimsuchten.

Als der bedeutendste arabische Schriftsteller des alchemistischen Zeitalters hat lange Zeit Geber gegolten, der während der ersten Hälfte des 8. Jahrbunderts gelebt haben soll. Er wurde als der Verfasser einer Anzahl Schriften genannt, die in lateinischer Übersetzung auf uns gekommen seien ${ }^{3}$ ). Diese Schriften, insbesondere das "Summa perfectionis magisterii“ betitelte Hauptwerk, sind in der Form, in der sie sich erhalten haben, im christlichen Europa etwa seit dem 13. Jahrhundert bekannt. Nach den Untersuchungen ${ }^{4}$ Berthelots und Steinschneiders sind Gebers Person und seine Bedeutung in geschichtlicher Hinsicht sehr in Dunkel gehüllt. Diejenigen arabischen Originalschriften, als deren Verfasser er allenfalls angeselien werden kann, enthalten nämlich wenig von dem Inhalt der später unter seinem Namen gehenden lateinischen Übersetzungen. Eine Probe aus einer dieser Schriften hat Berthelot mitgeteilt $\left.{ }^{5}\right)$. Danach handelt es sich meist

1) Nach E. v. Lippmann (a. a. O. S. 263) in der Zeit zwischen 300 und 600 n. Chr. Geb.

2) Über die Ergebnisse der neuesten Untersuchungen, die v. Lippmann hierüber angestellt hat, siehe den Anhang dieses Bandes.

3) Deutsche Ausgaben erschienen 1710 in Erfurt und 1751 in Wien. Eine Aufzählung der Schriften Gebers siehe bei Wüstenfeld, Geschichte der arabischen Ärzte und Naturforscher. 1840. S. 12 u. 13.

4) Siehe auch E. v. Lippmann in der Zeitschrift f, angewandte Chemie. 1901. H. 26.

5) Berthelot a. a. O. S. 61. 
um marktschreierische Anpreisungen und unklare Darstellungen. Geber empfiehlt in seinen Schriften, seine Mitteilungen geheim zu halten. Er beruft sich oft auf seinen religiösen Standpunkt als Muselmann, um dem etwaigen Verdacht, daß er übertreibe oder schwindele, zu begegnen. Die Metalle vergleicht Geber mit lebenden Wesen, wie es schon die alexandrinischen Alchemisten taten. Auch begegnet uns bei ihm die Lehre, daß jedes Ding neben seinen äußeren, erkemnbaren noch geheime (okkulte) Eigenschaften habe. So sagt er „Das Blei ist im Äußeren kalt und trocken und im Innern warm und feucht, während das Gold warm und feucht ist im Äußern, dagegen kalt und trocken im Innern". Dem entspricht die Anschauung, die uns bei Rhases begegnet, nach der das Kupfer in seinen verborgenen Eigenschaften Silber sei. Wem es gelänge, die rote Farbe aus dem Kupfer auszuscheiden, der führe es in das Silber, das es seiner verborgenen Natur nach sei, zurück. Eine kurze Darstellung des Inhalts der Pseudo-Geberschen Schriften ${ }^{1)}$ wird am besten über das Ziel und den Umfang der chemischen Kenntnisse des späteren Mittelalters belehren, wenn sich auch, in Anbetracht der großen Unvollständigkeit, in der die Literatur des Mittelalters durchforscht ist, nicht sicher feststellen läßt, wieviel die Verfasser jener Schriften selbständig gefunden und was sie früheren Schriftstellern entlehnt haben.

Die wichtigste Tatsache, die uns in den Pseudo-Geberschen Werken begegnet, ist die, daß man mit der Salpetersäure, der Schwefelsäure und dem Königswasser bekannt ist, während sich das Altertum nur im Besitz der Essigsäure befand. Die erstgenannten Säuren erhielt man durch Erhitzen von Salzen und Salzgemischen, eine Darstellungsart, die fïr die Schwefelsäure bis zur Erfindung des englischen Verfahrens die einzige blieb. Salpeter-

1) Die wichtigsten sind dic „Summa perfectionis magisterii“, die Schrift "de inventione veritatis" und die "Alchimia Geberi“. In der letzteren wird die Zubereitung der Salpetersäure und des Königswassers beschrieben. Nach Berthelot ist es unrichtig, wenn man annimmt, die genauere Kenntnis unserer Mineralsäuren und ihrer Salze sei auf die arabischen Autoren des 12. und 13. Jahrhunderts zurückzuführen. Vielmehr wurden die „komplizierten und umständlichen Darstellungsmethoden von damals erst im lateinischen Abendland im Laufe des 14. und 15. Jahrhunderts entwirrt".

Die Ergebnisse der Forschungen Berthelots erscheinen in neuester Zeit durch die von E. v. Lippmann in seiner "Alchemic" ïber Geber veröffentlichten Untersuchungen in mancher Hinsicht anfechtbar. Siehe den Anhang des vorliegenden Bandes. 
säure erhielt man durch Erhitzen eines Gemenges von Salpeter und Vitriol. Ein Zusatz von Salmiak zur Salpetersäure lieferte das Königswasser, dessen Eigenschaft, das Gold, den König der Metalle, aufzulösen, den Alchemisten nicht entging. Die Herstellung einer solchen Lösung hatte man lange angestrebt, weil man sich ron ihr die Heilung aller Krankheiten versprach.

Auf Grund der Kenntnis der Mineralsäuren konnte sich nun eine Chemie entwickeln, die auf nassem Wege verfuhr, während man bis dahin vorzugsweise eine Chemie der Schmelzprozesse betrieben hatte. So gelangte man durch Auflösen von Silber und anderen Metallen in Salpetersäure zum Höllenstein und vielen Salzen, welche den Alten, wie z. B. die Salze des Quecksilbers, nicht bekannt waren. Es bedarf kaum der Erwähnung, daß die erhaltenen Verbindungen zunächst sehr unrein waren. Doch kannte man auch schon die wichtigsten Verrichtungen, die auf eine Reindarstellung der gewonnenen Präparate abzielten. Es waren dies außer der Destillation, die man schon bei den Alexandrinern erwähnt findet, vor allem das Umkristallisieren, die Sublimation und das Filtrieren. Auch Wasserbäder und Öfen zu chemischem Gebrauch finden sich in den Pseudo-Geberschen Werken beschrieben $\left.{ }^{1}\right)$.

Mit dem chemischen Verhalten der Metalle waren die Verfasser jener Werke weit besser als das Altertum bekannt; sie stellten z. B. aus den Metallen eine Reihe von Sauerstoffverbindungen her. So finden wir bei ihnen die erste Nachricht über die Gewinnung des Quecksilberoxyds), einer Substanz, die in der späteren Entwicklung der Chemie die größte Rolle gespielt hat. Nicht nur mit Sauerstoff, sondern auch mit Schwefel wußte man die Metalle zu verbinden. Die entstandenen Sulfide fand man schwerer als das zur Verwendung kommende Metall, während man unrichtigerweise annahm, daß mit der Oxydation eine Verminderung des Stoffes verbunden sei.

Auch in der Kenntnis der Verbindungen der Leichtmetalle war man in dieser Periode einen Schritt weiter gekommen. Pottasche wurde durch Verbrennen von Weinstein, Soda nach dem bis zur Einführung des Leblancprozesses üblichen Verfahren (Einäschern von Seepflanzen) dargestellt. Durch einen Zusatz von Kalk

1) Siehe auch die Abhandlung von E. Wiedemann, Über chemische Apparate bei den Arabern; erschienen in Diergart, Beiträge aus der Geschichte der Chemie.

2) H. Kopp, Geschichte der Chemie. Bd. I. S. 53. 
machte man die Lösungen dieser beiden Salze ätzend und erhielt so Kalilauge und Natronlauge ${ }^{1}$ ). Letztere dienten zur Auflösung von Schwefel, der aus der alkalischen Lösung durch Säuren in feinster Verteilung als Schwefelmilch wieder ausgefällt wurde ${ }^{2}$.

Die chemischen Einzelkenntnisse suchte man auch unter den Gesichtspunkt einer Theorie (sie ist durch E.v. Lippmann in seiner "Alchemie" als alexandrinisch nachgewiesen) zu bringen, die bei dem damals noch herrschenden Mangel an Einsicht in den chemischen Prozeß die Wahrheit allerdings noch gänzlich verfehlte. Die Metalle hielt man für Gemenge von Quecksilber und Schwefel ${ }^{3}$ ). I)er Schwefel (Sulphur) war in den Metallen, wie in den brennbaren Substanzen überhaupt, der Träger der Brennbarkeit. Er sollte den Metallen auch die Farbe verleihen. Mercurius (Quecksilber) dagegen galt als derjenige Grundbestandteil, der die Schmelzbarkeit, den Glanz und die Dehnbarkeit bedingte. Unter dem Sulphur und dem Mercurius der Alchemisten muß man sich indessen nicht den gemeinen Schwefel und das gewöhnliche Quecksilber vorstellen. Diese Elemente bestanden nur vorwiegend aus Sulphur, beziehungsweise Mercurius, waren aber nicht damit identisch. Der gemeine Schwefel und der Sulphur der Alchemisten verhielten sich vielmehr zueinander etwa wie die Steinkohle und das Element Kohlenstoff. In den edlen Metallen sollte Mercurius überwiegen. Durch Abänderung des Verhältnisses dieser vermeintlichen Bestandteile konnten die Metalle ineinander übergeführt werden. So nahm das Kupfer eine Stelle zwischen Gold und Silber ein. Es mußte sich daher leicht in das eine oder in das andere umwandeln lassen. Durch Erhitzen mit Galmeit) wurde es dem Golde, durch Zusammenschmelzen mit Arsenik dem Silber angenähert. Die auf solche Weise herbeigeführte Änderung der roten Farbe in Gelb und Weiß hielt man für den Beginn des Überganges in ein anderes

1) $\mathrm{Na}_{2} \mathrm{CO}_{3}+\mathrm{Ca}^{\prime} \mathrm{OH}_{2}=2 \mathrm{NaOH}+\mathrm{CaCO}_{3}$.

2) $6 \mathrm{KOH}+12 \mathrm{~S}=\mathrm{K}_{2} \mathrm{~S}_{2} \mathrm{O}_{3}+2 \mathrm{~K}_{2} \mathrm{~S}_{5}+3 \mathrm{H}_{2} \mathrm{O}$

$\mathrm{K}_{2} \mathrm{~S}_{2} \mathrm{O}_{3}+2 \mathrm{HCl}=2 \mathrm{KCl}+\mathrm{SO}_{2}+\mathrm{S}+\mathrm{H}_{2} \mathrm{O}$

$\mathrm{K}_{2} \mathrm{~S}_{\text {, }}+2 \mathrm{HCl}=2 \mathrm{KCl}+\mathrm{H}_{2} \mathrm{~S}+4 \mathrm{~S}$.

3) In den echten Schriften Gebers ist nach Berthelot diese Theorie noch nirgends erwähnt (a. a. O. S. 65).

4) Die Kenntnis des metallischen Zinks läßt sich nicht weiter als bis gegen den Ausgang des Mittclalters zurückverfolgen. Nach E. v. Lippmann (siehe dessen ,Alchemie ${ }^{6}$ ) ist das metallische Zink sogar erst in der Neuzeit bekannt geworden. Die Legierung von Kupfer und Zink, das Messing, war dagegen schon zur römischen Kaiserzeit bekannt. Mitteil. z. Gesch. d. Med. u. d. Naturwissensch. 1903. S. 150 u. 174. 
Metall ${ }^{1}$. Zinn war reiner und enthielt mehr Mercurius als Blei. Daß letzteres sich durch Zusatz von Quecksilber in Zinn umwandeln lasse, galt als Tatsache. Bei allem weiteren Herumprobieren verfolgte man das Ziel, zunächst einen Stoff herzustellen, mit dem die Metallverwandlung völlig gelingen sollte. Diesen hypothetischen Stoff nannte man den Stein der Weisen. Die späteren Alchemisten des christlichen Abendlandes legten ihm die wunderbarsten Wirkungen bei. Da sie, wie auch die späteren arabischen Alchemisten im wesentlichen den gleichen, soeben entwickelten Ansichten huldigten und da zunächst auch keine bedeutende Vermehrung der Einzelkenntnisse stattfand, so kann von einem nennenswerten Fortschritt der Chemie im weiteren Verlaufe dieser Periode kaum die Rede sein. Vielmehr fand zwischen den beiden Pseudowissenschaften, der Alchemie und der Astrologie, eine immer größere Verschmelzung unter gleichzeitiger Durchtränkung mit mystischen Elementen statt.

Die Frage, woher das in den Pseudo-Geberschen Schriften enthaltene Wissen stammt, das uns in ihnen gegen das Ende des 13. Jahrhunderts, ,in völliger Vollendung und demnach als das Ergebnis einer längeren Entwicklung " entgegentritt", gehört auch heute noch zu den dunkelsten in der Geschichte der Chemie ${ }^{2}$ ).

\section{Die Pflege der Naturbeschreibung und der Heilkunde.}

Wir wenden uns jetzt den Verdiensten zu, die sich die Araber um die Erhaltung der alten naturgeschichtlichen Schriften erworben haben. Von einem wesentlichen Fortschritt auf dem Gebiete der Zoologie und der Botanik kann im Zeitalter dieses Volkes nicht die Rede sein, zumal die Araber vor anatomischen Untersuchungen geradezu einen Abscheu hegten. Auf dem Gebiete der menschlichen Anatomie beschränkten sie sich daher ganz auf Aristo-

1) Zur Erläuterung diene folgende von Berthelot (a. a. O. S. 66) wiedergegebene Stelle: „Das Kupfer wird von einem trüben und dicken Quecksilber und einem trüben und roten Schwefel erzeugt. - Das Zinn wird von einem klaren Quecksilber, das kurze Zeit mit einem weißen und klaren Schwefel gekocht wird, erzeugt. Wenn die Kochung von langer Dauer ist, gewinnt man Silber usw. Diese Erzeugung der Metalle wird im Schoß der Erde allerdings in dem langen Zeitraum von hundert Jahren vollendet, aber die Kunst kann die Vollendung abkürzen. Sie wird also in einigen Stunden oder in einigen Minuten in Erfüllung gehen."

2) E. v. Lippmann, Alchemie. 1919. S. 487. Ferner Stillmann und Sudhoff. 
teles und Galen, während sie sich bei der Beschäftigung mit der Tier- und Pflanzenwelt, wie das spätere Altertum, vorzugsweise von dem Bestreben leiten ließen, den Schatz der Heilmittel kennen $\mathrm{zu}$ lernen und zu vermehren.

Von dem gleichen Standpunkt aus wandten die Araber den Mineralien ihr Interesse zu. Ein Bild von den mineralogischen Kenntnissen und Anschauungen der Araber erhält man aus der im 13. Jahrhundert entstandenen Kosmographie des Ibn Mahmud al Qazwini ${ }^{1}$. Danach entstehen die durchsichtigen Mineralien aus Flüssigkeiten, die übrigen aus der Mischung des Wassers mit der Erde. Das Wasser soll ebenso zu Stein werden, wie sich Wasser aus der Luft verdichtet. "Wenn es möglich ist", sagt Al Qazwini, „daß das Wasser Luftform annimmt, so muß es auch möglich sein, daß es die Form des Wassers ablegt und diejenige der Erde annimmt." Die Besprechung im einzelnen wird mit der Bemerkung eingeleitet, daß nicht alle, sondern nur die wunderbarsten Eigenschaften der Mineralien beschrieben werden sollen. Unter diesen Eigenschaften sind vor allem Heil- und Zauberwirkungen verstanden. So heißt es vom Bleiglanz: „Aristoteles sagt: Dies ist ein bekannter Stein, der in vielen Gruben gewonnen wird. Es ist ein bleihaltiges Mineral; als Augenpulver ist es gut für die Augen, es verschönt sie und beseitigt das Fließen der Tränen." Die Eigenschaften des Bergkristalls werden mit folgenden Worten beschrieben: „Der Bergkristall ist eine Art Glas, nur daß er härter ist. Die Könige benutzen Gefäße aus Bergkristall auf Grund der Überzeugung, daß das Trinken daraus gesund sei."

Die Darstellung des roten Quecksilberoxyds durch längeres Erhitzen des Quecksilbers war bekannt. Die entstehende rote Masse wurde indessen für künstlichen Zinnober gehalten. Der natürliche Zinnober entstehe dagegen durch die Vereinigung von Quecksilber und Schwefel im Innern der Erde. Unter den Eigenschaften des Alauns wird erwïhnt, daß er Blutungen zum Stillstand bringe. Weiter heißt es: „Wenn die Färber ein Kleid färben wollen, tauchen sie es zuvor in Alaun. Die Farbe geht dann nie wieder weg." Besondere Zauberkrïfte wurden dem Amethyst beigelegt: "Das ist ein Stein, der das Fener auslöscht,

1) Eine unvollendet gebliebene Übersetzung wurde nach der Wüstenfeldschen Textausgabe von H. Ethé im Jahre 1868 herausgegeben. Den Abschnitt, der von den Steinen handelt, Lat $\langle 1895$ J. Ruska ïbersetzt und erläutert. Er wurdo hier zugrunde gelegt. 
wenn er darin liegt. Legt man ihn unter die Zunge und trinkt ein berauschendes Getränk darüber weg, so steigen die Dünste nicht zu Kopf, und man wird nicht betrunken." Interessant ist, daß das Bohren mit Diamanten schon Erwähnung findet. Die Werkleute befestigen nach Al Qazwini Stücke des Diamanten an den Rand des Bohrers und bohren damit die harten Steine. Mit einem auf geeignete Weise gefaßten Diamanten dringt ferner der Arzt in die Harnröhre ein, um steinige Konkretionen zu zerbröckeln. Vom Magneten wird berichtet: „Im indischen Ozean befindet sich eine Insel aus diesem Mineral. Wenn die Schiffe in die Nähe gelangen und etwas an ihnen aus Eisen ist, so fliegt es wie ein Vogel fort und heftet sich an den Magneten." Die Kosmographie Al Qazwinis gestattet auch einen Einblick in die zoologischen Kenntnisse und Anschauungen der Araber. Auch auf diesem Gebiete sind die letzteren im wesentlichen nur die Vermittler zwischen dem Altertum und der neueren Zeit gewesen. Selbständige Leistungen und neue Auffassungen lassen sich in den auf uns gekommenen arabischen Schriften zoologischen Inhalts kaum nachweisen, wenn es auch an einzelnen zutreffenden Bemerkungen nicht fehlt. So sagt Al Qazwini an einer Stelle, jedes Tier besitze die Glieder, die zu seinem Körper stimmen und solche Gelenke, welche zu seinen Bewegungen passen. Auch sei die Haut so beschaffen, wie es der Schutz der Tiere erfordere.

Die Einzelkenntnis der Tierformen erhielt durch die Araber eine bedeutende Erweiterung, da sich ihre Forschungsreisen nach China, Südasien, Ostafrika, ja selbst bis Sumatra und Java erstreckten. Wie in den zur Zeit des Mittelalters im Abendlande entstandenen zoologischen Schriften ${ }^{1}$ ), so nahmen auch in den Kosmographien der Araber die Tierfabeln einen großen Raum ein. Die Erzählung von dem Walfisch, der für eine Insel gehalten wird, an welcher die Schiffe landen, begegnet uns mit der Abänderung, daß die Rolle dieses Tieres bei den Arabern eine riesige Seeschildkröte einnimmt.

Neben den arabischen Bearbeitungen der Naturgeschichte der Tiere sind die Übersetzungen der Werke des Aristoteles und des Galen zu nennen. Ibn Sina (Avicenna), der zu Beginn des 11. Jahrhunderts lebte, soll sämtliche Schriften des Aristoteles in 20 Bänden erläutert haben. Ein Kommentar zu den von Aristoteles verfaßten Büchern iiber die Tiere hat sich in latei-

1) Siehe über den „Physiologus* an späterer Stelle. 
nischer Übersetzung erhalten 1 ). Auch Ibn Roschd (Averroes), der gleich Avicenna für die Philosophie des Mittelalters von hervorragender Bedeutung war, schrieb Kommentare zu den naturgeschichtlichen Schriften des Aristoteles.

Rein botanische Werke entstanden bei den Arabern ebensowenig wie bei den auf Theophrast folgenden griechischen Schriftstellern. Die Pflanzenkunde verfolgte auch bei ihnen fast ausschließlich praktische Z Zwecke, indem sie als Heilmittelkunde, Ackerbau oder Gartenbaulehre auftrat. Gleichzeitig schleppte sie dabei einen immer mehr anschwellenden, auf Nomenklatur und Synonymik hinauslaufenden Wust philologischer Gelehrsamkeit mit sich. Von den Schriften griechischen Ursprungs wurde besonders Dioskurides ins Arabische übersetzt und kommentiert. $\mathrm{Zu}$ allgemeineren Betrachtungen über die Pflanze hat sich wohl nur Avicenna erhoben. Letzterer unterschied drei Stufen der Beseelung: die Pflanzen-, die Tier- und die Menschenseele. Der Pflanzenseele schrieb er eine ernährende, eine auf das Wachstum gerichtete und eine erzeugende Kraft zu.

Unter den auf Landwirtschaft bezïglichen arabischen Schriften ist das Werk von Ibn Alawwâm zu nemnen, von dem noch melirere vollständige Handschriften vorhanden sind. Es entstand im 12. Jahrhundert in Spanien und handelt vom Boden, von der Düngung und der Bewässerung, ferner von der Baumzucht, vom Getreide- uud vom Gartenbau 2). Am genauesten wird über die Baumzucht berichtet. Zahlreiche Arten der Veredelung werden beschrieben und zum Teil durch Abbildungen erläutert. Ein besonderer Abschnitt handelt von dem Alter der Büume. Viele, die Pflanzen und ihre Verbreitung betreffenden Mitteilungen finden sich auch in der umfangreichen geographischen Literatur der Araber zerstreut.

Im 14. Jahrhundert ragt das Reisewerk Ibn Batutas, das demjenigen Marco Polos an die Seite gestellt werden kann, hervor ${ }^{3}$ ). Sein Verfasser bereiste nicht nur die Mittelmeerländer, sondern gelangte auch nach Indien und China. Es wird manche Pflanze der bereisten Länder beschrieben und ihre Verwendung gewürdigt. Doch hat Ibn Batuta seine Kenntnisse mehr auf

1) Siehe Carus, Geschichte der Zoologie. S. 173.

2) Meyer, Geschichte der Botanik. Bd. IIJ. S. 263.

3) Ins Englische übersetzt von S. Lee. London 1829.

Ins Französische von Defremerie u. Sanguinetti. Paris 1805 . Neue Autl. ebd. 1913. 
den Marktplätzen als in der freien Natur gesammelt, so daß der botanische Inhalt des Werkes dem geographischen gegenüber an Bedeutung zurücktritt.

Endlich ist noch zu erwähnen, daß im Anschluß an die Chemie und die Botanik auch die Heilkunde bei den Arabern eifrig gefördert wurde. Sie knüpften dabei an die ihnen von den Griechen (Galen) und von den Indern übermittelten Kenntnisse an. Was sie neu schufen, war insbesondere die Pharmazie, die im 8. Jahrhundert, in enger Verbindung mit der Chemie, in den arabischen Ländern zuerst als selbständige Wissenschaft aufkam $\left.{ }^{1}\right)$. Auch auf den Gebieten der Krankenpflege, des Hospitalwesens und der Heilmittellehre ist manches auf die Araber zuriickzuführen. Da ihnen ihre Satzungen die Zergliederung von Leichen verboten, blieben sie hinsichtlich der Anatomie auf Galen angewiesen. Daß die Chirurgie bei ihnen dennoch Fortschritte machte, ist auf indische Einflüsse zurückzuführen. Die Bearbeitung, welche Galens Schriften durch Ibn Sina (Avicenna) erfuhr, erschien um das Jahr 1000 unter dem Namen des "Kanon" und blieb für das Mittelalter maßgebend, bis Paracelsus die Werke Avicennas den Flammen übergab. Auch auf dem Gebiete der Augenheilkunde haben sich die Araber Verdienste erworben. Zwar fußten sie auf der von den Griechen geschaffenen Grundlage. Doch versahen sie diesen Teil der Medizin „mit eigenen Zutaten“ und gestalteten ihn „nach eigenem Plan“" 2).

Nachdem die arabische Kultur ihren anregenden Einfluß auf das christliche Abendland ausgeübt hatte, ging sie einem raschen Verfall entgegen. Das mächtige Kalifat von Bagdad löste sich in eine Anzahl kleinerer Reiche auf. Durch den im 13. Jahrhundert daherbrausenden mongolischen Völkerstrom wurden aber auch sie vernichtet. „Bis heute hat sich der Orient von den Schlägen jener grausigen Zeit noch nicht wieder erholen können ${ }^{3}$ ).“ lich erging es der maurischen Herrschaft in Spanien. Die kleinen Reiche mohammedanischen Bekenntnisses, die sich dort gebildet

1) Näheres enthält: Berendes, Das Apothekenwesen, seine Entstehung und geschichtliche Entwicklung. Stuttgart 1907. S. 61.

2) Siehe Hirschberg, Über das älteste arabische Lehrbuch der Augenbeilkunde (Berichte der Berliner Akademie der Wissenschạften. 1903).

Ferner J. Hirschberg, Geschichte der Augenheilkunde. Zweites Buch. 1. Abteil. Geschichte der Augenheilkunde bei den Arabern. Leipzig, W. Engelmann. 1905.

3, C. Brockelmann, Gesch. d. arab. Literatur. Bd. II (1902). S. 3. 
hatten, wurden durch die von Norden her vordringende christliche Bevölkerung unterjocht. Dadurch wurde über die blïhende Halbinsel zunächst der Fluch der Verödung gebracht. Die fanatische Zerstörungswut, welche die ersten Christen, wie auch die Araber im Beginn ihrer Laufbahn an den Schätzen der Wissenschaft ausließen, schien wieder aufgelebt zu sein. Als nach der Vereinigung von Kastilien und Aragon Granada fiel, ging z. B. die dortige große Bibliothek mit ihren Hunderttausenden von Bänden in Flammen auf, ein unersetzlicher Verlust, da sie zahlreiche arabische Ausgaben der alten Schriftsteller enthielt. Nach der durch die Mongolen herbeigeführten Verniclitung der arabischen Kultur in Vorderasien fand die arabische Wissenschaft zwar Zufluchtsstätten in Syrien und in Ägypten. Die arabische Literatur bildete aber seitdem kein Ganzes melir, sondern sie fristete nur noch in den einzelnen Ländern ein Sonderdasein ${ }^{1}$ ). Die Astronomie sank zu einer Art Küsterdienst an den Moscheen herab. Die Naturwissenschaften endeten in Zauberspuk und Spielereien. Schließlich gerieten Syrien und Ägypten in die Hände der osmanischen Sultane. Ein Glück war es noch immerhin, daß die Osmanen während der Blüte ihrer Herrschaft im Gegensatz zu den sinnlos wütenden Mongolen die Pflege der geistigen Güter nicht vernachlässigten. Muhammed, der Eroberer Konstantinopels, hat sich sogar eingehender mit wissenschaftlichen Dingen beschäftigt. Doch hatte damals der Orient schon längst die Führung auf den Gebieten des geistigen Lebens an den Occident, vor allem an Italien, abgetreten.

Indessen nicht nur die Befehdung durch andere Staaten brachte die Entwicklung der arabischen Kultur zum Stillstand. Es fehlte ihr vielmehr, gleich allen übrigen, dem Orient entsprungenen älteren Kulturen, an innerer Kraft, um dauernd Neues aus sich hervorzubringen. So kam es, daß mit dem Nachlassen des arabischen Einflusses gegen das Ende des Mittelalters der Orient aufhörte, in der allgemeinen Geistesentwicklung eine Rolle zu spielen. Die Führung ging vielmehr um jenen Zeitpunlit auf das Abendland mit seinen in Italien, Deutschland, England und Frankreich naclı der Völkerwanderung seßhaft gewordenen Bewohnern germanischer Abstammung über.

1) C. Brockelmann a. a. O. Bd. II. S. 6. 


\section{Die Wissenschaften unter dem Einfluß der christlich-germanischen Kultur.}

Während die arabische Wissenschaft und Literatur vom 9. bis zum 12. Jahrhundert einen fast ununterbrochenen Aufschwung nahm, finden wir während dieses Zeitraums im Abendlande nur unbedeutende Reste einer früheren Epoche und nur selten neue verheißungsvolle Ansätze. Was dort an Kenntnissen und an Kunstübung vorhanden war, kann in der Hauptsache nur als ein Überbleibsel der römischen Kulturwelt gelten, dem die germanischen Völker zunächst wenig hinzuzufügen wußten. Kennzeichnend für diese gesamte Periode in der Entwicklung des westlichen Europas ist das Übergewicht der religiösen Vorstellungen auf geistigem Gebiete und dasjenige der Kirche im gesamten öffentlichen Leben gegenüber allen anderen Regungen und Institutionen. Alle Wissenschaften sollten zur Erhöhung der Ehre Gottes beitragen. In Wahrheit dienten sie der Kirche und ihren Machthabern. Die sieben freien Künste oder das Trivium und das Quadrivium umfaßten die Summe des damaligen gelehrten Wissens unter jenem einen und einzigen Gesichtspunkt. Grammatik trieb man, um die Kirchensprache zu verstehen, Rhetorik, um sie anwenden zu können. Die Arithmetik offenbarte in mystischer Deutung die Geheimnisse der Zahlen. Die Hauptanfgabe der Astronomie bestand darin, den kirchlichen Kalender festzustellen. Auch die unter den sieben freien Künsten aufgeführte Musik verleugnete nicht ihren kirchlichen Charakter. Was man im Mittelalter anfangs an astronomischen Kenntnissen besaß, waren nur spärliche Reste der griechischrömischen Literatur über diesen Gegenstand. Zumal die germanischen Völker hatten nichts Eigenes auf dem Gebiete der Astronomie geschaffen. Erst durch die Berührung mit den Arabern trat hierin eine Änderung ein.

Daß die Araber schon so frühzeitig wissenschaftliche astronomische Kenntnisse besaßen, liegt daran, daß sie bald nach ihrem Auftreten in der Geschichte mit dem wichtigsten astronomischen 
Werk des Altertums, dem Almagest, bekannt geworden waren. Dadurch wurden sie in die Lage gesetzt, die vorbildliche griechische Wissenschaft fortzuführen und wesentlich zu bereichern.

Die nördlichen Länder Europas, die sich im frühen Mittelalter der Kultur erschlossen, lernten die Astronomie dagegen durch das wissenschaftlich ganz unbedeutende Werk des Martianus Capella kennen, das man dem Unterrichte im Quadrivium zugrunde legte. Es vermittelte einige Kenntnisse über die Sternbilder, die Planeten, die Sphärenharmonie, die Jahreszeiten usw., gab aber nirgends eine Begründung, sondern überall nur Zusammenfassungen. Außerdem wurde man mit einfachen astrologischen Texten griechischen Ursprungs durch lateinische Vermittlung bekannt. Das selbstgewonnene Wissen war so geringfügig, daß man nicht einmal zu Begriffen wie den Aquinoktien und den Solstitien gelangt war ${ }^{1}$. Neben Martianus Capella war Plinius in Geltung. Auf diese beiden stützten sich besonders Isidor von Sevilla und Rhabanus Maurus.

Erst nach und nach begann, von den Arabern angefacht, ein wissenschaftlicher Geist sich in den nördlichen Ländern Europas auszubreiten. Unter seinem Einfluß entstanden die Schriften des gleich zu erwähnenden Gerbert, des späteren Papstes Sylvester II. (940-1003). Auch ging man damals unter Benutzung der im Altertum geschaffenen Armillen und Astrolabien zu eigenen messenden Beobachtungen über. Auch mit der Sonnenuhr wurde der germanische Kulturkreis erst durch die Alten bekannt. Zuerst geschah dies in England und Irland im 7. Jahrhundert. In Deutschland verfertigte Gerbert die erste Sonnenuhr für Otto IIT. Er schrieb auch ein Buch über diesen Gegenstand. Erst seit dem 15. Jahrhundert wurden in Deutschland die zahlreichen Sonnenuhren an Burgen und an Kirchen angebracht, die oft noch heute erhalten sind. Sie bestanden aus einer vertikalen Scheibe mit einem Gnornon, der mit ihr einen Winkel von $45^{\circ}$ bildete.

Auch die Wagen, darunter die Schnellwagen, die in der Merowingerzeit aufkamen und heute noch als Grabbeilagen gefunden werden, lassen schon durch die Form erkennen, daß sie nach römischem Vorbild geschaffen waren.

Während das wissenschaftliche Denken in den Ländern einer neuen, auf den Trümmern der Antike sich entwickelnden germa-

1) F. Boll im Reallexikon der germanischen Altertumskunde von Hoops (1911-1918) unter ,Astronomie“. 
nischen Kultur nur in engster Anlehnung an die vom Altertum empfangenen spärlichen Dokumente erfolgte, verhielt es sich mit den im Mittelalter emporblïhenden Gewerben wesentlich anders. Auf diesem Boden waren es nicht selten die Kelten, deren Erbe die Germanen übernahmen und selbständig vermehrten. Dies galt z. B. vom Bergbau, den die Kelten vor dem Eindringen der Germanen in Mitteleuropa schon auf eine ziemlich hohe Stufe gebracht hatten. In der Salzgewinnung trat kaum ein Rückgang ein. In der frühesten Zeit gewann man Salz, indem man nach dem Zeugnis römischer Schriftsteller brennendes Holz mit dem Wasser salzhaltiger Quellen übergoß. Um den Besitz solcher Quellen führten germanische Stämme nicht selten untereinander Kämpfe. Später dampfte man die Soole in irdenen Töpfen ein; schließlich kam der Pfännereibetrieb auf. Seit der Zeit der Merowinger wurde Salz in zahlreichen größeren Betrieben gewonnen.

Bergbauliche Überreste, welche den Abban der Erze bezeugen, reichen bis in die vorgeschichtliche Zeit zurück. Nach Tacitus erzeugte Deutschland indessen nur wenig Eisen und weder Gold noch Silber. Urkundlich bezeugt wird der Abbau von Eisenerzlagern erst seit dem 8. Jahrhundert, so der auf dem Wetzlarer Gebiet im Jahre 780. Er reicht indessen viel weiter zurück. Auch Gold wird man früh in den Flüssen der Alpen durch Waschen gewonnen haben. Zunächst gab es nur Tagebau. Tiefbau war erst mit der Einrichtung größerer Betriebe möglich, und im 12. Jahrhundert war man mit der Herstellung von Schächten und Stollen schon ziemlich vertraut.

Das Ausschmelzen der Metalle aus den Erzen setzte die Gewinnung von Holzkohle voraus. Mit ihrer Hilfe wurden die Eisenerze in Vertiefungen oder auf besonderen Herden niedergeschmolzen. Man erhielt durch diesen, als Rennarbeit bezeichneten Prozeß, der anfangs durch Gebläse mit Handbetrieb unterhalten wurde, sogenannte Luppen von schmiedbarem Eisen. Indem man die Vertiefung, um die Flamme zusammenzuhalten, mit einer ringförmigen Mauer versah und diese nach und nach erhöhte, entstanden die Hochöfen, die uns in ihrer Urgestalt etwa zu Beginn des 15. Jahrhunderts begegnen. Ihr Erzeugnis war das kohlenstoffreiche Gußeisen, das erst durch weitere hüttenmännische Prozesse in Schmiedeeisen umgewandelt werden mußte.

Mit dem Abbau ron Silber, Kupfer, Zinn und Blei wurde man in Mitteleuropa erst verhältnismäßig spät bekannt. Der Goslarer Bergbau auf Silber und Blei begann unter Otto dem 
Ersten 1). Zinn wurde in Böhmen etwa seit dem 13. Jahrhundert abgebaut. Um diese Zeit besaß der Silberbergbau in Mitteleuropa schon eine große Ausdehnung. Er wurde nicht nur am Harz, sondern auch in der Gegend von Meißen, in Freiberg, im Jura und in den Alpen betrieben.

Zwischen diesen Anfängen der metallurgischen Technik und der Wissenschaft bestand zunächst nur eine sehr geringe Fühlung. Erst seit dem 15. Jahrhundert, nachdem A gricola seine gelehrten Werke über den Bergbau geschrieben hatte, begannen die Gelehrten sich diesem für das Emporblühen der neueren Naturwissenschaft so wichtigen Gebiete menschlicher Tätigkeit zuzuwenden.

Die Elemente der Bildung, welche die Römer nach Frankreich, England und Deutschland gebracht hatten, waren durch die Ereignisse der Völkerwanderung zum größten Teile vernichtet worden. Als nach der Beendigung der Wanderungen in Deutschland und im nördlichen Gallien das Reich der Franken entstand, und die Ausbreitung des Christentums durch diese politische Schöpfung sehr gefördert wurde, befanden sich die genannten Länder daher wieder im Zustande tiefer Unkultur. Der Gefahr einer Zersplitterung entging das neue Reich dadurch, daß es in die Hände der Pippiniden gelangte. Diese setzten der Überschwemmung Westeuropas durch die Araber einen Damm entgegen und begrindeten eine christlich-germanische Bildung in ihrem, sich immer gewaltiger ausdehnenden Reiche. Durch die tatkräftige, persönliche Anteilnahme, die Karl der Große trotz seiner zahlreichen Ḱriege für die Wissenschaft bekundete, kam die geistige Entwicklung des Abendlandes in etwas schnelleren Fluß. Insbesondere scheint sich nach der Eroberung Italiens in dem Kaiser der Wunsch geregt zu haben, seinem eigenen Lande literarische Hilfsmittel zuzufiihren und dadurch das Wissen zu fördern. Auch ron Britannien her wurde die gelehrte Bildung in Deutschland während jenes Zeitalters günstig beeinflußt. Gregor der Große hatte um 600 nach diesem entlegenen Lande eine Anzahl Benediktinermönche gesandt, und diese hatten dort durch Urbarmachen des Bodens und Milderung der Sitten große Aufgaben gelöst, daneben aber auch die Pflege der Wissenschaften nicht verabsïumt. Nachdem diese Mönche sich auf solche Weise im nördlichen Europa einen Stützpunkt geschaffen, traten sie belehrend und bekehrend unter den germanischen Stämmen Nitteleuropas auf. Der hervorragendste unter ihnen

1 Hoops, Reallexikon des german. Altertums. 
war Winfried oder Bonifazius ${ }^{1}$ ). Seine Schüler gründeten die Klosterschule zu Fulda. Ein anderer britischer Münch, Alkuin, unterwies den Kaiser in gelehrten Dingen. Und so kam es, daß dieser, von dem günstigen Einfluß der Mönche auf die besiegten Völker überzeugt, die Wirksamkeit dieser Männer nach Kräften förderte. Gelehrte Ausländer wurden an den Hof gezogen und eine Art Akademie gebildet, die indessen fast ausschließlich aus Briten bestand. Die Schulen sollten nach der Absicht Karls nicht ausschließlich der Erziehung der Geistlichen dienen, sondern Bildung in weitere Kreise tragen.

Alkuin wurde berufen, eine.Palastschule zu leiten. Sie umfaßte Schüler sehr verschiedenen Alters und Standes, die der Kaiser für leitende Stellungen ausersehen hatte. Auf Alkuin ist wahrscheinlich auch die Anordnung zurückzuführen, daß die Geistlichen ein bestimmtes $\mathrm{Maß}$ von wissenschaftlichen Kenntnissen haben sollten.

Den Gedanken, allgemeine Volksschulen zu gründen, hat der Kaiser indessen noch nicht gehegt. Die Klosterschulen zu Fulda, zu St. Gallen und Corvey wurden zu wissenschaftlichen Pflanzstätten ihrer Zeit und ihres Landes. Der gelehrte Leiter der ersteren, Rhabanus Maurus, welcher den Ehrennamen primus Germaniae praeceptor erhielt, hinterließ ein Sammelwerk ${ }^{2}$ ), das unter anderem einen Abriß der Naturkunde bietet. Man erkennt, daß dieses Wissen weit geringer war als dasjenige des Altertums. Der Abriß des Rhabanus Maurus enthält nämlich nichts Eigenes, sondern fußt auf den Schriften der Alten, deren Inhalt in verdorbener Darstellung wiedergegeben wird.

Sein Werk verfaßte Rhabanus Maurus in der Absicht, wie er sagt, nach Art der Alten über die Natur der Dinge und den Ursprung ihrer Benennungen zu schreiben. Daraus wird die vorwiegend grammatisch-philologische Behandlung erklärlich, die nicht nur seinen Vorgängern anhaftete, sondern bis in die neuere Zeit hinein iiberwog. Dadurch, daß Rhabanus Maurus ferner alle Dinge in Beziehung zur biblischen Überlieferung brachte, kam in sein Werk jener mystisch-allegorische Zug, der fast alle Schriften des Mittelalters kennzeichnet. Die erste Hälfte handelt von Gott, den Engeln, rom christlichen Leben und Gebräuchen. Im zweiten Teile ist von der Astronomie, der Geo-

1) Er wurde 754 in Friesland erschlagen und in Fulda beigesetzt.

2) De Universo libri. XXII. 
graphie, der Medizin und anderen Wissenschaften die Rede. Ein Buch handelt in neun Kapiteln vom Ackerbau, vom Getreide, von den Hülsenfrüchten, rom Weinstock, von den Bäumen, von den aromatischen Kräutern und vom Gemüse. Es sind im ganzen etwa hundert Pflanzen, die nach ihrem Vorkommen und ihren Eigenschaften betrachtet werden.

Ein Seitenstück zu diesem botanischen Buche bildet das „Capitulare de villis et cortis imperialibus", eine ausführliche Verordnung uiber die Verwaltung der kaiserlichen Guiter. Es finden sich darin unter anderem auch die Pflanzen verzeichnet, die in den Gärten des Kaisers gezogen werden sollten. Das Capitulare de villis ist eine der wichtigsten Quellen für die agrarischen Verhältnisse der Karolingischen Zeit.

Vorgeschrieben war z. B. der Bau von Krapp und Waid zum Färben, sowie der Anbau der Kardendistel, die bei der Bereitung des Tuches benutzt wurde. An Bäumen sollten die kaiserlichen Domänen neben Apfel-, Birn- und Kirschbäumen auch Kastanien, Pfirsiche, Mandel- und Maulbeerbäume, den Lorbeer und den Nußbaum ziehen.

Als das Frankenreich zerfiel und Kriege ohne Ende zwischen den neu entstandenen Reichen, sowie Fehden im Innern und zur Abwehr von außen herandrängender Feinde herrschten, wurden die geringen wissenschaftlichen Ansätze welche insbesondere die Regierung des großen Kaisers gezeitigt hatte, zum größten Teile wieder vernichtet. Vieles ist gänzlich verloren gegangen, anderes besaß nicht mehr die Kraft zu weiterer Entfaltung, weil das geistige Interesse durch den Wetteifer, der zwischen der Theologie und der scholastischen Philosophie entbrannte, völlig in Anspruch genommen wurde.

Erwähnenswert für die Zeit zwischen Karl dem Großen und Albertus Magnus ist Hildegard, die Äbtissin des Klosters zu Disibodenberg, die meist als Hildegard von Bingen bezeichnet wird. Sie ist die Verfasserin ron vier Büchern "Physica". Ihr Werk enthält nicht nur die ersten Anfänge vaterlïndischer Tierund Pflanzenkunde, sondern es bietet überraschenderweise eine, nicht allein aus Dioskurides geschöpfte, sondern auch aus der Überlieferung des Volkes hervorgegangene Heilmittellehre.

Die "Physika“ wurden um 1150 geschrielenen und enthalten viel Selbstbeobachtetes. In der Hauptsache bieten sie eine Flora und Fauna des Naliegebietes. Die Deutung der beschriebenen Arten, fïr welche die zu jener Zeit beim Volke iiblichen Namen gebraucht 
werden, ist meist nicht leicht und häufig unsicher ${ }^{1}$ ). Hildegard hat fast alle heutigen Obstarten, vor allem aber die im "Capitulare" aufgezählten Pflanzen berïcksichtigt und erweist sich weniger von den Alten beeinflußt als zahlreiche Verfasser späterer botanischer Bücher.

Auf das Zeitalter Karls des Großen folgte eine Periode, in welcher das Abendland fast ausschließlich in der Bekämpfung des Orients aufging. Dann erst setzte eine stetige Aufwärtsbewegung ein. Zwar hatten die Kreuzzüge den westlichen Europa manche Wunde geschlagen; sie hatten aber auch den Gesichtskreis in ähnlicher Weise erweitert, wie es zur Zeit des Griechentums die Züge Alexanders bewirkt hatten. Waren ferner in den vorhergehenden Jahrhunderten geistige Anregungen besonders von den mohammedanischen Bewohnern Spaniens ausgegangen, so kam man jetzt mit der während des Stillstandes der germanischen Völker ihre Blütezeit erlebenden islamitischen Kultur auch vom südlichen Italien her in Berührung. Dieser Einfluß erstreckte sich nicht nur auf den Norden der Halbinsel, sondern er wurde, zum Teil infolge der Romfahrten, auch auf den nördlich der Alpen gelegenen Teil Europas ausgedehnt. Auch von Byzanz und dem Orient selbst gelangten mannigfache Anregungen nach Mittelund Westeuropa.

Wir haben im vorhergehenden Abschnitt erfahren, daß die A raber die von den Griechen und den Indern empfangenen Kenntnisse nicht nur zu erhalten, sondern auch weiterzuentwickeln und mit ihren eigenen Geistesschöpfungen zu einer gewaltigen Literatur $\mathrm{zu}$ verschmelzen verstanden. Diese arabische Literatur war während des sp:̈ieren Mittelalters, wenn auch meist in lateinischer Übersetzung, im Aluendlande die herrschende. Da der Hauptgegenstand der arabischen oder aus arabischen Quellen entstandenen Schriften neben der Heilkunde die Astronomie und die Mathematik war, so ist es begreiflich, daß sich zu Beginn der Renaissance das Abendland zunächst diesen Wissenschaften zuwandte.

Die erste Bekanntschaft mit den von den Arabern gehüteten Geistesschätzen machte das Abendland in dem seit $711 \mathrm{im}$ mo-

1) L. Geisenheyner, Über die Physika der heiligen Hildegard und die in ihr enthaltene älteste Naturgeschichte des Nahegaues. Berichte über die Versammlungen des Botan. und des Zoolog. Vereins f. Rheinland-Westfalen. 1911. Bonn. Vgl. auch die Veröffentlichungen von $\mathrm{Ch}$. Singer, Oxford (siehe Mitteil. z. Gesch. d. Med. 1919. S. 338). 
hammedanischen Besitze befindlichen Spanien. Dorthin strömten aus Frankreich, England und Mitteleuropa wissensdurstige Männer in großer Zahl, um die erworbenen Kenntnisse später ihrer Heimat zuzuführen. Unter diesen Männern seien Gerbert, der spätere Papst Sylvester der $Z$ weite und Gerhard ron Cremona genannt.

Durch Gerbert (940-1003) und seine Schiiler lernte man unsere heutigen, noch jetzt arabisch genannten Ziffern kennen ${ }^{1}$.

Gerhard von Cremona (1114-1187) lieferte die erste Übersetzung des Almagest, jenes von Ptolemäos verfaßten Hauptwerks der Astronomie, das dieser Wissenschaft im Altertum und im Mittelalter ihre Bahnen vorgezeichnet hat ${ }^{2}$ ).

Auch die Elemente Euklids wurden aus dem Arabischen übersetzt ${ }^{3}$ ). Das mathematische Werk Ibn Musas und die arabischen Schriften, die sich auf Aristoteles bezogen, wurden durch Johannes von Sevilla (um 1150) in lateinischer Übersetzung den Abendländern zugänglich gemacht. Von der aristotelischen Philosophie empfing man allerdings nur einen höchst verderbten Abklatsch. Dies wird begreiflich, wenn man bedenkt, daß das griechische Original zuerst ins Arabische, dann ins Castilianische und endlich ins Lateinische übersetzt, und daß ferner manche schwierige Stelle nicht verstanden und infolgedessen unrichtig wiedergegeben wurde.

Nach Italien gelangten die mathematischen Kenntnisse der Araber um das Jahr 1200 durch Leonardo von Pisa 4). Die Geschichte dieses Mannes und seines mathematischen Werkes zeigt uns, wie eng die Entwicklung und die Ausbreitung der Wissenschaften mit den jeweiligen Kulturzuständen verbunden sind. L e onardos Vaterstadt Pisa war um 1200, infolge der im Zeitalter der Kreuzzüge entstandenen Beziehungen zum Orient, dic mächtigste Handelsstadt Italiens geworden. Ihr Reichtum latte mitgewirkt, um die ersten, noch heute jeden Besucher entzückenden Schöpfungen der neueren italienischen Kunst entstehen zu lassen. Der Handel entsprang praktischen Bedürfnissen und verfolgte materielle Ziele. Er suchte daher jeden geistigen Fortschritt, insbesondere auf dem Gebiete der Mathematik, unmittelbar nutz-

1) Tropfke, Geschichte der Elementarmathematik. Bd. I. S. 13.

2) Vgl. H. Würschmidt, Archiv f. Gesch. d. Mathem. 1913.

3) Durch den englischen Mönch Atelhart um 1120.

4) Auch Fibonacci oder Bonacci genannt. Fibonacci bedeutet Soln Bonaccis (filius Bonacci). 
bringend zu machen. Zu diesem Zwecke studierte Leonardo, der Sohn eines Pisaner Handelsherrn, auf seinen Geschäftsreisen, die ihn nach Sizilien, Griechenland, Ägypten und Syrien führten, die in jenen Ländern gebräuchlichen Rechnungsweisen. So entstand um 1200 das mathematische Hauptwerk des Mittelalters, Leonardos "Liber abaci“, mit dem die Geschichte der Mathemathik wohl einen neuen Zeitabschnitt beginnen läßt1).

In der Einleitung sagt Leonardo, die früheren Methoden seien ihm, verglichen mit derjenigen der Inder, als ebensoviele Irrtümer erschienen. Er habe daher das indische Verfahren seinem Werke zugrunde gelegt, habe eigenes hinzugefügt, auch manches aus der geometrischen Kunst des Euklid verwendet, damit das Geschlecht der Lateiner hinfort nicht mehr unwissend in diesen Dingen befunden werde ${ }^{2}$ ).

Die ersten Abschnitte handeln von den Grundoperationen mit ganzen Zahlen und Brüchen. Zum ersten Male begegnet uns der Bruchstrich, der auch als Zeichen für die Division gebraucht wird. An die ägyptische Bruchrechnung erinnert die im Liber abaci vorkommende Zerlegung von Brïchen in eine Summe von Stammbrüchen. Die weiteren Abschnitte befassen sich mit Regel de tri, Gesellschafts- und Mischungsrechnung, Potenzen und Wurzeln und endlich mit den Aufgaben der "Algebra und Almukabala“, d. h. der Lehre von den Gleichungen, die im engen Anschluß an Ibn Musa behandelt werden. Im einzelnen enthält das Buch Leonardos auch inanches, was dem Verfasser angehört; vor allem ist dieser Herr über den von ihm behandelten Stoff, den er in eigener, sicherer Auffassung seinen Landsleuten iibermittelt.

Gleichzeitig mit den mathematischen wurden auch naturwissenschaftliche Kenntnisse von den Arabern dem Abendlande übermittelt. Infolgedessen treten hier zu Beginn des 12. Jahrhunderts Männer auf, die sich der Alchemie und der von den Arabern besonders gepflegten Optik widmeten. Unter ihnen sind vor allem Albertus Magnus und Roger Bacon zu nennen, mit denen wir uns noch eingehend beschäftigen werden. Nach dem Vorbild der Araber wurde ferner die Heilkunde im 12. Jahrhundert in Salerno wieder zu einer Wissenschaft erhoben, während die Behandlung der Krankheiten in den christlichen Ländern bis dahin vorzugsweise eine Domäne des frommen Aberglaubens gewesen war.

1) Cantor, Bd. II. S. 3.

2) Eine ausführliche Inbaltsangabe des Liber abaci gibt Cantor in seiner Geschichte der Mathematik. Bd. II. S. 7-32. 
Auf dem Gebiete der Optik verdient vor allem Vitello (Witelo) Erwähnung. Er stammte aus Polen und schrieb in der zweiten Hälfte des 13. Jahrhunderts ein Werk über Optik, in dem er die Lehren Alhazens in Verbindung mit den von Euklid und Ptolemäos herrührenden Sätzen vortrug. Vitellos Werk wurde wiederholt gedruckt ${ }^{1}$. Es gehört zu den umfangreichsten, die ïber Optik geschrieben sind, enthält aber wenig Eigenes. Später hat Kepler seine optischen Untersuchungen an Vitello angeknüpft und sie in einem "Zusätze zu Vitello" betitelten Werk veröffentlicht ${ }^{2}$ ).

Vergegenwärtigen wir uns, daß um 1200 der große, von den älteren Völkern geschaffene Schatz von Anregungen und Keimen, die nur der Weiterentwicklung harrten, den romanischen und den germanischen Völkern durch die Verbreitung der arabischen Literatur zugänglich gemacht war, so läßt es sich begreifen, daß dieser Zeitpunkt von der neueren historischen Forschung wohl als ein Markstein in der Geschichte der Wissenschaften hingestellt worden ist $\left.{ }^{3}\right)$.

Von nicht geringem Einfluß war auch die Erweiterung des geographischen Gesichtskreises durch die Reisen ${ }^{4}$ ) des Venezianers Marco Polo. Marco Polo gelangte bis nach Peking und im Süden bis nach Sumatra. Er brachte viele Jahre (1275-1292) im Dienste eines mongolischen Fürsten zu und richtete seine Aufmerksamkeit auf alles, was ihm in den fremden Ländern begegnete. Seine Mitteilungen erstrecken sich auf sämtliche drei Naturreiche. Er erwähnt zahlreiche Edelsteine und Halbedelsteine. Durch ilın wurde erst allgemein bekannt, daß sich die Steinkohle als Brennstoff verwenden läßt. Auch auf das Petroleum, die Tusche, das Porzellan lenkte er die Aufmerksamkeit. Aus dem Pflanzenreich erwähnt Marco Polo zahlreiche Drogen, Arzneimittel, aromatische Stoffe, Farbhölzer, den Indigo usw. Die Verarbeitung des Bambus, der Baumwolle und der Seide werden geschildert. Zahlreich sind auch die Mitteilungen über die Fauna des ganzen asiatischen Kontinents. Die Angaben erstrecken sich auf das Zebu, den Yack,

1) Am bekanntesten ist die $\Lambda$ usgabe von F. Risner. Basel 1572 .

2) Ad Vitellonem Paralipomena, quibus astronomiae pars optica traditur. Francof. 1604.

3) So auch von Cantor in seiner großen Geschichte der Mathematik.

4) Die Reisen des Vencziancrs Marco Polo im 13. Jahrhundert. Zum ersten Male vollständig nach den besten Ausgaben deutsch mit einem Kommentar, von $\mathrm{Aug}$. Bürck. Leipzig 1845. 
verschiedene Pferderassen, Elefant, Rhinozeros, Moschustier, menschenähnliche Affen, Tiger, Schlangen usw. Von den Angaben iiber die Vogelwelt interessiert besonders die Erwähnung eines Riesenvogels auf Madagaskar, dessen Flügel sechzehn Schritt gespannt haben sollen ${ }^{1}$ ).

Von großer Bedeutung für die Entwicklung der Wissenschaften in dieser wie in jeder anderen Periode war auch das Emporblühen des Handels. Der Handel hob sich insbesondere durch die enge Fühlung, in die Italien, Deutschland und Frankreich sowohl unter sich wie mit dem Morgenlande traten. Mit dem Handel blühte das Städtewesen empor. Der in den Städten sich mehrende Wohlstand weckte die Teilnahme weiterer Kreise an geistigen Dingen. Reiche Städte haben auch stets die Wissenschaften im wohlverstandenen eigenen Interesse begünstigt. Gegen den Ausgang des Mittelalters entwickelten sich solche Städte besonders in Italien, wo in erster Linie Venedig, Pisa, Florenz und Genua zu nennen sind. Sie besaßen staatliche Macht und führten, wenn auch unter gegenseitiger Befeldung, durch das Streben, ihren Einfluß weithin auszudehnen, zur regsten Entfaltung aller gewerblichen, kommerziellen und künstlerischen 'Tätigkeit. In hoher Blüte stand z. B. die Kunst Metalle zu gießen und Glas zu formen. Etwas später entstanden im Norden städtische Gemeinwesen, die nicht nur Handelsemporien, sondern gleichzeitig die Pflegestätten eines ganz neuen Geistes waren. Die gewaltige Hansa und der rheinische Städtebund sind hier vor allem zu nennen. „Es ist", sagt Ranke, „eine prächtige, lebensvolle Entwicklung, die sich damit anbahnt. Die Städte bilden eine Weltmacht, an welche die bürgerliche Freiheit und die großen Staatsbildungen anknüpfen“"2). Als fernere Umstände, die für die gesamte Entwicklung von Bedeutung waren, sind das Schwinden der Sklaverei, der Übergang von der

1) Reste und Eier riesiger, ausgestorbener Vögel sind bekanntlich später in Madagaskar gefunden worden (̈̈pyornis). Ein Auszug über die zoologischen Angaben Marco Polos findet sich in Carus, Geschichte der Zoologie. München 1872. S. 197 u. f.

Unter dem Titel "Chemisches bei Marco Polo" hat E. v. Lippmann eine Abhandlung in der Zeitschrift für angewandte Chemie veröffentlicht. 1908. 34. Heft.

2) Die Gründung der Städte bedeutet eine der fruchtbarsten Errungenschaften des Mitteltalters. Dadurch erfolgte eine Loslösung der Arbeit von der Scholle. Vor der Entwicklung der Städtefreiheiten besaß im Mittelalter niemand Rechte und ausgiebige Lebensquellen, der nicbt mit der Scholle verknüpft war. Siehe Grupp im 2. Bande seiner Kulturgeschichte d. Mittelalters. 
Natural- zur Geldwirtschaft ${ }^{1}$ ) und endlich, vor allem für das Gebiet der Geisteskultur, die Einfuihrung der Papiererzeugung in Europa zu nennen, alles Geschehnisse des 13. Jahrhunderts, in dem somit eine ganze Reihe von Grundlagen für die gegen das Ende des Mittelalters vor sich gehende Neugestaltung des staatlichen und geistigen Lebens geschaffen wurde. Gleichzeitig begegnen uns der erste große Dichter der Neuzeit in Dante und die ersten vorurteilsfreieren Denker des christlichen Abendlandes in Albertus Magnus und Roger Bacon, deren Leben und Wirken uns in den nächsten Abschnitten am besten in die Denkweise und die wissenschaftlichen Bemiihungen dieses Zeitraumes einführen werden. Auch die bildnerische Kunst erlebte im 13. und 14. Jahrhundert ihre Wiedergeburt. Zunächst geschah dies auf dem Boden Italiens. Es braucht nur an die Schöpfungen Nicolo Pisanos und Giottos erinnert zu werden ${ }^{2}$ ), deren Erzeugnisse auf dem Gebiete der Bildhauerkunst und der Malerei noch heute in ergreifender Weise Zeugnis von der Gewalt jener künstlerischen Regungen des 13. und 14. Jahrhunderts ablegen, die auch in den zahlreichen gotischen Domen jenes Zeitraums ihren unvergänglichen Ausdruck fanden.

\section{Die Wiederbelebung der alten Literatur.}

Die Schwelle des 13. Jahrhunderts bedeutet nach Chamberlains Ausdruck den Zeitpunkt, an dem „die Menschheit unter der Fülırung der Germanen" ein neues geistiges Leben begann. Aus diesem Grunde hält dieser Verherrlicher der Kulturmission des Germanentums es für angezeigt, das Jahr 1200 als die Grenzscheide zwischen dem Mittelalter und der neueren Zeit zu betrachten. Jedenfalls erscheint es berechtigt, den Beginn der Renaissance bis an die Schwelle des 13. Jahrhunderts zurückzuverlegen.

Auch auf dem Gebiete des Bildungswesens fand die neue Zeit ihren Ausdruck. Hochschulen nach dem Muster der arabischen gelehrten Schulen entstanden in Neapel, Salerno und Bologna, darauf in Paris, Oxford und Cambridge. Im 14. Jahrhundert folgte Deutschland mit der Gründung der Universitäten zu Prag,

1) Der älteste bekannt gewordene Geldwechsel stammt aus dem Jahre 1207. Siehe Grupp, Kulturgeschichte d. Mittelalters. 1894. Bd. II. S. 56. Im Orient waren Wechsel, Geldanweisungen und Abrechnungsanstalten weit älter.

2) Beide gehören der ersten Hälfte des 14. Jahrhunderts an. 
Wien und Heidelberg. Zwar waren auch sie anfangs vorwiegend Stätten scholastischen Gezänks. Die Gelehrten waren jedoch vom klösterlichen Zwange befreit worden, ein Umstand, der fuir die Folge von großer Bedentung war. Um der Beengung zu entgehen, welche die Kirche während des Nittelalters jeder wissenschaftlichen Betätigung auferlegte, erfand man den Satz von der zwiefachen Wahrheit. Man verstand darunter die Lehre, es könne etwas in kirchlichen Dingen als wahr gelten, was in der Wissenschaft als falsch bewiesen sei. Dieselbe Person durfte somit, je nachdem sie sich auf den Standpunkt des Philosophen oder des Theologen stellte, ein und dieselbe Ansicht für richtig halten und sie in demselben Atemzuge verdammen ${ }^{1}$ ).

Man darf dieses auf den ersten Blick ganz unmoralisch erscheinende Verhalten nicht allzusehr verurteilen. Gilt doch auch heute noch für manchen der Satz, daß Glauben und IVissen als unvereinbare Gebiete scharf zu trennen sind, während man sich auf der anderen Seite bemüht, beide miteinander zu versöhnen. Man muß daher den zuerst in Paris und in Padua aufkommenden Satz von der zwiefachen Wahrheit als den ersten Versuch der Forschung ansehen, sich aus den Banden der Kirche zu befreien. Diese Lehre ist, sagt einer ihrer Beurteiler ${ }^{2}$, „ein Denkmal des forschenden Geistes, sich ein freies, weites Gebiet zu verschaffen". Insbesondere gelangte der Geist der wiederauflebenden Wissenschaften in zwei Männern zum Ausdruck, deren Lebensumstände und Verdienste uns zunächst beschäftigen sollen. Es waren dies Albertus Magnus in Deutschland und sein Zeitgenosse Roger Bacon in England.

Beide Männer gehören dem 13. Jahrhundert an. Es war die Zeit des großen Staufenkaisers Friedrichs des Zweiten und seines vergeblichen Ringens mit dem Papsttum. In das 13. Jahrhundert fallen einerseits die letzten Kreuzzïge und das Umsichgreifen der von fanatischen Mönchen geübten Ketzergerichte, während auf der anderen Seite Handel und Gewerbe, sowie die Schulen aufzublühen begannen. Auch auf dem Gebiete des geistigen Werdens war diese Zeit erfüllt ron Gegensätzen. Bis gegen das 13. Jahrhundert

1) Diese Lehre war aber nicht allgemein angenommen. (Bemerkung von Würschmidt.)

2) M. Maywald, Die Lehre von der zwiefachen Wahrheit, ein Beitrag zur Geschichte der scholastischen Philosophie. Berlin 1861. Siehe auch J. Tyndall, Religion und Wissenschaft, sowie Langes Geschichte des Materialismus. 
hatte im Mittelalter ausschließlich die Macht der Kirche und ihrer Dogmen gegolten. Die philosophischen Schriften des Altertums, insbesondere die Logik des Aristoteles, hatten Geltung, weil sie spitzfindigen, theologischen Streitigkeiten zu dienen vermochten. Was indessen die naturwissenschaftlichen Werke des Aristoteles anbetraf, so war fast jede Erinnerung an sie verloren gegangen. Auch die Auffassung von der Natur war zu einem Zerrbilde geworden. Hatten die älteren Kirchenväter sie zum Teil noch als einen Spiegel göttlicher Weisheit angesehen, so hatte später eine geradezu verächtliche Vorstellung Platz gegriffen. Die Natur erschien dem Mensehen des eigentlichen Mittelalters im trïben Widerschein einer Teufelslehre, geeignet, ihn mit Sinnenlust zu umstricken und von seiner, im Überirdischen ruhenden Bestimmung abzulenken.

Man kann sich rorstellen, welchen Eindruck auf ein so geartetes Geschlecht das überraschend schnell erfolgende Bekanutwerden der naturgeschichtlichen Schriften des Aristoteles zu Beginn des 13. Jahrhunderts ausiiben mußte. In lateiniseher, teils aus dem Arabischen, teils aus griechischen Originalen geschöpfter Übersetzung, verbreiteten sie sich bald iiber das ganze Abendland. Mit den griechischen Originalen war man im Verlauf der späteren Kreuzzuige in Konstantinopel und an anderen Orten des Orients bekannt geworden 1). Wie ganz anders stellte sich in diesen, die Gemuiter wie eine neue Offenbarung ergreifenden Werken die Welt dar. Sie war hier nicht die Inkarnation des Bösen und die Quelle der Verdammnis, sondern „ein wunderbar lrarmonisches, ineinander greifendes Geflecht vernünftiger Zwecke und Mittel" 2), deren Erforschung als die wïrdigste Aufgabe des denkenden Menschen hingestellt wurde. Daß dic Kirche der geschilderten Bewegung der Geister gegenïber nicht gleichguiltig blieb, läßt sich denken. So verfiigte sie z. B. im Jahre 1209 in Paris, daß bei Strafe der Exkommunikation weder die naturwissenschaftlichen Schriften des Aristoteles, noch die Kommentare dazu, sei es öffentlich, sei es insgeheim, gelesen werden dïrften.

1) Jourdain, Geschichte der aristotelischen Schriften im Mittelalter, iibersetzt von Ad. Stahr. Halle 1831.

2) Meyer, Geschichte der Botanik. Bd. IV. S. 


\section{Albertus Magnus.}

Ein Mann war es vor allem, in welchem die Naturphilosophie des Aristoteles einen begeisterten Vertreter fand. Das war. Albertus Magnus. Das Bild seines Lebens und Wirkens wird uns deshalb am besten in den geschilderten Zeitraum $\mathrm{zu}$ versetzen vermögen.

Albertus Magnus, dessen eigentlicher Name Albert von Bollstätt lautet, wurde zu Beginn des 13. Jahrhunderts in einem schwäbischen Städtchen geboren ${ }^{1}$. Er empfing seine Vorbildung in Padua. Später lehrte er an der Dominikanerschule zu Köln, zeitweilig auch an der Universität in Paris, wo sein Orden einige Lehrstühle besetzen durfte. In die Zeit seines Kölner Aufenthaltes fallen die Ausschachtungsarbeiten zur Fundamentierung des Domes. In Paris fand er einen solchen Zulauf, daß kein Gebäude die Schar seiner Hörer zu fassen vermochte. An Wissensdrang fehlte es im 13. Jahrhundert also nicht, wohl aber an einem würdigen Gegenstand zur Befriedigung dieses Dranges. Handelte es sich doch nur um Schriftwerke, die durch Übersetzungen bekannt wurden. Ihr Inhalt war es, welcher das damalige Wissen ausmachte. Jede selbständige Regung wurde durch einen Autoritätsglauben niedergehalten, wie ihn kein Zeitalter in solchem Grade wieder besessen hat. Verfolgung und Tod trafen denjenigen, der sich gegen diesen Autoritätsglauben, der alles mit Blindheit geschlagen zu haben schien, auflehnte. Man darf daher auch von Albertus Magnus nicht allzuviel Eigenes erwarten, wenn er auch zu den hervorragendsten Gelehrten gehört, die uns in der Geschichte des Mittelalters begegnen. Ihm ist es vor allem zu danken, daß man auf dem Gebiete der Naturwissenschaften wieder an die Schriften des Altertums anknüpfte. Und zwar begann man auf den griechischen Texten zu fußen, die zum Teil um diese Zeit schon von Konstantinopel aus in das Abendland gelangten, während man vorher die arabischen Bearbeitungen in das Lateinische übertragen hatte, eine zwiefache Hinüberleitung, durch welche der Inhalt entstellt und unrichtig übermittelt worden war.

Was man vor Albertus Magnus an Kenntnissen über die Tier- und Pflanzenwelt besaß, verdiente kaum noch den Namen

1) In Lauingen. Als Geburtsjahr ist neuerdings mit großer IVahrscheinlichkeit das Jahr 1207 nachgewiesen (Enders im Histor. Jahrbuch der Görresgesellschaft. 1910. S. 293). 
einer Zoologie und Botanik. Einiges Interesse brachte man zwar den in der Bibel erwähnten Geschöpfen entgegen, die in dem "Physiologus", einem sehr verbreiteten, in vielen Bearbeitungen vorhandenen Buche, behandelt wurden 1). Es enthielt indessen die unglaublichsten Fabeln. Trotzdem erfüllte der Physiologus fast 1000 Jahre die Rolle eines elementaren zoologischen Lehrbuches ${ }^{2}$, wenn auch nicht eines solchen in unserem Sinne, da er in den Schulen in erster Linie zu religiös erbaulichen Zwecken benutzt wurde ${ }^{3}$ ). Beriicksichtigt sind besonders Säugetiere und Vögel, ferner einige Reptilien und Amphibien und nur ein Geschöpf aus der Reihe der Gliedertiere, nämlich die Ameise. An Pflanzen kommen der Feigenbaum, der Schierling und die Nießwurz in Betracht. Auch einige Mineralien werden erwähnt; es sind der Diamant, der Achat, der „indische Stein“, welcher die Wassersucht heilen sollte, und die feuerbringenden Steine.

Noch dürftiger erscheint dieser Inhalt, wenn man bedenkt, daß der Physiologus nicht etwa eine einigermaßen vollständige Schilderung der erwähnten Geschöpfe enthält, sondern meist nur Hinweise auf Bibelstellen, einzelne Züge aus der Lebensweise, Erzählungen und Fabeln. So wird vom Panther erzählt, daß er bunt sei, nach der Sättigung drei Tage schlafe, dann mit Gebrüll erwache und einen so angenehmen Geruch verbreite, daß alle Tiere zu ihm kämen; nur der Drache sei sein Feind. Der Prophet Hosea sage: Ich werde wie ein Löwe sein dem Hause Juda und wie ein Panther dem Hause Ephraim usw. An die meisten Tierfabeln werden moralische Bemerkungen geknüpft. Von den Affen heißt es, man fange sie, indem man sie veranlasse, sich die Augen mit Leim zu verschmieren. So jage uns der Teufel mit dem Leim der Sünde. Wie der Biber sich die Hoden abbeiße, wenn man ihn verfolge, so solle der Mensch seine bösen Leidenschaften austilgen usw. Auch bloße Fabelwesen, wie die Sirenen und das in der Bibel mehrfach erwähnte Einhorn, bilden einen Gegenstand verschiedener Ausgaben des Physiologus. Welch gewaltiger Abstand zwischen dem mittelalterlich-kirchlichen Natur-

1) Siehe auch Peters, Der griechische Physiologus und seine orientalischen Übersetzungen. Berlin 1898. Das genannte Werk enthält auch eine Geschichte der merkwürdigen Schrift.

2) MI. Goldstaub, Der Physiologus und seine Weiterbildung, besonders in der lateinischen und byzantinischen Literatur. Philologus, 1901. Supplementband 8,3 .

3) H. Stadler, Neue Jahrbücher f, d. klass. Altertum. 1911. S. 86. 
wissen und demjenigen der Bluitezeit des griechischen Geisteslebens bestand, braucht nach dieser Probe nicht weiter ausgeführt zu werden.

Der älteste Physiologus entstand im 2. Jahrhundert n. Chr. in Alexandrien. Auf dieser griechischen Schrift beruhen eine Anzahl orientalischer Bearbeitungen der biblischen Zoologie. Albertus Magnus schöpfte aus einem lateinischen Physiologus, der auch ins Althochdeutsche und andere nordische Sprachen übersetzt wurde. In erster Linie ist aber das zoologische Werk Alberts, das in 26 Bücher zerfällt, eine Wiedergabe der zoologischen Schriften des Aristoteles. Indessen verraten insbesondere die letzten Bücher eine größere Selbständigkeit. Auch die Naturgeschichte des gleichfalls dem 13. Jahrhundert angehörenden Thomas ron Cantimpré hat Albert benutzt, doch ist dasjenige, was er selbst uns bietet, weit durchgearbeiteter. Daß sich bei ihm noch die alten anatomischen Unrichtigkeiten des Aristoteles finden, darf nicht wundernehmen. So nennt er gleichfalls die Sehnen Nerven und legt ihnen die eigentliche bewegende Kraft bei. Er läßt sie aus dem Herzen entspringen, während er von den eigentlichen Nerven noch keine Vorstellung hat $\left.{ }^{1}\right)$.

Albertus Magnus hat eine sehr umfangreiche literarische Tätigkeit entfaltet ${ }^{2}$. Eine allerdings nur mangelhafte Ausgabe seiner sämtlichen Werke rührt von Jammy her; sie erschien in 21 Foliobänden im Jahre 1651. Der 2., 5. und 6. Band enthalten die naturwissenschaftlichen Schriften. Der 2. Band enthält neben einer Wiedergabe der aristotelischen Physik die Grundzüge der Himmelskunde und fünf Bücher über die Mineralien. Bemerkenswert ist, daß Albert die Milchstraße für eine Anhäufung kleiner Sterne hielt, sowie seine Meinung, das Erscheinen der Kometen könne nicht mit den Geschicken einzelner Menschen verknüpft sein. Der 5. Band bringt Geographisches, sowie die sieben Bücher über die Pflanzen. Hervorgehoben sei eine Äußerung über die Antipoden. Nur rohe Unwissenheit, meint Albertus, könne behaupten, daß diejenigen fallen müßten, die uns die Füße zu-

1) Carus, Geschichte der Zoologie. S. 231.

2) Eingehender wird Albertus Magnus gewürdigt in E. Meyer, Geschichte der Botanik. Bd. IV. S. 9-84. Vgl. auch Fellner, Albertus Magnus als Botaniker. Wien 1881.

Eine kritische Ausgabe der botanischen Schriften rührt von E. Meyer und K. Jessen her: Alberti Magni de vegetabilibus libri VII. Berlin 1867. 
kehrten. Der 6. Band der Gesamtausgabe endlich umfaßt die 26 zoologischen Bücher.

Das Verdienst Alberts besteht darin, daß er über alle Dinge, über die er aristotelische Schriften kannte, ausführlich schrieb. Dabei leiteten ihn einerseits offener Sinn und liebevolle Hingabe an die Natur. Andererseits beengte ihn das Streben, die Naturauffassung des Altertums mit den Dogmen der katholischen Kirche in Einklang zu bringen. Aus dieser Abhängigkeit sich zur Freiheit des Denkens durchzuringen, war ihm nicht gegeben. Den Vortrag der aristotelischen Lehren wußte Albertus mit seinen eigenen Ansichten in der Weise zu vereinigen, daß er zunächst dem Aristoteles folgt und dann jedesmal hinzufügt, er wolle eine Disgression einschalten. Als eine solche ist das ganze zweite Buch der Botanik zu betrachten $\left.{ }^{1}\right)$. Es beginnt mit den Worten: „Das alles - nämlich den Inhalt des ersten Buches - haben die alten Naturforscher begründet. Doch scheint das etwas verworren zu sein. Ich werde daher von neuem beginnen und die allgemeine Botanik nach der Ordnung der Natur geben."

Daß Albertus auch auf anderen Gebieten nach Selbständigkeit strebte ${ }^{2}$ ), bezeugen die Worte, mit denen er die spezielle Botanik einleitet. Sie lauten: „Was ich hier schreibe, habe ich teils selbst erfahren, teils verdanke ich es Leuten, von denen ich überzeugt bin, daß sie nur das vorbringen, was sie selbst erfahren haben." Bei dem Wissen von den Einzelwesen handele es sich allein um Erfahrung, da hier Vernunftschliisse nicht möglich seien. Trotzdem finden sich, besonders bei der Beschreibung der Tiere, dem Geist der Zeit entsprechend, manche alten Fabeln wieder.

Sein Werk über die Pflanzen schrieb Albert in Anlehnung an eine Schrift ${ }^{3}$, die damals für aristotelisch gehalten wurde. Es umfaßt sieben umfangreiche Bücher und gehört zu den bedeutendsten älteren Werken botanischen Inhalts. Von Aristoteles, dem Begründer der Botanik, bis auf die Zeit Alberts des Großen war diese Wissenschaft immer tiefer gesunken; mit Albert erstand sie "wie der Phönix aus seiner Asche"4).

1) H. Stadler, Albertus Magnus als selbständiger Naturforscher (Folschungen zur Geschichte Bayerns. Bd. 14. S. 95-114).

2) H. Stadler a. a. O.

3) Des Nikolaos Damaskenos.

4) E. Meyer, Geschichte der Botanik. Bd. IV. S. 40.

Anzuerkennen waren jedoch die Verdienste der Araber um die Botanik. (Bem. von F. Wiedemann.) 
Zuerst befaßt sich Albert mit den Grundzügen der allgemeinen Botanik. Insbesondere beschäftigt er sich mit der Frage, ob die Pflanze beseelt ist. Sie ist es, führt er aus, gleich jedem Körper, der sich aus eigener Kraft bewegt. Ohne jene Bewegung sei kein Wachstum, keine Ernährung und keine Fortpflanzung möglich. Auf diese Funktionen beschränke sich indes die Tätigkeit der Pflanzenseele. Diesem geringen Umfang ihrer Tätigkeit entspreche auch die geringe äußere Verschiedenheit der Pflanzenteile, sowie das Vermögen der Pflanze, aus jedem ihrer Teile wie aus dem Samen neues zu erzeugen.

Bemerkenswert sind auch die Äußerungen Alberts über den Schlaf der Pflanzen. Wenn die Pflanze während des Winters infolge der Kälte zusammengezogen und ihr Saft und ihre Wärme nach innen zurückgedrängt seien, so schlafe sie. Daß einige Pflanzen ihre Blüten abends zusammenlegen und bei Tagesanbruch wieder öffnen, wird auch als Schlaf gedeutet.

Bezüglich der Sexualität räumt Albert den Pflanzen nur eine sehr entfernte Ähnlichkeit mit den Tieren ein. Das Wachstum der Pflanzen, so meint er im Hinblick auf die Eiche, die Zeder und andere Bäume, scheine wie das der Mineralien an kein bestimmtes $\mathrm{MaB}$ gebunden zu sein. Das Fehlen der Sinnes- und der Bewegungsorgane, durch die sich das höhere tierische Leben bekunde, sei der Grund, weshalb die Wurzel, als Mund der Pflanze, in die Erde gesenkt sei. Ströme die Nahrung nicht von selbst herbei, umgäbe sie die Wurzel nicht unablässig, so könne die Pflanze gar keine Nahrung zu sich nehmen. Würde ferner die geringe Eigenwärme der Pflanze nicht von außen durch die Sonnenwärme unterstuitzt, so würde jene allein nicht hinreichen, den eingesogenen Nahrungsstoff zu verdauen und zum Wachstum und zur Fortpflanzung geeignet zu machen.

$\mathrm{Da}$ also die Pflanze ihre Nahrung auf weit einfachere Weise $\mathrm{zu}$ sich nimmt und in sich verteilt wie das Tier, so hat sie nach Albert weder Adern, noch einen Magen, sondern nur Poren, wie sie auch das Tier unsichtbar auf seiner ganzen Oberfläche besitze. Alberts Kenntnisse in der speziellen Botanik, die er im 6. Buche bekundet, sind nicht gering. Doch teilt er mit vielen Schriftstellern des Altertums den Glauben an eine Umwandlung der Pflanzen. So sollen sich infolge des Alterns oder infolge mehr oder weniger guter Nahrung die Getreidearten ineinander umwandeln können. Auch entständen durch die Fäulnis einer Pflanze andere Arten. So überziehe sich ein kränkelnder Baum mit Parasiten, namentlich mit Misteln. 
Alberts Darstellung der allgemeinen Botanik ist der erste Versuch einer solchen. Denn was er in der Schrift des Nikolaos vorfand, hat sein Unternehmen eher ungünstig beeinflußt als gefördert. Es verstrichen Jahrhunderte, bevor ein zweites, dem seinigen vergleichbares Werk erschien. „Die Fehler des letzteren verschuldete sein Zeitalter, die Vorziige gehören ihm allein an"1). In seiner speziellen Botanik handelt Albert von den Bäumen und Sträuchern, den Stauden und Kräutern. Die Anordnung ist die alphabetische. Die Schärfe der Beobachtungen ist anzuerkennen. Beschreibungen von einer Genauigkeit, wie sie uns im Altertum nicht begegnet, widmete er z. B. der Esche und der Erle, dem Mohn, dem Borretsch und der Rose.

Seit Albertus Magnus war man auch bestrebt, die von den Alten beschriebenen Pflanzen wieder aufzufinden. Dies Bemühen war jedoch nur von geringem Erfolg, da einmal die vorhandenen Beschreibungen meist nicht hinlänglich genau waren, um danach die Arten feststellen zu können, und da man ferner, ohne Berücksichtigung der geographischen Verbreitung, die Pflanzen Griechenlands und Kleinasiens in Mitteleuropa suchte. Immerhin war es ein großer Fortschritt, daß man sich mit den Naturkörpern wieder unmittelbar zu beschäftigen begann. Die Wiederbelebung der beschreibenden Naturwissenschaften war in erster Linie die Folge eines solchen Bemühens. Dieses führte weiterlin zur Anlegung von botanischen Gärten und zur Herausgabe von Kräuterbüchern, den ersten botanischen Dingen, die uns an der Schwelle der neueren Zeit begegnen.

Von Albert dem Großen bis zur zweiten Hälfte des 15. Jahrhunderts waren die Fortsclrritte auf dem Gebiete der Botanik im übrigen nur gering ${ }^{2}$. Manche Nachricht über neue Pflanzen gelangte ans den durcl die Kreuzzüge dem Abendlande erschlossenen Ländern nach Europa, jedoch ohne daß dadurch die wissenschaftliche Einsicht wesentlich gefördert worden wäre. Auch durch die Reisen Marco Polos in Ostasien erfuhr die spezielle Pflanzenkenntnis eine nicht unbeträchtliche Erweiterung, wenn es sich naturgemäß in den Mittcilungen dieses Mannes auch

1) E. Meyer, Geschichte der Botanik.

2) Auch nach Warburg (Berichte der Deutschen botan. Gesellschaft. 1901. S. 153) hat das Mittelalter weder für die wissenschaftliche, noch für die angewandte Botanik neue Bahnen erschlossen, wenn auch die Araber auf dem Gebiete der Heilmittellehre manche neue 'Tatsache fanden. 
in erster Linie um solche Pflanzen handelte, die für den Handel in Betracht kamen.

TVie die botanischen, so enthalten auch die zoologischen Schriften des Albertus zahlreiche Angaben über eigene Beobachtungen. Insbesondere gilt dies von der deutschen Tierwelt. Es finden sich z. B. recht gute Schilderungen des Maulwurfs, der Spitzmaus, des Eichhörnchens und des Tgels. Albert führt fast alle deutschen Nager auf und zeichnet das Treiben des Eichhörnchens ganz musterhaft. Sehr zutreffend beschreibt er auch das Gebiß der Nagetiere. Erwähnung findet auch der Eisbär. Vom Walroß wird erzählt, daß es lange Eckzähne besitze, und daß man seine Haut zu Riemen zerschneide, die in Deutschland in den Handel kämen. Ferner wird der Grönlandwal beschrieben und sein Fang geschildert. Die Robben und die Delphine bezeichnet Albert als „Säugetiere mit festen Knochen, lebenden Jungen und einer Luftröhre“. Er fügt hinzu: „Die Angaben der Alten übergehe ich, demn sie stimmen mit denen erfahrener Leute nicht überein." Über die Gliedertiere macht Albertus sogar die Angabe, daß sich beim Krebs und Skorpion ein dem Rückenmark entsprechender Strang findet, der auf der Bauchseite durch den Körper lïuft. Das Treiben des Ameisenlöwen schildert er mit folgenden Worten: ..Der Ameisenlöwe ist nicht vorher eine Ameise, wie viele sagen. Denn ich habe oft beobachtet und habe es häufig Freunden gezeigt, daß dieses Tier Zeckengestalt hat. Es versteckt sich im Sande und gräbt darin eine halbkugelförmige Höhle, in deren Pol sein Mund ist. Läuft nun eine Ameise futtersuchend darüber, so fängt und frißt er sie. Dem haben wir oft zugesehen" 1 ).

Albertus Magnus war auch einer der ersten, der sich in Deutschland auf dem Gebiete der Chemie schriftstellerisch betätigte, ohne sich jedoch über die Araber zu erheben. Daß unedle Metalle sich in edle verwandeln lassen, war für ihn eine ausgemachte Sache. Dies geht aus dem von ihm verfaßten Werk "De rebus metallicis et mineralibus" mit Bestimmtheit hervor. Albertus glaubte auch an die Darstellbarkeit eines Elixiers, das

1) Nach H. Stadler, Albertus Magnus von Cöln als Naturforscher und das Kölner Autogramm seiner Tiergeschichte. Leipzig 1908.

Nach der Kölner Handschrift, welche nach Stadler von den vorhandenen Handschriften die beste ist, hat der Genannte eine Ausgabe der Tiergeschichte des Albertus Magnus veranstaltet: Albertus Magnus, De animalibus libri XXVI. Nach der Cölner Urschrift. Erster Band, Buch I-XII enthaltend. Münster i. W., Aschendorff. 1916. 
imstande sei, allen Metallen die schönste Goldfarbe zu verleihen. Er warnte zwar vor scheinbaren Umwandlungen, indessen wurden durch das hohe Ansehen, das er genoß, die alchemistischen Bestrebungen gefördert 1 ).

Auszüge aus dem Werke "De rebus metallicis et mineralibus" sind durch Kopp bekannt geworden 2). Aus ihnen geht hervor, daß es sich bei Albertus Magnus zum Teil um rein aristotelische, zum Teil um arabische Meinungen und Anschauungen handelt. Er nimmt an, daß die Metalle wie alles aus den vier Elementen zusammengesetzt sind. Bestehen sie auch zunächst aus Schwefel und Quecksilber, so ist ersterer doch wieder aus Luft und Feuer, das Quecksilber dagegen aus Wasser und Erde entstanden.

\section{Roger Bacon.}

Ein fast noch höheres Interesse als der „Doctor universalis“, wie man Albertus Magnus nannte, beansprucht Roger Bacon, der "Doctor mirabilis". Seine Schriften umfassen nicht nur die Naturbeschreibung, die Chemie und die Physik, sondern alle Wissenszweige, insbesondere auch die Philosophie und die Theologie. Der englische Franziskanermönch Roger Bacon ist ferner einer der ersten in der Reihe der Märtyrer, welche die Geschichte seit der Zeit des Wiederauflebens der Wissenschaften aufzuweisen hat.

Roger Bacon wurde im Jahre 1214 geboren ${ }^{3}$ ). Er studierte in Paris und dann in Oxford, wo er später ein Lehramt bekleidete. Von großem Einfluß auf die Entwicklung Bacons war Petrus Peregrinus, der in Paris lehrte und als Experimentator gerïhmt wurde. Bacon sagt von ihm, was dunkel sei, ziehe Peregrinus als Meister des Experiments ans Tageslicht4). Auch daß dieser für seine Zeit seltene Mann keine Wortgefechte liebte, sondern Beweise und Tatsachen verlangte, war für Peregrinus charakteristisch und für Bacon, der das Wort „Scientia experimentalis“

1) Die Albertus Magnus zugeschriebenen, eigentlich alchemistischen Werke sind nach E. v. Lippmann als Fälschungen zu betrachten.

2) Kopp, Beiträge z. Geschichte der Chemie. 3, 64 u. f.

3) Das Geburtsjahr steht nicht fest. Die Angaben schwanken zwischen 1210 und 1214. Doch nimmt man wohl meist 1214 an. (Feier in Oxford 1914. Vgl. „Die Roger Bacon-Commem.".)

4) Sebastian Vogl, Die Physik Roger Bacons. Inaug.-Dissertation. Erlangen 1906. 
prägte, von bestimmendem Einfluß ${ }^{1)}$. Schon Gerbert2) hatte übrigens die Beschäftigung mit der Natur als Gegengewicht gegen die scholastischen Streitereien empfohlen. Bacon tat dasselbe, indes mit größerem Nachdruck ${ }^{3}$ ). Als Quellen für seine Naturlehre benutzte Bacon die Griechen (Aristoteles, Euklid, Ptolemäos), die Römer (Plinius, Boëtius, Cassiodor) und die Araber. Unter den letzteren sind vor allem Avicenna (Ibn Sina) und Al Farabi zu nennen. Das Werk des letzteren, das eine Art Enzyklopädie darstellt, hatte Gerhard von Cremona unter dem Titel "Liber de scientiis" ins Lateinische übersetzt. Bacon besa $\beta$ nicht nur die umfassende Gelehrsamkeit eines Albertus Magnus, sondern er zeichnete sich vor diesem durch größere Klarheit und Freiheit des Denkens aus. In seiner Schrift über die Nichtigkeit der Magie ${ }^{4}$ ) bekämpfte Bacon den Glauben an die Zauberei. Den Anhängern dieses Glaubens verdankte er selbst gegen das Ende seines Lebens eine zehnjährige Kerkerhaft. Sehr wahrscheinlich hat jedoch die Anklage auf Zauberei seinem Orden nur als Vorwand gedient, um ihn daran zu hindern, daß er fortfuhr, gegen die kirchlichen Mißstände zu eifern. Besaß doch Bacon die Kühnheit, auf eine Reformation der Kirche an Haupt und Gliedern, sowie auf eine kritische Behandlung der heiligen Schrift auf Grund der Urtexte zu dringen.

$\mathrm{DaB}$ die Menschen in früheren Jahrhunderten nicht viel anders gewesen sind als heute, lassen folgende Stellen aus Bacons „Compendium studii theologiae" erkennen: "Das Haupthindernis für das Studium der Weisheit ist die unermeßliche Verderbnis, die in allen Ständen herrscht. Der ganze Klerus ist dem Hochmut, der Unzucht und der Habsucht ergeben. Wo Kleriker zusammenkommen, geben sie dem Laien Ärgernis. Die Fürsten und Herren drücken und plündern sich gegenseitig und richten das

1) Von Peregrinus ist noch eine Schrift über den Magneten erhalten. Peregrinus unterschied die Pole des Magneten und wies die Anziehung der ungleichnamigen Pole nach.

2) Gerbert war in Frankreich geboren. Er besuchte die arabischen Hochschulen in Sevilla und Cordova und wurde im Jahre 999 zum Papst gewählt; als solcher führte er den Namen Sylvester II.

3) Vogl a. a. O.

4) Epistola de secretis artis et naturae operibus atque nullitate magiae. 1260. Eine Ausgabe dieser Schrift erschien im Jahre 1542 in Paris.

Ausführlich über Bacon handelt Siebert, Roger Bacon, sein Leben und seine Philosophie. Marburg 1861. 
ihnen untertänige Volk durch Krieg und Steuern zugrunde. In den Königreichen geht man nur auf Vergrößerung aus. Man kümmert sich nicht darum, ob etwas mit Recht oder mit Unrecht erreicht wird, wenn man nur seinen Plan durchsetzt. Die oberen Stände dienen nur dem Bauch und den fleischlichen Lüsten. Das Volk wird durch dies schlechte Beispiel aufgereizt und zu Haß und Treubruch veranlaßt, oder es wird durch das schlechte Beispiel der Großen verdorben. Unzucht und Genußsucht sind schlimmer, als man es schildern kann. Bei den Kaufleuten herrschen List, Betrug, maßlose Falschheit usw. "So sieht Bacons Sittengemälde aus dem 14. Jahrhundert aus.

Was Bacon anstrebte, war eine freiere Gestaltung des religiösen Lebens. Und zwar geschah dies fast zur selben Zeit, als die Albigenser Südfrankreichs ihren Abfall von der Kirche schwer büßen mußten. Wenn Bacons Mahnung auch verhallte und nicht imstande war, einen Sturm zu entfesseln, wie ihn z. B. das Auftreten eines $\mathrm{HuB}$ zur Folge hatte, so verdient $B$ acon doch unter den Vorboten der Reformationsbewegung genannt zu werden. Daß er sich der Autorität des Aristoteles nicht unbedingt unterwarf, war für die damalige Zeit ein nicht geringeres Verbrechen.

Andererseits vermag auch Bacon es nicht, sich gänzlich von den Fesseln der griechischen Philosophie und der mittelalterlichen Theologie zu befreien. So hält er mit Aristoteles an dem Glauben fest, daß die Welt räumlich begrenzt sei. Er sucht auch dialektisch zu beweisen, daß es nicht mehrere Welten oder gar eine unendliche Welt geben könne. Erst viel später, bei Giordano Bruno, tritt uns der Begriff des unendlichen Alls entgegen. Wie Aristoteles, so weist auch Bacon mit dialektischen Gründen die Lehre vom Vakuum zurück, das die von Aristoteles bekämpften Anhänger der Atomenlelire als notwendige Voraussetzung für die Bewegung der Atome angenommen hatten $\left.{ }^{1}\right)$. Als Herrin der Wissenschaften gilt Bacon nicht die Philosophie, sondern die Theologie. Wenn ein Wissen, meint er, der heiligen Schrift widerspricht, so ist es irrig ${ }^{2}$ ). Innerhalb dieser Beschrïnkung verlangt er eine Erneuerung der Wissenschaften und eine Begriindung der Naturwissenschaften auf Beobachtung und Versuch. Manches, was später, im 16. Jahrluundert, sein Namensvetter Francis Bacon

1) Bacon, Opus tert. cap. 43. Siehe auch K. Werner, Die Kosmologie und allgemeine Naturlehre des Roger Baco. Wien 1879.

2) Opus majus cap. 1. 
gesagt hat, klingt an die schon von Roger Bacon ausgesprochenen Mahnungen und Forderungen an. „Diejenigen, die in den Wissenschaften neue Bahnen einschlugen ", sagt Roger Bacon"), "hatten alle Zeit mit Widerspruch und Hindernissen zu kämpfen. Doch erstarkte die Wahrheit und wird erstarken bis zu den Tagen des Antichrist". Für die Wissenschaft gibt es nach Bacon drei Wege, die Erfahrung, das Experiment und den Beweis. Insbesondere wird die Mathematik gepriesen, aber auch der Sprache, als dem formalen Ausdruck des Denkens, wird die größte Bedeutung beigelegt. So heißt es bei ihm: "Wir müssen bedenken, daß Worte den größten Eindruck ausüben. Fast alle Wunder sind durch das Wort vollbracht worden. In den Worten äußert sich die höchste Begeisterung. Deshalb haben Worte, welche tief gedacht, lebhaft empfunden, gut berechnet und mit Nachdruck gesprochen werden, eine bedeutende Gewalt."

Selbst wenn man annimmt, daß Bacons Wissen vollständig auf den alten Schriftstellern und den Arabern beruhe, muß man doch zugeben ${ }^{2}$ ), daß er kein bloßer Kompilator war, sondern das Vorhandene zu prüfen, sich anzueignen und selbständig wiederzugeben verstand. Sein Hauptverdienst bleibt aber, daß er zu den ersten Männern zählt, die auf den Weg des eigenen Forschens im Gegensatz zum Autoritätsglauben, hingewiesen haben, wenn es ihm selbst auch noch an Mitteln gebrach, diesen Weg unbeirrt zu verfolgen. Aus diesem Mangel an Befriedigung eines vorhandenen Dranges entspringt eine gewisse Sehnsucht, die sich darin ausspricht, daß Bacons Schriften mit luäufigen Ausblicken auf eine größere Herrschaft des Menschen über die Natur erfüllt sind ${ }^{3}$ ). Dieser Grundzug seines Wesens wird uns im 17. Jahrhundert bei seinem Namensvetter Franz Bacon wieder begegnen. Und es erscheint nicht ausgeschlossen, daß letzterer Roger mehr zu verdanken hat, als er durchblicken läßt4). Man kann dies als wahrscheinlich annehmen, ohne damit den späteren Bacon etwa des Plagiats bezichtigen $\mathrm{zu}$ wollen.

1) Opus majus cap. 13.

2) Vogl, Die Physik Roger Bacons.

3) Bacon erklärt die Förderung des geistigen und materiellen Wohlseins als Zweck sämtlicher Wissenschaften. Doch gibt es nach Bacon ein noch höheres Ziel, das er in dem Wort ausspricht: „Humana nihil valent nisi applicentur ad divina" (Opus majus p. 108).

4) Döring, Die beiden Bacon (Archiv für Geschichte der Philosophie. 1904. S. 341 ). 
Bacons Hauptwerk führt den Titel „Opus majus“. Es wurde 1267 vollendet und von $\mathrm{Bacon}$ dem Papste $^{1}$ ) gewidmet ${ }^{2}$. Im ersten Teil des Opus majus spricht Bacon von den Hauptursachen der herrschenden Unwissenheit. Als solche gelten ihm die Eitelkeit und der Autoritätsglaube, die althergebrachten Vorurteile und die zahlreichen unrichtigen und unzulänglichen Begriffe. Der zweite Abschnitt bietet einen Überblick iiber die Fundamente, welche die Griechen und die Araber geschaffen. Im Mittelpunkte dieser Darstellung steht selbstverständlich Aristoteles, von dem in freimütiger Kritik gezeigt wird, daß seine Schriften weder erschöpfend noch frei von Fehlern seien. Um die bisherigen Leistungen wiirdigen zu können, fordert Bacon im dritten Abschnitt das Studium der Urtexte an Stelle des bis dahin üblichen Lesens lateinischer und arabischer Übersetzungen. Vor allem stellt er diese Forderung in bezug auf die Bibel und die Schriften des Aristoteles auf. Der vierte Abschnitt handelt von der Mathematik, einschließlich der Astronomie und ihrer Anwendungen. Bacon erkannte die Fehlerhaftigkeit des julianischen Kalenders und machte dem Oberhaupt der Kirche Verbesserungsvorschläge. Der julianische Kalender, so führt er aus, rechne das Jahr zu $3651 / 4$ Tagen. Es sei aber erwiesen, daß es kürzer sei und in 130 Jahren ein Tag zuviel gerechnet werde.

Der nächste Abschnitt, der sich auf Alhazen stiitzt, laandelt von der Optik. Die Reflexionen durch parabolische Spiegel, sowie die Anatomie und Physiologie des Auges sind so klar und treffend dargestellt, daß diese Abschnitte besonders den fortgeschrittenen Standpunkt Bacons erkennen lassen. Den eigentlichen Vorgang des Sehens verlegt er in das Gehirn, mit der Begrün-

1) Clemens IV.

2) Eine Neuausgabc veranstaltete J. H. Bridges. London 1897-1909. 3 Bände. Das Werk enthält den lateinischen Text und eine ausfiihrliche Analyse jedes Kapitels in englischer Sprache, ferner eine Einleitung über das Leben und die Bedentung Bacons.

Eine ältere unzuverlässige Ausgabe wurde von Jebb (London 1733) herausgegeben.

Zur Feier des 700. Geburtstags Bacons erschien 1914 ein Erinnerungsband, der Abhandlungen über Bacons wissenschaftliche Täigkeit und Bedeutung enthält (Oxford, Clarendon press, 1914). Genannt seien: F. Picavet (Paris), La place de Roger Bacon parmi les philosophes du XIIIe siècle. E. Smith (New York), The place of R. Bacon in the history of mathematics. - E. Wiedemann (Ġlangen), R. Bacon und seine Verdienste um die Optik. - Pierre Duhem (Bordeaux), Roger Bacon et l'horreur du vide. - Pattison Muir (Cambridge), Roger Bacon, his relations to alchemie and chemistry. 
dung, daß sich nur so die Vereinigung der in den beiden Augen entstehenden Sinneseindrücke zu einer einzigen Wahrnehmung erklären lasse ${ }^{1}$ ).

Bacons optische Kenntnisse gingen über diejenigen Alhazens hinaus. So ist Bacon die sphärische Aberration bekannt, d. h. die Tatsache, daß Strahlen, die parallel der Achse einfallen, sich nur dann in einem Punkte schneiden, wenn sie den Spiegel in gleichem Abstande vom optischen Mittelpunkte treffen. Auch mit der Brennkugel ${ }^{2}$ ) und den Konvexspiegeln befaßt er sich in Anlehnung an Alhazen. Ferner untersucht Bacon, ob der Brennpunkt eines Hohlspiegels im Kugelmittelpunkte oder im Halbierungspunkte des Radius liegt. Er entscheidet sich für das letztere, also für die richtige Ansicht, und bemerkt ganz zutreffend, eigentlich könne nicht von einem Punkte der Strahlenvereinigung die Rede sein, sondern nur von einer kleinen Stelle. Damit ist schon das Wesen der Katakaustik angedeutet ${ }^{3}$.

Von der Fata morgana heißt es, sie werde von manchen für eine teuflische Gaukelei gehalten, während sie aus natürlichen Ursachen zu erklären sei. Bacon beschreibt ferner die Instrumente zur Bestimmung des Durchmessers von Mond und Sonne. Die Größe der Erde stehe zur Größe des Himmels und der übrigen Gestirne in gar keinem Verhältnis. So sei die Sonne $170 \mathrm{mal}$ so groß wie die Erde. Auch die Milchstraße bestehe aus vielen, zusammengedrängten Sternen, deren Licht sich mit dem der Sonne mische. Ebbe und Flut sollen dadurch zustande kommen, daß die Mondstrahlen beim senkrechten Auffallen die Dünste aufsaugen, auf deren Anwesenheit auch das Funkeln der Sterne zurückgeführt wird. Die Erscheinung, daß eine Flutwelle auch auf der dem Monde entgegengesetzten Seite der Erde entsteht, erklärt Bacon auf folgende Weise. Er nimmt an, die Fixsternsphäre sei fest; daher werfe sie die Strahlen des Mondes zurück. Diese reflektierten Strahlen treffen dann die dem Monde entgegengesetzte Seite der Erde und rufen dort dieselbe Erscheinung hervor, die sie beim direkten Einfallen erzeugen. Nach dieser Vorstellung sind der Fixsternhimmel und somit die Welt räumlich begrenzt.

1) "Visio non completur in oculis, sed in nervo" heißt es bei ihm (Opus majus $\mathrm{V}$ cap. 2).

2) Die Brennkugel erwähnen schon Aristoteles und Plinius.

3) J. Würschmidt, Roger Bacons Art des wissenschaftlichen Arbeitens, dargestellt nach seiner Schrift ..De speculis" (Roger Bacon Commemoration Essays $1 \mathrm{X}$. 
Hatte doch auch Aristoteles angenommen, daß die Fixsterne ihr Licht von der Sonne erhalten. Der Gedanke von der Unendlichkeit des Weitalls und der Vielzahl der Sonnen- und Weltsysteme konnte erst nach der Begrïndung des Kopernikanischen Systems aufkommen.

Der Regenbogen wird von Bacon in Anlehnung an Aristoteles und Avicenna zu erklären gesucht. Daß der Regenbogen verschwindet,. sobald die Sonne sich $42^{\circ}$ über den Horizont erhebt, ist Bacon bekannt. Für das runde Sonnenbildchen, das entsteht, wenn die Sonne durch unregelmäßige Öffnungen in dunkle Räume scheint, kann er keine Erklärung finden. Das Licht erfordert nach seiner Meinung Zeit und besteht nicht in einer Absonderung von Teilchen, da sonst die leuchtenden Substanzen wie der Moschus sich verflüchtigen müßten. Zur Erläuterung der Art, wie das Licht sich fortpflanzt, führt Bacon folgenden, schon Alhazen bekannten Versuch an. Werden drei Lichter vor die enge Öffnung eines Schirmes gestellt, so kreuzen sich die Strahlen in dieser Öffnung. Bacon betrachtete dies als einen Beweis dafür, daß sich die Spezies, d. h. dasjenige, worin er die Natur des Lichtes erblickte, nicht vermischen. Wir würden dafür heute sagen, daß die Lichtstrahlen, ohne sich gegenseitig zu stören, durch einen Punkt hindurchgehen.

Der sechste Abschnitt ist der Wissenschaft rom Experiment gewidmet. Er beginnt mit den Worten: „Ohne eigene Erfahrung (Versuche) ist keine tiefere Erkenntnis möglich"1). Das Experiment wird hier schon als das wichtigste Mittel hingestellt, die Theorie zu stützen und sie zu neuen Folgerungen zu führen. Den Schluß des Werkes (7. Teil) bilden Betrachtungen iiber die Aufgabe der Wissenschaft, die Menschheit nicht nur zur Erkenntnis, sondern auch zu höheren sittlichen Zielen zu leiten. Von besonderem Interesse ist die Stellung, die Bacon der Mathematik gegenüber einnimmt. Er nennt sie das Tor und den Schlüssel der iibrigen Wissenschaften. Die mathematischen Grundwahrheiten sind seiner Meinung nach dem Menschen eingeboren. Nur durch die Mathematik können wir zu vollen Wahrheit gelangen ${ }^{2}$. In den übrigen Wissenschaften herrscht umso weniger Irrtum und Zweifel, je mehr wir sie auf die Mathematik zu gründen verstehen ${ }^{3}$ ).

1) Sine expericntia nihil sufficienter sciri potest.

2) Opus majus IV cap. 3.

3) Ein Wort, dlas lebhaft an Kants späteren, oft zitierten Ausspruch erinnert. 
Bacons Schriften sind von phantastischen Ausblicken in die Zukunft erfüllt. So schreibt er: „Es können Wasserfahrzeuge gemacht werden, welche rudern ohne Menschen, so daß sie, während ein einziger Mensch sie regiert, mit einer größeren Schnelligkeit dahinfahren, als wenn sie voll schiffbewegender Leute wären. Auch können Wagen gebaut werden, die ohne Tiere mit einem unermeßlichen Ungestüm in Bewegung gesetzt werden" ${ }^{1)}$. Wie Bacon sich indessen die Ausführung dieser Gedanken dachte, gibt er nicht an. Es würde daher verfehlt sein, wollte man solchen Aussprüchen, wie es wohl geschehen ist, eine weitergehende Bedeutung beimessen.

Ferner finden sich Bemerkungen, auf Grund deren man Bacon die Priorität linsichtlich der Erfindung des Fernrohres zugeschrieben hat. Da aber nicht erwiesen ist, daß Versuche oder auch nur eine klare Einsicht in die Grundzüge der Konstruktion vorlagen, so sind solche Ansprïche, die von englischer Seite herrühren, zurückzuweisen, ohne daß hierdurch die Bedeutung des eigenartigen Mannes eine Schmälerung erlitte. Bacon konnte in Wirklichkeit nicht einmal mit dem Gebrauch der Brillen bekannt sein. Diese kamen wahrscheinlich erst um 1280 auf ${ }^{2}$. Wohl die erste handschriftliche Erwähnung findet sich in einem Briefe vom Jahre 1299. Jemand sagt dort, daß er ohne Brille, die vor kurzem zum Besten alter Leute mit geschwächtem Sehvermögen erfunden sei, weder lesen noch schreiben könne.

Gleich allen seinen Zeitgenossen, war Bacon in dem Glauben an die Möglichkeit der Metallveredelung befangen, wie er auch von dem Gedanken durchdrungen war, daß die Gestirne einen Einfluß auf die Erde und das Schicksal der Menschen ausüben.

Die astrologischen Lehren, zu denen das 13. Jahrhundert im Anschluß an das Altertum und an das frühe Mittelalter gelangt war, finden sich daher bei Bacon in großer Ausführlichkeit entwickelt. Die Astrologie hatte damals ihren Höhepunkt erreicht.

1) De secretis operibus artis et naturae, cap. 4 .

2) Als Erfiuder wird ein Salvino degli Armati in Florenz genannt. Nach anderer Nachricht ist Alexander de Spina als Erfinder der Brillen $z u$ betrachten. Beide Angaben sind unrichtig. Soviel ist jedoch sicher, daß die ersten Brillen in Italien gemacht wurden und daß dies gegen das Ende des 13. Jahrhunderts geschah (Wilde, Optik. Bd. I. S. 96).

Daß der geschliffene Smaragd, mittels dessen Nero die Zirkusspiele besah, ein Spiegel war, hat schon Lessing nachzuweisen gesucht: Lessing, Antiquarische Briefe. 45. Die Erzählung kommt bei Plinius vor (Nat, hist. XXXVII. S. 84. Sillig). 
Später büßte sie an überzeugender Kraft ein, bis sie im 17. Jahrhundert aus der gelehrten Bildung ganz verschwand. Man muß sich eigentlich wundern, daß sich bei einem im übrigen so hervorragenden Geist wie Bacon keine Zweifel regten. Da die astrologischen Lehren besonders geeignet sind, den Geist des Mittelalters zu kennzeichnen, soll noch einiges daraus in der ihnen ron Bacon gegebenen Fassung Platz finden.

Die Astrologen teilten den Himmel in zwölf „Häuser“. Jeder Planet (Mond und Sonne eingerechnet) hat ein "Haus", in dem er erschaffen ist. Der Löwe ist das Haus der Sonne, der Krebs das des Mondes, die Jungfrau dasjenige des Merkur usw. Jedem der fünf Planeten ist außerdem noch eins der fünf übrigen Häuser zugeteilt. Jupiter und Venus sind Glückssterne, Mars und Saturn Unglückssterne.

Von großem Einfluß sind die Konjunktionen der Planeten, d. h. ihr Zusammentreffen in einem und demselben Hause. Solche Konjunktionen zeigen Thronwechsel, Hungersnot und ähnliche Ereignisse an. Sie wirken auch auf den einzelnen Menschen. Zwar sollen sie nicht den Willen bestimmen. Wohl aber sollen die Himmelskräfte den Körper und, bei dem engen Zusammenhang von Leib und Seele, auch letztere beeinflussen.

Bacon schloß sich auch den orientalischen Lehren an, nach welchen bestimmte Planeten über gewissen Reichen dominieren, z. B. Saturn über Indien, Jupiter ïber Babylon, Merkur über Ägypten, der Mond über Asien. Vielleicht ist es auf astrologische Vorstellungen zurückzuführen, daß der Halbmond das Abzeichen der Tiirkei geworden ist.

Was den chemischen Inhalt der Baconischen Schriften ${ }^{1)}$ anbetrifft, so verdient hervorgehoben zu werden, daß Bacon ein Gemenge erwähnt, dessen Entzïndung eine furchtbare Erschütterung herrorbringe. Als einen Bestandteil dieses Gemenges nennt er Salpeter ${ }^{2}$. Offenbar haben wir es hior mit dem Schießpulver zu tun, das um diese Zeit von Ostasien her seinen Weg nach Europa

1) Sie werden neuerdings als nieht echt betrachtet (E. v. Lippmann).

2) Nach einer Untersuchung von H. W. L. Hime (R. B. Essays, Oxford 1914) hat er aus Salpeter, Kohlenpulver und Schwefel eine explosible Mischung wohl zufällig hergestellt und die Explosion des Gemisches beobachtet. Die Zusammensetzung des Gemisches hat er anagrammatiseh mitgeteilt, wohl um das Geheimnis nicht allgemein zugänglich zu machen und Sehwierigkeiten bei der kurz zuvor gegründeten Inquisition wegen dieser gefïhlichen Kunst zu vermeiden. (J. Würschmidt, Mon.-Hefte f. 1. nat. Unterr. 1915, 264.) 
gefunden hatte. Es wurde zuerst in Bergwerken zum Sprengen gebraucht ${ }^{1}$ ). Seit dem 14. Jahrhundert führte das Pulver eine Umwälzung in der Art der Kriegsführung herbei, die von großem Einfluß auf die politische Gestaltung Europas wurde ${ }^{2}$ ).

Gewissermaßen gehört Bacon auch $\mathrm{zu}$ den geistigen Urhebern der großen Entdeckungsreisen. Er vertrat nämlich die Ansicht, Asien erstrecke sich so weit nach Osten, daß seine östliche Küste durch eine kurze Fahrt über den atlantischen Ozean erreicht werden könne. Diese Ansicht Bacons nebst ihrer Begründung nahm Pierre d'Ailly in sein "Imago mundi“ betiteltes Werk ${ }^{3}$ ) auf. Und es ist bekannt, daß Columbus später insbesondere auch durch das Lesen dieses Werkes zu seiner Fahrt nach Westen angeregt wurde ${ }^{4}$ ).

Aus allem geht hervor, daß wir es in Bacon mit einem hochbedeutenden Menschen zu tun haben, der in der Entwicklung der Wissenschaften eine hervorragende Rolle gespielt und die Bewunderung, die man ihm gezollt, verdient hat $\left.{ }^{5}\right)$. Bacon ist einer der wenigen, das Dunkel des christlichen Mittelalters durchdringenden Sterne. Daß er sich nicht völlig von den Vorurteilen seiner Zeit frei zu machen wußte, darf die Anerkennung, die wir ihm spenden müssen, nicht beeinträchtigen.

\section{Auswüchse des mitteltalterlichen Denkens.}

Auf dem Gebiete der Wissenschaften tritt die Eigenart des Mittelalters besonders in den Bestrebungen der Astrologen und der Alchemisten zutage. Astrologie und Alchemie sind Wörter, bei deren Klang man sich sofort in jene Zeit, von der wir handeln,

1) Nach E. v. Lippmann ist dies jedoch nicht zutreffend.

2) Die Feuerwaffe wurde sehr wahrscheinlich in Deutschland erfunden. Ihr Erfinder ist nicht bekannt. Sicher ist nur, daß sich die neue Erfindung im 14. Jahrhundert schnell durch ganz Europa bis nach Asien verbreitete. Ariost wütet im .,Orlando furioso" gegen die „verruchte, dumme Teufelskunst", von der er sagt:

„Durch dich ging jeder Waffenruhm verloren,

Die Ritterehre ward zum eitlen Dunst!:

3) Das Buch war eine der Enzyklopädien des Mittelaiters. Es entstand im Anfang des 15. Jahrhunderts. Columbus wurde dadurch mit der Ansicht des Aristoteles und des Strabon bekannt, daß die Ostküste Asiens durch eine Fahrt nach Westen zu erreichen sein müsse.

4) Tschackert, Peter von Ailly. Gotha 1877. S. 335

5) Siehe K. Werner, Die Kosmologie und allgemeine Naturlehre des Roger Baco. Wien 1879. 
zurückversetzt fühlt. Nicht nur die mit diesen Namen bezeichneten Pseudowissenschaften, sondern mitunter auch Magie und Nekromantie waren damals Gegenstand von Universitätsvorlesungen.

Die größten alchemistischen Torheiten bezüglich der Wirkung der Materia prima oder des Steins der Weisen gingen von Raymundus Lullus aus. Lullus, der Doctor illuminatissimus, wurde um 1230 geboren. Seine Schriften, oder vielmehr was an solchen unter seinem Namen ging, fanden besonders im 14. Jahrhundert zahlreiche Leichtgläubige. Als eine Ausgeburt der Phantasie des Lullus begegnet uns seine Lehre von der Multiplikation. Der Stein der Weisen verwandelt danach zunächst die 1000 fache Menge Quecksilber in Materia prima. Und dies konnte mehrfach wiederholt werden, bis nach einer gewissen Abschwächung der verwandelnden Kraft die Materia prima die 1000 fache Menge Quecksilber in reines Gold rerwandelte. In Anbetracht derartiger Übertreibungen des alchemistischen Gedankens kann es nicht wundernehmen, wenn er sich zu dem Ausspruch verstieg: „Mare tingerem, si Mercurius esset" (das Meer würde ich in Gold verwandeln, wenn es aus Quecksilber bestände).

Unter den Auswüchsen und Irrungen, die uns im Mittelalter begegnen, sind neben der Alchemie, der Astrologie und der Magie der Hexenglauben zu nennen. Auch von dieser so unheilvollen, in der Hand des kirchlichen Fanatismus oft zur furchtbarsten Geißel1) gewordenen Verirrung wurde die Menschbeit durch das Emporkommen einer naturwissenschaftlichen Weltanschauung in Jahrhunderte dauerndem Kampf befreit. Zu den ersten, die den Kampf gegen die Astrologie aufnahmen, zählt der in der zweiten Hälfte des 15. Jahrhunderts lebende Pico von Mirandola.

Pico von Mirandola gehörte den humanistischen Gelehrten an, die im allgemeinen der Astrologie zugetan waren, da letztere ja dem späteren Altertum entsprungen war. Gehörte doch selbst Melanchthon zu ihren Anhängern, während Luther sich von den Sterndeutereien abwandte und sie für grobe Lügen erklärte, denen gegenüber man bei seinem einfachen Verstande bleiben müsse. Aus diesem heraus ist auch Pico von Mirandolas Einspruch hervorgegangen. Will man siclı von der Trüglichkeit aller Wahrsagerei überzeugen, so frage man die Sterndeuter und die

1) "Seit die Inquisition ibre Ketzerverfolgungen anfing und seit fanatische Pfaffenwut alle selbständigen Gedanken auszurotten trachtete, fielen vier Jahrhunderte lang zahlreiche Schlachtopfer in ganz Europa." M. Carrierre, Die philosophische Weltanschauung der Reformationszeit. Stuttg. 1847. S. 87. 
Handlinienbeschauer zu gleicher Zeit und sehe, wie sie einander widersprechen. Ihre Wetterprophezeiungen sind nicht minder unzuverlässig. So und ähnlich lauten seine Grïnde. Daß der Himmel die allgemeine Ursache des irdischen Geschehens sei, erkennt Pico an. Alles Besondere müsse aber aus den nächstliegenden Ursachen erklärt werden.

Über das Unheil, das die astrologische Lehre anrichtete, sagt Pico, sie zerstöre die Philosophie, verfälsche die Heilkunde, untergrabe die Religion, erzeuge den Aberglauben, begünstige die Abgötterei, verunreinige die Sitten, verleumde den Himmel und mache den Menschen zum unglücklichen Sklaven von Vorurteilen und Verführern.

Schon ein Jahrhundert vor Pico hat einer der größten unter den Humanisten, Francesco Petrarca, den Kampf gegen die Astrologie, die Magie und andere Ausflüsse des Aberglaubens geführt. Sein Bemühen war jedoch nicht minder erfolglos gewesen wie dasjenige seines Nachfolgers. Beide Männer haben indessen das Verdienst, daß sie den späteren Geschlechtern die Waffen in diesem Kampfe geschmiedet haben 1$)$.

Mit ähnlichen überzeugenden Gründen, wie Pico von Mirandola die Astrologie, bekämpfte der Arzt Jacob Weyer den Hexenglauben und die damit im Zusammenhange stelenden Verfolgungen. Er wies z. B. nach, daß das Alpdrücken eine Folge körperlicher Zustände sei und nicht etwa durch einen Dämon veranlaßt werde. Er erkannte die Rolle, welche die Phantasie, sowie die Neigung der Frauen zur Hysterie beim Zustandekommen abergläubischer Vorstellungen spielt. Docl fand er nur wenig Anhänger und zahlreiche Widersacher. Die angeblichen Hexen wurden noch bis in das 18. Jahrhundert hinein von Geistlichen, Inquisitoren und der fanatisierten Menge verfolgt und verbrannt.

Das Heilmittel für all diese Gebrechen der Zeit konnten nur die Naturwissenschaften sein. Sie waren zwar auf dem Marsche. Um die Beseitigung von Aberglauben und Vorurteilen, sowie um Anerkennung als Bildungsmittel für die breite Masse des Volkes mußten sie aber noch lange, ja selbst bis auf den heutigen Tag ringen.

1) Näheres über Pico von Mirandola siehe bei M. Carrierre, Die philosophische Weltanschauung der Reformationszeit. 1847. 


\section{Die Naturwissenschaften im 14. Jahrhundert.}

Von den naturwissenschaftlichen Kenntnissen und Vorstellungen, die um die Mitte des 14. Jahrhunderts herrschten, erhält man ein in mancher Hinsicht zutreffendes Bild durch Megenbergs Buch der Natur.

Konrad von Megenberg wurde um 1309 in der Maingegend geboren. Er empfing seine Vorbildung in Deutschland und Paris, wo er den Doktorgrad erwarb. Darauf lehrte er in Wien und schließlich wirkte er als Kanonikus in Regensburg. Dort schrieb er sein Werk, das er um 1350 bekannt gab ${ }^{1}$ ). Er starb in Jahre 1374.

Megenbergs Hauptquelle ist eine von Thomas von Cantimpré um 1250 verfaßte Schrift: Über die Natur der Dinge (De naturis rerum). Sie bietet eine Übersicht über das damalige Wissen von den lebenden und den leblosen Naturgegenständen. Und zwar ist Cantimprés Buch das erste Werk dieser Art, welches das Mittelalter hervorbrachte ${ }^{2}$ ). In zwanzig Büchern behandelt Thomas die Anatomie des Menschen, die Tiere, die Pflanzen, die Metalle und Edelsteine, die vier Elemente und das Himmelsgewölbe mit den sieben Planeten. Das Werk ist indessen nicht auf eigene Anschauung gegründet, sondern aus den verschiedensten Schriftstellern geschöpft. Am meisten benutzt sind Aristoteles, Galen

1) Es wurde 1862 nach den Handschriften von Fr. Pfeiffer veröffentlicht. Die neueste auszugsweise Bearbeitung rührt von H. Schulz her: Conrad von Megenberg, Das Buch der Natur. Die erste Naturgeschichte in deutscher Sprache. In neuhochdeutscher Sprache bearbeitet und mit Anmerkungen versehen von H. Schulz. Greifswald 1897.

2) Es sind noch zahlreiche Handschriften vorhanden, so in Breslau, Wolfenbüttel, Gotha, Paris, London usw. Siehe Carus, Geschichte der Zoologie. S. 214.

Über das Verhältnis Konrads von Megenbergs zu Thomas schreibt H. Stadler bei der Besprechung der ersten Auflage dieses Werkes in den Neuen Jahrbüchern f. d. klass. Altert. 1911. S. 86: „Es ist natürlich bei Konrad von Megenberg nicht an eine direkte Benutzung des Aristoteles, Galen, Plinius oder gar des Theophrast, den kein mittelalterlicher Autor wirklich kennt, zu denken, sondern alle diese Autorenzitate Megenbergs stammen aus Thomas von Cantimpré." Es existieren neben den vollständigen Handschriften (in Paris und München) des Werkes dieses Autors gekürzte. „Eine Handschrift letzterer Form übersetzte Konrad und fügte gelegentlich eine naive Kritik, eine erweiterte Moralisation und auch einige wenige sachliche Bemerkungen hinzu." 
und Plinius. Aber auch Theophrast, Isidor von Sevilla und die Kirchenväter werden herangezogen.

Megenbergs Buch der Natur lehnt sich so eng an die besprochene Schrift des Thomas an, daß es als eine gekürzte und dem Fortschritt des seitdem verflossenen Jahrhunderts Rechnung tragende deutsche Bearbeitung bezeichnet werden kann ${ }^{1}$ ). Doch hat $\mathrm{M}$ e genberg, wie er ausdrücklich bemerkt, wenn ihn das Buch des Thomas im Stiche ließ, auch andere Bücher benutzt. Dabei ist er durchaus kein bloßer Kompilator. Er weist sogar manches, was Thomas unbeanstandet aufnimmt, als unglaubwürdig zurück. Daß er trotzdem an Wunder, Zauberei und Beschwörungen glaubt, muß man auf Rechnung des Geistes seiner Zeit setzen. So ist das Buch Megenbergs eins der geeignetsten Zeugnisse für das vor dem Wiederaufleben der Wissenschaften sellust bei aufgeklärten Männern anzutreffende Fühlen und Denken. Einige Mitteilungen aus dem Inhalt des Buches mögen dies des Näheren dartun.

Der erste Abschnitt betrifft den Menschen. Es sind die Lehren des Aristoteles und des Galen, die uns hier in derjenigen Gestalt begegnen, die sie durch spätere Schriftsteller erfahren haben 2). Das Gehirn soll von Natur kalt, das Herz dagegen warm sein. Das Gehirn liege oberhalb des Herzens, damit seine Kälte durch die Wärme des Herzens gemildert werden könne. Die Natur lasse zuerst das Herz entstehen und danach das Gehirn. Vom Auge heißt es, es sei von dünnen Häuten umgeben. Dièse umschlössen die kristallinische Feuchtigkeit, auf welcher die Sehkraft beruhe. Der Sehnerv wird als eine hohle Ader bezeichnet, deren Aufgabe es sei, den Augen die eigentliche geistige Sinnestätigkeit zuzuführen. Man sieht, es sind verworrene Vorstellungen, aus. denen nicht ersichtlich ist, wie sich Megenberg den Vorgang des Sehens eigentlich denkt. Über das Herz und die Lungen äußert er sich mit folgenden Worten: Das Herz ist das erste Lebendige und das letzte Organ, das stirbt. Es besitzt zwei Kammern, eine rechte und eine linke. Sie bergen das Blut und

1) $\mathrm{Da} B$ es eine große Verbreitung fand, beweisen die zahlreichen Handschriften, die sich noch heute besonders in Süddeutschland finden. Auch erschien es bis 1500 sechsmal im Druck.

Negenbergs „Buch der Natur" ist eine Übersetzung des Thomas von Cantimpré und darf nicht als selbständige Arbeit betrachtet werden (H. Stadler, Albertus Magnus, Thomas von Cantimpré und Vinzenz von Beauvais, Natur und Kultur. 1906. S. 86-90;.

2) Siehe Ausgabe von Schulz, Vorrede. VI. 
die besonderen Geister, welche das Leben bedingen. Die Geister und das Blut strömen durch die Adern vom Herzen zu den übrigen Organen hin. Das Herz ist der Lunge angelagert, weil die weiche Lunge durch ihre Tätigkeit, Luft aufzunehmen, das Herz kühl halten kann, so daß es nicht in seiner eigenen Hitze erstickt. Eine genauere Unterscheidung zwischen Adern, Nerven und Sehnen findet auch bei Megenberg noch nicht statt.

Der zweite Abschnitt handelt ,von den Himmeln und den sieben Planeten". Außerhalb des Firmaments, an dem die Fixsterne befestigt sind, unterscheidet Megenberg noch zwei Sphären, den Wälzer und den Feuerbimmel. Nach innen folgen die sieben Planetenhimmel, von denen jeder nur einen Stern trägt. Alles bewegt sich in verschiedenen /eiträumen um den Mittelpunkt der Welt, die Erde. Jeder Planet hat seine besonderen Eigenschaften und Wirkungen. So ist Jupiter warm und trocken. Deshalb macht er das Erdreich fruchtbar und bringt ein gutes Jahr, wenn er in seiner vollen Kraft und günstigsten Stellung scheint. Mars ist heiß und trocken; daher crhitzt er der Menschen Herz und macht sie zornig. Der Sonne werden fünfzehn Eigenschaften zugeschrieben, die dann in allegorischer Weise auf die heilige Jungfrau bezogen werden.

Hinsichtlich der Kometen begegnen wir einer Auffassung, die von Aristoteles bis zu Tychos und Keplers Zeiten die herrschende blieb. Ein Komet ist danach kein eigentlicher Stern, sondern ein „Feuer, das im obersten Luftreich brennt". Genährt wird dieses Feuer durch fettigen, der Erde entstammenden Dunst. Die Dauer des Kometen hängt davon ab, wie lange dieser Dunst in hinreichender Menge nachströmt. Betrachtete man die Kometen als atmosphärische Erscheinungen, so war die Annahme, daß sie auf die Erde eine tiefere Wirkung als die Gestirne ausüben, ganz folgerichtig. Der Komet muß für das Land, dem er den Schweif zukehrt „ein Hungerjahr bringen, weil dem Boden dort die Feuchtigkeit entzogen wird". Die Milchstraße endlich wird ganz zutreffend auf "zahlreiche, nahe beieinander befindliche Sterne zurückgeführt, deren Schein vereint leuchtet".

Megenberg bespricht dann die atmosphärischen Vorgänge. Der Wind wird nicht etwa als eine Bewegung der Luft in ihrer ganzen Masse aufgefaßt, sondern als ein ,angesammelter irdischer Dunst" betrachtet, der sich durch dic Luft bewegt. Aus dem irdischen fetten Dunst, der gegen die Wolken stößt, sucht Megenberg anch Blitz und Domer zu erklären. Die Kraft des 
Anpralls bewirke die Entzündung, d. h. den Blitz. Der Regenbogen endlich wird als eine Spiegelung des Sonnenlichtes in den Wolken aufgefaßt. Durch die Annahme von Dünsten im Innern der Erde wird, unter Zuriickweisung alter Fabeleien, auch das Erdbeben erklärt. Auf die in den Höhlen der Gebirge befindlichen Dünste sollen die Gestirne, besonders Mars und Jupiter in der Art wirken, daß sie ihren Andrang gegen die Wände der einschließenden Hohlräume vermehren. Dadurch komme eine Erschütterung der Erde zustande. Megenberg berichtet dann über ein starkes Erdbeben, das 1348 in den Alpen und in Siiddeutschland verspürt wurde. In demselben Jahre wurde Europa durch den schwarzen Tod heimgesucht, das „größte Sterben, das je nach oder vielleicht auch vor Christi Geburt dagewesen". Allein in Wien seien an dieser Seuche 40000 Menschen in wenigen Monaten zugrunde gegangen. Megenberg ist nun geneigt, zwischen dem Erdbeben und jener Krankheit einen ursächlichen Zusammenhang anzunehmen. Bei dem Erdbeben entweiche nämlich giftiger Dunst aus dem Innern der Erde. Das Weltbild, das sich das Mittelalter nach dem Vorgange der Alten geschaffen und wie es uns in Megenbergs Schrift entgegentritt, wird durch eine Schilderung der Tiere, der Pflanzen und der wichtigsten anorganischen Naturkörper vervollständigt. Auf die Beschreibung des Tieres im allgemeinen, die ganz im Geiste und oft in wörtlicher Übereinstimmung mit Aristoteles gehalten ist, folgen Mitteilungen über das Aussehen und die Lebensweise der einzelnen Geschöpfe. Von einer systematischen Einteilung nach irgend welchen wissenschaftlichen Gesichtspunkten ist dabei noch keine Rede. Die Anordnung ist vielmehr die alphabetische. Auch wird über manches Tierwunder berichtet, das sich später als eine Ausgeburt der Phantasie älterer Schriftsteller erwiesen hat. So wird auch die alte Geschichte des Physiologus von dem Walfisch, dessen Rücken für eine Insel gehalten wird, wieder aufgefrischt. Manche Bemerkung iiber einheimische Tiere beruht auf eigener Beobachtung oder wenigstens auf der Beobachtung Mitlebender. Doch fehlen auch nicht Angaben alter Schriftsteller, die ohne Nachprüfung aufgenommen werden, so heißt es beim Pferde, Aristoteles sage, aus dem Haare dieses Tieres entstehe im Wasser ein Wurm. Nicht selten wird aber derartigen Mitteilungen ein treuherziges: "Das glaube ich nicht" hinzugefügt, so der Erzühlung des Plinius, daß der Luchs durch eine Wand zu sehen vermöge. 
Die nächsten Abschnitte handeln - gleichfalls in alphabetischer Folge - von den Bäumen und von den Kräutern. Die Beschreibungen beschränken sich auf den äußeren Habitus der ganzen Pflanze und das Aussehen der Früchte. Im Mittelpunkt der Darstellung stehen die physiologischen Wirkungen, die von den Pflanzen ausgehen. Zur Erklärung dieser wunderbaren Wirkungen genïgt nach Megenberg jedoch nicht die Mischung der in den Kräutern enthaltenen Elemente, sondern er nimmt daneben den Einfluß der Gestirne an. Oft komme auch der Einfluß der heiligen Worte in Betracht, mit denen man Gott anrufe, und durch die man die Kräuter beschwöre und segne, wie man ja auch das Weihwasser einsegne.

Durch den göttlichen Willen haben auch die Steine wunderbare Eigenschaften und Kräfte, vor allem besitzen sie einen segenbringenden Einfluß. Manche Mineralien sind giftwidrig, ja sie zeigen sogar durch Ausschwitzungen an, ob sich Gift in der Nähe befindet. Der Karneol besänftigt den Zorn und stillt Blutungen. Offenbar wurde ihm seit jeher diese Eigenschaft seiner roten Farbe wegen zugeschrieben. Auch bei den übrigen Mineralien werden die Eigenschaften ganz obenhin erwälnt, dagegen um so ausführlicher wird ihre Verwendung zu Amuletten gewiirdigt, ohne daß Megenberg Zweifel an der Richtigkeit der an die Mineralien sich knïpfenden, damals herrschenden, abergläubischen Vorstellungen kamen.

Wir haben das Buch der Natur etwas eingehender gewiirdigt, weil eine derartige Probe lehrreicher ist als lange Betrachtungen über den Geist des Mittelalters. Erst wenn wir uns den geistigen Besitz und das Fühlen und Denken jener Zeit an einem Schriftsteller wie Megenberg oder Thomas von Cantimpré vergegenwärtigt haben, können wir den Umschwung ermessen, der mit dem Wiederaufleben der Wissenschaften eintrat und der neueren mit Koppernikus, Galilei und Kepler anhebenden Naturforschung den Weg bereiten half. 


\section{Das Wiederaufleben der Wissenschaften.}

Bis zur Beendigung der Kreuzzïge hatte Westeuropa unter einer ïberwiegend kirchlichen Führung gestanden. Probleme religiöser und scholastisch-philosophischer Art nahmen während dieser Zeit das Denken vorzugsweise in Anspruch. Das nunmehr eintretende Sinken der Hierarchie hatte zur Folge, daß man sich auch anderen Gegenständen zuwandte.

Es sind vor allem zwei mächtige neue Bewegungen von nie versiegender Wirkung, welche die europäische Menschheit gegen den Ausgang des Mittelalters ergreifen, die Wiederbelebung des klassischen Altertums und die durch die Entdeckungsreisen erfolgende Ausdehnung des geographischen Gesichtskreises ïber die gesamte Erde.

Vorbereitet wurde der große geistige Umschwung, dessen Vorboten bis in das 13 . Jahrhundert zurïckreichen, durch einen wirtschaftlichen Vorgang, nämlich durch das Emporblühen des Städtewesens. Vor allem sind hier Pisa, Florenz, Venedig und Genua zu nennen. Diese waren durch den Handel zu Wohlstand und Macht und schließlich sogar zu einer meerbeherrschenden Stellung gelangt. Die Berïhrung mit sämtlichen Völkern des Mittelmeeres, das Emporblühen der Kunst und der Gewerbe, kurz die Erweiterung des gesamten Gesichtskreises brachten es mit sich, daß an diesen Stätten die Nacht des Mittelalters zuerst der Morgenröte eines neuen, besseren Tages wich.

Die ältere Geschichtsschreibung liebte es, die Renaissance als ein fast blitzartiges Aufleuchten hinzustelllen, wodurch das tiefe Dunkel des Mittelalters verscheucht und von Italien aus das iibrige Europa allmählich erhellt worden sei. Es war dies die besonders durch Burkhardt ${ }^{1}$ ) vertretene Anschauung. Burkhardt stand noch allzusehr unter dem Einflusse Vasaris, des

1) J. Burkhardt, Die Kultur der Renaissance in Italien. Derselbe, Geschichte der Renaissance in Italien. 
frühesten Geschichtsschreibers der Renaissance. Vasari¹), der um die Mitte des 16. Jahrhunderts schrieb, stand offenbar den von ilım geschilderten Begebenheiten zeitlich noch zu nahe, um ein zutreffendes, allgemeines Urteil fällen zu können. Auch war er bestrebt, die von ihm behandelte Epoche der vorangehenden Zeit gegenüber in hellem Glanze hervortreten zu lassen ${ }^{2}$.

Die neuesten Forschungen über die Entwicklung des geistigen Lebens und der Kunst lassen immer deutlicher erkennen, daß sich zwischen Mittelalter und Renaissance keine scharfe Grenze ziehen läßt. Vielmehr reicht die Bewegung, die wir mit dem Worte Renaissance kennzeichnen, in ihren Anfängen bis in das 13. Jahrhundert zurück. Auch war sie keineswegs auf den Boden Italiens beschränkt. Erlebte sie auch dort ihre höchste Blüte, so begegnet uns die Wiedergeburt der Künste und der Wissenschaften doch auch in Frankreich, in Deutschland und den Niederlanden. Und zwar lassen sich auch in diesen Ländern das Streben nach selbständiger Auffassung und eine dadurch bedingte Abkehr von der bisherigen Denkweise, gewissermaßen eine allmähliche Umwertung der Werte, bis in das 13. Jahrhundert zurückverfolgen. Dennoch darf man, im Gegensatz zur älteren historischen Schule (Burkhardt, Voigt, Libri) nicht so weit gehen, die Renaissance "als das Fesultat und die feinste Blüte des Mittelalters zu bezeichnen $\left.{ }^{3}\right)$. Ist doch die Renaissance, die wenn auch lange vorbereitete, allmähliche Überwindung derjenigen Momente, welche das christliche Mittelalter kennzeichnen. Als diese im geistigen Leben des Mittelalters überwiegenden Momente werden stets gelten miissen: erstens die Unterordnung der wissenschaftlichen und künstlerischen Betätigung unter den Einfluß der Kirche, ferner die Herrschaft der Autorität des geschriebenen Wortes und drittens die Abkehr von realistischer und die Versenkung in die spiritualistische Denkweise.

Die Wiederbelebung der römischen und der griechischen Literatur erfolgte seit dem 14. Jahrhundert in immer größercm Umfange und führte $\mathrm{zu}$ einer wachsenden Vertiefung in den Geist der Antike. Es entstand die Richtung, die man als den Humanismus bezeichnet. Brachte sic den Naturwissenschaften auch keinen

1) Giorgio Vasari, Vite di più eceellente pittori, scultori ed arehitetti. Florenz 1550. Dasselbe deutseh 1832-1849. 6 Bände.

2) W. Goetz, Mittelalter und Renaissance. Historische Zeitschrift. Bil. 98 (1907). S. 30.

3) IV. Goetz a. a. O. S. 50. 
unmittelbaren Gewinn, so bewirkte sie doch, daß mit den erwähnten mittelalterlichen Elementen, welche das Denken bisher gefangen hielten, gebrochen und für die Behandlung und die Darstellung wissenschaftlicher Gegenstände Vorbilder gewonnen wurden. Es wurde, wie ein hervorragender Geschichtsschreiber der Periode des Humanismus sagt ${ }^{1}$, „die vergessene Tiefe der Vorzeit heraufbeschworen und diese in ihren edelsten Schöpfungen noch einmal durchlebt". Das Land, wo der Humanismus seine erste Blüte erlebte, war Italien. Dort waren nämlich die Scholastik, die romantische Poesie und die gotische Baukunst nie zur vollständigen Herrschaft gelangt und immer noch eine Erinnerung an das Altertum übrig geblieben, die endlich im 15. Jahrhundert alle Geister ergriff und der Literatur ein neues Leben einhauchte ${ }^{2}$ ).

Auf dem Boden Italiens hatte die Berülırung der antiken IVelt mit dem germanischen Elemente vorzugsweise stattgefunden. War Italien dabei auch von vielen Völkern zertreten worden, so hatten sich doch manche Reste und Vermächtnisse der alten Kultur in die neue Zeit hinübergerettet. Die führenden Männer, denen wir die Wiederbelebung dieser Keime verdanken, waren vor allem Petrarka und Boccaccio. In den Beginn der großen literarischen Epoche, welche diese Männer verkörpern, gehört der bewundertste Dichter der italienischen Nation, Dante. Geboren wurde Dante 1265 in Florenz; er starb im Jahre 1321. Dante hat zwar von den besten römischen Dichtern, wie Horaz, Ovid und Vergil, manche Anregung empfangen, doch gehört er noch nicht zu den Erneuerern der alten Literatur. Seine Bildung beruht vielmehr noch vorzugsweise auf dem Trivium und dem Quadrivium der mittelalterlichen Philosophen. Der Geist, der aus Dante spricht, ist aus der Vereinigung der Scholastik mit der provenzalischen Romantik hervorgegangen. Und diesen Geist verrät auch sein geniales Meisterwerk, die göttliche Komödie. Sie ist nicht nur als ein hervorragendes Werk der Dichtkunst, sondern auch als eine Fundgrube für den Stand der Kenntnisse zu Beginn des 14. Jahrhunderts zu schätzen ${ }^{3}$ ). Es war nicht viel mehr als eine dunkle Ahnung, mit der Dante das Wesen der Antike er-

1) G. Voigt im Vorwort zu seinem Werke: Die Wiederbelebung des klassischen Altertums. Berlin 1859.

2) Ranke, Deutsche Geschichte im Zeitalter der Reformation. Bd. I. S. 174 u. f.

3) Siehe auch Libri, Histoire des sciences mathématiques en Italie. Bd. II. S. 173. 
faßte, in ihre Tiefen ist er noch nicht eingedrungen. Das geschah erst durch Francesco Petrarka ${ }^{1}$.

Petrarkas Vater besaß einige Schriften Ciceros. Sie und die Dichtungen Vergils, die das Mittelalter nie vergessen hatte, kamen dem jungen Petrarka in die Hände und wurden von ihm weniger des Inhalts als des Wohllauts der Sprache und des beredten Ausdrucks wegen mit Begeisterung gelesen. Da man nur einen kleinen Teil der Schriften Ciceros besuß - die Briefe z. B. waren in Vergessenheit geraten -, so begann Petrarka, als er heranwuchs, nach den verschollenen Werken des von ihm so hoch verehrten Schriftstellers zu suchen. Sein Umherstöbern in alten Klosterbibliotheken wurde mit Erfolg belohnt. Er selbst begab sich ans Abschreiben und wußte zahlreiche Männer in den Dienst seiner Bestrebungen zu stellen. Nach Spanien, Frankreich, Deutschland und Britannien, ja selbst nach Griechenland sandte er die Aufforderung, nach bestimmten, verschollenen Schriften zu forschen. Oft fügte er seinen Bitten und Mahnungen auch Geldbeträge bei. Die Schriften der Alten wurden aber nicht nur gesammelt und vervielfältigt, man betrachtete sie auch als Muster für den Ausdruck und bemühte sich, den eigenen Ausdruck danach zu vervollkommnen.

Petrarka wandte sein Interesse nicht nur den Literaturwerken, sondern auch allen übrigen antiken Überresten, wie Bauwerken, Münzen usw. zu, an denen der Boden Italiens so reich ist. Auch auf dic griechische Kultur lenkten Petrarka und seine Nachfolger die Aufmerksamkeit des Abendlandes. Zwar fehlte es im 14. Jahrhundert zunächst noch sehr an der Kenntnis der griechischen Sprache. Hierin trat aber eine Anderung nach dem Fall Konstantinopels ein, da viele griechische Flüchtlinge infolge dieses Ereignisses sich nach Italien wandten. Der treueste und eifrigste Jünger Petrarkas war Giovanni Boccaccio. Der Eifer von den alten Schätzen zu sammeln, was noch zu retten war, wurde fast durch die Besorgnis übertroffen, daß es schon zu spät sein möchte. Daß diese Besorgnis sehr gerechtfertigt war, beweist Boccaccios Bericht iber seinen Besuch der Bibliothek zu Monte Cassino. Er fand sie in einem vernachlässigten Raume und weder durch Schlösser noch durch Türen abgesperrt. Als er die Codices öffnete, bemerkte er Verstümmelungen aller Art. Weinend vor Unwillen verließ er den Raum. Scine Frage, warum man die herr-

1) G. Voigt, Die Wiederbelebung des klassischen Altertums. Berlin 1859. 
lichen Schätze so schmählich behandle, wurde von den Mönchen dahin beantwortet, daß man das herausgeschnittene Pergament zu Psaltern und Breven rerwende, die an Frauen und Kinder verkauft würden ${ }^{1}$. Und das geschah in Monte Cassino, einer Pflanzstätte der Gelehrsamkeit.

\section{Die Wissenschaften im Zeitalter des Humanismus.}

Auf die Zeit des Beginns des Humanismus folgte seine Ausbreitung. Sie geschah besonders durch Wanderlehrer und durch die Gründung von Gelehrtenrepubliken nach platonischem Muster. Es ist als eine große Tat der ersten Humanisten zu betrachten, daß sie die Fürsten, vor allem die Mediceer, ja den gesamten Adel des Landes, aber nicht minder das wohlhabende Bürgertum der italienischen Stadtrepubliken für ihre Bemühungen zu begeistern wußten. Dies war um so schwieriger, als ja zu jener Zeit die beweglichen Lettern noch nicht der Wissenschaft Flügel verliehen hatten, sondern die gehobenen literarischen Schätze noch durch Abschreiben vervielfältigt werden mußten. Der Humanismus fand auch an den Universitäten und bei den kirchlichen Machthabern eine Heimstätte. Vor allem war es Papst Nikolaus V., der nach mediceischem Vorbilde große Mittel für literarische Bestrebungen hergab. Auf seine Anregung hin wandte man sich besonders der griechischen Literatur zu. An Stelle der alten scholastischen Bearbeitungen traten jetzt im Abendlande die wirklichen aristotelischen und platonischen Schriften. Papst Nikolaus, dem es in erster Linie auf das Sammeln der Bücher ankam, der Begründer der großen, dem Ansehen des Papsttums entsprechenden vatikanischen Bibliothek, zog viele griechische Gelehrte nach Rom und ließ nach dem Fall Konstantinopels durch reisende Händler zahlreiche Bücher in Griechenland und in Kleinasien aufkaufen. Seitdem die humanistischen Bestrebungen durch Nikolaus V. ihren Mittelpunkt in Rom gefunden hatten, dehnte sich ihr Einfluß auch nördlich von den Alpen aus. Mit den Gelehrten waren zahlreiche griechische Texte, darunter z. B. die Werke des Archimedes, von Konstantinopel nach Italien gelangt. Der Humanismus erlebte jetzt nicht nur hier die Zeit seiner höchsten Blüte, sondern auch im übrigen Europa, vor allem in Deutschland, Comoed.

1) G. Voigt nach Benvenuti Insolensis Comment. in Dantes 
wo er durch den Kardinal Nikolaus von Cusa besonders Eingang fand, sowie in England.

Hatte Papst Nikolaus V. die humanistischen Studien mehr aus Liebhaberei und in der Absicht gefördert, Rom zum Mittelpunkt auch für die geistigen Bestrebungen zu machen, so bestieg bald nach ihm in $\mathrm{Pius}$ II. $\left.{ }^{1}\right)$ ein wirklicher Humanist den päpstlichen Stuhl. Er wandte sich der Geographie und der Geschichte $\mathrm{zu}$, suchte beide Wissenschaften in Beziehung zu setzen und schuf eine Kosmographie, die auch Columbus angeregt hat 2).

Pius II. verdient um so mehr Anerkennung, als die übrigen Humanisten dem wissenschaftlichen Vermächtnis des Altertums zunächst wenig Interesse und Verständnis entgegenbrachten. Mathematik, Naturwissenschaften und Medizin, kurz, strengere Wissenschaften fanden nur geringe Beachtung. Der Humanismus war herrschende Mode geworden und diese verlangte schöngeistige Leistungen. Das größte Gewicht wurde bei allem literarischen Scbaffen auf die Form gelegt, und durch dieses Bestreben erlangte, wiederum unter der Führung Petrarkas und Boccaccios, die heimatliche Sprache eine solche Vollendung, daß Galilei und seine Schüler es vorzogen, in der Sprache ihres Landes zu schreiben, während in Deutschland und den übrigen Ländern unter den Gelehrten kaum jemand daran dachte, sich einer anderen Sprache als der lateinischen $\mathrm{zu}$ bedienen.

Trotz aller Bestrebungen der Päpste, Rom zum Mittelpunkt der humanistischen Bestrebungen zu machen, gebührt Florenz der Ruhm, nicht nur die Wiege, sondern in der Folge auch der bedeutendste Hort des Humanismus gewesen zu sein. Die Geschicke von Florenz hingen während des gesamten 15. Jabrhunderts auf das Engste mit der über ungemessene Reichtümer verfügenden, gleichzeitig aber für Kunst und Wissenschaft begeisterten Familie der Mediceer zusammen. In Cosmo und in seinem Enkel Lorenzo, dem ..Prächtigen“, fanden die Künstler und die Gelehırten Gönner, die ihren Bestrebungen nicht nur eine jederzeit offene Hand, sondern auch ein rolles Verständnis entgegenbrachten. Cosmo selbst war der Stifter einer Akademie, in der sich die geistig und künstlerisch hervorragenden Männer aneinanderschlossen. Dem Beispiele der Päpste und der Mediceer folgte, wie nicht anders zu erwarten, alles, was Anspruch auf 
Reichtum und vornehme Herkunft machte. Auch die Frauen nahmen einen hervorragenden Anteil an dieser Bewegung, die ihre Kehrseite leider in den politischen und sittlichen Zuständen des damaligen Italiens fand. Die Freude, welche jene Bewegung in ihrer Lebensfülle hervorruft, wandelt sich in Anbetracht mancher Ergebnisse der neueren Geschichtsforschung mitunter in das Gefühl des Schanderns, während die älteren Schilderer jenes Zeitalters jene Kehrseite zu wenig beachteten und in dem Gemälde, das sie uns von der Renaissance entwarfen, nur die lichten Seiten hervortreten ließen ${ }^{\%}$.

Es war für die weitere Entwicklung des geistigen Lebens von der größten Bedeutung, daß mit dem Einsetzen der humanistischen Strömung die Erfindung des Buchdrucks und die Errichtung der ersten Universitäten auf deutschem Boden zusammenfielen. Das Universitätswesen war im 13. Jahrhundert in Spanien, Italien, Frankreich und England herangebliiht. In Deutschland fehlte es zwar nicht an Privat-, Pfarr- und Stadtschulen, eine weitergehende wissenschaftliche Bildung und akademische Würden konnten aber nur im Auslande erlangt werden. Einẹ Änderung trat erst ein, als Karl IV., gestiitzt auf Erfahrungen, die er selbst in Paris gemacht hatte, die erste deutsche Universität in Prag (1348) begründete. Noch in demselben Jahrhundert wurden die Universitäten zu Wien (1365) und Heidelberg (1386) ins Leben gerufen. Auch die norddeutschen Städte wollten nicht zurückstehen. Unter ihnen sind vor allem Köln und Erfurt zu nennen, weil sie gleichfalls noch im 14. Jahrhundert in ihren Mauern Hochschulen gründeten.

Die wissenschaftliche Bedeutung dieser Institute war, mit heutigem Maßstabe gemessen, allerdings noch gering. Ihre wichtigste Aufgabe erblickten sie in der Vorbildung der Geistlichkeit. Im Zusammenhange damit war im Universitätswesen der geistliche Einfluß der überwiegende. Die freie Forschung sollte sich an diesen Stätten erst allmählich und mit Überwindung des hartnäckigsten Widerstandes entwickeln. Im 15. Jahrhundert und weit darüber hinaus übte Hand in Hand mit der Kirche die scholastische Philosophie eine fast unbestrittene, jedes freiere Geistesleben einengende Herrschaft aus. Der Universitätsunterricht regte nicht zum Forschen an, sondern er vermittelte wesentlich durch Diktate und Disputierübungen Wortglauben und Autoritätsdünkel.

1) Lindner, Weltgeschichte. Bd. IV. S. 291. 
Durch das Eindringen des Humanismus in Deutschland wurden die deutschen Universitäten wesentlich gehoben. Sie ïbernahmen die Pflege jener neuen Richtung, wodurch ein freierer Zug in die bisherigen Stätten scholastischen Gezänkes, theologischer Disputierwut und Unduldsamkeit kam. Am erfreulichsten trat dieser günstige Einfluß in der Um- und Fortbildung des Unterrichts in die Erscheinung. Man schuf bessere Lehrbücher, ersetzte das Diktieren und Auswendiglernen durch fleißige Lektüre der durch bessere Textkritik geläuterten, alten Schriften und kehrte mit offenerem Blick zu den Erscheinungen zurück, die Natur- und Menschenleben darboten. Auch das Emporblïhen einer volkstiimlichen Kunst wirkte in dem Deutschland des 15. Jahrhunderts befreiend und fördernd ${ }^{1}$ ). Erlebte doch Deutschland damals in Albrecht Dürer eine Verbindung von Kunst und Wissenschaft, wie wir sie in Italien an Lionardo da Vinci bewundern.

Die hervorragendsten unter den Humanisten Mitteleuropas waren Agricola, Erasmus von Rotterdam, dem wir die erste griechische Ausgabe des Neuen Testaments verdanken, Reuchlin, der die hebräischen Studien ins Leben rief, und Melanchthon. Letzterer entfaltete eine ähnliche-Tätigkeit wie Rhabanus Maurus und hat deshalb in der Geschichte des Bildungswesens gleichfalls den Ehrentitel eines Praeceptor Germaniae erhalten. Er setzte sich vor allem das Ziel, in der Philosophie eine Reformation durch das Zurïckgehen auf die echten Schriften des Aristoteles zu bewirken, wie sie Luther in der Theologie dadurch herbeizuführen suchte, daß er einzig und allein das reine Evangelium als die wahre Quelle des religiösen Glaubens hinstellte ${ }^{2}$ ).

In Deutschland wurde Wittenberg zum Mittelpunkt des Humanismus. Von hier ging auch, durch letzteren gefördert, diejenige freiere Gestaltung des religiösen Lebens aus, die für das mittlere und nördliche Europa einen Aufschwung von nie gesehenem Umfang einleitèn sollte. Hatte doch bis dahin die hierarchische Gewalt nicht nur die Normen für den Glauben, sondern alle weltlichen Einrichtungen und Anschauungen beherrscht. Daß diese Gewalt ins Wanken geriet, mußte nicht nur in den $/ \mathrm{u}$ ständen jener Zeit, sondern auch im Reiche der Gedanken eine unermeBliche Veränderung hervorbringen ${ }^{3}$ ). $\quad 7 u$ diesen beiden

1) Lindner, Weltgeschichte. Bd. IV. S. 314.

2) Lange, Geschichte des Materialismus. Bd. I. S. 189.

3) J. Ranke, Die Geschichte des Zeitalter's d. Reformation. Bd. IV. S. 4. 
Elementen, der Renaissance, die erst wieder „das Auge für den Menschen und für die Dinge öffnete" 1) und als das Grundelement bezeichnet werden muß, und zu der Reformation trat die Naturwissenschaft hinzu, um im Verein mit ihnen die Weltanschauung und die Welt von Grund aus umzugestalten. An die Stelle der Lehre wurde die Forschung und an die Stelle des Himmels die veredelte Weltlichkeit gesetzt. Die Verheißung lautete nicht mehr „Unsterblichkeit“, sondern „ewiger Ruhm“2).

Der Angriff des Humanismus gegen die Scholastik ging besonders von Erasmus von Rotterdam aus. Er machte den Kampf gegen die Scholastiker der Klöster und der Universitäten zu seiner Lebensaufgabe. Sein „Lob der Narrleit" ist voll Spott und Bitterkeit gegen die Fesseln, welche die Philosophie und die Theologie jener Zeit beengten und jede freie Regung erstickten ${ }^{3}$ ). Das Büchlein, das in zahllosen Auflagen erschien und in viele Sprachen übersetzt wurde, bat besonders dazu beigetragen, dem 16. Jahrhundert eine antiklerikale Richtung zu geben $\left.{ }^{4}\right)$. Mit dem populären Angriff verband Erasmus den gelehrten. Wie die Humanisten Italiens forderte er, man solle die Wissenschaften aus den Schriften des Altertums erlernen, so die Naturgeschichte aus Plinius, die Erdbeschreibung aus Platon, die Gottesgelehrtheit nicht aus den Kirchenvätern, sondern aus dem neuen Testamente, usw. Es war also noch kein Kampf gegen den Autoritätsglauben, der mit den Humanisten anlob, sondern zunächst nur ein Zurückgehen auf ursprüngliche, reinere Quellen. Indes schon diese Wandlung, obgleich so maßvoll in ihren Zielen, ging nicht ohne den heftigsten Widerstand von seiten der kirchlichen Scholastiker vor sich.

Mit welcher Erbitterung gekämpft wurde, zeigt uns der Lebensgang eines Hutten. Daß es den Führern an Siegeszuversicht und an Begeisterung für die große Sache nicht fehlte, bekundet uns derselbe $\mathrm{Hu}$ tten durch sein Wort: "O Jahrhundert, die Studien blühen, die Geister erwachen; es ist eine Lust zu leben" ${ }^{4}$ ). Dieses Erwachen der Geister machte sich zunächst

1) A. Harnack, Geschichte d. Akademie d. Wissensch. zu Berlin. S. 3.

2) A. Harnack a. a. O. S. 3.

3) Das „Lob der Narrheit"6 (Encomium moriae) fand in Holbein einen seiner Bedeutung würdigen Illustrator.

4) Ranke a. a. O. S. 178.

5) Das Wort, mit dem Hutten sein Denkschreiben an den Humanisten Pirkbeimer schloß. 
weniger durch Neuschöpfungen geltend, als dadurch, daß man den Unterricht naturgemäßer gestaltete und auf wertvolleren Grundlagen errichtete, sowie vor allem dadurch, daß das ausschließlich kirchliche Denken, die "hierarchische Weltansicht", wenn auch nicht gebrochen, so doch eingeschränkt und daneben wenigstens die Duldung anders gearteter Ansichten erkämpft wurde.

Fast unvermittelt schloß sich an das Zeitalter des Humanismus für die Naturwissenschaften die Periode an, die auch den alten Schriftstellern keine unbedingte Autorität zuerkannte, mit dem Glauben brach und an seine Stelle die freie, unabhängige Forschung setzte. Diese Periode wird in Deutschland vor allem durch Koppernikus und durch Paracelsus, sowie durch die Begründung der neucren Naturbeschreibung (Brunfels, Bock, Gesner und Agricola) eröffnet. Mit dem Wirken dieser Männer werden wir uns in den nächsten Abschnitten eingehend zu befassen haben.

Die Wiederbelebung der Wisscnsschätze des Altertums kam auf naturwissenschaftlichem Gebiete vor allem der Astronomie zu gute, für welche selbst die Kirche immer ein, wenn auch zunächst nur praktisches, Interesse bewiesen hatte. Kleriker wie Laien waren nämlich ängstlich darauf bedacht, eine Verschiebung der Fasttage auf profane Tage, wie sie jede Unvollkommenheit des Kalenders mit sich bringen mußte, zu vermeiden. So waren, um ein Beispiel zu erwähnen, die Begleiter Magelhaens in hohem Grade bestürzt, als sich nach der ersten Weltumsegelung bei ihrem Eintreffen in Spanien aus der Schiffsrechnung ergab, daß man um einen Tag hinter dem Kalender zurïckgeblieben war und infolgedessen zu unrechter Zeit gefastet hatte. Anfangs glaubte man an einen Irrtum, bis man die Notwendigkeit einer solchen Erscheinung einsah und infolgedessen später die Datumsgrenze einführte ${ }^{1}$ ).

\section{Nicolaus von Cusa.}

Bei der Wiederbelebung der naturwissenschaftlichen Forschung spielte in diesem Zeitalter der Kardinal Nicolaus ron Cusa eine bedeutende Rolle. Wie einst Roger Bacou, so machte er ${ }^{2}$ ) Vorschläge zur Verbesserung des Kalenders, sowie der alfonsinischen Tafeln, ohne jedoch damit durclizudringen. Nicolaus von Cusa

1) Peschel, Geschichte der Erdkunde. 1877. S. 386.

2) Auf dem Konzil zu Basel im Jabre 1437. 
wurde im Jahre 1401 zu Cues an der Mosel als Sohn eines armen Fischers geboren. Seiner Begabung wegen fand er Unterstützung, studierte in Padua und zeichnete sich durch große, mit gewandtem Wesen vereinigte Gelehrsamkeit aus. In päpstlichem Auftrage reiste er nach Konstantinopel und brachte von dort wertrolle griechische Manuskripte nach Italien. Hier war er auch mit dem fast gleichaltrigen Paolo Toscanelli (geb. 1397 zu Florenz) bekannt geworden, welcher, durch die alten Schriftsteller angeregt, die beobachtende Astronomie auf europäischem Boden zu neuem Leben erweckte. Toscanelli hatte im Dome zu Florenz einen Gnomon angebracht, mit dem er die Kulmination der Sonne auf die Sekunde genau zu ermitteln vermochte. Die Einrichtung bestand in einer Platte, die sich $270 \mathrm{FuB}$ über dem Boden des Domes befand. Sie besaß eine Öffnung, durch welche ein Sonnenstrahl auf den Boden fiel. Nicolaus von Cusa zählte zu den Schülern Toscanellis, der auch eine, leider verloren gegangene, Seekarte entwarf. Sie ist sehr wahrscheinlich von Behaim bei der Anfertigung seines Globus verwertet werden. Zur Zeit Toscanellis kamen wahrscheinlich auch die ersten in Kupfer gestochenen Karten auf. Daran schlossen sich noch vor Ablauf des 15. Jahrhunderts die ersten in Holz geschnittenen und gedruckten Karten ${ }^{1)}$.

In Italien wurde Nicolaus von Cusa mit den aristotelischen Schriften im griechischen Original bekannt, und zwar geschah dies zu einer Zeit, als man in Deutschland nur die arabisch-lateinischen Bearbeitungen des Aristoteles kannte. Die Folge war, daß Nicolaus sich um die Ausbreitung des Humanismus in seiner deutschen Heimat sehr verdient gemacht hat. Im Verein mit dem Papste Nicolaus V. bemühte er sich, griechische Werke durch Übersetzung ins Lateinische zugänglicher zu machen. So hat er an der Herausgabe des Archimedes auf Grund des griechischen Originals hervorragenden Anteil genommen. Bei seiner Beschäftigung mit Mathematik, Mechanik und Astronomie kniipfte er überall an Euklid, Archimedes und andere alte Schriftsteller an. Er war es auch, der zuerst unter den Neueren die eingewurzelte Ansicht, daB die Erde der Mittelpunkt der Welt sei, er-

1) Das Original der ersten gedruckten Karte von Deutschland befindet sich im Germanischen Museum in Nürnberg. Die Karte (1491) rührt von Nicolaus von Cusa her. Die erste in Holz geschnittene Karte (Weltkarte) stammt aus dem Jahre 1475. 
schütterte. Nach seiner Lehre ist sie ein Gestirn und befindet sich, wie alles in der Natur, in Bewegung.

Gleich einer Stelle aus dem Dialog des Galilei mutet es uns an, wenn Nicolaus von Cusa ${ }^{1}$ ) schreibt: „Es ist jetzt klar, daß die Erde sich wirklich bewegt, wenn wir es gleich nicht bemerken, da wir die Bewegung nur durch den Vergleich mit etwas Unbeweglichem wahrnehmen." Auf den Gedanken, daß die Fixsterne ein solches Unbewegliches sind, kam Nicolaus von Cusa indessen nicht. Er würde sonst den Kern der koppernikanischen Lehre vorweg genommen haben. „Wüßte jemand nicht," so fährt er fort, „daß das Wasser fließt und sähe er das Ufer nicht, wie würde er, wenn er in einem auf dem Wasser dahingleitenden Schiffe steht, bemerken, daß das Schiff sich bewegt? Da es daher jedem, er mag auf der Erde, der Sonne oder einem anderen Sterne sich befinden, vorkommen wird, als stände er im unbeweglichen Mittelpunkte, während alles um ihn her sich bewege, so würde er in der Sonne, im Monde, im Mars stehend, immer wieder andere Pole angeben."

Die Bewegung der Erde um die Sonne hat Nicolaus von Cusa indessen noch nicht gelehrt. Auch gründen sich seine Behauptungen oft mehr auf allgemeine Überlegungen, denn auf Beobachtungen und mathematische Schlüsse. Blieb somit sein System 2) auch weit von der Wahrheit entfernt, so wurde doch zum erstenmal an der durch tausendjähriges Bestehen geheiligten Autorität des Ptolemäos gerüttelt und der großen Umwälzung, die 100 Jahre später durch Koppernikus auf dem Gebiete der Astronomie eintrat, vorgearbeitet ${ }^{3}$ ).

Auch um die Kartographie hat Nicolaus von Cusa sich Verdienste erworben. Sogar der Versuch, eine Weltkarte zu entwerfen, rührt von ihm her. Er bediente sich dabei der Kegelprojektion. Seine Karte, die während der Renaissance-

1) De docta ignorantia. II. 1 u. 2.

2) Nach diesem System wurde der Erde eine dreifache Bewegung bei-

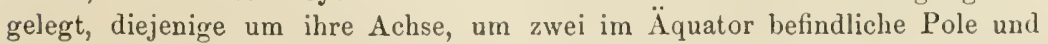
dic Bewegung um die Weltpole.

3) Über "Nicolaus von Cusa und seine Beziehungen zur mathematischen und physischen Geographie" äußert sich Günther in den Jahrbüchern über die Fortschritte der Mathematik (Jahrg. 1899, mit folgenden Worten: „Er zertrümmerte die Kiristallsphären der Griechen, verkïnclete die Wesensgleichheit der Erde unit anderen Weltkörpern, lebrto die Bewegung der Erde und entwarf als erster unter den Neueren eine Landkarte in richtigem geometrischen Netz." 
zeit sehr geschätzt wurde, ist noch in mehreren Exemplaren erhalten $\left.{ }^{1}\right)$.

Auch mit mechanischen Dingen hat sich Nicolaus von Cusa beschäftigt. So erdachte er zur Bestimmung der Tiefe eines Gewässers ein Bathometer. Eine leichte Kugel sollte mit einem Gewichte beschwert und dadurch zum Untersinken gebracht werden. Beim Berühren des Bodens sollte sich das Gewicht loslösen und die Kugel emporsteigen. Aus dem für beide Bewegungen erforderlichen Zeitaufwand konnte man dann die Tiefe des Gewässers berechnen. Nicolaus von Cusa ist einer der ersten gewesen, der verlangte, man solle bei allen Untersuchungen messend verfahren. Er kniipft diese Bemerkung an seine Betrachtungen über die $\left(W_{a g e}{ }^{2}\right)$ und erläutert sie durch Beispiele. So heißt es, man könne leicht feststellen, ob die Pflanzen ihre Nahrung aus der Luft oder aus dem Boden bekämen. Man brauche nur die Samen und die erforderliche Menge Erde abzuwägen und die Wägung nach dem Heranwachsen der Pflanze zu wiederholen. Solche Anregungen blieben jedoch zunächst noch vereinzelt. Sie wurden oft von denen, die sie aussprachen, nicht einmal verfolgt. So sollten noch zwei Jahrhunderte verfließen, bis Stephan Hales als der Erste die Methode des Wägens und des Messens in ausgedehnten Versuchsreihen auf pflanzenphysiologische Vorgänge anwandte.

\section{Lionardo da Vinci.}

Ein ähnliches Verhältnis wie zwischen den Cusaner und Koppernikus begegnet uns auf dem Boden Italiens zwischen Lionardo da Vinci und Galilei. Lionardo da Vinci wurde im Jahre 1452 in der Nähe von Florenz geboren. (Er starb 1519.) Da er frühzeitig künstlerische Begabung zeigte, führte ihn sein Vater einem Meister zu, bei dem er malen und modellieren, sowie Metall gießen und Gold schmieden lernte. Ein späterer Kunsthistoriker ${ }^{3}$ ) erzählt, Lionardo sei die Darstellung einer kleinen Nebenfigur auf dem Gemälde dieses Meisters in solchem Grade gelungen, daß letzterer sich verschworen habe, keinen Pinsel mehr

1) Max Jacobi, Das Weltgebäude des Kardinals Nicolaus von Cusa. Ein Beitrag zur Geschichte der Naturphilosophie und Kosmologie in der Frührenaissance. Berlin 1904.

2) De staticis experimentis dialogus.

3) Vasari. 
anzurühren, weil ihn ein Knabe übertroffen. Im beginnenden Mannesalter entwickelte Lionardo eine Vielseitigkeit sondergleichen. Er vereinigte mit körperlichen Vorzügen ungewöhnliche Verstandesschärfe und Genialität des künstlerischen Wirkens. Als Architekt, Bildhauer und Maler hat er IVerke von unübertroffener Schönheit geschaffen ${ }^{1}$ ).

Der Herzog Ludwig Sforza zog Lionardo nach Mailand. Den Anlaß dazu bot ein Sieg, den letzterer als Violinspieler in einem musikalischen Wettstreit errungen hatte. Und wie Iohnte der Künstler die fürstliche Gunst! Er beteiligte sich mit Eifer an dem Bau des Mailänder Domes und gründete, iadem er schon damals seine Vorliebe für die mathematisch-naturwissenschaftliche Richtung bekundete, eine Art Akademie. Auch die Schöpfung des Abendmahles, jenes Kolossalgemäldes, durch das sich Lionardo mit Raphael und Michel Angelo auf eine Stufe stellte, fällt in die Zeit seines Aufentbalts in Mailand.

Später sehen wir Lionardo da Vinci an verschiedenen Orten seines Vaterlandes als Ingenieur und Architekt mit Arbeiten großen Umfangs, wie Kanalbauten ${ }^{2}$, der Anlage von Befestigungswerken, sowie der Anfertigung von Maschinen aller Art - selbst Flugmaschinen fehlen nicht - beschäftigt. Aus dieser, auf das Praktische gerichteten Tätigkeit erklärt es sich, daß er viel über mechanische Probleme nachgedacht und Schriften darüber verfaßt hat, die allerdings infolge ungünstiger Umständ die Entwicklung der Wissenschaften wenig beeinflußt und erst in neuerer Zeit ihre Würdigung gefunden haben $\left.{ }^{3}\right)$. Diese Aufzeichnungen enthalten nämlich manche bemerkenswerten Ansätze, die zu den Arbeiten Galileis hinuiberleiten.

Zwölf Codices von Lionardos Manuskripten werden in der Bibliothek der französischen Akademie aufbewahrt. Vorher befanden sie sich in der Ambrosianischen Bibliothek zu Mailand. Von dort wurden sie 1796 von den Franzosen nach Paris gebracht, wo sie Venturi eingehend studierte. Er bezeichnete die dreizehn Folianten mit den Buchstaben A bis N. Im Jahre 1815 erhielt die Ambrosiana den Codex atlanticus (N), der sich be-

1) Lindner, Weltgeschichte. Bd. IV. S. 288.

2) Er schuf den Kanal von Martesano, welcher den 'I'essin mit der Adda verbindet.

3) Libri, Histoire des sciences mathématiques en Italie. 'T. III. Dühring, Kritische Geschichte der allgemeinen Prinzipien der Mechanik. Berlin 1873. S. $12 \mathrm{ft}$. 
sonders mit technischen Dingen befaßt, zurück. Mit der Veröffentlichung dieses wertvollen Nachlasses wurde erst 1881 begonnen: Les manuscrits de Lionarde de Vinci, publiés en facsimilés arec transcription littérale, traduction française etc. Im Druck erschienen war vor dem Ende des 19. Jahrhunderts nur Lionardos Abhandlung über die Malkunst (1651).

Lionardos wissenschaftliche und technische Bedeutung wurde anfangs kaum beachtet. Erst nachdem Libri und Venturi darauf hingewiesen hatten, fand Lionardo auch auf diesen Gebieten die verdiente Anerkennung, die allerdings nicht selten in ein kritikloses Überschätzen ausartete ${ }^{1}$ ).

Unter den alten Schriftstellern, auf welchen Lionardo da Vinci fußt, ist besonders Heron zu nennen. Er findet sich im Codex Atlanticus auch zitiert. W. Schmidt wies darauf hin, daß manche Ausführungen Lionardos augenfällig mit solchen der Heronschen Pneumatik übereinstimmen (Math. Bibl. [3.] III. 180-187).

Eine genauere Untersuchung über die Quellen, welche Lionardo benutzt hat, verdankt man dem französischen Physiker P. Duhem (Etudes sur Léonard de Vinci, ceux qu'il a lus et ceux qui l'ont lu. Paris 1906.). Danach hat da Vinci weit mehr gelesen, als es den Anschein hat. Er zitiert nämlich sehr selten. Infolgedessen kann man seine Quellen nur schwer ermitteln.

Nach Duhem (Études sur Léonard de Vinci, Troisième série. Paris 1913) und nach den "Origines de la Statique" (2 Bde. Paris 1905/6) desselben Verfassers hat die Scholastik auf dem Gebiete der Mechanik weit melır geleistet als man bisher anzunehmen geneigt war. Duhem kommt zu dem Ergebnis, daß die dynamischen Lehren, die im 14. Jahrhundert insbesondere von französischen Scholastikern ausgingen, die Grundlagen gebildet haben, auf der Galilei und seine unmittelbaren Vorgänger weiter arbeiten konnten. Bei der Beurteilung der Ergebnisse Duhems darf aber nicht vergessen werden, daß der fransösische Historiker dazu neigt, dasjenige besonders hoch einzuschätzen, was für das eigene Land und Volk als rïhmlich gelten kann. Unter den Scholastikern, die zu richtigen dynamischen Vorstellungen gelangten, ist auch Albert von Sachsen zu nennen. Er erkannte etwa 1368, daß der freie Fall ein Beispiel für die gleichförmig beschleunigte

1) Vgl. H. Grothe, Leonardo da Vinci als Ingenieur und Philosoph. Berlin 1874. 
Bewegung sei. Man darf dabei aber nicht vergessen, daß es den Scholastikern mehr um spekulative Definitionen als um die Untersuchung physikalischer Vorgänge zu tun war $\left.{ }^{1}\right)$.

Auf dem Gebiete der Mechanik stützte sich Lionardo auf Heron, Vitruv und auf die mittelalterlichen Lehrbücher des Jordanus Nemorarius und anderer. Die Lehre vom Erdschwerpunkt und die Gleichgewichtstheorie der Meere läßt sich auf Albert von Sachsen zurïckführen, den Lionardo auch gelegentlich zitiert. Bezüglich der Erklärung von Ebbe und Flut stützt sich Lionardo auf den Scholastiker Themon. Andererseits hat Lionardo aber auch einen nachweisbaren Einfluß auf Roberval, Cardano, Palissy und andere ausgeübt2).

Bekannt ist Lionardos Ausspruch, daß die Mechanik das Paradies der mathematischen Wissenschaften sei, weil man durch die Mechanik erst zu den Früchten dieser Wissenschaften gelange. Lionardo da Vinci handelt aber auch nach diesem Ausspruch, dessen Bedeutung erst die nächsten Jahrhunderte in vollem Maße gewiirdigt haben. So untersucht er die Wirkung des Hebels für den Fall, daß die Kräfte in beliebiger Richtung auf ihn wirken. Die Rolle und das Rad an der Welle werden auf den Hebel zurückgeführt. Seine auf das Praktische gerichtete Tätigkeit brachte es mit sich, daß er theoretisch und durch Versuche den Einfluß untersuchte, den der Reibungswiderstand auf die Bewegung der Maschinen ausübt. Es sind die ersten genaueren Untersuchungen dieser Art, die uns bei Lionardo begegnen. Ferner werden der freie Fall und der Fall auf der schiefen Ebene in Betracht gezogen, wenn auch hier Galilei die erschöpfende Behandlung vorbehalten blieb. In einigen Äußerungen Lionardos lassen sich schon die Keime des Trägheits- und des Energiegesetzes erkennen; so, wenn er sagt, jedes Ding „trachte in seinem gegebenen Zustande zu verharren" oder der bewegte Körper besitze "Wirkungsfähigkeit" und „wuchte in der Richtung seiner Bewegung".

Für die einfachen Maschinen sprach Lionardo schon das Prinzip aus, daß die im Gleichgewicht befindlichen Kräfte sich

1) H. Wieleitner, Das Gesetz vom freien Fall in der Scholastik, bei Descartes und Galilei. Mitteilungen zur Gesch. d. Medizin u. d. Naturwiss. Nr. 58. S. 488.

2) Siehe auch Fritz Schuster, Zur Mechanik Leonardo da Vincis (Hebelgesetz, Rolle, Tragfähigkeit von Ständern und Trägern). In.-Diss. Erlangen 1915. 153 Seiten.

Dannemann, Dio Naturwissenschaften, I, Bd, 2. Aufl. 
umgekehrt wie die virtuellen Geschwindigkeiten verhalten ${ }^{1}$ ). Seine klare Auffassung des Beharrungsvermögens bezeugen folgende Sätze ${ }^{2}$ ): „Keine vernunftlose Sache bewegt sich von selbst.“ "Jeder Impuls neigt zu ewiger Dauer."

Ferner stellt Lionardo die Möglichkeit des Perpetuum mobile $^{3}$ ) in Abrede und entwickelt unter Ablehnung aller Wunderund Geheimkräfte, insbesondere der scholastischen qualitates occultae, den Kraftbegriff in einem fast modermen Sinne. So heißt es bei Lionardo da Vinci: „Kraft ist Ursache der Bewegung und die Bewegung ist die Ursache der Kraft". Wenn er letztere eine geistige Wesenheit nennt, die sich mit den schweren Körpern verbinde, so erläutert er dies mit folgenden Worten: „Geistig, sage

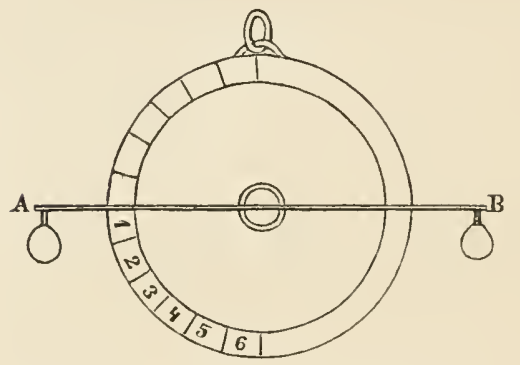

Abb. 56. Lionardos Hygrometer. ich, weil in ihr unsichtbares Leben ist, weil der Körper, in dem sie geboren wird, weder in der Form noch im Gewichte wächst. Die berührte Saite einer Laute bewegt ein wenig eine andere gleiche Saite von gleicher Stimme einer anderen Laute. Du wirst dies sehen durch Auflegen eines Strohhalmes auf die zweite Saite $\left.{ }^{4}\right) . "$

Beobachtungen, die Lionardo beim Wïgen hygroskopischer Substanzen machte, führten ilın zur Konstruktion eines, wenn auch noch recht unvollkommenen Hygrometers. An den Enden eines zweiarmigen Hebels brachte er zwei gleich schwere Kugeln

1) Siehe auch E. v. Lippmann in der Zeitschrift f. Naturwissensch. 72. Bd. S. 291. Siehe auch dessen Abhandlungen u. Vorträge.

2) Eine Zusammenstellung der wichtigsten Sätze aus dem großen, von der französischen Akademie herausgegebenen Manuskriptenwerk Lionardo da Vincis hat Marie Herzfeld unter dem Titel „Leonardo da Vinci, der Denker, Forscher und Poet" herausgegeben. Jena 1906.

Das Buch M. Herzfelds enthält 745 Notizen Lionardos, die nach bestimmten Gesichtspunkten geordnet sind: Über die Wissenschaft; Von der Natur, ihren Kräften und Gesetzen; Sonne, Mond und Erde; Menschen, Tiere und Pflanzen; Philosophische Gedanken; Aphorismen, Allegorien; Entwürfe zu Briefen; Allegorische Naturgeschichte; Fabeln; Schöne Schwänke; Prophezeiungen. Bei jeder Notiz ist auf die betreffende Manuskriptstelle hingewiesen.

3) Auch gegen die alchemistischen Bestrebungen wendet sich Lionardo.

4) Manuskript A. Fol. 22 v. 
an, von denen die eine mit Wachs, die zweite dagegen mit Baumwolle überzogen war. Nahm die Feuchtigkeit der Luft zu, so sank die zweite Kugel. Der Ausschlag konnte auf einer ringförmigen Skala abgelesen werden.

Ein Seitenstück zu diesem Feuchtigkeitsmesser ist der von Lionardo abgebildete und beschriebene Windmesser ${ }^{1}$. Er besteht aus einem mit Gradeinteilung versehenen Quadranten, der, wie aus der Abbildung ersichtlich ist, mit einer beweglichen Platte verbunden wird. Diese wird durch den Wind gehoben, so daß man die jeweilige Stärke des Windes auf der Gradeinteilung ablesen kann. Die gleiche Einrichtung besaß das fast 200 Jahre später erfundene Pendelanemometer Hookes, der bisher als der Erfinder dieses Instrumentes galt 2 ).

Auch die Theorie der Reibung und das schwierige Gebiet der Festigkeitslehre ${ }^{3)}$ beschäftigten Lionardo da Vinci, der auf fast allen Gebieten der

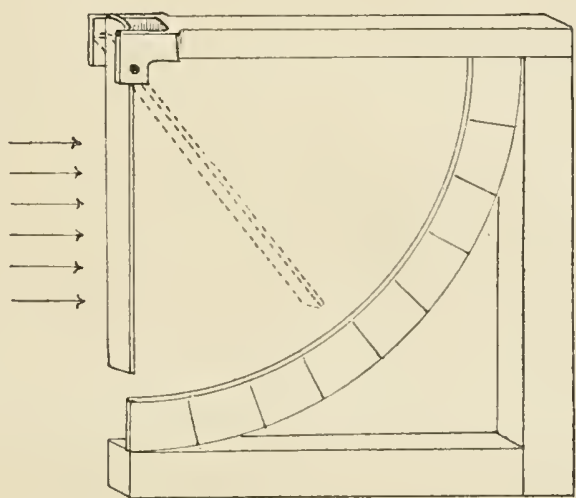

Abb. 57. Lionardos Windmesser.

Naturwissenschaft Anschauungen entwickelte, die ihn als einen seine Zeit und deren Denken überragenden Geist erkennen lassen.

So spricht er sich über die Rolle, welche die Luft bei der Verbrennung und der Atmung spielt, mit folgenden Worten aus: "Wo eine Flamme entsteht, da erzeugt sich ein Luftstrom um sie. Dieser dient dazu, die Flamme zu erhalten. Das Feuer zerstört ohne Unterlaß die Luft, durch die es unterhalten wird. Sobald die Luft nicht geeignet ist, die Flamme zu unterhalten, kann in ihr kein Geschöpf leben. Die Flamme disponiert zuerst die Materie, aus der sie entsteht, und kann sich dann davon ernähren. Indem sie Nahrung für die Flamme wird, formt sie sich in sie

1) Siehe F. M. Feldhaus, Leonardo, der Techniker u. Frfinder. E. Diederichs, Jena 1913. Mit 9 Tafeln und 131 Abbildungen im Text. S. 118.

2) L. Darmstïdter, Handbuch zur Geschichte der Naturwissenschaften u. der Technik. Berlin 1908. S. 136. Durt wird das Jahr 1667 als das Jahr der Erfindung angegeben.

3) Siehe F. M. Feldhaus, Leonardo, der Techniker und Erfinder. 
um." Daß Lionardo mit diesen Erklärungen fast überall den wahren Sachverhalt traf, setzt geradezu in Erstaunen. Um das Zuströmen der Luft zu erhöhen und dadurch die Leuchtkraft zu vergrößern, erfand Lionardo den Lampenzylinder. Auch die Idee des Fallschirmes, "mit dem sich ein Mensch aus beliebiger Höhe herunterlassen könne", ist auf Lionardo zurückzuführen. Der Gedanke wurde erst dreihundert Jahre später verwirklicht'1).

Auf die Versteinerungen und andere geologische Dinge, z. B. die Entstehung der Schichten durch Ablagerung, sowie auf mineralogische Fragen war Lionardo gelegentlich der Wasserbauten, die er als Ingenieur ausführte, aufmerksam geworden.

Die Versteinerungen, die man, entgegen den Lehren der Alten, immer noch meist für Naturspiele hielt, wurden von ihm als Überreste von Lebewesen gedeutet.

Um Lionardo voll zu würdigen, muß man bedenken, daß er einem vom Mystizismus noch ganz durchdrungenen Zeitalter angehörte. So mußte er in seinen Betrachtungen über die Versteinerungen besonders die Ansicht zurückweisen, daß die Versteinerungen als Naturspiele unter dem Einfluß der Sterne hervorgebracht seien. Auch zwei andere Vorstellungen seiner Zeit, die Quadratur des Zirkels und das Perpetuum mobile, bekämpfte Lionardo schon mit wissenschaftlichen Gründen.

Seine Tätigkeit als Künstler hat ihn veranlaßt, sich eingehend mit anatomischen Studien $\mathrm{zu}$ befassen. $\mathrm{Zu}$ diesem $\mathrm{Zwecke}$ setzte er sich mit einem Arzte in Verbindung ${ }^{2}$ ). Die Frucht der gemeinsamen Tätigkeit des Künstlers und des Naturforschers sind etwa 800 Bilder, die wir als die ersten, naturgetreuen anatomischen Zeichnungen ansprechen müssen ${ }^{3}$ ). Sie betreffen vor allem das Knochen- und das Muskelsystem. Doch sind auch Abbildungen der inneren Organe (Herz, Leber usw.) vorhanden.

Lionardo war wohl der erste, der sich eingehender mit Untersuchungen über die Mechanik des Körpers beschäftigte. Er studierte die Beugung und Streckung der Glieder, sowie das Gehen ganz im Sinne der heutigen Physiologie. Ferner setzte er auseinander, wie die Beschäftigung auf die Haltung wirkt, und welche Muskeln beim Werfen, Heben, Tragen usw. in Betracht kommen. Mit Vor-

1) Durch Lenormand im Jahre 1783.

2) E. v. Lippmann, da Vinci (Abhandl. u. Vortr. 1906. S. 346).

3) Eingehender handelt von der "Anatomie des Lionardo da Vinci" M. Roth im Archiv für Anatomie u. Physiologie. Jabrg. 1907. Anat. Abteil. Suppl.-Bd. S. 1-122. 
liebe belehrte er sich und seine Schüler auf dem Fechtboden über die verschiedenen Bewegungen des Körpers. Aus künstlerischem Drange hat sich Lionardo auch mit der Anatomie des Pferdes beschäftigt ${ }^{1}$ ).

Eine der wichtigsten unter den wissenschaftlichen Grundlagen der Kunst hat Lionardo erst geschaffen. Das ist die Lehre von der Perspektive, um die sich außer ihm auch die Brïder van Eyck und Battista Alberti verdient gemacht haben. Daß die Alten mit den Lehren der Perspektive nicht vertraut waren, haben schon Lessing ${ }^{2}$ ) und Lambert nachgewiesen. Lambert pries Lionardo als "den ersten, der an die Verfeinerung der Malkunst und an die Perspektive gedacht" habe. Dem Verfahren lag folgender Gedanke zugrunde. Bringt man zwischen das Auge und den Gegenstand, den man perspektivisch richtig zeichnen will, eine durchsichtige Tafel, so wird jeder Lichtstrahl die Tafel in einem bestimmten Punkte schneiden. Die Gesamtheit dieser Schnittpunkte gibt uns das perspektivische Bild, und die Lehre von der Perspektive läuft darauf hinaus, wie man ein solches Bild zeichnet, ohne die zur Erläuterung dienende Tafel zu benutzen.

Vom Auge handelt Lionardo eingehender im Manuskript $D^{3}$ ). Seine Ausführungen betreffen die Größe des Gesichtswinkels und den Vorgang des Sehens. Aus Versuchen wird geschlossen, daß der Gesichtssinn seinen Sitz in den Endigungen des Sehnerven habe (Manuskript D. S. 3). Zu dieser Erkenntnis war übrigens auch schon Roger Bacon gelangt. Im Manuskript $\mathrm{C}$ wird die Lehre vom Schatten durch viele Zeichnungen erläutert. Hier wie überall finden sich nur Ansätze. Ihre Bedeutung liegt darin, daß

1) Mit den biologischen Kenntnissen und Anschauungen Lionardo da Vincis befaßt sich de Toni in seiner Schrift „La Biologia in Leonardo da Vinci“". Discorso letto nell' adunanza solenne del R. Istituto Veneto, il 24 maggio 1903. De Toni erblickt den Ausgang der zahllosen Studien Lionardos in der Künstlernatur, die sich in die Gegenstände vertieft, um sie der Wirklichkeit entsprechend darzustellen. In Lionardos anatomischen Tafeln sind nach de Toni die Muskeln stellenweise so genau abgebildet, wie in den besten modernen Werken.

Das gleiche Thema behandelt M. Holl in der Inaugurationsrede „Ein Biologe aus der Wende des 15. Jahrhunderts". Graz 1905. Holl weist besonders auf die methodischen Grundsätze Lionardos hin und erwähnt als solche scine vergleichende Methode, die Anwendung des Experiments, die Bezugnahme auf dic Funktionen des Organismus und die Altersveränderung der Organe usw.

2) Im ,Laokoon" und in den „Bricfen antiquarischen Inhalts".

3) Les manuscrits de Léonard de Vinci. Paris 1881. 
stets experimentell und geometrisch verfahren, und daß jedes Problem frei von vorgefaßten Meinungen in Angriff genommen wird.

Bemerkenswert sind auch Lionardos gelegentliche Äußerungen über astronomische Gegenstände. Von der Erde heißt es, sie müsse den Bewohnern des Mondes und anderer Gestirne als Himmelskörper erscheinen, auch befinde sie sich nicht im Mittelpunkt der Sonnenbahn, ebensowenig wie sie die Mitte des Weltalls einnehme. „Die Erde“, heißt es an einer Stelle ${ }^{1}$, ist ein Stern ähnlich wie der Mond." Und ferner: „Mache Gläser, um den Mond groß zu sehen" 2).

Das Sehen führt Lionardo darauf zurück, daß das Auge nach Art einer Camera obscura Bilder hervorbringe. Er erläutert

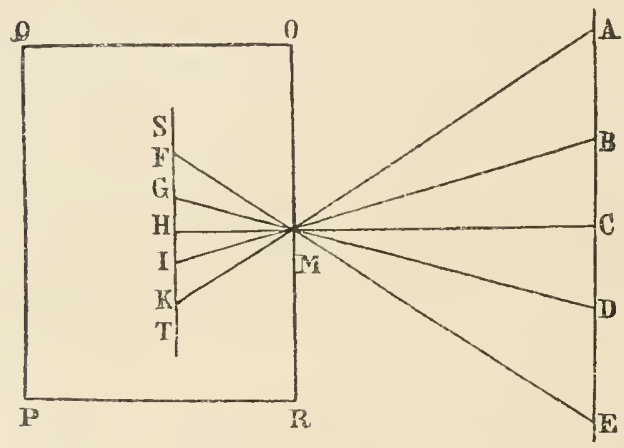

Abb. 58. Lionardos Erläuterung des Sehens ${ }^{3}$ ). dies in folgender Weise: Man lasse durch eine kleine Öffnung (Abb. 58, M) das Bild eines beleuchteten Gegenstandes in ein dunkles Zimmer treten. Dann fange man dieses Bild auf einem weißen Papier, das man in dem dunklen Raum nahe der Öffnung anbringt, auf. Man wird dann den Gegenstand auf dem Papier in seiner wirklichen Gestalt und Farbe sehen, aber viel kleiner und umgekehrt. Es sei A BCDE der, von der Sonne erleuchtete Gegenstand. ST sei der Schirm, der die Strahlen auffängt. Weil die Strahlen gerade sind, wird der von A ausgehende nach K, der von $\mathrm{E}$ ausgehende nach $\mathrm{F}$ gelangen. Dasselbe findet bei der Pupille statt". Dazu bemerkt er noch beim Studium der Natur des Auges ${ }^{4}$ ): "Hier sind die Figuren, die Farben, alle Wirkungen des Weltalls in einem Punkt gesammelt, und dieser Punkt ist ein solches Wunder! O staunenswerte Notwendigkeit! Du zwingst mit deinem Gesetz alle Wirkungen, auf kürzestem Wege an ihren Ursachen teilzuhaben. Schreibe in deiner Anatomie, wie in dem

1) Manuskript F. Fol, 69.

2) Manuskript CA. Fol, $190 \mathrm{v}$.

3) Gerland u. Traumüller, Abb. 100.

4) Manuskript CA. Fol. $345 \mathrm{v}$. in der Übersetzung von M. Herzfeld auf S. 42. 
winzigen Raume des Auges das Bild der sichtbaren Dinge wiedergeboren wird und sich in seiner Ausdehnung wiederherstellt".

Ähnlich tief empfunden zeigt sich die Darstellung Lionardos an vielen Stellen seiner Aufzeichnungen. Man wird an die später von Fechner entwickelten Anschauungen erinnert, wenn man bei Lionardo da Vinci liest, die Erde sei gleichsam ein organisches Wesen, das Meer ihr Herz und das Wasser ihr Blut. Und wenn er schließlich das Wasser als den „Kärrner der Natur" bezeichnet, so dürfte der moderne Geologe kaum einen treffenderen Ausdruck für die Rolle des flüssigen Elementes finden.

Die Sonne hielt Lionardo für einen sehr heißen Weltkörper. Auch wußte er das sogenannte aschfarbene Licht des Mondes, das wir neben der leuchtenden Sichel wahrnehmen, aus dem Wiederschein des von der Sonne auf die Erde gelangenden Lichtes $\mathrm{zu}$ erklären ${ }^{1)}$.

Leider haben sich die Aufzeichnungen Lionardo da Vincis nirgends zu einer abgeschlossenen, in sich abgerundeten Leistung verdichtet. Es sind meist geistreiche, treffende Einzeleinfälle, die erst die neuere Zeit voll Staunen über die Eigenart des Menschen, dem sie entstammen, der Vergessenheit entrissen hat. Die gelehrte Zunft wiirde ihn wohl schwerlich verstanden und gewürdigt haben. Für sie galt in erster Linie die Autorität, die Lionardo mit den Worten geißelt: „Wer sich auf die Autorität beruft, verwendet nicht seinen Geist, sondern sein Gedächtnis". "Das Experiment irrt nie", ruft er den Zeitgenossen zu, "sondern es irren nur eure Urteile“. Auf den Weg, den seiner Meinung nach die Forschung zu gehen hat, weist Lionardo mit folgenden Worten hin: „Der Interpret der Wunderwerke der Natur ist die Erfahrung. Sie täuscht niemals; es ist nur unsere Auffassung, die zuweilen sich selbst tïuscht. Wir müssen die Erfahrung in der Verschiedenheit der Fälle und der Umstände solange zu Rate ziehen, bis wir daraus eine allgemeine Regel ziehen können. Wenngleich die Natur mit der Ursache beginnt und mit dem Experiment endet, so müssen wir doch den entgegengesetzten Weg verfolgen, d. h. wir beginnen mit dem Experiment und müssen mit diesem die Ursache untersuchen“" ${ }^{2}$.

1) Nach E. Wiedemann hat Lionardo da Vinci sehr viel von den Arabern übernommen und ist sein schriftlicher Nachlaß zum großen Teile eine Sammlung von Notizen.

2) Manuskript F. Fol. 55 v. 
Diese Worte bekunden, daß Lionardo schon ein Jahrhundert vor Francis Bacon die Induktion für die allein sichere Methode der Naturwissenschaft hielt. Auf Grund dieser Erkenntnis vermochte er es, einen bewunderungswiirdig tiefen Einblick in die Natur zu tun. Die Vorstellungen, zu denen er gelangte, blieben leider in seinen Manuskripten vergraben, sonst würde sein Einfluß auf die Entwicklung der neueren Naturwissenschaft ein ganz anderer gewesen sein, worauf schon A. v. Humboldt hinwies.

Haben Männer wie Lionardo da Vinci') und Nicolaus von Cusa auch keine derartigen Grundlagen für die weitere Entwicklung geschaffen, wie Koppernikus und Galilei, welche das zur Ausführung brachten, wozu jenen das volle Vermögen fehlte, so erkennen wir doch aus der Betrachtung, die wir ihnen widmeten, daß das Wirken der großen Begründer der Wissenschaft kein unvermitteltes ist und keineswegs mit dem bisher Erstrebten und Erreichten außer Beziehung steht. Jene Großen haben häufig das, was ihre Zeitgenossen zwar ahnten, aber nur unvollkommen zum Ausdruck zu bringen vermochten, in voller Klarheit erfaßt und so begründet, daß es zum unveräußerlichen Besitz der Menschheit wurde. Auf dieser Errungenschaft bauten dann bescheidenere Kräfte weiter, bis ihr unverdrossenes Mühen, das für den Fortgang der Entwicklung aber unumgänglich nötig ist und nicht gering geachtet werden darf, wieder einem der Großen auf dem Gebiete der Wissenschaft den Weg geebnet. So hatte auch die Astronomie, bevor Koppernikus sein Wirken begann, in Deutschland eine besondere Pflege durch Peurbach und Regiomontan gefunden. Diese Männer, die ihrerseits wieder an die Alten anknüpften, haben Koppernikus besonders dadurch vorgearbeitet, daß sie die Beobachtungskunst förderten.

\section{Das Wiedererwachen der astronomischen Wissenschaft.}

Die Astronomie war zwar durch Cusa und Toscanelli zu neuem Leben erweckt worden. An Einsicht und an Kenntnissen standen diese Männer jedoch tief unter Hipparch und Ptolemäos. Die astronomische Wissenschaft mußte zunächst wieder auf diejenige Höhe gebracht werden, die sie im Altertum zur Zeit der Alexandriner besaß. Daß dies geschah, war vor allem das Ver-

1) Max Jacobi, Nicolaus von Cusa und Lionardo da Vinci, zwei Vorläufer des Nicolaus Coppernicus. Altpr. Monatsschr. Bd. 39. Heft 3 u. 4. 
dienst $\mathrm{Peurbachs,} \mathrm{des} \mathrm{Begründers} \mathrm{der} \mathrm{beobachtenden} \mathrm{und} \mathrm{rechnen-}$ den Astronomie im Abendlande1). Georg Peurbach wurde im Jahre 1423 in Oberösterreich geboren. Als Zwanzigjähriger war er in Rom mit Nicolaus von Cusa in Berührung gekommen. Um 1450 kehrte er nach Wien, wo er studiert hatte, zurück und erhielt dort den Lehrstuhl für Astronomie und Mathematik.

Peurbach übersetzte den Almagest. Er erkannte, daß eine Verbesserung der vorhandenen Planetentafeln die erste Bedingung für jeden weiteren Fortschritt der Astronomie sei. Die Abweichungen, die sich zwischen den alfonsinischen Tafeln ${ }^{2}$ ) und Peurbachs Beobachtungen ergaben, erreichten für den Mars z. B. Werte von mehreren Graden. Auch die trigonometrischen Tafeln des Almagest erfuhren durch Peurbach eine wesentliche Verbesserung, indem er statt der Sehne den Sinus einführte und eine

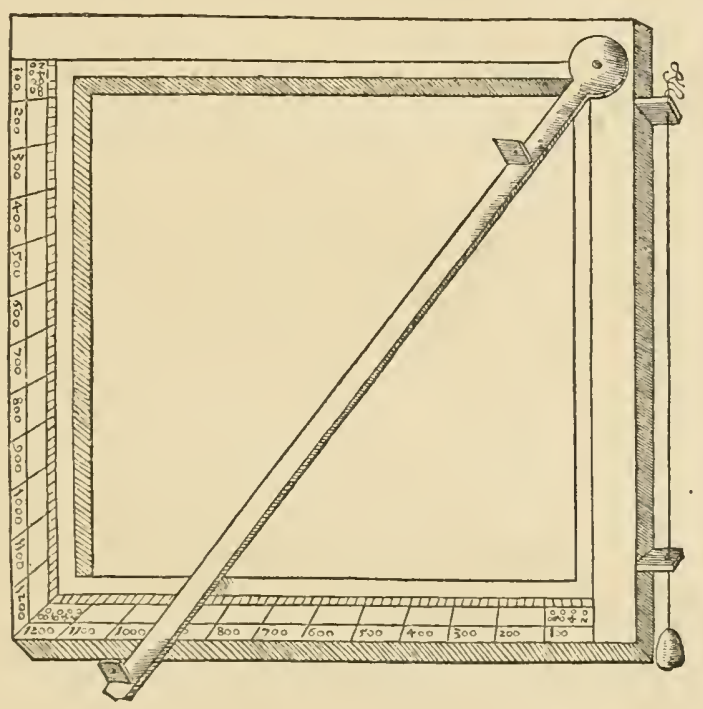

Abb. 59. Peurbachs Quadratum geometricum $\left.{ }^{3}\right)$.

Berechnung für alle Werte von $10 \mathrm{zu} 10$ Sekunden unter Zugrundelegung eines Radius von 60000 Einheiten lieferte.

Für seine astronomischen Messungen benutzte $\mathrm{Peurbach}$ das "Quadratum geometricum“ (s. Abb. 59). Dies ist ein quadratischer Rahmen, an dem ein bewegliches Lineal mit Dioptervorrichtungen

1) Einen Vorläufer besaß Peurbach in Johann von Gmunden (1380 bis 1442, der vor Peurbach an der Wiener Hochschule lehrte und wohl als der Vater der deutschen Astronomie bezeichnet wurde. Nach L. v. Lippmann erhob die Universität Protest gegen diese erstmalige Einrichtung einer Professur für Mathematik. Dieser Protest wurde aber durch den einsichtigen Kaiser Maximilian I. abschlägig beschieden.

2) Alfons X. von Kastilien hatte um 1250 die ptolemäischen Planetentafeln durch neue Tafeln ersetzen lassen.

3) Repsold, Zur Gescb. der astronomischen Meßwerkzeuge. W. Engelmann, Leipzig 1907. Abt. 7. - Vgl. hierzu Gerbert (J. Würschmidt, Archiv 
angebracht ist. Die Seiten des Quadrats waren in $120 \mathrm{Ab}$ schnitte eingeteilt. Auf diese Weise ließ sich die Tangente des beobachteten Winkels mit ziemlicher Genauigkeit ablesen.

Mit dem Almagest, dem Hauptwerk der griechischen Astronomie, war das Abendland zuerst durch die im 10. und 11. Jahrhundert in Spanien entstandenen arabischen Hochschulen bekannt geworden. Der Almagest, die Schriften des Euklid und des Aristoteles wurden von hier ans den Hochschulen des christlichen Abendlandes in lateinischer Übersetzung zugänglich. Durch diese Übertragung und die Vermengung mit Zutaten aller Art hatte der ursprüngliche Text natürlich manche Änderung erlitten und dadurch viel von seinem Werte eingebiißt. Auch die Astronomie der Griechen hatte durch die Araber keine wesentliche Förderung, dagegen eine Vermengung mit astrologischen Zutaten erfahren und so an wissenschaftlichem Gehalt Einbuße erlitten. Es war daher ein wichtiges Ereignis, daß im 15. Jahrhundert das astronomische Werk des Ptolemäos von Griechenland nach Italien gelangte. Peurbach war zwar auf das griechische Manuskript aufmerksam geworden $\left.{ }^{1}\right)$. Er benutzte aber dennoch den aus dem Arabischen ins Lateinische ïbersetzten minderwertigen 'Text, da er die griechische Sprache nicht verstand. Erst sein begabter Schüler, sein Nachfolger auf dem Wiener Lehrstuhl, Johann Müller aus Königsberg 2), genannt Regiomontanus (1436-1476) fußte auf dem griechischen Text des Almagest. Er gab im Jahre 1475 neue Tafeln heraus, die nicht nur für die Astronomie, sondern auch für die Entdeckungsreisen jener Zeit ein wichtiges Hilfsmittel wurden.

Regiomontan war ferner in Deutschland einer der ersten, der das Studium der Algebra förderte. Auch soll er die alte Hypothese von der Erdbewegung, die ihm schon wenigstens 60 Jahre vor Koppernikus zu gleicher Zeit mit Cusa „in den Sinn gekommen sei, zum besseren Verstïndnis der Astronomie wieder hervorgeholt haben" ${ }^{3}$ ). In mechanischen Dingen, erzählt sein Biograph4) weiter,

f. Gesch. d. Math. 1919!, der gleichfalls sich des Quadratum geometr. bediente. Er hatte es zweifellos von den Arabern übernommen.

1) Die Anregung empfing Peurbach durch den großen Humanisten Bessarion (um 1500), durch dessen Vermittlung zahlreiche Werke aus Konstantinopel nach Italien gelangten.

2) Es handelt sich um einen kleinen Ort dieses Namens in Unterfranken.

3) So berichtet Doppelmayr in seinem Werk "Historische Nachrichten“ von den Nürnberger Mathematicis und Künstlern. 1730. S. 22.

4) Siehe Doppelmayr a. a. O. 
war er einer der ersten, der ,eine künstliche Einrichtung mit Rädern, durch welche die eigentliche Bewegung der Sterne wiedergegeben wurde, zu vieler Verwunderung anfertigte". Ferner stellte Regiomontan einen parabolischen Brennspiegel von fünf Fuß Durchmesser aus Metall her. Regiomontans Tafeln wurden von ihm als "Ephemeriden" bezeichnet. Sie erschienen 1473, umfaßten den Zeitraum von 1474-1560 und enthielten für Sonne und Mond die Längen- und außerdem für den Mond die Breitenangeben. Ferner boten sie ein Verzeichnis der für die Zeit von 1475-1530 $\mathrm{zu}$ erwartenden Finsternisse.

Große Verdienste hat sich Regiomontan auch um die Trigonometrie, die wichtigste Hilfswissenschaft der Astronomie, erworben. Er war es, der die Tangensfunktion, mit welcher die Araber gleichfalls schon vertraut waren, im Abendlande einführte. Ein weiterer Fortschritt bestand darin, daß er sich der dezimalen Teilung bediente, indem er für seine Tangententafeln den Radius $r=100000$ zugrunde legte. Unzweifelhaft schöpfte R e gi om ontan bei seiner Darstellung der Trigonometrie auch aus arabischen Quellen. Doch ist der Zusammenhang im einzelnen nicht mehr nachzuweisen, da er in der Darstellung wie in der Fortbildung des empfangenen Wissenstoffes sehr selbständig verfuhr. Sein trigonometrisches Hauptwerk "De triangulis" entstand 1464. Durch letzteres lernte das Abendland den Sinussatz und die Tangensfunktion kennen. Auch entwickelte Regiomontan als erster darin den allgemeinen sphärischen Cosinussatz.

Regiomontans Tafeln waren in den Händen von Bartholomäos Diaz, sowie in denen Vasco da Gamas auf seinem Wege nach Ostindien. Sie halfen Columbus den neuen Weltteil entdecken. Amerigo Vespucci benutzte sie, um 1499 Längenbestimmungen in Siidamerika auszuführen. So sehen wir, wie dasjenige, was der stille Gelehrte in einsamen Nachtwachen erdacht und erforscht, die kiihnen Seefahrer und Konquistadoren befähigte, dem europäischen T'eil der Menschheit die Erde in ihrem ganzen Umfange zu erschließen. Trotz der schon um das Jahr 1200 erfolgten Einfülurung des Kompasses wagten nümlich die Portugiesen, selbst nachdem Heinrich der Seefahrer die Entdeckungsreisen organisiert hatte, zuniichst nicht, von der Küstenschiffahrt abzugehen. Viele Jahre kamen ihre Fahrzeuge nicht ïber Kap Bojador hinaus, weil man dort ein Riff sah, dessen "Brandung sich weit hinaus ins Meer erstreckte. Dem Ungewissen, das die Wasserwiiste des atlantischen Ozeans in sich barg, vermochte man 
erst zu begegnen, nachdem die Astronomie der Schiffahrt die zur Ortsbestimmung geeigneten Hilfsmittel verliehen hatte.

$\mathrm{Zu}$ diesen gehörte in erster Linie der Kreuz- oder Jakobsstab (siehe Abb. 60), ein Werkzeug, das zum Messen ron Winkeln auf bewegter See geeigneter war als die von Ptolemäos und Koppernikus benutzten Instrumente, unter denen das mit Kreisteilung versehene Astrolabium ${ }^{1}$ ) und das parallaktische Lineal an erster Stelle zu nemnen sind2). Der Kreuz- oder Jakobsstab mit verschiebbarem Querriegel, den Regiomontan benutzte, besaß eine Länge von $2 \frac{1}{2}$ Metern. Seine Anwendung hat man bis ins 14. Jahrhundert zurück verfolgen können. Waren die erwähnten Meßinstrumente fest aufgestellt und von hinlänglicher Größe, so

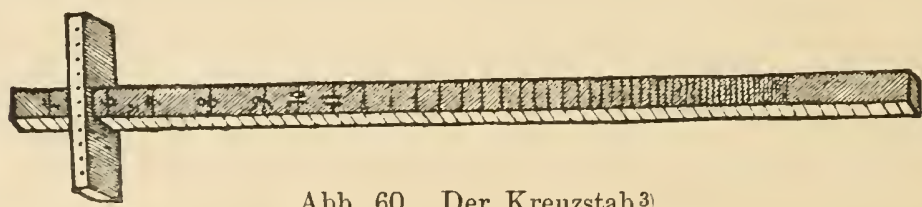

Abb. 60. Der Kreuzstab ${ }^{3}$.

ließen sich ziemlich scharfe Messungen damit anstellen. Tycho, dessen Arbeiten infolge ihrer Genauigkeit die Entdeckungen Keplers erst ermöglichten, berichtet, an seinen Astrolabien noch eine sechstel Bogenminute abgelesen zu haben.

Wahrscheinlich hat der Nürnberger Martin Behaim (1459 bis 1506), dem man den ersten neueren Erdglobus verdankt, den Kreuzstab nach Portugal gebracht und letzteren zu Messungen auf bewegter See empfohlen ${ }^{4}$ ). Aus Abbildung 61 ersehen wir den

1) Ein mit Gradteilung und Dioptern versehener Ring, in dem sich eine drehbare, gleichfalls mit Dioptern versehene Scheibe befindet. Eine derartige Vorrichtung wurde schon von Hipparch zum Messen von Winkeln benutzt.

2. Montucla, Histoire des mathémat. Paris. An VII. Tome I. p. 307.

3) Repsold, Zur Gesch. der astronomischen Meßwerkzeuge. W. Engelmann, Leipzig 1907.

Als Erfinder des Jakobsstabes gilt der Astronom Levi ben Gerson. Er hat dadurch (1325) ein bequemes Mittel für Ortsbestimmungen auf See geschaffen.

4) Breusing in der Zeitschrift für Erdkunde. Berlin 1868. Über Behaims Globus, sowie andere Globen aus dem Zeitalter der großen Entdeckungsreisen siehe: Matteo Fiorini, Erd- und Himmelsgloben, ihre Geschichte und Konstruktion; frei bearbeitet von S. Günther. Leipzig 1895. Kapitel V. Globen fertigten auch schon die Araber an, z. B. Edrisi im 12. Jahrbundert. 
Gebrauch dieses Instrumentes. Der Querstab a wurde so lange verschoben, bis das am Ende des Längsstabes b befindliche Auge die beiden Gegenstände, deren Winkelabstand gefunden werden sollte, iiber die Enden von a anvisierte; b trug eine Skala, von der man unmittelbar die jeder Stellung entsprechenden Winkel ablesen konnte. Mit einiger Zuverlässigkeit vermochte man indes um diese Zeit nur die geographische Breite zu bestimmen. Hinsichtlich der Länge mußte man sich mit einem Abschätzen begnügen. Die enge Beziehung, in welche zu Beginn des neueren Zeitalters die Astronomie zur Nautik trat, war beiden Gebieten sehr förderlich. Während der nächsten Jahrhunderte wurde die Mitarbeit der Astronomen außerdem durch hohe Belohnungen an-

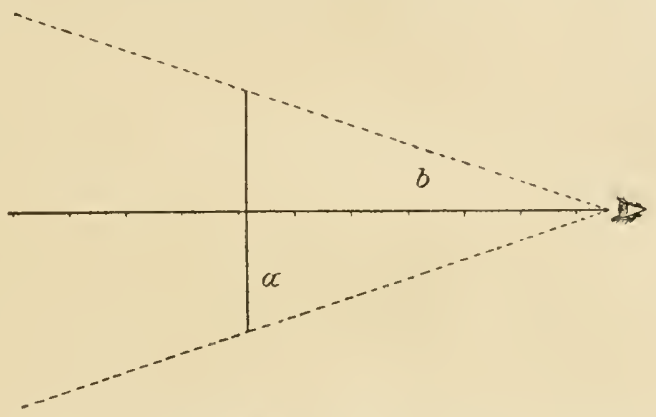

Abb. 61. Schematische Erläuterung des Kreuzstabes.

geregt, welche die Schiffalırt treibenden Nationen auf die Lösung praktisch wichtiger Aufgaben setzten. Geister ersten Ranges, wie Galilei und Euler, verschmähten es nicht, ihre Arbeit in den Dienst dieser Sache zu stellen.

Den ersten, noch erhaltenen Globus, fertigte Behaim 1492 an ${ }^{1}$. Erhalten sind auch noch Globen aus den Jahren 1515, 1520 und 1532. Mercator maclite aus der Herstellung vorziiglicher Erd- und Himmelsgloben schon ein Gewerbe. Zu seinen Abnelımern gehörten Kaiser Karl V. und andere Fïrsten. Von Mercator herrïhrende Globen finden sich noch in Duisburg, Nürnberg, Weimar und Wien ${ }^{2}$.

Das Duisburger Museum, das sich bemiiht, die Werke Mercators entweder im Original oder in Nachbildungen zu erwerben, besitzt einen von ihm verfertigten Erd- und Himmelsglobus. Sie wurden 1909 bei einem toskanischen Edelmann gefunden und gelangten durch Kauf in den Besitz des Museums. Der Erdglobus

1) Eine Ablildung enthält das Werk von Ghillany: „Geschichte des Seefahrers M. Behaim". Nürnberg 1853 .

2) Plastische Darstellungen der Erde fertigte man übrigens auch schon im Altertum an (s. Pesehels Gesch, d. Erdk. 1877. S. 51), und die Araber stellten Himmelsgloben her. 
stammt aus dem Jahre 1541, der andere ist 1551 hergestellt. Auf ihm sind die Sternbilder farbenprächtig ausgeführt. Während die frïheren Globen aus Holz oder Metall verfertigt waren, benutzte Mercator eine Mischung aus Gips, Sägespänen und Leim, die er auf eine aus Stäben hergestellte Hohlkugel auftrug.

Die Anregung zu den Entdeckungsreisen ist nicht nur auf die Fortschritte der Astronomie und die Bedürfnisse des Handels, sondern auch auf die Lektüre der alten Schriftsteller zurückznführen. Insbesondere gilt dies von Columbus. Die von den Alten herrührenden Nachrichten, welche die allmähliche Ausdehnung ihres geographischen Horizontes erkennen lassen, waren ihm durch das Weltbuch Alliacos $\left.{ }^{1}\right)$ geläufig geworden. Je weiter die Alten die östlichen Grenzen Asiens hinaus verlegt hatten, um so größer war die Wahrscheinlichkeit, daß eine Fahrt nach Westen bald zu bewohnten Ländern führen wiirde.

Dieser Gedanke erfüllte außer Columbus besonders den italienischen Astronomen Toscanelli, dessen Lieblingsprojekt die Verbindung Europas und Asiens auf dem Seewege nach Westen war. Toscanelli war der Meinung, daß die asiatische Küste höclıstens 120 Längengrade von Lissabon entfernt sein könne. Er stand mit Columbus in Briefwechsel und hat ihn in einem Schreiben vom 25. VI. 1474 von der Durchführbarkeit des Gedankens, der ihn erfüllte, zu überzeugen gewußt. Nach allem, was an eigenen und fremden Überlegungen, von denen sich Columbus leiten ließ, bekannt geworden, muß man seine Entdeckungsreisen über die früheren Unternehmungen dieser Art stellen. Welche Schwierigkeiten es zu ïberwinden galt, braucht hier nicht des näheren erörtert zu werden. Erinnert sei nur an die Versammlung zu Salamanca, welche den Plan des Columbus prüfen sollte. Was mag letzterer wohl empfunden haben, als man ihm entgegenhielt, wenn es auch gelingen sollte, zu den seiner Ansicht nach vorhandenen Gegenfüßlern hinunter zu fahren, so würde es doch unmöglich sein, wieder nach Spanien hinauf zu gelangen?

Daß sich trotz des gelehrten, am Buchstaben klebenden Dünkels, der nicht etwa nur diese Versammlung erfüllte, das Neue siegreich Bahn brach, ist vor allem der Erfindung der Buchdrucker-

1) Pierre d'Ailly (Petrus de Alliaco) lebte von 1350 bis 1420 . Er war ein hoher kirchlicher Würdenträger. In seinem Weltbuch (Imago mundi) findet sich die antike, von Roger Bacon wiederholte Ansicht, Asien erstrecke sich so weit nach Osten, daß seine Küste von Spanien aus in wenigen Tagen zu erreichen sei (Tschackert, Peter von Ailly. Gotha 1877. S. 335). 
kunst, sowie dem Umstande zu verdanken, daß man im Latein eine Weltsprache besaß, die einen raschen Austausch der Gedanken zwischen den Angehörigen aller Völker ermöglichte.

Es war um 1450, als Gutenberg das erste, mit beweglichen Lettern hergestellte Buch herausgab. In Paris, in Nïrnberg und an anderen Orten entstanden darauf große Druckereien, die für die damalige gelehrte Welt arbeiteten. Mit der Ausbreitung des Buchdruckes verringerte sich allmählich der Abstand zwischen dem zunftmäßigen Gelehrten- und dem Laientum. Die Errungenschaften des Forschens und Denkens wurden immer mehr zu einem Gemeingut.

Eins der glänzendsten Beispiele für die Vereinigung geistigen und gewerblichen Schaffens und für das Zusammengehen des gebildeten Bürgertums mit Künstlern und Gelehrten bot vor allem Nürnberg, wo vorübergehend anch Regiomontan und Behaim wirkten. Für Regiomontan errichtetete ein Nürnberger Kaufherr mit fuirstlicher Freigebigkeit eine Sternwarte, die von hervorragenden Mechanikern mit Astrolabien, Armillarsphären und anderen astronomischen Instrumenten ausgerüstet wurde. Öffentliche Vorträge belebten das Interesse für die Mathematik und die Naturwissenschaften. Eine im Jahre 1470, kurz vor der Ankunft Regiomontans in Nürnberg gegrïndete Druckerei wurde bald die bedeutendste in Deutschland 1). Behaim übermittelte die gewonnenen astronomischen Kenntnisse den seefalırenden Völkern. Er hielt sich von 1480-1484 in Portugal auf, zur Zeit, als auch Columbus dort weilte, und stand den Portugiesen bei ihren Unternehmungen zur Seite. Es ist schr wahrscheinlich, daß Diaz, Columbus und da Gama ihm die Bekanntschaft mit den Ephemeriden Regiomontans, sowie manche Belehrung über die Kunst, nach der Beobachtung der Sterne zu segeln, verdanken ${ }^{2}$.

Man darf jedoch neben den gelehrten Deutschen, die hier, wie so oft in der Entwicklung der Wissenschaften, wohl den Gedanken, aber nicht die Tat bracliten, den Portugiesen Pedro Nunez aus Coimbra nicht vergessen. Er war es, der zuerst ein Werk schuf, in dem die Nautik auf wissenschaftliche Grundlagen

1) Doppelmayr, Historische Nachrichten von den Nüruberger Mathematikern und Künstlern. 1730.

2) E. F. A pelt, Die Reformation der Sternkunde ron N. v. Cusa bis auf Kepler. Jena 1852. S. 58. Behaims Verdienst um die Entwicklung und die Übermittelung der wissensehaftlichen Nautik wird heute geringer eingeschätat. Siehe die Mitteilungen z. Geschichte d. Medizin u. d. Naturwiss. Nr. 60. S. 21. 
gestellt wurde (De arte atque ratione navigandi). Er war es ferner, der die Genauigkeit der Ablesung an den astronomischen Instrumenten verbesserte. Der Nonius wird nach ihm fälschlich so benannt. Der Erfinder dieser Einrichtung ist Pierre Vernier (1580-1637).

\section{Die Wiederbelebung der Naturbeschreibung.}

Auch die beschreibenden Naturwissenschaften, die Zoologie und die Botanik, erfuhren gegen den Anfang des Mittelalters manche Förderung. Das Wiederaufleben der alten Literatur, insbesondere das Bekanntwerden mit den zoologischen Schriften des Aristoteles, den man vorher ja nur aus arabischen und lateinischen Bearbeitungen kannte, war auch hier von Einfluß. Noch wichtiger war es aber, dab man sich immer melır mit offenen Sinnen der eigenen Beobachtung zuwandte und nach naturgetreuer Darstellung des Gesehenen strebte. Erinnert sei nur an die oben erwähnten anatomischen Abbildungen Lionardo da Vincis. Die Ausdehnung des geographischen Gesichtskreises führte dazu, daß man schon gegen den Ausgang des Mittelalters mit zahlreichen neuen Tieren und Pflanzen bekannt wurde. Das Wiederaufleben des wissenschaftlichen Sinnes machte sich auf dem Gebiete der Botanik nicht nur durch die zunehmende Neigung für eigenes Beobachten, sondern auch durch das allmähliche Zurücktreten der Rücksicht auf die Nutzanwendung der Pflanzen geltend. Das Beobachtungsvermögen wurde insbesondere durch zwei Umstände gefördert. Es waren dies die Einrichtung botanischer Gärten und die Anfertigung von Herbarien.

Den ersten botanischen Garten der neueren Zeit legte ein venetianischer Arzt1) im Jahre 1333 an, nachdem ihm die Republik dazu einen wüsten Platz überlassen hatte. Der erste Universitätsgarten begegnet uns in Padua. Er wurde 1545 gegründet. Einige Jahre später folgte Pisa. Und noch während des 16. Jahrhundert ahmten viele Universitäten des übrigen Europas das von Italien gegebene Beispiel nach ${ }^{2}$.

Nicht minder wichtig für die Erweckung selbsttätiger Beobachtung und Forschung war das Aufkommen der Herbarien. Ein eigentlicher Erfinder dieser Einrichtung läßt sich wohl nicht an-

1, E. Meyer, Geschichte d. Botanik. Bd. IV. S. 255. Zoologische Gärten finden sich schon bei den Arabern (E. Wiedemann).

2) Der Leydener Garten wurde 1577, der Heidelberger 1593 eingerichtet. 
geben. Die ersten Nachrichten über umfangreichere Sammlungen getrockneter Pflanzen stammen aus dem 16. Jahrhundert 1). Die älteste Anweisung zur Einrichtung von Herbarien begegnet uns nach Meyer (Gesch. der Botanik. Bd. IV. S. 267) indes erst zu Beginn des 17. Jahrhunderts. „Im Winter", heißt es dort, „mul3 man, da fast alle Pflanzen umkommen, die Wintergärten betrachten. So nenne ich die Bücher, in denen man getrocknete Pflanzen, auf Papier geklebt, verwabrt."

Ein weiteres Mittel, die Beobachtung anzuregen, war das Abbilden von Pflanzen und anderen Naturkörpern. Zwar, das Altertum hatte sich dieses Mittels ebenso bedient wie der Pflanzengärten. Kennt man doch noch heute mit Abbildungen versehene Ausgaben des Dioskurides, die aus dem 6. Jahrhundert stammen. Während des Mittelalters hatte die philologische Gelehrsamkeit und der Autoritätsglauben indessen die Wissenschaft in solchem Maße überwuchert, daß die Kunst, das Studium der Natur durch Abbildungen zu fördern, erst wieder zu neuem Leben erweckt werden mußte.

$\mathrm{Zu}$ den ältesten gedruckten Büchern mit Abbildungen von Naturkörpern gehört auch Konrad Megenbergs „Buch der Natur", auf das wir schon an anderer Stelle eingegangen sind. Megenbergs Buch enthält in Holzschnitt hergestellte, charakteristische Abbildungen von Säugetieren, Vögeln, Bäumen und Kräutern, unter denen sich z. B. Ranunculus acris, Viola odorata, Convallaria majalis und andere recht gut erkennen lassen. Allerdings felılt es bei der Beschreibung der Meeresungeheuer, der wunderlichen Menschen und anderer Dinge nicht an Abbildungen, die nur als fratzenhafte Phantasieerzeugnisse gelten können.

Erwähnenswert ist auch der gegen 1485 erschienene „Ortus sanitatis“ (Garten der Gesundheit), der zahlreiche, oft nachträglich kolorierte Abbildungen enthält, von denen manche der Natur ziemlich nahe kommen, während die Abbildungen exotischer Pflanzen meist erfunden sind 2 .

Wir haben hiermit die Betrachtung desjenigen Zeitabschnitts beendet, in dem das Wiederaufleben der Wissenschaften an-

1) E. Meyer, Geschichte der Botanik. Bd. IV. S. 273, ist geneigt, den Italiener Luca Ghini, der in Bologna lehrte, als den Erfinder der Herbarien zu betrachten.

In Leyden ist noch ein Herbarium von $R$ auw olf vorhanden, der 1573 in den Orient reiste. (Mitteilung von E. Wiedemann.)

2) E. Meyer, Geschichte der Botanik. Bd. IV. S. 284.

Dan nemann, Die Naturwissenschaften. I. Bd. 2. Anfi. 
hob. Zwar stützte man sich noch auf allen Gebieten auf die seit der Mitte des 15. Jahrhunderts aus reinerer Quelle fließenden Kenntnisse der Alten. Doch gab man sich nicht mehr wie früher gänzlich der Autorität gefangen. Selbstbeobachten, eigenes Forschen wurde in den hervorragendsten Köpfen dieses Zeitalters zum Losungswort. Und wenn auch noch kein neues Gebäude der Wissenschaften erstand, so wurde doch auf allen Gebieten mit den Vorarbeiten begonnen und die Tätigkeit des nachfolgenden Zeitalters erst ermöglicht, dessen Aufgabe es war, die Fundamente der neueren Naturwissenschaft zu legen.

Wenn wir uns die hier skizzierte Entwicklung vergegenwärtigen, welche die Wissenschaft seit ihrem Wiederaufleben im 14. und 15. Jahrhundert genommen, so sehen wir, daß sie nicht mehr in solchem Maße wie früher von den Geschicken eines oder einiger Völker abhängt, sondern daß ihr Gang stetiger und weniger als bisher durch gewaltsame Ereignisse der äußeren Geschichte beeinflußt erscheint. Die Geschichte der Wissenschaften ist auch in der Folge nicht so eng mit dem Gange der Weltgeschichte verknüpft wie in den früheren Perioden, in denen wir häufig genötigt waren, das Verständnis der Wissenschaftsgeschichte durch Heranziehen der allgemeinen Geschichte zu erschließen. 


\section{Die Begründung des heliozentrischen Weltsystems durch Koppernikus ${ }^{1}$.}

Das 16. Jahrhundert war auf allen Gebieten eine Zeit der Vorbereitung. Nur zögernd und langsam, gleichsam tastend, entwickelte sich während dieses Zeitraumes die neuere Methode der Naturforschung. Das 17. Jahrhundert bietet uns dagegen das Schauspiel eines nie vorher gesehenen Siegeslaufes unter der Führung eines Galilei, Kepler und Newton. Nunmehr vollzog sich die innige Verschmelzung der Naturwissenschaften mit der Mathematik, sowie die Ausgestaltung einer' streng induktiven Forschungsweise. Durch diese beiden Momente wurde ein Umschwung herbeigefiihrt, wie ihn die Geschichte der Wissenschaften nicht wieder erlebt hat.

Das wichtigste Ereignis des 16. Jahrhunderts ist die Aufstellung des heliozentrischen Weltsystems durch Koppernikus und die hierdurch herbeigeführte Umgestaltung des gesamten Weltbildes. Nicolaus Koppernikus wurde am 19. Februar, (alten Stils) des Jahres 1473 in Thorn geboren. Polen und Deutsche haben sich um den Ruhm gestritten, ihn zu den Ihren zählen zu dürfen. Ein solcher Streit ist miißig. Koppernikus war einer der großen Geister, die durch ihr Wirken der Welt gehören. Tatsache ist, daß 'Thorn zur Zeit seiner Geburt unter polnischer Oberhoheit stand, im übrigen aber, was den gebildeten 'Teil der Bevölkerung anbetraf, eine deutsche Stadt war. Die Mutter des Koppernikus ist deutscher Abkunft gewesen. Über die Stammeszugehörigkeit des Vaters läßt sich dagegen keine sichere Entscheidung treffen. Soviel ist jedoch gewiß, daß Koppernikus selbst in seinem Fühlen und Denken ein Deutscher war und sich in allen

1) Es ist archivalisch festgestellt, daß der Name Koppernigk lautete. Das Titelblatt des 1543 in Nürnberg gedruckten Werkes enthält zwar den Namen Copernicus. Es scheint hier aber ein Verschen des Herausgebers (Rheticus) vorzuliegen. Die richtige Schreibweise würde Coppernicus oder Koppernikus lauten. Siehe Max Jacobi, "Koppernikus oder Kopernikus". Artikel in der "'Täglichen Rundschau“ v. 14. 8. 1907 
Dokumenten, die auf uns gelangt sind, wenn er nicht Latein schrieb, der deutschen Sprache bediente.

Nachdem Koppernikus das Vaterhaus verlassen, bereitete er sich in Krakau für den medizinischen Beruf vor. Bei der Vielseitigkeit, mit der man in früheren Jahrhunderten die Universitätsstudien betrieb, wurde er indes auch mit der Mathematik und mit der Astronomie vertraut. Auf letzterem Gebiete genoß die Universität Wien, wo Peurbach und Regiomontan gelehrt hatten, einen vorzüglichen Ruf. Dorthin begab sich deshalb nach Beendigung seiner medizinischen Studien der spätere Reformator der astronomischen Wissenschaft. Zum Glück,für letztere war Koppernikus nicht gezwungen, sofort dem ärztlichen Berufe nachzugehen. Er war nämlich dadurch günstig gestellt, daß sein Oheim mütterlicherseits, der Bischof von Ermeland, sich seiner annahm und ihm später eine Domherrenstelle des Frauenburger Kapitels verschaffte. Von 1495-1505 hielt sich Koppernikus meist in Italien auf. Dort war im Zeitalter der Renaissance die Astronomie emporgeblïht. In Florenz war unter den Mediceern die erste Akademie nach platonischem Vorbild entstanden. Sternwarten wurden errichtet und Lehrstellen geschaffen. In Italien hatte auch Nicolaus von Cusa seine Anregungen empfangen und sie von dort nach Deutschland verpflanzt. Diesem Vorbild folgte Koppernikus, indem er sich in Italien fast ein Jahrzehnt in der praktischen Astronomie vervollkommnete. Doch ist aus diesem langen Abschnitt seines Lebens, der für die Entwicklung seiner wissenschaftlichen Vorstellungen ohne Zweifel von großer Bedeutung gewesen ist, sehr wenig bekannt geworden: Auch von den astronomischen Hilfsmitteln, deren sich Koppernikus bediente, weiß man nur wenig. Jedenfalls besaßen sie keinen hohen Grad von Genauigkeit. Wie die astronomischen Instrumente im Zeitalter des Koppernikus beschaffen waren, erfahren wir aus dem von dem Astronomen Apian ${ }^{1}$ ) um jene Zeit verfaßten "Instrument-Buch“.

Der Gedanke, der seinem System zugrunde liegt, bemächtigte sich des Koppernikus, sobald er in der Blütezeit des Mannes-

1) A pian lebte von 1495-1552. Er wurde von Kaiser Karl V. hoch geschätzt und verfertigte für diesen eine Maschine, durch deren Bewegung man den Lauf der Planeten darstellen konnte. Auch empfahl er dunkle Gläser zur Beobachtung der Sonne, in der Hoffnung, auf diese Weise den Vorübergang von Venus und Merkur sehen zu können. Auch der Vorschlag, die Monddistanzen zum Bestimmen der geographischen Länge zu benutzen, rührt von Apian her (Cosmographia §5). 
alters selbständig forschend an die Natur herantrat. Diesen Gedanken zu verfolgen und zu begründen, ersehien ihm als eine Aufgabe, wohl wert, sein ganzes übriges Leben in stiller Forscherarbeit ihr zu widmen. Seit der im Jahre 1505 erfolgten Rückkehr aus Italien bis zu seinem Tode am 24. Mai des Jahres 1543 blieb er deshalb, von einigen kleinen Reisen abgesehen, in seinem Bistum. Ein beschauliches Leben hat Koppernikus jedoch in dieser Zurückgezogenheit nicht geführt. Die Zeit, welche ihm die mit dem Domherrnamt verbundenen Pflichten übrig ließen, war der Armenpraxis in Frauenburg und der sorgfältigen Ausarbeitung jenes großen Werkes gewidmet, in dem er seine Theorie, sowie die jahrelangen Beobachtungen, auf die er sie stützte, niedergelegt hat.

Das für die neuere Astronomie grundlegende Hauptwerk des Koppernikus erhielt den Titel „Über die Kreisbewegungen der Himmelskörper". In der an den Papst gerichteten Vorrede wird der Anlaß zu dem Werke und seine Geschichte mitgeteilt. Wir erfahren daraus, daß die Schrift „bis in das vierte Jahrneunt hinein" 1 ) verborgen blieb, bis sie zum Druck gelangte. Obgleich Koppernikus um das Jahr 1530 den Ausbau der heliozentrischen Lehre beendet hatte, schwankte er, ob er mit seinen Ansichten an die Öffentlichkeit treten sollte. "Die Verachtung", sagt er, "die ich wegen der Neuheit und der scheinbaren Widersinnigkeit meiner Meinung zu befürchten hatte, bewog mich fast, das fertige Werk beiseite zu legen."

Jedoch hatten befreundete Astronomen, sowie Geistliche, die sich mit Astronomie beschäftigten, Kenntnis von dem Werk erlaalten. Ihrem Drängen nach Veröffentlichung setzte Koppernikus nicht nur aus dem erwähnten Grunde anfangs Widerstand entgegen, sondern er zögerte auch, weil ihn der Wunsch beseelte, wirklich Besseres an die Stelle des Vorhandenen zu setzen. Kam es ihm doch ror allem darauf an, der beobachtenden Astronomie einen Dienst zu erweisen und ihr das neue Lehrgebäude in einem solch vollkommenen Zustande zu übermitteln, daß es an die Stelle des alten, mit den praktisehen Bedürfnissen eng verwachsenen Systems treten konnte. Von einem völligen Gelingen blieb Koppernikus, wie er wohl selbst am besten wußte, indes noch weit entfernt. Auch mochte er wohl alınen, welchen Sturm sein Versuch entfesseln sollte. Galt es doch, einer seit Jahrtausenden geheiligten

1) Anspielung auf das Horazische nonumque prematur in annum. 
Anschauung den Boden zu entziehen ${ }^{1}$ ) und an ihre Stelle eine neue Lehre zu setzen, welche der bisher den wesentlichsten Teil der Welt ausmachenden Erde eine nur bescheidene Stelle unter zahllosen Körpern gleichen, ja selbst höheren Ranges einräumte. Ganz zu geschweigen der Gefahr, der eine solche Neuerung ausgesetzt war, als ketzerisch verdammt zu werden.

Erst ein Jahr vor seinem Tode vermochte man Koppernikus zur Herausgabe seiner "Kreisbewegungen“2) zu bestimmen. Osiander, welcher den in Nürnberg erfolgenden Druck des Buches iiberwachte, hielt es, ohne von Koppernikus hierzu ermächtigt zu sein, für geraten, in einer besonderen Einleitung das Ganze als eine bloße Hypothese hinzustellen. Wenn die Wissenschaft Hypothesen ersinne, so beanspruche sie damit keineswegs, daß man nun auch davon überzeugt sei. Sie wolle nur eine Grundlage für ihre Berechnungen schaffen. Hypothesen brauchten also nicht einmal wahrscheinlich zu sein. Es genüge vielmehr, daß sie eine Rechnung ermöglichen, die zu den Beobachtungen paßt. Mit diesen Ausführungen hat Osiander dasjenige, was wir heute als bloße Arbeitshypothese bezeichnen, durchaus richtig gekennzeichnet. Daß eine Abschwächung seiner Lehre jedoch durchaus nicht im Sinne des Verfasser's lag, geht aus der von Koppernikus herrührenden Vorrede deutlich genug hervor. Er sei, sagt er, entgegen der Meinung der Astronomen, ja beinahe gegen den gemeinen Menschenverstand dazu gekommen, sich eine Bewegung der Erde vorzustellen. $\mathrm{Zu}$ dieser Annnahme habe ihn der Umstand veranlaßt, daß die Astronomen bei ihren Untersuchungen sich über die Bewegungen der Himmelskörper gar nicht einig seien und die Gestalt der Welt und die Symmetrie ihrer Teile bisher nicht hätten finden können. Man habe zur Erklärung der astronomischen Erscheinungen die verschiedensten Arten von Bewegungen angenommen. Die einen bedienten sich nur der konzentrischen, die anderen der exzentrischen und epizyklischen ${ }^{3}$ ) Kreise. Doch sei das Erstrebte

1) „Dem Reformator", sagt Schiaparelli (Die Vorläufer des Koppernikus im Altertum, S. 87), ,der ein wesentlich neues Weltschema zur Geltung bringen wollte, konnte es nicht genügen, nur eine allgemeine Idee auseinanderzusetzen, sondern ihm fiel die Pflicht zu, seine Idee bis zu demselben Grade der Vollendung auszuarbeiten, bis zu dem Ptolemäos die seinige gebracht hatte."

2) Nicolai Copernici Torinensis, De revolutionibus orbium coelestium, libri VI. Eine Übersetzung von C. L. Menzzer hat der KoppernikusVerein zu Thorn im Jahre 1879 herausgegeben.

3) In dem Bestreben, die ungleichförmig erscheinenden Bewegungen der 
dadurch nicht erreicht worden. Endlich habe er durch viele und fortgesetzte Beobachtungen gefunden, daß, wenn die Bewegungen der ïbrigen Wandelsterne auf einen Kreislauf der Erde bezogen, und dieser dem Kreislauf jedes Gestirns zugrunde gelegt werde, nicht nur die Erscheinungen der Wandelsterne daraus folgten, sondern daß dann auch die Gesetze und Größen der Gestirne und ihre Bahnen so zusammenhingen, daß in keinem Teile des Systems ohne Verwirrung der übrigen Teile und des ganzen Weltalls irgend etwas geändert werden könne. Die Astronomen möchten die neue Lehre prüfen, und er zweifle nicht, daß sie ihm beipflichten würden. Damit aber Gelehrte und Ungelehrte sähen, daß er durchaus niemandes Urteil scheue, so wolle er sein Werk lieber dem Papste als irgend einem andern widmen.

Die Anregung zu seinem System empfing Koppernikus offenbar aus den Schriften der Alten. Nachdem er über die Unzulänglichkeit der bestehenden Theorien nachgedacht, durchforschte er alle Schriften, deren er habhaft werden konnte, um festzustellen, ob nicht irgend jemand einmal andere Ansichten als die herrschenden über die Bewegungen der Weltkörper geäußert habe. $\mathrm{Da}$ fand er denn zuerst bei Cicero, daß Nicetas geglaubt habe, die Erde bewege sich. Nachher fand er auch bei Plutarch, daß andere ebenfalls dieser Meinung gewesen seien. Hierdurch veranlaßt, fing er an, über die Bewegung der Erde nachzudenken, obgleich diese Ansicht ihm zuerst selbst widersinnig zu sein schien.

Indessen nicht nur unbestimmte Meinungen, sondern auch einen recht brauchbaren Ansatz zu seiner Theorie fand Koppernikus bei den Alten vor. Es war ihm nämlich die Meinung einiger alten Schriftsteller begegnet, daß Venus und Merkur sich um die Somne als ihren Mittelpunkt bewegten und deswegen von ihr nicht weiter fortgehen könnten, als es die Kreise ihrer Bahnen erlaubten. Koppernikus nennt Martianus Capella (5. Jahrhundert nach Chr. Geb.) als seinen Gewïhırsmann. Es heißt bei ihm: „Venus und Merkur bowezen sich nicht um die Erde, die nicht für alle Planetenbahnen den Mittelpunkt bildet, wenngleich sie unzweifelhaft der Mittelpunkt der Welt ist. Beide Planeten gehen zwar täglich auf und unter, sie bewcgen sich aber um die Sonne. In dieser, die viel größer als die Erde ist, haben sie ihren Bahnmittelpunkt." Mar-

Planeten auf gleichförmige Bewegungen zurückzuführen, nahm man an, diese Himmelskürper beschrieben Kreise, deren Mittelpunkt sich gleichzeitig der Peripherie eines zweiten Kreises entlang bewege; die so entstandenen Linien nennt man Ejpizyklen. 
tianus Capella verlegte gleich anderen Berichterstattern den Ursprung der erwähnten Lehre nach $\ddot{A}$ gypten. Neuere Forschungen haben jedoch den Beweis geliefert, daß sie auf Herakleides Pontikos, einen Schüler Platons, zurückzuführen ist $\left.{ }^{1}\right)$. Herakleides war auch darin ein Vorläufer des Koppernikus, daß er die tägliche, scheinbare Bewegung der Himmelkugel aus einer Drehung der Erde von West nach Ost erklärte. Ihre Fortsetzung fanden diese Lehren durch Aristarch von Samos. Aristarch $\left.{ }^{2}\right)$ setzte die Sonne, die er für $300 \mathrm{mal}$ so groß wie die Erde hielt, in den Mittelpunkt und ließ die Erde sich in jährlichem Umlauf um die Sonne bewegen. Die heliozentrische Weltansicht war dem Altertum also wohl bekannt. Sie fand sogar den Beifall vieler, trug indes ihrem Urheber, ganz ähnlich, wie es später den ersten erklärten Anhängern des koppernikanischen Systems erging, von gegnerischer Seite eine Anklage wegen Gottlosigkeit ein. Doch konnte die heliozentrische Theorie im Altertum nicht recht Wurzel schlagen, da sie noch nicht imstande war, den Anforderungen der praktischen Astronomie zu genügen. Letztere erblickte ihre Aufgabe ja weniger darin, die beobachteten Bewegungen der Sonne, des Mondes und der Planeten zu erklären, als sie genau zu messen und im voraus $\mathrm{zu}$ bestimmen.

Indem nun Koppernikus von der Ansicht des Martianus Capella ausging und Saturn, Jupiter und Mars auf denselben Mittelpunkt, die Sonne nämlich, bezog, gleichzeitig aber die große Ausdehnung der Bahnen der genannten Planeten berücksichtigte, die außer den Bahnen des Merkur und der Venus auch die der Erde umschließen, gelangte er zu seiner Erklärung der Planetenbewegung. Es stehe nämlich fest, führt er des weiteren aus, daß Saturn, Jupiter und Mars der Erde immer dann am nächsten seien, wenn sie des Abends aufgingen, d. h. wenn sie in Opposition zur Sonne ständen, oder die Erde sich zwischen ihnen und der Sonne befinde. Dagegen seien Mars und Jupiter am weitesten von der Erde entfernt, wenn sie des Abends untergingen, wir also die Sonne zwischen ihnen und der Erde hätten. Dies beweise hinreichend, daß der Mittelpunkt ihrer Bahn die Sonne und somit derselbe sei, um den auch Venus und Merkur kreisen. Da somit alle Planeten sich um einen Mittelpunkt bewegen, sei es notwendig, daß der Raum, der zwischen dem Kreise der Venus und dem des Mars übrig

1) Siehe S. 180 u. f. d. Bds.

2) Schiaparelli, Die Vorläufer des Koppernikus im Altertum, übersetzt von M. Curtze. 
bleibe, die Erde mit dem sie begleitenden Monde aufnehme. Er scheue sich daher nicht, zu behaupten, daß die Erde mit dem sie umkreisenden Monde zwischen den Planeten einen großen Kreis in jährlicher Bewegung um die Sonne durchlaufe. Auf solche Weise finde die Bewegung der Sonne in der Bewegung der Erde ihre Erklärung. Die Welt aber sei so groß, daß die Entfernung der Planeten von der Sonne, mit der Fixsternsphäre verglichen, verschwindend klein sei. Er halte dies alles für leichter begreiflich,

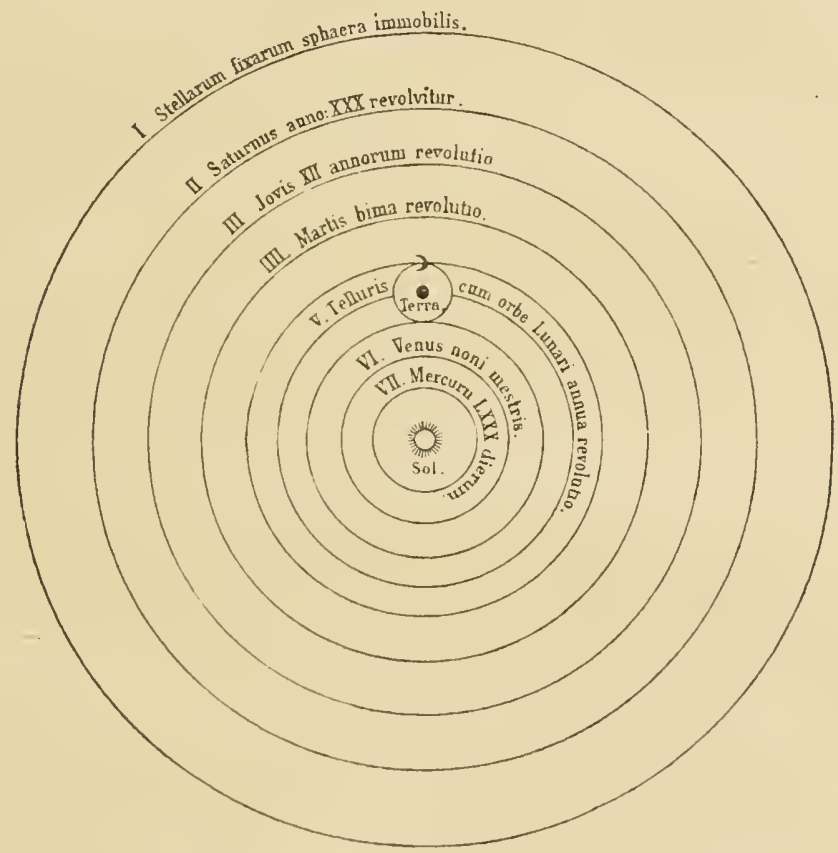

Abb. 62. Das koppernikanische Weltsystem.

(Aus Koppernikus' Werk über die Bewegung der Weltkörner.)

als wenn der Geist durch eine fast endlose Menge ron Ḱreisen verwirrt werde, was diejenigen herbeifuihrten, welche die Erde in den Mittelpunkt der Welt setzten.

Koppernikus bringt dann die vorstehend wiedergegebene Abbildung (62) seines Weltsystems und erläutert sic mit folgenden Worten: „Die erste und höchste von allen Sphären ist diejenige der Fixsterne, die sich selbst und alles iibrige enthält und daher unbeweglich ist. Es folgt der äußerste Planet, Saturn ${ }^{1}$, der in

1) Dic außerhalb des Saturn befindlichen Planeten Uranus und Neptun wurden erst_1781, beziehungsweise 1846 entdeckt. 
30 Jahren seinen Lauf vollendet; hierauf Jupiter mit einem zwölfjährigen Umlauf; dann Mars, der in zwei Jahren seine Bahn beschreibt. Die vierte Stelle nimmt der jährliche Kreislauf ein, in dem die Erde mit der Mondbahn enthalten ist. An fünfter Stelle kreist Venus in neun Monaten. Den sechsten Platz nimmt Merkur ein, der in einem Zeitraum von 80 Tagen seinen Umlauf vollendet. In der Mitte aber von allem steht die Sonne. Denn wer möchte in diesem schönsten Tempel diese Leuchte an einen anderen oder besseren Ort setzen?"

"So lenkt in der Tat die Sonne, auf dem königlichen Throne sitzend, die sie umkreisende Familie der Gestirne. Wir finden also in dieser Anordnung einen harmonischen Zusammenhang, wie er anderweitig nicht gefunden werden kann. Denn hier kann man bemerken, warum das Vor- und Zurückgehen beim Jupiter größer erscheint als beim Saturn und kleiner als beim Mars und wiederum bei der Venus größer als beim Merkur. Außerdem, warum Saturn, Jupiter und Mars, wenn sie des Abends aufgehen, der Erde näher sind als bei ihrem Verschwinden in den Strahlen der Sonne. Vorzüglich aber scheint Mars, wenn er des Nachts am Himmel steht, an Größe dem Jupiter gleich zu sein, während er bald darauf unter den Sternen zweiter Größe gefunden wird. Und dies alles ergibt sich aus derselben Ursache, nämlich aus der Bewegung der Erde. Daß aber an den Fixsternen nichts davon in die Erscheinung tritt, ist ein Beweis für die unermeßliche Entfernung dieser Sterne, eine Entfernung, welche selbst die Bahn der Erde oder das Abbild dieser Bahn am Himmel für unsere Augen verschwinden läßt $\left.{ }^{1}\right)$."

Die Grundlagen seines Systems hat Koppernikus am klarsten in einem "kurzen Abriß" ${ }^{2}$ ) niedergeschrieben, den er wahrscheinlich schon bald nach 1530 verfaßte. Er stellt diese Grundlagen in folgenden Sätzen zusammen:

1. Es gibt nur einen Mittelpunkt für die Gestirne und ihre Bahnen.

2. Der Erdmittelpunkt ist nicht auch der Mittelpunkt für die Welt, sondern nur für die Mondbahn und für die Schwere.

1) Die hierin liegende Schwierigkeit wurde erst von Bessel gehoben, der nachwies, daß die Fixsterne in der Tat infolge der jährlichen Bewegung der Erde ihren Ort, wenn auch in sehr geringem Maße, verändern.

2) Die Schrift galt lange als verschollen. Sie wurde erst im 19. Jahrhundert wieder entdeckt und (1878) herausgegeben. Näheres siehe in dem von A. Kistner herrührenden Bd. 39 von Voigtländers Quellenbiichern. 
3. Alle Planeten bewegen sich um die im Mittelpunkte ihrer Bahnen stehende Sonne. In sie fällt also der Weltmittelpunkt.

4. Der Abstand Erde - Sonne ist gegenüber dem Durchmesser des Fixsternhimmels verschwindend klein.

5. Was als eine Bewegung am Himmel erscheint, leitet sich von einer Bewegung der Erde her. Sie dreht sich nämlich täglich völlig $11 \mathrm{~m}$ ihre Axe. Dabei behalten ihre beiden Pole dauernd dieselbe Lage bei.

6. Was uns als eine Bewegung der Sonne erscheint, leitet sich auch nicht von diesem Gestirn, sondern von der Erde und ihrer Bahn her, in der sie sich um die Sonne ebenso bewegt, wie die ïbrigen Planeten es tun.

7. Das Vorschreiten und Zurückbleiben der Planeten ist nicht ihre eigene, sondern nur eine Folge der Erdbewegung.

Wie die ältere, so entsprach auch die neuere, von Koppernikus entwickelte Theorie den Beobachtungen bei weitem nicht in dem Maße, als ihr Begründer anfangs hoffen mochte. Es lag das daran, daß er gleich den Alten daran festhielt, die Bewegung der Himmelskörper erfolge gleichmäßig und im Kreise. Aristoteles hatte dies gelehrt. Für ihn und alle, die sich nach ihm mit der Astronomie befaßten, Koppernikus eingeschlossen, war dies ein von vornherein feststehender Satz. Die Welt ist kugelförmig, die Erde ist gleichfalls kugelförmig, die Bewegung der Himmelskörper erfolgt gleichmäßig, ununterbrochen und im Kreise. So lauten die Überschriften der wichtigsten Abschnitte des koppernikanischen Werkes. Und warum verhält es sich so? Weil Kreis und Kugel die vollkommensten Formen sind und kein Grund für eine ungleichförmige Bewegung vorliegt, lautet die Antwort. Auch Kepler war, wie wir sehen werden, anfangs in dem erw:ihnten Vorurteil befangen. Ihm gelang es aber, sich davon frei zu machen. Als er eingesehen, daß die Beobachtungen sich mit den hergebrachten Anschauungen nicht in Einklang bringen ließen, machte er die Annahme, daß sich die Planeten nicht in Kreisen, sondern in Ellipsen bewegen und daß ihre Bewegung ungleichförmig sei. Jetzt waren alle Widerspriiche, in denen die heliozentrische Theorie sich den Beobachtungen gegeniiber befand, gelöst, und diese Theorie damit erst lebensfähig geworden. Was ihr Begrïniler gut zu erklären wußte, waren vor allem das scheinhare Zuriickgehen und Stillstehen der Planeten, sowie die Veränderungen in der scheinbaren Grölse dieser Himmelskörper, 
die besonders beim Mar's beträchtlich sind. Zur Erklärung anderer Ungleichmäßigkeiten blieb jedoch nichts weiter übrig, als auf die Epizyklentheorie unter Beibehaltung der Sonne als Mittelpunkt des ganzen Systems zurückzugreifen.

Wir erkennen, daß eine neue Wahrheit bei ihrer Entdeckung selten vollendet ist. Sie geht gewöhnlich nicht aus dem Hirn eines einzelnen, sondern als Errungenschaft des Geistes einer Zeit aus den Bemühungen mehrerer, oft sogar zahlreicher Forscher und Denker hervor.

\section{Aufnahme und Ausbreitung der helio- zentrischen Lehre.}

Für die Richtigkeit seines Weltsystems konnte Koppernikus noch keine schlagenden Beweise, sondern lediglich die größere Einfachheit ins Feld führen. Dem Einwand, daß die jährliche Bewegung der Erde sich in einer scheinbaren Veränderung der Fixsternörter offenbaren müsse, wußte er nur dadurch zu begegnen, daß er diese Himmelskörper in eine Entfernung versetzte, gegen welche der Durchmesser der Erdbahn verschwindend klein sei. Das Einzige, was Koppernikus den Angriffen seiner Gegner gegeniiberstellen konnte, waren Gründe der Vernunft. „Es ist“, sagt er, "wahrscheinlicher, daß die Erde sich um ihre Achse dreht, als daß alle Planeten mit ihren verschiedenen Entfernungen, alle herumschweifenden Kometen und das unendliche Heer der Fixsterne dieselbe regelmäßige vierundzwanzigstündige Bewegung um die Erde ausfuihren".

Eigentliche Beweise, sowohl für die Drehung als auch für den Umlauf der Erde, haben erst spätere Jahrhunderte gebracht und dadurch die koppernikanische Lehre auf den Rang einer unumstößlichen Wahrheit erhoben $\left.{ }^{1}\right)$. Neben ihrer Einfachheit konnte Koppernikus für seine Theorie wie Aristarch auch den Umstand ins Feld führen, daß die Somne der bei weitem größere Weltkörper sei. Das Größenverhältnis von Mond, Erde, Sonne ist nach Koppernikus gleich 1:43:69372). Ferner nahm Koppernikus die Entfernung der Sonne auf Grund von Beobachtungen, die nach dem von Aristarch herrührenden Verfahren

1) Die Drehung der Erde wurde durch Fallversuche, sowie den Foucaultschen Pendelversuch nachgewiesen, während die Fortbewegung im Raume aus der Aberration und der Fixsternparallaxe geschlossen wurde.

2) Anstatt 1:49:1300000. 
angestellt wurden, zu 1197 Erdhalbmessern an. Auch dieses Ergebnis blieb weit hinter der Wahrheit zurück. Erst im 18. Jahrhundert fand man durch Messungen, welche die Vorübergänge der Venus vor der Sonnenscheibe zum Ausgang nahmen, einen zuverlässigen Wert für jenes Grundmaß der Astronomie. Dieser übertraf den von Koppernikus angegebenen Wert fast um das Zwanzigfache.

Das Erscheinen der „Kreisbewegungen“, deren erste Druckbogen Koppernikus noch auf dem Sterbebette gelesen haben soll, veranlaßte durchaus nicht einen solchen Aufruhr unter den Geistern, wie man es in Anbetracht der Wichtigkeit der darin ausgesprochenen Ansichten wohl hätte erwarten können. Dies hatte mehrere Griinde. Die zeitgenössische Astronomie beachtete die Neuerung wenig. Einige dem Koppernikus befreundete Astronomen ausgenommen, hielt man an der ptolemäischen Lehre fest, $\mathrm{zu}$ der man überdies in jener Zeit, die noch keine Lehrfreiheit kannte, verpflichtet war. Ferner gaben die dem neuen System noch anhaftenden Unvollkommenheiten den berufsmäßigen Astronomen, denen der praktische Wert ausschlaggebend sein mußte, ein gewisses Recht, zunächst das Hergebrachte in Geltung zu belassen. Brachte doch das heliozentrische System dem rechnenden Astronomen zunächst kaum nennenswerte Vorteile. Koppernikus hatte es verstanden, seine Neuerung in einer alles Polemische ausschließenden IVeise vorzutragen und jedes Hinüberspielen auf das Gebiet biblischer und religiöser Anschauungen zu vermeiden. So kam es, daß auch die Kirche, die von einer astronomischen Neuerung wohl eine Verbesserung ihres Kalenders erhoffte, das Buch, dem ja sogar eine Widmung an den Papst voranging, duldete und dem Gegensatz kein Gewicht beilegte, in den es, vom Standpunkt des starren Wortglaubens aus betrachtet, zur biblischen Überlieferung trat.

"Es scheint mir," schrieb Koppernikus in jener Widmung, „daß die Kirche aus meinen Arbeiten einigen Nutzen ziehen kann. War doch unter Leo X. die Verbesserung des Kalenders nicht möglich, weil die Größe des Jahres und die Bewegung der Sonne und des Mondes nicht genau bestimmt waren. Ich habe gesucht, diese näher zu bestimmen. Was ich darin geleistet habe, überlasse ich dem Urteile Deiner Heiligkeit und der gelehrten Mathematiker." Der großen Masse, selbst der Gebildeten, felıte bei der damals herrschenden Unkenntnis in naturwissensehaftlichen Dingen durehaus das Vermögen, mit eigenem Urteil an die neue Lehre heran- 
zutreten. Deshalb läßt sich die Äußerung Luthers wohl entschuldigen, der da meinte: „Der Narr will die ganze Astronomie umkehren. Aber die heilige Schrift sagt uns, daß Josua die Sonne stillstehen hieß und nicht die Erde." Daran, daß diese Neuerung auf dem Gebiete der Astronomie der Kirche schaden, geschweige denn das religiöse Gefühl beeinträchtigen könnte, hat Luther schwerlich gedacht. Etwas ängstlicher war schon $\mathrm{Me}$ lanchthon, der auch mehr Verständnis für das Unerliörte jener Neuerung besaß. Selbst ein eifriger Astrologe, hatte er das Gebäude der damaligen Astronomie in seinem Lehrbuch der Physik zur Darstellung gebracht. Die neue heliozentrische Ansicht hielt er für so gottlos, daß er sie zu unterdrücken empfahl ${ }^{1}$ ). Auch der viel später lebende Francis Bacon, den ïbertriebene Schilderungen als den Begründer der neueren Naturwissenschaft gefeiert haben, war ein erklärter Gegner des Koppernikus, und zwar zu einer Zeit, als die Frage nach der Richtigkeit des heliozentrischen Systems die Geister bewegte. Erst damals, im Zeitalter Galileis, nahm die Kirche zu dieser Frage entschieden Stellung und verbot die "Kreisbewegungen". Der beziigliche Erlaß stammt aus dem Jahre 1616 und wurde amtlich erst 1822 wieder aufgehoben, nachdem sein Bestehen jedoch fast in Vergessenheit geraten war. Er lautet: „Die heilige Kongregation ${ }^{2}$ ) hat in Erfahrung gebracht, daß die falsche, der Heiligen Schrift völlig widersprechende Lehre der Pythagoreer, von der Bewegung der Erde, wie sie Koppernikus und einige andere vorgetragen haben, gegenwärtig verbreitet und vielfach angenommen wird. Damit sich eine derartige Lehre nicht zum Schaden der katholischen Wahrheit ausbreitet, beschloß die heilige Kongregation daß die Bücher des Koppernikus und alle anderen, die dasselbe lehren, bis zur Verbesserung zu ver-

1) In seiner, sechs Jahre nach dem Tode des Koppernikus veröffentlichten Schrift „Initia doctrinae physicae 1549" (Die Anfangsgründe der Naturlehre) beschuldigt $\mathrm{Melanchth}$ on den Koppernikus, daß er lediglich zur Befriedigung seiner Eitelkeit Irrlelıren, die schon das Altertum als bloße Gedankenspiele erkannt habe, verbreitete (L. Prowe, Nicolaus Coppernicus. Bd. I, 2. S. 232). In den späteren Auflagen seiner "Naturlehre" hat Melanchthon diesen Vorwurf zwar abgeschwächt, den ablehnenden Standpunkt gegen die heliozentrische Lehre aber beibehalten. Melanchthon ließ sich von der Überzeugung leiten, daß auch in den Fragen der Naturwissenschaft die Bibel maßgebend sei. Siehe die Abhandlung von E. Wohlwill: ,Melanchthon und Copernicus". Mitteil. z. Gesch. d. Med. u. d. Naturw. 1904. S. 260 u. f.

2) Die kirchliche Behörde, der das Zensoramt oblag und die mißliebige Bücher auf den Index, d. h. das Verzeichnis der verbotenen Bücher setzte. 
bieten sind. Sie werden daher alle durch diesen Erlaß verboten und verdammt."

- Zu den ersten Anhängern der koppernikanischen Lehre gehörte der Dominikanermönch Giordano Bruno ${ }^{1}$ ), Spinozas Vorläufer in der Begrïndung einer pantheistischen Weltanschauung. Seinen divinatorischen Blicken erweiterte sich das Fixsterngewölbe zu einem in Raum und Zeit unendlichen Universum. Bruno war auch der erste, der die Fixsterne als Sonnen und als Mittelpunkte ungezählter, dem unseren gleichartiger Planetensysteme ansah.

Er hat manches intuitiv vorweggenommen, was erst spätere Zeiten auf Grund der Beobachtung sichergestellt haben. So nahm er an, daß nicht nur die Erde, sondern auch die Sonne um ihre Axe rotiere. Von der Erde behauptet er, daß sie an den Polen abgeplattet sein müsse. Die Präzession der Nachtgleichen erklärte er mit folgenden Werten: „Bei den unabsehbar mannigfaltig ineinandergreifenden Bewegungen der W eltkörper kann es nicht ausbleiben, daß auch die scheinbar festesten Punkte ihre gegenseitige Lage nach und nach verschieben. Die Erde wird also ihre Lage zum Himmelspol verändern $\left.{ }^{2}\right)^{6}$. Die Kometen betrachtete Bruno als eine besondere Gattung der Planeten. Da die Kometen ganz ohne Regel erschienen, so sei auch die Zahl der unsere Sonne umkreisenden Planeten noch nicht festgestellt ${ }^{3}$ ). Die Welten und die Weltsysteme endlich sind nach Bruno stetigen Änderungen unterworfen. Ewig ist nur die der Welt zu Grunde liegende schaffende Energie. Darin spricht sich schon eine gewisse Ahnung des Gesetzes von der Erhaltung der Energie aus. Brunos lange als Schwärmerei betrachtete Lehre von der Beseeltheit nicht nur der All-Materie, sondern auch der individuellen Beseeltheit der einzelnen Weltkörper hat neuerdings Fechner zur Anerkennung zu bringen gesucht.

Daß die Erde selbst ein lebendes Wesen ist, schloß Bruno aus ihrer Bewegung und daraus, daß sie lebende Wesen hervorbringt. Auch die übrigen Weltkörper sind belebt und ein Schau-

1) Giordano Bruno wurde zu Nola im Jahre 1548 geboren. Er durchwanderte lehrend Europa, geriet jedoch mit den herrschenden kirchlichen Dogmen in Widerspruch und wurde, weil er nicht widerrufen wollte, 1600 von der Inquisition zu Rom den Flammen übergeben. Siehe Landsbeck, Bruno, der Märtyrer der neuen Weltanschauung. Leipzig 1890.

2) De Immenso. L. III. c. 5 .

3) Wie klein erscheint $\mathrm{Hegel}$ dagegen, der aus spekulativen Gründen annahm, daß es nicht mehr als 7 Planeten geben könne. 
platz des Lebens. Daß sich letzteres in denselben Formen wie auf der Erde offenbart, darf man allerdings nicht annehmen.

Man hat Bruno als den ersten monistischen Philosophen der neueren Zeit zu betrachten. In seinen Schriften kam die geistige Eigenart der italienischen Renaissance besonders zum Ausdruck. Der Lebensauffassung jener Zeit entsprach auch seine, im Gegensatz zum Christentum stehende Lehre vom heroischen Affekt. Die neue astronomische Ansicht, die sich ihm und den Aufgeklärten unter seinen Zeitgenossen eröffnete, hat er im Sinne der „Schönheitsherrlichkeit der Welt verwertet ${ }^{1}$ ).

Giordano Brunos Reformation des Himmels: Lo spaccio (Die Vertreibung) della bestia trionfante (verdeutscht und erläutert von L. Kuhlenbeck, Leipzig 1889), ist eine Moralphilosophie, die an die Betrachtung der wichtigsten Sternbilder anknüpft. Die in italienischer Sprache erschienenen Werke Brunos gab P. de Lagarde (Göttingen 1888) heraus. Die astronomische Weltanschauung betrifft besonders das Werk Del infinito Universo et de i mondi2). Einige charakteristische Sätze aus diesem Werk mögen uns noch etwas eingehender mit Brunos Vorstellungen bekannt machen: „In dem unermeßlichen zusammenhängenden Raum, der alles in sich hegt und trägt, gibt es unzählige, dieser Welt ähnliche Weltkörper. Von ihnen ist der eine nicht mehr in der Mitte des Universums als der andere. Als unendliches All ist es ohne Mitte und ohne Umfang. Wie um unsere Sonne sieben Wandelsterne kreisen, so gibt es weitere Sonnen, die Mittelpunkte für andere Planetensysteme sind. Jeder dieser Weltkörper dreht sich um sein cigenes Zentrum. Trotzdem erscheint er seinen Bewohnern als eine stillstehende Welt, um die sich alle übrigen Gestirne drehen. In Wahrheit gibt es so viel Welten wie wir Fixsterne sehen. Sie befinden sich alle in dem einen Himmel, dem einen Allumfasser, wie unsere Welt, die wir bewohnen."

Daß es unendlich viele Einzelwelten geben müsse, folgert Bruno aus dem Wesen Gottes, dem er ein unendliches Können zuschreibt.

1) Dilthey, G. Bruno und Spinoza. Archiv der Philosophie. 1894. S. 269 u. f.

2) Übersetzt von Kuhlenbeck 1893 . 


\section{Astronomie und wissenschaftliche Erdkunde.}

In engster Beziehung zur Astronomie hat sich die wissenschaftliche Erdkunde, d. h. eine Erdkunde, die mehr sein wollte, als eine bloße Beschreibung der Länder und ihrer Erzeugnisse, entwickelt. Sie fand in dem auf Koppernikus folgenden Zeitalter in Deutschland einen hervorragenden Vertreter in Gerhard Kremer oder Mercator, wie er sich selbst, nach damaliger Sitte seinen Namen latinisierend, nannte ${ }^{1}$ ) und in Sebastian Münster.

Münster verfaßte eine „Cosmographia, Beschreibung aller Länder". Die darin enthaltenen Karten haben die Grundlage gebildet, von der die Kartographie in Deutschland ihren Ausgang nahm ${ }^{2}$ ).

Mercator wurde 1512 in einem flandrischen Städtchen geboren, wo sich seine, aus Jülich stammenden Eltern vorübergehend aufhielten. Als Arbeitsfeld wählte er, angeregt durch Gemma Frisius ${ }^{3}$, mit dem er während seiner Studienzeit verkehrte, die mathematische Geographie, als deren Neubegründer er von vielen Seiten anerkannt wurde4). Mit der Anfertigung von Landkarten, Globen und astronomischen Instrumenten erwarb sich Mercator seinen Unterhalt. Von 1552 bis zu seinem 1594 erfolgenden Tode lebte er in Duisburg, wo er neben seiner wissenschaftlichen Tätigkeit mathematischen Unterricht am Gymnasium erteilte.

Sein erstes größeres Werk war ein Erdglobus, auf dessen Verfertigung er ein und ein halbes Jahı verwendete. Zehn Jahre später (1551) lieferte Mercator einen großen Himmelglobus. Zu seinen Verehrern zählte auch Karl V. Dieser Monarch nahm an den Fortschritten der Astronomie und Geographie solch lebhaften Anteil, daß er während der Belagerung einer Festung mit Apianus ein Gespräch über diese Wissenschaften führen konnte, während die Kugeln rechts und links von ihnen einschlugen.

1) Breusing, Gerhard Kremer, genannt Merkator, der deutsche Geograph. Duisburg 1869.

H. Averdunk und J. Müller-Reinhard, Gerhard Mercator und die Geographen unter seinen Nachkommen. J. Perthes, Gotha 1914. VIII u. 188 S.

2) Die "Kosmographie" erschien 1544 in Basel (zuletzt 1628). Sie kam auch lateiniseh $(1550$, französisch, italienisch usw. heraus.

3) Professor der Medizin und der Astronomie in Löwen; lebte von 1535 bis 1577 .

4) Siehe Breusings zitierte Schrift S. 35 .

Dannemann, Die Naturwissenschafter. I, Bd, 2, Autl. 
Mit Apianus und Mercator beginnt für die Kartographie eine neue Zeit. Vor ihnen hatte man sich mit einem Abschätzen der Entfernungen und mit Itinerarien begnügt, sowie sich abgemüht, das neu erworbene Wissen mit dem des Ptolemäos in Einklang zu bringen. Jetzt entstanden Karten, die auf genaueren Vermessungen bcruhten. Unter diesen sind vor allem Apians1) „Bayrische Landtafeln" zu nennen. Sie erschienen 1568 auf 24 Blättern (Holzschnitt; Maßstab 1:144000) und gelten als das topograhische Meisterwerk des 16. Jahrhunderts. Kein Land wurde in jener Zeit mit gleicher Treue dargestellt.

Was Apian für ein engbegrenztes Stück der Erde leistete, strebte der belgische Geograph Ortelius ${ }^{2}$ ) für den gesamten Erdkreis an. In seinem "Theatrum orbis terrarum" (53 Karten in Kupferstich, Antwerpen 1570) schuf er ein Werk, das sich von Ptolemäos freimachte. Die Mehrzahl jener von Ortelius herausgegebenen 53 Karten war nach den besten Arbeiten anderer Kartographen verfertigt.

Fast zu selben Zeit (1569) vollendete Mercator seine große Weltkarte. Es war dies ein für die Geschichte der Erdkunde und der Nautik hochbedeutsames Ereignis. Von diesem Zeitpunkt, sagt Mercators Biograph, datiert die Reform der Kartographie, die kein zweites Werk von gleicher Bedeutung zu verzeichnen hat. Die Vorschriften, die Mercator den Seefahrern für die Benutzung seiner Karte gab, gelten auch heute noch ${ }^{3}$ ).

Ein für jene Zeit großes Verdienst erwarb sich Mercator dadurch, daß er die damals noch in hohem Ansehen stehende Geographie des Ptolemäos an Stelle der ungenauen Karten älterer Geographen mit Karten versah, die sich den Angaben des Ptolemäos genau anschlossen. Eine Sammlung von Karten europäischer Länder vereint mit Karten einzelner Erdteile und Übersichten der ganzen Erde veranstaltete Mercator mit seinem Sohne ${ }^{4}$ ). Sie erschien 1595 unter dem von Mercator gewählten

1) Philipp Apian (1531-1589), Sohn des Astronomen Peter Apian (zu deutsch Bienewitz).

2) $1526-1598$.

3) Nova et aucta orbis terrae descriptio ad usum navigantium emendata accommodata. Duisburgi mense Augusto, 1569. Auf 8 Blättern, im ganzen $1,26 \mathrm{~m}$ hoch und $2 \mathrm{~m}$ breit. Die Karte wurde nach den Originalen in der Stadtbibliothek zu Breslau im Jahre 1891 von der Gesellschaft für Erdkunde in Berlin herausgegeben.

4) Rumold Mercator. 
Titel „Atlas“1), der seitdem für derartige Sammlungen gang und gäbe geblieben ist.

Die Grundsätze der Kartographie entwickelte Mercator $\left.{ }^{2}\right)$ so klar, wie es kein auderer vor ihm vermocht hatte. Er war der erste, der die Bedingungen, die jede Projektionsart voraussetzt, genauer untersuchte, und den Begriff der Konformität aufstellte, d. h. der Forderung, daß eine ebene Figur die größtmögliche Ähnlichkeit mit der Kugelfläche erhalten müsse. Da die Alten immer nur Teile der Erdoberfläche darzustellen liatten, und ihre Projektionsarten dieser Aufgabe anpaßten, war Mercator, als es galt, die ganze Erde kartographisch darzustellen, vor eine ganz neue Aufgabe gestellt. Er löste sie durch das nach ihm benannte Verfahren in der trefflichsten, für den Gebrauch geeignetsten Weise. "Wenn," sagt Mercator in der Erläuterung, die er seiner Weltkarte hinzufügt, ,von den vier Beziehungen, die zwischen zwei Orten in Ansehung ihrer gegenseitigen Lage stattfinden, nämlich Breitenunterschied, Längenunterschied, Richtung und Entfernung, auch nur zwei berücksichtigt werden, so treffen auch die übrigen genau zu, und es kann nach keiner Seite hin ein Fehler begangen werden, wie dies bei den gewöhnlichen Seekarten so vielfach und zwar um so mehr, je höher die Breiten sind, der Fall sein muß." Mercator erzielte diesen Vorteil dadurch, daß er die Erdoberfläche auf einen die Erde im $\ddot{A} q u a t o r$ berïhrenden Zylinder projizierte, dessen Achse der Erdachse parallel ist. Die Ausbreitung, welche dadurch die Längengrade nach den Polen hin erfahren, wird durch eine in demselben Verhältnis stattfindende Ausdehnung der Breitengrade ausgeglichen. Eine solche Karte ist winkeltreu, d. h. sie gibt die Winkel so wieder, wie sie auf der Erdoberfläche erscheinen; sie wahrt auch die Formähnlichkeit (Konformität) der Ländergestalten ${ }^{3}$ ) sie ist jedoch nicht flächentreu, da ihr Maßstab mit der Entfernung vom $\ddot{A} q u a t o r$ wächst.

1) Atlas sive cosmographicae meditationes de Fabrica mundi et fabricati figura. Duysburgi Clivorum 1595.

2) In seiner Schrift „Über die geographische Kunst".

3) Die Bedingung der Konformität aufgestellt zu haben, gilt gewöhnlich als ein Verdienst Lamberts (siehe a. a. St.). Mercator spricht sie aber fast mit denselben Worten aus. Die Bedingung der Konformität ist dann erfüllt, wenn das Verhältnis zwischen den Breiten- und Längengraden überall auf der Karte gewahrt bleibt. 


\section{Die ersten Ansätze zur Neubegründung der anorganischen Naturwissenschaften.}

Wie auf dem astronomischen, so machte sich auch auf den übrigen Gebieten der Naturwissenschaft während des 16. Jahrhunderts das Bestreben geltend, die Fesseln der Autorität zu sprengen und Beobachtung und Nachdenken an ihre Stelle zu setzen. Eine zweite epochemachende Tat, die sich derjenigen des Koppernikus an die Seite stellen ließe, haben wir jedoch in dieser Periode nicht zu verzeichnen.

Als Physiker ist unter den Zeitgenossen des Koppernikus vor allem Maurolykus (1494-1575) zu nennen. Er lehrte in Messina und entstammte einer derjenigen Familien, die nach der Eroberung Konstantinopels diese Stadt verlassen hatten, um sich den Verfolgungen der Türken zu entziehen. Maurolykus machte sich um die Mathematik verdient, indem er in einem umfangreichen Sammelwerke alles das zusammenfaßte, was er selbst an mathemathischem Wissen den griechischen und arabischen Schriftstellern verdankte. Ein besonderes Verdienst erwarb er sich durch die Herausgabe der archimedischen Werke, sowie von Schriften des Apollonios, dessen Lehre von den Kegelschnitten durch ihn sogar erweitert wurde. Sein mathematisches Können betätigte Maurolykus ferner auf dem Gebiete der Optik, das sich von jeher für die mathematische Behandlung besonders geeignet erwiesen hatte. Sein optisches Werk, das er „Über Licht und Schatten" betitelte ${ }^{1}$ ), enthält manchen Fortschritt und viele Richtigstellungen früherer Irrtümer. Maurolykus ist z. B. der erste Physiker, der die Wirkung der Linse im Auge erklärt, indem er dartut, daß sich die Strahlen hinter der Linse schneiden. Die Kurz- und Übersichtigkeit leitet er aus einem übermäßigen oder zu geringen Grad der Linsenkrümmung ab. Wenn er damit auch nicht ganz das Wesen der Sache traf, da man heute Unregel-

1) Maurolykus, De lumine et umbra. Venedig 1575. 
mäßigkeiten in den Abmessungen des Augapfels als den Grund dieser Mängel betrachtet, so erschloß sich doch ein theoretisches Verständnis der Brillen, die schon seit dem 13. Jahrhundert im Gebrauch waren.

Ein schönes Beispiel, wie verschieden ein und dasselbe Problem in aristotelischem Sinne und in Geiste der neueren, den wissenschaftlichen Grundsätzen sich erschließenden Zeit belıandelt wurde, bietet die Erklärung des runden Sonnenbildchens. Es ist eine allbekannte Erscheinung, daß die Sonnenstrahlen, die durch eine unregelmäßig gestaltete Öffnung senkrecht auf eine ebene Fläche fallen, dort ein kreisförmiges Bild hervorrufen. Die Aristoteliker waren mit ihrer Erklärung, welche die Hohlheit des nicht durch genügende Induktion gestützten philosophischen Denkens treffend dartut, bald fertig. Sie schrieben die Erscheinung einer "Zirkularnatur" des Sonnenlichtes zu, setzten also an Stelle der Erklärung ein Wort, welches das bezeichnet, was zu erläutern ist. Geht man dagegen von der Tatsache aus, daß jeder Punkt der Sonnenoberfläche Licht aussendet und ein Bild von der Gestalt der Öffnung gibt, so werden die unzähligen Bilder, die sich teilweise decken, insgesamt ein Flächengebilde entstehen lassen, das sich als eine Projektion des leuchtenden Körpers darstellt. Daher muß das Bildchen bei einer Sonnenfinsternis, der Gestalt der Somnenscheibe entsprechend, sichelförmig erscheinen, wie es die Beobachtung auch dartut ').

Die Erklärung des kreisförmigen Sonnenbildchens aus der "zirkulären Natur"“ des Sonnenlichtes ist ein treffendes Beispiel für das, was man eine "verborgene Qualität", eine "qualitas occulta" genannt hat. Solch unbestimmte Begriffe führten die Aristoteliker während des ganzen Mittelalters, oft genug einer einzigen Erscheinung wegen, ein, wenn sie eine aus den Tatsachen entspringende Erklärung nicht zu geben vermochten.

Etwas später fällt die Wirksamkeit des Italieners Johann Baptista Porta (1538-1615). Dieser Mann ist typisch fuir diejenige Stufe einer Disziplin, auf der sie noch nicht zu strengerer Wissenschaftlichlieit gelangt ist. Wir finden bei Porta und seinen Zcitgenossen, die sich mit pliysikalischen und chemischen Dingen beschäftigen, eine Verquickung von Richtigem und

1) Die Erklärungr des M a urolykus beruht gleichfalls auf der geradlinigen Fortpflanzung des Lichtes; jeder Punkt der Öffinung wird dabei als die Spitze eines von der Sonne ansgehenden Strahlenkegels betrachtet, der auf der andern Seite der Öfinung seine Fortsetzung findet. 
Unrichtigem, von Klarheit mit Mystik und Aberglauben, die heute, nachdem das Niveau der gesamten Bildung ein so viel höheres geworden ist, eigentümlich anmutet. Das Streben dieser Männer nach größerer Einsicht ging ferner mit einem marktschreierischen Treiben Hand in Hand, durch das sie ihr eigenes Ansehen und das ihrer Wissenschaft den Zeitgenossen gegenüber heben wollten.

Das Buch, in dem Porta, ganz dem Geschmacke seiner Zeit entsprechend, die Naturwissenschaften behandelt, ist „Die natürliche Magie" betitelt ${ }^{1}$ ). Es ähnelt in manchen Teilen einem modernen Zauberbuche, da es dem Verfasser nicht selten darauf ankommt, den Leser zu unterhalten oder durch das Überraschende der Erscheinung in Verwunderung zu setzen. Wichtig ist, daß Porta in seinem Buche eine von ihm getroffene Verbesserung der Camera obscura beschreibt. Bis dahin hatte man bei diesem Apparat das Licht durch eine Öffnung auf einen dahinter befindlichen Schirm fallen lassen. Porta brachte in der vergrößerten Öffnung eine Linse an, wodurch die Bilder bedeutend an Schärfe gewannen ${ }^{2}$ ).

Von Interesse ist ferner eine von Porta herrührende Einrichtung, den Dampf zum Heben von Wasser zu benutzen. Das Wasser befindet sich in einem Gefäß; der Dampf drückt auf die

1) J. P. Portae Neapolitani, Magia naturalis. 1553 (nicht mehr vorhanden). 10̄60. 1589.

2) Eine Beschreibung der schon viel älteren Lochkamera findet sich auch bei Lionardo da Vinci. Sie lautet: „Wenn die Bilder von beleuchteten Gegenständen durch ein kleines Loch in ein sehr dunkles Zimmer fallen, so sieht man diese Bilder im Innern des Zimmers auf weißem Papier, das in einiger Entfernung von dem Loche aufgestellt ist, in voller Form und Farbe. Sie sind aber in der Größe verringert und stehen auf dem Kopfe." Die Umkehrung des Bildes leitete Lionardo da Vinci ganz richtig von dem Gang der Lichtstrablen ab.

Von frïheren abendländischen Gelehrten haben sich Vitello, Peckham und $\mathrm{R}$ oger Bacon mit der Abbildung der Sonne durch verschieden gestaltete Öffnungen beschäftigt; im 14. Jahrhundert hat sich Levi ben Gerson der Camera obscura zu Beobachtungen bei Sonnen- und Mondfinsternissen bedient, Ma urolykus im 15. Jahrhundert eine genügend richtige Abbildung der Sonne durch eine enge Öffnung gegeben.

Von den arabischen Gelehrten hat schon Alkindi $(750-800)$ den Strahlengang für den Fall der Lochkamera untersucht, dann haben der große Ibn al Haitam und sein ebenfalls bedeutender Kommentator Kamâl al D în die Theorie ausführlich entwickelt. J. Würschmidt, Zeitschr. f. math. u. naturwiss. Unters. $1915,466$. 
Oberfläche des Wassers und treibt es durch ein heberartiges, bis auf den Boden tauchendes Rohr aus dem Behälter heraus. Eine derartige Vorrichtung, die gegen das Dampfrad Herons keinen wesentlichen Fortschritt bedeutet, als die erste Stufe der Dampfmaschine zu bezeichnen, ist nicht gerechtfertigt. Doch läßt sich nicht verkennen, daß man durch die von Heron und Porta beschriebenen Versuche mit der Wirkung gespannter Dämpfe vertraut wurde, und daß dadurch der Gedanke, diese Wirkung auf die einfachen Maschinen der Mechanik zu übertragen, allmählich heranreifte. Erst von diesem Fortschritt an, den wir später zu betrachten haben, kann von einer eigentlichen Dampfmaschine die Rede sein.

Es zeigt sich hier wie auch bei Galilei und anderen Forschern, daß die Physik der Gase und der Flüssigkeiten im 17. Jahrhundert besonders infolge der Anregungen ausgebaut wurde, die man dem Altertum in Herons Schriften verdankte 1). So schuf Porta eine „Pneumatik“, die zwar keine bloße Wiedergabe der "Pneumatik" Herons ist, indessen auf ihn zuriickgeht 2). Auch Schwenter (s. folg. Seite) hat in seinen "Erquickstunden" manche Angaben Herons, besonders diejenigen, die in Herons Druckwerken enthalten sind, verwertet. Dasselbe gilt von Schott, dem Freunde Guerickes, und seiner 1657 erschienenen „Mechanica hydraulico-pneumatica". Sogar de Caus, dem die Franzosen die Erfindung der Dampfmaschine zuschreiben möchten, geht auf Heron zuriick ${ }^{3}$ ). Selbst die Wasserkiinste der fürstlichen Gärten des 17. Jahrhunderts sind teilweise den von Heron ausgehenden Anregungen zu verdanken.

Auch den magnetischen Erscheinungen wandte man jetzt eine größere Aufmerksamkeit zu. Indessen gerade dieses Gebiet wurde von Porta und Männern verwandten Geistes noch außerordentlich nit Mystik und Aberglauben verwoben. Mit der Deklination, deren Größe Porta für Italien gleich $9^{\circ}$ östlich angibt, war man schon vor Columbus bekannt geworden. Letzterer machte die Beobachtung, daß sich die Deklination (sie war damals im ganzen Gebiete des Mittelmeeres östlich) bei einer Reise nach Westen

1) W. Schmidt, Heron von Alexanilien im 17. Jahrliundert. In den Abhandlungen z. Gesch. d. Mathem. 8. Heft (1898, S. 195.

2) Porta, Pneumaticorum libri tres. Neapoli 1601 .

3) Seine Vorrichtung, mit Hilfe gespannter Dämpfe Wasser zu beben, kann noelı nicht als Dampfmaschine bezeichnet werden. Außerdem ist es zweifelhaft, oh de Caus ein Franzose oder ein Deutseher war. 
verringerte und schließlich in eine westliche überging. Auf Grund dieser Erkenntnis suchte sich Columbus auf seiner zweiten Reise, wenn die Schiffsrechnung unsicher war, durch einen Vergleich der Deklinationen zu orientieren. Es war dies der erste, später oft wiederholte Versuch, die Deklination zur Auffindung der geographischen Länge zu verwerten. Eine brauchbare Lösung des Längenproblems, das schon Hipparch und Ptolemäos große Schwierigkeiten bereitet hatte, sollte jedoch nicht auf diesem Wege, sondern erst durch die Erfindung genauer Chronometer ermöglicht werden. Das zweite Element des tellurischen Magnetismus, die Erscheinung nämlich, daß die um eine horizontale Achse drehbare Nadel eine geneigte Lage einnimmt, hat zuerst der Engländer Norman genauer beobachtet. Er gab im Jahre 1576 die Größe dieser, als Inklination bezeichneten Neigung für London zu $71^{\circ} 50^{\circ}$ an ${ }^{1}$ ). Auf die wechselnde Intensität des Erdmagnetismus wurde man dann gegen das Ende des 18. Jahrhunderts aufmerksam, so daß erst seit dieser Zeit eine allseitige, auch das Qnantitative in der Erscheinung berücksichtigende Kenntnis dieser Naturkraft Platz greifen konnte.

Unter den Männern, die etwas später die Naturwissenschaften ganz im Geiste Portas behandelten, ist Daniel Schwenter zu nennen (geboren 1585; gestorben 1636 als Professor der Mathematik in Altdorf). Sein bekanntes Werk, "Die mathematischen und philosophischen Erquickstunden" "2), ist ein würdiges Seitenstück zu Portas "Magia naturalis" und erscheint besonders geeignet, um den Standpunkt, den die Naturwissenschaften zumal in Deutschland vor der großen, durch Galilei, Kepler und ihre Mitarbeiter hervorgerufenen Umwälzung einnahmen, erkennen zu lassen.

Bezeichnend ist zunächst, daß Schwenter es für nötig hält, die Beschäftigung mit der Natur gegen den Vorwurf zu verteidigen, es handele sich dabei um eine unnütze, ja kindliche Tätigkeit. Ein Kind, sagt er, werfe wohl einen Stein ins Wasser und freue sich über die vielen Kreise. Das sei eine kindliche Freude. Die Ursache dieser Erscheinung nachzuweisen, sei dagegen kein Kinderwerk. Einige Beispiele mögen dartun, wie unzulänglich und un-

1) Gilbert, De magnete. I, 1. Ton dem Deutschen Georg Hartmann (1489-1564) rührt eine noch ältere, aber ganz ungenaue Beobachtung der Inklination her $9 \mathrm{Grad}$ anstatt etwa $70 \mathrm{Grad})$.

2) Deliciae physico-mathematicae. Nach dem Tode Schwenters erschienen. Eine Übersetzung rührt von Harsdörffer her. 
bestimmt die Ansichten waren, die man an der Schwelle des 17. Jahrhunderts noch hegte. Wir werden dann den großen Fortschritt, den die Wissenschaft um jene Zeit durch die Begründung der induktiven Forschungsweise erfuhr, um so besser würdigen können. So ist das ganze Wissen Schwenters über die Fallbewegung in folgenden Sätzen enthalten ${ }^{1}$ ): ., Wenn ein Körper fällt, so bewegt er sich um so geschwinder, je näher er der Erde kommt. Je höher der Körper herabfällt, eine um so größere Gewalt besitzt er. Denn alles was schwer ist, eilt nach der Philosophen Meinung unverhindert zu seinem natürlichen Ort, d. i. zum Zentrum der Erde, wie der Mensch, der in sein Vaterland zurückkehrt, um so begieriger ist, je näher er kommt, und daher. um so mehr eilt. Dazu kommt noch eine andere natïrliche Ursache. Die Luft nämlich, die von der Kugel zerteilt wird, eilt über der Kugel geschwind wieder zusammen und treibt sie immer stärker an. Was aber schon bewegt ist, läßt sich leichtlich weiter und geschwinder bewegen". Ein Fortschritt dem Aristoteles gegenüber ist in diesen Auffassungen nirgends zu bemerken. Im Gegenteil, man muß sie als rein aristotelisch bezeichnen. Nicht minder gilt dies von Schwenters Auffassung der Wurfbewegung. Er setzt sie aus drei Bewegungen zusammen, die er als genötigte, als gemischte und als natürliche Bewegung bezeichnet. Danach treibt z. B. das Pulver die Kugel in einer genötigten Bewegung schräg aufwärts, bis der höchste Punkt der Flugbahn erreicht wird. Dann fängt, „nachdem eine solche gewalttätige Bewegung schier ihr Ende nehmen will, die gemischte Bewegung durch einen Bogen an". Endlich gelie die Kugel in die natürliche Bewegung über und falle senkrecht auf die Erde. Aus dieser Theorie sucht Sch wenter die Erfahrungstatsache abzuleiten, daß die größte Schußweite bei einem Winkel von $45^{\circ}$ erzielt wird.

Interessant sind auch die Bemerkungen über den senkrechten Schuß. Er verleihe dem Geschoß weit mehr Gewalt als der horizontale Schuß, "weil das Feuer von Natur über sich begehre". Wenn ferner das Geschütz in die Höhe gerichtet werde, so presse die Kugel das Pulver und widerstrebe der Gewalt des Pulvers auch mehr. Dadurch werde bewirkt, daß sich das Pulver gleichsam erziirne, ehe es die Kugel austreibe. Endlich werde cine schwere Kugel, welche widerstreben könne, viel weiter getrieben als eine leichte, z. B. eine solche von Holz, die nicht widerstreben könne. 
Die Tatsache, daß die Kugel beim senkrechten Schuß in der Nähe des Geschützes wieder niederfällt, wird als Beweismittel gegen die koppernikanische Lehre verwertet $\left.{ }^{1}\right)$ : „So die Kugel 2 Minuten in der Luft bleibt, müßte indessen der Böller 30 deutsche Meilen gelaufen sein. Dies ist unmöglich, denn man würde dann keine Kugel mehr finden". Die Koppernikaner, sagt Schwenter, seien zwar der Ansicht, die Luft bewege sich mit der Erde und zwar mit der gleichen Geschwindigkeit wie die Erde. Die empor geworfene Kugel miisse daher von der Luft getrieben nicht weit von dem Böller niederfallen. „Es ist aber", fügt Schwenter hinzu, „nicht glaublich, ja unmöglich, daß die Luft imstande ist, eine schwere Kugel in solch kurzer Zeit 30 Meilen fortzutreiben." Diese Schwierigkeit stand der Annahme des koppernikanischen Systems also noch 100 Jahre nach seiner Aufstellung im Wege. Sie konnte erst durch die allgemeine Anerkennung des Beharrungsgesetzes. gehoben werden.

In dem optischen Teil werden die Camera obscura, das Glasprisma, die Lichtbrechung und der Regenbogen abgehandelt. Trotzdem Schwenter den letzteren auch an Springbrunnen und an mit Regentropfen bedeckten Spinnengeweben beobachtet hat, hält er ihn dennoch für ein iibernatürliches Werk. Der Regenbogen ist für ihn ,ein Spiegel, in dem der menschliche Verstand seine Unwissenheit am hellen Tage sehen kann". Die Physiker hätten "clurch ihr vielfältiges Nachsinnen nichts anderes darin gefunden, als daß sie noch das Wenigste, so in der Natur verborgen sei, ausspekuliert liätten".

Gelegentlich der von ihm für glaubwürdig gehaltenen Erzählung von den Brennspiegeln des Archimedes bemerkt Schwenter, daß man auch durch eine Anzahl flacher Spiegel Pulver entzünden könne, wenn man die Sonnenstrahlen durch die Spiegel sämtlich auf einen Punkt werfe.

In dem Abschnitt, der von der Wärme handelt, beschreibt Schwenter auch ein Instrument, mit dem man den Grad der Hitze und der Kälte messen könne. Er bringt in ein Gefäß mit langem Halse etwas Wasser und kehrt das Gefäß dann unter Wasser um, so daß die Flüssigkeit einen Teil des Halses füllt. Im Winter, sagt Schwenter, steigt das Wasser hoch herauf, so daß es fast den ganzen Hohlraum füllt; im Sommer dagegen sinkt es tief herab. 
Schwenter ist noch mit Porta der Ansicht, daß sich das Wasser durch einen Heber über hohe Berge leiten lasse. Man solle, meint er, eine Röhre über den Berg legen und an der höchsten Stelle der Röhre einen Trichter anbringen. Verstopfe man dann die beiden Mündungen der Röhre, so könne man sie ganz mit Wasser füllen. Nach diesen Vorbereitungen sei es nur nötig, die Mündungen gleichzeitig zu öffnen. Das Wasser werde dann fort und fort aus dem Behälter, in den man die eine Mündung getaucht, durch die Röhre ausströmen, wenn nur die zweite Mündung tiefer gelegen sei. Jeder Versuch würde Porta und Schwenter gelehrt haben, daß über einen "Berg" von 10 Metern Höhe das Wasser nicht durch einen Heber geführt werden kann.

Daß Schwenter indessen fremde Angaben auch nachprüft, geht aus manchen Stellen seiner Schrift hervor. So hat ihm jemand mitgeteilt, das Wasser steige aus einem tiefer befindlichen Gefäß in ein loöher gelegenes, wenn man beide Gefäße durch einen wollenen Faden verbinde. Schwenter bemerkt dazu: „Ich finde durch den Versuch, daß diese Kunst nicht angeht, denn es ist damit wie mit einem Heber beschaffen. Das Wasser läuft nämlich nicht durch das wollene Band, wenn sein Ende nicht tiefer liegt als der Wasserspiegel, in den das andere Ende eintaucht".

Wir haben Schwenters Werk etwas ausführlicher behandelt, nicht etwa, weil es die Wissenschaft durch neue Gedanken oder Entdeckungen bereichert hätte, sondern weil wenige von den in Deutschland zu Beginn des 17. Jahrhunderts verfaßten Schriften über das gesamte Gebiet der Naturlehre so geeignet sind, uns eine Vorstellung von dem Wissensstand und den Anschauungen zu geben, die damals herrschten. Im gleichen Sinne wie Porta und Schwenter wirkten während der ersten Hälfte des 17. Jahrhunderts in Deutschland A thanasius Kircher, Kaspar Schott und andere Männer. Sie alle waren Gelehrte von oft polyhistorischem Wissen, die uns wohl dickleibige, zur Beurteilung jener Zeit wichtige Folianten hinterlassen, die Wissenschaft selbst aber weder durch neue Ideen, noch durch Entdeckungen bereichert haben. Insbesondere der gehehrte Jesuit Kircher verdient mehr als bloße Erwähnung.

Athanasius Kircher wurde in der Nähe von Fulda im Jahre 1601 geboren. Er wirkte als Professor der Mathematik zunächst an der Universitiit Würzburg, später in Rom, wo er 1680 starb. Von Kirchers zahlreichen Schriften sind besonders drei hervorzuheben, weil sie uns einen Einblick in den damaligen Vu- 
stand der Naturwissenschaften gewähren. Es ist das Werk vom Licht und rom Schatten (Ars magna lucis et umbrae 1646), ferner ein Werk über den Magnetismus (Magnes, sive de arte magnetica 1643) und drittens die für die Entwicklung der geologischen Vorstellungen wichtige Schrift über „Die unterirdische Welt" (Mundus subterraneus 1664).

In dem optischen Werke Kirchers wird u. a. schon auf die Fluoreszenz hingewiesen. Kircher nahm sie an dem wässerigen Auszug wahr, den man aus einem mexikanischen Holz, dem „Nierenholz", herstellt1). Diese Lösung zeigte im auffallenden Lichte eine tiefblaue Farbe, während die Fliissigkeit beim Hindurchblicken farblos wie Brunnenwasser aussah. Unter Umständen erschien sie auch grün oder rötlich. Eine Erklärung dieser auffallenden Erscheinung vermochte Kircher nicht zu geben.

Sehr ausführlich handelt er von dem bononischen (Bologneser) Leuchtstein. Ein Alchemist hatte den in der Nähe von Bologna vorkommenden Schwerspat unter Beimengung reduzierender Mittel im Ofen erhitzt und wahrgenommen, daß der Rückstand im Dunkeln leuchtet, wenn er vorher von der Sonne beschienen wurde. Die Entdeckung ${ }^{2}$ ) erregte, wie begreiflich, das größte Aufsehen. Auch Galilei beschäftigte sich damit. Er meinte, sie spreche deutlich gegen die Ansicht, daß das Licht eine unkörperliche Qualität sei, weil der Stein das Sonnenlicht aufnehme, als ob es ein Körper wäre, und es nach und nach wieder zurückgebe. Kircher ist derselben Meinung. Er stellte den

1) Dieses Holz hatten Jesuiten in Mexiko kennen gelernt; es wurde Nierenholz (lignum nephriticum) genannt, weil man es gegen Nieren- und Blasenkrankheiten anwandte.

Ausführlicher hat G. Berthold über die Geschichte der Fluoreszenz in Poggendorffs Annalen der Physik und Chemie, Bd. 158 (1876, S. 620, berichtet. Danach rührt die älteste Nachricht über die Fluoreszenz eines Aufgusses des liguum nephriticum von Monardes (16. Jahrh.) her. Auch Boyle, Grimaldi, Newton und andere haben sich mit dem Phänomen beschäftigt. Newton hat zuerst den Aufguß in homogenem Lichte untersucht. Eingehender geschah dies durch E. W ünsch (Versuche und Beobachtungen über die Farben. Leipzig 1792). Bei Musschenbroek findet sich die Bemerkung, daß Erdöl dieselbe Erscheinung zeige wie der Aufguß des Nierenholzes Introductio ad philos. nat. 1762. Bd. II. S. 739). Goethe beschrieb sie an dem Aufguß der frischen Rinde der Roßkastanie (Nachträge zur Farbenlehre. Nr. 10). Da indessen die Erklärung dieser Erscheinung nicht gelang, geriet sie in Vergessenheit, bis sie um die Mitte des 19. Jahrhunderts zum Gegenstande sehr eingehender Experimentaluntersuchungen gemacht wurde. (Siehe Bd. IV.)

2) Sie soll um 1630 erfolgt sein. 
Bologneser Stein her, indem er den Spat mit Eiweiß und Leinöl mischte und das Gemenge glühte.

Überraschende Entdeckungen sind fast immer in ihrer Tragweite überschätzt und zu kühnen, nicht stichhaltigen Erklärungen verwertet worden. Dies gilt auch von dem Bologneser Leuchtstein. So schrieb Kircher dem Auge die gleichen Eigenschaften $\mathrm{zu}$, die dieser Stein besitzt, um die ron ihm zuerst geschilderten physiologischen oder subjektiven Farben zu erklären. Gemeint ist die Erscheinung, daß das Auge, nachdem es längere Zeit auf farbige Gegenstände und dann auf eine weiße Fläche gerichtet wird, die Umrisse jener Gegenstände in gewissen Farben erblickt. Dies sollte daher rühren, daß das Auge, wie der Leuchtstein, das Licht einsauge und es allmählich wieder ausstrahle. Ein Zeitgenosse Kirchers suchte sogar das graue Licht des ron der Sonne nicht beleuchteten Teiles der Mondoberfäche durch die Annahme zu erklären, daß auch der Mond ein Bologneser Stein sei.

Von gutem Beobachtungsvermögen zeugen Kirchers Bemerkungen über den Farbenwechsel des Chamäleons. Er brachte das Tier auf weiße und rote Tücher und zeigte, daß sein Farbenwechsel dadurch beinflußt wird.

Bei Kircher begegnet uns ferner eine genaue Beschreibung der Laterna magica. Man hat ihn daher als den Erfinder dieses Apparats bezeichnet, wahrsclieinlich aber mit Unrecht1). Kircher bediente sich schon der transparenten Glasbilder. Ein erbauliches Beispiel für seinen theologischen Eifer möge nicht unerwähnt bleiben. Die Zauberlaterne erscheint ihm nämlich als ein vortreffliches Mittel, Gottlose durch Vorführung des Teufels auf den rechten Weg zuriickzubringen.

Kirchers Werk iiber den Magneten steht hinter der viel früher erschienenen, den gleichen Gegenstand behandelnden Schrift des Engländers Gilbert weit zurück. Hervorzuheben ist Kircher's Verfahren, mittelst der Wage die Tragkraft des Magneten zu bestimmen. Auch stellt er die durch Jesuitenmissionäre im Auslande gemachten Beobachtungen über Größe und Änderungen der Deklination in einer Tabelle zusammen. Wie kritiklos indessen auch auf diesem Gebiete Kircher und Schwenter hüufig verfahren, geht daraus hervor, daß sie die alte Fabel, daß der Magnet durch gewisse Pflanzen seine Kraft verliere, ohne Nachpriifung aufnehmen.

1) Siehe Wilde, Geschichte der Optik. Bd. I. S. 294. 
Der Magnet verliert, sagt Schwenter, durch Feuer und durch Knoblauch seine Kraft. "Wie die Erfahrung bezeugt" setzt er sogar hinzu.

Wie Schwenter handelt Kircher im übrigen bei der Besprechung der magnetischen Erscheinungen oft von Spielereien, deren Schilderung mit starken Übertreibungen und Fabeln aller Art durchsetzt ist. Beide Schriftsteller erörtern beispielsweise die Möglichkeit, vermittelst des Magneten eine Art Telegraphie zu bewerkstelligen. Zwei Personen, von denen die eine in Paris, die andere in Rom sein könne, müsse man mit kräftigen Magneten ausrüsten. Bei genügender Stärke werde der eine Magnet auf den anderen zu wirken vermögen. Es sei dann nur erforderlich, unter jeder Nadel eine Scheibe mit Buchstaben anzubringen. Der Sprechende habe nur seine Nadel auf die verschiedenen Buchstaben einzustellen, um die Nadel des Empfängers zu den gleichen Einstellungen zu veranlassen. Kurz, es ist der Grundgedanke des Zeigertelegraphen, der uns hier entwickelt wird. Nur schade, daß das Mittel zur Übertragung nicht ausreichte. Das sah auch Schwenter ein, denn er fügt hinzu: "Die Invention ist schön, aber ich achte nicht davor, daß ein Magnet solcher Tugend auf der Welt gefunden werde."

Das bedeutendste Ereignis der folgenden Periode ist die Begründung der Dynamik durch Galilei. Auch dies geschah nicht unvermittelt. Fanden sich schon bei Lionardo da Vinci klare, wenn auch noch nicht hinreichend durchgearbeitete Begriffe auf diesem Gebiete der Physik, z. B. bezüglich des Fallens über die schiefe Ebene ${ }^{1}$ ) vor, so mehren sich die Ansätze, je weiter wir uns dem Auftreten Galileis nähern. Vor allem greift eine bessere, schon auf physikalischen Grundsätzen beruhende Auffassung der Wurfbewegung Platz. Man erkennt, daß die Bahn des geworfenen Körpers eine einzige krumme Linie ist, nicht aber aus geraden und krummen Stücken besteht, wie die Peripatetiker behaupteten, sowie daß die größte Wurfweite bei einem Elevationswinkel von $45^{\circ}$ erzielt wird ${ }^{2}$ ). Auch die Meinung der Aristoteliker, daß ein Körper um so schneller falle, je schwerer er ist, wird schon

1) Schon im 13. Jahrhundert versuchte der Deutsche Jordanus Nemorarius, mechanische Probleme auf dynamischem Wege zu lösen (Liber Jordani Nemorarii de ponderibus. Herausgegeben von Peter A pian, 1533). Näheres siehe Gerland und Traumüller, Geschichte der physikalischen Experimentierkunst. Leipzig, W. Engelmann. 1899. S. 78 u. f.

2) Tartaglia, Nuova scienza (Venedig 1537). 
vor Galilei, der sie glänzend widerlegt, durch den Italiener Tartaglia erschüttert. Dieser lehrte, daß Körper von verschiedenem Gewicht beim freien Fall in gleichen Zeiten gleiche Strecken zurücklegen, sowie daß ein im Kreise geschwungener Gegenstand beim Aufhören der Zentralbewegung sich in tangentialer Richtung fortbewegt.

Obwohl man solche Vorarbeiten als die Anzeichen des beginnenden Umschwunges hoch bewerten muß, ist doch erst Galilei als der eigentliche Begründer der Dynamik zu betrachten, weil durch ihn wie mit einem Schlage fast alles beseitigt wurde, was jener Wissenschaft an Verschwommenbeit und aristotelischer Betrachtungsweise noch anhaftete.

Für die Chemie sollte ein entsprechender Fortschritt noch lange auf sich warten lassen. Zwar wurde er hier durch anerkennenswerte Leistungen weit mehr vorbereitet als die fast unvermittelt uns entgegentretenden Errungenschaften Galileis. Die Umgestaltung zur exakten Wissenschaft vollzog sich aber trotzdem auf dem Gebiete der Chemie erst im Verlauf des 18. Jahrhunderts. Während nämlich die Grundlagen der Mathematik, der Astronomie und der Statik der neueren Epoche schon in wissenschaftlicher Gestalt vom Altertum iiberliefert wurden, war die Alchemie, deren Grundlagen zwar auch im Altertum, wenn auch erst in den letzten Jahrhunderten dieses Zeitraums entstanden, doch im wesentlichen ein Erzeugnis des Mittelalters und, dem Hange jener Zeit entsprechend, durch mystische Zusätze stark getrübt. Wie Roger Bacon und Albertus Magnus wandelten die Vertreter der Chemie zu Beginn der neueren Zeit noch ganz in den rom Mittelalter vorgezeichneten Bahnen. An den Stein der Weisen, dessen Herstellung nach wie vor das Hauptziel aller Bemühungen blieb, knüpfte man die abenteuerlichsten Hoffnungen. Der Stein sollte nicht nur, wie bei den älteren Alchemisten, beim Zusammenschmelzen mit unedlen Metallen Gold erzeugen, und zwar unbegrenzte Mengen, oder wenigstens $1000 \times 1000$ Teile, sondern er sollte auch das Leben verlängern, dem Alter die Jugend zurückgeben und alle Krankheiten heilen. Doch begegnen uns diese Vorstellungen auch schon in weit frïherer Zeit ${ }^{1}$ ).

Von der Überzeugung, daß die Darstellung der Materia prima gelungen, und Gold mit ihrer Hilfe dargestellt sei, war man übrigens fest durchdrungen. Die Alchemie erlangte sogar eine gewisse poli-

2) Nach v. Lippmann. 
tische Bedeutung. An den Fürstenhöfen besaßen Männer, die sich angeblich im Besitze des Geheimnisses befanden, großen Einfluß. Nachdem z. B. die englische Regierung die Gelehrten und die Geistlichen aufgefordert hatte, die Hilfe Gottes zu erflehen, damit die Herstellung des Steins der Weisen endlich gelinge und man die Staatsschulden bezahlen könne ${ }^{1}$ ), gedieh die Sache bald darauf schon weiter. Dasselbe Land nahm nämlich keinen Anstand, aus alchemistischem Golde geprägte Miinzen in Umlauf zu bringen. Doch war man, zumal in den geschädigten Nachbarländern, aufgeklärt genug, um bald zu erkennen, daß es sich hier um eine arge Täuschung handelte ${ }^{2}$ ).

So bildete denn während des langen Zeitraums von mehr als einem Jahrtausend das Suchen nach Gold ${ }^{3}$ ) die treibende Kraft für die chemische Wissenschaft. Denn als eine Wissenschaft müssen wir die Chemie auf jener Entwicklungsstufe gelten lassen, wenn auch als eine rein empirisch betriebene. Wurden doch während dieses ausgedehnten Zeitraums eine unübersehbare Fülle von Tatsachen über das chemische Verhalten der Körper beobachtet, eine Unzahl neuer Verbindungen hergestellt, die wichtigsten chemischen Operationen ausgebildet, kurz eine breite Grundlage geschaffen, die für die spätere Errichtung eines Lehrgebäudes ganz unerläßlich war. Wir dürfen ferner bei der Beurteilung der Alchemisten nicht vergessen, daß viele von ihnen von einem heißen, wenn auch noch unklaren Streben nach dem Eindringen in die für sie mit dem tiefen Schleier des Geheimnisvollen und Unerklärlichen verhüllte Natur erfüllt waren und weiter, daß auch heute noch die Hoffnung auf materiellen Gewinn oder wenigstens auf Nutzen für das Gemeinwohl für sehr viele wissenschaftliche Unternehmungen, insbesondere für diejenigen, welche der Staat mit seinen Mitteln fördert, die wichtigste Triebfeder ist.

1) Dies geschah im Jahre 1423.

2) Übrigens betrieb Karl VII. von Frankreich, dem die Engländer den Thron zugunsten ihres Königs Heinrich VI. streitig machten, dieselbe Art von Falschmünzerei.

Siehe auch H. Schelenz: „Hermes und seine Kunst, Alchemie in England". Pharmazeutische Post. Wien 1902. Nr.6. Danach wurde im Jahre 1440 einer englischen Firma sogar das Privileg zur Herstellung von künstlichem Gold gegeben. Doch sank dadurch der Wert der englischen Goldmünzen um die Hälfte. Nach v. Lippmann handelte es sich um gefälschte Münzen.

3) Es lehrte, sagt Chamberlain treffend, schärfer beobachten, verdoppelte die Erfindungsgabe, flößte die kühnsten Hypothesen ein und schenkte endlose Ausdauer und Todesverachtung (Chamberlain, Grundlagen. S. 756). 
$\mathrm{Zu}$ den eifrigsten Beschützern der Alchemisten und der Astrologen gehörte der deutsche Kaiser Rudolf II., der auf den Lebensgang des großen Kepler einen solch tiefgreifenden Einfluß ausgeübt hat. Als Rudolf II. im Jahre 1612 starb, fand man in seinem Nachlaß große Mengen Gold und Silber, die als Erzeugnisse der alchemistischen Kunst betrachtet wurden. Wenige Jabre später berichtet van Helmont, ein Mann, von dessen Ehrlichkeit in wissenschaftlichen Dingen wir überzeugt sein dürfen, der aber ein ganz unklarer Phantast war, dal3 es ihm gelungen sei, acht Unzen Quecksilber mit 1/4 Gran der gesuchten Substanz, die auf eine etwas mysteriöse Weise in seine Hände gelangt war, in Gold zu verwandeln.

Unter den ersten, die sich von der Alchemie, wie auch von der Astrologie, abwandten, ist der an anderer Stelle wegen seiner Verdienste um die Geologie genannte Franzose Palissy (1510 bis 1590) zu nennen. Für seinen Zeitgenossen Rabelais waren die Astrologen und die Alchemisten sogar ein unerschöflicher Gegenstand beißenden Spottes. Etwa. zur selben Zeit wandte sich auch Lionardo da Vinci gegen die ,lügnerische und verderbliche Kunst der Alchemie und ihre betrügerischen Anhänger". Er bestritt, daß Schwefel und Quecksilber Bestandteile der Metalle seien und erklärte die künstliche Darstellung des Goldes für ebenso unmöglich wie die Quadratur des Kreises und das Perpetuum mobile1).

$\mathrm{DaB}$ die alchemistischen Bestrebungen stets von neuem Nahrung fanden, und sich bis in das 18. Jahrhundert2) hinein fortsetzen konnten, so daß wir auf sie noch zurückkommen müssen, darf unter solchen Umständen nicht wundernehmen. Die Chemie erhielt jedoch in dieser Periode, wenn sich ihr Gesamtcharakter zunächst auch wenig änderte, eine Anregung, die für ihre weitere Entwicklung von Bedeutung werden sollte. Als zweite wichtige, die Erzeugung des Steines der Weisen immer mehr in den Hintergrund drïngende Aufgabe wurde es nämlich betrachtet, gecignete Präparate zum Heilen der Krankheiten herzustellen. Es beginnt damit das Zeitalter der medizinischen oder Jatrochemie.

1) Siehe in v. Lippmanns Werk „Die Alchemie“ $(1919$, den Abschnitt, der von der Alchemie nach 1300 handelt (S. 495 u. f.).

2) Vereinzelt selbst bis ins 19. Jahrhundert. So entstand 1894 in Paris eine Société lıcrmétique und bald darauf eine Société alchimique. Fristeten diese Regungen ihr Dasein immer wieder durch ihre Verbindung mit Mystik und Okkultismus, so erhielten sie neue Nahrung durch die Umwandlungen, die man am Radium und den radioaktiven Stoffen entdeckte.

Dannemann, Die Naturwissenschalteu. I. Bd. 2. Aufl. 
Der Hauptvertreter der Jatrochemie war Paracelsus. Dieser merkwürdige Mann, dessen Lebenslauf hier nicht eingehender betrachtet werden kann, wenn er auch ein Stück Kulturgeschichte zu entrollen geeignet ist, wurde im Jahre 1493 zu Einsiedeln in der Schweiz geboren. Theophrastus Paracelsus (von Hohenheim) bekleidete eine Zeitlang eine Professur in Basel, führte jedoch im iibrigen ein unstätes Leben, bis er 1541 gänzlich mittellos starb. Sein ganzes Auftreten kennzeichnet ihn als einen Vertreter des reformatorischen Geistes jener Zeit, der sich keineswegs auf das kirchliche Gebiet beschränkte. Insbesondere wandte sich Paracelsus gegen die anerkannten wissenschaftlichen Autoritäten, die bislang auf dem Gebiete der Chemie und dem der Medizin gegolten hatten. Paracelsus spricht es unumwunden aus, daß der wahre Zweck der Chemie nicht darin bestehe, Gold zu machen, sondern daß es ihre Aufgabe sei, Arzneien zu bereiten, die man bis dahin nach dem Vorgange Galens fast ausschließlich dem Pflanzenreiche entnommen hatte. In etwas theatralischer Weise uibergab Paracelsus, als er seine Vorlesungen in Basel gegen alles Herkommen in deutscher Sprache eröffnete, ältere Werke, deren Inhalt er bekämpfte, den Flammen. Und zwar geschah dies, bald nachdem Luther die Briicke dadurch hinter sich vernichtet hatte, daß er die päpstliche Bannbulle öffentlich verbrannte.

Paracelsus hat bis vor kurzem als umherschweifender, dem Trunke ergebener Charlatan gegolten Die neuere Paracelsusforschung ${ }^{1}$ ) hat mit dieser Auffassung gebrochen. Der Wandertrieb des Paracelsus ist aus einer griindlichen Abkelır vom herkömmlichen Bücherstudium und aus seinem Triebe zur Naturerkenntnis zu erklären. Paracelsus begriindet sein ihm oft zum Vorwurf gemachtes Verhalten mit folgenden Worten: „Mir ist not, daß ich mich verantworte von wegen meines Landfahrens. Daß ich so gar nirgends bleiblich bin, zeichnet den Weg derer, die den Biichern den Rücken wenden und in die Natur hinaustreten. Mein Wandern hat mir wohl erschlossen, daß keinem sein Meister im Haus wachset noch seinen Lehrer hinter dem Ofen hat. Die Künste sind nicht verschlossen in Eines Vaterland, sondern ausgeteilt durch die ganze Welt, sie sind nicht in einem Menschen oder an einem Ort, sie müssen zusammengeklaubt werden und gesucht, da sie sind. Die Kunst geht keinem nach, aber ihr muß nachgegangen werden. Wie mag hinter dem Ofen ein guter Kos-

1) Besonders die Studien Sudhoffs. 
mographus wachsen oder ein Geograph?" An einer andern Stelle sagt er: „Die Weisheit ist eine Gabe Gottes. Da er sie hingibt, in demselbigen soll man sie suchen. Also auch da er die Kunst hinlegt, da soll sie gesucht werden ... Die Schrift wird erforschet durch ihre Buchstaben, die Natur aber von Land zu Land, so oft ein Land so oft ein Blatt. Also ist Codex Naturae, also muß man ihre Blätter umkehren"1).

Paracelsus verhielt sich den Anhängern Luthers und $\mathrm{Z}$ winglis gegenüber ebenso ablehnend wie gegen das Papsttum und seine Lehre. Er stand über den kirchlichen Streitereien seiner Zeit. Seine Frömmigkeit war eine rein menschliche, sein Herz erfüllt von der Liebe zum Nächsten. Diese solle die Berufstätigkeit des Arztes durchdringen ${ }^{2}$ ).

Am größten ist der Einfluß des Paracelsus auf die damalige, häufig nur auf verderbter Überlieferung der alten Literatur beruhende Heilkunde gewesen. Die Werke Galens, das hervorragendste Erzeugnis der antiken Heilwissenschaft, hatten nämlich einen großen Umweg gemacht, um nach Mitteleuropa zu gelangen. Die Araber hatten sie iiberliefert. Die Erläuterungen waren vorzugsweise in Spanien und Italien entstanden, und schließlich waren Galens Werke noch in jenes barbarische Latein übertragen, das vor dem Emporblühen des Humanismus die Schriftsprache der mitteleuropäischen Universitäten war. Als Lehrbuch wurde besonders der um das Jahr 1000 entstandene Kanon des Avicenna (Ibn Sina) benutzt, ein umfangreiches Werk, welches das Ganze der antiken und frühmittelalterlichen Chemie und Medizin umfaßte ${ }^{3}$ ).

Diesem Zustande machte Paracelsus durch sein kühnes Auftreten ein Ende. Er war es, der zuerst die in bloßer Buchgelehrsamkeit erstarrte Heilkunde wieder als reine Erfahrungswissenschaft auffassen lehrte $\left.{ }^{4}\right)$. Im Verkehr mit Bergleuten, Handwerkern und den anf sich angewiesenen, der Natur noch unbefangen gegenüberstehenden Bewohnern einsamer Wälder und

1) Siehe F. Strunz, Theophrastus Paracelsus, sein Leben und seine Persönlichkeit. Ein Beitrag zur Geistesgeschichte der deutschen Renaissance. Leipzig, E. Diederichs. 1903.

2) Siehe E. Sudhoffs Bericht über die neuesten Wertungen Hohenheims in den Mitteil. z. Geseh. d. Medizin u. Naturwiss. 1904. S. 475.

3) Im Druck erschien es zuerst 1493 und zuletzt in Basel in fünf Bänden 1523, also kurz bevor Paracelsus dort auftrat.

4) Voll Selbstbewußtsein sprach er einst das Wort: ,Engländer, Franzosen, Italiener, ihr mir nach, nicht ich euch!.* 
Gebirge sammelte er seine Kenntnisse. Der Natur müsse man nachgehen von Land zu Land, und die Augen, die „an der Erfahrenheit Lust" hätten, seien die wahren Professoren. In Paracelsus lebte ein tiefer Geist, der aber ,von dem einen Punkte, den er ergriffen, die Welt erobern zu können meinte: yiel zu weit ausgreifend, selbstgenügsam, trotzig und phantastisch" ${ }^{1}$ ). Auf die wunderlichen medizinischen Vorstellungen des Paracelsus näher einzugehen, nach denen z. B. eine schaffende Kraft alle Lebenstätigkeiten regelt, ihrerseits aber wieder in einem engen Zusammenhange mit den Gestirnen steht, verbietet sich von selbst. Die Verbindung der Heilkunde mit der Chemie ergibt sich nach Paracelsus daraus, daß die Krankheiten auf Anderungen in der chemischen Zusammensetzung des Körpers zurückzuführen seien. Chemisch wirksame Mittel müßten also den normalen Zustand wieder herbeiführen können. Alle Krankheiten sind von diesem Gesichtspunkte aus entweder durch Zufuhr oder durch Beseitigung des im gegebenen Falle in Betracht kommenden Elementes heilbar. Fieber wird auf ein Überwiegen von Sulfur (Schwefel), Gicht auf die Ausscheidung von Mercurius (Quecksilber) zurückgeführt, Elemente, die nach der Lehre des Paracelsus neben Sal (Salz) die Grundbestandteile aller Dinge sind. Kupfervitriol, Quecksilberchlorid, die schon vor Paracelsus als Heilmittel empfohlenen Verbindungen des Antimons und zahlreiche andere, teils giftige, teils ungiftige Präparate wandern damit in das Arsenal der ärztlichen Heilmittel. Aus den oben genannten drei Elementen sind nach Paracelsus alle Mineralien, Ptlanzen und Tiere zusammengesetzt. Es ist im wesentlichen die alte, auf die aristotelischen Elemente zurückzuführende Lehre der Alchemisten. Der Sulfur war für Paracelsus das Prinzip der Verbrennlichkeit, Mercurius bedingte die Verflüchtigung, Sal endlich galt als der feuerbeständige Anteil, der nach dem Verbrennen übrig bleibt.

Seit dem Zeitalter der Jatrochemie entwickelt sich der Stand der chemisch vorgebildeten Pharmazeuten, aus dem manches für den weiteren Ausbau der Wissenschaft bedeutende Talent hervorgegangen ist. Waren doch seit dem Verschwinden der schwarzen Küche der Adepten bis gegen das Ende des 18. Jahrhunderts die Apotheken vorzugsweise diejenigen Stätten, von denen die praktische Beschäftigung mit der Chemie und die Fortbildung dieser Wissenschaft ihren Ausgang nahmen. 
Schon Kaiser Friedrich II. erließ eine Verordnung, nach der die Arznei genau nach Vorschrift des Arztes und zwar zu einem bestimmten Preise herzustellen war. In Deutschland entstanden die ersten eigentlichen Apotheken erst gegen die Mitte des 13. Jahrhunderts. Die Einrichtung breitete sich indessen nur langsam aus, denn die Gründung der ersten Apotheke in Berlin erfolgte erst im Jahre 1488. Weit später folgten die nordischen Länder (Schweden 1552)1).

Mit der Entwicklung der Chemie ist das Emporblühen der Mineralogie stets eng verknüpft gewesen. Um 1500 begegnet uns das erste, sogar deutsch geschriebene mineralogische Lehrbuch, das nicht ein bloßer Abklatsch der aus dem Altertum überkommenen Werke ist, sondern Selbständigkeit und Beobachtungsgabe verrät. Es führt den Namen "Bergbüchlein"2) und wurde dem lange Zeit als Verfasser zahlreicher chemischer Schriften geltenden Basilius Valentinus zugeschrieben. Wir haben es indessen bei diesem nicht mit einer historischen, sondern mit einer erst später (um 1600) erdichteten Persönlichkeit zu tun.

Auch Paracelsus schrieb über die Mineralien. Als der eigentliche Vater der neueren Mineralogie ist jedoch Georg Bauer zu betrachten. Er wurde 1494 in Zwickau geboren, wo er auch einige Jahre als Rektor einer Schule vorstand, und nannte sich, nach der damaligen Gelehrtenmode seinen Namen latinisierend, Agricola. Später studierte er in Leipzig und Italien Heilkunde und wirkte von 1527 an zuerst in Joachimstal, später in Chemnitz als Arzt. Er starb im Jahre 1555.

Das Interesse für den Bergbau und das Hüttenwesen seiner Heimat bewogen Agricola, die Zeit, welche der Beruf ihm übrig ließ, auf die Beobachtung jener Zweige der Gewerbtätigkeit zu verwenden und alles, was er vorfand, mit den mineralogischen

1) Über die Anfänge des Apothekenwesens im frühen Mittelalter siehe S. 294 d. Bds.

2) Es wurde im Jahre 1505 veröffentlicht. Der Titel lautet: „Ein wolgeordnet vĩ nutzlich büchlin wie man Bergwerck siochen und finden sol/von allerley Metall / mit seinen figuren / nach gelegenheyt, des gebijrges / artlych angezeygt / Mit anhangenden Bercknamen / den anfahenden Bergleuten vast dienstlich.“ In dem Buch spricht „Daniel der Bergner stendig / zum jungen Knappjo". Einen Abdruck dieses seltenen Werkes hat die ,Zeitschrift für Bergrecht" in Band XXVI gebracht.

Siehe die Besprechung von O. Vogel in den Nitteilungen z. Gesch. d. Medizin u. d. Naturwiss. 1909. S. 299. Ferner IV. Jacobi, Das älteste Lehrbuch für den Bergbau. Der Erzbergbau. 1909. Heft 3, S. 52. 
Kenntnissen der Alten, deren Schriften ihm bekannt waren, zu vergleichen. Agricolas Aufmerksamkeit wurde auch dadurch auf die Mineralogie gelenkt, daß in der alten Literatur metallische Heilmittel erwähnt werden, deren man sich besonders bei äußeren Krankheiten bediente. Er sammelte daher alle mineralogischen Kenntnisse der Alten in der Hoffnung, damit seinen, im gewerblichen Leben stehenden Zeitgenossen nützen zu können. Zu seinem Erstaunen ward er aber gewahr, daß olne jedes Zutun der zunftmäßigen Wissenschaft in den deutschen Gebirgsländern eine Kenntnis der Metalle, Mineralien und Gesteine, sowie der metallurgischen Prozesse entstanden war, die eine neue, den Alten fast unbekannte Welt bedeutete. Es galt nur, die Erfahrungen, Entdeckungen und Erfindungen, die man im Verlauf des Mittelalters gemacht hatte, in der Sprache der Gelehrten darzustellen, um so eine neue Wissenschaft den früheren anzureihen. „Dies getan zu haben und zwar mit eigener Einsicht und dem unabhängigen Eifer, der allein wissenschaftliche Erfolge zu sichern vermag, ist Agricolas Verdienst. Er hatte das Glück, nicht Anfänge oder zweifelhafte Versuche, sondern erprobte und zusammenhängende Kenntnisse, beinahe Systeme der Mineralogie und der Metallurgie darbieten zu können, die eine Grundlage der späteren Studien geworden sind 1 ). “

Als überzeugter Anhänger der Alchemie kann Agricola nicht betrachtet werden. Jedenfalls sprach er sich offen gegen ihre Grundlehre aus, daß die Metalle aus Sulfur und Mercurius beständen. Auch äußerte er sich über die Möglichkeit der Metallverwandlung sehr zurückhaltend. Die Ergebnisse seiner Bemühungen legte Agricola in mehreren Schriften nieder, die, wie Werner, der Lehrer Alexanders von Humboldt und Leopolds von Buch dankbar anerkannte, das Fundament der Mineralogie bis zur neuesten, insbesondere durch die drei genannten Forscher begründeten Epoche dieser Wissenschaft gewesen sind. Das bedeutendste unter den Werken Agricolas ist das erst im Jahre 1556 vier Monate nach dem Tode des Verfassers erschienene Bergwerksbuch 2). Es bietet ein vollständiges Bild des damaligen

1) Beckmann, Geschichte der Erfindungen. Bd. III.

Siehe auch Ranke, Deutsche Geschichte im Zeitalter der Reformation. Bd. V. S. 348.

2) Agricolas Bergwerksbuch: Übersetzt von Bechius 1621. Vgl. auch Agricolas mineralogische Schriften, übersetzt und mit Anmerkungen von E. Lehmann. Freiburg 1816. Der Titel des Originalwerkes lautet: De re 
Berg- und Hüttenwesens, sowie der Probierkunde und enthält zahlreiche treffliche Holzschnitte, die nicht nur die hïttenmännischen

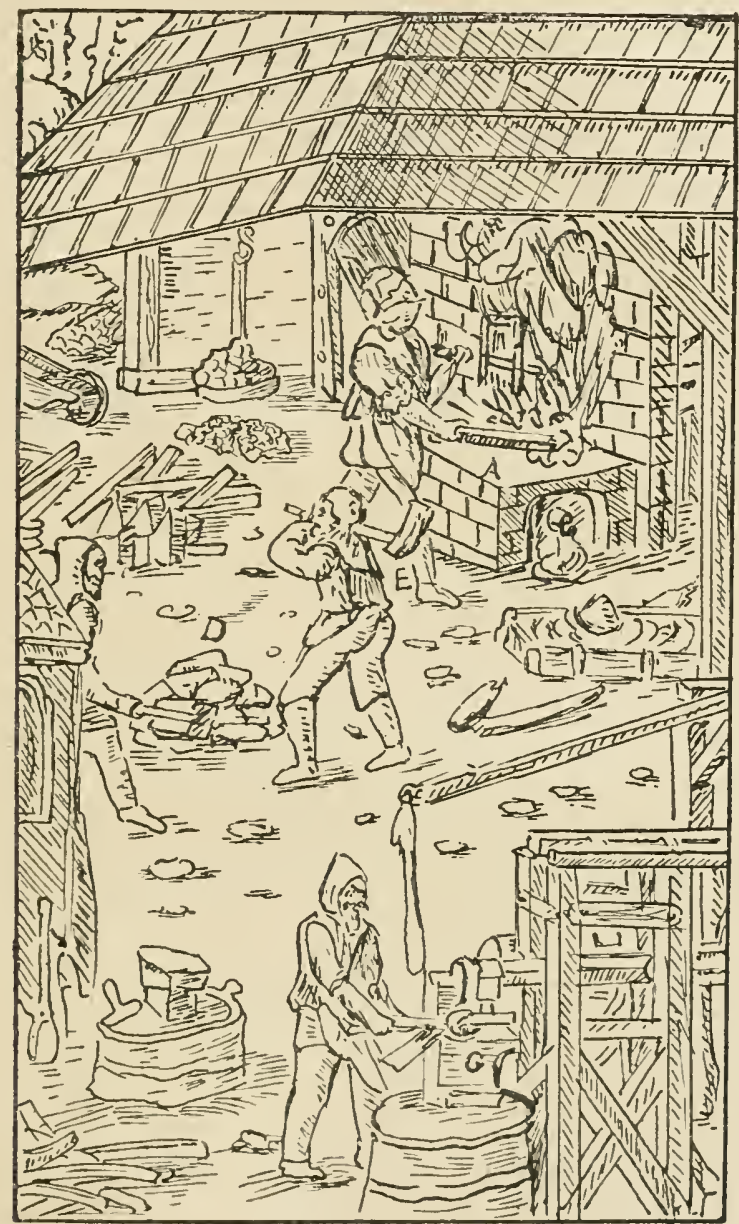

Abb. 63. Hüttenwerk nach Agricola.

Prozesse, sondern auch geologische Einzelheiten, wie Erzgänge, Durchsetzungen, Verwerfungen usw. darstellen.

metallica libri XII. 1556. Ein Jahr nach dem Erscheinen von Agricolas „De re metallica" wurde eine deutsche Übersetzung von $\mathrm{Ph}$. Beek unter dem Titel ,Vom Bergwerk XII Bücher" hcrausgegeben. Sie erlebte mehrere Auflagen $(1580,1621)$. Eine neuere deutsche Übersetzung gribt es nicht, wohl aber eine vorzügliche englische vom Jahre 1912 O. Vogel, Stahl und Eisen. Jahrg. 1916. S. 405 . 
Die Verwendung des Kompasses zu bergmännischen Zwecken wird in dem Buche zum ersten Male geschildert. Agricola bringt auch eine Abbildung des bergmännischen Kompasses. Das Verfahren, mit seiner Hilfe Gruben anzulegen nennt er Marktscheidern. Etwas später begegnet uns die erste ausführliche Anleitung zu dieser Kunst ${ }^{1}$ ).

Die maschinellen Einrichtungen, die Agricola beschreibt, unterscheiden sich nur wenig von den aus dem Altertum bekannten. Doch tritt schon deutlich das Bemühen hervor, an die Stelle der Menschenkraft diejenige der Tiere oder der unorganischen Natur zu setzen. Die Pumpen z. B. werden durch Wasserkraft betrieben, ebenso größere Hämmer, wie die aus Agricolas Werk herrührende Abb. 63 erkennen läßt. Die Ventilationsapparate werden durch den Wind in Bewegung gesetzt usw. Man faßte also im Mittelalter die großen Aufgaben, welche der Technik harrten, schon ins Auge, wenn auch die Lösungen, zu denen man gelangte, noch recht unvollkommen waren ${ }^{2}$ ).

Von den neueren metallurgischen Verfahrungsweisen erwähnt Agricola auch den Amalgamationsprozeß, der für die Ausbeutung der neuentdeckten, an Gold und Silber reichen Länder Amerikas später eine solch große Bedeutung gewinnen sollte. Zwar war man schon im Altertum mit dem Verhalten des Quecksilbers gegen Gold und Silber bekannt. Die Verwendung des erstgenannten Metalles zur Gewinnung der Edelmetalle aus dem Muttergestein blieb jedoch der Neuzeit vorbehalten. Erfunden ist das Amalgamationsverfahren in Deutschland ${ }^{3}$ ). In großem Maßstabe wurde es aber zuerst in Mexiko ${ }^{4}$ ) und in Peru ${ }^{5}$ ) angewandt. D A costa beschrieb es in seiner Natur- und Sittengeschichte Indiens $\left.{ }^{6}\right)$, die uns auch über die ersten Entdeckungen auf botanischem und zoologischem Gebiete Auskunft gibt. Das Silbererz wurde der Einwirkung von Kochsalz und Quecksilber ausgesetzt und das ge-

1) Vom Marktscheiden, kurzer und gründlicher Unterricht durch E. Reinhard. Erfurt 1574 .

2) Über die Anregungen, die der Bergbau im Laufe der Kulturgeschichte der Naturwissenschaft und der Technik gegeben hat, berichtete E. Gerland im Archiv für Geschichte der Naturwissensch. u. der Technik. Jahrg. 1910. S. 301 u. f.).

3) Lindner, Gesch. Bd. IV. S. 431.

4) Seit 1566 .

5) Seit 1574.

6) Historia natural y moral de las Indias. 
wonnene Amalgam durch Erhitzen zerlegt. Agricola bringt auch Mitteilungen über das Erdöl11).

Zu der Zeit, als Agricola schrieb, glaubte man noch allgemein, die Welt sei noch heute im wesentlichen in dem Zustande, in dem Gott sie erschaffen habe. War es doch kein geringes Wagnis, dem in der Bibel entháltenen Schöpfungsbericht zu widersprechen, an dem selbst die Gebildeten damals blindlings festhielten 2). Dem gegenüber vertrat Agricola die Anschauung, daß die Gesteine und die Mineralien den Naturkräften ihren Ursprung verdanken. Durch welche Kräfte er sich die Berge entstanden denkt, schildert er mit folgenden Worten ${ }^{3}$ ): „Da wir sehen, daß die Gänge durch das Gestein der Gebirge gehen, so muß ich zunächst die Entstelıung der letzteren und darauf den Ursprung der Gänge auseinandersetzen. Die Hügel und die Berge werden durch zwei Ursachen hervorgebracht, nämlich durch den Andrang der Gewässer und durch die Kraft der Winde. Zerstört und aufgelöst werden die Hügel und die Berge durch drei Ursachen, denn zu den beiden soeben genannten kommt noch die innere Glut der Erde hinzu.

Daß die Gewässer die meisten Berge erzeugen, liegt klar vor Augen. Sie spülen zunächst die weiche Erde fort. Dann reißen sie die härtere Erde weg und endlich wälzen sie die Steine herab. Indem sie auf diese Weise Höhlungen hervorrufen, bewirken sie in vielen Menschenaltern, daß das stehenbleibende Land bedeutend hervorragt. Von dem steilen Abhang solcher Hervorragungen werden dann durch häufige Regengüsse erdige Massen so lange abgelöst, bis sich ein steiler Abhang in einen geneigten verwandelt." Agricola schildert somit schon ganz zutreffend den talbildenden Vorgang, den man als Erosion bezeichnet, sowie die Abtragung der Gebirge. Hätte er schon eine Vorstellung von der gebirgs-

1) Näheres siehe in den Mitteilungen z. Gesch. d. Med. u. d. Naturwiss. Nr. 59. S. 592 .

2) Diejenigen Stellen der Bibel, welche der Entwicklung der Geologie besonders hinderlich waren, lauten nach der Ausgabe von E. Kautzsch, Die Heilige Schrift des Alten Testaments, 1896, S. 1 und S. 750:

Da sprach Gott: Es sammle sich das Wasser unterhalb des Himmels an einem Ort, so daß das Trockne sichtbar wird. Und so geschah es, und Gott nannte das Trockne Erde, die Ansammlung der Gewässer aber nannte er Meer. (Die Schöpfung der Welt. Text S. 1.)

Ehe die Berge geboren, und die Erde und der Erdkreis, hervorgebracht wurden' und von Ewigkeit zu Ewigkeit bist du, o Gott. (Text S. 750. Ps. 90.)

3) Agricola, De ortu et causis sulterrancorum. Basileac 1546. Liber tertius, p. 36 . 
bildenden Tätigkeit des Vulkanismus gehabt, so würden seine Anschauungen sich den heutigen noch mehr genähert haben. $\mathrm{Er}$ fährt dann fort: „Auch die Vertiefungen, die jetzt die Meere aufnehmen, waren einst nicht sämtlich vorhanden. An vielen Stellen war Land, bevor die Kraft der Winde das in der Brandung aufbrausende Meer in das Land hineintrieb. In gleicher Weise zerstört auch der Andrang der Gewässer die Hügel und die Berge vollständig. Obgleich all diese Veränderungen in großem Maße stattfinden, bemerkt man sie gewöhnlich nicht, da sie infolge der langen Zeiträume, die sie beanspruchen, aus dem Gedächtnis der Menschen schwinden."

Diese Worte erinnern an diejenigen des Aristoteles (S. 124), den Agricola an vielen Stellen seiner Schriften zitiert.

Auch Avicenna (S. 312) hat eine Theorie der Entstehung der Gebirge gegeben, die mit derjenigen Agricolas fast übereinstimmt, weil beide direkt oder durch Vermittlung auf dieselben alten Schriftsteller zurückgingen. Über die Ansichten Avicennas berichtet Lyell $\left.{ }^{1}\right)$.

Danach erwähnt Avicenna als Ursache der Gebirgsbildung die Erdbeben, durch die "Land erhoben wird und einen Berg bildet". Eine weitere Ursache ist nach ihm wie nach Agricola „die Aushöhlung durch Wasser, wodurch Hohlräume entstehen und bewirkt wird, daB das angrenzende Land hervorragt und ein Gebirge bildet".

Die zur Zeit des Wiederauflebens der Wissenschaften unter dem Einfluß der antiken Schriftsteller entstandenen geologischen Elemente fanden ihre Fortsetzung besonders durch Steno, von dem an einer späteren Stelle die Rede sein wird.

Ein Jahrzehnt vor dem Erscheinen des Bergwerksbuches veröffentlichte Agricola sein grundlegendes Buch iiber die Mineralien ${ }^{2}$. In diesem Werk begründete er das erste, auf den äußerlichen Kennzeichen beruhende Verfahren zum Bestimmen der Mineralien. Trotz aller Unvollkommenheiten verdient es doch Beachtung, weil die späteren Versuche ron dem System Agricolas ausgingen. Agricola berücksichtigt Farbe, Glanz, Durchsichtigkeit, Geschmack, Geruch und die Wirkung auf den Tastsinn (Fettigkeit, Glätte, Rauhigkeit usw.). Ferner kommen für ihn als Mittel zur genauen Beschreibung der Mineralien die Zähig-

1) Principles of geology. 11. Aufl. Bd. I. London 1872. S. 27-28.

2) Georgius Agricola, De natura fossilium. Basel 1546. 
keit, Biegsamkeit, Schwere und Spaltbarkeit in Betracht. Seine Angaben über die Gestalt der Mineralien sind noch sehr unbestimmt. Er unterscheidet tafelförmige, eckige (drei- bis sechseckige und vieleckige) und gewissen Gegenständen ähnliche Mineralien (pfeilförmig, sternförmig, linsenförmig usw.). Die Brauchbarkeit dieser Übersicht wurde für spätere Mineralogen dadurch erhöht, daß jedes der erwähnten Kennzeichen nicht nur angegeben, sondern durch typische Mineralien erläutert und auf diese Weise gute Vergleichspunkte geschaffen wurden.

Schon während des Altertums hatte man die Versteinerungen von den Mineralien unterschieden und erstere ganz richtig als die Überreste organischer Wesen gedeutet. Im Mittelalter dagegen war man auf Grund der aristotelischen Lehre von der elternlosen Zeugung niederer Tiere zu der sonderbaren Vorstellung gelangt, daß die Versteinerungen einem im Erdinnern wirkenden Bildungstrieb, einer vis plastica oder formativa, ihren Ursprung verdankten ${ }^{1}$ ). Es dauerte Jahrhunderte, bis die im 15. Jahrhundert wieder auflebende Wissenschaft sich von dieser Lehre frei zu machen wußte. Thren letzten Ausläufern begegnen wir sogar noch um die Mitte des 18. Jahrunderts. Nach Agricolas Auffassung waren also die Versteinerungen Überreste ron Organismen. Insbesondere macht A gricola diesen Ursprung für fossiles Holz, Blattabdriicke, Knochen und die bekannten Fischabdrücke des Mannsfelder Kúuperschiefers geltend. Dagegen hält er die in den Gesteinen eingeschlossenen Muscheln, Ammonshörner und Belemniten für „verhärtete Wassergemenge."

Auch in Frankreich und in Italien, wo es geringere Schwierigkeiten bot, die Ähnlichkeit fossiler Konchylien mit noch jetzt in den benachbarten Meeren lebenden Arten zu erkennen, neigten aufgeklärte Zeitgenossen Agricolas der richtigen Annahme zu, daß die Versteinerungen organischen Ursprungs seien. Erst als die Geologie ihr Hauptziel in der Deutung des mosaischen Schöpfungsberichtes erblickte und die Versteinerungen für die wichtigsten Zeugen der Sintflut ausgab, fand diese Lehre allgemeinen Anklang. Die heute geltende Ansicht findet sich wohl zuerst bei Lionardo da Vinci und vor allem bei dem in Verona lebenden Arzt Fra-

1) Als Begründer dieser irrigen Ansicht ist Avicenna (980-1037) zu betrachten. Auch Albertus Magnus huldigte ihr. Doch meinte er, Tiere und Pflanzen könnten auch wohl an solchen Orten zu Stein erhärten, wo eine steinmachende Kraft vorbanden sci. (Zittel, Geschichte d. Geol, u. Paläont. 1899. S. 15.) 
castoro (1483-1553) ganz klar ausgesprochen. Als man in Verona, bei der Errichtung von Bauten, Muscheln aus dem Erdinnern zutage förderte, erklärte Fracastoro, daß es sich hier weder um die Schöpfungen einer vis plastica noch um Zeugen der Sintflut handeln könne. Etwaige Beweisstücke einer allgemeinen Überflutung müßten nämlich, wie er ausführt, die Oberfläche der Erde bedecken, während die gefundenen Dokumente tief im Boden gefunden seien. Als einzige Annahme bleibe übrig, daß die Versteinerungen von Geschöpfen herrühren, die an der Stelle, wo sie sich befinden, frïher gelebt haben und so erkennen lassen, daß das Meer einst dort wogte, wo jetzt festes Land ist.

Um die Mitte des 16. Jahrhunderts begegnen uns auch die ersten, mit Abbildungen versehenen Werke über Versteinerungen, unter denen dasjenige Gesners, des deutschen Plinius, hervorzuheben ist $\left.{ }^{1}\right)$. Allerdings gelangte auch er hinsichtlich der Versteinerungen $\mathrm{zu}$ keiner klaren Ansicht. Er vergleicht sie zwar mit Pflanzen und Tieren, ohne sie indessen bestimmt als Überreste organischer Wesen anzusprechen 2 ).

Den Standpunkt Fracastoros vertrat unter den Schriftstellern, die im 16. Jahrhundert über Gegenstände der Geologie schrieben, vor allem der Franzose Bernhard Palissy. In einem, klares Denken und vorurteilsfreie Beobachtung bezeugenden Werke weist er darauf hin ${ }^{3}$, daß manche Versteinerungen den noch jetzt lebenden Tieren und Pflanzen gleichen und offenbar an Orten entstanden sind, die früher vom Meere oder von süßem Wasser bedeckt waren $\left.{ }^{4}\right)$.

Die häufig anzutreffende Annahme, daß Lionardo da Vinci, Fracastoro und Palissy lediglich durch eigenes, vorurteilsfreies Denken zu richtigen Vorstellungen über die Versteinerungen und den Wechsel von Meer und Land gekommen seien, ist nicht zutreffend. Auch diese Männer empfingen die Anregung zu ihren Spekulationen ganz offenbar aus den Schriften der Alten, besonders aus den Büchern des Aristoteles, welche der Neuzeit die Vorstellungen übermittelten, zu denen die griechischen Forscher,

1) Konrad Gesner, De omni rerum fossilium genere. 1565.

2) Zittel, Geschichte der Geologie und Paläontologie. 1899. S. 18.

3) Palissy, Discours admirable de la nature des eaux et fontaines, des métaux, des sels et salines, des pierres, des terres, du feu et des émaux. Paris 1580. Nach E. v. Lippmann wird seine Originalität neuerdings stark bezweifelt.

4) Zittel, a. a. O. S. 22 . 
besonders Demokrit, in geologischen Dingen gelangt waren. Palissy bedient sich in seinem "Discours admirable" betitelten Buche der Form des Dialogs. Seine eigenen Ansichten legt er der "Praxis", die gegnerischen der "Theorie" in den Mund. Auf cinen Einwurf der "Theorie" antwortet Palissy: „Wie wäre es möglich, daß Holz sich in Stein verwandelt, wenn es sich nicht längere Zeit in mineralhaltigen Gewässern befunden hätte. Wären letztere nicht ebenso flüssig und fein wie die gewöhnlichen, so hätten sie nicht in das Holz eindringen und es in allen seinen Teilen durchtränken können, ohne ihm irgendwie seine ursprüngliche Form zu nehmen. Wie das Holz, so wurden auch die Muscheln in Stein verwandelt, ohne ihre Form zu verlieren".

Palissy war ein einfacher Töpfer. Er hatte indessen bei dem gelehrten Cardanus gelesen, daß die Schalen der Muscheln an vielen Orten dadurch versteinert seien, daß die Substanz sich änderte, während die Form erhalten blieb $\left.{ }^{1}\right)$. Wie es kommt, daß die versteinerten Organismen sich nicht nur an der Oberfläche der Erde finden, sondern das ganze Gebirge durchsetzen, schildert Palissy zutreffend mit folgenden Worten: „Die versteinerten Organismen wurden an demselben Orte erzeugt, an dem wir sie finden und zwar zu einer Zeit, während sich an der Stelle der Felsen nur Schlamm und Wasser vorfand. Letzterer ist seitdem mit den Organismen versteinert. Und zwar versteinerten die Erde und der Schlamm durch dieselbe Kraft, die auch die Fossilien erzeugt hat, nämlich durch die alles durchdringenden Minerallösungen." In einem Punkte urteilt Palissy richtiger als Cardanus. Letzterer glaubte nämlich mit den meisten Gelehrten seiner Zeit, soweit sie nicht die Versteinerungen für bloße Naturspiele oder "Schöpfungsübungen Gottes" hielten, die versteinerten Organismen seien Überbleibsel einer die gesamte Erde bis zu den Spitzen der Berge bedeckenden Flut, also gewissermaßen Zeugen der Sintflut. Gegen diese Ansicht wendet sich Palissy mit dem Hinweis darauf, daß sich die Fossilien nicht nur an der Oberfläche der Erde befänden, sondern auch an den tiefsten Stellen, an die man durch das Ausbrechen der Steine gelange. „Durch welches Tor", fragt er seine Gegner, „drang denn das Meer ein, um die Fossilien in das Innere der dichtesten Felsen zu tragen?"

1) Nach Löwenheim stimmen Palissy und Cardanus mitunter fast wörtlich überein. Siche S. 74 u. 75 . 


\section{Die ersten Ansätze zur Neubegründung der organischen Naturwissenschaften.}

Nicht nur für die anorganischen Naturwissenschaften, einschließlich der Mineralogie und der Geologie, wurden im 16. Jahrhundert Grundlagen geschaffen, auf denen sich mit Erfolg weiter bauen ließ, sondern das Gleiche gilt anch von den übrigen Gebieten der Naturbeschreibung, der Botanik, der Zoologie, sowie der Lehre vom Bau und von den Verrichtungen des menschlichen Körpers. Diese Gebiete wurden zunächst durch das Bekanntwerden der auf sie bezüglichen Schriften der Alten zu neuem Leben erweckt. Dann trat aber für sie noch ein zweiter gïnstiger Umstand hinzu. Infolge der Entdeckungsreisen und durch die daran sich anknüpfenden neuen Handelsverbindungen wurde nämlich die europäische Menschheit mit einer solchen Fïlle neuer Naturerzeugnisse bekannt, wie es nie zuvor in gleichem Maße geschehen war.

\section{Naturbeschreibung und Entdeckungsreisen.}

Die Geschichte der Entdeckungsreisen gilt schon in der üblichen, mehr das Persönliche und Zufällige schildernden Darstellung als eine der fesselndsten Episoden der Weltgeschichte. Sie gewinnt aber außerordentlich an allgemeinem Interesse, wenn wir sie in ursächliche Beziehung zu dem Gange der wissenschaftlichen Entwicklung setzen. Letztere ist es, welche die Entdeckungsreisen bedingt hat, um andererseits durch sie auch wieder den gewaltigsten Impuls zu empfangen.

Wir haben schon an anderer Stelle erfahren, daß die Schifffahrt gegen den Ausgang des Mittelalters durch die Einführung des Kompasses, sowie die Entwicklung der Astronomie und der auf astronomischen Prinzipien beruhenden nautischen Instrumente viel von ihren Gefahren und Zufälligkeiten verloren hatte. Infolgedessen vermochte die Nautik sich auch weitere Ziele zu stecken. Da der Verkehr zu Lande mit den südlichen und östlichen Teilen 
Asiens, die ja schon im Altertum in den Gesichtskreis der Europäer getreten waren und für Europa gegen den Ausgang des Mittelalters immer mehr an Bedeutung gewannen, in hohem Grade mühsam, kostspielig und gefährlich war, so regte sich in weiterschauenden Männern der Gedanke, ob jene asiatischen Länder nicht durch eine Fahrt nach Westen oder durch eine Umschiffung Afrikas zu erreichen seien. Dieser Gedanke fand den günstigsten Boden in Portugal und Spanien, die durch ihre Lage mehr als Italien auf das offene Meer hinausgewiesen waren und durch das Übergewicht, das Venedig im Mittelmeere ausiibte, auf neue Wege für ihren Handel hingedrängt wurden.

In Portugal wurde dieses Streben besonders durch Heinrich "den Seefahrer"1) unterstuitzt. Um diesen scharten sich gelehrte und kühne Männer, unter anderen der Geograph und Astronom Martin Behaim ${ }^{2}$ ) aus Nürnberg. Um die Mitte des 15. Jahrhunderts begann das Vordringen entlang der Westkiiste Afrikas. Das Auftauchen bewaldeter Vorgebirge zerstörte zunächst das mittelalterliche Vorurteil, daß in der Nähe des Äquators alles Leben von der Glut der Sonne versengt sei. Ferner bemerkte man, daß die Küste Afrikas immer weiter nach Osten zurückweicht, wodurch die Hoffnung, einen östlichen Seeweg nach Indien zu entdecken, neue Nahrung empfing. Durch Bartholomeo Diaz, der 1486 die Südspitze des dunklen Erdteils erreichte, und durch Vasco da Gama, der 1498 nach der Umschiffung Afrikas in Ostindien landete, wurde diese Hoffnung endlich verwirklicht. Rasch breiteten sich die Herrschaft und der Handel der Portugiesen über das südliche Asien und die im Südosten dieses Kontinentes gelegenen Inseln aus.

Mit welcher Fülle von neuen Naturerzeugnissen die europäische Menschheit dadurch bekannt wurde, kann hier nur angedeutet werden. An den Küsten und auf den Inseln Ostafrikas fielen besonders die gewaltigen Dracaenen und der riesige Brotfruchtbanm (Adansonia digitata) auf. In Ceylon gelangte man in den Besitz der Zimtwälder. Man wurde mit der wunderbaren maledivischen NuB, mit dem Gewiirznelkenbaum und denjenigen Pflanzen bekannt, welche die Muskatnüsse, den Kampfer, Benzoe, Indigo, Strychnin usw. liefern. In nicht geringerem Maße wurde die Wissenschaft durch die Entdeckung zahlreicher nener. 'Tier-

1) Den jüngsten Sohn König Johanus des Ersten.

2) Siehe S. 399 . 
formen bereichert. Und der gelehrte Clusius (geb. zu Arras 1526) unternahm es, das Wichtigste über die neuen fremdländischen Naturerzeugnisse zusammenzustellen ${ }^{1}$ ). Bei Clusius begegnen uns zum ersten Male, in Abbildungen und Beschreibungen, der fliegende Hund, der Molukkenkrebs, die gewaltigen, plumpen, zur Ordnung der Waltiere gehörenden Sirenen, der heute ausgestorbene Dodo, jener unbeholfene Vogel, den Vasco da Gama auf den Mascarenen in so großer Menge antraf. Auch die Bewohner Amerikas, seine Faultiere, Gürteltiere und Kolibris und endlich die so abenteuerlich gestalteten Fische, die das Meer der Tropen beleben, schildert Clusius.

Den Portugiesen wurde der indische Handel durch die Niederländer entrissen, deren Seegeltung so machtvoll emporwuchs, nachdem sie das spanische Joch abgeschüttelt hatten. Die wissenschaftliche Erforschung der neuentdeckten Länder nahm unter diesem Volke, das auch daheim den regsten wissenschaftlichen Sinn bekundete, einen bedeutenden Aufschwung. War doch auch Clusius ein Niederländer.

Der Gedanke, durch eine Seefahrt nach WVesten die Küsten Ost- und Südasiens zu erreichen, tauchte im Renaissancezeitalter zuerst in dem Florentiner Astronomen Toscanelli (1397-1482) auf. Dieser Mann, der auch durch seine Einwirkung auf Nicolaus von Cusa zum Wiederaufleben der Astronomie in Deutschland beigetragen hatte, wußte den großen Genuesen, dem Europa die Entdeckung der westlichen Hemisphäre verdankt, für seinen Gedanken zu erwärmen. Dennoch sollten zehn Jahre nach dem Tode Toscanellis verfließen, bis Columbus nach Überwindung zahlloser Schwierigkeiten in Westindien landete. Schon auf der ersten Reise wurde man mit dem Tabak, der Yamswurzel und dem Mais bekannt. Bald folgte die Entdeckung der Ananas, von Agave Americana, Theobroma Cacao, der Batate, der Sonnenblume, von Manihot und zahlreichen anderen, wichtigen und charakteristischen amerikanischen Pflanzen.

Nachdem Cabot (1497) das nordamerikanische Festland, Cabral (1500) Brasilien entdeckt hatten, und Cortez und Pizzaro erobernd in das Innere des neuen Kontinentes eingedrungen waren, begann eine sorgfältige naturgeschichtliche Erforschung der entdeckten Länder. Vor allem waren es gelehrte Kleriker, die sich dieser Aufgabe mit Eifer und Erfolg widmeten. So schrieb der

1) Exoticorum libri $\mathrm{X}$. 
Jesuit d'Acosta eine "Natur- und Sittengeschichte der Indier", in der auch die gewaltigen fossilen Knochen Suidamerikas Erwähnung finden. d'Acosta hielt sie für Überreste von Riesen und erörtert ganz ernsthaft die Frage, wie die Tiere Amerikas nach ihrem heutigen Wohnsitz gelangten, da sie doch in der Arche Noahs eingeschlossen gewesen seien.

Mit noch größerem Eifer als den Pflanzen und den Tieren wandte man sich den Bodenschätzen der neu entdeckten Länder zu. In Mexiko und Peru wurde der Bergbau bald mit so großem Erfolge betrieben, diı die Einfuhr des dort gewonnenen Edelmetalls in Europa umgestaltend auf die wirtschaftlichen Verhältnisse dieses Erdteils wirkte. Auf die Erschließung des neuen Kontinentes folgte ein Austausch seiner Erzeugnisse mit denjenigen der alten Welt. So wird der Tabak schon 1559 in Portugal gebaut1), um in Europa zunächst als Mittel gegen Geschwiire Verwendung $z u$ finden. $Z u$ den ersten, die ihn rauchten, gehörte der große Naturforscher Gesner. Die neue Welt empfing dagegen u. a. den Kaffeebaum, das Zuckerrohr und die Obstarten.

Hand in Hand mit der unendlichen Bereicherung, welche die Wissenschaft durch die Entdeckungsreisen erfuhr, ging ein Aufschwung der gesamten Kultur und eine Erweiterung des gesamten Gesichtskreises, wie ihn kein früheres oder späteres Zeitalter erfahren. Der Handel hörte auf, das Privilegium einiger mächtigen süd- und mitteleuropäischen Städte zu sein und wurde Welthandel. Die Mittelmeerländer waren nicht fürder eine Welt für sich, sondern die ganze Erde wurde zu einer Domäne der weißen Rasse. Und innerhalb dieser Rasse erlangte endlich immer mehr das germanische Element das Übergewicht. Waren doch die Völker germanischen Stammes den Romanen an Tatkraft überlegen, an Intelligenz mindestens gleichwertig, und endlich durch ihre Wohnsitze am offenen Weltmeer auf die Fortentwicklung des durch die Entdecker und Konquistadoren eröffneten Welthandels ganz besonders hingewiesen. Alles Momente, welche in Verbindung mit der im nördlichen Europa entstehenden Glaubens- und Gewissensfreiheit, die Verpflanzung der in Italien wiedergeborenen Wissenschaft nach Mittel- und Nordwesteuropa ganz besonders begünstigten.

1) Sprengel, Geschichte der Botanik. Bd. I. S. 352 . 


\section{Die Erneuerung der Botanik.}

Wir wenden uns nach diesen allgemeineren Ausführungen den organischen Naturwissenschaften im einzelnen zu. Daß man im Zeitalter der Renaissance und der Entdeckungsreisen die Augen öffnen lernte und die Fesseln des Autoritätsglaubens und der Büchergelehrsamkeit abstreifte, ist für die weitere Entwicklung der beschreibenden Naturwissenschaften von großem Einfluß gewesen. Waren diese Wissenszweige früher nur nebenbei und meist zu Heilzwecken gepflegt worden, so bot sich jetzt eine solche Fiille von neuem Material, daß die Tätigkeit derjenigen, die sich der Naturbeschreibung wirmeten, dadurch vollauf in Anspruch genommen wurde. Damit trat die Beziehung dieser Fächer zur Heilkunde, ihrer eigenen Bedeutung gegenüber, allmählich zurïck.

Besonders fiir die Botanik trat im 16. Jahrhundert der Zeitpunkt ein, in dem dieser Wissenszweig sich über die Grenzen der Heilmittellehre hinaus entwickelte, da man die Pflanzen ihrer selbst wegen zu betrachten begann $\left.{ }^{1}\right)$. Auch wurde mit dem lange herrschenden Vorurteil gebrochen, als hätten die Alten schon die ganze Fülle der Pflanzenwelt erschöpft. Der Trieb nach eigener wissenschaftlicher Betätigung äußerte sich auf botanischem Gebiete in diesem Zeitalter vor allem darin, daß eine Anzahl von Spezialfloren mit Abbildungen, die sogenannten Kräuterbuicher, entstanden. In weiten Kreisen wurde diesen Erzeuguissen des emporblühenden Buchgewerbes Interesse entgegengebracht. Infolgedessen verwandten die Verleger die größte Sorgfalt auf die Ausstattung der Kräuterbücher mit musterhaften Abbildungen. Und in dem Maße, wie die Kunst des Holzschnittes auf diesem Gebiete Fortschritte machte, nahm anch die Fähigkeit des Beschreibens mit zutreffenden Worten einen Aufschwung. Infolge der wachsenden Pflanzenkenntnis und der Verschärfung der Beobachtung wurde aber auch die natiirliche Verwandtschaft immer mehr durchgefühlt, so daß man häufig zur Vereinigung verwandter Arten zu Gattungen, ja selbst ähnlicher Gattungen zu familienähnlichen Gruppen gelangte. Einen Ansatz zu dieser Art von Systematik hatte zwar schon das Altertum zu verzeichnen, indem z. B. Theophrast verschiedene Arten von Eichen, Fichten usw. zusammenfaßte. Da jedoch die allgemeine Botanik, abgesehen von dem vereinzelt gebliebenen Bemïhen des Albertus Magnus, keine Fortschritte

1) E. Meyer, Geschichte der Botanils. Bd. IV. S. 290. 
gemacht hatte, so verfuhr man bei diesen ersten Schritten an der Schwelle der Neuzeit mehr intuitiv, ohne imstande zu sein, die gewonnenen Begriffe durch klare Definitionen festzuhalten.

Der im vorstehenden kurz gekennzeichnete Fortschritt der Botanik ist vor allem das Verdienst einiger deutschen Gelehrten, die man wohl als die Väter der Pflanzenkunde bezeichnet hat. Sie heißen Brunfels, Bock und Fuchs. Mit demselben Rechte, mit dem man Agricola den Vater der neueren Mineralogie genannt hat, kann man die Genannten als die Begriinder der neueren Botanik bezeichnen. Ihre Kräuterbiicher wurden dadurch veranlaßt, daß die kommentatorischen Bemiihungen, die man auf die botanischen Werke der Alten verwendet hatte, aus mehreren Gründen gescheitert waren. Bei dem Glauben an die Unfehlbarkeit der Alten war man nämlich an ihre botanischen Schriften in der Meinung herangetreten, daß die darin abgehandelten Pflanzen das gesamte Pflanzenreich darstellten. Des weiteren suchte man die von den Alten beschriebenen Pflanzen, ohne von der geographischen Verbreitung eine klare Vorstellung zu besitzen, in Mitteleuropa, wo sie bei der bedeutenden Verschiedenheit der Floren Griechenlands und Deutschlands nur zum kleinsten Teil gefunden werden konnten. Erst als man die Unhaltbarkeit jener Voraussetzungen einsah, verlegte man sich auf das genaue Beschreiben derjenigen Gewäclıse, die man in der Heimat vorfand.

An der Spitze der neueren Botaniker steht Otto Brunfels. Brunfels wurde um 1490 in der Nähe ron Mainz geboren und empfing dort gelehrten Unterricht. Nachdem er einige Zeit ein Schulamt bekleidet, erwarb er die Würde eines Doktors der Medizin 1). Sein Hauptverdienst um die Botanik besteht darin, mit Hilfe eines hervorragenden Künstlers die erste Sammlung naturgetreuer, künstlerisch vollendeter Pflanzenabbildungen herausgegeben zu haben. Das TVerk erschien unter dem 'Titel „Herbarum vivae eicones" im Jahre 1532. Es enthielt melırere hundert Abbildungen in so sicheren Umrissen, daß die dargestellten Pflanzen

1) Eine ausführliche Schilderung des Lebenslaufes von Brunfels und seiner Verdienste um die Botanik enthält die Abhandlung von F. W. E. Roth: „Otto Brunfels, 1489-1534, ein deutscher Botaniker". Botanische Zeitung 1901. S. 191 u. f. Brunfels trat als Kartäusermönch mit den bedeutendsten Humanisten, darunter mit Ulrich von Hutten, in Verbindung. Mit Hilfe des letzteren entfloh Brunfels dem Kloster, um offen als Lutheraner auf:utreten. Später wirkte er als Lehrer am Gymnasium in Straßburg. Er starb im Jahre 1534, nachdem er einige Jahre vorher die medizinische Doktorwürde erworben batte. 
gar nicht rerkannt werden konnten. Es handelte sich dabei in erster Linie um die wildwachsenden, häufiger vorkommenden Pflanzen der oberrheinischen Tiefebene.

Der Text, den Brunfels diesen Abbildungen beigegeben, ist von geringerem Wert. Er lehnt sich noch in der Hauptsache an die älteren Schriftsteller an und ist bestrebt, die heimatlichen Pflanzen mit den von Dioskurides, Plinius und Galen beschriebenen zu identifizieren. Brunfels gab seinem Kräuterbuche folgende Einrichtung. Unter jede Abbildung setzte er zuerst einen deutschen Namen. Hinzugefügt wurden dann die lateinischen und die griechischen Benennungen, sowie Angaben aus Theophrast, Dioskurides, Plinius usw. Den Schluß bildeten Mitteilungen iiber die Wirkungen der Pflanzen.

Gewisse Versuche, die heimatlichen Pflanzen naturgetreu abzubilden, wurden übrigens in Deutschland schon vor Brunfels im 15. Jahrhundert gemacht. Vorbildlich war nach dieser Richtung vor allem die Kunst eines Albrecht Dürer (1471-1528). Die Pflanzendarstellungen, die sich auf seinen Gemälden, sowie denjenigen mancher älteren deutschen Künstler finden, waren recht naturgetreu. Dürer liebte es, auf seinen Bildern als Beiwerk Pflanzen und Tiere zu malen. Er folgte darin einem damals herrschenden Brauche. Im ganzen hat Dürer etwa 180 verschiedene Pflanzen und Tiere dargestellt. Zumal im reiferen Alter des Künstlers zeigen diese Bilder, wie z. B. Veilchen, Pfingstrosen, Lilien usw., einen unübertrefflichen Grad von Naturwahrheit. „Dürer gebührt daher in der Geschichte der naturkundlichen Illustration, die freilich erst geschrieben werden muß, ein dauernder Ehrenplatz"1).

Kunst und Wissenschaft wetteiferten somit darin, die Naturkunde wieder auf eigene Beobachtung zu gründen und sich von den überkommenen Schriften der Alten, die bis zum 15. Jahrhundert als einzige Quelle dem Studium zugrunde gelegt wurden, frei zu machen. Daß trotzdem der neueren Wissenschaft nur nach und nach die Flügel wuchsen, hat die verschiedensten Gründe.

Ein Mitarbeiter des Brunfels ist Hieronymus Bock ${ }^{2}$. Bock wurde 1498 in der Nähe von Zweibrücken geboren, studierte

1) S. Killermann, Dïrers Pflanzen- und Tierzeichnungen und ihre Bedeutung für die Naturgeschichte. Heft 119 der Studien zur deutschen Kunstgeschichte. Mit 22 Tafeln. Straßburg 1910.

2) Brunfels lernte, wahrscheinlich im Jahre 1533, die Sammlungen Bocks kennen und veranlaßte ihn zur Herausgabe des Kräuterbuches. 
alte Sprachen und wurde durch den Pfalzgrafen von Zweibrücken mit der Aufsicht iiber dessen Garten betraut. Zu gleicher Zeit bekleidete er die Stelle eines Lehrers. Bock stellte botanische Wanderungen in der Eifel, dem Hunsrïck, den Vogesen, dem Jura, den Schweizer Alpen an und beobachtete überall die dort wachsenden Pflanzen mit der größten Sorgfalt. Sein Fehler, dem jedoch sein Zeitgenosse Fuchs, wie wir gleich lören werden, entgegentrat, bestand darin, daß er den ron ihm aufgefundenen Pflanzen griechische und lateinische Namen der alten Botaniker beilegte, mit welchen diese ganz andere, in Südeuropa heimische Gewächse bezeichnet hatten.

Bock wagt sogar den Versuch einer natürlichen Anordnung und stellt zum Beispiel die Lippenblüter, die Kompositen und die meisten Kreuzbliiter zusammen. Das Werk, das ihn in der Geschichte der Botanik unsterblich gemacht hat, fülurt den Titel ..New Kreutterbuch"1). Es erschien zuerst im Jahre 1539, und zwar ohne Abbildungen, während die späteren Auflagen mit solchen versehen waren. Die Abbildungen Bocks bleiben hinter denjenigen des Brunfels zurïck, dafür hat es aber Bock in der Kunst des Beschreibens viel weiter gebracht als jener, so daß er sich den Ruhm erwarb, er vermöge in seinen Beschreibungen die Natur wirklich zu malen. Vor allem versteht es Bock, den ganzen Habitus der Pflanze vortrefflich zu beschreiben, während er auf die Beschreibung der Blumen und Früchte geringere Sorgfalt verwendet. Auch berücksichtigt er keine Pflanze, die er nicht selbst gesehen, "soviel dersclben im Teutschen Land ihm zu handen gestoßen". Auch das Vorkommen und die Zeit des Bliihens der beschriebenen Pflanzen findet man berücksichtigt. Ferner erklürt sich Bock entschieden gegen die alphabetische Anordnung, durch wclche ähnliche Pflanzen getrennt würden. Im ganzen hat Bock sechshundert PHanzen beschrieben.

Als Probe möge hier seine Beschreibung der Ackerwinde (Convolvulus arrensis) und der Zaunwinde (Convolvulus sepium) Platz finden. Sie lautet: „/wei gemeine Windenkrïuter wachsen in unserem Land allenthalben mit weißen Schellen- oder Glockenblumen. Das größte sucht seine Wolınung gern bei den 'Zäuncn, kriecht ïber sich, wickelt und windet sich. Das kileine Glockenkraut (C. arvensis) ist dem großen in der Wurzel, den runden

1) Hieronymus Bock (1498-1554;, New Kreuterbuch von Underscheidt, Würkung und Namen der Kreuter, so in teutsehen Lauden wachsen. 
Stengeln, den Blättern und den Glocken gleich, in allen Dingen aber dünner und kürzer. Etliche Glockenblumen an diesem Gewächs werden ganz weiß, etliche schön leibfarben, mit braunroten Strömlein gemalt. Diese wachsen in dürren Wiesen und Gärten. Es schadet dadurch, daß es mit seinem Kriechen und Umwickeln andere Gartenkräuter zu Boden drückt. Auch ist es schwer auszurotten".

Die Anordnung der Pflanzen in den Kräuterbüchern war meist die alphabetische. Allmählich entwickelte sich aber auf Grund der zahllosen Einzelbeobachtungen das Gefühl für die Zusammengehörigkeit des Älınlichen und damit die Voraussetzung zur Begründung eines natürlichen Systems. So wurden bald die Nadelhölzer, die Lippenblüter, die Korbblüter und andere Familien als natürliche Gruppen herausgefühlt, ein großer Fortschritt gegen die Einteilung in Bäume, Sträucher und Kräuter, der wir im Altertum zumeist begegnen. Das medizinische Element nahm jedoch in den Kräuterbiichern immer noch einen breiten Raum ein, wie es auch bei der Anlage botanischer Gärten maßgebend war. Naiv genug mutet uns noch manches in den Kräuterbüchern, diesen Erstlingserzeugnissen der neueren botanischen Wissenschaft an. So beginnt Bock mit folgenden Worten: „Nach Erkundigung aller Geschrift erfindet sichs klar, daß der allmächtige Gott und Schöpfer der allererste Gärtner, Pflanzer und Baumann aller Gewächse ist." Sodann wird Adam als der zweite Botaniker gepriesen, weil er alle Pflanzen mit ihrem rechten Namen belegt habe. Auf ihn folgen die Botaniker Kain, Noah usw.

Als dritter in der Reihe der Begründer der neueren Botanik ist der Bayer Leonhard Fuchs zu nennen. Fr wurde 1501 geboren, studierte wie seine Vorgänger Medizin und alte Sprachen und gab im Jahre 1542 seine berühmte „Historia stirpium“, eine Beschreibung vieler in Deutschland wild wachsender Pflanzen heraus, zu denen noch etwa 100 Gartenpflanzen kamen. Das Werk stellt sich denjenigen von Bock und Brunfels als ebenbürtig an die Seite. Fuchs war ein sehr gelehrter Mann. Seine eindringende Gelehrsamkeit ließ ilın die Mängel, die den arabischen Schriften über Medizin und Botanik und ihren lateinischen Nachahmungen anhafteten, klar erkennen. Er drang deshalb darauf, daß man in der Medizin auf die griechischen Urschriften, in der Botanik aber auf die Natur selbst zurückgehen solle. Letzteres erschien ihm als der einzige Ausweg, aus der Verwirrung heraus- 
zukommen, welche durch die Übertragung der alten Pflanzennamen auf die heimatlichen Gewächse entstanden war ${ }^{1}$ ).

Unter den Botanikern des 16. Jahrhunderts ist auch der Niederländer Dodonaeus zu nemnen, wie denn überhaupt die Niederländer frühzeitig unter den Neubegründern der Naturwissenschaften und der Philosophie hervorragten, eine Erscheinung die sicherlich in der geographischen Lage des Wohnsitzes und in der staatlichen und religiösen Entwicklung dieses Volkes begründet ist.

Dodonaeus wurde 1517 in Mecheln geboren. Sein Hauptwerk $\left.{ }^{2}\right)$, „Die Naturgeschichte der Gewächse“, erschien im Jahre 1583. Was Dodonaeus unter den zeitgenössischen Botanikern besonders hervorhob, war das bewußte Streben, eine wissenschaftliche Anordnung der Pflanzen zu finden. Zwar blieb es bei einem rohen Versuch, doch hat er viele Gattungen und Familien und manche wenig ins Auge fallende verwandtschaftliche Beziehungen der Pflanzen schon erkannt. Die Pflanzen, die er beschreibt, gehören teils der heimatlichen Flora an, teils sind sie den Gärten entnommen, die von den Niederländern schon damals sehr gepflegt und infolge der ausgedehnten Handelsbeziehungen dieses Volkes mit mancher seltenen Art versehen wurden $\left.{ }^{3}\right)$. Selbst Dodonaeus vergleicht noch die ihm vorliegenden Pflanzen mit den von den alten Schriftstellern erwähnten. Doch hindert ihn das nicht, seine eigenen Beschreibungen auf genaue und eingehende Beobachtungen zu stützen, so daß seine Beschreibungen ausführlicher als diejenigen irgendeines seiner Vorgänger ausgefallen sind.

Weit vielseitiger und vorgeschrittener als die genannten Männer war der große Polyhistor Konrad Gesner, ein Mann, der für

1) Einige der von Fuchs zum ersten Male abgebildeten deutschen Arten seien hier aufgezählt: Ligustrum vulgare, Salvia pratensis, Hordeum vulgare, Avena sativa, Convolvulus arvensis, Lysimachia Nummularia, Cyclamen europaeum, Lilium candidum, Paris quadrifolia, Daphne Merzereum, Saponaria officinalis, Euphorbia Cyparissias, Prunus spinosa, Clematis Vitalba, Ranunculus acris, Digitalis purpurea, Genista tinctoria, Orchis Morio, Equisetum arvense, Pteris aquilina usw.

2) Dodonaei stirpium historiae pemptades sex sive libri XXX. Antwerpiae, ex officina Christophori Plantini, 1583, in fol.

3) Von der Einführung amerikanischer Pflanzen handelt S. Killermann in der Naturwiss. Wochenschrift. 1909. S. 193. Danach ist der Mais in der ersten Hälfte des 16. Jahrhunderts nach Europa gekommen. Die Agave americana wurde nach Caesalpin 1561 eingeführt. Weitere Angaben finden sich über Nicotiana tabacum, Solanum tuberosum, Capsicum annuum usw.

Mitgebracht hat den Mais übrigens schon Columbus, wie er (nach E. v. Lippmann) selbst bezeugt. 
sein Zeitalter etwa die Bedeutung besaß, wie sie Albert dem Großen für das 13. Jahrhundert beizumessen ist. Konrad Gesner wurde im Jahre 1516 in Zürich als der Sohn eines armen Kürschners geboren. Er erhielt jedoch mit Unterstützung seines Oheims eine gute Schulbildung. Sein Oheim, der ein großer Gartenfreund war, erweckte auch in dem jungen Gesner die Liebe zur Naturwissenschaft. Gesner studierte in Straßburg und Paris Medizin und Naturwissenschaften. Bedenkt man, daß derselbe Mann auch praktischer Arzt war und eine Zeitlang eine Professur der griechischen Sprache bekleidete, so erhalten wir einen Begriff von der vielseitigen Gelehrsamkeit, die uns in der auf das Emporblühen des Humanismus folgenden Zeit so häufig begegnet. Seine Neigung zur universalen Bildung brachte ihn mit den mannigfaltigsten älteren und neueren Schriftwerken in Berührung 1). Zunächst verwaltete Gesner ein Lehramt. Dann ließ er sich als Arzt in Zürich nieder, wo er gleichzeitig eine Professur für Philosophie bekleidete. Erst 1558 erhielt er die sichere und besser besoldete Professur für Naturgeschichte. Aber schon wenige Jahre später, im Dezember 1565 wurde er durch die Pest dahingerafft.

Das Lebenswerk Gesners ist eine große Naturgeschichte der Pflanzen und Tiere, ein Unternehmen, das Zeit und Kräfte des Einzelnen trotz unermüdlicher Arbeit bei weitem überstieg. Für die Naturgeschichte der Pflanzen hat Gesner im wesentlichen nur die Abbildungen, etwa 1500 an der Zahl, gesammelt und gezeichnet oder zeichnen lassen. Das große Verdienst, das er sich trotzdem um die Botanik erworben hat, besteht darin, daß uns in seinen Abbildungen zum ersten Male genaue Zeichnungen der Blütenteile und der Früchte begegnen, die seine Vorgänger fast ganz vernachlässigt hatten ${ }^{2}$ ).

Aus Gesners Briefen geht hervor, daß er diesen Teilen der Pflanze besonderen Wert beilegte, wenn es sich um die Verwandtschaft handelte. Er unterscheidet auch mit klaren Worten Gattungen und Arten. "Ich halte dafür", sagt er, „daß es fast keine Pflanzen gibt, die nicht eine Gattung bilden, welche wieder in zwei oder mehr Arten zu teilen ist"3). Auch der Begriff der Spielart begegnet uns schon bei Gesner. Als ihm einst ein $Z_{\text {weig von }}$

1) E. Meyer, Geschichte der Botanik. Bd. III. S. 325.

2) Conradi Gesneri, Opera botanica. 2 Bde. Nürnberg 1751-1771. Dieser Nachlaß Gesners wurde also erst lange nach seinem Tode herausgegeben (durch Schmiedel).

3) E. Meyer, Geschichte der Botanik. Bd. IV. S. 334. 
Ilex aquifolium gesandt wurde, dessen Blätter nur eine Spitze aufwiesen, bat er den Einsender festzustellen, ob diese Abweichung konstant sei oder nicht.

Der Gedanke, medizinisch wertrolle und auch andere Pflanzen nicht, nur vom Zufall geleitet, im Freien zu suchen, sondern sie in Gärten amzubauen, um dadurch jederzeit über sie verfügen zu können, begegnet uns zu allen Zeiten. Von den Gärten, welche Theophrast und Mithridates unterlalten haben sollen, können wir uns keine Vorstellung mehr machen. Besser sind wir durch die Kapitularien ïber die Gärten zur Zeit Karls des Großen unterrichtet 1 . Von dem Kalifen Abdurrahman I. wird erzählt daß er einen botanischen Garten bei Cordova anlegen und ihn mit Gewächsen Asiens bepflanzen ließ2). Die Gärten, die in Salerno und in Venedig im 14. Jahıhundert entstanden, dienten wohl nur medizinischen Zwecken. Den renetianischen Garten legte ein Arzt an, um „die für seine Kunst erforderlichen Kräuter zur Hand zu haben" "3). Ein im eigentlichen Sinne botanisches Forschungsmittel von höchstem Werte wurde aus solchen Gärten erst, als man sie seit der Mitte des 16. Jahrhunderts als ein notwendiges Lehrmittel der Universitäten zu betrachten anfing und gleichzeitig die Botanik iiber eine bloßje Heilmittellehre hinaushob.

Die ersten Universitätsgärten entstanden in Padua und Pisat). In Pisa waren es die Mediceer, die Land für einen solchen Garten zur Verfügung stellten und dafür sogar Samen und Pflanzen im fernen Orient sammeln lieBen. Bald darauf erhielten auch Florenz und Bologna botanische Gärten. In Venedig sorgten die Cornaros und die Morosinis durch ihren weitverzweigten Handel und die Anlage von Gärten gleichfalls für die Belebung des botanischen Interesses. Nachdem die reichen italienischen Handelsstädte ein solch rühmliches Beispiel in der Pflege der mit ihren Interessen Hand in Hand gehenden Naturwissenschaft gegeben, wollten auch die übrigen Länder in der Betätigung dieses Simnes nicht zurückstehen. So entstanden denn in Montpellier, in Bern, Basel, Straßburg, Antwerpen, Leipzig, Nürnberg und an manchen anderen Orten, teils in Verbindung mit Universitäten, teils aus privaten Mitteln, noch im 16. Jahrhundert Einrichtungen, die als botanische Gärten bezeichnet werden können.

1) Siehe S. 337.

2) A. v. Humboldt, Kosmos. Bd. II. S. 256.

3) Pro herbis necessariis artis suae.

4) 1540 und 1547. 
Etwa zur selben Zeit begegnet uns zum erstenmale das Verfahren, Pflanzen zu pressen und in Herbarien auf Papier geklebt aufzubewahren. Das Herbarium Bauhins $(1550-1624)$ wird noch heute in Basel gezeigt ${ }^{1}$ ). Als der Erfinder der Herbarien gilt Luca Ghini, der von 1534-1544 in Bologna lehrte ${ }^{2}$ ).

\section{Die Erneuerung der Zoologie.}

Wie auf botanischem, so regte sich auch auf zoologischem Gebiete das Bestreben, über das von den Alten überlieferte Maß an Kenntnissen hinauszuschreiten und die bekannten Tierformen, deren Zahl sich durch Entdeckungsreisen immerfort vergrößerte, auf Grund eigener Beobachtung zu beschreiben und mit möglichster Naturtreue darzustellen. So entstanden mehrere umfassende Werke, wie diejenigen des Schweizers Konrad Gesner (1516-1565) und des Italieners Aldrovandi (1522-1607).

Weit größer als in der Botanik war Gesners Einfluß auf die Entwicklung der Zoologie. Hier gebührt ihm das große Verdienst, zum ersten Male die zu seiner Zeit bekannten Tierformen vom Standpunkte des Naturforschers aus geschildert zu haben. Dies geschah in seiner großen, vom Jahre $1551 \mathrm{ab}$ erschienenen Geschichte der Tiere (Historiae animalium lib. V). Von den fünf Foliobänden behandelt der erste die Säugetiere, der zweite die eierlegenden Vierfüßer, der dritte die Vögel und der vierte die Fische und Wassertiere. Ein fünfter, die Insekten behandelnder Band wurde aus Gesners Nachlaß zusammengestellt. Gesner, dem sein Vaterland das erste Naturalienkabinett verdankt, beschrieb in seinem Werke den äußeren Bau der Tiere unter Berücksichtigung ihres Vorkommens, ihrer Lebensweise, des Nutzens, den sie gewähren usw. Seine Anordnung ist die alphabetische, was in bezug auf Systematik gegen Aristoteles, der die großen natiirlichen Gruppen, wie wir sahen, schon erkannt hatte, einen offenbaren Rückschritt bedeutet. Doch macht sich bei Gesner das Bestreben geltend, die Zoologie von den gerade auf diesem Gebiete so sehr überwuchernden Fabeln zu reinigen. Letztere werden zwar gewissenhaft angeführt, doch geschieht dies nicht, ohne daß Bedenken dagegen erhoben werden.

1) E. Meyer, Geschichte der Botanik. Bd. IV. S. 270.

2) H. Schelenz, Über Kräutersammlungen und das älteste deutsche Herbarium. Verhandlungen der Versammlung deutscher Naturforscher und Ärzte. 1906. II. 2. 
Während Albert der Große das zoologische Wissen im engen Anschluß an die dem Abendlande übermittelten naturwissenschaftlichen Schriften des Aristoteles wiederzugeben suchte, ging Gesners Plan dahin, unter Einschränkung des in den mittelalterlichen Schriften ïberwuchernden, philologischen Verbalismus, alles was man zu seiner Zeit vom Tierreich wußte, zusammenfassend darzustellen. Gleichzeitig suchte er jede Tierform, die er zum Gegenstande seiner Betrachtung machte, unter Berïcksichtigung der Medizin und der Kulturgeschichte zu schildern. War auch die Anordnung, die er innerhalb der großen, natiirlichen, schon Aristoteles geläufigen Gruppen befolgte, die alphabetische, so erkennt er doch selbst an, daß ein solches Verfahren sich nur aus Gründen der Bequemlichkeil empfiehlt und naturwissenschaftlich von keinem Wer't sei. Jedes Geschöpf wird in Gesners Geschichte der Tiere nach folgenden Gesichtspunkten behandelt. Der erste Abschnitt gilt der Nomenklatur. Der zweite ist der wertvollste; er betrifft das Vorkommen und bringt die Beschreibung des Tieres. Dann folgt eine Schilderung der biologischen Erscheinungen unter Berücksichtigung der Krankheiten. Hieran schließt sich eine Schilderung des seelischen Lebens, d.h. der dem Instinkt entspringenden Handlungen. Die folgenden Abschnitte handeln dam von dem Nutzen der Tiere, insbesondere ihrer Jagd, Haltung und Zähmung, ferner von ihrer Nahrung, den Heilmitteln, die sie etwa darbieten usw. Mitunter fehlen auch nicht die Fabeln, Wundergeschichten und Weissagungen, die man von jeher an manche Tierarten geknïpft hatte. Solche Mitteilungen gibt Gesner indessen mehr der Vollständigkeit halber und nicht etwa kritiklos wie manche seiner Vorgänger. Dabei versäumt er selten, das Unwahrscheinliche zuriickzuweisen oder wenigstens seinem 'Zweifel Ausdruck zu verleihen. Besteht doch der grolse Fortschritt, der sich bei Gesner geltend macht, darin, daß er seine Beschreibungen nach planmäßBiger Beobachtung abfaßte, während man vor ihm die eigene Beobachtung nur gelegentlich zur Bestätigung der überlieferten Angaben anwindte und diesen stets den ausschlaggebenden Wert beimaß. Ferner beschrïnkt sich Gesner nicht auf eine Beschreibung des ¿̈ußeren Körperbaues, sondern er geht auch auf anatomische Eigentïmlichkeiten ein. Doch werden diese noch nicht durch Vergleichen in Bezichung gesetzt, so daß es an einer wissenschaftlichen Verwertung der anatomischen Kenntnisse zur festeren Begriindung natürlicher Gruppen bei Gesner noch fehlt. 
In bezug auf die Abbildungen ragt sein Werk über alle früheren zoologischen Schriften hervor. Unter den Künstlern, die ibm zur Seite standen, ist Albrecht Dürer zu nennen.

Beruht das Werk Gesners auch zum größten Teile auf der Verarbeitung des zu seiner Zeit vorhandenen zoologischen Wissens, so ist ihm deslualb doch nicht etwa der Vorwurf der bloßen Kompilation zu machen. "Das Talent zu einer solchen", sagt Ranke1), „ist nicht so häufig, wie man meint. Soll sie der Wissenschaft dienen, so muß sie nicht allein aus vielseitiger Lektüre hervorgehen, sondern auf echtem Interesse und eigener Kunde beruhen und durch feste Gesichtspunkte geregelt sein. Ein Talent dieser Art von der größten Befähigung war Konrad Gesner".

Gesner ist als der früheste deutsche Zoologe zu bezeichnen. Sein Werk über das Tierreich ${ }^{2}$ ) ist die Grundlage für die neuere Zoologie geworden. Gesners Grundsatz war, nichts zu wiederholen und nichts fortzulassen. Da ein einzelner die unermeßliche Arbeit nicht bewäligen konnte, setzte er zahlreiche einheimische und auswärtige Hilfskräfte in Bewegung. War somit auch sein Werk in erster Linie die Leistung eines geschickten, seinen Stoff beherrschenden Sammlers, so ist doch sein Nutzen für das Leben nicht minder wie für die Wissenschaft ein bedeutender gewesen. Dem Menschen hat Gesner keinen Platz innerhalb des Tierreiches angewiesen.

Auf dem Boden Italiens erstand Gesner ein gleichstrebender Genosse in dem etwas juingeren Aldrovandi. Auch er versuchte eine enzyklopädische Darstellung der Tierkunde, die zwar im ganzen die Arbeit Gesners nicht ereicht, in Hinsicht auf die anatomischen Verhältnisse und die Anordnung indessen einen Fortschritt darbietet ${ }^{3}$ ). Den Versuch einer mehr systematischen, auf die großen aristotelisehen Gruppen zurïckgehenden Anordnung des Tierreichs hatte in der Zeit zwischen dem Erscheinen des Gesnerschen Werkes und desjenigen Aldrovandis mit gutem

1) L. Ranke, Deutsche Geschichte im Zeitalter der Reformation. 5. Bd. 4. Aufl. S. 346.

2) Conradi Gesneri, Historiae animalium libri, opus philosophis, medicis, grammaticis, philologis, poetis et omnibus rerum linguarumque variarum studiosis utilissimum simul jucundissimumque.

3) Ulisse Aldrovandi wurde 1522 in Bologna geboren. Er gründete dort 1567 einen botanischen Garten. Sein Nachfolger in der Leitung dieses Gartens war der Botaniker Caesalpin. Aldrovandi, Opera omnia. 13 Bde. 
Erfolge der Engländer Edward Wotton (geboren in Oxford 1492) gemacht. Auf dieser Grundlage konnte Aldrovandi fußen. Wotton gab im Jahre 1552 eine Schrift „Über die Verschiedenheiten der Tiere"1) heraus, die nicht nur eine allgemeine Schilderung des tierischen Organismus und seiner Teile enthält, sondern auch eine auf den Grundzügen der natiirlichen Verwandtschaft beruhende Ü̉hersicht bietet. Gleich Aristoteles beginnt Wotton die Reihe der blutführenden Tiere mit dem Menschen. Es begegnen uns die Gruppen der Einhufer, der Zweihufer und der Spaltfüßer. Die eierlegenden Vierfüßer werden mit den Schlangen zusammengefaßt. Die niederen Tiere werden in Insekten, Weichtiere (Kopffüßer), Krustentiere, Schaltiere und Pflanzentiere eingeteilt. $\mathrm{Zu}$ letzteren rechnet Wotton schon die Seesterne, Medusen, Holothurien und Schwämme.

Wotton machte also, im Anschluß allerdings an Aristoteles, zum ersten Male unter den Neueren den Versuch einer naturgemäßen Einteilung des gesamten Tierreichs, und hierin folgte ihm Aldrovandi, der im Jahre 1599 die Herausgabe seines großen zoologischen Werkes begann. Es sollte zwar die ganze Naturgeschichte umfassen, doch konnte Aldrovandi selbst nur fünf Bände erscheinen lassen, nämlich drei Bände iiber die Vögel, einen Band über die Insekten und endlich einen Band über die „iibrigen Blutlosen“. Die weiteren Bände wurden von anderen Zoologen herausgegeben.

Aldrovandi konnte infolge der ausgedehnten Entdeckungsreisen seines Zeitalters manche Tierform berücksichtigen, die Gesner noch nicht kannte, doch verfuhr er im allgemeinen mehr kompilatorisch und weniger kritisch als sein großer Vorgänger. Trotz seines Strebens nach besserer systematischer Gruppierung bringt er es noch fertig, die Fledermaus und den Strauß zu einer Abteilung der "Vögel mittlerer Natur" zu vereinigen, während schon Wotton die Fledermäuse den Säugetieren zugerechnet hatte.

Ein weiterer, wichtiger Fortschritt auf zoologischem Gebiete hestand darin, daß man sich nicht mehr auf das Beschreiben der äußeren Form beschrïnkte, sondern in den Bau der Tiere einzudringen suchte. Wir finden bei Aldrovandi schon Abbildungen des Skeletts, der Muskulatur, sowie der Eingeweide. So wird z. B. das Skelett des Adlers abgebildet. Beim Huhn sind melırere,

1 De differentiis animalium. 
allerdings nur ungenaue Zeichnungen zur Erläuterung des inneren Baues beigegeben. Das Skelett der Fledermaus und des Straußes finden sich gleichfalls unter den Zeichnungen, die mitunter anatomische Einzelheiten, wie die Zunge mit ihrer Muskulatur beim Spechte, das Brustbein des Schwans und anderes mehr betreffen. Die Muskulatur wird bei mehreren Vögeln genauer beschrieben.

Groß waren die Opfer, welche die Naturhistoriker jener Zeit mitunter bringen mußten, um ihre Pläne zu verwirklichen. So beschäftigte Aldrovandi, wie er in der Vorrede mitteilt, zur Herstellung seiner Originalfiguren 30 Jahre einen Maler gegen ein Gehalt von 200 Goldstücken. Außerdem setzte er noch mehrere Zeichner und Holzschneider in Tätigkeit. Das Verdienst von Männern wie Gesner und Aldrovandi ist darum besonders hoch zu schätzen, weil sie zuerst Klarheit und Übersicht in dem immer mehr anschwellenden zoologischen Material zu schaffen suchten und in weiteren Kreisen ein lebhaftes Interesse für die Tierkunde und damit für die Naturkunde im allgemeinen erweckten.

\section{Das Wiederaufleben der Anatomie.}

Das Wiederaufleben der Anatomie läßt sich bis in das 13. Jahrhundert zurïckverfolgen. Ein besonderes Interesse wandte der freigeistige Staufenkaiser Friedrich II. ${ }^{1}$ ) diesen Wissenszweigen zu. Er verfaßte eine Schrift über die Falken ${ }^{2}$ ), ließ ausländische Tiere nach Europa kommen und gestattete die anatomische Untersuchung menschlicher Leichen. In den nachfolgenden Jahrhunderten wurden diese Zergliederungen zu medizinischen und rein wissenschaftlichen Zwecken immer häufiger ausgeïbt. Wurde schon dadurch der Sinn für die Natur erschlossen und das Studium von der bloßen Buchgelehrsamkeit abgelenkt, so steigerte sich das Interesse für die Anatomie dadurch um ein Bedeutendes, daß nicht nur die Gelehrten, sondern auch die großen Künstler der Renaissance mit offenem Auge und frei ron Vorurteilen in den Wunderbau des Organismus einzudringen suchten. Hier ist vor allem, als einer der größten unter ihnen, Lionardo dá Vinci zu nennen. Seine anatomischen Zeichnungen sind von einer der artigen Vollendung und Treue, daß sie alles bisher auf diesem

1) Nach Dantes Inferno ruht Friedrich II. in einem feurigen Grabe.

2) Siehe S. 313. 
Gebiete Geleistete übertrafen. Die Zeit für eine Neubegründung der Anatomie, ohne Rücksicht auf die Autorität Galens und aufgebaut auf selbständige Erforschung der Natur, war also gekommen. Diese Neubegründung erfolgte durch die Italiener Fallopio $(+1562)$ und Eustachio $(\dagger 1571) 1)$, vor allem aber durch den Niederländer Vesal. Letzterer ist als der eigentliche Begriinder der wissenschaftlichen Anatomie des Menschen zu nennen.

Andreas Vesal (1514-1564) war der Sprößling einer aus Wesel stammenden deutschen Ärztefamilie. Er wurde in Brüssel geboren. Schon als Knabe wandte sich der spätere Professor der Anatomie und Chirurgie und Leibarzt Kaiser Karls V. der anatomischen Untersuchung kleinerer Tiere zu. In den letzten Jahrhunderten des Mittelalters hatten zwar hin und wieder Zergliederungen menschlicher Leichen stattgefunden; man verfolgte dabei indes keinen anderen Zweck als den, die Lehren Galens, der eine unbedingte Autorität genoß, als richtig zu bestätigen. Wie schwierig es selbst später war, sich Material zum Studium der Anatomie zu verschaffen, geht unter anderem daraus hervor, daß der junge Vesal, um in den Besitz eines menschlichen Skeletts zu gelangen, einen Gehenkten mit Gefalır seines Lebens vom Galgen entwenden mußte.

Ähnlich lagen die Verliältnisse in Deutschland. So galt es als eine Aufsehen erregende Neuerung, daß im Jahre 1526 ein Anatom einen menschlichen Kopf zergliederte ${ }^{2}$ ). Es blieb aber zunächst bei solchen gelegentlichen Versuchen, die Anatomie auf die Untersuchung von Leichen zu gründen. Erst Vesal brach gänzlich mit den alten Vorurteilen, indem er das Lehrgebäude der Anatomie von Grund aus und sogleich in fast unübertrefflicher. Weise als reine Erfahrungswissenschaft errichtete.

Sein großes Hauptwerk führt den Titel „Über den Bau des menschlichen Körpers". Als es erschien, hatte Vesal noch nicht das dreißigste Lebensjahr überschritten. Durch scharfe Erfassung und klare Wiedergabe des Gegenstandes, durch Ursprünglichkeit des Inhalts und Schönheit der sprachlichen Darstellung ragt sein

1) Eustachio lieferte unter anderem eine genaue Untersuchung des Gehörorgans und entdeckte dabei den Steigbügel (um 1546). Hammer und Amboß waren schon früher aufgefunden (um 1480). Haeser, Geschichte der Medizin. Bd. II. S. 61.

2) L. v. Ranke, Deutsche Geschichte im Zeitalter der Reformation. Bd. V. S. 345 . 
Werk weit über alle ähnlichen Erzeugnisse jener Periode hervor und erregte die höchste Bewunderung der späteren Jahrhunderte. Die meisterhaften Abbildungen des Werkes, die besonders zu seiner großen Verbreitung beitrugen, rühren von einem Schüler ${ }^{1}$ ) Tizians her. Um dem Leser einen Begriff von ihrer naturgetreuen Ausfülırung zu geben, ist in der nachfolgenden Abbildung 64 eine der zahlreichen, das Muskelsystem betreffenden Tafeln wiedergegeben.

Das Abhängigkeitsverhältnis, in das Vesal zum Hofe Karls V. geriet, lat ihn leider gehindert, seine Untersuchungen $\mathrm{zu}$ vollenden. Auch hatte er am Hofe von den Anhängern Galens zu leiden ${ }^{2}$.

Im Beginn seiner Laufbahn hatte Vesal mehrere Male in Padua die Anatomie nach Galen vorgetragen, sich dann aber entschieden davon losgesagt. Seine wissenschaftliche Überzeugung iiber die anerkannte Autorität zu setzen, war damals kein geringes Wagnis. Freunde hatten ihn vor der Herausgabe seines großen Werkes gewarnt. Als es erschienen war, erhob sich zunächst ein Sturm der Entrüstung. Man erklärte Vesal für einen wahnsinnigen Ketzer. Das Buch wurde der Inquisition vorgelegt. Vesal verliels deshalb Italien. Später lebte er in Spanien als Leibarzt Philipp des $Z$ weiten. Schließlich wurde er, vielleicht infolge neuer Verfolgungen seitens der Inquisition, schwermütig ${ }^{3}$ ).

Vesal beschränkte sich keineswegs auf den Menschen, sondern er flocht zahlreiche Hinweise auf die Anatomie der Tiere in seine Darstellung ein. Es war das um so weniger zu verwundern, als er ja ron der anatomischen Untersuchung der Tiere ausgegangen und sich erst später der Anatomie des Menschen zugewandt hatte. Vesals Hauptwerk erschien 15434). Die sieben Biicher behandeln: 1. Das Skelett. 2. Bänder und Muskeln. 3. Gefäße. 4. Nerven. 5. Eingeweide. 6. Herz. 7. Gehirn und Sinnesorgane.

Große Verdienste um die Fortbildung der Anatomie auf der von Vesal geschaffenen Grundlage hat sich auch Eustachio erworben. Doch ist bezeichnend, daß dieser, obgleich auch ihm die

1. Namens Johann Stephan von Calcar. Jedoch ist dessen Autorschaft nicht sichergestellt. Siehe Mitteilungen z. Geschichte d. Medizin u. d. Naturwiss. 1903. S. 282.

2) Sprengel, Geschichte der Arzneikunde. Bd. III. § 46-78.

3, Wunderlich, Geschichte der Medizin. Stuttgart 1859. S. 70.

4, De humani corporis fabrica libri VII. Basel 1543. 


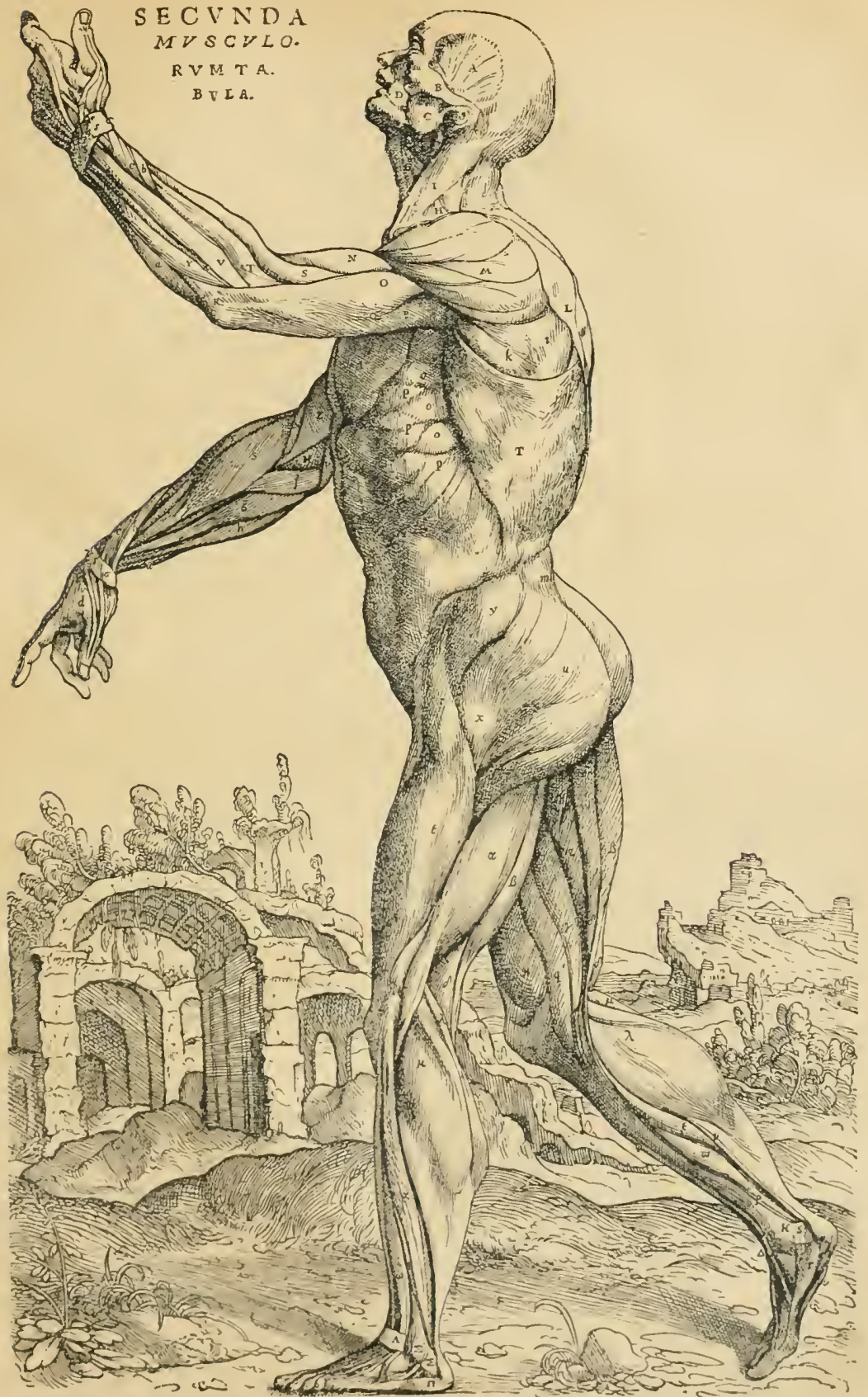

Abb. 64. Abbildung aus Vesals De humani corporis fabrica. 1543. (Zweite, das Muskelsystem betreffende Tafel.)

Dannemann, Die Naturwissenschaften. I. Bd. 2, Aufl. 
Abweichungen seiner Befunde von den Angaben Galens klar zutage lagen, lieber eine Veränderlichkeit des Körperbaues annehmen als der gefeierten Autorität des Altertums Abbruch tun wollte.

Vor dem Auftreten eines Vesal und Eustachio waren bei dem großen Mangel auf eigener Anschauung beruhender anatomischer Kenntnisse erfolgreiche chirurgische Eingriffe kaum möglich. Erst nach der durch diese Männer bewirkten Erneuerung der Anatomie konnte sich aus den bis dahin üblichen, rohen, ja oft barbarischen Operationsverfahren eine auf wissenschaftlicher Grundlage beruhende Chirurgie entwickeln. Daß dies geschah, war vor allem das Verdienst von Ambroise Paré (1517-1590), der sich den Ehrennamen eines Reformators dieses Zweiges der Medizin verdient hat.

Paré war gleich Vesal Militärchirurg und als solcher dem Stande der gelehrten Ärzte verhaßt, zumal er kein Latein verstand. Sein hervorragendes Buch über Schußwunden (1545) ist das erste in französischer Sprache geschriebene wissenschaftliche medizinische Werk ${ }^{1}$ ). Paré wandte bei Amputationen zuerst das Verfahren des Abbindens der Arterien an. Vor ihm hatte man sich der Cauterisation mittelst des Glüheisens bedient. Auch der Gebrauch des Bruchbandes ist auf Paré zurückzuführen. Die Feindschaft der Ärztezunft wurde besonders heftig, als Paré die Wirksamkeit einiger der gebräuchlichsten Arzneien anzweifelte. Trotzdem wurde Paré rom Könige sehr geschätzt. Er soll einer der wenigen Hugenotten gewesen sein, die der König in der Bartholomäusnacht zu schonen befahl.

Die Erkenntnis, daß sich ein volles Verständnis der Form erst durch das Studium ihrer Entwicklung erschließen läßt, begegnet uns gleichfalls schon im 16. Jahrhundert, wenn sich auch diese Erkenntnis erst in späteren Perioden, gestützt auf die Verschärfung, welche der Gesichtssinn durch das Mikroskop erfuhr, allseitig Bahn brechen konnte. So wird die Entwicklung des Hühnchens im Ei, ein Problem, das schon Aristoteles beschäftigt hatte, zum Gegenstand eingehender Untersuchungen gemacht. Dies geschah durch den verdienten italienischen Anatomen Fabricio ${ }^{2}$. Er bemerkte auch, daß sich die Klappen der Venen nach dem Herzen zu öffnen. Diese Entdeckung hat nebst anderen, die

1) Wunderlich, Geschichte der Medizin. Stuttgart 1859.

2) Fabricio ab Aquapendente (1537-1619), De formatione ovi. 
Organe des Kreislaufs betreffenden Beobachtungen ${ }^{1)}$ einen der größten Fortschritte des 17. Jahrhunderts, die Entdeckung des Blutkreislaufs durch Harvey nämlich, vorbereitet.

Hiermit schließt der erste Teil dieser Schilderung, die von den Anfängen bis gegen den Ausgang des 16. Jahrhunderts gefiihrt hat. Der zweite Band wird die Begründung der neueren Naturwissenschaft, die etwa mit der Schwelle des 17. Jahrhunderts anhebt, zur Darstellung bringen.

1) Zum Beispiel, daß die Herzscheidewand, durch die Galen das Blut aus dem rechten in den linken Ventrikel hindurchtreten ließ, undurchdringlich ist. 


\section{Verzeichnis der im I. Bande enthaltenen Abbildungen.}

Figur

aus

1. Gleichschenkliges Dreieck

2. Geometrische Elemente aus altägyptischen Verzierungen

3. Keilschriftprobe

4. Babylonischer Grenzstein

5. Der Tierkreis von Dendera

6. Altbabylonisches Gewicht

7. Wage, einem altägyptischen Totenbuche entnommen

8. Gewinnung von Eisen nach altägyptischen Wandgemälden

9. Geometrische Konstruktionen der Inder

10. Die Quadratur des Kreises bei den Indern

11. Radkarte der Erde

12. Der Satz des Hippokrates

13. Konstruktion zur Lösung des delischen Problems

14. Der Tragbalken des Aristoteles

15. Der Satz vom Parallelogramm der Kräfte

16. Der Embryo des glatten Hais des Aristoteles

17. Vorrichtung zum Heben großer Lasten

18. Das Verhalten des Hohlspiegels nach Euklid

19. Die Spiegelung an einem Konkav- und einem Konvex-Spiegel nach der Darstellung Euklids

20. Das zum Messen der Sonnenhöhe dienende Instrument der Alten

21. Die Gradmessung des Eratosthenes

22. Aristarchs Verfahren, die Entfernungen des Mondes und der Sonne zu bestimmen

Cantor, Bd. I. 1880 , S. 58, Abb. 6 u. 7.

nach Layard.

Ibel, Die Wage im Altertum und Mittelalter.

A. de Rochas, Les origines de la science et ses premières applications.

Cantor, Geschichte der Mathematik. Bd. I. 1880. Fig. 34.

Claus, Lehrbuch der Zoologie. 1883. S. 677.

Heronausgabevon Schmidt. Op.II. 1 Fig. 62.

Euklidausgabe von Heiberg und Menge. Bd. 7. desgl.

Schaubach, Geschichte der griechischen Astronomie. Tab. III Fig. 2. 
\begin{tabular}{c|}
\hline Figur \\
\hline 23. Breitenbestimmung mit dem Gnomon
\end{tabular}

24. Stereographische und orthographische Projektion

25. Die Feuerspritze nach Heron

26. Heron verwendet den Dampf zum Betreiben einer maschinellen Einrichtung

27. Der Heronsball

28. Herons Abbildung eines Hebers

29. Herons Automat zum Öffnen der Tempel

30. Wasserorgel

31. Philons Thermoskop

32. Philons Saugkerze

33. Herons Flaschenzug

34. Herons Wegmesser

35. Herons Winkelmeßapparat

36. Herons Vermessung eines Feldes

37. Herons Tunnelaufgabe

38. Der Meßapparat der Römer

39. Die Rekonstruktion der Groma

40. Peutingers Karte

41. Römisches Hebezeug

42. Römische Schnellwagen

43. Chirurgische Instrumente

44. Zur Erläuterung der Epizyklentheorie

45. Das parallaktische Lineal

\section{Solstitial-Armille des Ptolcmäos}

47. Ptolemäos mißt die Brechungswinkel

48. Destillierapparat

49. Probe aus dem Stockholmer Papyrus

50. Albirunis Bestimmung des Erdumfanges

51. Trigonometrische Berechnungen

52. Einführung der Tangensfunktion aus

Peschel, Geschichte d. Erdkunde 1877. S. 44.

Herons Pneumatik. Ausgabe v. Schmidt. Bd. I. Fig. 29.

Herons Pneumatik. Ausgabe v. Schmidt.

desgl.

desgl.

Mach, Prinzipien derWärmelehre. Leipzig 1896. S. 5.

Heronausgabev.Schmidt. Fig. 115. desgl.

Opera omnia. Ausgabe v. Schmidt. Bd. II. S. 102.

Jahrbuch des kaiserl. deutschen archäolog. Instituts. $\mathrm{Bd}$. XIV 1899. 3. Heft.

Herons Opera omnia. Ausgabe v. Schmidt.

desgl.

Neue Jahrbücher f. d. klass. Altertum. Bd. 13 (1904).

desgl.

Gerland u.Traumüller, Geschichte der physikal. Experimentierkunst. 1899. Fig. 58.

desgl.

Montucla, Histoire des mathématiques. Bd. I. S. 307.

Repsold, Zur Geschichte der astronomischen Meßwerkzeuge.

Archiv für Geschichte der Naturwissenschaften und der Technik. Bd. I. S. 66 . 


\begin{tabular}{l|l|l}
\hline Figur & aus \\
\hline
\end{tabular}

53. Alhazens Darstellung des Auges

54. Alhazen untersucht die Brechung

55. Alhazen bestimmt die Höhe der Atmosphäre

56. Lionardo da Vincis Hygrometer

57. Lionardos Windmesser

58. Lionardos Erläuterung des Sehens

59. Peurbachs Quadratum geometricum

60. Der Kreuzstab

61. Schematische Erläuterung des Kreuzstabes

62. Das Koppernikanische Weltsystem

63. Hüttenwerk nach Agricola

64. Das Muskelsystem darstellende Tafel
Gerland $u$. Traumüller, Geschichte der physikal. Experimentierkunst. Fig. 62.

Gerland u. Traumüller, Geschichte der physikal. Experimentierkunst. Fig. 65 .

Gerland u. Traumüller. Fig. 99.

Repsold, Zur Geschichte der astronomischenMeßwerkzeuge. Fig.7.

Repsold, a. a. O. Fig. 12

Aus Koppernikus Werk über die Bewegung der Weltkörper.

Aus Vesals Werk: De humani corporis fabrica. 


\section{Namen- und Sachverzeichnis.}

A.

Abendstern 25.

Aberration, sphärische 358 .

Abu Mansur 321.

Acosta D' 440, 449.

Ägyptische Bauwerke 3.

Ägyptische Kultur 2.

Äquinoktialpunkte 36 .

Agricola 437, 443.

Ahmes 7, 11.

Akustik 115.

Alaun 50 .

Albattani 304, 306.

Albertus Magnus 346-3ว̌3, 443.

Albiruni 303.

Alchemie 278, 3533, 363, 431, 432.

Alchemistische Theorien 325.

Aldrovandi 460, 461.

Alfarabi 312.

Alfons von Kastilien 251.

Alfragani 304.

Algebra 57, 253, 311.

Alhazen 314, 315, 316, 357.

Alkmäon 101.

Alkohol 322.

Alkuin 336.

Alliaco 398.

Almagest 33, 255, 302.

Altäre 53.

Altertum, Verfall 283.

Amalgamationsprozeß 440 .

Amulette 300.

Anatomie 59, 102, 206, 235, 326, 366, $462,463,464$.

Anaxagoras 76, 77, 98.

Anaximander 36, 67, 79, 90, 100, 269.

Antipoden 118, 227, 289.

Apianus 404, 418.

Apokatastasis 243.
A pollonios 248.

Apotheken 48, 60, 437.

Arabische Kultur 331.

Archimedes 218.

Aristarch von Samos 92, 93, 122, 408.

A ristophanes 89.

Aristoteles 28, 69, 73, 74, 78, 97-151, $233,345,355$.

Aristoteliker 421.

Armillen 255, 256.

Arsenik 321.

Aryabhatta 52, 58.

Arzneipflanzen 230.

Asklepiades 208.

Astrolabium 306, 396.

Astrologie 16, 24, 31, 364.

Astronomie 20, 332, 393.

-, griechische 80.

-, Ursprung 20.

-, Wiedererwachen 393.

Astronomische Meßwerkzeuge 256.

- Urkunden 26.

Asymptoten 86.

Atmosphäre, Höhe 317.

Atome 71, 75, 241.

Attalos 2⿺辶.

Aufgang, heliakischer 22.

Auge 315, 389, 420.

Augustin 289, 287.

Averroes 313 .

A vicenna 270, 312, 321, 435, 442, 443.

B.

Bacon, Francis 414.

Bacon, Roger 35̃3-362.

Bartholomeo Diaz 447.

Bäune 230.

Baumzucht 329.

Bazillentheorie 223. 
Behaim 396, 397, 447.

Benedikt von Nursia 271.

Bergbau 334, 437, 440.

Bernstein 268.

Berosos 368 .

Bessarion 394.

Bibel 18.

Bibliothek, alexandrinische 297.

Bibliotheken 301, 302.

Blitzableiter 269.

Blütenteile 456.

Blutkreislauf 234.

Boccaccio 372, 373.

Bock 458.

Boëthius 293.

Bologneser Leuchtstein 429.

Botanik, Erneuerung 450.

Botanische Gärten 400, 457.

Brahmagupta 52, 56, 310.

Brechung 260, 265, 316.

Brennglas 58.

Brennkugel 358.

Brennspiegel 58, 395, 428.

Brillen 318, 360.

Bronze 42.

Brüche 19.

Brunfels 451, 452 .

Brunnenaufgabe 205.

Buffon 231.

Bussole 308 .

Caesar 213.

\section{C.}

Camera obscura 423, 426.

Capitulare de villis 337 .

Cardanus 74, 445.

Cassiodor 292.

Cato 210, 239.

Celsus 223.

Celtes 214.

Chaldäer 32, 33, 37, 89.

Chemes 274.

China 60.

Chinesische Astronomie 61.

Chirurgie 48,466 .

Chronometer 424 .

Cicero 210, 407.

Clusius 448.

Columbus 261, 362, 375, 398, 423, 424, 448.
D.

Damianos 266.

Dämmerung 317.

Dante 372.

Datumsgrenze 379.

De Caus 423.

Deklination 423.

Delisches Problem 85.

Demokrit 71, 73, 75, 78, 99.

Destillation 50, 321 .

Destillierapparat 276.

Deszendenzlehre, Keime 100.

Diamanten 328.

Dionysios der Große 287.

Diopbant 56, 57, 253, 254.

Dioptra 201, 203.

Dioskurides 231, 238, 245, 337, 401.

Dodonaeus 455 .

Doppelelle, babylonische 38 .

Doppelstunden 24.

Dreiecksberechnung 11.

Dreiteilung eines Winkels 84 .

Dürer 377, 452, 460.

Dynamik, Begründung 430.

\section{E.}

Einhardt 302.

Eisen 41.

Ekliptik, Schiefe 90.

Elemente 70, 436.

Ellipse 87.

Elmsfeuer 269.

Emissar 204.

Empedokles 70, 76, 97-99.

Entdeckungsreisen 362, 398, 448, 449.

Enzyklopädie 292.

Ephemeriden 395.

Epikur 75, 100.

Epizyklentheorie 120, 249, 250.

Erasistratos 206, 233.

Erasmus v. Rotterdam 378.

Eratosthenes 255.

Erdbeben 368 .

Erde, Bewegung 381.

-, Gestalt 96, 117, 227, 289.

Erdkern 70.

Eudemos 81, 95.

Eudoxos 78, 119, 120, 248.

Euklid 82 
Eutokios 85.

Evektion 247.

Exhaustionsmethode 84.

Experimente 79, 235, 356, 359, 391.

Fabricio 466.

Fallversuche 412.

Farbenwechsel 429.

Färber 327.

Färberei 280, 320.

Fechner 415.

Feldmeßkunst 200, 211.

Fernrohr 360.

Feuervergoldung 280.

Fibonacci 339.

Finsternisse 6 .

Flaschenzug 198.

Flavio Gioja 308.

Fluorescenz 428.

Fracastoro 444.

Francesco Petrarca 364.

Friedrich II. 313, 437, 462.

Fuchs 454.

\section{G.}

Galen 233-237, 239, 270.

Galle 103.

Gas 277.

Gassendi 75 .

Geber 322.

Gebirgsbildung 442.

Gegenerde 94.

Geld 14.

Geminos 31.

Gemma Frisius 417.

Geologie 70, 391, 411.

Geometrie 6, 53, 66 .

Gerbert 333.

Gerhard von Cremona 338.

Germanentum 290.

Gesner 447, 449, 455, 460.

Gewichte 38.

Gewichtsstücke 39.

Gewitter 269, 367.

Gezeiten 358.

Gift 240.

Gilbert 424.

Giordano Bruno 415.
Glas 44, 244.

Gleichungen 9, 56, 254, 311, 340 .

Globus 120, 397, 417.

Gnomon 36, 61, 67, 89, 380.

Gold 43.

Gradmesser 303.

Grenzstein 26.

Groma 212.

Guldinsche Regel 264.

\section{H.}

Hammurabi 45.

Harmonie 80.

Harmonie der Sphären 91.

Hartmann 424.

Haustiere 49.

Hebelgesetz 113.

Heber 194. 427.

Hebezeug, römisches 216.

Heilkunde, Anfänge 45, 101, 236, 294, $314,330,435$.

Heilmittel 46, 60.

Heilvorschriften 46 .

Hekataeos 67.

Hellenismus 209.

Helmont, van 433.

Herakleides Pontikos 78, 92, 93, 94, 96.

Heraklit 70 .

Herbarien 401, 458.

Hermes Trismegistos 275.

Herodot 6, 36, 45, 89, 262.

Heron 58, 193, 205, 257.

Herophilos 206, 233.

Herons Automaten 195.

Herons Ball 193.

Herons Dampfkugel 193.

Heronsche Formel 203.

Hesiod 68, 96.

Hettiter 16.

Hexenglauben 364.

Hieroglyphenschrift 3 .

Hildegard von Bingen 337.

Himmelsgebäude 118.

Himmelsgloben 120, 306.

Hipparch 37, 122, 248, 251.

Hippias von Elis 87.

Hippokrates von Chios 83, 84, 89.

Hippokrates aus Kos 102.

Hochöfen 234. 
Höllenstein 324.

Homer 96.

Horaz 239.

Humanismus 372, 374.

Humboldt 232.

Hutten 378.

Hüttenwesen 437.

Hygrometer 386.

Hyperbel 86, 87.

\section{$\mathrm{J} \cdot$}

Jahr 88.

Jatrochemie 433, 434.

Ibn al Haitam 314.

Ibn Alawwam 329.

Ibn Batuta 329.

Ibn Junis 306.

Ibn Musa 311.

Ibn Roschd 329.

Ibn Sina 298, 312, 328, 330.

Indien 51.

Indigo 245.

Ingenieur 217, 218.

Ingenieurmechanik 13, 215.

Inhaltsbestimmungen 11 .

Inklination 424.

Insekten 230.

Instrumente, chirurgische 236.

Johannes von Sevilla 339.

Jordanus Nemorarius 430.

Irrationalität 83.

Isidor von Sevilla 294.

Islamitische Kultur 338.

Jupiter 34.

\section{K.}

Kaiserzeit 219.

Kalender 88, 89, 213, 357.

Kanäle 13.

Karl der Große 335.

Karten 380.

Kartographie 259, 381, 417, 419.

Katakaustik 358.

Kegelschnitte 86 .

Keilschriftfunde 16, 17, 25.

Kepler 92, 411.

Kirchenväter 286.

Kircher 427-429.

Knochenbrüche 48 .
Königswasser 321.

Kombinationslehre 57.

Kometen 61, 121, 243, 367.

Kompaß 61.

Konformität 419.

Konjunktionen 34, 361.

Koppernikus 403-414.

Krankheiten 101.

Kräuterbücher 453, 454 .

Kreis $5,7$.

Kreta 63.

Ktesibios 257.

Kugel 87.

Kulturpflanzen 49 .

Kupfer 14, 42, 43.

L.

Lactantius 287, 288.

Iänderkunde 261.

Landwirtschaft 238.

Längenbestimmungen 395 .

Längenproblem 424.

Laterna magica 429.

Leidener Papyros 279.

Leonardo von Pisa 339.

Leukipp 71, 73.

Levi ben Gerson 396.

Liber Abaci 340.

Licht 318.

Lionardo da Vinci 382-392, 400.

Literatur, babylonisch-assyrische 18 .

Literatur, indische 52.

Luca Ghini 458.

Lucretius Carus 74, 100, 240, 242, 268.

Luft 194.

Lunulae Hippokratis 83.

Luther 414.

M.

Magie 422.

Magnet 268, 429, 430.

Mago 238.

Marco Polo 329, 341.

Marcus Graecus 310.

Marinus 259, 262, 263.

Martianus Capella 294, 333, 407, 408.

Maschinen 385 .

Maße 38.

Mathematik, Anfänge 7.

-, griechische 78 . 
Maurolykus 420, 421.

Mechanik 111, 218, 385.

Mediceer 375.

Negenberg 232, 365, 368, 369, 401.

Melanchthon 414.

Menächmos 87 .

Menelaos 252.

Mensch 226.

Mercator 397, 417, 418, 419.

Meßapparat 212.

Metallurgie, Anfänge 40.

Metallveredelung 278.

Meteoriten 77.

Metrologie 38.

Milchstraße $30 \tilde{8}$.

Mine 38.

Mineralien 327, 369, 442.

Mineralogie, Neubegründung 438.

Mönchstum 291.

Niond 37, 88, 90.

Mondbewegung 31, 35 .

Monddistanzen 404.

Mondfinsternis 33.

Morgenstern 20 .

Musik 293.

Münster 417.

\section{N.}

Naturalienkabinett 458 .

Naturerklärung 71.

- philosophie 69.

Nestorianer 299, 300.

Nicetas 407.

Nicolaus von Cusa 379, 382.

Nikolaus V. 374.

Nippurtafeln 17.

Nonius 400.

Norman 424.

Null 56.

Nullmeridian 258.

\section{o.}

Obelisk 14.

Observatorium 5

Oenopides 89.

Olympiodor 277.

Optik 341.

Opus majus 357.

Osiander 406.
P.

Paläontologie, Anfänge 443.

Palissy 438, 444, 445.

Pappos 198, 264.

Papyrus Ebers 48.

- Rhind 7.

Parabel 86, 87.

Paracelsus 42, 43t-436.

Parallaktisches Lineal 255 .

Parallelogrammgesetz 114 .

Paré 466.

Peregrinus 353 .

Perpetuum mobile 386.

Perspektive 389.

Petrarka 372, 373.

Peurbach 393.

Peutingers Karte 214.

Pflanzenabbildungen 451 .

- beschreibungen 35̃1, 453.

- kenntnis 47, 59, 97.

Pflanzen, Anordnung 455.

—, Beseelung 70.

-, Nahrung 382.

-, Schlaf 3500.

- Sexualität 350 .

Philolaos 92, 93, 94.

Philon 197.

Philons Saugkerze 197.

Phönizier 63.

Phosphoreszenz 428.

Physiologie 388.

Physiologus 347.

Pico von Mirandola 363 .

Pierre d'Ailly 362.

Pius II. 375.

Planeten 32, 34, 66, 90, 91, 114, 247, $248,251$.

Platon 78, 85, 92, 95, 96, 102, 118, 119, 248, 268.

Plattkarte 268.

Plinius 206, 210, 218, 220-232, 239, $244,245,268,270$.

Plinius der Jüngere 221.

Plutarch 407.

Pneuma 207.

Polyeder, reguläre 82.

Pompeji 240, 243.

Pomponios Mela 220, 226 .

Positionssystem 56. 
Präzession der Nachtgleichen 122, 252, 415.

Projektionsart 262.

Proklos 81.

Prokop 289.

Proportionen 82.

Pseudo-Demokritos 281, 278.

- -Gebersche Schriften 323.

Ptolemäos 35, $246-266$.

Pyramiden 4, 12, 87.

Pythagoras 79-82, 101.

Pythagoreer 80, 91.

Pythagoreischer Lehrsatz 9, 53.

\section{Q.}

Qazwini 327.

Quadratrix 87.

Quadratum geometricum 393.

Quadratur des Kreises 54, 84.

Quadrivium 332.

Quecksilber 272.

Quecksilberoxyd 324, 327.

Quellen 242.

\section{R.}

Radkarte der Erde 67.

Raymundus Lullus 363.

Rechenkunst 20, 56.

Reformation 35̃5, 377.

Refraktion, atmosphärische 266, 318.

Regenbogen 35̃, 428.

Regiomontanus 394, 395, 399.

Reguläre Körper 81 .

Reihen 9, 56.

Renaissance 334, 371.

Rennarbeit 334.

Rhabanus Maurus 289, 336.

Rhases 323.

Römer 208.

Rudolf II 433.

S.

Salpeter 300 .

- säure 321, 323.

Salzgewinnung 334.

Saros 37, 65.

Sehen 116, 315, 389, 390.

Sehstrahlen 267.

Seife 245.
Seilspannen 54 .

Seneca 242, 243, 261.

Sexagesimalsystem 18.

Sinus 59.

Sirius 22.

Snellius 268.

Sonnenbewegung 247.

- bildchen 421.

- jahr 22.

- uhren 62, 215, 333.

Sosigenes 213 .

Spektrum 242.

Spezifische Gewichte 318.

Sphären, homozentrische 118.

Sphärenmusik 121.

Spiegel, parabolische 3507.

Spielart 456.

Sumerer 15.

Summierungsformel 10 .

Susruta 59, 64, 115.

\section{Sch.}

Schall 243.

Schaltjahr 29.

Schattenmessung 67.

Schießpulver 59, 310, 361.

Schnellwagen 217.

Schott 427.

Schwenter 424, 427.

\section{St.}

Städtewesen 342 .

Stein der Weisen 275, 326, 431.

Sterne, Zahl 229.

Sternwarte 399.

Stereometrie 87.

Stockholmer Papyrus 279, 320.

Strabon 206, 259, 260.

\section{T.}

Tacitus 221.

Tafeln von Senkereh 19.

Tartaglia 431.

Telegraphen 430 .

Tell el Amarna-Tafeln 16.

Thales 64, 65, 67, 79.

Theophrast 97, 107, 230.

Thermoskop 197.

Thomas von Cantimpré 348, 365. 
Tiefenmesser 382 .

Tiere, Anordnung 461.

-, Naturgeschichte 459, 460.

Tierfabeln 328, 347.

Tierformen 328.

- kreis von Dendera 27.

- kreisbilder 25, 36.

- system, koisches 103.

- zeichnungen 452 .

Timäos 95̃, 102.

Töpferei 44.

Toscanelli 380, 448.

'Tragbalken 113.

Transmutation 275.

Treibhäuser 244.

Trigonometrie 4, 37, 58, 253, 305, 395.

Trivium 332.

Tunnelaufgabe 204.

- bauten 203.

Tycho 95, 122.

Tyrische Weltkarte 262.

\section{U.}

Universitäten 344,376 .

Universum, unendliches 416 .

Untergang, heliakischer 22.

\section{V.}

Variation 250.

Varro 222, 223, 292.

Vasari 371.

Vasco da Gama 447.

Vedas 53.

Venus 25, 35.

Verbrennung 387.

Vermessung da6 römischen Reiches 213.

Vernier 400.

Versteinerungen 260, 380, 443, 445.

Vesal 366, 463.

Vesuvausl,ruch 221.

Virgil 224.

Vitello 341.

Vitruv 95̃, 215, 216, 244, 261.
Vögel 314.

Vulkane 248, 260.

\section{w.}

Wagen 39, 333, 382.

Walfisch 368 .

Waltiere 99.

Wasserbäder 324.

— orgel 196.

- uhren 23, 257, 302.

Wegmesser 199.

Weltanschauung, heliozentrische 93.

- bild des Mittelalters 367.

- entstehungslehre 68, 72.

- karte 381, 418.

- system, heliozentrisches 402, 409 bis 413 .

Weyer, Jacob 364.

Wiederkehr, stete 121.

Windmesser 387.

Winkelmeßinstrumente 2055.

Wirbelbeweguug 77.

Wissenschaften, ihr Verfall 28ó.

Wohnungshygiene 47.

Wotton 461.

Wurf bewegung 425,430 .

Würfelverdoppelung 85 .

Wurzeln 57.

\section{Z.}

Zahlenmystik 80 .

Zahnkaries 46.

Zahnradübertragung 199.

Zeitmessung 23.

Zellentheorie 224.

Zentralfeuer 93.

Ziffernsystem, indisches 305.

Zink 42, 271.

Zinn 42, 271.

Zitterrochen 270.

Zoologie, Anfänge 99, 458.

Zosimos 274, 276, 277.

Zucker 322.

Zweckbegriff 73, 74 . 


\section{Ergänzungen, Zusätze und Berichtigungen ${ }^{1}$ ).}

(Aufgenommen, soweit der Raum es erlaubte.)

Zu S. 2: In Anmerkung 2 muß es heißen, ,Siehe auch A. Wiedemann $(\mathrm{Wi})^{6 / 6}$.

Zu S. 11: Bezügl. der Dreiecksberechnung ist die Hypothese zu beachten, die M. Simon in seiner Geschichte der Mathematik im Altertum 1909 auf S. 46 gibt. Danach würde es sich nicht um gleichschenklige, sondern um rechtwinklige Dreiecke handeln (Wü).

Zu S. 14: Über die ältere Geschichte der Metalle findet sich eine sehr ausführliche Darstellnng in dem Anhang zur "Alchemie“ von Lippmanns. Kupfer wurde danach in Ägypten schon in der Steinzeit zu Geräten verwandt (S. 539). Silber und Eisen lernte man erst später kennen (Li).

Zu S. 15: Die Herkunft der Sumerer ist nicht sicher festgestellt. Sie sind nicht semitischen Ursprungs und hatten schon vor 3000 eine hohe Kulturstufe erreicht, a. a. besaßen sie eine ausgebildete Schrift, die Keilschrift (Li).

Zu S. 19: vergleiche man E. Hoppe, Mathematik und Astronomie im klassischen Altertum S. 17 u. f. (Wü).

$\mathrm{Zu}$ S. 19: Es verdiente schon hier erwähnt zu werden, daß die Araber neben dem Sexagesimalsystem auch das Dezimalsystem benutzt haben (Wi).

Zu S. 31 (Dauer des synodischen Monats): Die genaue Übereinstimmung beruht darauf, daß eine sehr große Anzahl von Umläufen genommen wurde und nicht etwa darauf, daß die Beobachtungen bis auf Sekunden genau waren. Es wäre wohl angebracht, hierauf besonders hinzuweisen (Wi).

Zu S. 38, unten: Die Übereinstimmung ist sicher Zufall. Sie rührt daher, daß die menschliche Elle rund $1 / 2 \mathrm{~m}$ lang ist. Die Assyriologen haben aber stets die Neigung zum Geheimnisvollen gehabt (Wi).

Zu S. 43 Anm. 3: Man vergleiche damit die von derjenigen Wilsers zum Teil abweichende Ansicht, die E. von Lippmann in seiner "Alchemie“ über die ältere Geschichte des Kupfers entwickelt. Die Meinungen der Forscher gehen hier, zumal was das Auftauchen von Kupfer in Nord- und Mitteleuropa betrifft, noch stark auseinander.

Zu S. 50, Anm. 2: Nach E. v. Lippmann hat sich die Destillation aus unvollkommenen Anfängen entwickelt, so daß sich bestimmte Angaben über ihren Ursprung nicht machen lassen. Die ältesten Abbildungen und Beschreibungen von Destillierapparaten finden sich in Schriften, die angeblich im 1. Jahrh. n. Chr. entstanden sind („Alchemie“", S. 46-48).

Zu S. 60 (Ayur-Veda): Die Entstehung der Veden fällt in die Zeit von 1500 bis 500 v. Chr. Das Wort Veda bedeutet das Wissen.

1) Sie rühren zum̄ größten Teile von E. Wiedemann (Wi), E. v. Lippmann (Li) und J. Würschmidt (Wü) her. 
Zu S. 67: Über seine Methode der Schattenmessung für beliebige Winkel vergleiche man E. Hop pe, Math. u. Astr. i. klass. Altertum (IVü). Danach hat Thales (nach Plutarch) seinen Stab bei irgendeiner Sonnenhöhe in den Endpunkt des Schattens gesteckt und gelehrt, daß die Schattenlänge des Stabes sich zur Schattenlänge der Pyramide verhalte wie die Länge des Stabes zur Höhe der Pyramide.

Zu S. 80, unten: Näheres über die fünf regelmäßigen Körper (platonische Körper) siehe bei E. v. Lippmann (Alchemie, S. 127).

Zu S. 90: Die früheren Angaben über die Schiefe der Ekliptik sind nach v. Lippmanns Mitteilung vermutlich babylonischer Herkunft. Ob tatsächlich chinesische Astronomen schon um 1100 v. Chr. den ziemlich richtigen Wert von $23^{\circ} 52^{\prime}$ für die Schiefe der Ekliptik kannten, bleibe dahingestellt (Li).

Zu S. 113: Über die Frage der Echtheit der „mechanischen Probleme6 siehe die Anm. auf S. 128.

Auf S. 115 heißt es richtiger 2:1 statt 1:2.

Zu S. 116: Das Wort Rückschritt ist hier nicht zeitlich zu nehmen, da Leukipp und Demokrit ihre Vorstellungen vor A ristoteles entwickelten.

Zu S. 123: Das Nordlicht ist auch in unseren Zeiten, wenn auch sehr selten im südlichen Europa beobachtet worden.

Zu S. 128, Anm. 2: Mit Recht warnt auch E. Wiedemann davor, solchen Vorahnungen und Andeutungen einen zu hohen Wert beizumessen. „Ich stehe", bemerkt er, ,ihnen sebr skeptisch gegenüber, denn man kann im Altertum alles finden, positiv und negativ".

Zu S. 156: Bezüglich des 14. und 15. Buches der „Elemente“, die nicht von Euklid herrühren, findet man das Nähere in E. Hoppes Mathematik und Astronomie im klassischen Altertum 1911, S. 314 u. f. (IVü).

Zu S. 171 (A rchimedisches Prinzip): Hierzu sind die Dissertationen von Th. Ibel, Die Wage im Altertum und Mittelalter, Erlangen 1908 und von H. Bauerreiß, Zur Geschichte des spezifischen Gewichtes im Altertum und Mittelalter"6, Erlangen 1914 zu vergleichen (Wi).

Zu S. 178, Anm. 2: Nach Hoppe, Math. u. Astr. i. klass. Altertum, S. 283, beläuft sich der Wert des griechischen Stadiums auf 185,136 m und derjenige des kleinen pharaonischen Stadiums auf $174,5 \mathrm{~m}$. Siehe auch Decourdemanche, Traité pr. d. poids et mesures. 1909. p. 134 (Wii).

Zu S. 183, Anm. 1: Da der Hang zur Astrologie zu dem Bilde, das man sich im übrigen von Hipparch als kühlem Forscher macht, wenig paßt, so hat man seine Beschäftigung mit astrologischen Dingen wobl angezweifelt. Sie kanu aber heute für ihn wie auch für Ptolemäos als erwiesen betrachtet werden.

Zu S. 189: Ob Hipparch die stereographische Projektion kannte, ist nach Hoppe, Matlı. u. Astron. i. klass. Altertum nicht sicher (Wii). Siehe dort S. 325 .

Zu S. 200: Schreibweise ist Theodolit. Die Herkunft des Wortes ist unbekannt.

Zu S. 215: Ausführliches über dic Uhren findet sich bei E. Wiedemaun und J. Würschmidt (Wü).

Zu S. 228, Anm. 1: Gïnther und mit ihm auch Wïrschmidt und andere bevorzugen die Schreibweise Copernicus. Siehe indessen die Aum. 1 auf S. 403. Die erwünschte Einigung in solchen Dingen ist kaum herbei- 
zuführen, da in der gesamten Literatur die verschiedenen Schreibweisen nebeneinanderlaufen.

$\mathrm{Zu}$ S. 251, Anm. 1: Der Heibergsche Text ist dem von Halma vorzuziehen (Wi).

Zu S. 256: Über die Geschichte des Astrolabs berichtet ausführlich Josef Frank in den Sitzungsberichten der physikalisch-medizinischen Sozietät

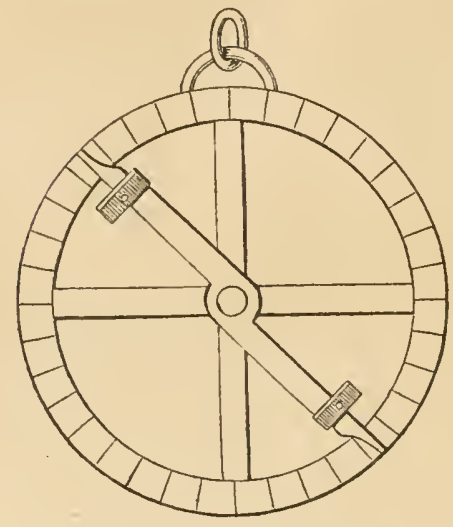

Einfachste Form eines Astrolabiums nach $\mathrm{Peschel}$. (Gesch. d. Erdk. S. 386.) zu Erlangen (Bd. 50. 51. 1918/19). Die Abhandlung ist durch eine Anzahl Abbildungen erläutert.

Das ursprünglich für die Aufnahme der Sterne bestimmte Instrument erhielt allmählich verschiedene Abänderungen, die alle als Astrolabien bezeichnet werden und sich in den älteren astronomischen Werken abgebildet finden.

$\mathrm{Zu}$ S. 261: Ob der Verfasser der Naturales quaestiones mit dem Tragöden Seneca identisch ist, steht immer noch nicht fest $(\mathrm{Li})$.

Zu S.264, Anm.2: Nach E. Wiedemann ist die "Optik" des Ptolemäos vor Govi wohl auch von anderen, z. B. Venturi, bemerkt worden.

Zu S. 271: Über die Kenntnis und Verwendung von Zink und Zinn im Altertum siehe von Jippmanns, ,Alchemie“6 v. S. 577-609.

Zu S. 274: Über die ersten Erwähnungen der Chemie und ihres Namens sowie über die Herkunft des Namens Chemie handelt E. v. Lippmann sehr ausführlich in seiner "Alchemie" S. 282-314. Etwas Sicheres läßt sich danach über die Herkunft des Namens „Chemie“" nicht feststellen.

Auch v. Lippmann gibt als älteste Quelle für das Vorkommen des Namens „Chemie“ Zosimos an. Dieser' gehört danach schon dem 3. Jahrhundert an. Er schrieb eine Anzahl griechischer Werke, die, wenn auch in entstellter Form, zum 'Teil noch erhalten sind und ausdrücklich die Chemie als Kunst des Gold- und Silbermachens erwähnen (Chem.Ztg. 1914, S. 685). Die Ableitung des Wortes Chemie von Chemes findet sich nach v. Lippmann bei Zosimos jedoch nicht.

Zu S. 27õ: Ebenso unsicher wie die Ableitungen des Wortes "Chemie" sind alle Nachrichten über den "Stein der Philosophen" oder "der Weisen". Nach von Lippmann kommt diese Bezeichnung zuerst in Schriften vor, die wahrscheinlich in 1. nachchristlichen Jahrhundert entstanden sind (,Alchemie S. 51).

Zu S. 277: Dunkel sind nach v. Lippmann auch die mystischen Beziehungen zwischen der Alchemie und der Astrologie, wie sie sich in der auf S. 277 gegebenen Zusammenstellung der Metalle mit bestimmten Planeten ausgesprochen finden.

Z. S. 303: Al Biruni (973-1048 etwa) war Mathematiker, Astronom und Geograph. Er hat besonders wissenschaftliche Beziehungen der arabischen Welt zu Indien vermittelt. 
Meisterhaft schilderte Al Biruni die Dämmerungserscheinungen, unter denen auch das Zodiakallicht deutlich erkennbar ist.

Die kupferrote Mondfarbe, die bei einer totalen Mondfinsternis infolge des Erdscheins auftritt, vermochten weder Al Biruni noch die übrigen arabischen Astronomen zu erklären. (Nach Meyerhofs Sammelbericht; S. S. 314.)

Zu S. 304: Albattanis Werk wurde von Nallino arabisch und lateinisch in trefflicher Bearbeitung herausgegeben (Wi).

Z. S. 310: Zu Marcus Graecus' Schrift schreibt v. Lippmann: „Sie ist erst um $120_{0}$ verfaßt. Berthelots Angabe, Marcus Graecus habe den Salpeter gekannt, ist ganz unhaltbar. Diels ist ihm mit Unrecht gefolgt". (Li.)

Z. S. 310, unten: Man kann ein ganzes Verzeichnis der Umschreibungen des Namens Alchwarizmi zusammenstellen. Ruska (Zur ältesten arabischen Algebra und Rechenkunst, Heidelberg 1917) führt etwa ein Dutzend solcher Umschreibungen an.

Der vollständige Name lautet Muhammed ibn Musa Alchwarizmi.

Z. S. 311: Ausfübrlicher über Ibn Mrusa handelt die Schrift von Ruska: Zur ältesten arabischen Algebra und Rechenkunst, Heidelberg 1917 (Sitzungsber. d. Heidelb. Akad. d. Wissensch.).

Nach Ruska sind über die Grundlagen der arabischen Algebra viele sich ausschließende Ansichten geäußert worden. Eine genauere Vergleichung der Texte und der Übersetzungen war danach nötig. Eine Algebra im heutigen Sinne hat Ibn Musa nicht geschrieben. Sein Buch will weiter nichts sein, als eine auf zahlreiche Musterbeispiele gestützte Einführung in das angewandte Rechnen (a. a. O.S. 7). Woher Ibn MIusa seinen Stoff hat, deutet er nirgends an.

Die verschiedenen Übersetzungen der Ausdrüeke algabr und almukabalah vermögen keine klare Vorstellung von ilırem mathematischen Sinn zu geben. Cantor spricht von Wiederherstellung und Gegenüber'stellung, Ruska dagegen von Ergänzung und Ausgleichung. In dem Abschnitt, der von den sechs Formen der Gleichungen handelt, wird nämlich gesagt, daß jede andere Gleichung durch das erwähnte Verfahren auf eine der sechs Normalformen gebracht werden könne.

Zu S. 314: Bezüglich der Optik der Araber kommt der neueste Standpunkt in Meyerhofs zusammenfassenden Abhandlungen zum Ausdruck (Wi): Siehe M. Meyerh of, „Die Optik der Araber" i. d. Zeitschrift f. ophthalmologische Optik. Berlin, Verlag v. J. Springer 1920.

Z. S. 314: In Ergänzung der im vorliegenden Werk gegebenen Darstellung sei nach diesem Sammelbericht noch auf folgendes hingewiesen:

Die Verfasser der seit dem 8. Jahrlundert in arabischer Sprache entstandenen Literatur waren zum allergeringsten Teile Araber, dagegen vor-

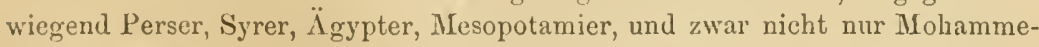
daner, sondern auch Christen und Juden.

Die bedeutendste optische Schrift der Araber, der Thesaurus Opticae des Alhazen (Ibn al-Haitham) ist zwar seit dem 13. Jahrlundert der abendländischen Welt lekannt. Dic genauere Erforschung der arabischen Optik auf Grund der Übersetzung der Urtexte erfolgte jedoch erst in den letzten Jahrzehnten und zwar auf ophthalmologischem Gebietc durch J. Hirschberg, auf physikalischem durch E. Wiedemann. Leider ist der arabische Urtext der Optik Alhazens trotz aller Bemühungen bisher nocl nicht gefunden worden.

Dannemann, Die Naturwissenschaften. I. Bd. 2. Aufl. 
Die Lebensgeschichte Alhazens ist von E. Wiedemann getreulich nach den arabischen Gelehrtenbiographien dargestellt worden. (Archiv f. d. Gesch. d. Naturw. u. d. Technik 1910. 3, S. 1-53.

Die Übersetzung ins Lateinische, welche der Risner'schen Ausgabe zugrunde liegt, ist vermutlich im 13. Jahrhundert entstanden.

Eine genauere Inhaltsangabe der 7 Bücher gibt M. Meyerh of in seinem Sammelbericht in der Zeitschr. f. ophthalmolog. Optik. VIII $\{1920$, Heft 3.

Z. S. 315: Bei der Darstellung der Anatomie des Auges stützt sich Alhazen im wesentlichen auf Galen. Wie er unterscheidet er 3 Feuchtigkeiten (Kammerwasser, Linse, Glaskörper) und 4 Häute. Die Linse verlegt auch Alhazen in den Mittelpunkt des Auges.

Z. S. 316: Im Gegensatz zu den meisten Griechen und seinen arabischen Fachgenossen stellt Alhazen vollbewußt die Theorie auf, daß das Sehen durch Strahlen zustande kommt, die in gerader Linie vom Gegenstande zum Auge hinziehen (Meyerhof, a. a. O. S. 42).

Z. S. 317: Daß das Licht zu seiner Fortpflanzung Zeit gebraucht, glaubt Alhazen daraus schließen zu dürfen, daß die Farben des Farbenkreisels (der schon Ptolemäos bekannt war) bei rascher Umdrehung nicht mehr einzeln unterschieden werden (a. a. O. S. 43).

Z. S. 318: Daß die Gestirne in der Nähe des Horizontes größer erscheinen als im Zenit erklärt Alhazen als eine optische Täuschung. Diese entstehe dadurch, daß das Auge die Größe der Gegenstände nach derjenigen des Gesichtswinkels und der mutmaßlichen Entfernung schätzt. Letztere erscheint am Horizont wegen der dazwischen liegenden Gegenstände größer. Aus dem gleichen Grunde erscheine das Himmelsgewölbe abgeplattet (a. a. O. S. 45,

Die erste Erwähnung der Dunkelkammer findet sich in der von E. Wiedemann übersetzten Schrift Alhazens, „Über die Gestalt des Schattens". Es heißt dort nämlich: „Tritt das Licht der Sonne zur Zeit ihrer Verfinsterung aus einem engen runden Loche heraus und gelangt zu einer gegenüber liegenden Wand, so hat das Bild Sichelgestalt". Den Beweis gibt Alhazen durch eine ausführliche Abhandlung (Übersetzt v. E. Wiedemann). Sein Kommentator Kemal al-Din, der etwa 300 Jahre später lebte, entwickelt die Theorie der Camera sehr eingehend. J. Würschmidt nimmt an, daß die abendländischen Gelehrten die Erfahrungen der Araber ïber die Dunkelkammer übernahmen.

Die Tatsache, daß bei einer Sonnenfinsternis hinter einer engen Öffnung ein sichelförmiges Bild der Sonne entsteht, war schon im Altertum bekannt.

In seiner Schrift ,"Über Brennspiegel nach Kegelschnitten" (herausgegeben von J. L. Heiberg und E. Wi edemann, Bibl. math. III. Folge, Bd. 10, Heft 3) erwähnt Alhazen die Beobachtung der Alten, daß Spiegel von der Form eines Umdrehungsparaboloids alle Strahlen in einem Punkte vereinigen and wirksamer sind, als alle anderen Spiegel. Die Entdeckung soll von Diokles um 350 v. Chr. gemacht worden sein. Alhazen vermißt die theoretische Konstruktion, die er dann vollständig gibt. Indessen hatte schon Appollonios die richtige Lage des Brennpunktes bei paraboloiden Hohlspiegeln festgestellt.

Z. B. 318: Einen guten Überblick über den Stand, den die Augenheilkunde bei den Arabern erreicht hatte, gibt eine von C. Prïfer und M. Meyer- 
hof in der Zeitschrift „Der Islam“ (6. Jahrg. 3. Heft 1915) herausgegebene ausführliche Abhandlung über diesen Gegenstand.

Z. S. 319: Daraus, daß in dieser Tabelle der Alkohol fehlt, schließt von Lippmann, daß man um 1120 den Alkohol noch nicht kannte. Nach $\mathrm{ihm}$ ist dieser gar keine arabische Entdeckung, sondern eine verhältnismäßig späte abendländische. Bisher war man allgemein der Ansicht, daß der Alkohol schon seit dem 9. Jahrhundert den Arabern bekannt gewesen sei.

Über die Geschichte des Aräometers siehe auch v. Lippmanns Abhandlung in der Chemiker-Zeitg. 1912, Nr. 68.

Z. S. 319: „Über Wagen bei den Arabern" handelt E. Wiedemann (Sitzsber. d. Phys. Mediz. Soziet. in Erlangen Bd. 37, 1905, S. 388 u. f.). Wiedemann berichtet dort von der Verwendung physikalischer Kenntnisse zu allerhand Betrügereien. So stellte man Wagen her, deren Balken hohl war und etwas Quecksilber enthielt. In einem arabischen Werk, das eine Reihe von 'Taschenspielerkunststücken schildert, heißt es: „Soll das Gold leicht erscheinen, so läßt man das Quecksilber nach der Seite der Gewichte fließen"*. Auch dadurch wurde betrogen, daß der Bankier einen Ring trug, in dem sich ein Magnetstein befand. Diesen brachte er beim Wägen in geeigneter Weise an die eiserne Zunge der Wage. Daß derartige Betrügereien recht alt waren, geht auch daraus hervor, daß schon der Koran dagegen eifert.

Zu S. 318 und 327: Al Qazwini und Al Khazini sind zwei verschiedene arabische Scliriftsteller. Al Khazini lebte um 1130. Von ihm rühren die sehr genauen Bestimmungen einer Anzahl von spezifischen Gewichten her. Al Qazwini, der Verfasser des Steinbuches, lebte etwa hundert Jahre später. Er schrieb eine große Erdbeschreibung: „Die Wunder der Schöpfung und die Denkmäler der Länder". Sein vollständiger Name lautet: Zakarija ibn Muhammad ibn Mahmud al-Qazwini.

Die arabischen Steinbücher enthalten auch Vorschriften zur Gravierung von Planetenbildern auf die den einzelnen Planeten zugeteilten Steine. Bei jedem der sieben Planeten wird angegeben, bei welcher Konstellation das genau beschriebene Planetenbild in den dem Planeten geweihten Stein graviert werden soll und welche Wirkung das Amulett hat, wenn noch gewisse rituelle Vorschriften erfïllt werden. Dem Saturn entspricht ein Stein in einem Ring aus Blei, dem Mars ein Stein in einem Ring aus Eisen usw. Näheres bei J. Ruska, Griechische Planetendarstellungen in arabischen Steinbüchern. (Sitzgsber. d. Heidelb. Akad. d. Wiss., Heidelberg 1919.)

Zu S. 320, 8. Z. v. oben: Neben Spanien verdient Sizilien Erwähnung, da auch von hicr aus die arabische Wissenschaft dem Abendlande übermittelt wurde (Wi).

Z. S. 322: Über Geber berichtet ausführlicher und dem Ergebnis der neuesten Forschungen entsprechend v. Lippmann in seiner, Alchemie".

Zu S. 322: Nach v. Lippmann ist der Alkohol eine Erfindung des Abendlandes, die vermutlich erst im 11. Jahrliundert gemacht wurde und zwar wahrscheinlich in Italion (Alchemic 472). Das Wort "Kohol" bezeichnet ursprünglich cin schır feines Pulver. Al ist der arabische Artikel. Näheres siehe bei v. Lippmann, Chemiker-Zeitung 1913, S. 1313, ebd. 1917, S. 865. 
Z. S. 325: Es sei bemerkt, daß die Gleichungen unter 2) nur zur Erläuterung dienen. Die Salzsäure, durch die hier die Zerlegung bewirkt wird, war damals noch nicht bekannt.

Z. S. 326: Wunderbare Wirkungen wurden dem Stein der Weisen indessen auch schon von den frühesten griechischen Alchemisten beigelegt (Li).

$\mathrm{Zu} \mathrm{S.} \mathrm{327,} \mathrm{unten:} \mathrm{Es} \mathrm{muß} \mathrm{jedoch} \mathrm{anerkannt} \mathrm{werden,} \mathrm{daß} \mathrm{die} \mathrm{Araber}$ recht gute botanische Kenntnisse besaßen (Wi).

Z. S. 330: Über die medizinischen Kenntnisse bei den Arabern hat ausführlich G. Seidel in den Sitzungsber. d. phys. med. Sozietät in Erlangen berichtet (Bd. 47, S. 1915).

Z. S. 352: Die Albertus Magnus 'zugeschriebenen, eigentlich alchemistischen Werke sind nach v. Lippmann Fälschungen.

Zu S. 390: Inbezug auf die Optik Lionardos sei auf Werners in Erlangen erschienene Dissertation hingewiesen. Werner weist nach, daß sich in den optischen Studien Lionardo da Vincis zablreiche Andeutungen finden, die auf seine Bekanntschaft mit den Schriften Albazens schließen lassen.

Zu S. 401: ..Ortus" wird im Mittelalter häufig statt „Hortus" gebraucht. 


\section{Einige Auszüge aus den Besprechungen der ersten Auflage.}

Des Verfassers Grundriß einer Geschichte der Naturwissenschaften hat in zweiter Auflage G. W. A. Kahlbaum I, 160 und III, 75) in anerkennendster Weise besprochen und zugleich die Gefühle ausgesprochen, die angesichts der Erfolge dieses Werkes jeden Historiker der Naturwissenschaften beseelen müssen. Aus den gleichen Gründen begrüßen wir es heute freudigst, daß unser Gesellschaftsmitglied und Mitarbeiter den zweiten Teil dieses Buches $\mathrm{zu}$ einem vierbändigen Werke ausgestalten will und davon bereits den ersten Band vorzulegen vermag.

(H. Stadler in den Mitteilungen zur Geschichte der Medizin und der Naturwissenschaften, Bd. X, 2. Heft.)

Der soeben erschienene 2. Band dieses großen Werkes behandelt die Zeit von Galilei bis zur Mitte des 18. Jahrhunderts, also jene Epoche, in welcher die Grundlagen der neueren Naturwissenschaften gelegt wurden. Auch in diesem Bande hat sich der Verfasser mit Erfolg bemüht, eine Darstellung zu schaffen, die nicht nur dem Historiker dient, sondern für jeden anregend ist, der sich überhaupt für die Naturwissenschaften interessiert.

(Kölnische Zeitung, 20. Februar 1911.)

Ähnlich wie Cantors Vorlesungen über Geschichte der Mathematik ein „standard work"6 allerersten Ranges bleiben werden, so wird auch Dannemanns Werk von bleibendem Wert sein, das für den Geschichtsforscher wie für den Mediziner, für den Lehrer wie für den Techniker großen Nutzen haben und dessen Lektüre für jeden, der sich für die Naturwissenschaften interessiert, eine Quelle hohen Genusses bilden wird.

(Monatsschrift für höhere Schulen, 1911, 6. Heft.)

Man weiß nicht, was man mehr bewundern soll, die überraschende Belesenheit des Autors oder seine Gabe, selbst die schwierigsten Probleme wissenschaftlicher Forschung nicht nur dem Kenner, sondern auch dem interessierten Laien leichtfaßlich in ernst-vornehmer Form vorzutragen.

(Pharmazeutische Zeitung, 1911, Nr. 13.)

Besonders dankenswert erscheint, wie Dannemann in allen diesen Wissenschaften die verbindenden großen Gedanken herauszuschälen weiß, die im hohen Maße geeignet sind, die Vertreter der einzelnen naturwissenschaftlichen Disziplinen vor Einseitigkeit zu bewahren.

(Ärztliche Rundschau, 1910, XX. Jahrgang, Nr. 47.) 
Dem Techniker, dem Lehrer, dem Arzte, jedem, der sich lebhafter für Naturwissenschaften interessiert, vor allem also auch unseren Studierenden, dürfte das Buch eine unerschöpfliche Quelle des Genusses und der Anregung sein. Einen ganz besonderen Wert besitzt das Werk dadurch, daß es gewissermaßen den Rahmen für Ostwalds Klassiker der exakten Wissenschaften abgibt und so die Beziehungen aufweist, durch welche die einzelnen,Gebiete sich gegenseitig beeinflußt haben.

Für die Hebung der Kultur unseres Volkes kann dieses Buch, das die Wissenschaft und ihre Erfolge als etwas Werdendes vorstellt, von größtem Nutzen sein, da es die Erfolge fortschrittlichen Denkens gegenüber den Schwächen dogmatischer Gesinnung aufs deutlichste vergegenwärtigt.

(Prometheus, 26. November 1910, XXII. Jahrgang.)

L'ouvrage me paraît excellent; il a d'ailleurs une qualité inappréciable; c'est de n'avoir pas d'équivalent.

(Revue générale des Sciences. Paris 15. III. 1912.)

Das Gesamtwerk, dessen Inhalt durch gute Register und Literaturverzeichnisse übersichtlich zusammengehalten wird, liegt nun, auch in äußerlich schönem Gewande, vollständig-vor; es gehört fraglos zu den besten, bestgeschriebenen, originellsten und nutzbringendsten der neueren naturwissenschaftlichen Literatur und ist mehr als jedes andere geeignet, den immer unheilvoller hervortretenden Folgen der völligen Zersplitterung unter den Naturforschern abzuhelfen und deren allgemeine Fortbildung wieder zu heben. Es gereicht dem Verfasser zur Ehre, nicht minder aber auch der ganzen deutschen Literatur.

(Prof. Dr. E. O. von Lippmann in der Chemiker-Zeitung 1913.)

Seit Jahren empfehle ich meinen Hörern in der einführenden Vorlesung über experimentelle Chemie das Dannemann sche ausgezeichnete, noch nicht nach Gebühr verbreitete Werk „Die Naturwissenschaften in ihrer Entwicklung und in ihrem Zusammenhange".

(Dr. A. Stock, Prof. a. d. Univ. Berlin und am Kaiser-Wilh.-Inst. Dahlem, in d. Monatsschrift f. d. chem. u. biol. Unterr. 1920.) 
Von dem Verfasser erschienen ferner:

\section{Leitfaden für die Übungen im chemischen Unter-} richt der oberen Klassen höherer Lehranstalten.

6. Aufl. B. G. Teubner, Leipzig 1920.

Aus der Werkstatt großer Forscher. 430 Seiten. 3. Aufl. Leipzig 1908. Wilhelm Engelmann.

$$
\text { Gebunden M. 9.- und 50\% V.-T.-Z. }
$$

„Es sei jeder, der sich bisher noch nicht mit diesem vortrefflichen Werke bekannt gemacht hat, darauf hingewiesen, die sehr wertvolle Bekanntschaft nicht länger hinauszuschieben."

(Prof. Dr. Will. 0stwald.)

Der naturwissenschaftliche Unterricht auf praktisch - hemristischer Grundlage. Hannover 1907. Hahnsche Buchhandlung. Geh. MI. 6.-, geb. M. 6.80.

„Das Werk entwickelt in recht überzeugender Weise die Bedeutung und die Grundzüge des praktisch-heuristischen Verfahrens. - Der Arbeit kann das Verdienst nicht vorenthalten werden, mit Gründlichkeit und Energie für eine gute Sache eingetreten zu sein."

(J. Norrenberg,

in der Zeitschrift für lateinloses Schulwesen 1908.)

Naturlehre fiir höhere Lehranstalten, anf Schiileriibnngen gegriindet. Hannover 1908. Hahnsche Buchhandlung.

"Der Verfasser" hat so alle Momente vereinigt, die zur Erteilung eines zeitgemäßen Unterrichts von Belang sind und zwar so, daß zu dem neuen Plane ein Übergang von dem bestehenden her möglich ist." (Dentsche literaturzeitung, 1909, Nr. 5.)

\section{Handbuch fïr den physikalischen Unterricht.} .J. Peltz, Langensalza 1919.

"Was in diesem Buche gesagt wird, faßt alle lebenskräftigen Reformgedanken der letzten. Jahre in geschickter "Woise zusammen."

(R. Winderlich,

i. d. Ztschr. f. I. math. u. naturw. Lnterr.) 


\section{Geschichte der physikalisehen Experimentied-} kunst ron Prof. Dr. E. Gerland und Prof. Dr. F.Traumiiller. Mit 425 Abbildungen zum größten Teil in Wiedergabe nach den Originalwerken. (XVI und 442 Seiten, gr. 8.)

Geheftet M. 14.-. In Halbfranz gebunden M. 17.-.

Aus den Besprechungen:

„Das treffliche Buch darf weder in der Bibliothek einer mittleren oder höheren Lehranstalt, noch in der eines Experimentalphysikers fehlen."

(Monatshefte f. Mathematik nnd Physik. 1900. Heft 1.)

„Eine eingehende Kenntnis der Geschichte der Physik läßt den Lehrer erst den wahren Wert der einzelnen Tatsachen, Begriffe und Theorien erkennen, liefert ihm überaus dankbare Nittel, den Unterricht kräftig zu beleben, und macht ihn auf die Schwierigkeiten anfmerksam, die der menschliche Geist bei dem ersten Eindringen in die einzelnen Gebiete der Plhysik zu überwältigen hat. Das vorliegende Werk erschlieft in trefflicher. Weise ein neues und wichtiges Gebiet der Geschichte der Physik; es darf in der Hausbibliothek keines Lehrers fehlen, dem sein Unterricht und die ihm anvertraute wissensdurstige Jugend am Herzen liegt."

(Hahn-.Machenheimer,

Zeitschr. f. d. physik. u. (hem. Unterricht. März 1900. Heft 2.)

\section{Zur Geschichte der astronomischen Meßwerk-} zeuge von Purbach bis Reichenbach 1450-1830 von Joh. A. Repsold. 1. Band. Mit 171 Abbildungen (VIII und 132 Seiten gr. 8). M. 16.-.

Aus den Besprechungen:

„Das Buch, das sich überall als eine reiche Quelle der Belehrung über die Zweckdienlichkeit und die sachgemäße Verwendung der Instrumente, sowie über die Vorteile und Nachteile der einzelnen Konstruktionen darbietet, wird gewiß nicht verfehlen einen daueruden, großen Nutzen für die Wissenschaft zu stiften."

(Astronomische Nachrichten, Bd.17\%, Nr.6.)

„Ein höchst interessantes, lehrreiches Werk ist es, das der Verfasser, der wie kein anderer dazu berufen war, es zu schreiben, den Mechanikern und Astronomen darbietet."

(Zeitschrift fiir Instrumentenkunde. XXVIII. Jahrg., Sept. 1908.)

Auf vorstehende Preise 50\% Verleger-Teuerungszuschlag. 

THE LIBRARY

UNIVERSITY OF CALIFORNIA

Santa Barbara

THIS BOOK IS DUE ON THE LAST DATE STAMPED BELOW.

Series 9482 



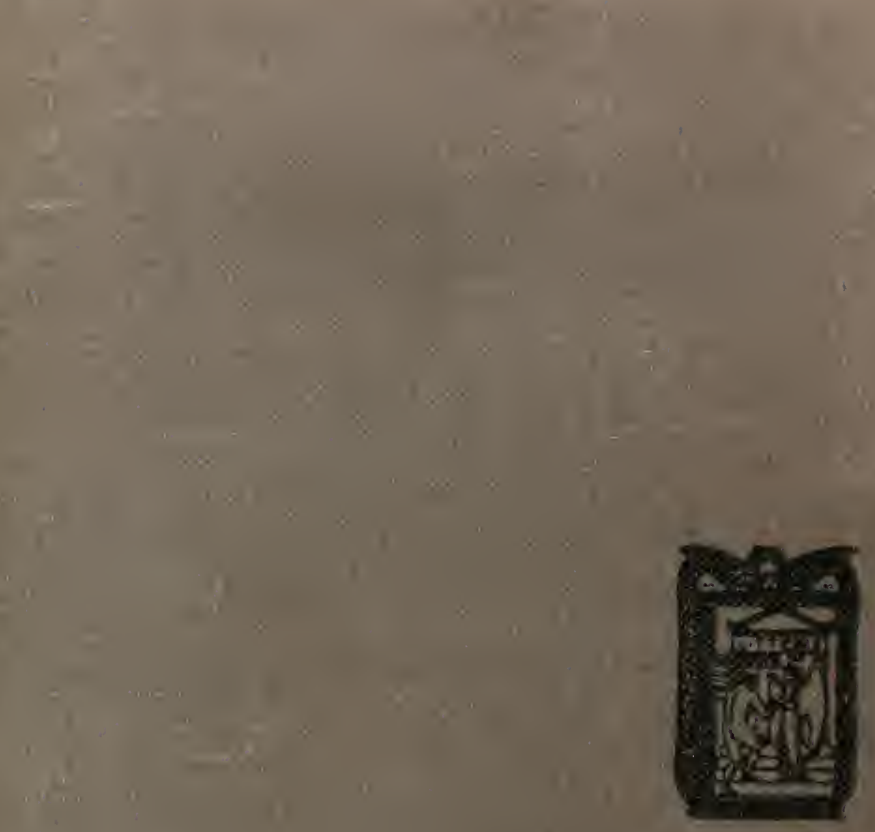

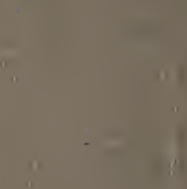

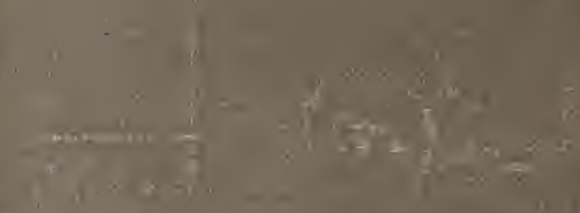

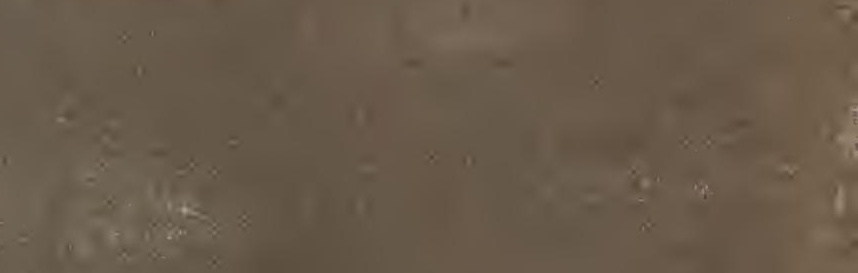
at

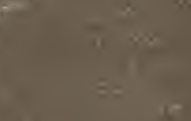

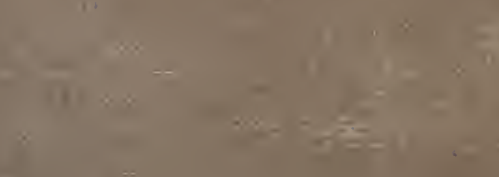
sie

$\%$ *.

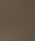

